UNIVERSIDAD DE BURGOS

Departamento de Biotecnología y Ciencia de los Alimentos Área de Ingeniería Química

\title{
Optimización del proceso de elaboración de QUeSO senticurado de mezcla a partir de concentrados de ultrafiltración
}

TESIS DOCTORAL David Delgado Fuente Burgos 2010 



\section{UNIVERSIDAD DE BURGOS \\ Área de Ingeniería Química}

OPTIMIZACIÓN DEL PROCESO DE ELABORACIÓN DE QUESO SEMICURADO DE MEZCLA A PARTIR DE CONCENTRADOS DE ULTRAFILTRACIÓN

TESIS DOCTORAL

David Delgado Fuente

Burgos, 2010 



\section{OPTIMIZACIÓN DEL PROCESO DE ELABORACIÓN DE QUESO SEMICURADO DE MEZCLA A PARTIR DE CONCENTRADOS DE ULTRAFILTRACIÓN}

Memoria para optar al grado de Doctor por la Universidad de Burgos que presenta el licenciado DAVID DELGADO FUENTE 



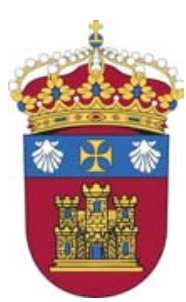

\section{UNIVERSIDAD DE BURGOS \\ DEPARTAMENTO DE BIOTECNOLOGÍA \\ Y CIENCIA DE LOS ALIMENTOS \\ ÁREA DE INGENIERÍA QUÍMICA}

DR. GONZALO SALAZAR MARDONES PROFESOR ASOCIADO DEL ÁREA DE INGENIERÍA QUÍMICA DE LA UNIVERSIDAD DE BURGOS

\section{CERTIFICA:}

Que el licenciado D. David Delgado Fuente ha realizado bajo su dirección el trabajo titulado "Optimización del proceso de elaboración de queso semicurado de mezcla a partir de concentrados de ultrafiltración".

Considerando que dicho trabajo reúne los requisitos exigidos para ser presentado como Tesis Doctoral, expresa su conformidad con dicha presentación.

Y para que conste, firma el presente certificado en Burgos a veintiséis de marzo de dos mil diez.

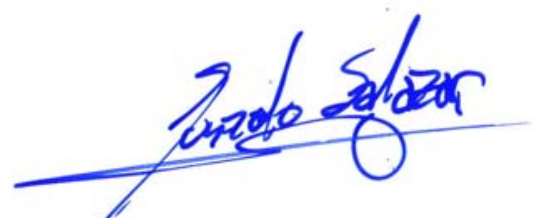

Fdo. Gonzalo Salazar Mardones 



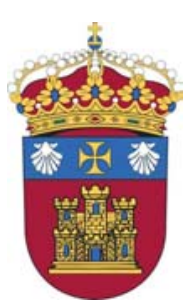

\section{UNIVERSIDAD DE BURGOS \\ DEPARTAMENTO DE BIOTECNOLOGÍA \\ Y CIENCIA DE LOS ALIMENTOS}

Dña. SAGRARIO BELTRÁN CALVO, DIRECTORA DEL DEPARTAMENTO DE BIOTECNOLOGÍA Y CIENCIA DE LOS ALIMENTOS DE LA UNIVERSIDAD DE BURGOS

\section{CERTIFICA:}

Que la memoria titulada "Optimización del proceso de elaboración de queso semicurado de mezcla a partir de concentrados de ultrafiltración" presentada por el licenciado David Delgado Fuente para optar al grado de Doctor por la Universidad de Burgos ha sido realizada en el Área de Ingeniería Química de este Departamento bajo la dirección del doctor Gonzalo Salazar Mardones, y en representación del consejo de departamento autoriza su presentación para ser defendida como Tesis Doctoral.

Y para que así conste, y a los efectos oportunos, firmo el presente certificado en Burgos a 26 de marzo de 2010.

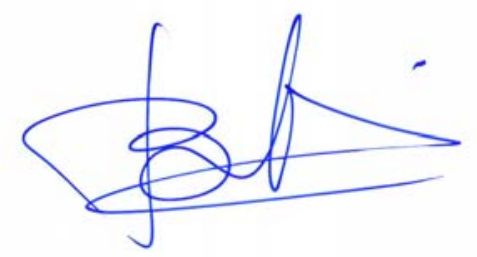

Fdo. Sagrario Beltrán Calvo Directora del Departamento

ILMO. SR. PRESIDENTE DE LA COMISIÓN DE DOCTORADO DE LA UNIVERSIDAD DE BURGOS. 

A mi padre....

...y su gran corazón 

Agradecimientos

En primer lugar quiero mostrar mi agradecimiento a mis directores de Tesis, al Dr. Gonzalo Salazar Mardones -que desde la Universidad de Burgos me animó a emprender este interesante $y$ gratificante trabajo- por la amistad consolidada a lo largo de estos años; y en segundo lugar a D. Manuel García Castillo -desde la Estación Tecnológica de la Leche (ITACyL)- por encauzar mi trabajo a través de sus consejos y su experiencia.

En segundo lugar quiero agradecer al Instituto Tecnológico Agrario de Castilla y León el darme la oportunidad y proporcionarme los medios para llevar a cabo este trabajo. En concreto a la Estación Tecnológica de la Leche y a todo su personal -auxiliar, administrativo, analista y técnico-, a los que han pasado y a los que continúan, ya que todos son parte de esta investigación: como apoyo en los análisis, formación del panel de cata, instrumento de medida en el panel, consejos, amistad...

Seguidamente es inevitable mostrar el mayor de los agradecimientos a mi familia, madre, hermana y toda la gente que se está sumando, en especial a ese pequeño gran degustador de queso -gracias Gael por no parar de hacerme reír-. Y como no, a toda la gente que me ha brindado su amistad y su talento -como en los diseños de esta Tesis-, y que continúa haciéndolo, a través del triángulo: Químicas-Moscú-Solarana.

Por último quiero agradecer de forma especial a la gente que me ha aguantado estos últimos meses de intensa dedicación a la escritura, por sus pequeños pero grandes consejos $y$, especialmente, por el hecho de estar ahí, son parte de mi vida y sin quererlo se han convertido en parte de esta Tesis. 



\section{RESUMEN}

El desarrollo de nuevas tecnologías que incorporen un mayor control sobre los procesos productivos, así como la búsqueda de productos más seguros y de mayor calidad han favorecido la implantación de sistemas de ultrafiltración en la Industria Láctea, desde su aparición industrial. En concreto la ultrafiltración, como etapa suplementaria e incluso sustitutiva de las tecnologías tradicionales de fabricación de queso, es bien conocida a escala industrial en la elaboración de quesos de corta maduración y elevado contenido en humedad.

En este trabajo se introduce la ultrafiltración, mediante módulos de membrana espirales, para el desarrollo de un queso de mezcla de pasta prensada, madurado. El interés de este producto radica tanto en su amplia demanda por parte de los consumidores, como por la importancia del sector lácteo en la región, ya que Castilla y León es el mayor productor de leche de oveja y segundo de leche de vaca a nivel nacional.

Se pretenden incorporar al proceso las ventajes productivas asociadas a la mayor eficacia de planta, al ahorro de ingredientes y a un aumento de rendimientos -por la incorporación de las proteínas solubles- mediante la ultrafiltración de la leche. Estos beneficios ya se vienen obteniendo industrialmente en la elaboración de quesos de menor maduración, sin embargo, debido a los elevados factores de concentración requeridos para quesos de pasta prensada de mayor grado de maduración, el empleo de ultrafiltración requiere de un estudio tecnológico del proceso global de elaboración, el cual se aborda en esta Tesis.

Se realiza una secuencia experimental en tres etapas que maximiza tanto el rendimiento como la calidad sensorial del queso (evaluada mediante panel de cata entrenado). Inicialmente se realiza un cribado de variables, para estudiar el efecto y la significación de un gran número de factores. En una segunda etapa, a través de un diseño factorial completo resuelto mediante análisis de respuesta múltiple, se establecen las mejores condiciones de los factores identificados en el primer diseño. Para finalizar la optimización se analiza la etapa de prensado mediante análisis de superficie respuesta, actuando sobre el tiempo de prensado y la activación del fermento. De esta forma, se consigue alcanzar el pH óptimo del queso a la salida de prensa en las mejores condiciones sensoriales y productivas posibles, garantizando la calidad y seguridad del producto.

Los quesos obtenidos en las condiciones óptimas de cada diseño se comparan frente al queso elaborado con la tecnología tradicional. El estudio comparativo se realiza a través de análisis físico-químico, microbiológico, sensorial, instrumental (textura y color), microestructural (microscopía electrónica), estudios de maduración y seguimiento de los procesos tecnológicos de filtración, elaboración y maduración a lo largo de cuarenta días.

Como conclusión destacar que la calidad sensorial del queso final según el proceso de fabricación propuesto es comparable a la del queso tradicional, aunque con diferencias significativas en parámetros estructurales y de textura. El aumento en rendimiento y el ahorro de ingredientes obtenidos favorecen la implantación industrial, si bien se hace imprescindible la sustitución de la tecnología tradicional por equipos que permitan operar con productos de alta viscosidad, así como sistemas de procesado en continuo, desde la etapa de ultrafiltración hasta la etapa de prensado. 



\section{ÍNDICE}

\section{CAPÍTULO I}

1. Introducción

1.1. El queso 23

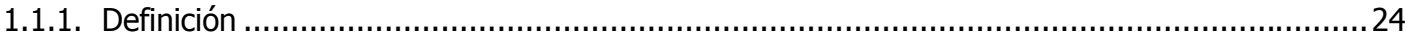

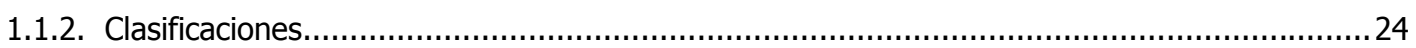

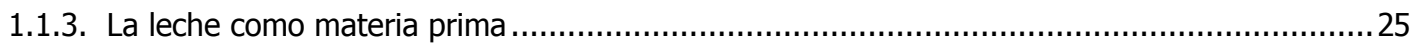

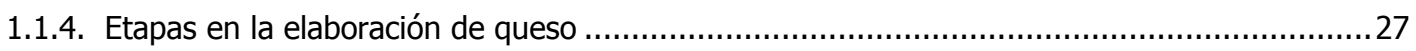

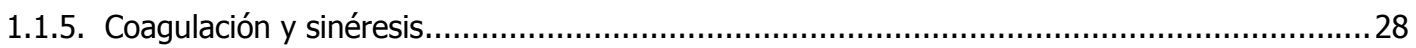

1.2. El queso de mezcla__ 30

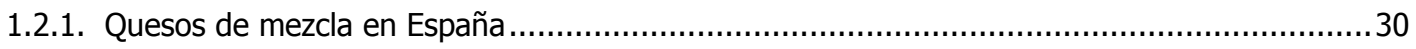

1.2.2. Quesos de mezcla en Castilla y León ................................................................... 31

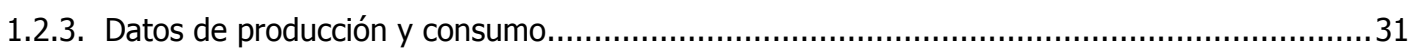

1.3. Procesos de separación con membranas __ 33

1.3.1. Aspectos generales sobre la filtración tangencial ...................................................... 33

1.3.2. Clasificación de los procesos de separación cuya fuerza impulsora es la presión...................35

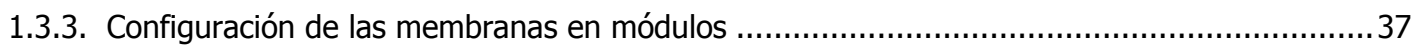

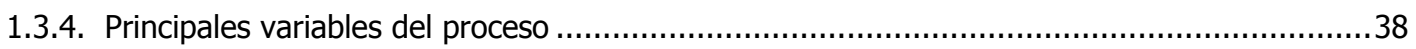

1.3.5. Modelización clásica de los procesos de filtración tangencial ........................................41

1.3.6. Fenómenos implicados en la transferencia de materia ................................................4 42

1.3.7. Aplicaciones de la tecnología de membranas en la industria láctea ...............................45

1.4. Ultrafiltración aplicada a la elaboración de queso___ 48

1.4.1. Estandarización del contenido proteico de la leche ...............................................49

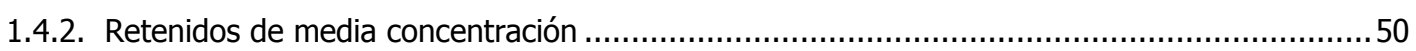

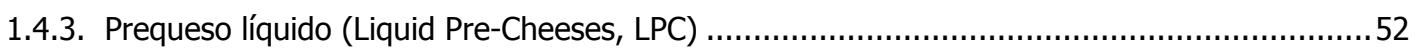




\section{CAPÍTULO II}

2. Justificación y objetivos

2.1 Justificación 59

2.2 Objetivos 61

\section{CAPÍTULO III}

\section{Metodología}

3.1. Estudios preliminares

3.1.1. Optimización de las condiciones hidrodinámicas de filtración.....................................67

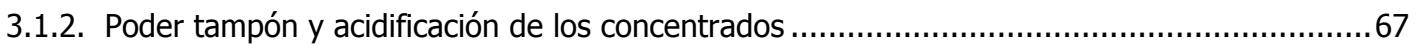

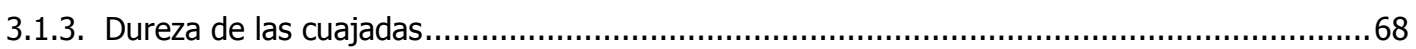

3.2. Establecimiento de las condiciones iniciales__ 68

3.3. Optimización de las variables significativas. Diseño Factorial _ـ 70

3.4. Optimización del proceso de acidificación en prensa ___ 71

3.5. Seguimiento de los resultados experimentales __ 72

3.6. Comparación de los quesos obtenidos en las condiciones óptimas de los diseños frente a la elaboración tradicional

\section{CAPÍTULO IV}

4. Materiales y métodos 79

4.1. Estandarización de la leche 79

4.2. Método tradicional de elaboración de queso 80

4.2.1. Pasteurización...

4.2.2. Cuajado y sinéresis 80 


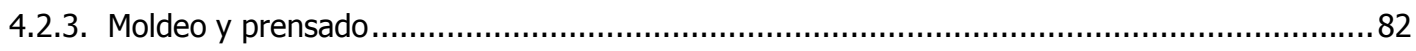

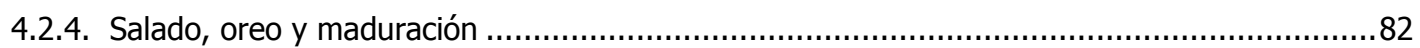

4.3. Ultrafiltración de leche para la elaboración de queso ___ 82

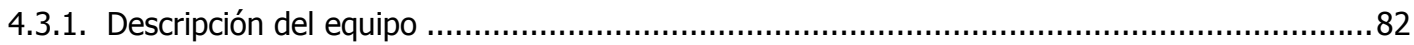

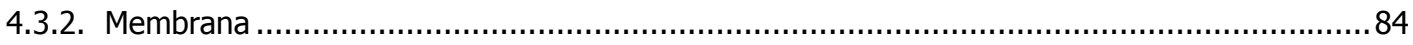

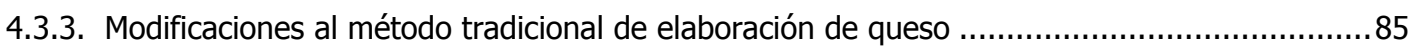

4.4. Análisis Físico-Químico _ 85

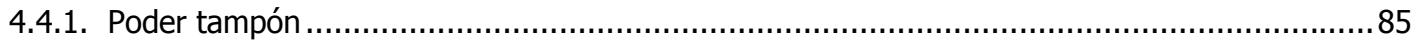

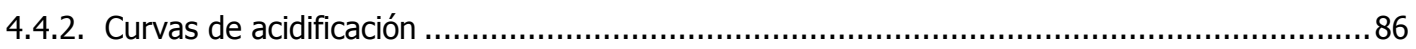

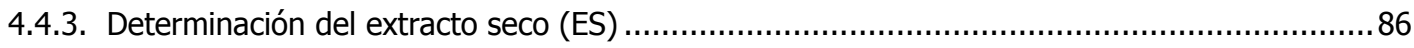

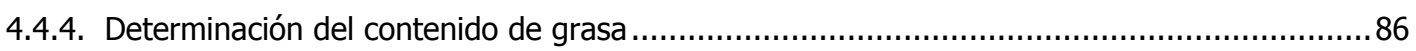

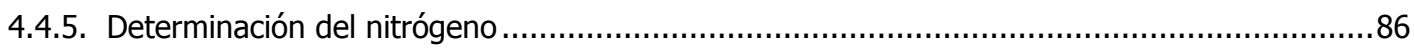

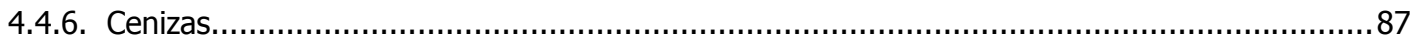

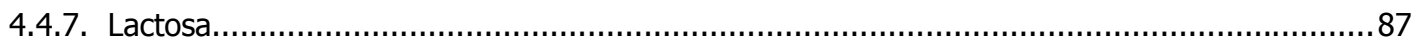

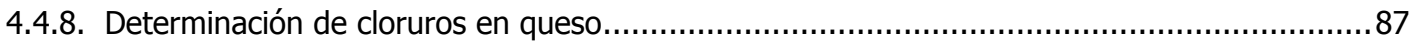

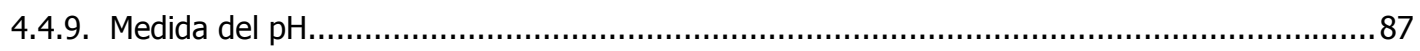

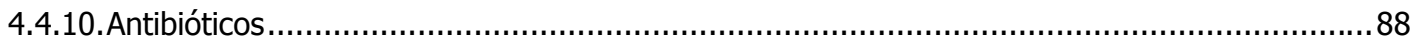

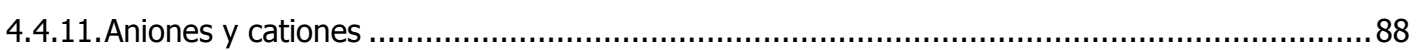

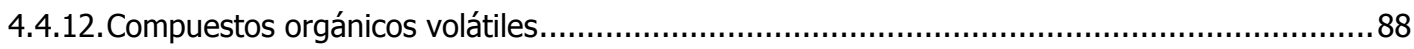

4.5. Análisis microbiológico _ـ 89

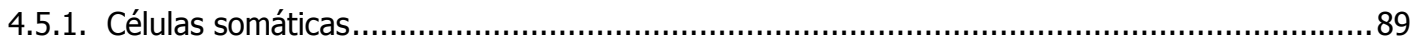

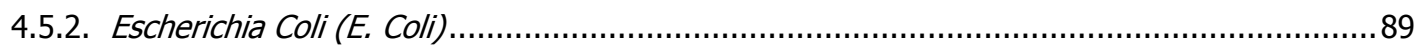

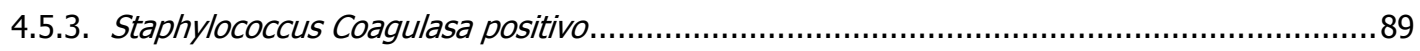

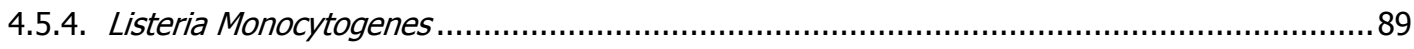

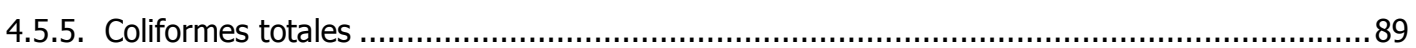

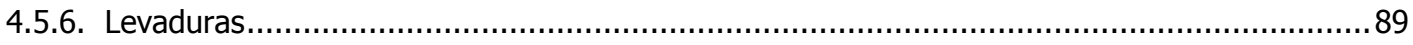

4.6. Análisis reológico y estructural _ـ_ 89

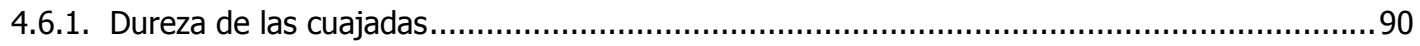

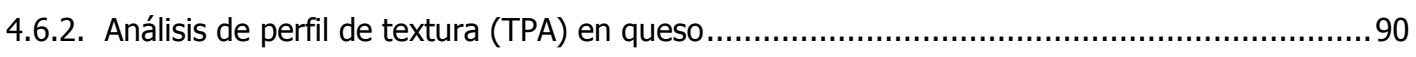

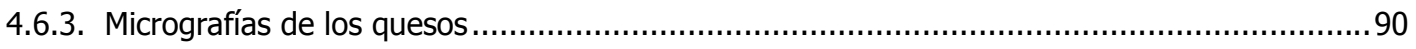

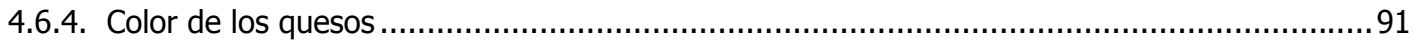

4.7. Análisis sensorial de los quesos ___ 91

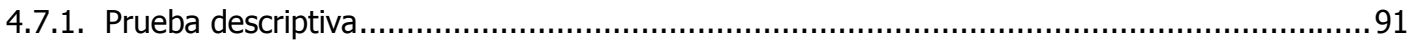

4.8. Software de tratamiento estadístico de resultados __ 93

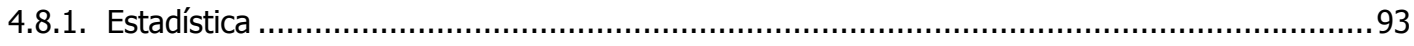

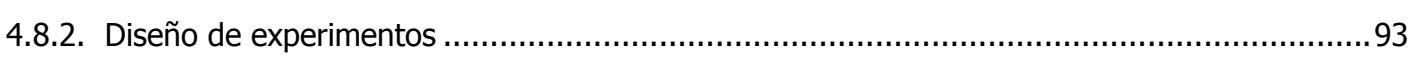

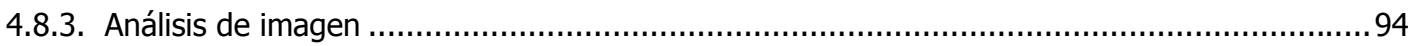


5.1. Estudios Preliminares __ 98

5.1.1. Optimización de las condiciones hidrodinámicas de flujo ................................................98

5.1.2. Estudio del poder tampón y acidificación de los concentrados ......................................... 102

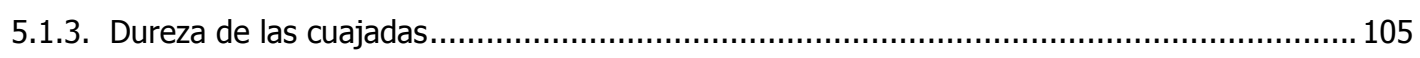

5.2. Establecimiento de las condiciones iniciales de elaboración y filtración __ 108

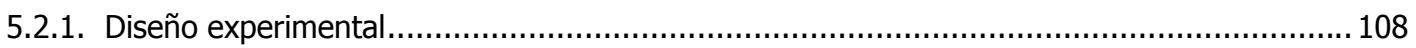

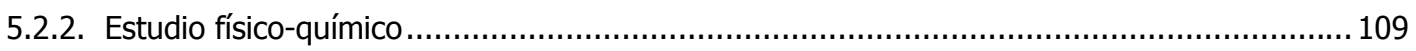

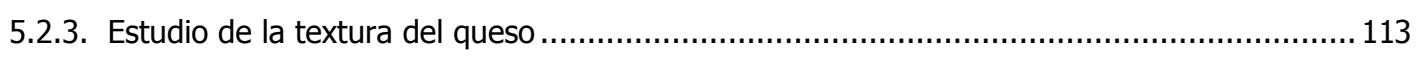

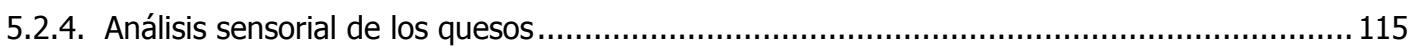

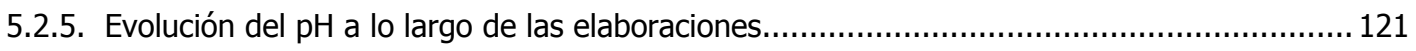

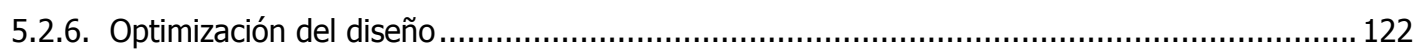

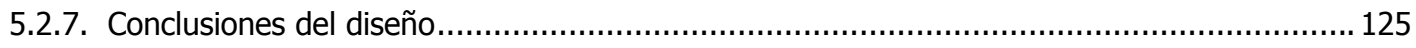

5.3. Optimización de las variables significativas. Diseño Factorial ___ 128

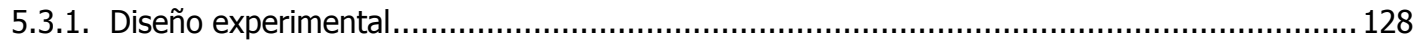

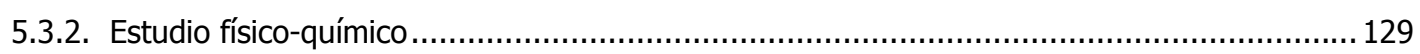

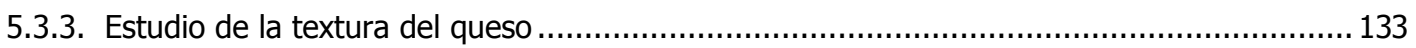

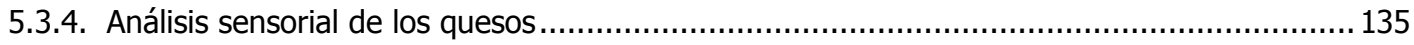

5.3.5. Evolución del pH a lo largo de las elaboraciones........................................................... 141

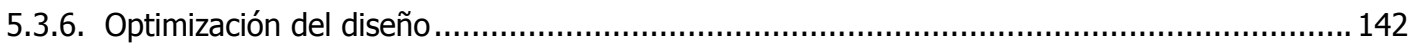

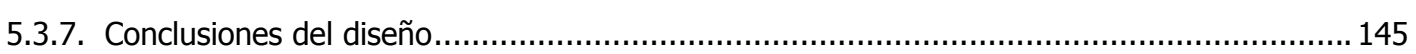

5.4. Optimización del proceso de acidificación en prensa ___ 147

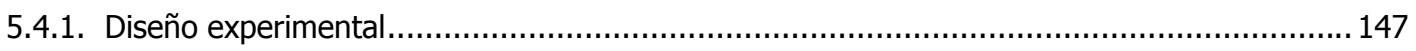

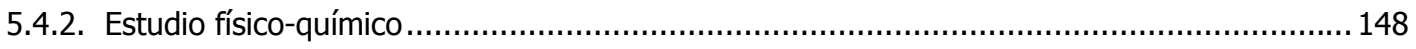

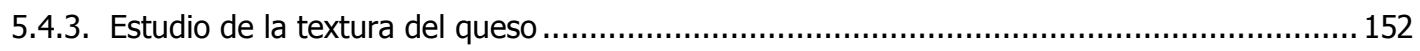

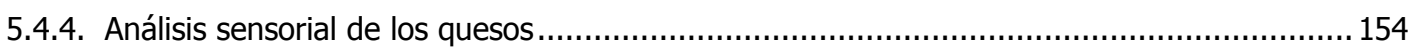

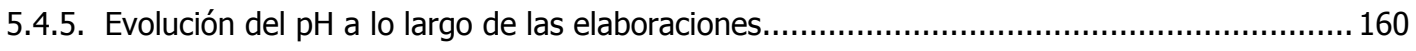

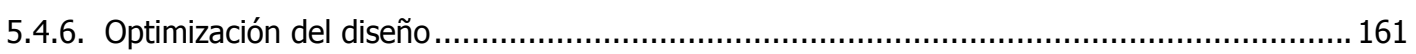

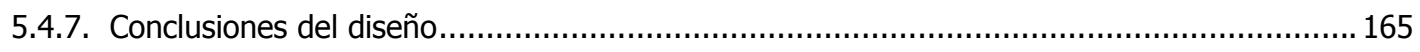

5.5. Comparación respecto a la tecnología tradicional _ـ_ 167

5.5.1. Condiciones óptimas de fabricación a partir de concentrados de ultrafiltración ................... 167

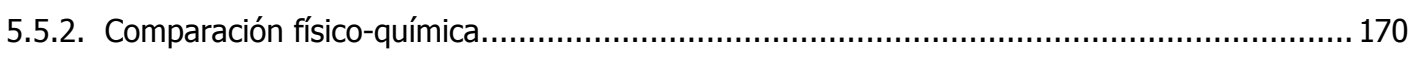

5.5.3. Seguimiento del proceso de maduración: proteolisis y lipolisis.......................................... 176

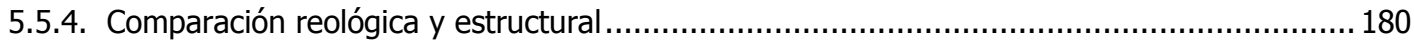

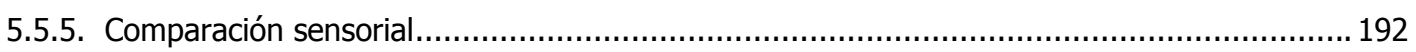




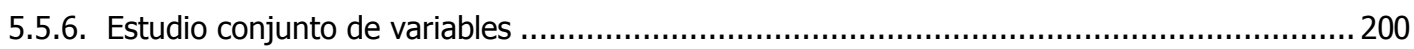

5.5.7. Estudio microbiológico..................................................................................... 203

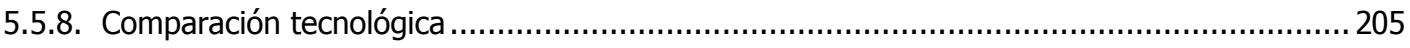

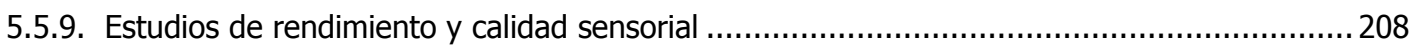

\section{CAPÍTULO VI}

6. Conclusiones

\section{BIBLIOGRAFÍA}

Bibliografía

\section{ANEXOS}

A.1. Composición físico-química de las leches de vaca y oveja 235

A.2. Composición química de los quesos a lo largo de la maduración 239

A.3. Resúmenes de las optimizaciones PB y DF 245

A.4. Fotografías quesos Diseño Plackett-Burmann 247

A.5. Fotografías quesos Diseño Factorial 249

A.6. Fotografías quesos Diseño Superficie Respuesta 253

A.7. Fotografías del queso tradicional y el óptimo final 257

A.8. Micrografías en detalle de los quesos 261

A.9. Análisis de componentes principales 263

\section{LISTADOS}

Tablas 267

Figuras 271 



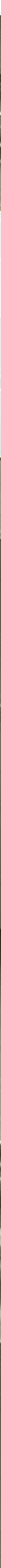





\section{INTRODUCCIÓN}

Se describe, en este primer capítulo, un breve resumen sobre tecnología quesera que incorpora unas definiciones generales, posibles clasificaciones del queso, así como la descripción de las etapas que constituyen el proceso de elaboración.

Como el objetivo de la Tesis se centra en la producción de un queso de mezcla se evalúa también la importancia de esta tipología que hace interesante su estudio.

Por último, esta introducción recoge conceptos básicos sobre la tecnología de membranas -en general-, y sobre su aplicación a la elaboración de queso, por ser la tecnología empleada para modificar las características de la leche a partir de la que, a lo largo de la Tesis, se evaluará la producción de queso por ultrafiltración desde diferentes puntos de vista.

\subsection{EL QUESO}

El queso es una de las formas más antiguas que se conocen para conservar la leche. La historia sobre el origen del queso se pierde entre mitos y leyendas, si bien no cabe duda que es uno de los primeros alimentos transformados. Su descubrimiento es contemporáneo a la domesticación del ganado, siendo el hallazgo arqueológico más importante relacionado con los derivados lácteos el Friso de la Lechería, Figura 1.1, friso sumerio que data del tercer milenio a.C. Esta representación de las distintas etapas en el ordeño y cuajado de la leche se conserva en el museo nacional de Irak, en Bagdad.

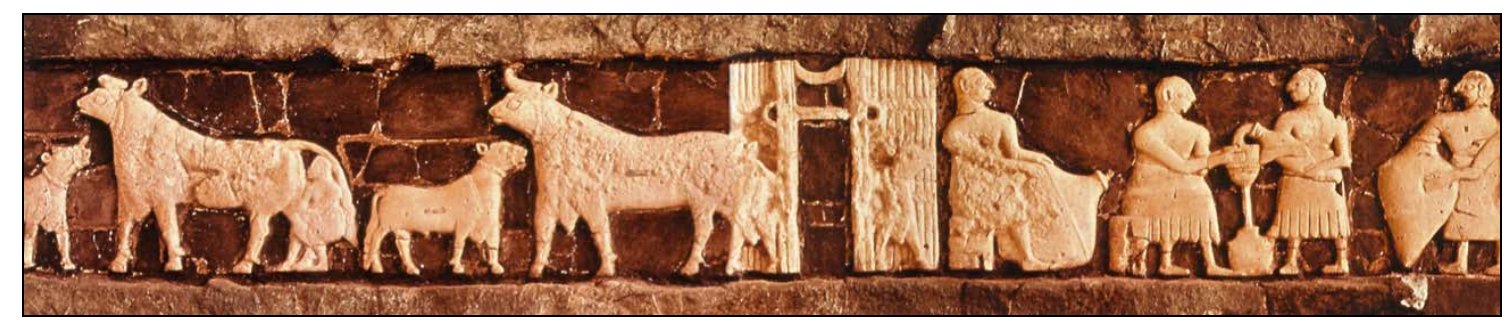

Figura 1.1. Friso de Lechería

A partir de ese momento las referencias documentadas al queso son numerosas. Se popularizó en la época Grecorromana; en la Edad Media (siglo X) los monjes en los monasterios de Europa ya producían diferentes variedades de quesos (Bonet et al. 2009). El pastoreo, la trashumancia y el peregrinaje durante la Edad Media ayudaron a difundir los diferentes tipos de quesos por toda la Península.

La elaboración a gran escala de este producto llegó con la Revolución Industrial y en la actualidad se dice que en el mundo existen más de 1.000 variedades de queso (Romero del Castillo y Mesters 2004), cada una de ellas con sus particularidades tanto en la leche de partida y los ingredientes de fabricación como en su tecnología de producción. 


\subsubsection{DEFINICIÓN}

El queso es un derivado lácteo que lleva jugando un papel muy importante en la nutrición humana durante años, siendo un producto con mayor vida útil que la leche de partida debido, entre otros factores, a su menor $\mathrm{pH}$ y su menor actividad de agua.

En este apartado, y con el fin de comprobar si el producto que se espera obtener en el desarrollo de la Tesis está acorde con la denominación de "queso", se incorpora su definición. Muchas son las definiciones de queso que se pueden encontrar, atendiendo a distintos puntos de vista como el sensorial, tecnológico, alimentario e incluso algunas con cierto aire poético como la ofrecida por Ramón Gómez de la Serna quien habla del queso como la eternidad de la leche (Arroyo y García 1988).

Con el fin de unificar criterios entre la gran variedad de tipos de quesos existentes se publicó en 2006 la Norma de calidad para Quesos y Quesos Fundidos (RD 1113/2006) donde queda definido el queso como:

"Se entiende por queso el producto fresco o madurado, sólido o semisólido, obtenido de la leche, de la leche total o parcialmente desnatada, de la nata, del suero de mantequilla o de una mezcla de algunos o de todos estos productos, coagulados total o parcialmente por la acción del cuajo u otros coagulantes apropiados, antes del desuerado o después de la eliminación parcial de la parte acuosa, con o sin hidrólisis previa de la lactosa, siempre que la relación entre la caseína y las proteínas séricas sea igual o superior a la de la leche."

Considérese la amplitud de la definición, que incorpora las diferentes formas posibles de la materia prima (leche), así como las diferentes formas de cuajado y de eliminación de agua/lactosuero, para albergar en ella a la tecnología de ultrafiltración. Por otra parte, el único límite se establece en la relación entre los diferentes tipos de proteínas, comparándola con la de la materia prima.

\subsubsection{CLASIFICACIONES}

Las clasificaciones, al igual que las definiciones, también pueden ser muy variadas, si bien las más relevantes, recogidas también en el RD 1113/2006, se realizan en base al origen de la leche y al grado de maduración alcanzada:

\section{SEGÚN EL ORIGEN DE LA LECHE}

Los quesos que se fabriquen con leche distinta de la de vaca, deberán incluir en su denominación, después de la palabra queso, la indicación de la especie que corresponda. Los quesos elaborados con mezcla de leche de dos o más especies, deberán incluir en su denominación, después de la palabra queso, la indicación de las especies animales de las que proceda la leche, en orden descendente de proporciones; si bien esta denominación podrá reemplazarse por la de Queso de mezcla. La descripción de los quesos de mezcla y su importancia se incorpora posteriormente en esta Tesis en base a su tipología y a datos nacionales de producción.

\section{ATENDIENDO A SU MADURACIÓN}

Atendiendo a su maduración, los quesos se denominarán de la siguiente forma: 
Queso fresco: es el que "está dispuesto para el consumo al finalizar el proceso de fabricación".

c Queso blanco pasterizado: "es aquel queso fresco en el que el coágulo obtenido se somete a un proceso de pasterización, quedando dispuesto para el consumo al finalizar su proceso de fabricación".

C Queso madurado: es el que, tras el proceso de fabricación, requiere mantenerse durante cierto tiempo a una temperatura y en condiciones tales que se produzcan los cambios físicos y químicos característicos del mismo. La palabra madurado podrá sustituirse por los calificativos según el grado de maduración alcanzado por el producto a la salida de fábrica que figuran en la Tabla 1.1.

Tabla 1.1. Denominación facultativa para quesos madurados. Fuente: RD 1113/2006

\begin{tabular}{|c|c|c|}
\hline \multirow{2}{*}{$\begin{array}{c}\text { DENOMINACION } \\
\text { FACULTATIVA }\end{array}$} & Peso > 1,5 kg & Peso $\leq \mathbf{1 , 5}$ kg \\
\cline { 2 - 3 } & \multicolumn{2}{|c|}{ Maduración mínima en días } \\
\hline Tierno & \multicolumn{2}{|c|}{} \\
\hline Semicurado & 35 & 20 \\
\hline Curado & 105 & 45 \\
\hline Viejo & 180 & 100 \\
\hline Añejo & 270 & \\
\hline
\end{tabular}

Queso madurado con mohos: es aquel en el que la maduración se produce, principalmente, como consecuencia del desarrollo característico de mohos en su interior, en la superficie o en ambas partes. Dicha denominación podrá sustituirse por la de queso azul o queso de pasta azul, cuando corresponda.

Otra clasificación bastante empleada, sobre todo por las diferencias organolépticas que origina entre los productos, es la basada en el método de cuajado. En ella se distingue entre queso de coagulación enzimática, en las que la coagulación se produce por la acción de enzimas coagulantes, y los quesos de coagulación láctica, donde se produce una precipitación de las proteínas al acidificarse la leche. Esta clasificación resulta de gran importancia desde el punto de vista tecnológico, ya que condiciona enormemente la composición mineral de la cuajada y por tanto la estructura final del queso.

\subsubsection{LA LECHE COMO MATERIA PRIMA}

La leche es un medio acuoso caracterizado por la presencia de diferentes fases en equilibrio inestable (Luquet 1991a):

c Una fase estable en solución acuosa verdadera con moléculas (lactosa) e iones (como el calcio) disueltos, como fase principal.

r Soluciones coloidales de proteínas, inestables por naturaleza, compuestas por dos tipos de coloides: 
- Por un lado las albúminas y las globulinas, relativamente estables al ser hidrófilas, conocidas como proteínas solubles, las cuales pasan al suero en las etapas de fabricación de queso.

- Por otro la caseína, proteína mayoritaria de la leche, en forma de micela fosfocálcica (de forma y masa variable) y cargada negativamente, lo que evita su agregación y separación de la fase acuosa. Esta proteína tiene una gran importancia tecnológica ya que formará la estructura final del queso.

c Por último una emulsión de grasa, en forma de glóbulos de grasa, rodeada de una membrana lipoproteica que la protege frente a oxidaciones, a la vez que la proporciona una carga total negativa.

Las principales especies animales utilizadas para la producción de leche y su transformación en queso (en el territorio nacional) son vaca, oveja y cabra, bien de forma individual o en alguna de sus mezclas.

Además de otros factores como el clima, la estación del año, la alimentación, el momento de lactación o el estado de salud del animal (Ramírez 2005) la mayor variación en la composición de la leche es debida a la especie productora, como se muestra en la Tabla1.2. No obstante, dentro de cada especie hay variaciones importantes entre razas e incluso entre individuos.

Tabla 1.2. Composición química de la leche para distintas especies (Luquet 1991a)

\begin{tabular}{|c|c|c|c|c|c|}
\hline$\% \mathrm{~m} / \mathrm{m}$ & GRASA & PROTEÍNA & LACTOSA & CENIZAS & Extracto Seco (ES) \\
\hline VACA & 3,4 & 3,3 & 4,9 & 0,9 & 13,0 \\
\hline OVEJA & 7,4 & 5,5 & 4,6 & 1,0 & 18,5 \\
\hline CABRA & 4,1 & 3,6 & 4,8 & 0,8 & 13,2 \\
\hline
\end{tabular}

La calidad de la leche, entendida como aptitud para dar un buen queso, va a depender tanto de los criterios físico-químicos recogidos en las Tablas 1.2 y 1.3 , como de otros criterios referentes a contaminantes como (Romero del Castillo y Mesters 2004) residuos de antibióticos, células somáticas o contaminación bacteriana, cuyos valores se encuentran limitados bajo el Reglamento (CE) $853 / 2004$.

Tabla 1.3. Propiedades físicas de la leche para distintas especies (Luquet 1991a)

\begin{tabular}{|c|c|c|c|c|}
\hline & $\mathrm{pH}\left(20^{\circ} \mathrm{C}\right)$ & Acidez ('D) & Densidad $\left(\mathrm{g} / \mathrm{cm}^{3}\right)$ & $\mathrm{T}_{\text {congelación }}\left({ }^{\circ} \mathrm{C}\right)$ \\
\hline VACA & $6,5-6,7$ & $15-18$ & $1,028-1,036$ & $<-0,520$ \\
\hline OVEJA & $6,65-6,75$ & $18-22$ & $1,020-1,035$ & $<-0,560$ \\
\hline CABRA & $6,5-6,7$ & $12-14$ & $1,026-1,042$ & $<-0,540$ \\
\hline
\end{tabular}

Las características de la leche de partida para la elaboración quesera van a condicionar, además de la calidad y seguridad del producto final, la aptitud tecnológica en las distintas etapas de elaboración. 


\subsubsection{ETAPAS EN LA ELABORACIÓN DE QUESO}

Desde un punto de vista meramente físico-químico, se pueden definir cuatro etapas en la elaboración de queso (Castillo 2001):

c Coagulación: modificación físico-química de la micela de caseína por la acción de enzimas proteolítcas o determinados ácidos que producen la desestabilización de dichas partículas.

c Desuerado: sinéresis y evacuación del lactosuero con separación de la fase sólida y la fase líquida. Generalmente se inicia tras la rotura mecánica del coágulo (corte) y se facilita bien por tratamiento térmico y/o mecánico (agitación), disminuciones del $\mathrm{pH}$, moldeado, aplicación de presión o durante el afinado.

c Salado: fenómenos de transporte de materia conducentes a la incorporación de sal a la cuajada. Puede hacerse aplicando el sólido desde la superficie, incorporándolo en la masa de leche o por inmersión en salmuera.

r Afinado: transformaciones bioquímicas de los componentes de la cuajada, bajo la acción de enzimas, principalmente microbianas. La digestión enzimática de la cuajada modifica su estructura y composición, acentuando el aroma y el sabor y confiriendo a la cuajada nuevas características, en lo referente al aspecto, la consistencia y el color. Estos cambios se producen durante lo que se conoce como maduración del queso.

La clasificación más empleada y que engloba todas las fases de producción del queso se realiza desde un punto de vista tecnológico del proceso de elaboración, dividiéndose en las siguientes etapas (Luquet 1991b): tratamientos previos, premaduración, coagulación, desuerado, moldeo, prensado, salado, oreo, maduración y afinado. Todas ellas se resumen a continuación (Castillo 2001).

c Tratamientos previos: operaciones de preparación de la leche como limpieza (tamizado, filtrado o clarificación por centrifugación), normalización en grasa (desnatado), estandarización en proteína (adición de caseína, concentración, ultrafiltración) conservación e higienización (refrigeración, termización, pasteurización, bactofugación, microfiltración o tratamientos por altas presiones).

c Premaduración: adición de cultivos y otros ingredientes como el $\mathrm{CaCl}_{2}$ para compensar el equilibrio salino de la leche, alterado en etapas previas de la elaboración. La premaduración puede ser rápida (antes del cuajado) o lenta (el día anterior).

c Coagulación: desestabilización de las micelas de caseína formando un gel que atrapa grasa, bacterias y toda la fase acuosa.

c Desuerado: separación de la cuajada del lactosuero mediante corte, agitación y/o calentamiento. Esta etapa permite regular la humedad y el pH de los granos de cuajada. El mecanismo de contracción y reorganización de la cuajada recibe el nombre de sinéresis. A su vez, se pueden realizar otras operaciones adicionales dentro de esta etapa como la eliminación de lactosa (delactosado) mediante intercambio de agua por lactosuero para evitar excesos de acidez en ciertas variedades de queso.

c Moldeo: introducción de la cuajada en moldes, que darán la forma final al queso. 
c Prensado: la cuajada ya en el molde se somete a presión, bien por gravedad o por aporte externo, para eliminar el suero residual y regular el $\mathrm{pH}$ final del queso antes de la maduración.

c Salado: adición de $\mathrm{NaCl}$, normalmente por salado superficial en seco o por inmersión en salmuera. Se realiza para completar el desuerado, favorecer la formación de corteza, disminuir la actividad del agua y realzar el sabor del queso. Por otra parte con la incorporación de sal en el queso se consigue una regulación del desarrollo bacteriano.

c Oreo, maduración y afinado: conservación en condiciones controladas de temperatura, humedad y velocidad del aire para facilitar la digestión enzimática dirigida o maduración biológica de la cuajada, desarrollándose la textura, el aroma y el sabor típico de cada queso. Durante esta etapa se produce la degradación de los constituyentes de la leche -azúcares, grasas y proteínas- mediante procesos de glicolisis, lipolisis y proteolisis.

\subsubsection{COAGULACIÓN Y SINÉRESIS}

Desde el punto de vista del trabajo desarrollado en la presente Tesis Doctoral, como se justificará posteriormente, las principales etapas del proceso de elaboración son la coagulación de la leche por la acción de enzimas coagulantes (cuajo), para la formación de una cuajada de carácter eminentemente enzimático, y el desuerado por sinéresis de la cuajada formada. Los fundamentos de ambas etapas se detallan a continuación.

\section{COAGULACIÓN DE LA LECHE}

Desentrañar el mecanismo de la coagulación de las micelas de caseína, por la ruta que sea, es un asunto complejo (Christian 2007). Para intentar comprender y explicar este proceso es necesario, en primer lugar, conocer la organización de las caseínas en su forma micelar. Para explicar su dispersión coloidal en la leche existen varias hipótesis, destacando entre ellas la de Schmidt por ser una de las más aceptadas.
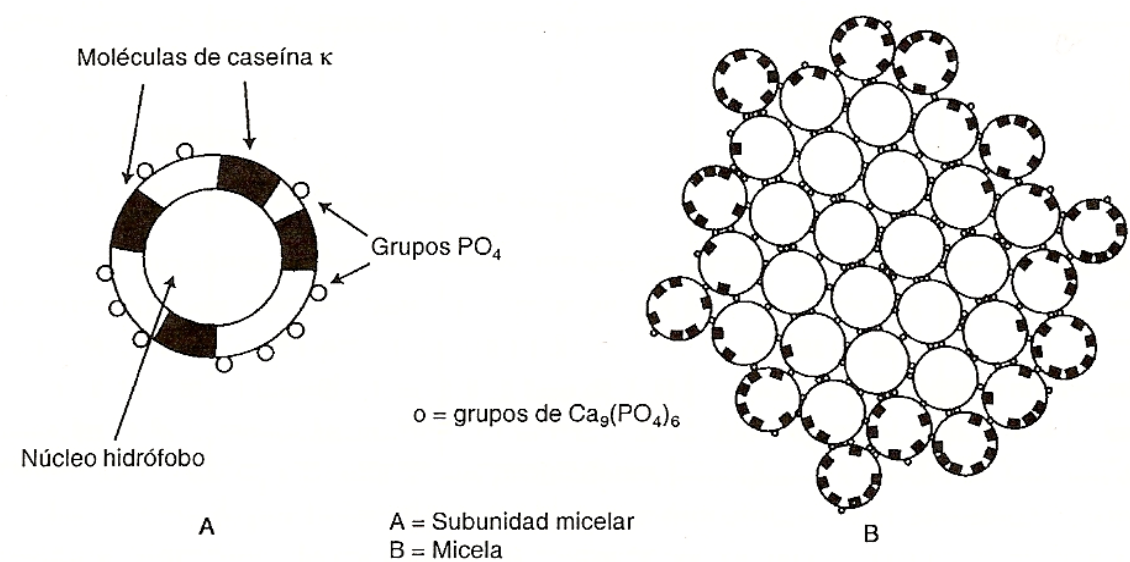

Figura 1.2. Estructura de la micela de caseína según Schmidt. (Goudedranche et al. 1980)

El modelo de Schmidt propone que la micela, a su vez, está compuesta de un conjunto de sub-micelas, de base proteica y composición variable. Estas sub-micelas se asocian unas a otras a través de fosfatos de calcio y magnesio para formar la micela. Las sub-micelas, de unos $15-20 \mathrm{~nm}$ de diámetro y 250.000 Da de peso molecular, son el resultado de la agrupación de entorno a una 
docena de monómeros caseínicos. Su estructura no es uniforme, al diferir en la proporción de cada uno de los distintos tipos de caseínas. Las sub-micelas se componen de un núcleo hidrófobo y una corteza hidrófila de carácter polar constituida por grupos fosfoséricos de las $\alpha \mathrm{s} 1$, $\alpha \mathrm{s} 2$ y $\beta$-caseínas, así como por grupos - $\mathrm{COOH}$ de las $\kappa$-caseínas. La agrupación en micelas se realiza a través de los grupos fosfoséricos, quedando las sub-micelas ricas en $\kappa$-caseína, con sus fibras de proteínas libres en el exterior de la micela, donde posteriormente actuará la enzima coagulante del cuajo, como se muestra en la Figura 1.2 (Goudedranche et al. 1980).

El mecanismo de coagulación de la leche, a través del ataque enzimático de la quimosina y pepsina (enzimas predominantes en el cuajo) se realiza en tres etapas, las cuales se representan en la Figura 1.3. Estas tres etapas son (Goudedranche et al. 1980):

c Hidrólisis enzimática de la $\kappa$-caseína (fase primaria).

c Agregación de las micelas desestabilizadas (fase secundaria).

c Formación del gel (coagulación visible).

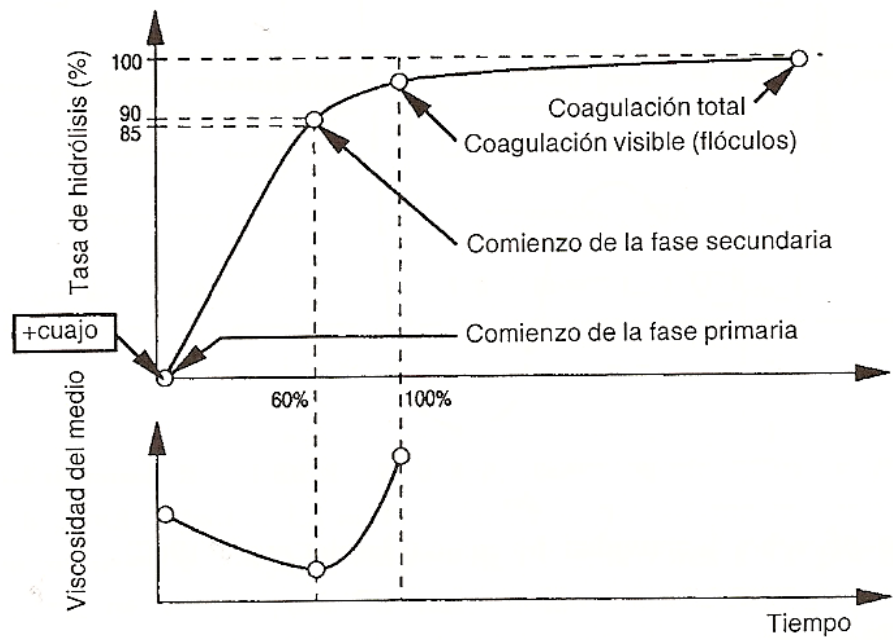

Figura 1.3. Evolución de la hidrólisis de la к-caseína. (Goudedranche et al. 1980)

La hidrólisis enzimática se realiza por la ruptura específica en el enlace Phe105-Met106, dividiendo la molécula de caseína en dos segmentos. El primer segmento (1-105 ó paracaseína $\kappa$ ) es hidrófobo, básico y permanece dentro de la micela mientras que el segmento final (106-169 ó caseinomacropéptido) es muy hidrófilo, ácido y pasa a formar parte del lactosuero. De esta forma se produce una disminución de la electronegatividad de la micela, a la vez que desciende su grado de hidratación.

La posterior agregación de las micelas se produce por uniones electrostáticas e hidrófobas entre las micelas modificadas (paracaseína $\kappa$ ). Las micelas agregadas sufren una profunda reorganización mientras se generan enlaces para constituir el gel, a través del calcio soluble, que atrapa en su interior el suero y la materia grasa. Debido al alto grado de mineralización de la micela, al tratarse de un proceso de coagulación enzimático, el gel formado es flexible, muy cohesivo, impermeable y contráctil. Las características específicas de los distintos geles van a depender de diversos factores como son el grado de mineralización (contenido en calcio), la relación grasa/proteína o la incorporación de proteínas solubles a la matriz de caseína. 


\section{PROCESO DE SINÉRESIS}

El gel enzimático formado en la etapa de coagulación presenta una cohesión, una elasticidad y una porosidad alta, pero una escasa permeabilidad, por lo que para obtener una cuajada con un elevado contenido en materia seca, es necesario realizar (después del corte) distintas operaciones como la agitación y el calentamiento. Durante este proceso de drenaje de suero se produce una redispersión de la malla de caseína. A su vez se producen interacciones hidrófobas dentro de la micela que ayudan a la formación de la estructura final. Este proceso global de eliminación de suero recibe el nombre de sinéresis (Govindasamy-Lucey et al. 2005).

Como indica Balcones (1996), entre los principales factores que favorecen la sinéresis destacan una disminución del $\mathrm{pH}$ a niveles entre 6,6 y 5,9, valores moderados de grasa -no homogeneizada-, el aumento de la temperatura, el aumento de la concentración de cuajo o la adición de cloruro cálcico.

Por otro lado, los tratamientos térmicos intensos de le leche, antes del cuajado, provocan la desnaturalización de las proteínas solubles y la disminución de la sinéresis por la mayor retención de agua en la matriz de caseína (Goudedranche et al. 1980). Del mismo modo, aumentos en la concentración de proteína también pueden dificultar la expulsión del suero.

\subsection{EL QUESO DE MEZCLA}

Bajo la denominación española de quesos de mezcla, se puede enmarcar al queso elaborado a partir de cualquier combinación de leche de las especies vaca, oveja y cabra, bien dos a dos o en mezcla de las tres. En esta Tesis se estudia este tipo de queso, a partir de la mezcla vaca/oveja.

\subsubsection{QUESOS DE MEZCLA EN ESPAÑA}

En España se elaboran más de cien variedades distintas de queso, de las que aproximadamente una cuarta parte están protegidas por alguna denominación de origen.

Los quesos de mezcla, aunque son quesos muy comerciales, son difíciles de enmarcar en una región determinada o bajo una denominación de origen u otra marca de garantía que los avale. No obstante la Orden de 9 de julio de 1987, donde se aprueban las Normas de Composición para los quesos Hispánico, Ibérico y De la Mesta (ORDEN 16728/1987), intenta identificar y conservar estos tres tipos de quesos de mezcla, todos ellos de gran tradición en nuestro país. En esa orden se especifica, entre otros aspectos, la composición mínima de la leche de partida para la elaboración de los distintos tipos de queso. Estas proporciones se recogen en la Tabla 1.4. Según estos valores, el queso de mezcla estudiado en esta Tesis sería similar al Hispánico, si bien no podría llevar ese calificativo debido a que no llega al porcentaje mínimo de leche de oveja.

Tabla 1.4. Mezclas de leche para queso Hispánico, Ibérico y De la Mesta. (ORDEN 16728/1987)

\begin{tabular}{|c|c|c|c|}
\hline$\%$ en Volumen & VACA & OVEJA & CABRA \\
\hline Hispánico & $>50$ & $>30$ & \\
\hline Ibérico & $>50$ & $>10$ & $>30$ \\
\hline De la Mesta & $>15$ & $>75$ & \\
\hline
\end{tabular}


Algunos ejemplos de quesos de mezcla (en cualquiera de sus variedades), con características similares de elaboración que el estudiado en el presente trabajo y reconocidos como autóctonos de las distintas Comunidades Autónomas españolas son en Andalucía los quesos de Grazalema y Calahorra; en Aragón el queso Tronchón; en Canarias el queso Flor de Guía; en Cantabria los Quesucos de Liébana o en Valencia el queso de Cervera (Ramírez y ILE 2009).

\subsubsection{QUESOS DE MEZCLA EN CASTILLA Y LEÓN}

En Castilla y León los quesos autóctonos son principalmente de oveja y cabra, si bien dentro de la categoría de mezcla se puede encontrar el queso de Burgos (Ramírez y ILE 2009), el queso fresco más conocido en nuestro país, así como otras variedades que han sido elaboradoras a lo largo de la historia, la mayoría de ellas de producción artesanal como los quesos de Cordiñales, Los Llanos o de Salamanca.

En la actualidad la marca de garantía Quesos Región del Duero, certificada en marzo de 2004, engloba dentro de su reglamento los quesos de mezcla vaca/oveja y vaca/cabra/oveja. Dicha denominación cuenta con queserías en siete de las nueve provincias que componen la comunidad de Castilla y León y bajo ella se comercializó, en su primer año, aproximadamente el 2,7 \% del total de queso producido en la comunidad.

Por otro lado la Consejería de Agricultura y Ganadería de esta comunidad, en el marco del I Plan de Promoción y Comercialización del sector agroalimentario de Castilla y León 2008-2011 y con el afán de dinamizar iniciativas de adecuación al mercado y a sus exigencias de competitividad, ha desarrollado la marca de garantía Tierra de Sabor cuya finalidad es distinguir en el mercado determinados productos agroalimentarios de calidad diferenciada producidos, elaborados $\mathrm{y} / \mathrm{o}$ transformados en el territorio de Castilla y León, entre ellos el queso en todas sus variedades (www.tierradesabor.es).

\subsubsection{DATOS DE PRODUCCIÓN Y CONSUMO}

Según datos facilitados por la Federación Nacional de Industrias Lácteas (FENIL), publicados por el Ministerio de Medio Ambiente y Medio Rural y Marino para el año 2008, la producción total de leche en España fue de 6.607.800 Tn, de la cual un 88,7 \% corresponde a leche vaca, un 5,7\% oveja y el 5,6 \% restante de cabra. Del total nacional, Castilla y León contribuyó con un $18 \%$ de la producción lechera.

Según las distintas especies, la leche de vaca producida en Castilla y León representa un $15 \%$ de la producción bovina nacional, mientras que la oveja llega a ser el $63 \%$ de la producción ovina nacional. Los datos globales de producción en Castilla y León para 2008 se recogen, por provincias, en la Tabla 1.5.

Tabla 1.5. Producción de leche en Castilla y León en el año 2008 (Fuente M.A.R.M.)

\begin{tabular}{|c|c|c|c|c|}
\hline miles de litros & Leche de Vaca & Leche de Oveja & Leche de Cabra & TOTAL \\
\hline Ávila & 113.915 & 4.591 & 11.567 & 130.073 \\
\hline Burgos & 75.369 & 15.646 & 761 & 91.776 \\
\hline León & 264.326 & 29.437 & 7.694 & 301.456 \\
\hline Palencia & 140.323 & 36.672 & 361 & 177.356 \\
\hline Salamanca & 47.561 & 26.071 & 2.332 & 75.964 \\
\hline
\end{tabular}




\begin{tabular}{|c|r|r|r|r|}
\hline miles de litros & Leche de Vaca & Leche de Oveja & Leche de Cabra & TOTAL \\
\hline Segovia & 85.582 & 6.724 & 1.208 & 93.514 \\
\hline Soria & 4.509 & 233 & 56 & 4.798 \\
\hline Valladolid & 67.119 & 76.347 & 1.442 & 144.908 \\
\hline Zamora & 101.656 & 68.885 & 3.707 & 174.249 \\
\hline Castilla $\boldsymbol{y}$ León & $\mathbf{9 0 0 . 3 6 0}$ & $\mathbf{2 6 4 . 6 0 6}$ & $\mathbf{2 9 . 1 2 8}$ & $\mathbf{1 . 1 9 4 . 0 9 4}$ \\
\hline
\end{tabular}

Algo más de la mitad del total de leche recogida en España se destinó a leches de consumo mientras que otra parte importante se destinó a la elaboración de queso. En total, según datos de la FENIL para 2008, se elaboraron un total de $317.000 \mathrm{Tn}$, sin contar los quesos fundidos (45.600 Tn), divididas según el origen de la leche de la siguiente manera:
c. Queso de vaca
$129.000 \mathrm{Tn}$
$(40,7 \%)$
c Queso de oveja
$45.300 \mathrm{Tn}$
$(14,3 \%)$
c. Queso de cabra
$20.400 \mathrm{Tn}$
$(6,5 \%)$
๙ Queso de mezcla $122.400 \mathrm{Tn} \quad(38,5 \%)$

El consumo doméstico de queso en España fue de 6,5 $\mathrm{kg}$ por persona y año en 2008 (FENIL). Aunque su tendencia va en aumento desde el año 1984 cuando estaba en 4,4 kg por persona y año, como se muestra en la gráfica de evolución de la última década (Figura 1.4), sus posibilidades de aproximación a los consumos europeos están aún por desarrollar.

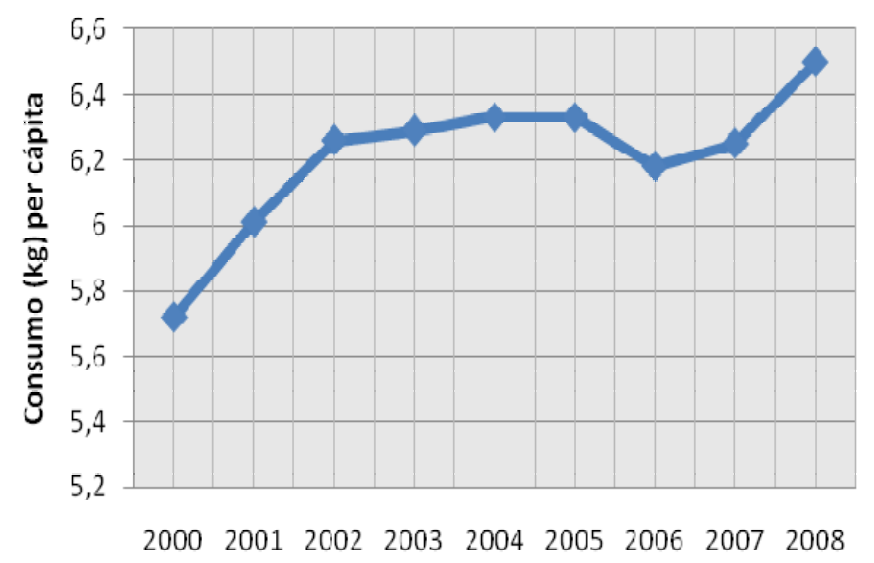

Figura 1.4. Evolución del consumo de queso en España en los últimos años (Fuente: M.A.R.M.)

Cabe destacar, según un estudio publicado por la FENIL en 2009 (realizado entre junio 2007/junio 2008) que del total consumido, aproximadamente un $75 \%$ se consumía en el hogar, superando en términos de volumen los 270 Millones de $\mathrm{kg}$.

No obstante, la previsión de consumo de queso en la UE, según datos de la FAPRI (2009), aumentará un $12,98 \%$ durante el periodo 2008-2018. Por todo ello parece que podría ser el momento adecuado para generar la estructura futura, que permita una mejora continua de la competitividad y del valor añadido de los productos mediante el uso de nuevas tecnologías que ofrezcan un valor añadido al producto final, como se pretende en esta Tesis. 
Por último, en la Tabla 1.6 se puede observar como el tipo de queso más demandado por el consumidor es el queso semicurado, con un consumo per cápita medio de 2,30 kg a un precio medio de $9,74 € / \mathrm{kg}$, que indica el valor añadido introducido en el queso por el procesado de la leche y los periodos de curado.

Tabla 1.6. Consumo en hogares según el tipo de queso para el año 2008 (Fuente: M.A.R.M.)

\begin{tabular}{|c|r|r|r|c|}
\hline PRODUCTO & $\begin{array}{c}\text { Volumen } \\
\text { (miles de kg) }\end{array}$ & $\begin{array}{c}\text { Valor } \\
\text { (miles de } \boldsymbol{\epsilon} \text { ) }\end{array}$ & $\begin{array}{c}\text { Precio } \\
\text { medio (kg) }\end{array}$ & $\begin{array}{c}\text { Consumo (kg) } \\
\text { per cápita }\end{array}$ \\
\hline Queso & $289.797,61$ & $2.152 .934,10$ & 7,43 & 6,43 \\
\hline Queso fresco & $93.393,94$ & $465.311,53$ & 4,98 & 2,07 \\
\hline Queso fundido & $36.150,34$ & $217.150,61$ & 6,01 & 0,81 \\
\hline Queso semicurado & $103.152,52$ & $1.004 .300,42$ & 9,74 & 2,30 \\
\hline Queso de bola & $6.055,96$ & $53.498,96$ & 8,83 & 0,13 \\
\hline Queso Emmental y Gruyere & $3.614,91$ & $29.827,36$ & 8,25 & 0,11 \\
\hline Queso azul & $2.794,35$ & $28.938,68$ & 10,36 & 0,06 \\
\hline Otros tipos & $44.635,63$ & $353.906,57$ & 7,93 & 1,00 \\
\hline
\end{tabular}

Si bien estas preferencias pueden cambiar por comunidades o países, las tecnologías que consigan mejorar la producción de este tipo de quesos (incrementando rendimientos o generando una mayor aceptación del consumidor) tendrán una mayor viabilidad económica y una mayor influencia sobre el mercado.

\subsection{PROCESOS DE SEPARACIÓN CON MEMBRANAS}

El término membrana designa un sistema sólido o líquido que separa dos fases macroscópicas, verificando un control selectivo de la transferencia de materia y energía a su través (Ibañez 1989).

En este apartado se resumen algunos conceptos generales sobre la filtración tangencial con membranas, en lo que se refiere, únicamente, a procesos de separación basados en el principio de permeabilidad selectiva en función del estado de solvatación y la estructura de los constituyentes de una disolución, haciendo intervenir un gradiente de presión entre ambos lados de la membrana.

En particular, se introducen los sistemas de filtración tangencial, microfiltración (MF), ultrafiltración (UF), nanofiltración (NF) y ósmosis inversa (OI), que consiguen controlar los depósitos en o sobre el medio filtrante mediante barrido del retenido sobre la membrana, los cuáles han tenido aplicación industrial en el sector lácteo en distinta medida.

\subsubsection{ASPECTOS GENERALES SOBRE LA FILTRACIÓN TANGENCIAL}

Frente a los procesos de filtración en torta (dead-end) donde la limitación a la permeabilidad se establece principalmente por los depósitos sobre la membrana, la filtración tangencial consigue su eliminación parcial mediante el barrido continuado de la superficie de la membrana por el retenido. Esta particularidad, junto con la reducción de costes y la optimización de procesos, ha permitido el desarrollo de los sistemas industriales de filtración. 
El origen de los procesos de filtración tangencial se puede establecer en el descubrimiento de los fenómenos de ósmosis -transporte de agua o solvente a través de una membrana semipermeableobservado en el año 1748 por Abbe Nollet. Un siglo más tarde, en 1856, Fick desarrolló la primera membrana sintética, a partir de nitrocelulosa, dando origen a lo que se conoce como la separación por membranas.

A partir de ese momento la evolución de las distintas técnicas ha sido notable, destacando hitos como el desarrollo de nuevos materiales poliméricos y de membranas inorgánicas -como las cerámicas- en la década de los ochenta, los cuales han abierto multitud de campos de aplicación en todos los sectores, entre ellos el alimentario.

Sobre el proceso de filtración afectan características dependientes de la membrana -como su composición química, carga, hidrofobicidad, potencial zeta-, del módulo -como su diseño o material de fabricación-, de los parámetros de operación -como la diferencia de presión a través de la membrana o la velocidad tangencial (que por su importancia son abordados más adelante en este trabajo)-, o de los procesos de ensuciamiento y limpieza de la membrana que afectan tanto a su selectividad como a su permeabilidad.

\section{POSIBILIDADES TECNOLÓGICAS}

La tecnología de membranas engloba distintos procesos de separación de compuestos a nivel molecular. Cada uno de estos procesos requiere unos equipos y unas condiciones de trabajo específicas, que les hace apropiados para aplicaciones de separación, concentración y/o fraccionamiento.

Como se observa en la Figura 1.5, según el tamaño de la molécula que se desee separar, con gradiente de presión como fuerza impulsora, encontramos cuatro tipos de técnicas diferentes, que se separan de la filtración convencional: microfiltración (MF), ultrafiltración (UF), nanofiltración (NF) u ósmosis inversa (OI). Si bien la investigación básica se centra en otras técnicas más innovadoras como la destilación con membranas o la pervaporación, la aplicación de estas tecnologías a sistemas industriales -objetivo último de esta Tesis- necesita de desarrollos aún importantes, exceptuando aplicaciones puntuales ampliamente instauradas.

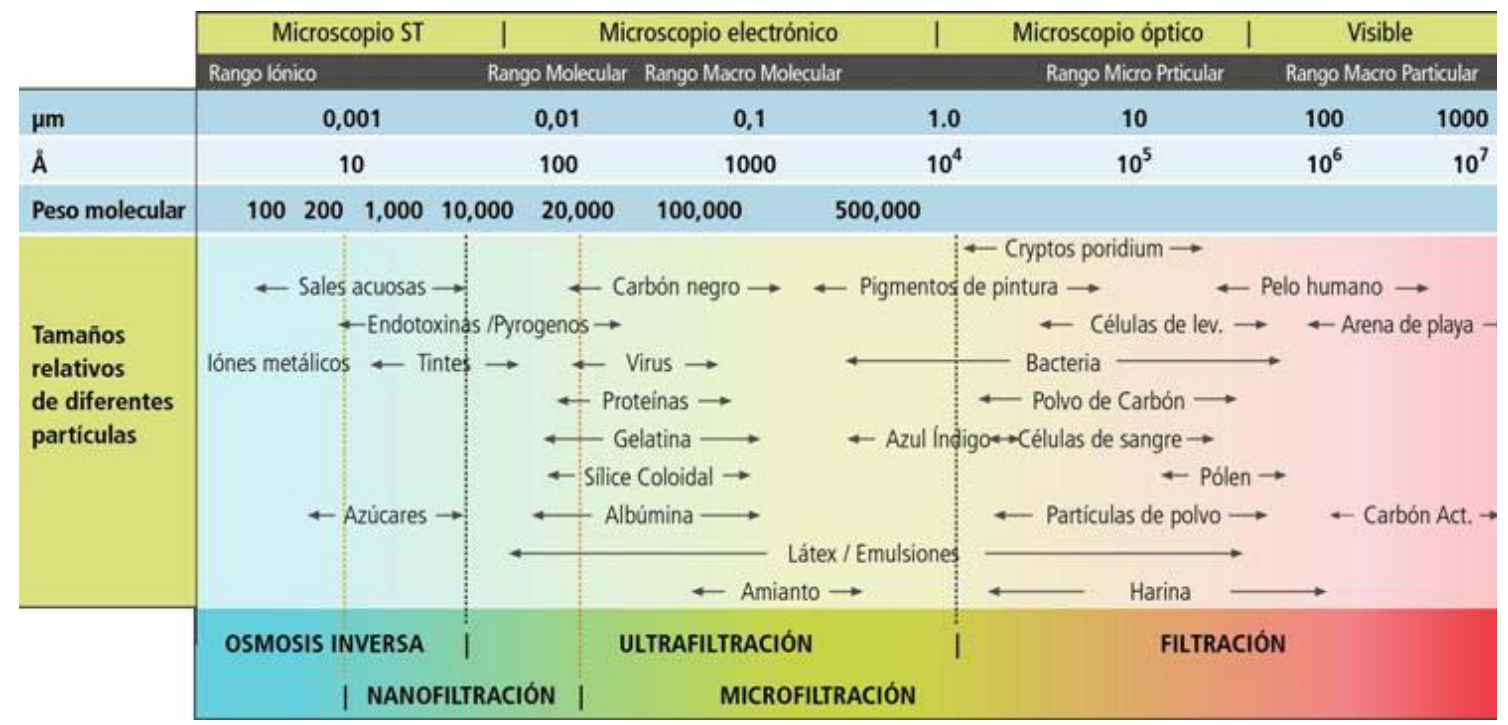

Figura 1.5. Espectro de filtración 
Las aplicaciones de la tecnología de membranas, como muestra la Figura 1.5, se dan en una gran variedad de campos, tomando especial importancia en la industria agroalimentaria por las condiciones limitadas de temperatura a las que permiten operar, acorde a las necesidades específicas de sus productos.

\section{COMPOSICIÓN Y ESTRUCTURA DE LAS MEMBRANAS}

La aplicación industrial de estas tecnologías ha pasado por importantes desarrollos en el campo de los materiales empleados para la fabricación de las membranas, con el fin de conseguir mayor selectividad, mayor duración o menor coste.

En cuanto a la naturaleza de las membranas poliméricas orgánicas los materiales más empleados, por orden cronológico, son acetato de celulosa y celulosa regenerada (empleados en las primeras filtraciones a pesar de su escasa resistencia química y microbiológica) seguidos de polisulfonas, polietersulfonas y poliamidas (de coste reducido y resistencias moderadas a temperaturas y $\mathrm{pH}$ ), y por último poliacrilonitrilo y fluoruro de polivinilideno (de superior resistencia química y térmica).

También es posible el empleo -a pesar de un coste ligeramente superior- de membranas realizadas con materiales inorgánicos. Se trata de membranas elaboradas a partir de materiales como óxidos de titanio y zirconio sobre alúmina, carbón o acero inoxidable. Dichos materiales les confieren una mayor resistencia tanto química como térmica en comparación a las poliméricas.

La selección de los materiales viene dada por razones de operabilidad -las membranas poliméricas tiene una vida útil de 9 a 18 meses, con ciclos diarios de limpieza normales, mientras que en las inorgánicas se puede prolongar hasta los 14 años (Cheryan y Wilson 2000a) - o por razones económicas de coste -las membranas cerámicas son de entre 10 y 30 veces más caras que las poliméricas-.

Las mejoras y descubrimientos en la fabricación de membranas en cuanto a materiales, resistencia o economía son factores clave para el desarrollo de estas técnicas a escala industrial. Otro hito importante en este sentido es la posibilidad de fabricación asimétrica de las membranas, frente a las de estructura homogénea que presentaban menor permeabilidad. Como ejemplo de membranas asimétricas, destacar la fabricación multicapa basada en la superposición de soportes porosos (de entre 100 y $200 \mu \mathrm{m}$ ) de alta permeabilidad con capas filtrantes de mayor selectividad y menor espesor.

Hoy en día, la mayoría de las membranas poliméricas son asimétricas, con una capa fina superficial de $0,1-0,2 \mu \mathrm{m}$ de espesor en la superficie que establece el umbral de corte de la membrana. Esta capa es la que marca el alcance de la separación mientras el resto, de elevada porosidad, actúa como soporte de esa capa (denominada "piel").

\subsubsection{CLASIFICACIÓN DE LOS PROCESOS DE SEPARACIÓN CUYA FUERZA IMPULSORA ES LA PRESIÓN}

Por tratarse de los procesos más empleados en agroalimentación, y en particular en tratamientos ya existentes en la industria láctea -muchos de ellos incorporados en quesería- se incorpora una breve descripción de las diferentes tecnologías en función del corte molecular de la membrana, es decir, en función del tamaño de las moléculas que se retienen en la superficie de la misma, de acuerdo con el espectro de filtración mostrado en la Figura 1.5. 
Los procesos con membranas que se describen a continuación constituyen una técnica de separación en los que un gradiente de presión fuerza el paso selectivo de unos componentes sobre otros a través de una membrana permeable (Chacón 2006). La corriente que contiene los componentes que atraviesan la membrana, por tener un tamaño menor al de la porosidad de la misma, recibe el nombre de permeado. Aquellos componentes no permeables a la misma se concentran en la corriente de retenido.

\section{MICROFILTRACIÓN (MF)}

Por medio de este proceso se separan selectivamente partículas de alto peso molecular, que se encuentran en suspensión o en estado coloidal, mayores de $200.000 \mathrm{Da}$, mediante membranas con tamaño de poro de entre 0,1 y 2,0 $\mu \mathrm{m}$. Las presiones de trabajo son de hasta 4 bar (Cheryan y Wilson 2000a).

Las referencias a tamaño de poro deben interpretarse como una distribución de tamaños y se caracterizan según el corte de la membrana o molecular weight cut-off (MWCO), definido como el peso molecular de una disolución patrón (normalmente proteínas globulares o etilenglicoles) retenidas en un $90 \%$ en unas condiciones estándar.

\section{ULTRAFILTRACIÓN (UF)}

Proceso de separación selectivo de macromoléculas de peso molecular entre 1.000-500.000 Da, con un tamaño de poro entre 1 y $50 \mathrm{~nm}$ (Cheryan y Wilson 2000a; Cheryan y Wilson 2000b), mediante un flujo tangencial a lo largo de la superficie de la membrana a presiones inferiores a $1.000 \mathrm{kPa}$ (10 bar).

La diafiltración (DF) es un modo particular de operación de la UF, donde el retenido se diluye con agua para reducir la concentración de los componentes capaces de atravesar la membrana, ya que por atravesar la membrana se reparten entre retenido y permeado.

Gracias al empleo de membranas inorgánicas se ha ampliado el rango de aplicación en las operaciones debido a su mayor estabilidad al $\mathrm{pH}(0,5-13,5)$ y a la temperatura (hasta $350{ }^{\circ} \mathrm{C}$ ), pasando a ser limitantes por su resistencia los materiales de fabricación de módulos y juntas y no la resistencia química o térmica de la membrana.

\section{NANOFILTRACIÓN (NF)}

Separa compuestos de bajo peso molecular, de entre 200 y $1.000 \mathrm{Da}$, mediante tamaños de poro inferiores a $2 \mathrm{~nm}$, como moléculas disociadas de pequeño tamaño, en proporción inversamente proporcional a su valencia. Las presiones a través de la membrana utilizadas están entre 15 y 25 bar (Cheryan y Wilson 2000a).

\section{ÓSMOSIS INVERSA (OI)}

Es un proceso de eliminación de agua, mayoritariamente, que opera a elevadas presiones (de 5 a 10 veces las presiones usadas en la UF). Mediante la OI se separan solutos de peso molecular aproximado menor de 150 Da mediante membranas densas con tamaño de poro entre 5 y $10 \AA$. Para vencer la elevada presión osmótica asociada a los compuestos de bajo peso molecular retenidos, es necesario operar a presiones de entre 30 y 60 bar (Cheryan y Wilson 2000a). Este 
mismo motivo limita los grados de concentración alcanzados, permitiendo únicamente alcanzar retenidos de hasta un $30 \%$ de extracto seco.

\subsubsection{CONFIGURACIÓN DE LAS MEMBRANAS EN MÓDULOS}

Según las condiciones específicas de cada proceso de concentración y/o separación se puede trabajar con la membrana dispuesta en distintas configuraciones, las más comunes se detallan a continuación (Cheryan 1998).

\section{TUBULARES}

La alimentación fluye a través de un tubo de entre 85 y $600 \mathrm{~cm}$ de longitud y de 3 a $25 \mathrm{~mm}$ de diámetro interno. Su diámetro condiciona el consumo de energía y el coste de fabricación.

Su modo normal de operación es mediante la circulación de la alimentación por el interior de la membrana, consiguiendo alcanzar elevadas velocidades de barrido. Las membranas de esta conformación se conectan en serie o en paralelo en módulos multitubulares.

En esta conformación tubular se desarrollan sistemas multicanal que en una única membrana contienen varios canales longitudinales paralelos, incrementando la superficie filtrante.

Las membranas tubulares son fáciles de limpiar y permiten procesar fluidos con partículas y líquidos de elevada viscosidad, aunque presentan la menor relación área/volumen de todas las configuraciones. En determinadas aplicaciones su uso puede requerir mayores flujos de alimentación, debido a las altas viscosidades, lo que conlleva un mayor consumo energético $\left(0,6-1,0 \mathrm{~kW} / \mathrm{m}^{2}\right)$.

La posibilidad de elevadas velocidades tangenciales y flujos en régimen turbulento, facilitan los procesos de limpieza. Esta conformación permite un montaje y reemplazo sencillo de las membranas.

\section{FIBRAS HUECAS}

Son sistemas tubulares de haces de membranas de menor diámetro que las tubulares, entre 0,19 y $1,25 \mathrm{~mm}$, inmersas en una carcasa que puede contener entre 500 y 3.000 fibras en paralelo. Las fibras actúan simultáneamente como soporte y medio filtrante.

La alimentación circula por su interior y el permeado se recoge en el módulo que contiene el haz de fibras.

Como ventaja más destacable de esta conformación se encuentra su elevada relación superficie/volumen con un reducido volumen muerto. Como inconvenientes destacar la necesidad de sustitución completa de los módulos en caso de fallo o la imposibilidad de operar con productos viscosos. La presión transmembrana está restringida a $170-270 \mathrm{kPa}$, por su mayor fragilidad, lo que supone menores consumos energéticos (entorno a $0,2 \mathrm{~kW} / \mathrm{m}^{2}$ ).

\section{MEMBRANAS PLANAS}

Estos módulos se basan en la agregación de membranas planas y separadores alternadamente al estilo de los cambiadores de calor de placas. El conjunto se puede montar tanto en vertical como 
en horizontal, tratándose de una configuración simple y de fácil ampliación, en la que toma especial relevancia la distancia entre membranas (espaciador).

La relación superficie/volumen que se alcanza es intermedia a la conseguida con fibras huecas y tubulares. La energía de bombeo requerida está entorno a los $0,5-0,7 \mathrm{~kW} / \mathrm{m}^{2}$ (Maubois y Brulé 1982).

Históricamente han sido las más empleadas por la industria láctea ya que combinan una velocidad de circulación intermedia, con un espacio entre membranas -definido por los separadoressuficientemente elevado para evitar su obturación (clogging). Además, es factible la sustitución de parte de las membranas, en caso de obturación, rotura o mal funcionamiento, sin necesidad de sustituir el módulo completo.

\section{MEMBRANAS ESPIRALES}

En la actualidad se trata de la configuración más empleada en la industria láctea y alimentaria en general. La bajada de los precios de los módulos hace factible la sustitución de módulos completos en casos de ensuciamiento o rotura. La mejor comprensión y el mayor control de los procesos de filtración con membranas evitan, por ejemplo, la realización de limpiezas inadecuadas que degraden completamente los módulos. Por último la adaptación de nuevos materiales a los módulos espirales ha permitido su creciente implantación.

Están constituidas por dos membranas planas separadas por un espaciador, enrollado a un tubo perforado por donde se recoge el permeado. Cuando la alimentación fluye por la superficie de la membrana el permeado la atraviesa y se recoge en el tubo central. Entre las membranas se instala una rejilla plástica de espesor variable que permite aumentar la turbulencia en su superficie minimizando el ensuciamiento. Las etapas de limpieza y desinfección pueden ser más complicadas que con otras configuraciones, especialmente cuando se trabaja con líquidos muy viscosos.

Algunas ventajas de esta conformación son su elevada compacidad (300 a $1.000 \mathrm{~m}^{2} / \mathrm{m}^{3}$ ), un reducido consumo energético y un moderado coste. Como desventajas indicar la posibilidad de puntos muertos en el sistema o una elevada pérdida de carga en los módulos.

Esta configuración es adecuada para todos los tipos de operaciones existentes, ya que la naturaleza y el diseño del soporte de la membrana permiten trabajar a elevadas presiones sin que la membrana se vea dañada.

\subsubsection{PRINCIPALES VARIABLES DEL PROCESO}

En este apartado se describen las variables que afectan significativamente en la hidrodinámica del proceso de filtración sobre los valores de densidad de flujo de permeado a través de la membrana. Entre ellas se recogen como más importantes la presión y la temperatura de operación o la velocidad de barrido en la superficie de filtración. Todas estas variables condicionan otros factores como el grado de concentración alcanzado o el porcentaje de retención de los distintos constituyentes de la alimentación.

\section{DIFERENCIA DE PRESIÓN A TRAVÉS DE LA MEMBRANA}

En los procesos de filtración descritos en el Apartado 1.3.2, se establece un diferencial de presión entre ambos lados de la membrana denominado "presión transmembrana (TMP)" que será la 
fuerza que impulse la separación. Esta TMP es la diferencia existente entre los dos lados de la membrana, el retenido y el permeado. Como en cualquier configuración de membranas, lo que se conoce es la presión a la entrada y la salida de retenido y permeado, además de la TMP local en cada punto de la membrana, se define una TMP promedio entre las entradas y salidas de ambas corrientes, que se calcula según la Ecuación [1.1].

$$
T M P=\frac{P_{r, e}+P_{r, s}}{2}-\frac{P_{p, e}+P_{p, s}}{2}
$$

Donde $\quad P_{r, e}$ : presión a la entrada del retenido

$P_{r, s}:$ presión a la salida del retenido

$P_{p, e}:$ presión a la entrada del permeado

$P_{p, s}:$ presión a la salida del permeado

El adecuado manejo de la TMP es muy importante para reducir el impacto de la colmatación, ya que el efecto de compresión bajo una presión muy acentuada puede provocar un agudo incremento en la resistencia hidráulica y una disminución de la selectividad de la membrana.

\section{FACTOR DE REDUCCIÓN DE VOLUMEN Y PORCENTAJE DE RETENCIÓN}

El factor de reducción de volumen (VCR) se utiliza para medir el grado de concentración en el proceso global, y se calcula como:

$$
V C R=\frac{V_{A}}{V_{R}}=\frac{V_{R}+V_{P}}{V_{R}}=1+\frac{V_{P}}{V_{R}}
$$

Donde $\quad V_{i}$ : denota los volúmenes de alimentación $(\mathrm{A})$, retenido $(\mathrm{R})$ o permeado $(\mathrm{P})$

El factor de reducción, también conocido como factor de concentración, puede ser obtenido a partir tanto de los volúmenes como de la masa total de las corrientes. Para operaciones en continuo se calcula a través de los caudales o los flujos másicos de las distintas corrientes (alimentación, retenido y permeado) siguiendo la base de la Ecuación [1.2].

El VCR también puede calcularse a partir de la Ecuación [1.2] y del balance de materia para el extracto seco $(E S)$, sobre las tres corrientes presentes, alimentación $(A)$, retenido $(R)$ y permeado $(P)$, a través de la fórmula:

$$
V C R=\frac{E S_{R}-E S_{P}}{E S_{A}-E S_{P}}
$$

El porcentaje de retención o rechazo de un componente dado $\left(\% R_{i}\right)$ se define como la relación entre la concentración de dicho componente entre las corrientes de permeado y retenido, restado de la unidad según:

$$
\% R_{i}=1-\frac{\text { Concentración del componente " } i \text { " en el permeado }}{\text { Concentración del componente " } i \text { " en el retenido }}
$$


Acorde a la definición, un compuesto de tamaño molecular superior al corte de la membrana será retenido en su totalidad y el $\% R_{i}$ tomará el valor de uno, ya que la concentración en el permeado será cero para él. Si por su tamaño atraviesa libremente la membrana su concentración se iguala a ambos lados, por lo que el cociente de la ecuación será uno y el valor de retención será cero. Para compuestos que son retenidos parcialmente $\% R_{i}$ tomará valores entre cero y uno, aunque en ocasiones puede tomar también valores negativos.

\section{DENSIDAD DE FLUJO DE PERMEADO}

La densidad de flujo de permeado $(J)$ se define como el volumen filtrado por unidad de tiempo y de área de membrana. Cuanto mayor sea el valor de esta variable menores serán los tiempos de operación. Como se muestra en la Figura 1.6, la relación entre la densidad de flujo de permeado y la TMP es lineal para el disolvente puro, pero no así para una disolución de macromoléculas, en cuyo caso se observan dos regiones diferenciadas (Cheryan 1998).

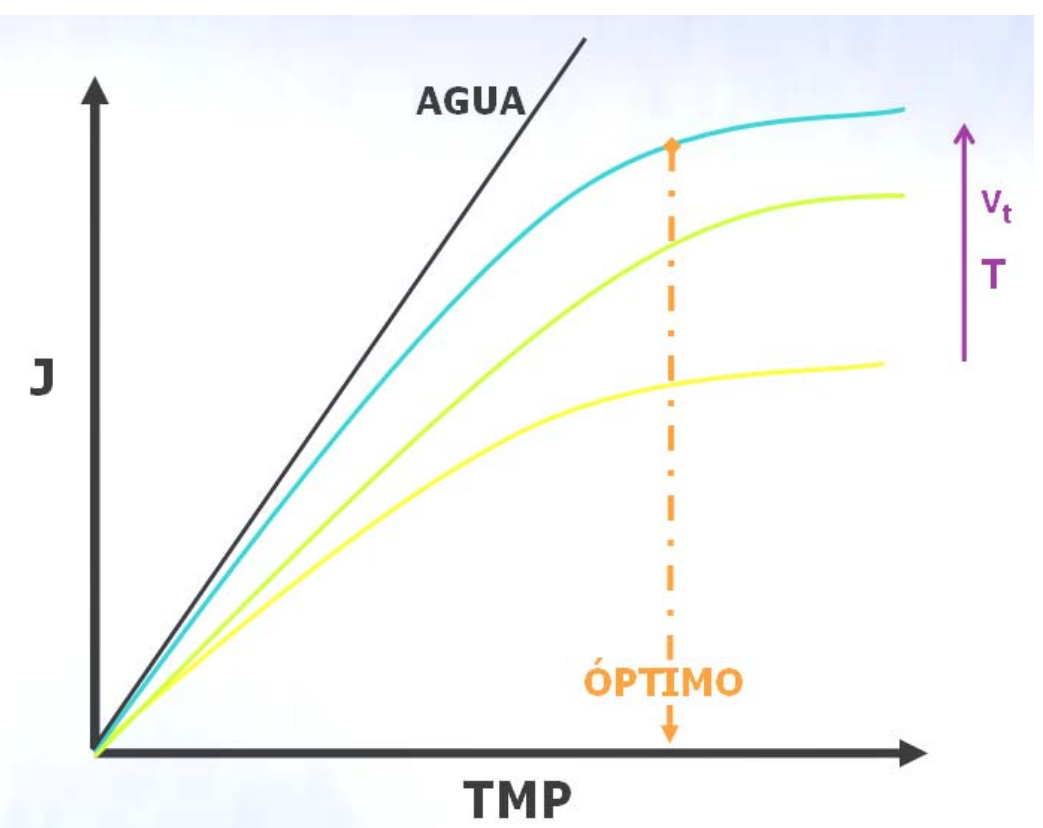

Figura 1.6. Flujo de permeado en función de la presión transmembrana

El comportamiento observado en la Figura 1.6 se puede explicar a través de varios modelos. Como indican Field et al. (1995), de acuerdo con la teoría del flujo crítico existen dos zonas de flujo según la presión aplicada entre ambos lados de la membrana. En la primera de ellas, zona de control por presión, la TMP se encuentra por debajo de la presión crítica y la filtración se realiza sin formación de un depósito en la superficie de la membrana que limite la densidad de flujo en función de la fuerza impulsora, por lo que a medida que se incrementa la TMP mayor cantidad de materia atraviesa la membrana por unidad de tiempo.

La filtración en la primera zona, empleada mayoritariamente en operaciones de microfiltración (Howell 1995), se conoce por algunos autores como flujo subcrítico y es interesante en ocasiones para obtener la máxima selectividad. En esta zona los flujos alcanzados son menores, haciéndose necesario un mayor área de membrana o superiores tiempos de operación.

En la segunda zona, de control por difusión, la TMP está por encima de la presión crítica y la densidad de flujo tiende a un valor constante -denominado densidad de flujo límite-. Este comportamiento se explica a través de modelos de filtración en gel o modelos de transporte 
inverso. En esa zona la densidad de flujo de permeado es independiente de la presión y del tamaño de poro. El flujo a través de la membrana está controlado exclusivamente por la transferencia de materia entre la superficie de la membrana -en la que hay una concentración local mayor a la del seno de la alimentación- y el lado del permeado, según las leyes de difusión y transporte de materia. Por tratarse de un flujo controlado por los fenómenos de transferencia, y por tanto función del gradiente de concentración de las diferentes especies, la constancia de la concentración debido a, por ejemplo, la formación de un gel superficial hace a la densidad de flujo de permeado independiente de la TMP.

La selectividad en procesos de separación o fraccionamiento no es óptima en muchos casos al trabajar en la segunda zona de la gráfica de la Figura 1.6. Este efecto se acentúa al incrementar en demasía la TMP por encima de la crítica, por una compactación excesiva de la capa de gel.

Para operaciones de concentración, normalmente, se trabaja en la intersección de ambas zonas (densidad de flujo óptima) donde el flujo y la presión se denominan límites o críticos, obteniendo simultáneamente unos adecuados valores tanto de densidad de flujo de permeación como de selectividad. En otros casos, como en el fraccionamiento de proteínas, donde se persigue la máxima selectividad, se elige operar en la zona de control por presión.

\section{LA VELOCIDAD DE RECIRCULACIÓN Y LA TEMPERATURA}

Las plantas normales de filtración cuentan con una bomba de alimentación que transfiere la presión al fluido y una bomba de recirculación que proporciona elevada velocidad tangencial $\left(v_{t}\right)$ en la superficie de la membrana. A menudo mayores velocidades tangenciales aumentan la densidad de flujo de permeado debido a que actúa a modo de barrido sobre la superficie de filtración, minimizando la polarización de la concentración y el ensuciamiento. Cuanto mayor sea la velocidad mayor será J, si bien mayor será también la caída de presión en el módulo.

Aumentos de la temperatura de operación tienen un comportamiento similar, incrementando $J$, por el efecto que tiene en la disminución de la viscosidad de la alimentación, mejorando la fluencia.

Como se muestra en la Figura 1.6 el efecto del incremento en el valor de cualquiera de estas variables, o ambas, se traduce en un aumento de la pendiente para la primera zona donde la relación entre Jy TMP sigue un comportamiento lineal. Tanto los valores de temperatura como de caída de presión en el módulo ( $y$ por tanto la velocidad de recirculación) estarán limitados por las especificaciones técnicas de la membrana utilizada.

\subsubsection{MODELIZACIÓN CLÁSICA DE LOS PROCESOS DE FILTRACIÓN TANGENCIAL}

Los fenómenos implicados en la filtración pueden modelarse empleando sistemas sencillos y tradicionales, como la Ley de Darcy, con modificaciones que incorporan diferentes términos de resistencia hidráulica o de presión osmótica. Modelos más complejos, aplicados a medios multicomponentes de macromoléculas, incorporan potenciales $Z$ o interacciones entre los distintos componentes y de éstos con la membrana.

Cuando el sistema de filtración tangencial opera en condiciones de estado estacionario, pueden aplicarse modelos clásicos para el transporte de fluidos a través de los poros de la membrana, tratando la operación como un flujo laminar a través de un canal, donde el flujo de permeado es directamente proporcional a la presión aplicada. Estos modelos son muy descriptivos de los fundamentos del proceso de separación. 
Mediante la ley de Darcy se expresa la dependencia lineal entre la presión transmembrana y el flujo de permeado, a través de la viscosidad del permeado $\left(\mu_{0}\right)$ y la resistencia al flujo $\left(R_{m}\right)$ que ofrece la membrana (Jeantet et al. 2000).

$$
J=\frac{T M P}{R_{m} \cdot \mu_{0}}
$$

El inverso de la resistencia se conoce como permeabilidad $\left(1 / R_{m}\right)$ y es función tanto de la estructura de la membrana, como de los depósitos que se forman en el interior y en la superficie.

En cualquier operación de filtración con membranas que incorpora solutos además del disolvente, deben añadirse las resistencias hidráulicas asociadas a la aparición de la polarización por concentración o/y del ensuciamiento $\left(R_{f}\right)$ o la formación de una capa de gel $\left(R_{g e l}\right)$. En estos casos, la resistencia total se establece mediante un modelo de resistencias en serie que incluye esos efectos.

$$
R_{\text {tot }}=R_{m}+R_{f}+R_{g e l}
$$

La determinación de estas resistencias en función de las condiciones de operación o de la composición físico-química de la corriente filtrada, permite estimar los fenómenos involucrados en el proceso de filtración.

Otros modelos mejorados como el Modelo Osmótico, desarrollado por Kozinsky et al. (1972), complementan la ley de Darcy para disoluciones donde la presión osmótica $(\Delta \Pi)$ juega un papel importante en contra de la presión de transferencia (Jeantet et al. 2000). Estos modelos permiten interpretar con mayor precisión el flujo, definiendo una presión efectiva (TMP- $\Delta \Pi$ ) que se incorpora en el numerador de la Ecuación [1.5] cuando se opera en nanofiltración u ósmosis inversa.

\subsubsection{FENÓMENOS IMPLICADOS EN LA TRANSFERENCIA DE MATERIA}

Como se recoge en el apartado anterior, todos los fenómenos generados pueden englobarse a partir de una serie de resistencias -además de la ejercida por la propia membrana- que limitan la transferencia de materia a su través, si bien los citados fenómenos de transferencia y flujo, tanto del disolvente como de los solutos, son complejos y se ven afectados por múltiples factores.

Así, el transporte selectivo a través de un medio filtrante induce, en el seno de la disolución, un movimiento convectivo que arrastra hacia la membrana a todas las especies presentes en la misma, creando de ese modo una acumulación de materia en las proximidades de la membrana. Según el grado de acumulación y su reversibilidad se alcanza la denominada polarización de concentración o el ensuciamiento de la membrana, ambos fenómenos modificadores de la selectividad y del flujo de permeación.

\section{POLARIZACIÓN DE LA CONCENTRACIÓN}

A medida que transcurre el tiempo en la filtración, se registra una disminución progresiva de la densidad de flujo de permeado, debido a una serie de fenómenos simultáneos, uno de ellos es la denominada polarización de la concentración. La composición de la alimentación difiere de la composición en la superficie de la membrana, formándose una capa límite en la interfase de 
ambas. El gradiente de concentración que se genera en el lado de la alimentación reduce la eficacia de separación y aumenta el potencial de ensuciamiento, por lo que un objetivo de todo proceso ha de ser la minimización de esa capa (Wijmans y Wilson 2000).

La polarización por concentración no se considera estrictamente ensuciamiento, aunque también afecta al flujo y la selectividad. La polarización se considera un fenómeno reversible que puede ser controlado por ajustes de velocidad, pulsos, ultrasonidos o campos eléctricos.

Este fenómeno se suele abordar mediante el estudio del transporte convectivo y por difusión generado en la capa de polarización, a través de un estudio de la capa límite en estado estacionario (Maubois y Brulé 1982). En la Figura 1.7 se muestran las distintas corrientes que entran en juego según este modelo.

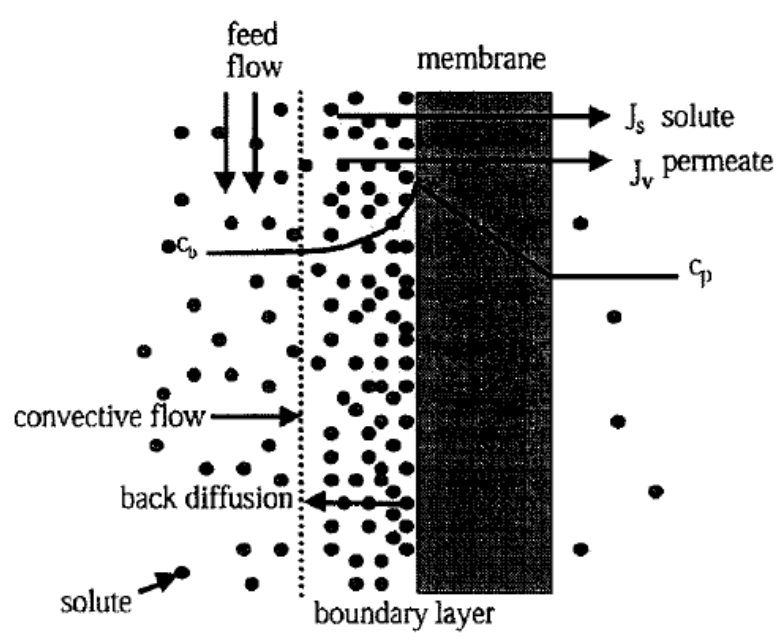

Figura 1.7. Perfil de concentración en la capa límite

Como indican Sablani et al. (2001) en su revisión sobre los fenómenos de polarización de concentración, un modelo simple para el estudio de la polarización por formación de gel es el que asume la formación de una capa en la superficie de la membrana, así como que el efecto de la presión osmótica de la solución de macromoléculas es despreciable.

Cuando se trabaja con macromoléculas, como proteínas, este modelo resulta muy interesante ya que está ampliamente aceptado que en estos casos la concentración de soluto en la interfase excede de un valor límite de concentración, conocido como concentración de gel $\left(c_{g}\right)$, dejando de ser fluido y formando una capa en la superficie de la membrana, que pasa a ser una resistencia adicional a la transferencia con la correspondiente disminución de flujo de permeado. Cuando se alcanza la concentración de gel en la superficie de la membrana y el estado estacionario, la densidad de flujo de permeado se puede calcular como:

$$
J_{\lim }^{c}=\rho \cdot k_{b l} \cdot \ln \left[\frac{c_{g}}{c_{b}}\right]
$$

Donde $\quad \rho$ es la densidad de la corriente de concentrado

$c_{g}$ y $c_{b}$ son las fracciones en peso del componente $i$, en la capa de gel y en el seno de la disolución

$k_{b l}$ coeficiente de transferencia de materia $\left(\mathrm{cm} \cdot \mathrm{s}^{-1}\right)$ 
Este flujo es conocido como flujo límite, ya que cualquier aumento en la presión transmembrana se transforma en un aumento del espesor de la capa de gel, sin aumentar el flujo de permeado, como se muestra en la Figura 1.6. A partir de esa condición el flujo deja de estar controlado por la presión y pasa a estarlo por la transferencia de materia, que dependerá del coeficiente de difusión en la capa límite, turbulencias en el canal, así como la viscosidad y densidad de la corriente de concentrado.

Para minimizar la polarización de la concentración se debe maximizar el coeficiente de transferencia de materia en la capa límite. Una de las formas de conseguirlo es aumentando la velocidad tangencial, con el inconveniente de aumentar la caída de presión. Otra forma más eficaz es elegir el material del espaciador óptimo o introducir promotores de turbulencia, los cuales inducen aumentos de la transferencia de materia.

La interpretación de los fenómenos referidos se incorpora en diferentes modelos teóricos, una buena parte de ellos están aplicados a operaciones de MF y UF (Romero y Davis 1988; Romero y Davis 1991; Ould-Dris et al. 2000).

\section{ENSUCIAMIENTO}

El ensuciamiento es el factor limitante en todas las aplicaciones con membranas. Los depósitos en la membrana hacen disminuir el flujo de permeado, afectando simultáneamente a la selectividad de la filtración. La colmatación o ensuciamiento de la membrana se produce por una acumulación de solutos mediante mecanismos de adsorción o bloqueo, tanto en el interior de los poros como en la superficie de la membrana.

El ensuciamiento es un proceso más complicado que la polarización de concentración, formado por fenómenos físicos, químicos y biológicos que generan una pérdida de permeabilidad en la membrana, que a largo plazo puede ser irreversible (Sablani et al. 2001).

A corto plazo se forma un ensuciamiento de carácter reversible, bien bloqueando los poros o formando una capa en la membrana, que puede ser eliminado mediante una correcta elección de las propiedades hidrodinámicas. La acumulación de materia en tiempos prolongados causa reducciones en el flujo de permeado, debiendo eliminarse mediante una etapa eficaz de limpieza más agresiva que un simple cambio hidrodinámico.

Con el fin de evitar alcanzar estados irreversibles de ensuciamiento (que no puedan ser eliminados mediante protocolos de limpieza) o a limpiezas muy continuadas o agresivas (que disminuyen el tiempo efectivo de operación), se han estudiado algunas alternativas para reducir este fenómeno como módulos vibrantes o módulos con discos rotatorios bajo la superficie de la membrana, si bien son difíciles de escalar y caros para una aplicación industrial. Asimismo, se pueden emplear ondas acústicas, ultrasonidos o campos eléctricos que impidan la estabilización de los colmatantes sobre o en el interior de la membrana, aumentando los tiempos efectivos de operación.

También, en el ámbito hidrodinámico, se consigue disminuir el ensuciamiento empleando espaciadores y promotores de turbulencia para crear inestabilidad en el flujo, si bien estos sistemas pueden generar problemas de puntos muertos en las limpiezas.

Con el fin de disminuir la colmatación sin recurrir a limpiezas químicas, principalmente en microfiltración, se desarrollan técnicas de flujo inverso pulsante de agua o permeado (backwash) o de gas (backflushing). Estos sistemas pueden estar limitados por el tipo de membrana, ya que la configuración espiral no tolera su aplicación por un posible desenrrollamiento de la membrana. 


\subsubsection{APLICACIONES DE LA TECNOLOGÍA DE MEMBRANAS EN LA INDUSTRIA LÁCTEA}

Dentro de la industria alimentaria, el sector lácteo cuenta con el mayor número de membranas instaladas. Si en los años 80 había instalados $250.000 \mathrm{~m}^{2}$, en el 2000 esta cifra había ascendido hasta los $850.000 \mathrm{~m}^{2}$ (Daufin et al. 2001) con un aumento anual del 7,5\%. Del total instalado la mayor parte correspondía con operaciones de ultrafiltración y nanofiltración (400.000 UF, $300.000 \mathrm{NF}, 100.000$ OI y $50.000 \mathrm{~m}^{2} \mathrm{MF}$ ). En torno al $40 \%$ instalado en la industria alimentaria, corresponde a la industria láctea.

La primera aplicación conocida de estas técnicas en la industria láctea data de 1967 en Estados Unidos y Francia para el tratamiento de lactosuero por ósmosis inversa. Dos años después, en 1969, tiene lugar la verdadera revolución en lo que se refiere a su aplicación industrial, con la invención del proceso MMV (Maubois, Mocquot y Vassal) en el cual, mediante ultrafiltración de leche, se conseguía un concentrado con una composición final similar al queso (prequeso) antes de la coagulación (Maubois et al. 1969).

Los procesos de separación con membranas han revolucionado la industria láctea de una manera importante, a través del desarrollo de nuevos productos y nuevos procesos tecnológicos. En sus inicios, hace ya 40 años, los procesos se centraron en la UF y OI, si bien más recientemente se vienen empleando otras técnicas como la MF y la NF. En la actualidad la mayor parte de las membranas instaladas en la industria láctea se emplean para estandarización en proteína de la leche en quesería.

Mediante el uso individual o combinado de estas cuatro técnicas -microfiltración, ultrafiltración, nanofiltración u ósmosis inversa- son muchas las posibilidades de separación, concentración y/o fraccionamiento que se pueden ensayar, tanto para el tratamiento de leche como de lactosuero, como muestran las Figura 1.8 y 1.9.

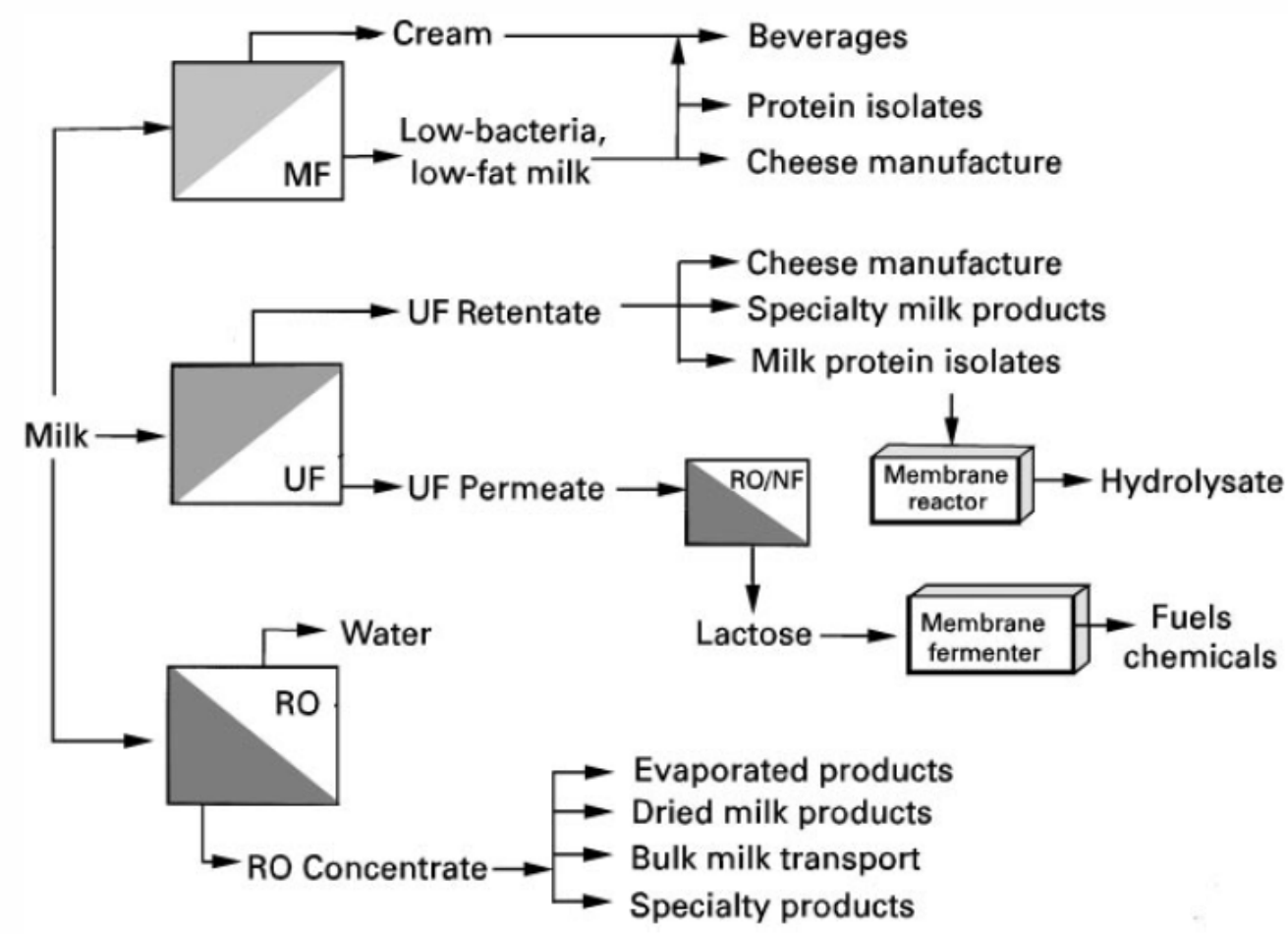

Figura 1.8. Procesado de leche mediante tecnología de membranas. Fuente: Cheryan et al. (2000a) 


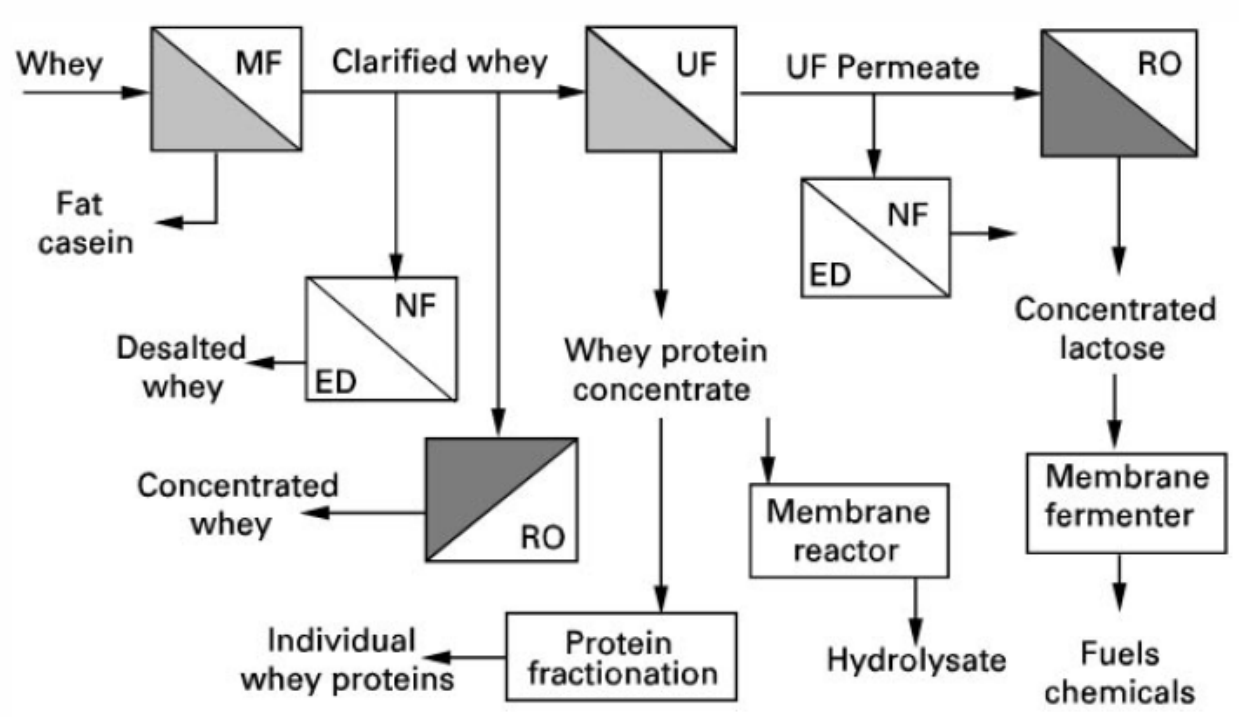

Figura 1.9. Procesado de suero mediante tecnología de membranas. Fuente: Cheryan et al. (2000a)

Dos factores importantes para conseguir una buena combinación entre los componentes retenidos y transmitidos a través de la membrana, además de la selectividad derivada del tamaño de corte, son la uniformidad del tamaño de poro (las membranas poliméricas presentan una distribución de tamaño de poro amplia respecto a las cerámicas, lo que dificulta los procesos de purificación) así como unas adecuadas condiciones de filtración, que deben ser lo más uniformes posibles a lo largo de la membrana, sobre todo en lo que se refiere a la diferencia de presión entre el lado del retenido y el del permeado. Con este fin se han desarrollado conceptos, sobre todo aplicados a procesos de microfiltración, como el de presión transmembrana uniforme (UTP) en membrana tubulares o gradientes de porosidad (GP) en la membrana, como indican en su revisión sobre las técnicas de microfiltración Saboya y Maubois (2000), lo que demuestra un continuo avance tecnológico.

Como ya se ha comentado, para conseguir la viabilidad de cualquier proceso es fundamental controlar el ensuciamiento. Dicho ensuciamiento, a su vez, afecta a la selectividad, ya que a mayor ensuciamiento menor superficie efectiva de poros disponible, cambiando la retención de los distintos componentes. Esto se debe a que el diámetro efectivo será menor que el teórico y determinados compuestos que deberían atravesar la membrana se retienen en mayor o menor medida. Además del posible cambio en la selectividad otra consecuencia clara del ensuciamiento es la disminución de la densidad de flujo de permeado, nuevamente debido al taponamiento parcial de los poros de la membrana, por lo que al trabajar con leche o derivados lácteos todas estas consideraciones han de tenerse en cuenta.

Algunas aplicaciones de la tecnología de filtración tangencial (OI, NF, UF y MF) en el sector lácteo, desarrolladas a distinta escala, se recogen a continuación, según el proceso empleado.

\section{MICROFILTRACIÓN (MF)}

c Separación y fraccionamiento de la grasa trabajando sobre leche entera (Goudédranche et al. 2000; Brans et al. 2004).

c Pasterización en frío de leche mediante la eliminación de esporas y microorganismos (Saboya y Maubois 2000; Daufin et al. 2001; Brans et al. 2004; Chacón 2006). 
c Eliminación de bacterias en la elaboración de queso mediante bactofugación (Saboya y Maubois 2000).

c Concentración de micelas de caseína en leche desnatada (Punidadas y Rizvi 1998; Vadi y Rizvi 2001).

c Eliminación de grasa en lactosuero (Saboya y Maubois 2000).

c. Purificación de salmueras, empleadas en el salado de queso (Saboya y Maubois 2000).

\section{ULTRAFILTRACIÓN}

c Fabricación de queso. Por la importancia para este trabajo, los estudios en este ámbito se explican en mayor profundidad en el Apartado 1.4.

c Elaboración de productos fermentados y yogur (Mohr et al. 1989).

c Normalización del contenido proteico de la leche (Kosikowski 1986).

c Concentración de lactosuero incrementando su contenido en extracto seco para disminuir los costes de la posterior concentración por evaporación (Daufin et al. 2001).

c. Fraccionamiento/aislamiento de proteínas mediante combinación de procesos de UF con diferentes cortes moleculares y funcionalidades de las membranas (Zydney 1998; Chaufer et al. 2003; Muller et al. 2003).

\section{NANOFILTRACIÓN}

c Preconcentración y desmineralización parcial de lactosuero (Van der Horst et al. 1995; Doyen et al. 1996).

c Preconcentración de leche para la elaboración de queso Quarg (Mucchetti et al. 2000).

c Desmineralización de leche (Suárez et al. 2009).

c Recuperación de proteínas y lactosa en lactosuero (Atra et al. 2005).

c Recuperación de efluentes en la industria láctea (Balannec et al. 2005).

c Regeneración de disoluciones de limpieza (Dresch et al. 1999).

\section{ÓSMOSIS INVERSA}

c Preconcentración de leche y suero. Con el fin de disminuir los costes de la posterior evaporación (Cheryan y Wilson 2000a).

c Recuperación de efluentes en la industria láctea (Balannec et al. 2005).

c Concentración de permeados de ultrafiltración (Mohr et al. 1989). 


\subsection{ULTRAFILTRACIÓN APLICADA A LA ELABORACIÓN DE QUESO}

A continuación se describe en detalle esta aplicación, ya que en ella se basa el trabajo de la presente Tesis, y se indican los antecedentes, mediante un recorrido por el panorama quesero mundial, que justifican la elección de la ultrafiltración como tecnología para conseguir los objetivos que posteriormente se plantean.

Como ya se ha indicado, una de las aplicaciones más relevantes de la UF en la industria láctea es la fabricación de queso. La fabricación de queso mediante tecnología de membranas comenzó al final de la década de los 60 con el desarrollo del proceso MMV (Maubois et al. 1969), patentado en 1969 por los investigadores que le dan nombre Maubois, Mocquot y Vassal. A partir de este momento su aplicación empezó a crecer en la industria quesera, y ya en 2001 más de $450.000 \mathrm{Tm}$ de queso se fabricaron mediante UF en todo el mundo.

Desde la aparición del proceso MMV los trabajos de investigación sobre la aplicación de la UF tanto en la fabricación de queso como en el aprovechamiento de lactosuero, han crecido exponencialmente, si entre 1979-1983 había 213 publicaciones científicas, dos décadas después, entre 1995-2002, la cifra ascendió a 1.200 (Mistry y Maubois 2004). A partir de 1969, las aplicaciones en la elaboración de queso se han dirigido por numerosas vías hasta abarcar la casi totalidad de quesos existentes: fabricación de quesos frescos, de pasta blanda, semidura o dura a partir de leche de oveja, cabra, vaca o sus mezclas.

Algunos de los beneficios alcanzados mediante el uso de la UF son (Cheryan 1998):

c Aumento del rendimiento quesero, pudiéndose incrementarse hasta en un 10-20\%, debido a la incorporación de las proteínas solubles.

c Menor cantidad de ingredientes empleados, como cuajo y fermentos, disminuyendo los costes de fabricación.

c Reducción del volumen de leche a manejar, para conseguir la misma cantidad de queso, por lo que es menor el volumen de los equipos empleados. Es decir, se consigue un aumento de la capacidad productiva.

c Menor producción de lactosuero en la elaboración del queso, ya que al menos parte de sus componentes se incorporan en el queso y en algunos casos la etapa de desuerado se elimina completamente.

c Incremento del valor nutritivo del queso, asociado a las proteínas del lactosuero.

c Posibilidad de usar sistemas de producción en continuo. En alguna de las aplicaciones, la concentración alcanzada mediante UF permite el cuajado en línea, disminuyendo enormemente los tiempos de elaboración.

c Ahorro de energía y reducción de tiempos de elaboración.

Algunos de los quesos que se fabrican a nivel industrial mediante UF, en todo el mundo, son los tipos: Feta, Quarg, Queso Blanco de Turquía, Domiati y Kariesh en Egipto, Teleme en Grecia, Queso Fresco Español y Sudamericano, Quesos de Cabra, Camembert, Ricotta, Mozzarella, Cheddar o Quesos Fundidos (Mistry y Maubois 2004), lo que demuestra el gran potencial de esta tecnología aplicado a la diversidad de tipos de queso existentes. 
Las aplicaciones de la ultrafiltración a la elaboración de los distintos tipos de quesos se pueden clasificar según tres categorías (Mistry y Maubois 2004). Se distingue entre estandarización del contenido proteico de la leche, retenidos de concentración media y obtención de un prequeso líquido (basado en la idea del proceso MMV).

Una cuarta posibilidad, que se recoge dentro del concepto de prequeso líquido en el presente trabajo, sería la combinación de la concentración mediante ultrafiltración con otras técnicas como la evaporación, para conseguir factores de concentración más elevados, que pueden alcanzar hasta 7,5 veces respecto al volumen inicial de leche (Bech 1993).

\subsubsection{ESTANDARIZACIÓN DEL CONTENIDO PROTEICO DE LA LECHE}

Una de las primeras aplicaciones de la UF en la industria láctea (Poulsen 1978) fue la estandarización del contenido proteico de la leche hasta valores de entre un 4 y $5 \%$ de proteína para la elaboración de queso Camembert (Lawrence 1989). Esta práctica es muy común en Europa, como alternativa a otros medios de incrementar el contenido proteico como la adición de concentrados de proteínas séricas o de caseinatos o para solventar las variaciones estacionales de la composición de la leche (Fernández-Albalat 2002).

En las plantas de queso altamente mecanizadas, el contenido de proteína se eleva hasta el $3,7-4,5 \%$, para estandarizar la leche de partida en cuanto a mejora de la materia prima. En EEUU se denominó a este tipo de práctica bajo las siglas de LCR "low concentrated retentates" (Kosikowski 1986). Se han realizado numerosos estudios a nivel piloto e industrial aplicando dicho concepto a la elaboración de gran variedad de queso como, por ejemplo, los quesos de pasta dura tipo Cheddar.

El factor de concentración (VCR) óptimo para este tipo de aplicaciones está entre el 1,7 y 1,8. De esta forma, en la fabricación se pueden emplear equipos convencionales y la implantación en cualquier quesería es sencilla. Las plantas de UF deberán disponer de equipos de medición en línea de grasa y proteína de la leche de entrada para conseguir la estandarización de los dos componentes.

El coste adicional de la etapa de UF puede ser compensado con un pequeño aumento en la eficiencia del proceso, debido al aumento de kilogramos de queso por cuba y por día, sumado a la menor cantidad de cuajo empleada y el aumento de la calidad del queso, así como a un pequeño aumento en el rendimiento (menor del $1 \%$ ) debido a las menores pérdidas de cuajada en forma de finos (Kosikowski 1986). La retención de proteínas del suero es muy pequeña, en comparación con las tecnologías basadas en el proceso MMV. Además, el suero obtenido tiene una mayor proporción de proteína/sólidos totales, es decir un mayor valor añadido, ya que parte del agua ha sido eliminada en la etapa de ultrafiltración.

Al igual que en otros casos, está técnica ha sido ampliamente estudiada para la fabricación de queso Cheddar (Guinee et al. 1994; Neocleous et al. 2002). Otras muchas variedades de queso que se elaboran por el método LCR son Minas Frescas (da Cunha et al. 2006), Cottage, Brick, Colby, Edam, Danbo, Mozzarella o Saint Paulin (Bush et al. 1983; Zall y Chen 1986; Oommen et al. 2000). Esta técnica también ha sido empleada para mejorar la calidad de quesos bajos en grasa (Mistry et al. 1996).

En la última década se están utilizando en Estados Unidos retenidos de leche obtenidos por ultrafiltración a baja temperatura $\left(<7^{\circ} \mathrm{C}\right)$ en la elaboración de distintos tipos de queso, como Cheddar, Mozarella o Parmesano, debido a que la FDA (Food and Drug Administration) aprobó su 
utilización en 1996 para la estandarización de leche (Govindasamy-Lucey et al. 2004; Govindasamy-Lucey et al. 2005).

\subsubsection{RETENIDOS DE MEDIA CONCENTRACIÓN}

Mediante esta técnica se elaboran también multitud de quesos, desde pastas blandas hasta duras, así como quesos frescos, queso crema, Camembert, Feta, Pasta Filata, Cheddar, Cottage, etc.

En este caso, a la hora de elaborar el queso son necesarios equipos especiales para cortar y manipular la cuajada formada, a causa de la elevada dureza de los geles obtenidos a partir de concentrados con VCR oscilando entre 2 y 5.

En muchas ocasiones, además de la UF se realiza una etapa adicional de diafiltración (DF) con agua pura, salada o acidificada, para reducir la concentración de sales y lactosa, de acuerdo con los estudios de Brulé et al. (1974).

La aplicación más importante, por su elevada implantación a nivel industrial, es la elaboración de queso tipo Feta, debido a que se trata de un queso con elevado contenido en humedad, lo que supone una menor cantidad de suero a eliminar tras la ultrafiltración.

Estas técnicas se caracterizan por la obtención de dos corrientes residuales: un permeado del proceso de concentración y un lactosuero del proceso de elaboración del queso. Esto se debe a que, a pesar de la concentración, se sigue generando un lactosuero que se separa en una etapa de sinéresis, la cual se modifica respecto a la elaboración tradicional debido a las características singulares de los geles generados a partir de leche concentrada.

\section{PROCESO APV-SIROCURD}

Entre los procesos que emplean o han empleado la UF para alcanzar grados intermedios de concentración, destaca el proceso APV-Sirocurd (Garret y APVCoLtd 1987), el cual fue desarrollado por un grupo de investigadores australianos (CSIRO) en colaboración con la empresa APV en el año 1983. Se instalaron plantas industriales en Australia y EEUU entre 1986 y 1990 (Cheryan 1998), aunque el proceso ha dejado de funcionar por razones técnicas y económicas. Mediante este proceso se podían conseguir unos incrementos en el rendimiento quesero de entre el 6 y el $8 \%$ (Mistry y Maubois 2004).

Se aplicaba a la elaboración de queso tipo Cheddar, queso madurado de origen inglés, de distinta curación, del cual se fabrican más de 3 millones de toneladas/año, resultando muy interesante desde el punto de vista económico retener las proteínas del lactosuero. La primera planta para queso Cheddar se instaló en 1985 en Australia. La leche entera estandarizada y pasterizada se concentraba, a $50^{\circ} \mathrm{C}$ hasta un VCR de 5 mediante ultrafiltración con módulos de membrana espirales, incluyendo dos etapas de diafiltración al $5 \%$ para alcanzar entre un 38 y un $40 \%$ de extracto seco. El concentrado se cuajaba en continuo en un equipo formado por cilindros estáticos de coagulación, una vez cuajado se cortaba en continuo en cubos de $1 \mathrm{~cm}$ y se llevaba a un tambor rotatorio para su calentamiento y sinéresis en línea. Por último la chedarización también se realizaba en línea.

En este proceso un $8 \%$ de la leche inicial se pierde después de la coagulación en forma de suero de alto contenido proteico. El trabajo mecánico en la sinéresis es muy pequeño, minimizándose los daños a la cuajada. El tiempo de producción se reduce en $1 \mathrm{~h}$, hay ahorro de ingredientes y una menor probabilidad de contaminación por bacteriófagos. La alta automatización permite gran 
control sobre variables como $\mathrm{pH}$, humedad y sal, además de ser un proceso flexible adaptable a otros tipos de queso y a variaciones estacionales en la composición química de la leche. Por otra parte, el suero puede ser utilizado en la elaboración de yogur o helados, mientras que el permeado puede ser concentrado y desmineralizado para usos farmacéuticos, comida infantil, salsas, etc.

Resumiendo, las principales ventajas alcanzadas son: aumento de rendimiento entre el 6-8 \%, reducción del tiempo total en $1 \mathrm{~h}$, ahorro de $1 / 3$ en la cantidad de cuajo, menores riesgos de contaminación, control automático del proceso y menores variaciones en la composición del queso por efectos estacionales (Garret y APVCoLtd 1987).

\section{APLICACIÓN DE UF A LA FABRICACIÓN DE QUESO TIPO FETA}

Este proceso fue desarrollado en Dinamarca, como respuesta a la demanda por parte de países mediterráneos, donde los consumidores preferían quesos con apariencia y textura similar a los tradicionales (presencia de ojos mecánicos), cosa que se había perdido al elaborar el queso Feta mediante prequeso líquido (proceso MMV).

A partir de leche estandarizada en grasa (pasterizada y homogeneizada) se obtenía, mediante ultrafiltración a $50^{\circ} \mathrm{C}$, un concentrado con el $28,5 \%$ de extracto seco, equivalente a un VCR de 3. Al concentrado pasterizado se le añadía lipasa y fermento de bacterias acidolácticas o glucona- $\delta$-lactona como regulador del $\mathrm{pH}$. Tras un breve tiempo en el tanque de mezcla se bombea a un equipo especialmente diseñado para tratar el coágulo. El cuajo se añade en línea y se mezcla y coagula a través de unos tubos. La cuajada se corta en cubos y se coloca en moldes $\left(16-24 \mathrm{~h} / 10-14{ }^{\circ} \mathrm{C}\right.$ ) hasta que el $\mathrm{pH}$ desciende hasta 4,6 (punto isoeléctrico de las caseínas).

El producto final es prácticamente indistinguible respecto al tradicional, con un aumento de rendimiento del $14 \%$ en base seca. Si se usa el método de prequeso líquido el rendimiento puede aumentar hasta un $30 \%$, por lo que muy pocas industrias producen queso tipo Feta mediante esta tecnología (Mistry y Maubois 2004).

\section{APLICACIÓN EN LA PRODUCCIÓN DE OTROS TIPOS DE QUESOS}

Han sido muchos los estudios realizados para la fabricación de distintos tipos de queso, llegándose a concentrar la leche desde 2 hasta 5 veces respecto al volumen inicial. Algunos ejemplos son:

c Queso Havarti, queso semiblando de origen Danés, concentrando la leche hasta un $36 \%$ de ES.

c Queso Quarg, queso fresco de coagulación láctica, la UF se llevaba a cabo a bajo pH $(4,7)$ para evitar excesos de acidez en la pasta, concentrando hasta un VCR de 3-4 (Cheryan 1998).

c Queso Gouda, a partir de leche entera ultrafiltrada hasta un VCR de 3,3 y diafiltrada hasta 5 . Se consiguieron quesos con un contenido en humedad, grado de proteolisis y dureza similares al tradicional y un ahorro en cuajo del 33 \% (Spangler et al. 1990; Spangler et al. 1991). El desarrollo acelerado del flavor se estudió con el uso combinado de lipasas encapsuladas y células congeladas de lactobacillus he/veticus.

c Queso azul, obteniendo que las cualidades organolépticas eran similares a los quesos de referencia para concentrados del 3,2-10\% en proteína, ya que a partir de $12 \%$ de proteína en el concentrado eran necesarios equipos especiales para la agitación y el corte de la cuajada. Este proceso fue consumado satisfactoriamente en Francia en 
1996 por la French Guilloteau Society con la variedad "La Roche" (Mistry y Maubois 2004).

c. Ultrafiltración de leche de cabra como alternativa a la congelación de cuajadas lácticas, ya que los concentrados soportan mejor el almacenamiento. Al mismo tiempo se consiguen aumentos de rendimiento del $12-20 \%$ y reducciones del cuajo empleado del $80 \%$ (Cheryan 1998).

r En cuanto a la elaboración de quesos curados o semicurados, han sido muchas las invenciones patentadas empleando la ultrafiltración. Mediante procesos patentados por Van Leeuwen y colaboradores se establecen las condiciones tecnológicas para la elaboración de distintas variedades de quesos curados a partir de concentrados de ultrafiltración (Van Leeuwen et al. 1984; Van Leeuwen et al. 1990). Algunos ejemplos de estas fabricaciones son la obtención de queso Cheddar con distintos factores de concentración, queso Colby o queso Parmesano.

\subsubsection{PREQUESO LÍQUIDO (LIQUID PRE-CHEESE, LPC)}

Mediante esta técnica la leche se concentra por UF hasta alcanzar la composición de la cuajada desuerada para, posteriormente, añadir el cuajo. La pérdida de suero es mínima debido a la eliminación de la fase de desuerado y sinéresis y no es necesaria la utilización de cubas ya que el trabajo una vez cuajada la leche es mínimo. La tecnología descrita se conoce como proceso MMV (Maubois et al. 1969).

Las primeras aplicaciones del concepto LPC fueron para la elaboración de queso Camembert, aunque en la actualidad han sido muchas las tecnologías de fabricación desarrolladas mediante este proceso, abarcando desde quesos frescos como el Quarg hasta quesos de pasta semidura como el Saint-Paulin.

A menudo esta tecnología no se ha podido aplicar a quesos con elevado contenido de sólidos, como los quesos duros o semiduros, ya que la alta viscosidad de los concentrados y los bajos flujos de permeado alcanzados limitan el grado de concentración. Para VCR mayores de 5 el flujo de permeado alcanzado, con leche desnatada, es un $10 \%$ del inicial, debido al ensuciamiento. Esta tecnología funciona especialmente bien con quesos frescos o quesos de pasta blanda como el Camembert, para VCR inferiores a 5 (Hinrichs 2001).

\section{APLICACIÓN A LA PRODUCCIÓN DE QUESOS FRESCOS NO MADURADOS}

En la elaboración de queso Quarg o demás quesos frescos de coagulación láctica, los cuales presentan baja acidez y elevada humedad (Lawrence 1989), el uso de VCR entorno a 3 alcanzó las primeras aplicaciones industriales.

Para la elaboración de los primeros quesos frescos de pasta láctica la leche se concentraba directamente antes de la adición del cuajo y del cultivo iniciador. Se encontraron sabores fuertemente ácidos y metálicos, frecuentemente asociados a amargores por la presencia de lactato cálcico (Brulé et al. 1974). Estos efectos eran atribuibles al alto contenido mineral de la cuajada y, consecuentemente, a su alto poder tampón (Lawrence 1989). Reducciones en el sabor ácido se lograron preacidificando la leche a valores de $\mathrm{pH}$ próximos a 6,0 o concentrando a mayores niveles de lo requerido para luego diluir con agua. 
La introducción de membranas minerales, que permiten tratar productos altamente viscosos, resolvió los problemas organolépticos encontrados, ya que es posible ultrafiltrar el coágulo formado tras la fermentación inicial de la leche hasta $\mathrm{pH} 4,6$ (como en el proceso tradicional) eliminando selectivamente el agua y la lactosa y conservando la totalidad de las proteínas solubles (Stenne 1973; Fernández-Albalat 2002).

Los flujos de permeado iniciales son altos, si bien decrecen con el tiempo significativamente, debido a la estructura altamente viscosa de la capa de polarización formada en la superficie de la membrana.

Muchos otros quesos frescos han sido elaborados mediante el proceso LPC similar al proceso MMV desarrollado por Maubois, et al. (1969). Algunos ejemplos son Ricotta, quesos Crema o Mascarpone (Maubois 1978).

De gran relevancia en la Industria Española ha sido la elaboración de queso fresco y queso blanco pasterizado de coagulación enzimática tipo Burgos. Como recoge Fernández-Albalat (2002), para este tipo de quesos se ha encontrado que un tratamiento térmico intenso de la leche de partida mejora la calidad sensorial de los mismos, por modificaciones en la red proteica del coágulo. En este sentido, se han desarrollado trabajos, como el patentado por Rodríguez et al. (1999), para la elaboración de queso fresco bajo en grasa mediante la mezcla de leche desnatada de vaca con leche de cabra y oveja, sin pérdidas de sabor apreciables respecto el queso elaborado con leche entera.

\section{APLICACIÓN A LA FABRICACIÓN DE QUESOS DE PASTA BLANDA}

Como ya se ha indicado previamente, el primer queso desarrollado por el proceso MMV (Maubois et al. 1969) fue el Camembert, queso francés afinado superficialmente con moho. La empresa Alfa-Laval desarrolló un proceso con moldeo/desmoldeo en continuo denominado "Camatic" en el cual la leche pasterizada se ultrafiltraba a $50^{\circ} \mathrm{C}$ hasta un VCR de 5 y un contenido total en ES del $35 \%$. Este proceso ha sido implantado satisfactoriamente en Alemania, mientras que en Francia ha encontrado dificultades comerciales debido a una excesiva densidad de la pasta -por la falta de ojos mecánicos- lo cual no fue aceptado por el consumidor al tener la impresión de recibir menos queso por su dinero (Mistry y Maubois 2004).

El mayor éxito del proceso MMV ha sido la fabricación de queso Feta. Hasta 1997 el queso Feta representaba el $35 \%$ del queso producido en Dinamarca y ya en ese año más del $90 \%$ se producía por UF.

La fabricación de queso Feta por el método MMV permite fabricar el queso en su propio recipiente, con aumentos de rendimiento del $30 \%$, bastante por encima de lo que cabría esperar incluso con la retención completa de proteínas solubles (20\% máximo incremento esperable) debido a la incorporación de humedad asociada a las proteínas solubles principalmente y a la eliminación casi total de pérdidas de grasa y finos de queso.

Un concepto similar se aplica en la fabricación de queso Domiati (variedad egipcia) donde la leche entera se ultrafiltra hasta un VCR de 5.

En el caso de la Mozzarella hay estudios desde mediados de los años 70 (Covacevich y Kosikowski 1978) donde se aplica el proceso MMV concentrando la leche desnatada hasta un 33,6 \% de ES (VCR de 6). 


\section{APLICACIÓN A LA FABRICACIÓN DE QUESOS DE PASTA SEMIDURA}

El queso Saint-Paulin es un queso francés de consistencia semidura, afinado superficialmente con bacterias, cuya composición es aproximadamente del $47 \%$ en ES y un 2,5\% de sal. En la fabricación mediante UF es necesario obtener por lo menos un $21 \%$ de proteína (45\% de ES), lo cual es más factible con membranas cerámicas que con las poliméricas convencionales. Se consiguen aumentos en rendimiento de hasta un $19 \%$, con ahorros de cuajo de hasta el $85 \%$ (Goudedranche et al. 1980). La aparición de sabores ácidos y la lenta maduración se puede controlar reduciendo el contenido en lactosa en el concentrado (por debajo del $1,9 \%$ ) a la vez que se reduce el contenido en cenizas (Delbeke 1987).

En los trabajos sobre quesos de larga curación elaborados bajo el concepto de prequeso líquido, se suelen encontrar defectos sensoriales cuando son comparados con la elaboración tradicional. En los trabajos de Covacevich (1978) elaborando queso Cheddar, a partir de concentrados de leche desnatada de VCR 7 mezclados con nata para alcanzar extractos secos de hasta el $60 \%$, se obtenían quesos de textura y sabor pobre comparados con la elaboración tradicional. Por otro lado los prequesos así obtenidos son difíciles de manejar debido a su alta viscosidad y elevado poder tampón, sobre todo en torno a 5,8 de pH (Covacevich 1978).

La aplicación de factores de concentración muy elevados (mayores de 7) han sido estudiados en Francia (Mistry y Maubois 2004) en nuevas variedades de queso, con fermentación propiónica. El procedimiento incluye la preparación de un concentrado en dos etapas: una primera concentración hasta VCR 3 con diafiltración en continuo, seguida de una segunda hasta VCR 7,5. Se requerían equipos especialmente diseñados, con cartuchos más estrechos para alcanzar mayores velocidades de barrido de la membrana y bombas de desplazamiento positivo en la recirculación para mover un fluido de tan elevada viscosidad. En el moldeo se emplea vacío para eliminar los gases disueltos y un sistema especial de inyección de cuajo.

Bajo esta categoría se han desarrollado multitud de invenciones, desde la de Maubois et al. en 1969. En la mayoría de los casos la etapa de ultrafiltración se realiza sobre leche desnatada, como en el trabajo de Schaap et al. (1982) quienes patentaron un método para la elaboración de queso semicurado a partir ultrafiltración y diafiltración de leche desnatada, alcanzando un $27-28 \%$ de proteína y mezclando el concentrado con nata.

\section{OTRAS APLICACIONES DEL CONCEPTO LPC}

También se recogen en la bibliografía trabajos sobre elaboración de quesos azules a partir de retenidos de leche desnatada empleando el concepto de prequeso líquido (Tanahashi et al. 1975).

Existen, así mismo, estudios interesantes para la sustitución de queso Cheddar en quesos fundidos por retenidos de UF con un 30 \% de ES tratados enzimáticamente (Sood y Kosikowski 1979). Por otro lado, se ha encontrado que quesos obtenidos a partir de concentrados de UF pueden sustituir perfectamente a quesos jóvenes en la elaboración de queso fundido tradicional. Un proceso australiano se comercializó en EEUU para la fabricación de quesos fundidos mediante combinación de UF y evaporación a vacío hasta el 64 \% de ES (Ernstrom et al. 1980), existiendo también un proceso similar desarrollado en Dinamarca.

Otra práctica ensayada es rociar con LPC prefermentado la superficie de quesos frescos, en vez de usar métodos manuales o mecánicos de lavado, pudiéndose aplicar a la fabricación de quesos afinados superficialmente con moho. Esta técnica permite tener una capa superficial colonizada por bacterias ácido lácticas, previniendo el ataque de bacterias indeseables (listeria o psudomonas entre otras) además de conseguir acelerar la maduración. 
Mediante esta tecnología es posible abarcar problemas de deslocalización de los productores de leche o de bajadas estacionales de la producción, ya que se ha comprobado la estabilidad, tanto de las proteína como de la grasa, en leche de oveja ultrafiltrada hasta el $37 \%$ de extracto seco y congelada durante 6 meses hasta ser empleada en la elaboración de queso de pasta blanda madurado en salmuera (Voutsinas et al. 1995a; Voutsinas et al. 1995b).

Asimismo es posible, mediante UF y secado en torre, conseguir un prequeso en polvo que luego puede ser reconstituido para elaborar queso. El uso principal de este producto es la exportación a países con baja producción de leche, donde mediante la adición de agua, fermentos y cuajo puedan elaborar el queso. Este mismo sistema podría emplearse para elaboración casera de queso. Estos prequesos en polvo presentan mejores características que las leches en polvo, ya que no generan lactosuero y los costes de transporte son aún menores. Esta tecnología no ha encontrado aplicación, en parte debido a la regulación en la exportación de productos lácteos en polvo, las cuales son subvencionadas (Mistry y Maubois 2004). 



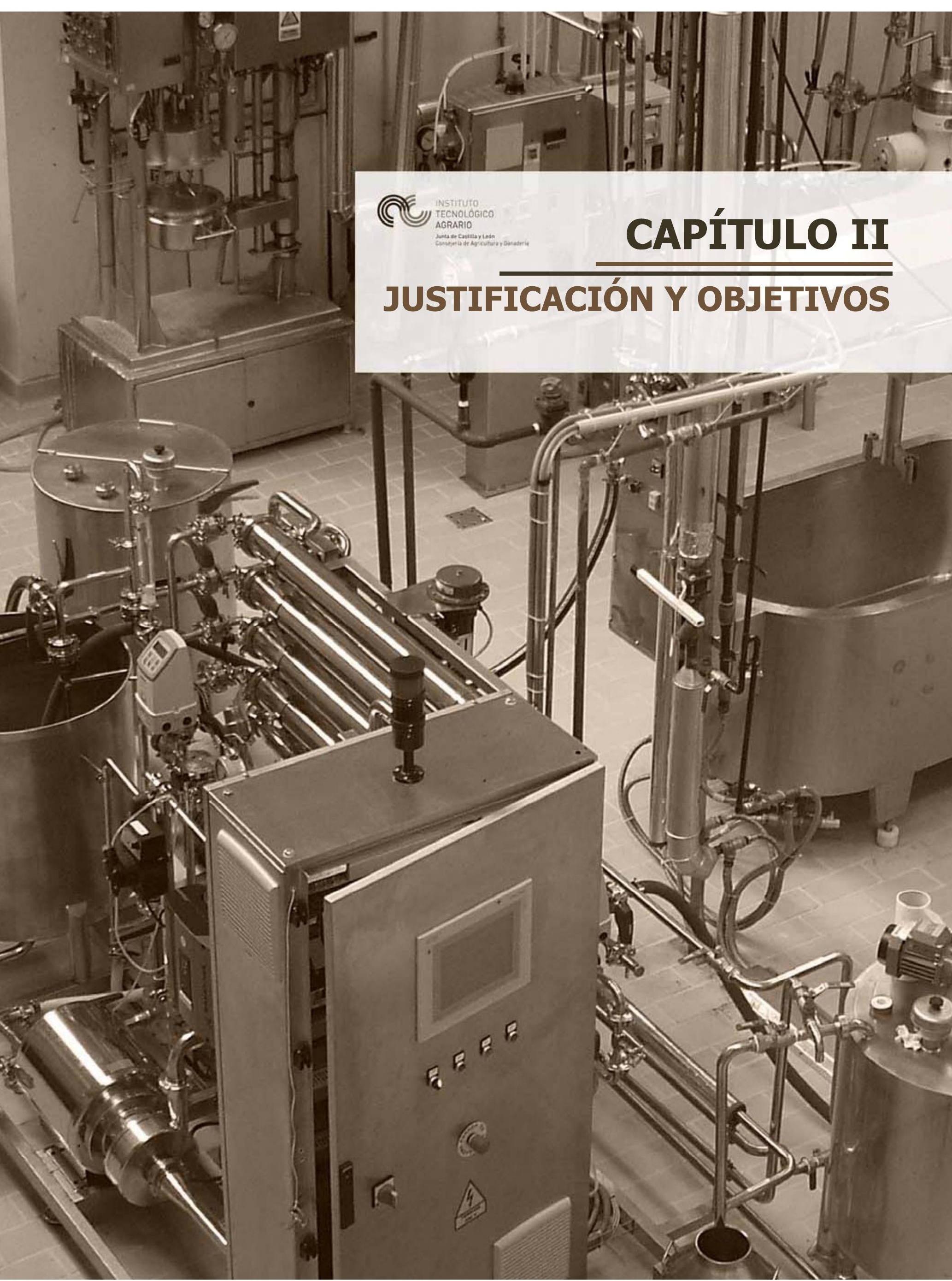





\section{JUSTIFICACIÓN Y OBJETIVOS}

A continuación se recoge una breve descripción de los motivos que han llevado a la realización de esta Tesis Doctoral.

Del mismo modo se establecen los objetivos que con ella se pretenden alcanzar, sirviendo la fase final de conclusiones de este trabajo, Capítulo VI, para la evaluación de su consecución.

\subsection{JUSTIFICACIÓN}

La experimentación de este trabajo se ha llevado a cabo íntegramente en la Estación Tecnológica de la Leche, perteneciente al Instituto Tecnológico Agrario de Castilla y León -ente público de derecho privado adscrito a la Consejería de Agricultura y Ganadería de la Junta de Castilla y León- cuyo principal objetivo es el avance científico en la actividad del sector agroalimentario (lácteo) y de sus industrias de transformación, dinamizando la innovación tecnológica y las iniciativas que conlleven nuevas orientaciones productivas y de adecuación al mercado.

Junto a este hecho, indicar que el sector lácteo en la comunidad de Castilla y León es un pilar importante de la industria agroalimentaria, representando el $16 \%$ de la facturación regional, con un total de 1.200 millones de euros facturados en 2008 (M.A.R.M.) a través de sus 254 empresas ( $8 \%$ del total de empresas en el sector).

Ambos aspectos, unidos al íntimo contacto con el sector quesero y su demanda de nuevos productos, hacen plantear como base de este trabajo la elaboración de un queso novedoso, adaptando la tecnología tradicional de elaboración quesera hacia nuevas tecnologías que aporten un valor añadido al producto final. Este beneficio deberá referirse tanto a la calidad y seguridad del queso como a la mejora de los procesos tecnológicos existentes, en busca de una óptima producción a través de procesos más sostenibles.

Como tecnología de mejora se elige la filtración tangencial mediante membranas de ultrafiltración, por ser una técnica ampliamente conocida e implantada a nivel industrial en el sector lácteo. La aplicación de la ultrafiltración a la elaboración de queso es conocida desde hace ya cuatro décadas, cuando se desarrolló el proceso MMV (Maubois et al. 1969), cuya aplicación a la elaboración de queso fresco tipo Burgos o queso blanco pasterizado está desplazando ampliamente a la tecnología tradicional tanto a nivel nacional como regional.

Dadas las características específicas del sector lácteo en Castilla y León y las tendencias actuales de producción y consumo nacionales, el queso escogido para ser elaborado a partir de concentrados de UF es un queso semicurado de mezcla. La elaboración se realiza a partir de leche pasterizada de vaca y oveja (en relación aproximada $85 / 15$ ). Se trata de un queso de coagulación mixta -con predominio enzimático-, de pasta prensada no cocida y tipo semicurado, al haber superado una maduración mínima de cuarenta días y presentarse en formatos de aproximadamente un kilogramo, como establece la Norma de Calidad para Quesos y Quesos Fundidos (RD 1113/2006). 
Esta elección se fundamenta en los datos de producción y consumo recogidos en el Capítulo I (Apartado 1.2.3), cuyos principales valores se resumen a continuación:

c Castilla y León cuenta con una producción muy importante de leche de oveja, la mayor del país con un $63 \%$ del total nacional.

c En cuanto a cifras totales de producción de leche, la mayor cantidad producida es leche de vaca -segunda región productora-, llegando a ser tres veces del volumen respecto al de leche de oveja. La leche de cabra también cuenta con una producción importante - quinta productora a nivel nacional- aunque mucho más localizada que el resto (ver Tabla 1.5). Estos datos de producción lechera en la comunidad de Castilla y León justifican la elección de la mezcla de leches.

c El tipo de queso más consumido en España es el elaborado con leche de vaca, seguido muy de cerca por el de mezcla, el cual supone aproximadamente el 38,5\% del total producido. Estos datos justifican la elección de la materia prima (leche de mezcla) en base a los datos de producción de queso.

c Por último, de las distintas variedades de queso, el más demandado por el consumidor es el semicurado. Este tipo supone aproximadamente el $18 \%$ del total de queso consumido en los hogares españoles.

La ultrafiltración para estandarizar leche o elaborar quesos frescos y pastas blandas, así como para el desuerado de cuajadas lácticas, ha sido ampliamente estudiada a nivel de investigación y posteriormente implantada a nivel industrial con susceptibles mejoras respecto al proceso tradicional. Sin embargo, no se puede decir lo mismo en el caso de su aplicación en la producción de quesos con un mayor grado de maduración y menor contenido de humedad, como son los quesos semicurados o curados. Aunque existe un amplio número de trabajos de investigación relacionados con este último tipo de quesos, no ha tenido el mismo impacto su aplicación industrial, debido a diversos problemas encontrados (Cheryan 1998):

c Aumentos drásticos de la viscosidad de los concentrados, a partir del $12-14 \%$ de proteína, que se procesan con mayor dificultad en los sistemas de membranas.

c Aumento del poder tampón de los retenidos, que afecta a los procesos de acidificación.

c. Posible homogenización parcial de la grasa en el proceso de filtración, favoreciendo oxidaciones y enranciamientos, pudiendo verse dañadas también las proteínas solubles, lo que genera problemas tecnológicos.

c Imposibilidad de llegar a un prequeso lo suficientemente concentrado, manteniéndose la necesidad de etapas posteriores de desuerado con las que no se consigue sacar la máxima rentabilidad al producto.

Por todo ello, el presente trabajo se plantea como un reto de investigación innovador para el sector lácteo de Castilla y León, en cuanto a la consecución total o parcial de los beneficios que esta técnica ya viene brindando a otros tipos de quesos, como (Cheryan 1998): aumento de rendimiento, ahorro de ingredientes, reducción del volumen de leche a tratar, eliminación o reducción de la cantidad de suero, mayor uniformidad y calidad del producto y mayor automatización del proceso y posibilidad de elaboración en continuo. 


\subsection{OBJETIVOS}

El objetivo principal del presente trabajo ha sido la obtención de un queso de mezcla (vaca/oveja), semicurado, de pasta prensada, obtenido a partir de retenidos de ultrafiltración de alto grado de concentración mediante adaptación de la tecnología tradicional de elaboración. Al mismo tiempo, se pretende conseguir un queso que aporte mayor rentabilidad, con las mejores cualidades organolépticas posibles, sin tener que imitar en todos sus atributos al queso fabricado mediante la tecnología tradicional de cuajado y desuerado en cuba.

Para llevar a cabo este objetivo general se plantearon los siguientes objetivos parciales:

c Optimización de las condiciones hidrodinámicas de flujo para la concentración de la leche en una planta piloto de ultrafiltración con membranas espirales poliméricas.

c Optimización secuencial, mediante diseño de experimentos, del proceso global de fabricación de queso ultrafiltrado teniendo en cuenta tanto la concentración de los retenidos, como las condiciones de cuajado, desuerado y prensado. La optimización se realizará en cuanto a calidad sensorial y rendimiento quesero.

Para evaluar la optimización conseguida se propone la realización de comparaciones, desde distintos puntos de vista, entre los quesos obtenidos a partir de concentrados de ultrafiltración -según cada secuencia de optimización- con queso de mezcla elaborado mediante tecnología convencional, a lo largo de cuarenta días de maduración.

Para esta comparación se han realizado estudios:

c Microbiológicos, desde el punto de vista de seguridad alimentaria.

cr Físico-químicos de composición.

c Organolépticos, mediante análisis descriptivo.

c De análisis estructural mediante micrografía ESEM.

c De análisis instrumental de textura y de color.

c Del proceso de maduración a través de fracciones proteicas y compuestos orgánicos volátiles.

c Del proceso de elaboración (seguimiento de temperatura y $\mathrm{pH}$ en el tiempo).

La propuesta final del trabajo pretende ser un protocolo de fabricación de un queso, con los mayores beneficios económicos por incremento del rendimiento quesero, a la vez que se mantienen unas adecuadas características organolépticas que faciliten su aceptación por el consumidor. 



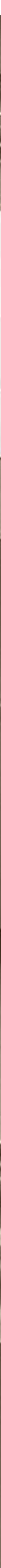





\section{METODOLOGÍA}

Se presenta a continuación una breve descripción de la metodología empleada para abordar los trabajos planteados en este estudio. Previamente a la mejora de las condiciones de procesado son necesarios unos estudios preliminares para la mejor comprensión del proceso de fabricación, al sustituir la leche por concentrados de ultrafiltración. En estos estudios se optimizarán las condiciones hidrodinámicas del proceso de filtración y se analizarán las consecuencias sobre las etapas de elaboración de factores como el poder tampón de los concentrados de ultrafiltración o la mayor dureza de las cuajadas obtenidas a partir de ellos.

A continuación, mediante una secuencia de diseños experimentales, se obtendrán las condiciones óptimas de fabricación de queso a partir de concentrados de UF. Finalmente, todos los quesos obtenidos en los óptimos experimentales serán comparados frente al queso de mezcla tradicional.

Con el fin de retener las proteínas solubles en el queso en su estado nativo -que en los procesos tradicionales de elaboración se pierden en un $95 \%$ al ser solubles en el suero lácteo (Lawrence 1989)-, la secuencia experimental se resolverá mediante análisis de respuesta múltiple que maximice tanto el rendimiento como la calidad sensorial del queso. De este modo se establecerán las condiciones óptimas, tanto de las variables del proceso de concentración de la leche por ultrafiltración como de las variables de elaboración del queso a partir del concentrado obtenido.

Tanto la aceptación sensorial como el rendimiento quesero, se seleccionan como respuestas a optimizar en todos los diseños, por el efecto económico final sobre la producción y sobre la aceptación del consumidor. Su definición e interés se recoge a continuación.

\section{c Rendimiento quesero}

La viabilidad económica de la producción quesera depende enormemente del rendimiento final alcanzado, por lo que los métodos para calcularlo deben ser inequívocos.

Una forma muy común de expresión del rendimiento es la cantidad obtenida de queso $(\mathrm{kg})$ por cada cien kilogramos de leche, calculado normalmente tras las etapas de prensado o salado.

$$
\% R=\frac{k g_{\text {queso }}}{k g_{\text {leche }}} 100
$$

Para que los distintos contenidos de humedad entre quesos no distorsionen los resultados, ha de estandarizarse el rendimiento a un contenido en sólidos (ES) del queso determinado (St-Gelais et al. 1998), transformando la Ecuación [3.1] a la forma:

$$
\% R_{\text {corregido }}=\frac{k g_{\text {queso }}}{k g_{\text {leche }}} 100 \frac{E S_{\text {queso }}}{E S_{\text {estándar }}}
$$

En este trabajo, cuando se emplean concentrados de ultrafiltración para elaborar el queso, se multiplica el peso de concentrado por el factor de concentración alcanzado en la etapa de 
ultrafiltración (VCR) para determinar los kilogramos de leche, de acuerdo con la Ecuación [1.2]. De esta manera se unifica la base de cálculo para el rendimiento en cuanto a la leche inicial con el fin de poder comparar el queso tradicional con los quesos elaborados a partir de concentrados de UF.

Para el tipo de queso estudiado un valor adecuado de referencia es el del $55 \%$ de extracto seco en el momento de su consumo ( $E S_{\text {estándar }}=55 \%$ ) similar al contenido en sólidos del queso Gouda, queso semiduro de origen holandés (Dejmek 1986).

\section{c Evaluación sensorial}

En todo momento deberá considerarse la aceptación olfato-gustativa del queso, ya que en muchas ocasiones se han atribuido sabores y textura atípicos en el estudio de quesos madurados obtenidos a partir de concentrados de leche por ultrafiltración. Estos defectos se atribuyen, en algunas ocasiones, a la hidrólisis de las proteínas solubles durante la maduración con formación de compuestos azufrados.

Como las proteínas en estado nativo son resistentes a la hidrólisis por la quimosina, plasmina o las bacterias lácticas (Mistry y Maubois 2004), en el proceso que se desarrolla se pretende evitar su desnaturalización y conseguir su conservación en la cuajada en estado nativo, para que realicen únicamente funciones de relleno inerte.

La incorporación de proteínas solubles al queso -dependiente del tipo de queso y del grado de concentración alcanzado en la ultrafiltración- provoca que en la matriz de cuajada parte de la caseína sea remplazada por proteínas solubles, dando una textura más blanda al queso. Por ello en la evaluación sensorial también se tendrá en cuenta la textura y la valoración visual del mismo, tanto interior como exterior.

Para caracterizar y comparar los distintos quesos se realiza un análisis sensorial mediante descriptores de olor, sabor y textura ya que, para conocer las propiedades sensoriales del producto, el método más flexible, comprensible y útil resulta ser el análisis descriptivo (Murray et al. 2001).

Para evaluar el resultado de las fabricaciones y optimizar los diseños se tomará el promedio de las puntuaciones obtenidas en la evaluación sensorial global de la sensación olfato-gustativa y de la impresión visual.

La leche de partida se estandariza a un 4,0 $\pm 0,2 \%$ de materia grasa y un 3,5 $\pm 0,1 \%$ en proteína para evitar la variabilidad que la materia prima pueda añadir a los resultados. Dicha estandarización corresponde a un relación grasa/proteína de 1,14 (o caseína/grasa de 0,7) como la empleada por Oommen et al. (2000) en la elaboración de queso Cheddar. Esta etapa de estandarización de la leche se llevará a cabo en todos los experimentos, en la ultrafiltración para optimizar las condiciones de flujo, en la ultrafiltración para elaborar queso con el concentrado y en la elaboración de queso mediante la tecnología tradicional.

Conforme a estas premisas el trabajo se secuenció en las cinco fases que se detallan a continuación.

\subsection{ESTUDIOS PRELIMINARES}

Previos a la concentración de la leche por ultrafiltración para elaborar el queso, fueron imprescindibles la puesta a punto del equipo y el estudio de la influencia de las condiciones de UF. 
Una vez obtenidos los primeros concentrados se realizan medidas del poder tampón y la dureza de las cuajadas, debido a la gran influencia que ambos factores tendrán en el comportamiento de la cuajada -obtenida a partir de concentrado de ultrafiltración- para la fabricación de queso.

\subsubsection{OPTIMIZACIÓN DE LAS CONDICIONES HIDRODINÁMICAS DE FILTRACIÓN}

Las condiciones en que se realiza la ultrafiltración son muy importantes desde el punto de vista del efecto sobre las proteínas que se incorporarán posteriormente en el queso, tanto caseínas como proteínas del suero. Se cree que el propio proceso de UF desnaturaliza una parte de las proteínas, concretamente entre un 5 y un $50 \%$ de la $\beta$-lactoglobulina según Lawrence (1989), dependiendo del grado de recirculación, la temperatura y el aire atrapado en los circuitos del equipo, por lo que es difícil controlar la proporción exacta de proteína nativa y soluble, en base sólo al tratamiento térmico.

Dependiendo del tipo de queso, el grado de desnaturalización óptimo para las proteínas solubles varía. Éste puede ser elevado para quesos tipo Feta o Quarg, mientras que para Cheddar o Mozzarella se introducen las proteínas en estado nativo, principalmente para evitar problemas de sabor y de textura, ya que las proteínas desnaturalizadas incrementan la cantidad de agua retenida (Rao y Renner 1988).

Por todo ello, la etapa de ultrafiltración debe ser lo más corta posible, además de por la rentabilidad económica que conlleve la reducción de tiempos, para evitar en todo lo posible la excesiva desnaturalización proteica.

Las condiciones hidrodinámicas deberán establecerse intentando alcanzar la mayor densidad de flujo de permeado (J), trabajando en condiciones de flujo límite como se definió en el Capítulo I (Apartado 1.3.4). Para ello, se realizarán estudios de $J$ en función de la diferencia de presión a través de la membrana (TMP), para distintas velocidades tangenciales.

La limitación de la concentración a alcanzar a causa de los módulos empleados (espirales) -más compactos y económicos- conlleva estudios previos de determinación del factor de concentración alcanzable, realizados estableciendo el comportamiento de $J$ como función de la concentración.

\subsubsection{PODER TAMPÓN Y ACIDIFICACIÓN DE LOS CONCENTRADOS}

Cuando la leche se ultrafiltra a su pH normal $(6,6-6,8)$, las sales minerales (de $\mathrm{Ca}$, $\mathrm{Mg}$ y $\mathrm{P}$ ) unidas a las micelas de caseína se concentran en el mismo factor que la proteína, debido a que parte se encuentran unidas a la caseína (Maubois et al. 1969). Este hecho conlleva un incremento en el poder tampón del retenido, lo cual modifica algunos parámetros básicos del proceso de elaboración de queso como la cinética de acidificación de las bacterias lácticas, el pH final del queso, la cinética de coagulación de la leche, las propiedades reológicas de la cuajada, la lipolisis durante la maduración, el crecimiento y supervivencia de microorganismos patógenos o la expulsión de agua durante la maduración (Rash y Kosikowski 1982; Saboya et al. 2001). Todo esto puede provocar, en muchas variedades de queso, el desarrollo de un sabor ácido excesivo.

Por otro lado, un exceso de sales de calcio son liberadas en la cuajada durante la acidificación, aumentando la fuerza iónica y modificando la agregación de las caseínas, desencadenando texturas arenosas más frágiles y desmenuzables y perdiendo elasticidad en el queso. 
Para tener una estimación de la magnitud de estos efectos se propuso la realización de los siguientes estudios:

c Capacidad tampón para distintos valores de $\mathrm{pH}$, tanto en leche de mezcla estandarizada como en retenidos de distinto grado de concentración.

r Seguimiento de la cinética de acidificación de distintas concentraciones de bacterias lácticas, tanto en la leche como en el concentrado. Estos estudios proporcionan una estimación de la cantidad de fermento que deberá emplearse en el proceso de elaboración del queso a partir de concentrados de ultrafiltración, respecto a la empleada en la elaboración tradicional.

\subsubsection{DUREZA DE LAS CUAJADAS}

Cuando se emplean concentrados de ultrafiltración de leche a los que se añade la misma cantidad de cuajo que a la leche sin ultrafiltrar, el tiempo de gelificación (tiempo de toma) no se ve afectado por el incremento de proteína; sin embargo, el tiempo hasta el corte de la cuajada (tiempo de coagulación) se reduce considerablemente (Maubois et al. 1971; Garnot et al. 1982). Este comportamiento es debido a numerosos fenómenos como, por ejemplo, el aumento en la velocidad de la reacción enzimática al aumentar el contenido proteico. Por este motivo, una práctica común cuando se trabaja con concentrados de leche, es la reducción de la cantidad de cuajo utilizada, ya que excesiva firmeza de la cuajada puede empeorar las etapas posteriores de corte y desuerado 0 de moldeo y prensado.

Con el fin de estudiar este efecto en los diferentes concentrados obtenidos se propuso como parte de estos estudios previos el:

c Seguimiento mediante texturómetro de la dureza de los geles a lo largo del tiempo, para diferentes concentraciones de cuajo, tanto en leche como en retenidos de distintos grados de concentración. Estos resultados permitirán establecer los niveles de concentración de cuajo para ser ensayados en los diseños experimentales.

\subsection{ESTABLECIMIENTO DE LAS CONDICIONES INICIALES}

Con objeto de identificar los factores, tanto del proceso de ultrafiltración como de fabricación, susceptibles de ser significativos -bajo una optimización de respuesta múltiple que maximice el rendimiento final obtenido y la calidad sensorial- y para establecer sus condiciones iniciales en la elaboración con concentrados de leche, se empleó una matriz de experimentos Plackett-Burmann, que sirve de método de barrido (screening) en la citada identificación.

Esta matriz Plackett-Burmann se aplica al estudio de ocho factores (también denominadas variables) mediante doce experimentos independientes y aleatorizados, con una resolución III, donde las interacciones dobles se confunden con los efectos principales.

Se trata de un diseño a medio camino entre los factoriales y los fraccionados que, por el hecho de considerar las interacciones como despreciables, permite alcanzar las mismas conclusiones que un diseño fraccionado empleando un número menor de experimentos. 
Los ocho factores se recogen a continuación, agrupados según la etapa en que aparecen, bien en el proceso de ultrafiltración o en distintas etapas de la fabricación del queso (adición de ingredientes, coagulación y corte de la cuajada) incluyendo también la etapa de prensado.

\section{c Variables del proceso de ultrafiltración}

En la etapa de concentración por ultrafiltración se evaluó la posibilidad de incluir dos factores que se pueden considerar como dos sub-etapas:

- La diafiltración en discontinuo, mediante adición al concentrado de la cantidad de agua correspondiente a cada nivel del diseño (calculada como porcentaje de la leche inicial). Para la diafiltración se añade agua de red, una vez alcanzado un VCR de 3 -como en los trabajos de Spangler et al. $(1990,1991)$ sobre queso Gouda- para posteriormente ser eliminada hasta alcanzar el grado de concentración objetivo. Se estudia la inclusión o no de esta etapa por su influencia en la reducción del contenido en lactosa del concentrado.

- La modificación del pH inicial de la leche antes de ser ultrafiltrada, mediante adición de disolución de glucona- $\delta$-lactona comercial $(60 \mathrm{~g} / 100 \mathrm{~L}$ de leche) como regulador del $\mathrm{pH}$, actuando durante $45 \mathrm{~min}$ a $45^{\circ} \mathrm{C}$, en agitación, antes de proceder a la ultrafiltración.

El estudio de estas etapas resulta interesante ya que muchos de los defectos de textura de los quesos, obtenidos a partir de concentrados de leche, como arenosidad, menor firmeza o mayor friabilidad, están provocados por el alto contenido en calcio de los concentrados cuando la leche se filtra a pH 6,7. La mineralización de la cuajada juega por tanto un papel fundamental en las propiedades reológicas del queso (Maubois y Kosikowski 1978). Con la inclusión de estás dos etapas se estudiará la influencia del contenido final en sales del retenido.

Por otro lado, el grado de concentración alcanzado es otra variable a tener en cuenta en el estudio. Se pretende alcanzar el mayor grado de concentración posible, mediante el uso de membranas espirales, para trabajar bajo el concepto de prequeso líquido.

\section{c Adición de ingredientes}

Según los resultados obtenidos en los estudios preliminares, se elegirán los rangos de concentración, tanto de fermento como de cuajo, que serán estudiados en el diseño.

Mediante la variación de la concentración de fermento se intentará paliar el aumento del poder tampón y la disminución de la velocidad de acidificación, sin afectar -en la medida de lo posible- el sabor final del queso. Se partirá de la concentración empleada en la elaboración tradicional y se elevará la dosis para estudiar su efecto en el queso final.

Con la variación de la dosis de cuajo se pretende un ahorro en la cantidad de enzima coagulante, siempre que se obtengan durezas de cuajadas y tiempos de coagulación adecuados para el proceso global.

\section{c Coagulación y corte de la cuajada}

El cuajo es activo a temperaturas comprendidas entre $10-40{ }^{\circ} \mathrm{C}$ si bien a valores por debajo de $30^{\circ} \mathrm{C}$ el tiempo de consolidación de la cuajada disminuye significativamente (Mahaut et al. 2003). Por ello se estudiará un rango de temperaturas de cuajado por encima de la temperatura normal de cuajado de este tipo de queso $\left(32^{\circ} \mathrm{C}\right)$ y sin sobrepasar las temperaturas alcanzadas en la etapa de sinéresis en la elaboración tradicional de queso $\left(37^{\circ} \mathrm{C}\right)$. 
El estudio del tamaño de corte de la cuajada se realizará a valores ascendentes respecto a los empleados en el queso tradicional, ya que a menor tamaño de grano se alcanza un mayor grado de desuerado y, consecuentemente, mayor pérdida de proteína soluble en su estado nativo.

\section{r. Etapa de Prensado}

Se estudió el efecto de la presión de prensado sobre el queso final, como variable discreta, dividida en dos intervalos $\left(P_{\text {final }} / P_{\text {inicial }}\right)$, donde la presión inicial es la que actúa desde el inicio hasta el volteo y la final la aplicada desde el volteo hasta el desmoldeo. Una de las funciones del prensado es favorecer la unión de los granos de cuajada (Mahaut et al. 2003), y el valor de presión utilizado para quesos de pasta prensada varía entre los 2,0 y 5,0 bar dependiendo del tamaño y la consistencia final del queso.

Se seleccionaron valores de presión mayores a los empleados en la elaboración del queso tradicional -entre 2,0 y 2,5 bar- al considerar que una mayor dureza de la cuajada hace necesarias presiones superiores para favorecer la fusión de los granos tras la etapa de corte.

Para las ocho variables aquí definidas -etapa de diafiltración, disminución del pH inicial de la leche, extracto seco del concentrado, concentración de cuajo, dosis de fermento, temperatura de cuajado, tamaño de corte de la cuajada y presión en la etapa de prensado- se establecieron dos niveles de trabajo, alto y bajo, para delimitar la región de estudio sobre la que se aplica el diseño de experimentos Plackett-Burmann.

\subsection{OPTIMIZACIÓN DE LAS VARIABLES SIGNIFICATIVAS. DISEÑO FACTORIAL}

Una vez establecidas las condiciones iniciales de fabricación del queso ultrafiltrado, se investigan simultáneamente los efectos y las interacciones de los factores cuya influencia resultó significativa en el diseño anterior, mediante un experimento factorial completo $\left(2^{3}\right)$. Debido a la posibilidad de que el efecto de un factor cambie en presencia de los niveles de otro factor, es decir, que los factores interactúen, surge la necesidad de su estudio conjunto.

Puesto que la composición de la leche no es homogénea a lo largo de la lactación y puede intervenir en los niveles de los factores de estudio -aún habiendo sido estandarizada en grasa y proteína- el diseño se realiza bloqueado en cuanto a la leche de partida. De este modo, se elimina su influencia mediante el control de la misma, creando bloques de observaciones en los que esta variable asume un valor constante. Mediante esta estrategia se consigue al mismo tiempo estimar el efecto de la variable bloqueada (composición de la leche).

Los factores estudiados en el diseño, y las causas de su selección, han sido:

c Tamaño de corte de la cuajada.

c. Concentración de fermento.

c Tipo de fermento.

Los dos primeros se seleccionaron por ser significativos en el estudio de las condiciones iniciales, como se verá en el Capítulo V (Apartado 5.2). El tercero se selecciona para contrarrestar el poder 
tampón de los concentrados mediante el uso de un fermento puramente acidificante (R703) en comparación con el fermento empleado en la elaboración tradicional (MA4001), así como para estudiar su influencia respecto a las propiedades sensoriales del queso.

La composición de ambos fermentos, tradicional (MA4001) y acidificante (R703), es:

c CHOOZIT $^{\mathrm{TM}}$ MA4001: mezcla de bacterias mesófilas y termófilas acidificantes homofermentativas (lactococcus lactis ssp. lactis, lactococcus lactis ssp. cremoris y streptococcus salivarius ssp. thermophilus) con bacterias productoras de aromas (lactococcus lactis ssp. lactis var diacetylactis).

c HANSEN R703: mezcla de bacterias mesófilas homofermentativas (lactococcus lactis ssp. lactis y lactococcus lactis ssp. cremoris).

Para tener una mejor estimación del error experimental el diseño se ejecuta por duplicado, constando en su totalidad de 16 experimentos (fabricaciones) independientes y aleatorizados.

\subsection{OPTIMIZACIÓN DEL PROCESO DE ACIDIFICACIÓN EN PRENSA}

Una vez establecidos el tipo y la dosis de fermento -mediante el diseño factorial- se optimiza, nuevamente en cuanto a valoración sensorial global y rendimiento, el proceso de acidificación del queso hasta alcanzar el valor final de $\mathrm{pH}$ a la salida de prensa $(5,1-5,3)$ en las mejores condiciones posibles.

Para ello el experimento se ajusta a un modelo de segundo orden, mediante diseño de superficie respuesta central compuesto (St-Pierre y Weiss 2009). Éste se compone de un diseño factorial $2^{\mathrm{k}}$ $(\mathrm{K}=2)$ aumentado por puntos axiales y centrales, convertido en rotable (misma precisión de estimación en todas las direcciones) mediante la elección adecuada de la distancia axial.

Con este tipo de diseño se llegará mejor al valor deseado de $\mathrm{pH}$, ya que permite conocer el espacio respuesta con más detalle al moverse sobre una superficie, frente a los modelos factoriales de primer orden que se mueven sobre un plano.

El diseño se divide en bloques, para eliminar la posible influencia de la leche de fabricación de cada uno de los días, y se repite para estimar mejor el error experimental. En total, contabilizando las réplicas, el diseño consta de veinte experimentos independientes y aleatorizados.

Las variables seleccionadas para el estudio de la cinética de acidificación, y los motivos de esa selección, fueron:

C El tiempo de prensado.

c El tiempo de activación (premaduración) del fermento a $37^{\circ} \mathrm{C}$.

Con el primero de ellos se pretende tener un control lo más exacto posible de la duración de la etapa de prensado, ya que variaciones en el tiempo de prensado entre distintas fabricaciones/lotes -o lo que es lo mismo en la cinética de acidificación del fermento- provocan pérdidas de calidad debido a una mayor variación en las cualidades sensoriales del queso entre lotes. Para ello se controla la temperatura de la sala de prensado entre 22 y $24^{\circ} \mathrm{C}$ al mismo tiempo que se estudia la posibilidad de activar el fermento comercial, con intención de ganar tiempo al añadir las bacterias reconstituidas frente a la presentación comercial liofilizada. 
El objetivo es optimizar el tiempo de prensado para alcanzar el valor óptimo de $\mathrm{pH}$, establecido entre 5,15 y 5,30 para quesos de similares características, como puede ser queso semicurado de mezcla (Rodríguez et al. 1996), queso Gouda (Spangler et al. 1990), queso Cheddar (McGregor y White 1990) o queso Saint-Paulin (Delbeke 1987).

Por otro lado, alcanzar valores de $\mathrm{pH}$ mayores de 5,3 puede afectar a la mineralización de la cuajada y a la seguridad del alimento al ser éste más susceptible de contaminación por microorganismos patógenos, como indican Rash et al. (1982) en su estudio sobre los recuentos de $E$. Coli en queso Camembert elaborado a partir de retenidos de ultrafiltración. De igual forma, valores de pH por debajo de 5,1 provocarán defectos de textura, como pérdidas de elasticidad y cohesividad de la cuajada, aumentos de adherencia, al igual que sabores indeseables por excesos de acidez y/o presencia de amargores.

Por último, la elección de la temperatura de activación se realizó a partir de un estudio anterior en el que se evaluaron tres temperaturas de premaduración ( 32,35 y $\left.37^{\circ} \mathrm{C}\right)$. En esas condiciones se elaboraron quesos a partir de concentrados de UF y se efectuaron pruebas de preferencia mediante el panel de cata entrenado de la Estación Tecnológica de la Leche (ITACyL). En estas pruebas los catadores eligieron de forma significativa los quesos elaborados a partir de fermentos premadurados a $37^{\circ} \mathrm{C}$.

\subsection{SEGUIMIENTO DE LOS RESULTADOS EXPERIMENTALES}

En las tres etapas de optimización estudiadas (Apartados 3.3, 3.4 y 3.5) se ha centrado el estudio en maximizar simultáneamente el rendimiento y la valoración sensorial global del queso (olfato-gustativa y visual) a través de las puntuaciones de un panel de cata entrenado.

No obstante, para el seguimiento de los resultados de los experimentos indicados en esta metodología se realizan determinaciones complementarias como el análisis físico-químico de las corrientes líquidas, acorde a los parámetros recogidos en la Tabla 3.1.

Se analizan las leches de partida (vaca, oveja y mezcla estandarizada) para garantizar su calidad, comprobando la ausencia de residuos de antibióticos, puesto que su presencia puede crear resistencia frente a microorganismos además de inhibir el desarrollo del fermento.

Se realizan recuentos de células somáticas, ya que recuentos altos de células afectan de forma significativa al rendimiento quesero (Kosikowski y Mistry 1988; Barbano et al. 1991). Conforme a lo establecido por la Unión Europea (Reglamento (CE) 853/2004) los recuentos de células somáticas no deben superar, en vaca, las 400.000 células $/ \mathrm{mL}$; respecto a la oveja no está legislado el contenido mínimo de células, por lo que se establecerán, como parámetro de calidad, recuentos menores de 800.000 células $/ \mathrm{mL}$. Otro párametro de calidad que recoge el citado reglamento son los recuentos de gérmenes a $30^{\circ} \mathrm{C}$, si bien como la leche -o el concentrado- se somete a tratamiento térmico no se realizará dicho análisis. Se comprobará la seguridad microbiológica del producto final de acuerdo con la legislación vigente (Reglamento(CE) 2073/2005) para estudiar la seguridad del queso obtenido mediante la nueva tecnología en comparación con el obtenido por la tecnología tradicional.

A su vez, los concentrados de ultrafiltración se analizan para comprobar que cumplen las premisas en cuanto a factor de concentración alcanzado y para verificar su composición. 
Por último, se analizan los permeados generados en la etapa de ultrafiltración, para comprobar el grado de retención de los constituyentes de la leche que se desean incorporar al queso.

Tabla 3.1. Determinaciones realizadas a las corrientes líquidas

\begin{tabular}{|c|c|c|c|c|c|c|c|c|}
\hline & 嵒 & 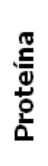 & 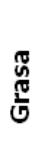 & 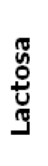 & $\begin{array}{l}\frac{\mathscr{N}}{\mathbb{N}} \\
\frac{N}{\mathbb{N}} \\
\text { Un }\end{array}$ & $\frac{T}{2}$ & 瓷 & 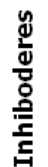 \\
\hline Leche Oveja & $x$ & $x$ & $x$ & $x$ & $x$ & $x$ & $x$ & $\mathrm{X}$ \\
\hline Leche Vaca & $\mathrm{X}$ & $\mathrm{x}$ & $x$ & $x$ & $\mathrm{X}$ & $\mathrm{x}$ & $x$ & $x$ \\
\hline Leche Mezcla & $x$ & $\mathrm{x}$ & $x$ & $x$ & $\mathrm{X}$ & $x$ & $x$ & $\mathrm{x}$ \\
\hline Concentrado & $\mathrm{x}$ & $x$ & $x$ & $x$ & $\mathrm{x}$ & $\mathrm{x}$ & & \\
\hline Permeado & $\mathrm{x}$ & $x$ & $x$ & $x$ & $\mathrm{X}$ & $x$ & & \\
\hline Suero en óptimos diseños & $x$ & $\mathrm{X}$ & $X$ & $x$ & $\mathrm{X}$ & $x$ & & \\
\hline Suero en el queso tradicional & $\mathrm{x}$ & $\mathrm{X}$ & $\mathrm{X}$ & $\mathrm{x}$ & $\mathrm{X}$ & $\mathrm{x}$ & & \\
\hline
\end{tabular}

Para evaluar y comparar los resultados de todas las fabricaciones de queso llevadas a cabo a lo largo de los tres diseños se efectuaron sobre todos ellos las determinaciones recogidas en la Tabla 3.2 .

Tabla 3.2. Análisis realizados a los quesos de los distintos experimentos.

( $P B=$ Plackett-Burmann; $D F=$ diseño factorial; $S R=$ diseño de superficie respuesta)

\begin{tabular}{|c|c|c|c|c|c|c|c|c|c|c|c|c|c|c|c|c|c|c|c|c|c|c|c|c|c|}
\hline \multirow{2}{*}{ 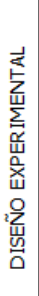 } & \multirow{2}{*}{ 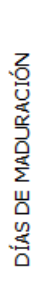 } & \multicolumn{6}{|c|}{$\begin{array}{l}\text { COMPOSICIÓN } \\
\text { FÍSICO-QUÍMICO }\end{array}$} & \multicolumn{5}{|c|}{$\begin{array}{c}\text { TEXTURA } \\
\text { TEXTURÓMETRO }\end{array}$} & \multicolumn{7}{|c|}{$\begin{array}{c}\text { SENSORIAL } \\
\text { OLFATO-GUSTATIVO }\end{array}$} & \multicolumn{4}{|c|}{ SENSORIAL VISUAL } & \multicolumn{2}{|c|}{ PROCESO } \\
\hline & & 嵩 & $\frac{\pi}{\frac{\pi}{0}}$ & 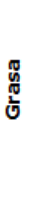 & $\bar{\omega}$ & $\begin{array}{l}\frac{y}{N} \\
\frac{N}{5} \\
\text { Un }\end{array}$ & $\frac{T}{2}$ & 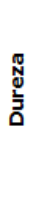 & 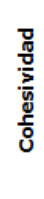 & $\begin{array}{l}\frac{\pi}{\pi} \\
\frac{\pi}{2} \\
\frac{\pi}{\bar{y}} \\
\frac{5}{\mathbf{q}}\end{array}$ & 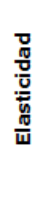 & 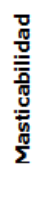 & 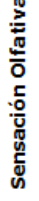 & 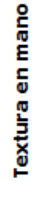 & 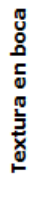 & $\frac{9}{\frac{9}{3}}$ & 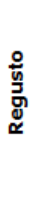 & 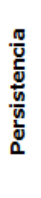 & $\begin{array}{l}\bar{\pi} \\
\text { 은 } \\
\end{array}$ & 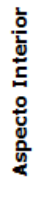 & 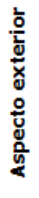 & 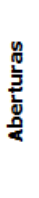 & $\begin{array}{l}\overline{0} \\
\text { 은 } \\
\text { On }\end{array}$ & $\frac{T}{2}$ & $\frac{\stackrel{2}{c}}{\frac{0}{E}}$ \\
\hline \multirow{3}{*}{$\stackrel{\infty}{0}$} & 0 & & & & & & $\mathbf{x}$ & & & & & & & & & & & & & & & & & \multirow{3}{*}{$\mathbf{X}$} & \multirow{3}{*}{ X } \\
\hline & 20 & $\mathbf{x}$ & $\mathrm{x}$ & $\mathbf{X}$ & $\mathbf{x}$ & $\mathbf{x}$ & $\mathbf{x}$ & & & & & & & & & & & & & & & & & & \\
\hline & 40 & $\mathbf{x}$ & $\mathbf{x}$ & $\mathbf{x}$ & $\mathbf{x}$ & $\mathbf{x}$ & $\mathbf{x}$ & $\mathbf{x}$ & $x$ & $\mathbf{x}$ & $\mathbf{x}$ & $\mathbf{x}$ & $\mathbf{x}$ & $x$ & $\mathbf{x}$ & $\mathbf{x}$ & $\mathbf{x}$ & $\mathbf{x}$ & $x$ & $\mathbf{x}$ & $\mathbf{x}$ & $\mathbf{x}$ & $x$ & & \\
\hline \multirow{3}{*}{ 㟧 } & 0 & & & & & & $\mathbf{x}$ & & & & & & & & & & & & & & & & & \multirow{3}{*}{$\mathbf{x}$} & \multirow{3}{*}{$\mathbf{x}$} \\
\hline & 20 & $\mathbf{x}$ & $\mathbf{x}$ & X & $\mathbf{X}$ & $\mathbf{x}$ & $\mathbf{x}$ & & & & & & & & & & & & & & & & & & \\
\hline & 40 & $\mathbf{x}$ & $\mathrm{x}$ & $x$ & $\mathbf{x}$ & $\mathbf{x}$ & $\mathbf{x}$ & $\mathbf{x}$ & $x$ & $\mathbf{x}$ & $\mathbf{x}$ & $x$ & $x$ & $x$ & $\mathbf{x}$ & $\mathbf{x}$ & $\mathrm{x}$ & $x$ & $x$ & $x$ & $\mathbf{x}$ & $\mathrm{x}$ & $x$ & & \\
\hline \multirow{3}{*}{ ตै } & 0 & & & & & & $\mathrm{x}$ & & & & & & & & & & & & & & & & & \multirow{3}{*}{$\mathbf{x}$} & \multirow{3}{*}{$\mathbf{x}$} \\
\hline & 20 & $\mathbf{x}$ & $\mathbf{X}$ & $\mathbf{X}$ & $\mathbf{X}$ & $\mathbf{x}$ & $\mathbf{x}$ & & & & & & & & & & & & & & & & & & \\
\hline & 40 & $\mathbf{X}$ & $\mathbf{X}$ & $\mathbf{X}$ & $\mathbf{X}$ & $\mathbf{X}$ & $\mathbf{X}$ & $\mathbf{X}$ & $\mathbf{x}$ & $\mathbf{X}$ & $\mathbf{X}$ & $\mathbf{X}$ & $\mathbf{x}$ & $x$ & $\mathbf{x}$ & $\mathbf{x}$ & $\mathbf{x}$ & $x$ & $x$ & $\mathbf{x}$ & $\mathbf{x}$ & $x$ & $\mathbf{x}$ & & \\
\hline
\end{tabular}

En cuanto a la caracterización físico-química se realizaron análisis tanto a la mitad como al final de la maduración para estimar la evolución de la etapa de secado, exceptuando la medida de pH que se realizó durante todo el proceso de elaboración para establecer la cinética de acidificación del fermento utilizado.

Además de la valoración sensorial global a partir de la que se optimizan los diseños, se eligieron una serie de descriptores sensoriales de olor, sabor, textura y aspecto visual, sobre los cuales se encontraba entrenado el panel de cata. 
En lo referente a la textura, se realiza un análisis instrumental mediante análisis de perfil de textura (TPA) para completar los datos obtenidos con el panel de cata. Al igual que el análisis sensorial, el instrumental se llevó a cabo a los 40 días de maduración del queso.

Mediante la inclusión de los análisis recogidos en las Tablas 3.1. y 3.2 quedan perfectamente caracterizados los quesos elaborados en el amplio rango de condiciones que ofrecen los diseños experimentales, por lo que se obtendrá gran información sobre el efecto de los distintos factores sobre las cualidades organolépticas y de textura del queso.

\subsection{COMPARACIÓN DE LOS QUESOS OBTENIDOS EN LAS CONDICIONES ÓPTIMAS DE LOS DISEÑOS FRENTE A LA ELABORACIÓN TRADICIONAL}

Tras los ensayos descritos anteriormente en esta metodología, y su interpretación, se realizan una serie de elaboraciones, con el fin de establecer la idoneidad de los diseños planteados y de los óptimos alcanzados, así como de conocer las diferencias encontradas entre los quesos de la secuencia de optimización respecto del elaborado mediante la tecnología tradicional. Estas fabricaciones se corresponden con:

c OPB = fabricación en las condiciones del óptimo alcanzado en el diseño inicial Plackett-Burman.

c ODF = fabricación en las condiciones del óptimo alcanzado en el Diseño Factorial de optimización de las variables significativas.

c $\mathbf{O S R}=$ fabricación en las condiciones del óptimo alcanzado en el diseño de Superficie Respuesta para obtener el pH final del queso.

c $\mathbf{M}=$ fabricación de queso de mezcla mediante tecnología tradicional, que sirva de referencia para las comparaciones.

En todos los casos se realizaron tres lotes de fabricación distintos a partir de los que se obtuvieron los valores medios para cada variable estudiada.

Sobre la leche de partida (oveja, vaca y mezcla), concentrado y permeado de ultrafiltración (en su caso) así como a los suero obtenidos, se realizaron los análisis recogidos en la Tabla 3.1.

Sobre los quesos obtenidos en cada uno de los tres lotes de las cuatro fabricaciones anteriores se realizaron las determinaciones que se recogen en las Tablas 3.3 y 3.4 .

Según la Tabla 3.3 el análisis de composición de los quesos se realiza en tres fases, al final de la elaboración (tras el salado), a los 20 y a los 40 días de maduración. Del mismo modo que en los quesos de los diseños experimentales, se realiza un análisis detallado de descriptores sensoriales y de textura. La caracterización de los quesos se completa mediante la medida del color (con colorímetro) para comparar el óptimo final (OSR) con el queso tradicional (M).

Para profundizar en el proceso de maduración se realiza un seguimiento del nitrógeno no caseínico (NNC) y del nitrógeno no proteico (NNP) a lo largo de la maduración, según se recoge en la Tabla 3.4. Con el mismo propósito se realiza un análisis de los compuestos orgánicos volátiles que se generan durante el afinado del queso. 
Debido a la singularidad de las cuajadas generadas a partir de concentrados de ultrafiltración se realiza un análisis estructural a los 40 días de maduración mediante microscopía de barrido electrónico para caracterizar las cualidades estructurales, como porosidad o diámetro medio de poro, de los quesos resultantes de las cuatro tecnologías de fabricación.

Como se trabaja con alimentos se realizan análisis de contaminantes patógenos, conforme a la legislación vigente, para asegurar la inocuidad del queso (Tabla 3.4). En lo que respecta a la calidad del queso se estudiará también el crecimiento de microorganismos alterantes susceptibles de contaminar el producto final.

Tabla 3.3. Análisis generales realizados a los quesos de las fabricaciones: OPB, ODF, OSR y M

\begin{tabular}{|c|c|c|c|c|c|c|c|c|c|c|c|c|c|c|c|c|c|c|c|c|c|c|c|c|c|c|c|c|c|}
\hline \multirow[b]{2}{*}{ 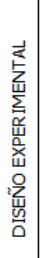 } & \multirow[b]{2}{*}{ 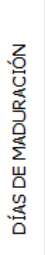 } & \multicolumn{6}{|c|}{$\begin{array}{l}\text { COMPOSICIÓN } \\
\text { FísICO-QUÍMICO }\end{array}$} & \multicolumn{5}{|c|}{$\begin{array}{c}\text { TEXTURA } \\
\text { TEXTURÓMETRO }\end{array}$} & \multicolumn{7}{|c|}{$\begin{array}{c}\text { SENSORIAL } \\
\text { OLFATO-GUSTATIVO }\end{array}$} & \multicolumn{4}{|c|}{ SENSORIAL VISUAL } & \multicolumn{3}{|c|}{ COLOR } & \multicolumn{3}{|c|}{ PROCESO } \\
\hline & & 屎 & $\begin{array}{l}\frac{\pi}{5} \\
\frac{\pi}{\mathrm{g}} \\
\frac{0}{2}\end{array}$ & $\begin{array}{l}\text { w. } \\
\text { w. } \\
\text { on }\end{array}$ & $\bar{\varpi}$ & 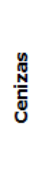 & $\frac{I}{a}$ & 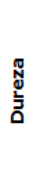 & 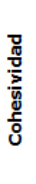 & 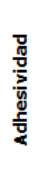 & 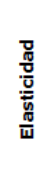 & 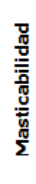 & 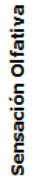 & 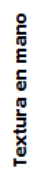 & 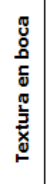 & $\frac{2}{0 ! 0}$ & 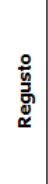 & 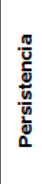 & 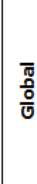 & 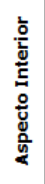 & $\begin{array}{l}\frac{\mathrm{o}}{\mathrm{c}} \\
\frac{\mathrm{v}}{\mathrm{d}} \\
\frac{\mathrm{g}}{\mathrm{g}} \\
\frac{\mathrm{g}}{2}\end{array}$ & 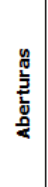 & $\begin{array}{l}\bar{\pi} \\
\text { ô } \\
\text { U }\end{array}$ & $* 0$ & $\stackrel{*}{*}$ & $\stackrel{*}{*}$ & $n$ & I & 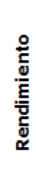 \\
\hline \multirow{3}{*}{$\begin{array}{l}\mathbf{\omega} \\
0 \\
0\end{array}$} & 0 & $x$ & $x$ & $x$ & $x$ & $x$ & $x$ & & & & & & & & & & & & & & & & & & & & \multirow{3}{*}{$x$} & \multirow{3}{*}{$x$} & \multirow{3}{*}{$x$} \\
\hline & 20 & $x$ & $x$ & $x$ & $x$ & $x$ & $x$ & & & & & & & & & & & & & & & & & & & & & & \\
\hline & 40 & $x$ & $x$ & $x$ & $x$ & $x$ & $x$ & $x$ & $x$ & $x$ & $x$ & $x$ & $x$ & $x$ & $x$ & $x$ & $x$ & $x$ & $x$ & $x$ & $x$ & $x$ & $x$ & & & & & & \\
\hline \multirow{3}{*}{ 㟧 } & 0 & $x$ & $x$ & $x$ & $x$ & $x$ & $x$ & & & & & & & & & & & & & & & & & & & & \multirow{3}{*}{$x$} & \multirow{3}{*}{$x$} & \multirow{3}{*}{$x$} \\
\hline & 20 & $x$ & $x$ & $x$ & $x$ & $x$ & $x$ & & & & & & & & & & & & & & & & & & & & & & \\
\hline & 40 & $x$ & $x$ & 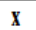 & $\mathrm{X}$ & $x$ & $x$ & $\mathrm{X}$ & $\mathrm{X}$ & $x$ & $\mathrm{X}$ & $x$ & $x$ & $x$ & $x$ & $\mathrm{x}$ & $\mathrm{x}$ & $x$ & $x$ & $\mathrm{x}$ & $\mathrm{x}$ & $x$ & $x$ & & & & & & \\
\hline \multirow{3}{*}{ 遌 } & 0 & $x$ & $x$ & $x$ & $x$ & $x$ & $x$ & & & & & & & & & & & & & & & & & $x$ & $x$ & $\mathrm{x}$ & \multirow{3}{*}{$\mathrm{x}$} & \multirow{3}{*}{$x$} & \multirow{3}{*}{$x$} \\
\hline & 20 & $x$ & $x$ & $x$ & $x$ & $x$ & $x$ & & & & & & & & & & & & & & & & & $x$ & $x$ & 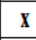 & & & \\
\hline & 40 & $x$ & $x$ & $x$ & $x$ & $x$ & 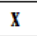 & $x$ & $\mathrm{X}$ & $x$ & $x$ & $x$ & $x$ & $x$ & $x$ & $\begin{array}{l}x \\
\end{array}$ & $\mathrm{x}$ & $x$ & $\bar{x}$ & $x$ & $x$ & $x$ & $x$ & $x$ & $x$ & $\bar{x}$ & & & \\
\hline \multirow{3}{*}{$\Sigma$} & 0 & $x$ & $x$ & $x$ & $x$ & $x$ & $x$ & & & & & & & & & & & & & & & & & $x$ & $x$ & $x$ & \multirow{3}{*}{$x$} & \multirow{3}{*}{$x$} & \multirow{3}{*}{$\mathrm{X}$} \\
\hline & 20 & $x$ & $x$ & $x$ & $x$ & $x$ & $\mathrm{X}$ & & & & & & & & & & & & & & & & & $x$ & $\begin{array}{ll}x \\
\end{array}$ & $\begin{array}{l}x \\
\end{array}$ & & & \\
\hline & 40 & $x$ & $x$ & $x$ & $\mathrm{x}$ & $x$ & $x$ & $x$ & $x$ & $x$ & $x$ & $x$ & $x$ & $x$ & $x$ & $x$ & $\mathrm{x}$ & $x$ & $x$ & $x$ & $x$ & $x$ & $\mathbf{x}$ & $x$ & $x$ & $x$ & & & \\
\hline
\end{tabular}

Tabla 3.4. Análisis específicos realizados a los quesos de las fabricaciones: OPB, ODF, OSR y M

\begin{tabular}{|c|c|c|c|c|c|c|c|c|c|c|c|}
\hline \multirow[b]{2}{*}{ 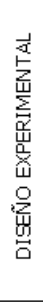 } & \multirow[b]{2}{*}{ 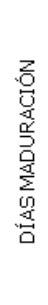 } & \multicolumn{3}{|c|}{ MABDURACIÓN } & \multirow[b]{2}{*}{ 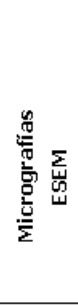 } & \multirow[b]{2}{*}{ 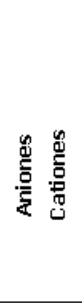 } & \multicolumn{5}{|c|}{ MICROBIOLOGIA } \\
\hline & & 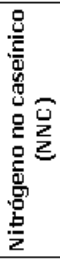 & 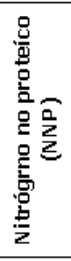 & 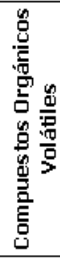 & & & 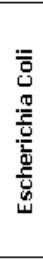 & 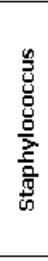 & & 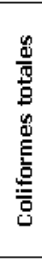 & 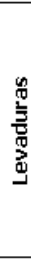 \\
\hline \multirow{3}{*}{ 兽 } & 0 & $x$ & $x$ & & & & & $\mathrm{X}$ & $x$ & $\mathbf{x}$ & $x$ \\
\hline & 20 & $x$ & $x$ & & & & & $\mathrm{x}$ & $\mathrm{x}$ & $\mathrm{x}$ & $x$ \\
\hline & 40 & $x$ & $X$ & & $\mathrm{X}$ & & & $\mathbf{X}$ & $x$ & $\mathbf{X}$ & $x$ \\
\hline \multirow{3}{*}{ 㟥 } & 0 & $x$ & $x$ & & & & & $\mathrm{X}$ & $x$ & $\mathbf{x}$ & $x$ \\
\hline & 20 & $x$ & $x$ & & & & & $\mathrm{X}$ & $\mathrm{x}$ & $\mathbf{x}$ & $x$ \\
\hline & 40 & $x$ & $x$ & X & $X$ & & & $\mathbf{X}$ & $X$ & $\mathbf{X}$ & $x$ \\
\hline \multirow{3}{*}{ 喜 } & 0 & $x$ & $x$ & & & & $x$ & $\mathrm{X}$ & $x$ & $\mathbf{X}$ & $x$ \\
\hline & 20 & $x$ & $x$ & & & & $\mathbf{x}$ & $\mathrm{x}$ & $x$ & $\mathbf{x}$ & $x$ \\
\hline & 40 & $x$ & $x$ & $\mathbf{x}$ & $\mathrm{X}$ & $x$ & $\mathbf{x}$ & $\mathrm{X}$ & $\mathbf{x}$ & $\mathbf{x}$ & $x$ \\
\hline \multirow{3}{*}{$\Sigma$} & 0 & $x$ & $x$ & & & & $X$ & $\mathbf{X}$ & $x$ & $\mathbf{x}$ & $x$ \\
\hline & 20 & $x$ & $x$ & & & & $\mathrm{x}$ & $\mathrm{X}$ & $x$ & $\mathrm{x}$ & $x$ \\
\hline & 40 & $x$ & $x$ & $\mathbf{x}$ & $x$ & $x$ & $\mathbf{x}$ & $\mathrm{X}$ & $\mathbf{x}$ & $\mathbf{x}$ & $x$ \\
\hline
\end{tabular}





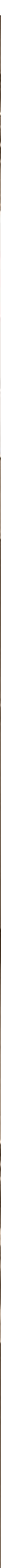





\section{MATERIALES Y MÉTODOS}

A continuación se define la tecnología de fabricación empleada en el proceso tradicional de elaboración de queso, desde la preparación de la leche de partida (mezcla estandarizada de leche de vaca y oveja) hasta la maduración final del mismo, así como el equipamiento para su desarrollo empleado en este trabajo.

Posteriormente se incorpora la tecnología empleada para la ultrafiltración de la leche que permite llegar a los concentrados con los que se elaborará el queso, describiendo tanto el equipo, como los módulos y membrana utilizados.

Establecidos los métodos de elaboración, se describen los métodos de análisis (físicos, químicos, microbiológicos y estructurales) -realizados sobre las distintas corrientes líquidas y sólidosdescritos en el Apartado 3.5 del capítulo de Metodología.

Asimismo, se establecen los descriptores empleados en el análisis sensorial realizado sobre los quesos.

\subsection{ESTANDARIZACIÓN DE LA LECHE}

La leche de partida, en todas las fabricaciones y filtraciones, será leche de mezcla (vaca/oveja) proveniente de la Escuela de Capacitación Agraria "Viñalta" (Palencia), estandarizada a un:

c $4,0 \pm 0,2 \%$ de materia grasa

c $3,5 \pm 0,1 \%$ en proteína

La estandarización en proteína $(P)$ de la leche de mezcla $(L M)$ se realiza a través de la combinación de leche de vaca ( $L V$ ) y oveja ( $L O)$ de acuerdo con los balances de materia global (Ecuación [4.1]) y a la proteína (Ecuación [4.2]):

$$
\begin{aligned}
& L O=L M-L V \\
& L O \cdot P_{L O}+L V \cdot P_{L V}=L M \cdot P_{L M}
\end{aligned}
$$

Despejando:

$$
L V=L M \frac{P_{L O}-P_{L M}}{P_{L O}-P_{L V}} \quad \text { y } \quad L O=L M \frac{P_{L M}-P_{L L V}}{P_{L O}-P_{L V}}
$$

Para la estandarización en grasa $(G)$ se calcula la grasa teórica que debería de tener la leche de vaca $\left(G_{T L V}\right)$, conocida la grasa de la leche de oveja $\left(G_{L O}\right)$ para que la mezcla total de leche $(L M)$ tenga un $4 \%$ en grasa:

$$
G_{T L V}=\frac{L M \cdot 4-L O \cdot G_{L O}}{L V}
$$


Se mezclará leche de vaca entera ( $L V E)$, bien con nata $(N)$ o leche desnatada de vaca (LVD), obtenidas ambas por centrifugación, para obtener la cantidad total de leche de vaca (LV) calculada según la Ecuación [4.3] que deberá tener la composición $G_{T L V}$ calculada con la Ecuación [4.4].

Para los cálculos se supone un contenido en grasa del $53 \%$ para la nata y del 0,05\% para la leche desnatada. Conocida la grasa inicial de la leche de vaca $\left(G_{L V}\right)$ se deben cumplir los balances:

$$
\begin{aligned}
& L V=L V E+N+L V D \\
& L V \cdot G_{T L V}=L V E \cdot G_{L V}+N \cdot 53+L V D \cdot 0,05
\end{aligned}
$$

\subsection{MÉTODO TRADICIONAL DE ELABORACIÓN DE QUESO}

Se describen las distintas fases o etapas que componen un proceso normal de elaboración de queso. El proceso se adapta al tipo de queso motivo de la presenta Tesis, el cual se puede definir como un queso de mezcla, elaborado a partir de leche pasterizada de vaca y oveja (en relación aproximada 85/15) de coagulación mixta pero predominio enzimático, de pasta prensada no cocida y tipo semicurado, debido a que ha sufrido una maduración mínima de cuarenta días y se presenta en formatos de aproximadamente un kilogramo, como establece la Norma de Calidad para Quesos y Quesos Fundidos (RD 1113/2006).

El proceso de elaboración del queso de mezcla, que servirá de patrón para la comparación con los quesos ultrafiltrados, se detalla en el diagrama de flujo de la Figura 4.1.

\subsubsection{PASTEURIZACIÓN}

La pasteurización de la leche, una vez estandarizada, se realiza en discontinuo en la misma cuba de cuajado, mediante la combinación temperatura/tiempo de $63^{\circ} \mathrm{C}$ durante $30 \mathrm{~min}$.

\subsubsection{CUAJADO Y SINÉRESIS}

Una vez pasterizada la leche se enfría a $32{ }^{\circ} \mathrm{C}$ manteniendo agitación suave $(4 \mathrm{~Hz})$.

Se añade cloruro cálcico comercial (concentración 38,5\% masa/masa) en relación $2 \mathrm{~mL} / 4 \mathrm{~L}$ de leche para compensar los desequilibrios salinos ocasionados en la etapa de pasterización.

No antes de 10 min se añade fermento comercial CHOOZIT ${ }^{\mathrm{TM}}$ MA4001 en relación 4 DCU/100 L de leche.

Transcurrido un tiempo de premaduración de entre 30 y $45 \mathrm{~min}-\mathrm{y}$ alcanzado un $\mathrm{pH}$ de la leche de entorno a 6,56- se añade extracto de cuajo líquido comercial (fuerza 1:15.000) obtenido a partir de cuajares de ternero en relación $40 \mathrm{~mL} / 100 \mathrm{~L}$ de leche. Tras la adición, se deja la leche en reposo hasta la etapa de corte.

Pasados entre 45 y 50 minutos se corta la cuajada en cubos, con lira vertical y horizontal de $1,5 \mathrm{~cm}$ de haz. El punto de corte se establece por comprobación visual de la consistencia.

Mediante calentamiento progresivo (por debajo de $38^{\circ} \mathrm{C}$ ) y agitación, se procede al endurecimiento y secado del grano, en lo que se conoce como proceso de sinéresis. 


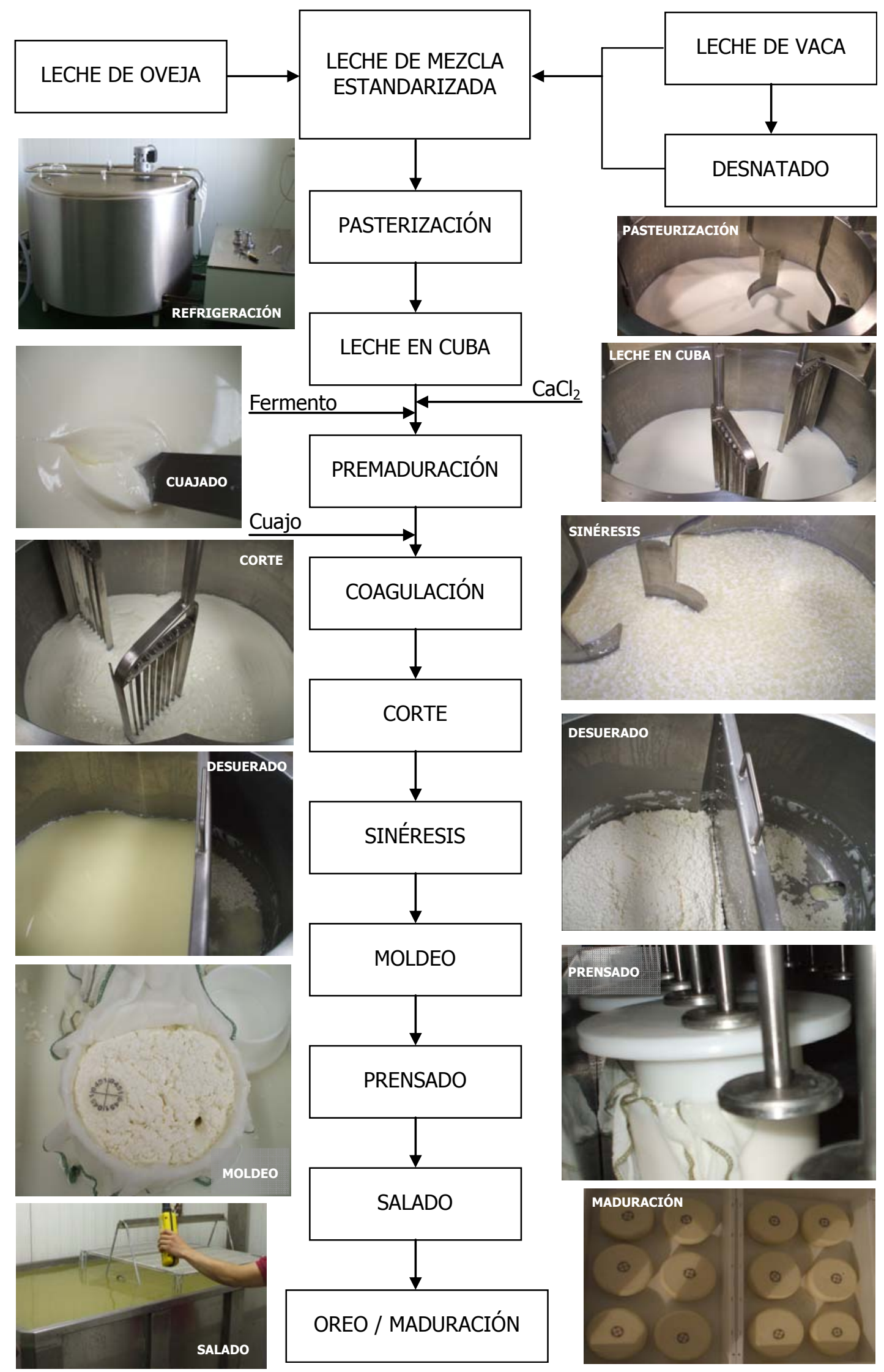

Figura 4.1. Diagrama de flujo del proceso tradicional de elaboración de queso 


\subsubsection{MOLDEO Y PRENSADO}

Cuando el grano tiene la consistencia y el pH correcto (entorno a 6,30), se elimina el lactosuero y se introduce la cuajada en moldes de $14 \mathrm{~cm}$ de diámetro interno y $10 \mathrm{~cm}$ de altura, con trapo, para conseguir quesos de aproximadamente $1 \mathrm{~kg}$ a la salida de prensa.

El prensado se realiza mediante prensa neumática controlando la presión y el tiempo de duración. Esta etapa se divide en 2 fases:

c. Inicial: 60 min a 2 bar, finalizado se procede al volteo del queso.

c Final: aproximadamente 90 min a 2,5 bar hasta $\mathrm{pH}$ 5,15-5,30.

\subsubsection{SALADO, OREO Y MADURACIÓN}

El salado se realiza mediante la introducción del queso en salmuera de concentración 20 'Baumé durante $2 \mathrm{~h}$ y $30 \mathrm{~min}$, a una temperatura de $8^{\circ} \mathrm{C}$.

En este trabajo, todos los quesos tendrán un proceso de curado de 40 días a una temperatura de $9^{\circ} \mathrm{C}$, divido en dos periodos de 20 días cada uno, con velocidad del aire $\left(v_{a}\right)$ y humedad relativa $(\varphi)$ controladas. En ambos periodos se realizan volteos periódicos para garantizar la uniformidad en el secado del queso:

c. Oreo: primeros 20 días; $\left(v_{a}=0,3-0,7 \mathrm{~m} / \mathrm{s}\right.$ y $\left.\varphi=80 \%\right)$

c Maduración: últimos 20 días; $\left(v_{a}=0,2-0,3 \mathrm{~m} / \mathrm{s}\right.$ y $\left.\varphi=85 \%\right)$

\subsection{ULTRAFILTRACIÓN DE LECHE PARA LA ELABORACIÓN DE QUESO}

A continuación se realiza una descripción detallada de la planta piloto de ultrafiltración mediante la que se realiza la concentración de la leche.

También se describen las especificaciones técnicas de las membranas empleadas para la concentración selectiva de la proteína y la grasa de la leche y las variaciones introducidas respecto a la tecnología tradicional de elaboración.

\subsubsection{DESCRIPCIÓN DEL EQUIPO}

Para realizar la concentración de la leche mediante ultrafiltración se usa la planta piloto de filtración tangencial que se muestra en la Figura 4.2.

Dicha planta consta de cuatro módulos para trabajos de MF/UF/NF/OI mediante membranas espirales de 4 pulgadas de diámetro exterior. En la planta piloto se opera en discontinuo, al no ser necesarios unos grandes volúmenes de fabricación.

El entramado de tuberías, válvulas, bombas y demás elementos con los que cuenta la planta se pueden ver en el diagrama de flujo de la Figura 4.3. 


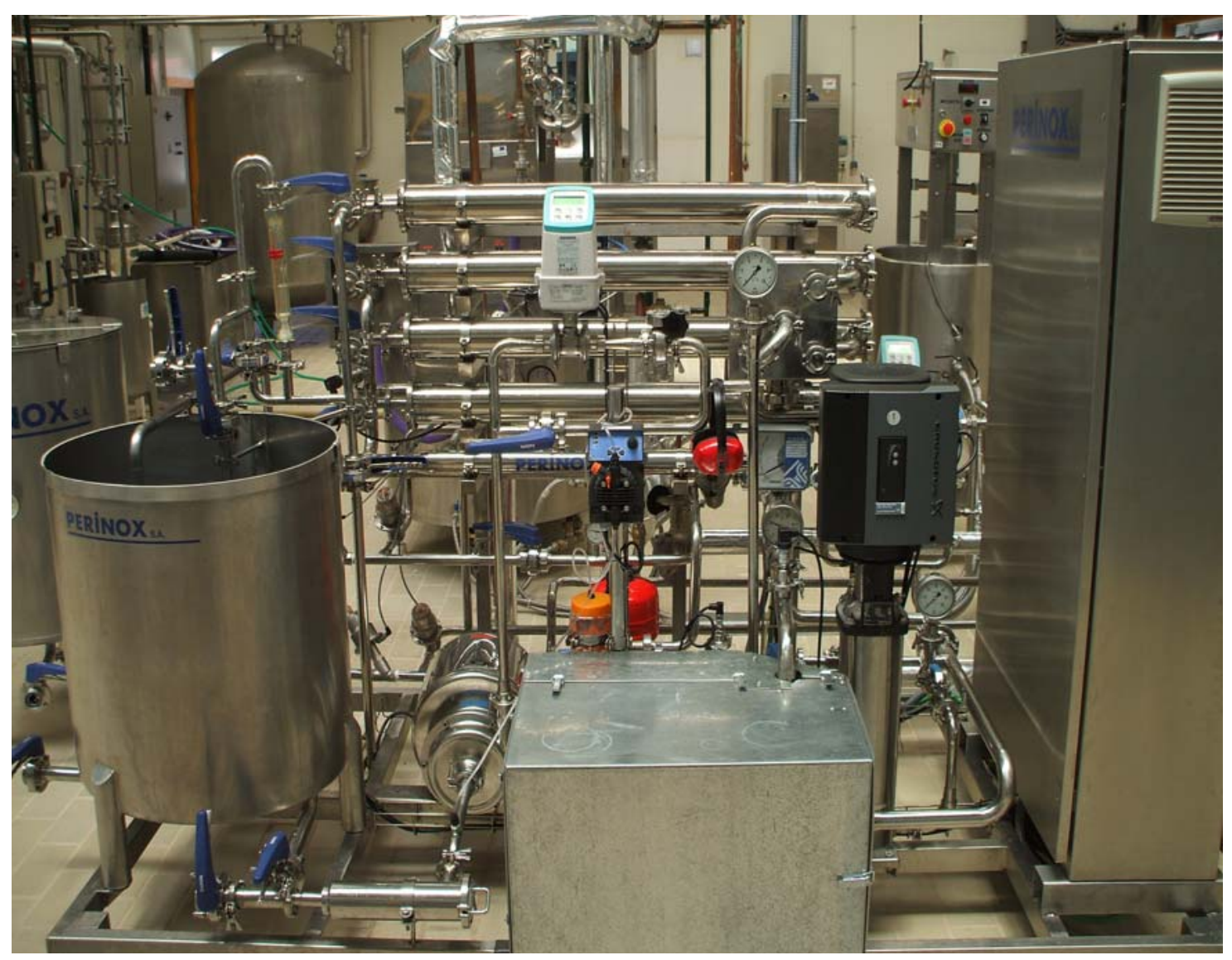

Figura 4.2. Planta piloto de filtración tangencial

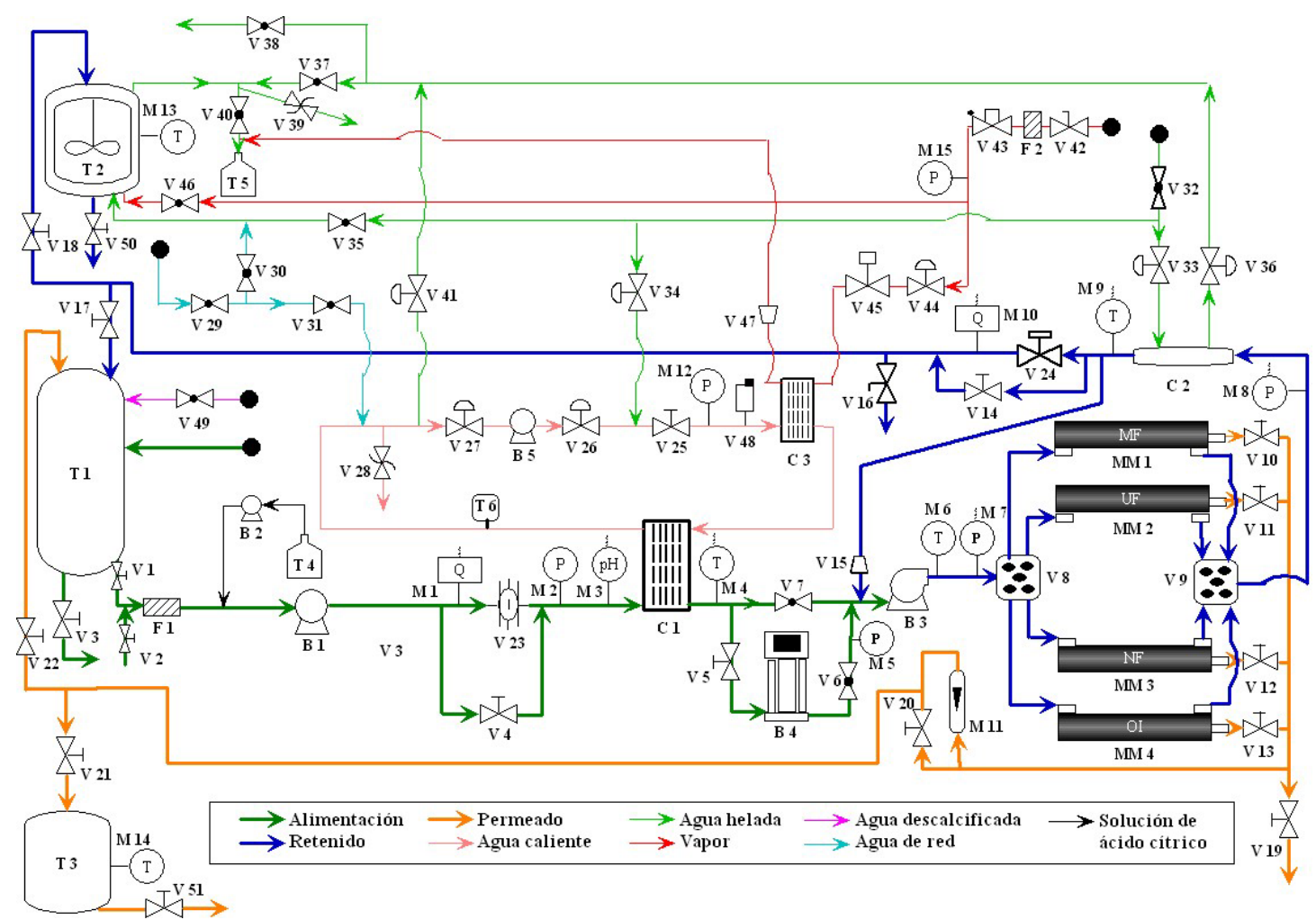

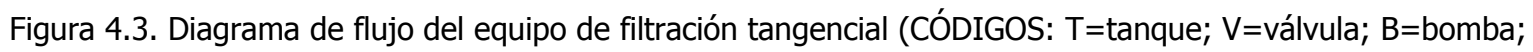
$\mathrm{C}=$ cambiador de calor; $\mathrm{M}=$ medidor; $\mathrm{MM}=$ módulo de membrana; $\mathrm{F}=$ filtro) 
Para realizar los trabajos de ultrafiltración la leche estandarizada se introduce en el tanque de alimentación (T1). Mediante una bomba centrifuga (B1) se hace pasar por un cambiador de calor de placas ( $\mathrm{C} 1)$ para unirse con parte de la corriente de retenido y conducirse al módulo de ultrafiltración (MM2) mediante la bomba de recirculación (B3). Del módulo de UF salen dos corrientes, el permeado que atraviesa la membrana -recogido en un tanque (T3)- y el retenido, que parte es recirculado para unirse con la alimentación mientras que el resto se conduce de nuevo al tanque de alimentación (T1).

Los posibles calentamientos que pueda sufrir la corriente de retenido debido a la recirculación a alta velocidad se compensan mediante un cambiador de calor tubular (C2).

El equipo cuenta a su vez con un sistema de control automático de temperatura, mediante el circuito de agua caliente que alimenta al cambiador de calor (C1) y otro de control automático de caída de presión en el módulo que actúa sobre el variador de la bomba de recirculación (B3).

Según lo descrito la planta trabaja en configuración de "recirculación y purga (feed and bleed)", con retorno continuo del concentrado y salida continua de permeado.

Los estudios de filtración se realizan a presión transmembrana (TMP) constante mediante el sistema de automatización de la planta.

La planta (Figura 4.2 y 4.3 ) está equipada con un sistema continuo de medida y registro de temperaturas de entrada (M4) y salida (M9), caudal de alimentación (M1) y de retenido (M10), presión de entrada (M7) y salida (M8) del módulo de membrana y variadores de las bombas de alimentación (B1) y recirculación (B3).

Para el cálculo del grado de concentración (VCR) alcanzado se coloca el tanque de permeado (T3) sobre una báscula de pesaje industrial cuyo visor permite conocer en todo momento la masa de permeado recogida. Según el peso inicial de leche de mezcla estandarizada (LM) y el grado de concentración deseado, la cantidad de permeado (P) a eliminar se calcula -de acuerdo con la Ecuación [1.2]- como:

$$
P=L M\left(1-\frac{1}{V C R}\right)
$$

Tras conseguir recoger esa cantidad de permeado, se finaliza la filtración, retirando el concentrado para continuar su procesado.

\subsubsection{MEMBRANA}

En todos los procesos de concentración de leche se utiliza una membrana espiral -modelo $\mathrm{ABCOR}^{\circledR}$ 3838 HFK-FYT- fabricada en polietersulfona de 10.000 Da de corte molecular, como la mostrada en la Figura 4.4.

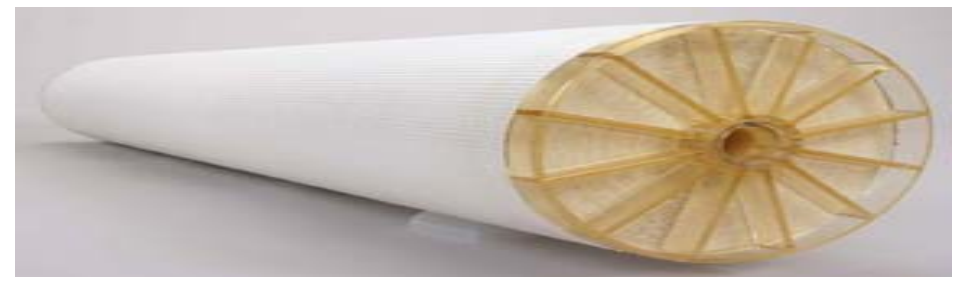

Figura 4.4. Membrana espiral 
Entre los modelos espirales evaluados, este tipo de módulo es el que ofrece unos espaciadores con mayor separación, lo cuál facilita alcanzar un mayor grado de concentración de la leche. El espaciador empleado proporciona una separación entre láminas de membrana de 2,03 $\mathrm{mm}$. Cada módulo tiene un área total de membrana de $3,3 \mathrm{~m}^{2}$.

\subsubsection{MODIFICACIONES AL MÉTODO TRADICIONAL DE ELABORACIÓN DE QUESO}

Debido a factores como la viscosidad de los concentrados, el aumento del poder tampón respecto a la leche inicial o la elevada humedad del queso UF a la salida de prensa, es necesario realizar algún cambio respecto al proceso de elaboración descrito en el Apartado 4.2.

Se realizan las siguientes modificaciones en lo que se refiere a las etapas de premaduración, sinéresis, prensado y salado:

c Una vez añadido el fermento y distribuido por toda la masa, sin etapa de premaduración en cuba, se añade el cuajo en su dosis correspondiente. Se deja reposar hasta cuajado (unos 25 min dependiendo del ES y la concentración de cuajo) y se procede al corte con lira vertical y horizontal en cubos según el tamaño de grano deseado para cada experimento.

c Una vez cortado se introduce en moldes de $14 \mathrm{~cm}$ de diámetro interno y $10 \mathrm{~cm}$ de altura, con trapo, para conseguir quesos de aproximadamente $1 \mathrm{~kg}$ al finalizar la siguiente etapa, el prensado.

c El tiempo de prensado, para los quesos ultrafiltrados elaborados antes de la optimización del proceso de acidificación en prensa, es de $5 \mathrm{~h}$. En estos primeros diseños, antes de proceder al salado por inmersión en salmuera, los quesos se mantienen en los moldes, sin trapo y en condiciones de refrigeración $\left(8^{\circ} \mathrm{C}\right)$, hasta el día siguiente para que el pH siga descendiendo.

c En la etapa de salado, debido a la mayor humedad de las cuajadas respecto a las tradicionales, el tiempo se reduce en treinta minutos para alcanzar concentraciones finales de sal en el queso similares, estableciéndose en $2 \mathrm{~h}$.

\subsection{ANÁLISIS FÍSICO-QUÍMICO}

Las determinaciones se realizan sobre leche, permeado, concentrado o queso, aplicando las variaciones específicas del método que ello conlleve.

Todos los análisis se realizan por duplicado y se calcula su valor medio.

\subsubsection{PODER TAMPÓN}

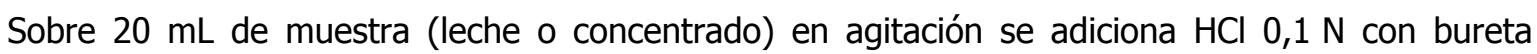
automática a razón de 0,2 $\mathrm{mL} / \mathrm{min}$ (Salaün et al. 2005) y se mide el $\mathrm{pH}$ al final de cada adición con pH-metro Crison GLP 22 equipado con sonda de penetración con compensación automática de temperatura. El pH inicial de la muestra se ajustó en todos los casos a 6,60. 
El poder tampón se expresa según la definición de Van Slyke (1992) como:

$$
\frac{d B}{d p H}=\frac{(\text { volumnen de ácido }) \cdot(\text { normalidad del ácido })}{(\text { volumen de muestra }) \cdot(\text { cambio de } p H \text { producido })}
$$

\subsubsection{CURVAS DE ACIDIFICACIÓN}

En matraz erlenmayer de $250 \mathrm{~mL}$ se pesa con balanza analítica, de $1 \mathrm{mg}$ de precisión, la cantidad de fermento a ensayar y se añaden $150 \mathrm{~mL}$ de muestra (leche o concentrado) ajustada a un $\mathrm{pH}$ de 6,55 y una temperatura de $32^{\circ} \mathrm{C}$. Se agita vigorosamente para facilitar la disolución del fermento y se introduce en un baño a $32{ }^{\circ} \mathrm{C}$. Mediante $\mathrm{pH}$-metro Crison Multimeter 44 se registra en continuo la evolución del pH y la temperatura a lo largo del tiempo, con sonda de penetración con compensación automática de temperatura, durante un periodo mínimo de $12 \mathrm{~h}$.

\subsubsection{DETERMINACIÓN DEL EXTRACTO SECO (ES)}

El extracto seco en queso se determinó por desecación en estufa Selecta Digitheat 80L a $102 \pm 2{ }^{\circ} \mathrm{C}$ según ISO 5534:2004 y sus modificaciones para leche y derivados (Casado 1991).

\subsubsection{DETERMINACIÓN DEL CONTENIDO DE GRASA}

Para leche, suero, permeado y concentrado se analiza por el método Gerber (ISO 488/2008).

En queso se analizó por el método de Van GuliK (ISO 3433:2008).

\subsubsection{DETERMINACIÓN DEL NITRÓGENO}

El nitrógeno total se obtiene por el método Kjeldhal para leche, sueros, permeados y concentrados (ISO 8968-1:2001).

En todos los casos la cantidad de nitrógeno se convierte en proteína mediante la multiplicación por el factor 6,38 (Casado 1991).

Como recogen Furtado et al. (1988) la maduración de los quesos se puede seguir a través de los conocidos índices de maduración, obtenidas las distintas fracciones nitrogenadas del queso.

c Por un lado la relación entre el nitrógeno no caseínico (también llamado nitrógeno soluble) y el nitrógeno total, se conoce como índice de maduración aparente (ARE "Apparent Rippening Extension") el cual es proporcional a la actividad proteolítica total.

c. Por otro lado la relación entre el nitrógeno no proteico (NNP) y el nitrógeno total, conocido como índice de profundidad de la maduración (RD "Ripenning Depth") da cuenta de la actividad aminopeptidasa de las bacterias lácticas del fermento.

Para queso se realizaron las siguientes modificaciones para el cálculo conjunto de las fracciones proteicas (Ardö 1999): 


\section{NITRÓGENO TOTAL EN QUESO}

Pesar $10 \mathrm{~g}$ de queso en una botella pirex de $100 \mathrm{~mL}$ y añadir $50 \mathrm{~mL}$ de citrato sódico $0,5 \mathrm{M}$ a $40^{\circ} \mathrm{C}$. En una placa calefactora se mantiene en continua agitación durante 1 hora a $50{ }^{\circ} \mathrm{C}$. Se pasa el contenido a un matraz de $250 \mathrm{~mL}$ y se enrasa con agua ultrapura. Para el análisis, según ISO 8986:2001, usar $5 \mathrm{~mL}$ de la dispersión en citrato.

\section{NITRÓGENO NO CASEÍNICO (NNC) EN QUESO}

Tomando $80 \mathrm{~mL}$ de la dispersión en citrato en vaso de precipitados de $100 \mathrm{~mL}$, añadir $\mathrm{HCl} 1 \mathrm{~N}$ hasta que el $\mathrm{pH}$ sea de 4,45 . Llevar la mezcla a matraz aforado de $100 \mathrm{~mL}$ y enrasar con agua ultrapura. Filtrar con filtro Whatman 40. Para el análisis según ISO 8986:2001, usar $10 \mathrm{~mL}$ del filtrado. A esta fracción también se la conoce como nitrógeno soluble.

\section{NITRÓGENO NO PROTEICO (NNP) EN QUESO}

Se añaden $25 \mathrm{~mL}$ de la fracción soluble a $\mathrm{pH} 4,45$ a un matraz aforado de $50 \mathrm{~mL}$ y enrasa con ácido tricloroacético (TCA) al $24 \%$. Tras mantenerse toda la noche en frigorífico a $4{ }^{\circ} \mathrm{C}$, filtrar con filtro Whatman 40. Para el análisis, según ISO 8986:2001, usar $25 \mathrm{~mL}$ del filtrado.

\subsubsection{CENIZAS}

El contenido en cenizas se obtiene por desecación de la muestra, en cápsula de porcelana, a $550{ }^{\circ} \mathrm{C}$ en mufla Heraeus M110 según las indicaciones de Casado (1991).

\subsubsection{LACTOSA}

La lactosa se determinó por diferencia, conocidos el resto de componentes del extracto seco, según el siguiente balance de materia:

$$
\text { Lactosa }(L)=\text { Extracto Seco }(E S)-\text { Grasa }(G)-\text { Proteína }(P)-\text { Cenizas }(C)
$$

\subsubsection{DETERMINACIÓN DE CLORUROS EN QUESO}

La determinación se lleva a cabo mediante valoración colorimétrica. Sobre la muestra de queso se realiza una destrucción de la materia orgánica del queso con permanganato potásico y ácido nítrico. La valoración se realiza en disolución de ácido nítrico, en presencia de sulfato amónico-férrico como indicador, según recoge Casado (1991).

\subsubsection{MEDIDA DEL pH}

La determinación se realiza con pH-metro Crison GLP 22 y electrodo de penetración con compensación automática de temperatura. Para quesos la medida se realizó sobre muestras picadas (Casado 1991). 


\subsubsection{ANTIBIÓTICOS}

Se realiza un test de inhibición bacteriana mediante el kit Eclipse 100 de la marca ZEU Inmunotec. Se comprueba la presencia/ausencia de betalactámicos y tetraciclinas.

\subsubsection{ANIONES Y CATIONES}

Se prepara un extracto $(2 \mathrm{~g} / 200 \mathrm{~mL})$ de la muestra mediante calentamiento y agitación en el mismo eluyente usado para la cromatografía. El extracto se centrifuga a $4.200 \mathrm{rpm}$ durante 5 minutos, se filtra a través de un filtro de pliegues y se pasa por un filtro de $0,45 \mu \mathrm{m}$.

Para el análisis se emplea un Cromatógrafo iónico 882 Compact IC Plus (Methrom) con detector de conductividad, previamente calibrado en el rango adecuado para todos los iones a analizar.

Para la determinación de los cationes ( $\mathrm{Ca}, \mathrm{Mg}$ y $\mathrm{K}$ ) se utilizó como eluyente ácido dipicolínico $0,7 \mathrm{mmol} / \mathrm{L}$ y ácido nítrico $1,7 \mathrm{mmol} / \mathrm{L}$. Columna Metrosep C4 150, 150/4,0 mm y precolumna Metrosep C4S Guard. El volumen de inyección es $20 \mu \mathrm{L}$, el flujo es de $0,9 \mathrm{~mL} / \mathrm{min}$ y el tiempo de análisis 28 minutos.

Para la determinación de los aniones (fósforo en forma de fosfato, $\mathrm{PO}_{4}^{3-}$ ) se utiliza como eluyente hidrógeno carbonato de sodio $1,0 \mathrm{mmol} / \mathrm{L}$ y carbonato de sodio $3,2 \mathrm{mmol} / \mathrm{L}$. Se emplea Columna MetroSep A Supp 5, 150/4,0 mm y precolumna Metrosep A Supp 4/5 Guard. Se usa supresión secuencial para reducir la conductividad del eluyente y para el módulo de supresión química se usa una columna de intercambio regenerada mediante ácido sulfúrico $50 \mathrm{mM}$ que posteriormente se lava con agua ultrapura. El volumen de inyección es $20 \mu \mathrm{L}$, el flujo $0,7 \mathrm{~mL} / \mathrm{min}$ y el tiempo de análisis 33 minutos.

Los picos se identifican por sus tiempos de retención y se cuantifican por comparación de las áreas con las de la recta de calibración.

\subsubsection{COMPUESTOS ORGÁNICOS VOLÁTILES}

La determinación de compuestos volátiles se lleva a cabo por cromatografía de gases con detección de masas. En un tubo de ensayo se pesa $1 \mathrm{~g}$ de muestra de queso picado -con precisión de $1 \mathrm{mg}-$ y $2 \mathrm{~g}$ de sulfato sódico anhidro; se agregan $50 \mu \mathrm{L}$ de ciclohexanona $(0,2 \mathrm{mg} / \mathrm{mL})$ como patrón interno y se homogeniza completamente. Las muestras se concentran y volatilizan en purga y trampa Teledyne Tekmar. Los volátiles se extraen usando un flujo de helio $(40 \mathrm{~mL} / \mathrm{min})$ durante 20 min a $40{ }^{\circ} \mathrm{C}$, separados en cromatógrafo de gases Agilent Technologies G6890N con detector de masas G3171A. Se empleó una columna modelo 19091N-136, HP INNOWAX 60•0,25 y 0,25 de diámetro. El flujo de helio es de $1,0 \mathrm{~mL} / \mathrm{min}$ y el gradiente de temperatura de $45^{\circ} \mathrm{C}$, incrementando $4,0^{\circ} \mathrm{C} / \mathrm{min}$ hasta $110^{\circ} \mathrm{C}$ y manteniéndose durante $10 \mathrm{~min}$; posteriormente se lleva hasta $240^{\circ} \mathrm{C}$ a $18,0^{\circ} \mathrm{C} / \mathrm{min}$. La temperatura del detector es $250^{\circ} \mathrm{C}$. El rango de masas utilizado es de $33-250 \mathrm{~m} / \mathrm{z}$.

Los picos se identifican por su tiempo de retención y su espectro de masas y se comparan con la librería de espectros del software del equipo y con patrones puros. Los resultados se expresan como abundancia relativa con respecto al patrón interno (ciclohexanona). 


\subsection{ANÁLISIS MICROBIOLÓGICO}

Para caracterizar la leche y el queso se aplican métodos estándar cuyas normas de referencia se recogen a continuación.

\subsubsection{CÉLULAS SOMÁTICAS}

El recuento de células somáticas en leche se realizó mediante conteo fluoro-opto-electrónico de acuerdo con la norma ISO 13366-2:2006 en equipo Fossmatic FC.

\subsubsection{ESCHERICHIA COLI (E. COLI)}

Recuento en placa según la norma ISO 16649-2:2001, para muestras de queso.

\subsubsection{STAPHYLOCOCCUS COAGULASA POSITIVO}

Detección según la norma ISO 6888-2:1999, para muestras de queso.

\subsubsection{LISTERIA MONOCYTOGENES}

Detección según la norma ISO 11290-1:1996, para muestras de queso.

\subsubsection{COLIFORMES TOTALES}

Recuento en placa según la norma ISO 4832:2006, para muestras de queso.

\subsubsection{LEVADURAS}

Recuento en placa según la norma ISO 6611:2004, para muestras de queso.

\subsection{ANÁLISIS REOLÓGICO Y ESTRUCTURAL}

Se recogen los ensayos realizados tanto en la caracterización de cuajadas como en el análisis estructural de los quesos.

De igual modo, se detalla la sistemática de preparación de muestras para la observación de los quesos mediante microscopía electrónica de barrido. 


\subsubsection{DUREZA DE LAS CUAJADAS}

Para la comparación de la dureza de las cuajadas, obtenidas a partir de leche o concentrado, se desarrolla el siguiente método experimental: en vasos de precipitados de $500 \mathrm{~mL}$ se toman porciones de $200 \mathrm{~mL}$ de muestra (leche o concentrado), se calienta a $32{ }^{\circ} \mathrm{C}$ y se añade con micropipeta la cantidad de cuajo a ensayar -cuajo líquido comercial (fuerza 1:15.000) obtenido a partir de cuajares de ternero-. Se agita vigorosamente y se deja reposar en baño termostático.

Mediante texturómetro Aname TA-XT2 equipado con sonda cilíndrica de $6 \mathrm{~cm}$ de diámetro se mide a lo largo del tiempo de coagulación la fuerza en compresión y vuelta al inicio necesaria para penetrar la muestra $0,5 \mathrm{~mm}$, con velocidades de pre-ensayo y post-ensayo de $2 \mathrm{~mm} / \mathrm{s}$ y de ensayo de $1 \mathrm{~mm} / \mathrm{s}$.

\subsubsection{ANÁLISIS DE PERFIL DE TEXTURA (TPA) EN QUESO}

El análisis se lleva a cabo sobre muestras de queso cilíndricas de $2 \mathrm{~cm}$ de altura y $2 \mathrm{~cm}$ de diámetro, a temperatura controlada entre $18-20^{\circ} \mathrm{C}$, mediante texturómetro Aname TA-XT2 con sonda cilíndrica de $6 \mathrm{~cm}$ de diámetro.

Los parámetros del ensayo son $2 \mathrm{~mm} / \mathrm{s}$ de velocidad de pre-ensayo, ensayo y post-ensayo y 7,5 mm de distancia de penetración.

Mediante el método de análisis de perfil de textura (TPA), ver Figura 4.5, se determinan de manera instrumental los atributos sensoriales de (O'Callaghan y Guinee 2004):

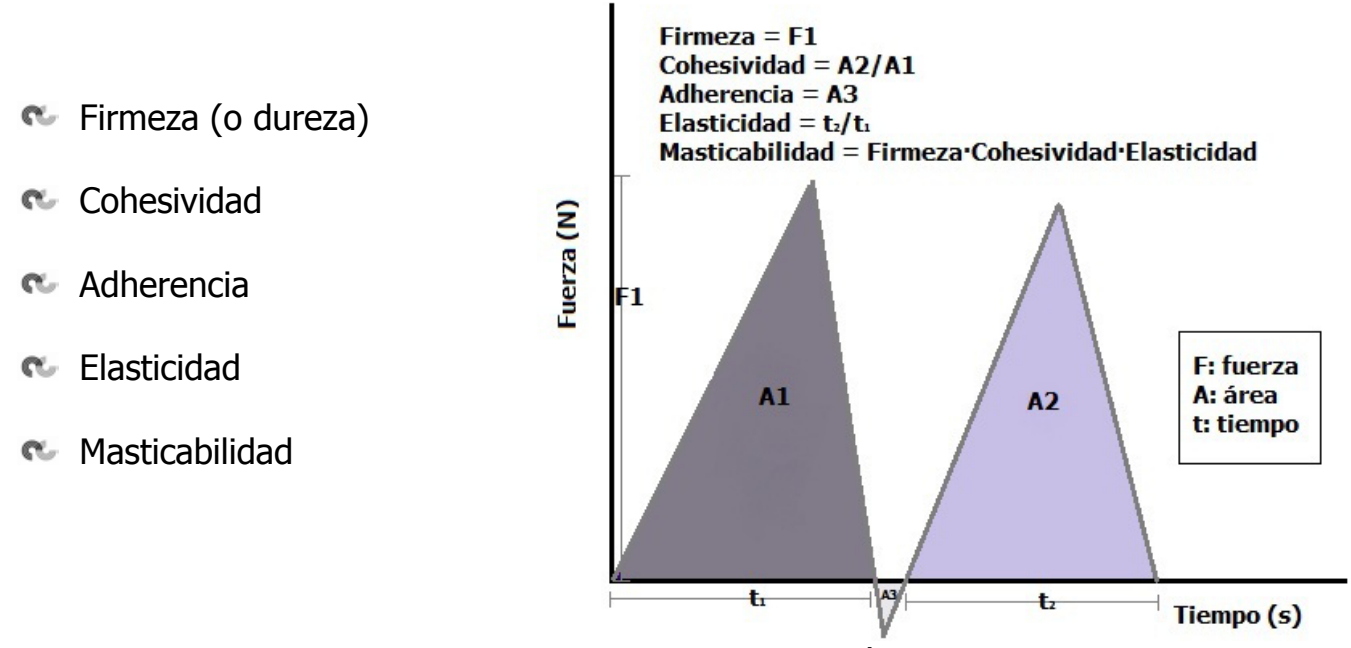

Figura 4.5. Análisis de perfil de textura (TPA)

\subsubsection{MICROGRAFÍAS DE LOS QUESOS}

Para la preparación de las muestras se corta el queso en cubos de 5-6 mm de lado con un cuchillo afilado y se realiza el siguiente pretratamiento (Madadlou et al. 2007; Kuo y Gunasekaran 2009):

c. Fijación en glutaraldehido al 2,5\% y tampón fosfato $0,1 \mathrm{M}(\mathrm{pH}=7)$ durante $48 \mathrm{~h}$, refrigerado a $4^{\circ} \mathrm{C}$.

c Lavado con agua destilada en seis series de 1 minuto cada una. 
c Deshidratación en series de etanol de concentración creciente: 40, 55, 70, 85, 90, $100 \%$, permaneciendo sumergido 30 minutos en cada una de ellas.

c Desgrasado en cloroformo mediante tres series de 10 minutos.

c Guardar la muestra refrigerada y cubierta en etanol hasta su fractura por congelación en nitrógeno líquido.

Tras la fractura se observan y fotografían mediante microscopio electrónico de barrido ambiental (Environmental Scanning Electron Microscopy, ESEM), modelo FEI-Quanta 200FEG provisto con cañón de Emisión de Campo con filamento Schottky y voltajes de aceleración: 0.2-30 kV. El estudio se realiza entre $\times 2.000$ y $\times 30.000$ aumentos, con diferencias de potencial entre 2,5 y 3,5 kV y analizadas a bajo vacío con detector de amplio espectro (Large Field Detector, LFD).

\subsubsection{COLOR DE LOS QUESOS}

Se realizan mediciones del interior y exterior de los quesos, a temperatura controlada entre $15-20{ }^{\circ} \mathrm{C}$, mediante colorímetro Konica Minolta CR-410 con iluminante D65 y observador estándar de $2^{\circ}$. Se evalúan los resultados mediante el espacio de color CIELAB con las coordenadas de cromaticidad $\left(a^{*}\right.$ y $\left.b^{*}\right)$ y luminosidad $(L)$. Dichas coordenadas han de entenderse como:

c Luminosidad (L), escala de 0-100 que va desde el negro al blanco.

r $a^{*}$, valores negativos indican verde $\mathrm{y}$ valores positivos rojo.

c $b^{*}$, valores negativos indican azul y positivos amarillo.

\subsection{ANÁLISIS SENSORIAL DE LOS QUESOS}

Todas las pruebas de análisis sensorial se realizaron con el panel de cata entrenado de la Estación Tecnológica de Leche, compuesto por diez catadores experimentados y entrenados en la evaluación sensorial descriptiva sobre quesos de pasta prensada de distinto grado de maduración.

\subsubsection{PRUEBA DESCRIPTIVA}

Para conocer las diferencias sensoriales entre los quesos, se realizó un análisis descriptivo, tanto olfato-gustativo como visual, en escala de 1-7 (Ibañez y Barcina 2001) entendidos los distintos valores de la escala como:

\begin{tabular}{c|c|c|c|c|c|c}
$\mathbf{1}$ & $\mathbf{2}$ & $\mathbf{3}$ & $\mathbf{4}$ & $\mathbf{5}$ & $\mathbf{6}$ & $\mathbf{7}$ \\
\hline Nada & Muy poco & Levemente & Propiedad & $\begin{array}{c}\text { Moderada- } \\
\text { mente } \\
\text { Apreciable }\end{array}$ & $\begin{array}{c}\text { Muy } \\
\text { Apreciable }\end{array}$ & $\begin{array}{c}\text { Excesivamente } \\
\text { Apreciable }\end{array}$
\end{tabular}

El perfil sensorial estudiado ha sido el siguiente: 


\section{Sensación olfativa}

c Intensidad: grado de la sensación percibida.

c Calidad: grado de aceptación de la sensación percibida.

Textura en mano

c Rugosidad: percepción de granos en la superficie del queso.

c Elasticidad: rapidez de recuperación de una deformación o el grado de ésta.

c Firmeza: fuerza requerida para deformar el alimento.

Textura en boca

c Friabilidad: aptitud a generar numerosos trozos desde el principio de la masticación.

^ Adherencia: trabajo realizado para despegar un producto del paladar o los dientes.

c Solubilidad: sensación percibida cuando la muestra funde con la saliva.

r Granulosidad: percepción al final de la masticación de granos o cristales.

c Humedad: percepción del grado de humedad de la muestra.

Sensación en boca

c Intensidad: grado de la sensación percibida.

c Calidad: grado de aceptación de la sensación percibida.

c Salado: intensidad del sabor elemental a sal encontrado.

c Ácido: intensidad del sabor elemental ácido encontrado.

c Amargo: intensidad del sabor elemental amargo encontrado.

c Regusto: grado de aceptación de la sensación que aparece tras la eliminación del producto.

c Persistencia: sensación percibida cuando el producto se encontraba en la boca, que permanece durante un periodo de tiempo medible.

Aspecto exterior

c Homogeneidad/uniformidad de forma y color.

Aspecto interior

r Homogeneidad/uniformidad pasta y color.

c Valoración de aberturas en cuanto a forma, tamaño y distribución.

Valoración global en las fases 
c Visual (aspecto exterior y aspecto interior).

c Olfato-gustativo (sensación olfativa y en boca, textura en mano y en boca).

\subsection{SOFTWARE DE TRATAMIENTO ESTADÍSTICO DE RESULTADOS}

Se describen los programas de software empleados tanto en el tratamiento estadístico de los datos como en la definición de los diseños de experimentos.

\subsubsection{ESTADÍSTICA}

Los resultados estadísticos fueron procesados mediante el programa SPSS ${ }^{\circledR}$ versión 9.0 en lo que se refiere a cálculo de:
c. Media aritmética
c Desviación estándar (S)
c ANOVA de un factor
r Análisis de Componentes Principales (CP)
c. Análisis de correlación bilateral entre variables

El error de las mediciones ha sido calculado en todos los casos al $95 \%$ de probabilidad a partir de la desviación estándar $(S)$ y del número de réplicas realizadas $(n)$ según:

$$
\text { Error }=1,98 \cdot \frac{S}{\sqrt{n}}
$$

\subsubsection{DISEÑO DE EXPERIMENTOS}

El establecimiento de los diseños de experimentos, así como su resolución y optimización, se realiza mediante el programa estadístico STATGRAPHICS Plus ${ }^{\circledR}$ Version 5.1. Se llevaron a cabo tres tipos de diseños distintos:

c. Diseño factorial fraccionado de Plackett-Burmann.

c Diseño factorial completo $\left(2^{\mathrm{k}}\right)$.

c Diseño de superficie respuesta, central compuesto.

Para interpretar más fácilmente los resultados que ofrece el diseño de experimentos y detectar los efectos que son significativamente importantes, se convierten los datos en gráficos estadísticos mediante Diagramas de Pareto. En este formato se representa en ordenadas una escala de valores normalizados para los efectos y en abscisas se disponen los efectos, propiamente dichos, ordenados de mayor a menor. Mediante una barra vertical se indica a partir de qué punto un factor es estadísticamente significativo para un determinado intervalo de confianza, en todos los casos 
del $95 \%$. Obtenemos además otra información adicional, de tipo cualitativo, ya que el signo que un factor muestra en un diagrama de Pareto, se puede asociar a una relación directa, en caso de signos positivos, o inversa si el signo es negativo, entre la variación del factor y la variación de la respuesta medida.

La resolución de los diseños se realiza mediante optimización de respuesta múltiple.

Los supuestos que se deben cumplir para que el modelo sea válido hacen referencia al error experimental. En todos los casos se comprueba que:

c El error sigue una distribución normal (de media cero y varianza $\sigma^{2}$ ), verificado mediante gráficos de Probabilidad Normal para los residuos.

c Los errores son independientes unos de otros, para lo que se aleatorizó la secuencia experimental.

c La varianza es constante (homogénea) y no varía con cada observación. Mediante gráficos de residuos frente a valores estimados se comprobaba la ausencia de patrones o tendencias.

\subsubsection{ANÁLISIS DE IMAGEN}

Para el análisis de las micrografías se emplea el programa Sigma ScanPro ${ }^{\circledR}$ versión 3.00.030. Con él, mediante análisis gráfico, se calcula la porosidad, el diámetro de poro y el factor de forma de los poros a partir de las micrografías de los diferentes quesos. 


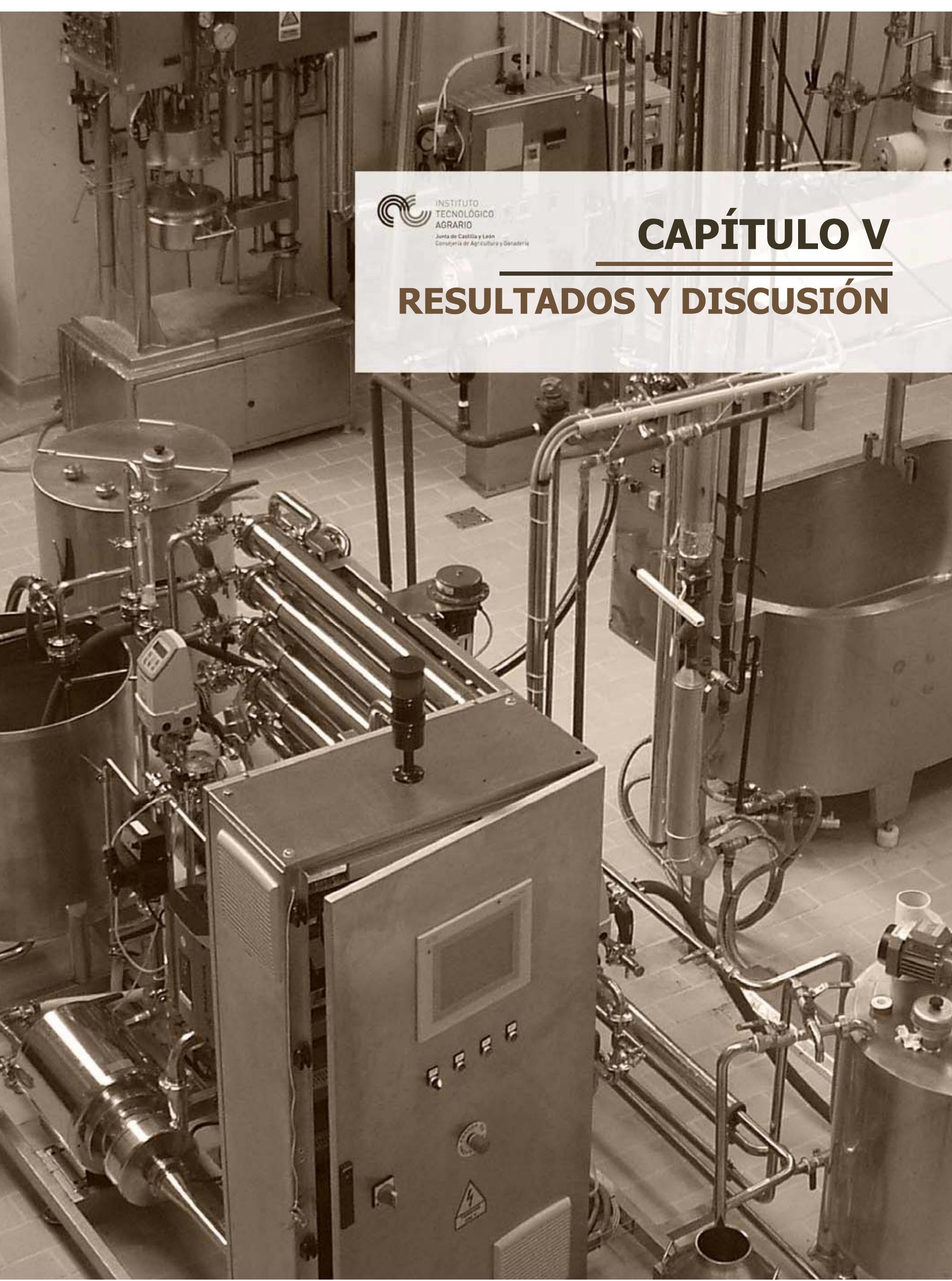





\section{RESULTADOS Y DISCUSIÓN}

En este capítulo se exponen los resultados más significativos alcanzados, de acuerdo con la metodología experimental descrita. La discusión de estos resultados se realiza a través de cinco apartados:

PRIMERO- El estudio preliminar, donde se realizarán los primeros experimentos de ultrafiltración y los estudios sobre el comportamiento de los concentrados ante los procesos tecnológicos de elaboración, en lo que se refiere a acidificación y cuajado.

SEGUNDO, TERCERO Y CUARTO- Terminados y optimizados los estudios iniciales se realizarán tres diseños experimentales que optimizan la tecnología de elaboración:

El primero de ellos sirve para el establecimiento de las variables de partida del proceso de elaboración en las mejores condiciones posibles, teniendo en cuenta la gran cantidad de factores que influyen sobre las características finales del queso.

En el segundo se realiza un estudio detallado de las variables que resultaron significativas en el estudio inicial, con el fin de establecer las mejores condiciones para cada una de ellas.

Con el último diseño experimental se concluye el proceso de optimización, logrando un queso con las mejores cualidades posibles desde el punto de vista sensorial, tecnológico y económico.

QUINTO- Se comparan los resultados de los tres diseños con el mismo tipo de queso -pasta prensada, semicurado, fabricado a partir de leche pasteriza de mezcla- elaborado mediante la tecnología tradicional de cuajado y desuerado en cuba. 


\subsection{ESTUDIOS PRELIMINARES}

Se incluyen, por un lado los estudios de optimización de las condiciones de flujo de la planta piloto de ultrafiltración, en cuanto a maximizar la densidad de flujo de permeado. Al mismo tiempo se estudian los límites operacionales que ofrecen las membranas espirales en la elaboración de queso a través de la obtención de un prequeso líquido.

Obtenidos los primeros concentrados se realizan pruebas de coagulación y acidificación por las bacterias lácticas, estudiando la capacidad tampón en función del factor de concentración de la leche.

Los resultados obtenidos permitirán tomar decisiones sobre las concentraciones de ingredientes a ensayar en las posteriores etapas de optimización.

\subsubsection{OPTIMIZACIÓN DE LAS CONDICIONES HIDRODINÁMICAS DE FLUJO}

A continuación se detallan los resultados que conducen a la optimización de las condiciones de flujo. En esta fase se establecerán los límites de concentración operativos alcanzables mediante el uso de membranas poliméricas en configuración espiral.

\section{OPTIMIZACIÓN DE LA DENSIDAD DE FLUJO DE PERMEADO}

Como indica Zulaica (2002), en operaciones de ultrafiltración, la variabilidad de las propiedades de las macromoléculas presentes en la leche -bajo la influencia de los parámetros de operaciónaumenta con frecuencia las dificultades en la separación. Por ello, un buen conocimiento tanto del fluido a tratar como del efecto de los parámetros de operación (TMP, T, J y $v_{t}$ ) resulta ser una etapa esencial para estimar la transferencia de materia. Con este fin se realiza el seguimiento de la densidad de flujo de permeado en función de la presión transmembrana (TMP) y así identificar la zona donde el flujo deja de ser dependiente de la presión para depender únicamente de la transferencia de materia -flujo límite- (Field et al. 1995).

Actuando sobre el variador de la bomba de recirculación se obtienen distintas curvas en función de la velocidad tangencial $\left(\mathrm{v}_{\mathrm{t}}\right)$ de barrido en la superficie de la membrana, calculada a partir del caudal de recirculación $\left(Q_{R}\right)$-medidor del equipo- dividido entre la sección perpendicular al flujo $\left(0,0027 \mathrm{~m}^{2}\right.$ Koch Membrane Systems, Inc). Puesto que a medida que aumenta la velocidad tangencial, aumenta la caída de presión $(\Delta \mathrm{P})$ en el lado del retenido, en todo momento se emplean caudales que no superen el valor límite de caída de presión de acuerdo con las especificaciones de la membrana (1,4 bar).

Las correspondencias entre estas tres variables $\left(\mathrm{v}_{t} / \mathrm{Q}_{\mathrm{R}} / \Delta \mathrm{P}\right)$, para ultrafiltrar la mezcla de leche estandarizada con la que se realizarán las elaboraciones de queso, se encuentran recogidas en la Tabla 5.1.

Tabla 5.1. Equivalencias entre $\Delta P, Q_{R}$ y $v_{t}$

\begin{tabular}{|c|c|c|}
\hline$\Delta \mathbf{P}($ bar $)$ & $\mathbf{Q}_{\mathbf{R}}\left(\mathbf{m}^{\mathbf{3}} / \mathbf{h}\right)$ & $\mathbf{v}_{\mathbf{t}}(\mathbf{m} / \mathbf{s})$ \\
\hline 1 & 9 & 0,9 \\
\hline 1,2 & 10 & 1,0 \\
\hline 1,4 & 11 & 1,1 \\
\hline
\end{tabular}


Esta equivalencia es efectiva en las primeras etapas de la UF y se modifica a lo largo de la misma, debido al aumento de viscosidad que experimenta la alimentación al operar con recirculación de retenido.

Para la obtención de los datos de densidad de flujo de permeado se opera en condiciones de estado estacionario, a recirculación total tanto de permeado como de retenido con el fin de mantener constante las características y concentraciones de la alimentación al módulo de membranas. A su vez la temperatura se mantuvo controlada entre $45-50{ }^{\circ} \mathrm{C}$. Esta temperatura es la normal de operación con corrientes lácteas, para evitar viscosidades elevadas desde el comienzo de la UF. No se emplean valores superiores -que disminuirían la viscosidad- para evitar la desnaturalización de proteínas y por la resistencia térmica de la propia membrana.

Los valores de densidad de flujo alcanzada en la ultrafiltración de leche entera de mezcla, estandarizada a un $4,0 \pm 0,2 \%$ de grasa y un $3,5 \pm 0,1 \%$ de proteína, están recogidos en la Tabla 5.2 .

Tabla 5.2. Datos para la optimización de la densidad de flujo de permeado

\begin{tabular}{|c|c|c|}
\hline$v_{t}(m / s)$ & TMP (bar) & $J\left(L \cdot h^{-1} \cdot m^{-2}\right)$ \\
\hline \multirow{4}{*}{0,9} & 1 & $13,6 \pm 1,1$ \\
\hline & 2 & $21,2 \quad \pm 1,9$ \\
\hline & 3 & $26,4 \pm 0,7$ \\
\hline & 4 & $27,3 \pm 1,5$ \\
\hline \multirow{4}{*}{1} & 1 & $15,2 \pm 0,7$ \\
\hline & 2 & $24,8 \pm 1,5$ \\
\hline & 3 & $29,1 \pm 0,9$ \\
\hline & 4 & $30,9 \pm 1,2$ \\
\hline \multirow{4}{*}{1,1} & 1 & $16,7 \pm 1,9$ \\
\hline & 2 & $30,0 \pm 1,6$ \\
\hline & 3 & $36,1 \quad \pm 0,8$ \\
\hline & 4 & $37,0 \pm 0,8$ \\
\hline
\end{tabular}

*Valores medios calculados a partir de tres filtraciones

En la Figura 5.1 se encuentran representados gráficamente los tres grupos de valores, el error representado en cada experimento corresponde al mayor de los valores obtenidos a cada velocidad.

Se observa claramente un aumento de la densidad de flujo a medida que aumenta la velocidad tangencial en la superficie de la membrana, debido a una disminución de la capa de polarización de concentración, la cual es significativamente apreciable para valores de presión transmembrana superiores a dos.

Estos resultados, relativos a las densidades de flujo máximos, son acordes con los encontrados por D'Souza et al. (2003) ultrafiltrando lactosuero con membranas planas, a velocidad tangencial de $1,5 \mathrm{~m} / \mathrm{s}$ o los resultados de Gandison et al. (2000) ultrafiltrando leche desnatada. 


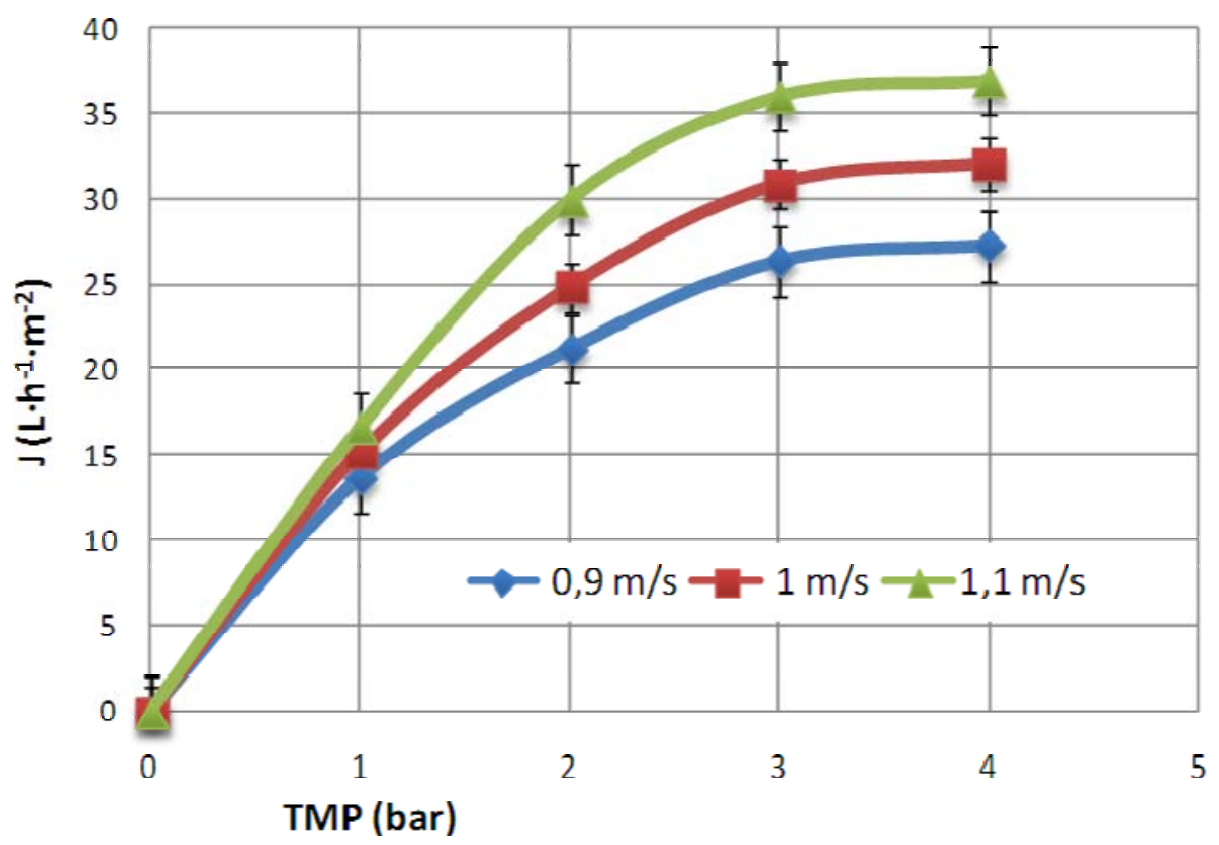

Figura 5.1. Densidad de flujo de permeado en función de la presión transmembrana en la UF de leche

También se observan claramente las dos zonas de densidad de flujo recogidas en la Figura 1.6 de la Introducción (Apartado 1.3.4). La primera zona, de flujo subcrítico, llegaría hasta valores de TMP de entre 2,0 y 3,0 bar, siendo mayor a medida que aumenta la velocidad tangencial. En la segunda zona, para valores de TMP superiores a 3,0 el flujo se hace independiente de la TMP.

Acorde a los resultados alcanzados, las condiciones hidrodinámicas que se mantendrán para todos los experimentos de UF de leche de mezcla estandarizada, trabajando a una temperatura de 45-50 ํㅡ, serán:

$$
\begin{aligned}
& \text { c. } \mathrm{TMP}=3,0 \text { bar } \\
& \text { c. } \mathrm{V}_{\mathrm{t}}=1,1 \mathrm{~m} / \mathrm{s}
\end{aligned}
$$

Con estas condiciones se consiguen densidades de flujo de permeado iniciales de $36 \mathrm{~L} /\left(\mathrm{h} \cdot \mathrm{m}^{2}\right)$. Los resultados alcanzados coinciden con los obtenidos por Atra et al. (2005) ultrafiltrando leche desnatada con membranas planas a $50^{\circ} \mathrm{C}$ y $\mathrm{v}_{\mathrm{t}}$ de $1,7 \mathrm{~m} / \mathrm{s}$, quienes obtuvieron valores de TMP crítica entre 2,0 y 4,0 bar y densidad de flujo de permeado entre $30-35 \mathrm{~L} /\left(\mathrm{h} \cdot \mathrm{m}^{2}\right)$ con membrana de 10.000 Da de corte molecular, equivalentes a las empleadas en este trabajo. Estos investigadores obtenían que la densidad de flujo aumenta linealmente con la temperatura a razón de $0,5 \mathrm{~L} /\left(\mathrm{h} \cdot \mathrm{m}^{2} \cdot{ }^{\circ} \mathrm{C}\right)$ debido a la disminución de la viscosidad y la mayor difusividad de los componentes a través de la membrana.

De igual modo Makardij et al. (1999) obtenían también densidades de flujo similares de 30-35 $\mathrm{L} /\left(\mathrm{h} \cdot \mathrm{m}^{2}\right)$ ultrafiltrando leche con membranas planas de 3.500 Da.

\section{FACTOR DE CONCENTRACIÓN MÁXIMO ALCANZABLE}

La operación en modo concentración discontinua supone un incremento del contenido en sólidos totales de la corriente de retenido que, por aumentar su viscosidad simultáneamente al incremento del ensuciamiento de la membrana, provoca una disminución de la densidad de flujo de permeación. 
Para establecer los límites operacionales de factor de concentración (VCR) mediante la utilización de membrana espiral (ABCOR ${ }^{\circledR} 3838$ HFK-FYT) de elevada separación entre láminas (amplio espaciador), se realiza un seguimiento de la densidad de flujo de permeado a lo largo del tiempo. La operación se realiza con salida continua de permeado y recirculación total de retenido (modo de concentración discontinuo), partiendo de $150 \mathrm{~L}$ de leche de mezcla estandarizada. Los datos registrados a lo largo del tiempo se representan en la Figura 5.2.

Se observa una disminución de la densidad de flujo más pronunciada a partir de una hora de operación $-\mathrm{J}<20 \mathrm{~L} /\left(\mathrm{h} \cdot \mathrm{m}^{2}\right)-$, que corresponde con un factor de concentración entorno a cuatro, lo que supone una concentración aproximada de proteína del $14 \%$. Este hecho ya fue apuntado por Lawrence (1989), en su revisión sobre la ultrafiltración aplicada a la elaboración de queso, donde afirmaba que cuando el contenido de proteína excede del $12-14 \%$ se produce un aumento drástico en la viscosidad del retenido. Consecuentemente se produce un aumento del espesor de la capa de depósito sobre la membrana, lo que se traduce en una disminución de la densidad de flujo. Este depósito de proteína se postula como el mayor responsable del descenso de flujo observado experimentalmente, si bien, también influyen otros constituyentes como la grasa y las sales inorgánicas o la presencia de microorganismos, todos ellos responsables de los problemas de ensuciamiento.

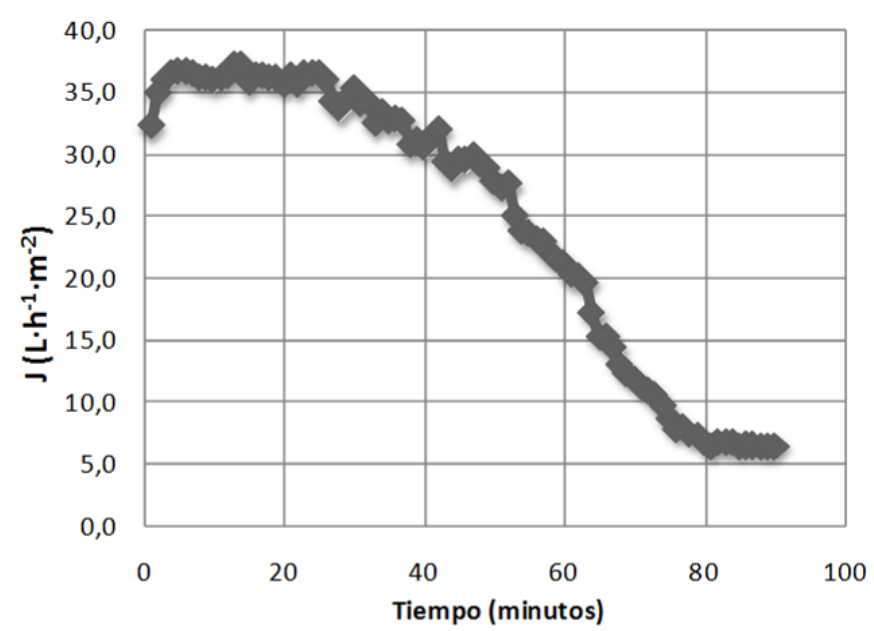

Figura 5.2. Evolución de J en la ultrafiltración de leche entera con membranas poliméricas (10.000 Da)

Una forma más clara de conocer los límites de la membrana, a partir de los datos anteriores, es a través de la gráfica de la Figura 5.3, donde se enfrenta la densidad de flujo de permeado (J) al factor de concentración volumétrico (VCR).

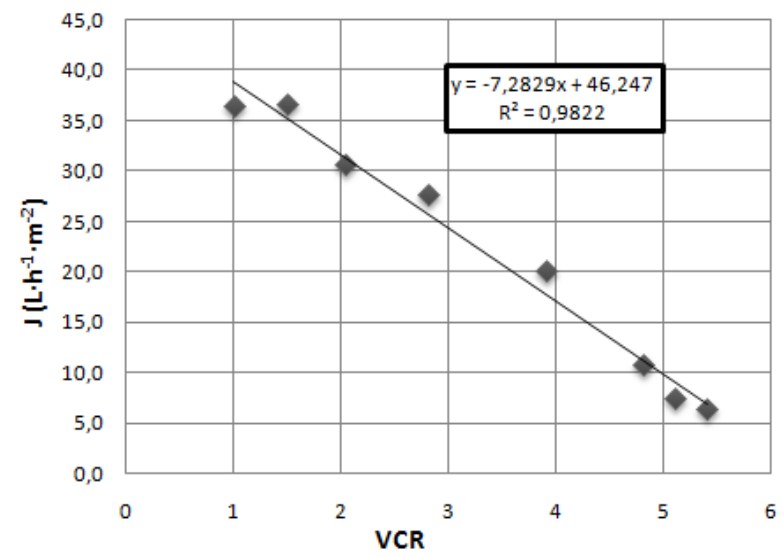

Figura 5.3. J vs VCR. UF de leche entera con membranas poliméricas (10.000 Da) 
A través del ajuste del comportamiento lineal detectado, por el método de mínimos cuadrados, se obtiene una relación de la forma:

$$
J=-7,3 \cdot(V C R)+46,2
$$

Considerando como flujo mínimo, desde un punto de vista operacional (Schreier et al. 2010), valores por debajo de $10 \mathrm{~L} /\left(\mathrm{h} \cdot \mathrm{m}^{2}\right)$ y despejando de la Ecuación [5.1] se obtienen factores de concentración máximos de 4,8. Este valor de VCR transformado en extracto seco del concentrado (suponiendo una leche entera estandarizada con un $13,2 \%$ de sólidos totales y un permeado del 5,4\%) corresponde, según la Ecuación [1.3], a un extracto seco del retenido del $43 \%$.

Estos resultados sirven para establecer los valores del factor de concentración (o lo que es lo mismo extracto seco del concentrado) que se emplearán en las etapas posteriores de optimización. Estos límites se establecen en VCR=4,5 ( $41 \%$ de $E S$ ) y VCR=4,0 (36 \% de ES).

La aplicación de la técnica de UF, con este equipo, a la elaboración de quesos madurados mediante el concepto de prequeso líquido es limitada, al no alcanzarse extractos secos similares al del queso tradicional al final de la etapa de salado (entorno al $52 \%$ de ES). Por ello se hace imprescindible controlar las pérdidas de suero en etapas posteriores a la concentración, es decir en el proceso de elaboración (corte/moldeo/prensado/salado/maduración) para lograr retener al final del proceso global las proteínas solubles, mayoritariamente en su estado nativo (Rao y Renner 1988).

Los resultados obtenidos relativos al comportamiento de la densidad de flujo de permeación (Figura 5.1) son totalmente acordes con los conocimientos clásicos de filtración, como recogen Marshall et al. (1993) en su completa revisión sobre la ultrafiltración y microfiltración de soluciones de proteínas.

\subsubsection{ESTUDIO DEL PODER TAMPÓN Y ACIDIFICACIÓN DE LOS CONCENTRADOS}

La importancia de estos efectos se ha explicado previamente en la Metodología (Apartado 3.1.2). El poder tampón se estudia mediante el seguimiento de la variación del $\mathrm{pH}$ a medida que se va acidificando la muestra. Se obtiene el poder tampón de la disolución, denotado por $(\mathrm{dB} / \mathrm{dpH})$, como indicativo directo de la cantidad de protones que es capaz de asimilar la disolución sin cambiar su pH (Van Slyke 1922). En la Figura 5.4 se muestra la evolución de dicho parámetro frente al $\mathrm{pH}$, tanto para la leche de mezcla estandarizada como para retenidos de ultrafiltración de distinto grado de concentración (VCR de 3,5 y 4,5).

Esta capacidad de la leche y los concentrados para autorregular el pH se atribuye a las proteínas y sales que los constituyen. Aunque en distintas proporciones, algunos investigadores han atribuido el mayor peso a las sales minerales, seguido de la caseína y por último las proteínas solubles (Kirchmeier 1980; Srilaorkul et al. 1989; Lucey 2008). Según Srilaorkul et al. (1989) las sales son responsables de un $58,6 \%$ del poder tampón, mientras que el resto es atribuible a las proteínas: un $36 \%$ a la caseína y el 5,4 \% restante a las proteínas solubles, debido a su carácter anfótero.

Se observa un aumento significativo en el poder tampón, respecto del de la leche de origen, de los retenidos a medida que aumenta el factor de concentración. Al aumentar el grado de concentración de la leche aparecen dos máximos en la capacidad tampón. El más significativo se alcanza a valores de pH de 5,15 y el segundo a 4,90. El primero de ellos se atribuye al poder tampón de la caseína, ya que se ha encontrado que esta proteína presenta un máximo poder 
tampón a valores de $\mathrm{pH}$ entre 5,0-5,5 y de forma específica atribuible a los residuos de fosfofoserina e histidina (Salaün et al. 2005). El segundo máximo corresponde con la capacidad tampón de los distintos aniones (fosfato, citrato, lactato, carbonato, acetato y propionato) y cationes (calcio y magnesio) presentes en la leche, cuyos máximos, asociados a sus equilibrios de disociación, se encuentran entre valores de $\mathrm{pH}$ de 4,0 y 4,8 de acuerdo con los resultados de Salaün et al. (2005). En cuanto a las proteínas solubles, la máxima capacidad reguladora se encuentra entre valores de $\mathrm{pH}$ de 3,0 y 4,0 por lo que su contribución se considera despreciable en la zona de pH estudiada.

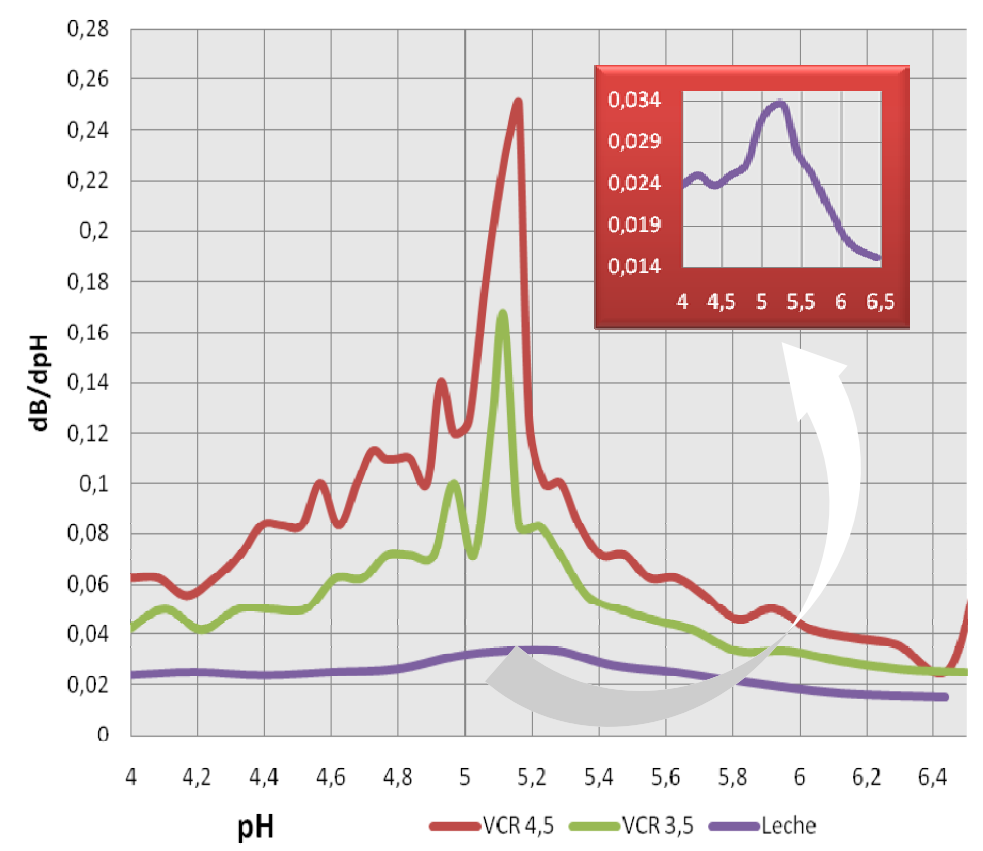

Figura 5.4. Evolución del poder tampón en función del pH, para leche y concentrados

En la Tabla 5.3 se puede ver la magnitud del poder tampón para los dos máximos y la proporción en que aumenta respecto al valor de la leche, llegando a ser hasta casi nueve veces mayor que el de la leche de partida, para un concentrado de $\mathrm{VCR}=4,5$ a $\mathrm{pH}$ de 5,3.

Tabla 5.3. Valores máximos de poder tampón del concentrado y relación respecto a la leche

\begin{tabular}{|c|c|c|c|c|c|}
\hline \multirow{2}{*}{ pH } & LECHE & \multicolumn{2}{|c|}{ VCR 3,5 } & \multicolumn{2}{c|}{ VCR 4,5 } \\
\cline { 2 - 6 } & $\mathbf{d B} / \mathbf{d p H}$ & $\mathbf{d B} / \mathbf{d p H}$ & $\mathbf{V C R} /$ LECHE & $\mathbf{d B} / \mathbf{d p H}$ & VCR/LECHE \\
\hline $\mathbf{5 , 1 5}$ & 0,03 & 0,17 & 5,6 & 0,26 & 8,6 \\
\hline $\mathbf{4 , 9 0}$ & 0,03 & 0,10 & 3,8 & 0,14 & 5,4 \\
\hline
\end{tabular}

Los valores de poder tampón calculados para la leche son acordes con los obtenidos por Lucey et al. (1993) con máximo poder tampón $(0,03)$ entorno a 5,5 de pH. Por su parte, los valores calculados en leche concentrada coinciden con los de Mistry and Kosikowski (1985) con capacidad máxima a pH de 5,1-5,3 y poder tampón de 0,15 para VCR de 3,4 respecto al contenido proteico, trabajando sobre leche desnatada.

Destacar la relación observada en este trabajo entre la capacidad tampón y el VCR, mediante ajuste por mínimos cuadrados, que permite establecer una relación lineal entre ambos. Se obtienen elevados coeficientes de correlación $\left(R^{2}\right)$, como se muestra en la Figura 5.5, para un valor dado de $\mathrm{pH}$-en este caso se aplica a los dos máximos observados en la gráfica de la Figura 5.4-. Para cada valor de $\mathrm{pH}$ se puede establecer que: 


$$
\begin{aligned}
& d B / d p H_{(p H=5,15)}=0,064 \cdot(V C R)-0,038 \\
& d B / d p H_{(p H=4,90)}=0,032 \cdot(V C R)-0,007
\end{aligned}
$$

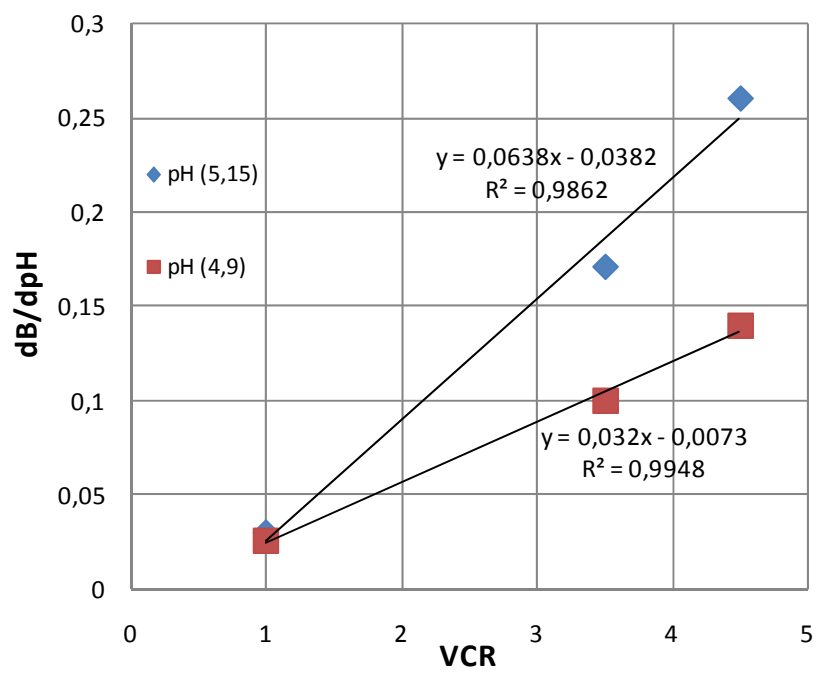

Figura 5.5. Relación entre el poder tampón y el factor de concentración para la UF de leche entera

Tecnológicamente, como indica Salaün (2005), este gran aumento en el poder tampón hace preveer un retraso en la cinética de acidificación de las bacterias lácticas. Por este motivo, si no se está en la región apropiada de $\mathrm{pH}$, la capacidad tampón puede influir negativamente tanto en la actividad enzimática como en el crecimiento microbiano.

Este efecto se observa experimentalmente en la Figura 5.6, en la que se representa la disminución de $\mathrm{pH}$ a lo largo del tiempo, tanto en leche de mezcla estandarizada como en concentrado de ultrafiltración (VCR 4,5), cultivados todos ellos a $32{ }^{\circ} \mathrm{C}$ durante $12 \mathrm{~h}$. En la gráfica se compara la concentración del fermento (MA4001) empleada en la elaboración del queso tradicional (4 DCU/100L) con valores creciente de concentración de fermento sobre leche concentrada. Se observa que para un VCR de 4,5 la concentración de fermento ha de ser 4 veces mayor (16 DCU/100L) a la empleada en leche para obtener cinéticas similares; si bien en las etapas finales (valores de $\mathrm{pH}$ inferiores a 5,2 ) se produce un retardo notable en la velocidad de disminución del pH, el cuál resulta ser independiente de la cantidad de fermento inoculado.

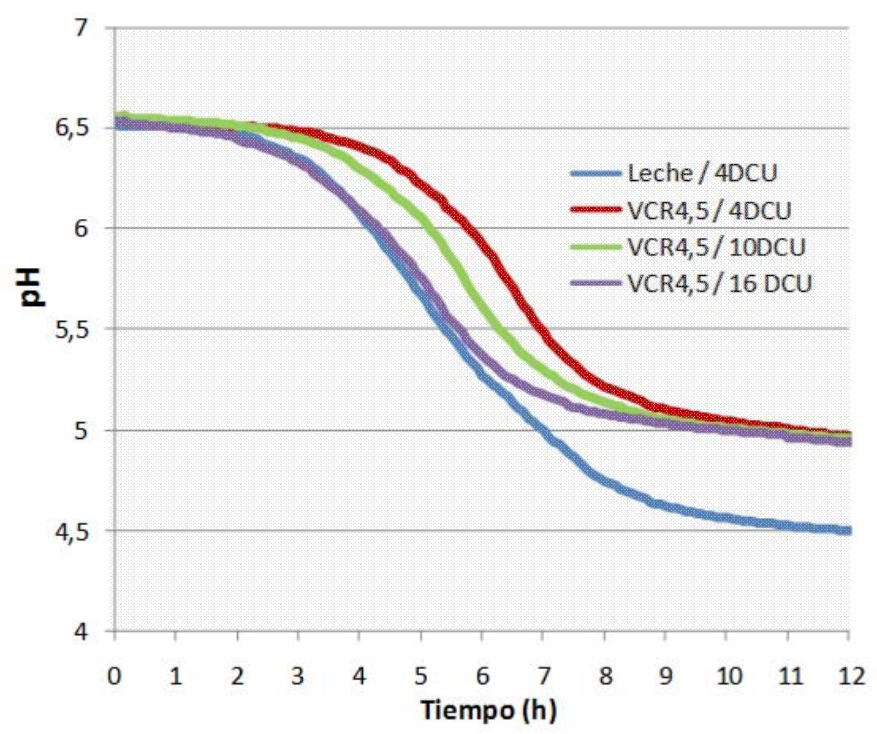

Figura 5.6. Curvas de acidificación para leche y concentrado a VCR 4,5. Fermento MA4001 
En todos los casos se muestra una primera zona -entre las 2-3 horas iniciales- donde prácticamente no hay disminución de pH. Esta zona corresponde con el tiempo de aclimatación y activación de los microorganismos, ya que éstos se encuentran en estado liofilizado en el momento de la siembra. Pasado ese tiempo inicial aparece una zona intermedia, donde la disminución del pH es casi lineal con el tiempo, hasta llegar a valores cercanos a 5,15 donde se encontraba el máximo poder tampón de los concentrados (Figura 5.4). En la última zona el pH se vuelve prácticamente constante con el tiempo, hacia un valor asintótico cercano a 4,9 y coincidiendo esta vez con el segundo máximo encontrado en el poder tampón de los concentrados.

A tiempos prolongados se observa la verdadera magnitud del poder tampón ya que por elevada que sea la dosis de fermento no se alcanza el valor de $\mathrm{pH}$ de 4,6 (punto isoélectrico de las caseínas). Este comportamiento tiene especial relevancia al elaborar quesos de coagulación láctica, por lo que en este tipo de quesos se aconseja realizar la ultrafiltración después de la acidificación (Fernández-Albalat 2002). A efectos prácticos, en el proceso de elaboración, esto se va a traducir en un incremento de los tiempos de acidificación y en un aumento de la producción de ácido láctico, que puede desencadenar sabores y texturas atípicas en el queso.

En este sentido, el crecimiento microbiano no se ve afectado por el alto contenido proteico y salino de los concentrados (Mistry y Kosikowski 1985). Esta característica de autorregulación del pH a causa del elevado contenido proteico y mineral de los concentrados, los convierte en un medio apropiado para el crecimiento microbiano, al permitir mantener el pH del medio cercano al óptimo de crecimiento de las bacterias lácticas durante tiempos prolongados. Si bien, deberá tenerse en cuenta la disminución de la actividad de agua a medida que aumenta el grado de concentración, la cual puede llegar a inhibir el fermento. De acuerdo con estas consideraciones, se han realizado numerosos estudios donde los retenidos de ultrafiltración son empleados para la producción de fermentos (Mistry y Kosikowski 1986; Mistry 2002).

En base a los resultados mostrados -donde se demuestra que el poder tampón aumenta con la concentración de sales y proteína- y ante el efecto que supone sobre la posterior elaboración de queso, las tres posibilidades de reducción de dicho poder tampón más aceptadas son (Brulé et al. 1974):

c La preacidificación de la leche antes de la ultrafiltración, para aumentar la proporción de calcio soluble frente al calcio micelar;

c la diafiltración con agua, para eliminar mayor cantidad de lactosa y, por último,

c la adición de cloruro sódico, para solubilizar mayor cantidad de sales de magnesio y calcio por intercambio iónico $\mathrm{Na} / \mathrm{Ca}$ en la micela de caseína.

Según estudios realizados por St-Gelais et al. (1992), mediante una buena elección de las condiciones de preacidificación y diafiltración se puede reducir el poder tampón del concentrado en un $78 \%$ pasando de valores de 0,15 a valores de 0,06 en su capacidad tampón.

Acorde con estos resultados, en las primeras etapas de optimización se estudiará la posibilidad de reducir el contenido en sal y lactosa mediante diafiltración o reducción del pH inicial de la leche, introduciendo ambas etapas como factores de estudio en el diseño experimental Plackett-Burmann.

\subsubsection{DUREZA DE LAS CUAJADAS}

Como ya se ha indicado en la metodología, y debido al efecto de la duraza de los geles formados por la acción de enzimas sobre las etapas posteriores de corte y desuerado; se cuantificó mediante 
texturómetro, a lo largo del tiempo, la dureza de los geles cuajados a partir de leche de mezcla y concentrados de UF de VCR 4,0 y 4,5 .

Empleando la misma concentración de cuajo que en el proceso tradicional de elaboración $(40 \mathrm{~mL} / 100 \mathrm{~L})$ se obtiene la gráfica de la Figura 5.7.

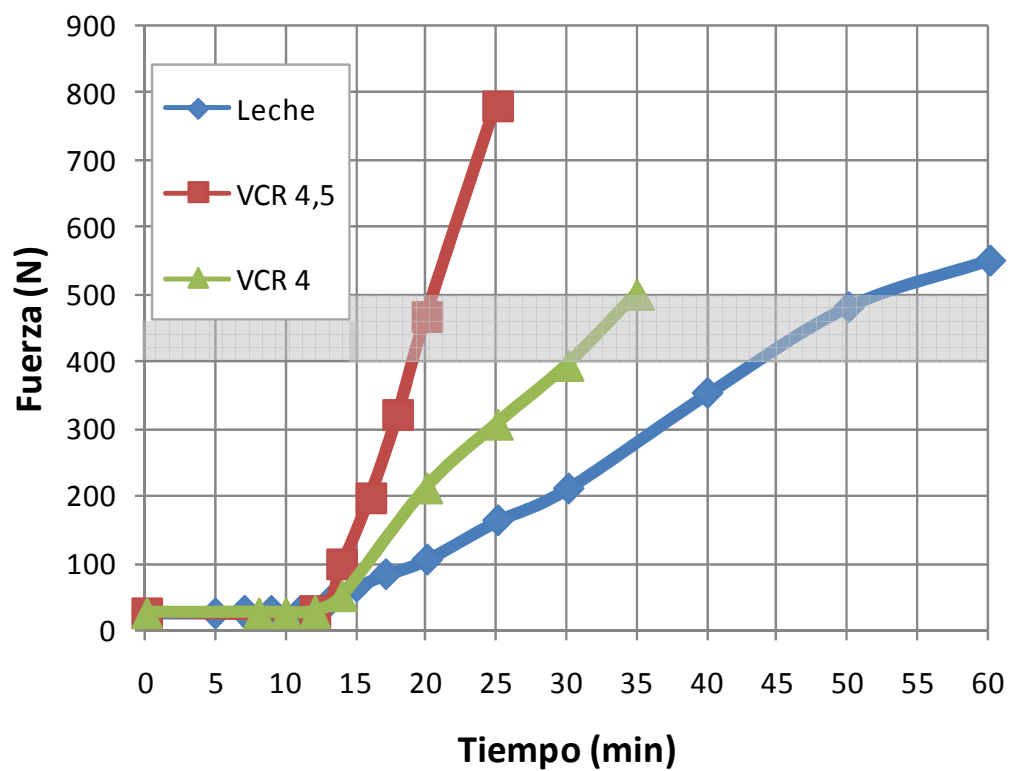

Figura 5.7. Dureza de los geles cuajados con $40 \mathrm{~mL}$ de cuajo por cada $100 \mathrm{~L}$ de leche o concentrado

Se observa un aumento significativo en la dureza de la cuajada al aumentar el factor de concentración, del mismo modo que se recoge en la bibliografía (Singh y Waungana 2001). El tiempo al que se forman las primeras agregaciones de caseína (tiempo de toma o floculación), sin embargo, permanece constante en todos los experimentos, con valores próximos a los 12 minutos. Estos resultados concuerdan con los de Maubois (1989), quien indicaba una menor proporción de к-caseína hidrolizada en el momento de la formación de los primeros flóculos en los retenidos de ultrafiltración, respecto a la leche sin concentrar.

A los 45-50 minutos, cuando se procede al corte de la cuajada en la elaboración tradicional, la dureza del gel es de entre 400 y $500 \mathrm{~N}$. Si se realizara el corte a ese mismo valor de dureza con los concentrados, el tiempo se reduciría hasta los 20 minutos para un VCR de 4,5 y hasta los 30-35 minutos para VCR de 3,5.

Según estos datos, y de acuerdo con la bibliografía, una reducción en la concentración de enzima coagulante parece factible, documentándose en los mejores casos reducciones de hasta el $85 \%$ en la cantidad de cuajo (Mistry y Maubois 2004).

Para estimar el porcentaje de la posible reducción en la cantidad de enzima coagulante empleada al cuajar concentrados de UF, respecto al utilizado con leche sin concentrar, se realiza el mismo experimento sobre los retenidos de UF a dos concentraciones de cuajo menores, $30 \mathrm{y}$ $15 \mathrm{~mL} / 100 \mathrm{~L}$. Los resultados obtenidos se recogen en la Figura 5.8 .

Mediante el uso de menores concentraciones de cuajo se observa como aumenta el tiempo de toma en unos 2-3 min al pasar de 40 a $30 \mathrm{~mL} / 100 \mathrm{~L}$ y en unos $10-12$ min cuando se disminuye la concentración de cuajo de 40 a $15 \mathrm{~mL} / 100 \mathrm{~L}$. Estos resultados son acordes con los obtenidos por Karlsson et al. (2007), quienes también demostraron que al aumentar la concentración de cuajo aumenta la firmeza del gel de una manera lineal. 


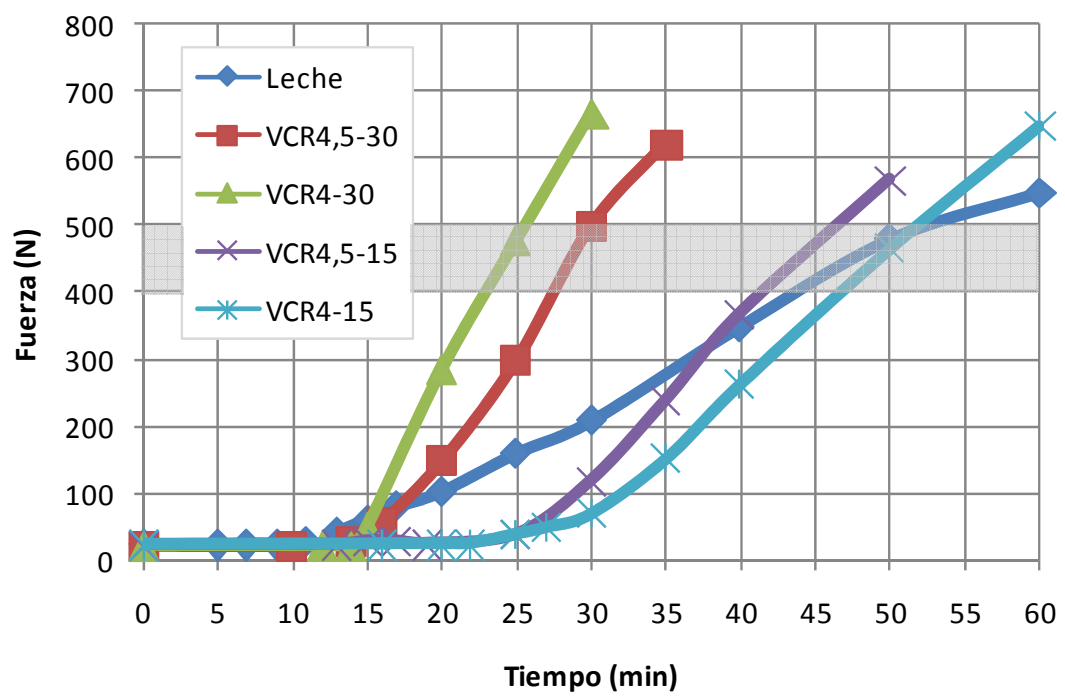

Figura 5.8. Dureza de los geles cuajados con 30 y $15 \mathrm{~mL}$ de cuajo por cada $100 \mathrm{~L}$ de concentrado. La leche ha sido cuajada nuevamente con $40 \mathrm{~mL} / 100 \mathrm{~L}$

Acorde con los resultados presentados en la Figura 5.8, los tiempos de corte para alcanzar firmezas de 400-500 N deberán estar entre 25 y 30 min para concentraciones de cuajo de $30 \mathrm{~mL} / 100 \mathrm{~L}$ y entre 40 y 50 min para concentraciones de $15 \mathrm{~mL} / 100 \mathrm{~L}$, dependiendo del VCR alcanzado en la concentración.

En el diseño experimental Plackett-Burmann se estudiarán ambos niveles de concentración (15 y $30 \mathrm{~mL} / 100 \mathrm{~L}$ ) para conocer las variaciones sobre el rendimiento y la calidad del queso que puedan producirse por una reducción excesiva de la cantidad de enzima coagulante. En el proceso de elaboración no se estudiará el efecto del tiempo total de coagulación -desde la adición del cuajo hasta la etapa de corte-, ya que, como se recoge en la bibliografía, mayores tiempos de cuajado no repercuten en mejores propiedades de textura del queso, como mayor firmeza o elasticidad (Spangler et al. 1991). Los tiempos de corte obtenidos de los resultados de este estudio se comprobarán de manera visual en las distintas elaboraciones. 


\subsection{ESTABLECIMIENTO DE LAS CONDICIONES INICIALES DE ELABORACIÓN Y FILTRACIÓN}

A continuación se muestran los resultados que conducen a la definición de las condiciones de partida, tanto del proceso de filtración como del proceso de elaboración de queso de mezcla a partir de concentrados de ultrafiltración.

Como se ha indicado en la metodología, en este primer diseño experimental se realizará una selección de variables significativas para continuar su estudio en etapas posteriores. Una vez definidas las variables y realizado el diseño se lleva a cabo un estudio comparativo de los distintos quesos elaborados a través de análisis físico-químico, análisis instrumental de textura y evaluación sensorial. Al mismo tiempo se realizará un seguimiento de las distintas elaboraciones ensayadas, para resolver el diseño en base al rendimiento quesero y la evaluación sensorial del queso.

\subsubsection{DISEÑO EXPERIMENTAL}

En la ultrafiltración se añadirá la etapa de diafiltración con un $14 \%$ de agua respecto a la leche de partida (factor A), porcentaje similar al usado por Spangler et al. (1991) en la elaboración de queso Gouda o por Ernstrom (1980) en la elaboración de queso Cheddar. También se estudiará la bajada del pH inicial de la leche desde su valor normal (entorno a 6,7) hasta valores de 6,4 a través de la adición de glucona- $\delta$-lactona $(F)$, rango de $\mathrm{pH}$ similar al estudiado por Spangler et al. (1991) para la elaboración de queso Gouda. Por último en lo que se refiere a la etapa de filtración, se ajustará el extracto seco del concentrado al 41 y al $36 \%$, lo que se corresponde con VCR de 4,5 y 4,0 respectivamente (D), como se vio en los estudios preliminares.

En cuanto a ingredientes, los niveles estudiados para cada factor son, la dosis de cuajo (C) entre 30 y $15 \mathrm{~mL}$ por cada $100 \mathrm{~L}$ de concentrado y la dosis de fermento (B) que se aumentará de los $4 \mathrm{DCU} / 100 \mathrm{~L}$ del queso tradicional a $6 \mathrm{DCU} / 100 \mathrm{~L}$, acorde a los resultados alcanzados en los estudios preliminares.

Las variables estudiadas en el diseño Plackett-Burmann se recogen en la Tabla 5.4.

Tabla 5.4. Niveles de las variables para el diseño Plackett-Burmann

\begin{tabular}{|c|c|c|c|c|}
\hline Código & FACTORES & $\begin{array}{c}\text { Rango } \\
\text { alto }\end{array}$ & $\begin{array}{c}\text { Rango } \\
\text { Bajo }\end{array}$ & Unidades \\
\hline A & Etapa de Diafiltración (DF) & 14 & 0 & $\%$ de agua/leche de partida \\
\hline B & Cantidad de fermento & 6 & 4 & *DCU/100 L de concentrado \\
\hline C & Concentración de cuajo & 30 & 15 & $\mathrm{~mL} / 100 \mathrm{~L}$ de concentrado \\
\hline D & Extracto seco del concentrado & 41 & 36 & $\%$ ES \\
\hline E & Temperatura de cuajado & 37,0 & 32,0 & oC \\
\hline F & pH inicial de la leche filtrada & 6,7 & 6,4 & Unidades de pH \\
\hline G & Tamaño de corte de la cuajada & 3,0 & 1,5 & $\mathrm{~cm}$ de haz de lira \\
\hline H & Presión de prensado & $+1(3,0 / 2,5)$ & $-1(2,5 / 2,0)$ & bar \\
\hline
\end{tabular}

*Una unidad DCU contiene aproximadamente de $1 \cdot 10^{11}$ a $2 \cdot 10^{11}$ bacterias 
En la etapa de fabricación las variables consideradas y sus intervalos (como se expuso en el Apartado 3.2 de la Metodología) son la temperatura de cuajado (E), realizándose a 32 y $37^{\circ} \mathrm{C}$ y el tamaño del corte de la cuajada (G), que se realiza con una lira de haz estándar para el tipo de queso a ensayar $(1,5 \mathrm{~cm})$ y con una de tamaño doble. Por último en la prensa se usará la presión normal de 2,5/2,0 bar y una mayor de 3/2,5 bar; al tratarse de una variable discreta tomará los valores de $+1 /-1$ a efectos de análisis.

Los doce experimentos del diseño, aleatorizados según la secuencia experimental, se muestran en la Tabla 5.5. También se recogen para cada experimento los valores experimentales de las dos variables respuesta con los que se realizará la optimización múltiple final: \% R (expresado como rendimiento corregido) y puntuación sensorial global (olfato-gustativa y visual).

Tabla 5.5. Matriz del diseño de experimentos Plackett-Burmann

\begin{tabular}{|c|c|c|c|c|c|c|c|c|c|c|}
\hline PB & A & B & C & D & E & F & G & H & \% R* & Sensorial \\
\hline $\mathbf{1}$ & 14 & 6 & 30 & 36 & 37 & 6,7 & 1,5 & 1,0 & 12,85 & 4,5 \\
\hline $\mathbf{2}$ & 0 & 6 & 30 & 41 & 32 & 6,7 & 3 & $-1,0$ & 15,18 & 4,5 \\
\hline $\mathbf{3}$ & 14 & 6 & 15 & 41 & 37 & 6,4 & 3 & $-1,0$ & 13,58 & 4,7 \\
\hline $\mathbf{4}$ & 14 & 6 & 15 & 41 & 32 & 6,4 & 1,5 & 1,0 & 12,62 & 4,9 \\
\hline $\mathbf{5}$ & 14 & 4 & 30 & 36 & 32 & 6,4 & 3 & 1,0 & 14,40 & 4,1 \\
\hline $\mathbf{6}$ & 0 & 4 & 15 & 36 & 32 & 6,4 & 1,5 & $-1,0$ & 12,70 & 4,1 \\
\hline $\mathbf{7}$ & 0 & 4 & 30 & 41 & 37 & 6,4 & 3 & 1,0 & 14,15 & 4,1 \\
\hline $\mathbf{8}$ & 14 & 4 & 30 & 41 & 32 & 6,7 & 1,5 & $-1,0$ & 13,66 & 4,4 \\
\hline $\mathbf{9}$ & 0 & 4 & 15 & 41 & 37 & 6,7 & 1,5 & 1,0 & 13,58 & 4,3 \\
\hline $\mathbf{1 0}$ & 0 & 6 & 15 & 36 & 32 & 6,7 & 3 & 1,0 & 15,07 & 4 \\
\hline $\mathbf{1 1}$ & 0 & 6 & 30 & 36 & 37 & 6,4 & 1,5 & $-1,0$ & 12,86 & 4,1 \\
\hline $\mathbf{1 2}$ & 14 & 4 & 15 & 36 & 37 & 6,7 & 3 & $-1,0$ & 14,79 & 3,8 \\
\hline
\end{tabular}

* Rendimiento corregido para quesos de un $55 \%$ de extracto seco $(\mathrm{kg} / 100 \mathrm{~kg}$ de leche)

Previo a la realización de la optimización múltiple del diseño (en cuanto a rendimiento y calidad sensorial) se determina la influencia de cada uno de los factores del diseño sobre el resto de parámetros y descriptores analizados en cada una de las fabricaciones. Para estudiar esta influencia se resuelve el diseño introduciendo como variables respuesta la composición físico-química de los quesos, los datos de textura instrumental y la totalidad de descriptores cuantificados por el panel de cata en la evaluación sensorial.

\subsubsection{ESTUDIO FÍSICO-QUÍMICO}

De las corrientes líquidas se realizaron análisis químico y físico tanto a las leche de partida (vaca/oveja) como a la mezcla estandarizada y a los concentrados obtenidos tras la etapa de ultrafiltración.

Los quesos obtenidos a partir de los 12 experimentos del diseño se analizaron, a los 20 y 40 días de maduración, en composición química y pH. 


\section{LECHES Y CONCENTRADOS}

En las Tablas A.1-A.2 recogidas en el Anexo A.1 se muestra la composición química (grasa, proteína, lactosa, cenizas y extracto seco) y el pH de las leches de oveja y vaca con las que se realizaron las mezclas estandarizadas. Mediante su estudio queda de manifiesto la gran variabilidad que experimenta la leche, sobre todo en cuanto a la concentración de grasa y proteína, y su correspondiente impacto sobre el extracto seco. Esta variación, en muchos casos estacional, es mayor para la leche de oveja que para la de vaca. Por tanto, se hace necesaria la estandarización de la leche y así evitar un factor de variabilidad que pueda distorsionar los resultados alcanzados en la optimización del diseño.

Respecto a la calidad de la materia prima, el análisis de antibióticos mostró ausencia en todas las leches. El recuento de células somáticas para la leche de vaca resultó ser menor de las 400.000 células/mL, de acuerdo con el Reglamento 853/2004, y para el caso de la leche de oveja por debajo de las 800.000 células $/ \mathrm{mL}$, por lo que las materias primas se consideran de calidad para la elaboración de queso.

La composición de las leches de mezcla estandarizadas, a partir de las que se realizarán los distintos experimentos del diseño, se muestra en la Tabla 5.6. La composición se encuentra controlada en los márgenes establecidos $(4,0 \pm 0,2 \%$ de grasa y 3,5 $0,1 \%$ de proteína) minimizando su contribución a la variabilidad de los factores sujetos de estudio. Por su parte el pH, como parámetro de calidad, se encuentra entorno a los valores normales de la leche $(\approx 6,75)$.

Tabla 5.6. Composición química y pH de la leche de mezcla. Diseño Plackett-Burmann

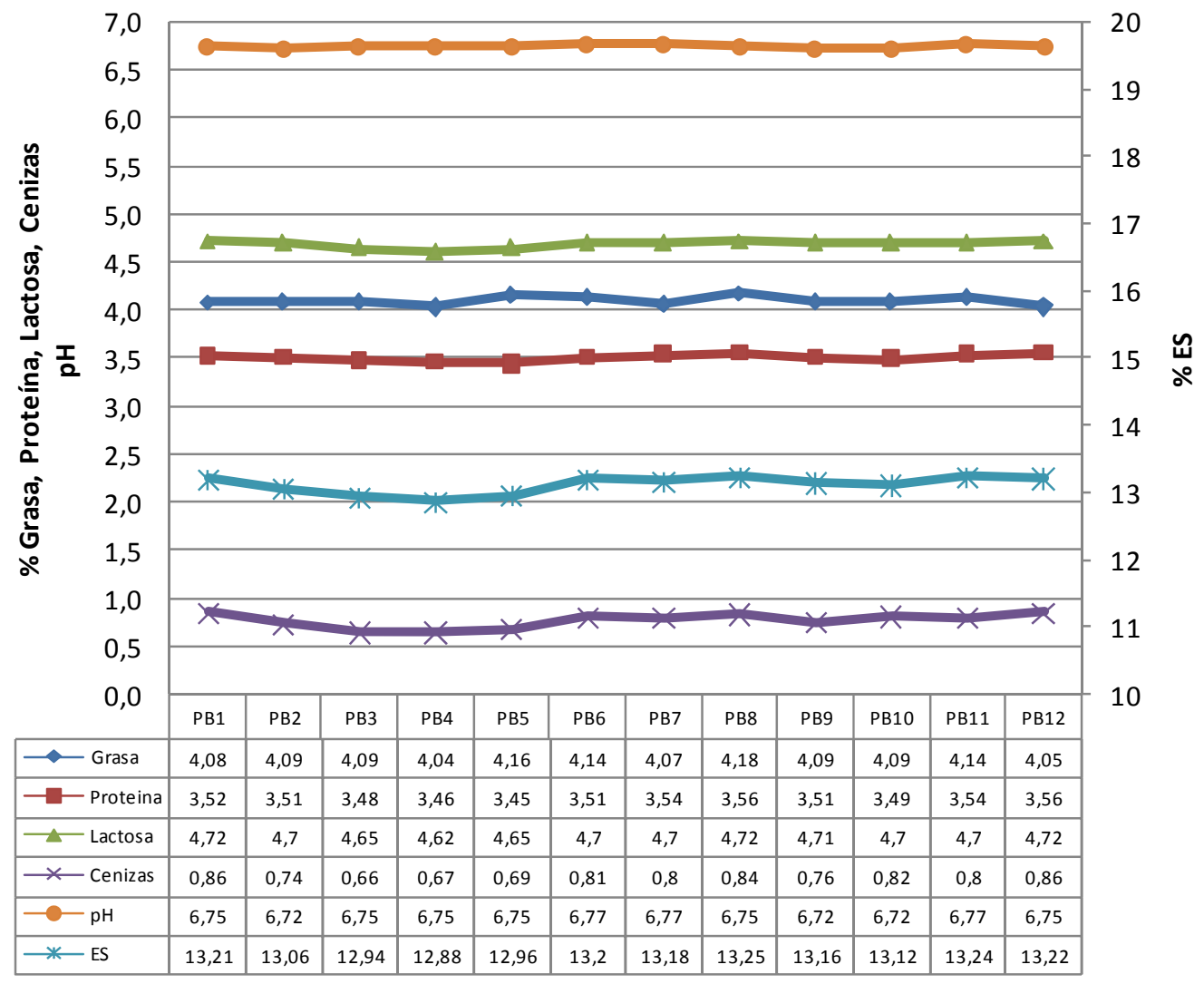

Después de llevar a cabo la etapa inicial de todos los experimentos -ultrafiltración, con diafiltración y bajada inicial de pH cuando así lo indica el diseño- la composición de los concentrados a partir de los que se fabrica el queso se recoge en la Tabla 5.7. Los datos de concentración de lactosa 
han sido calculados mediante diferencia del resto de constituyentes con el ES, por lo que se consideran meramente indicativos.

Los valores de ES se agrupan en dos grandes conjuntos, uno para el nivel bajo (PB1, PB5, PB6, PB10, PB11 y PB12) y otro para el alto (PB2, PB3, PB4, PB7, PB8 y PB9) del diseño. Dentro de cada uno de ellos se observan otros tres sub-grupos interconectados entre sí. Similares resultados se encuentran para la proteína y la grasa. Estas tendencias se muestran en la Figura 5.9.

Tabla 5.7. Composición química y pH de los retenidos de UF. Diseño Plackett-Burmann

\begin{tabular}{|c|c|c|c|c|c|c|c|c|c|c|c|c|}
\hline$\%$ peso & PB1 & PB2 & PB3 & PB4 & PB5 & PB6 & PB7 & PB8 & PB9 & PB10 & PB11 & PB12 \\
\hline Grasa & $\begin{array}{c}17,25^{\mathrm{ab}} \\
\pm 0,05\end{array}$ & $\begin{array}{c}19,25^{\mathrm{bc}} \\
\pm 0,05\end{array}$ & $\begin{array}{l}19,75^{c} \\
\pm 0,05\end{array}$ & $\begin{array}{l}19,75^{c} \\
\pm 0,05\end{array}$ & $\begin{array}{c}17,25^{\mathrm{ab}} \\
\pm 0,05\end{array}$ & $\begin{array}{l}17,25^{a} \\
\pm 0,05\end{array}$ & $\begin{array}{l}20,75^{\mathrm{c}} \\
\pm 0,05\end{array}$ & $\begin{array}{l}20,25^{c} \\
\pm 0,05\end{array}$ & $\begin{array}{c}19,25^{\mathrm{bc}} \\
\pm 0,05\end{array}$ & $\begin{array}{l}16,75^{\mathrm{a}} \\
\pm 0,05\end{array}$ & $\begin{array}{c}17,25^{\mathrm{ab}} \\
\pm 0,05\end{array}$ & $\begin{array}{c}17,50^{\mathrm{ab}} \\
\pm 0,00\end{array}$ \\
\hline Proteína & $\begin{array}{c}14,23^{\mathrm{ab}} \\
\pm 0,40\end{array}$ & $\begin{array}{l}17,11^{\mathrm{d}} \\
\pm 0,05\end{array}$ & $\begin{array}{l}17,41^{\mathrm{d}} \\
\pm 0,08\end{array}$ & $\begin{array}{l}17,42^{\mathrm{d}} \\
\pm 0,01\end{array}$ & $\begin{array}{c}14,56^{\mathrm{ab}} \\
\pm 0,05\end{array}$ & $\begin{array}{l}14,66^{\mathrm{b}} \\
\pm 0,23\end{array}$ & $\begin{array}{l}16,52^{\mathrm{c}} \\
\pm 0,33\end{array}$ & $\begin{array}{l}16,54^{\mathrm{c}} \\
\pm 0,14\end{array}$ & $\begin{array}{c}16,84^{\mathrm{C}} \\
\pm 0,06\end{array}$ & $\begin{array}{c}14,32^{\mathrm{ab}} \\
\pm 0,12\end{array}$ & $\begin{array}{l}14,06^{\mathrm{a}} \\
\pm 0,18\end{array}$ & $\begin{array}{c}14,21^{\mathrm{ab}} \\
\pm 0,15\end{array}$ \\
\hline Lactosa & 2,75 & 3,04 & 56 & 55 & 2,60 & 65 & 2,26 & 2,44 & 3,02 & 2,84 & 2,71 & 2,66 \\
\hline Cenizas & $\begin{array}{l}1,35^{\mathrm{a}} \\
\pm 0,04\end{array}$ & $\begin{array}{c}1,79^{d} \\
\pm 0,13\end{array}$ & $\begin{array}{r}1,36^{\mathrm{a}} \\
\pm 0,01\end{array}$ & $\begin{array}{c}1,37^{\mathrm{a}} \\
\pm 0,02\end{array}$ & $\begin{array}{c}1,36^{\mathrm{a}} \\
\pm 0,02\end{array}$ & $\begin{array}{l}1,45^{\mathrm{b}} \\
\pm 0,08\end{array}$ & $\begin{array}{c}1,44^{\mathrm{b}} \\
\pm 0,04\end{array}$ & $\begin{array}{l}1,39^{a} \\
\pm 0,03\end{array}$ & $\begin{array}{l}1,68^{\mathrm{cd}} \\
\pm 0,01\end{array}$ & $\begin{array}{l}1,58^{\mathrm{bc}} \\
\pm 0,01\end{array}$ & $\begin{array}{r}1,46^{\mathrm{b}} \\
\pm 0,05\end{array}$ & $\begin{array}{l}1,39^{\mathrm{a}} \\
\pm 0,02\end{array}$ \\
\hline ES & $\begin{array}{c}35,58^{\mathrm{ab}} \\
\pm 0,05\end{array}$ & $\begin{array}{l}41,18^{f} \\
\pm 0,01\end{array}$ & $\begin{array}{l}41,07^{f} \\
\pm 0,02\end{array}$ & $\begin{array}{l}41,08^{f} \\
\pm 0,04\end{array}$ & $\begin{array}{c}35,76^{\mathrm{bc}} \\
\pm 0,02\end{array}$ & $\begin{array}{l}36,01^{\mathrm{c}} \\
\pm 0,17\end{array}$ & $\begin{array}{c}40,96^{\mathrm{ef}} \\
\pm 0,22\end{array}$ & $\begin{array}{l}40,62^{d} \\
\pm 0,10\end{array}$ & $\begin{array}{c}40,79^{\text {de }} \\
\pm 0,01\end{array}$ & $\begin{array}{c}35,49^{\mathrm{a}} \\
\pm 0,04\end{array}$ & $\begin{array}{l}35,48^{\mathrm{a}} \\
\pm 0,07\end{array}$ & $\begin{array}{c}35,76^{\text {bc }} \\
\pm 0,07\end{array}$ \\
\hline pH & $\begin{array}{l}6,53^{\text {gh }} \\
\pm 0,01\end{array}$ & $\begin{array}{l}6,45^{\text {ef }} \\
\pm 0,02\end{array}$ & $\begin{array}{r}6,35^{c} \\
\pm 0,01\end{array}$ & $\begin{array}{l}6,38^{\text {cd }} \\
\pm 0,01\end{array}$ & $\begin{array}{l}6,41^{\text {de }} \\
\pm 0,02\end{array}$ & $\begin{array}{c}6,30^{\mathrm{b}} \\
\pm 0,01\end{array}$ & $\begin{array}{l}6,25^{\mathrm{a}} \\
\pm 0,01\end{array}$ & $\begin{array}{l}6,53^{\text {gh }} \\
\pm 0,02\end{array}$ & $\begin{array}{l}6,49^{f g} \\
\pm 0,02\end{array}$ & $\begin{array}{l}6,55^{\mathrm{h}} \\
\pm 0,01\end{array}$ & $\begin{array}{l}6,34^{\mathrm{bc}} \\
\pm 0,02\end{array}$ & $\begin{array}{l}6,52^{g h} \\
\pm 0,02\end{array}$ \\
\hline
\end{tabular}

${ }^{*}$ Valores designados en la misma fila con la misma letra no son significativamente diferentes $(p<0,05)$

En ninguno de los casos se encuentran desviaciones mayores a $\pm 1 \%$ de ES, respecto al 36 y $41 \%$ que marca el diseño, por lo que los datos de partida se consideran adecuados para las posteriores elaboraciones de queso.

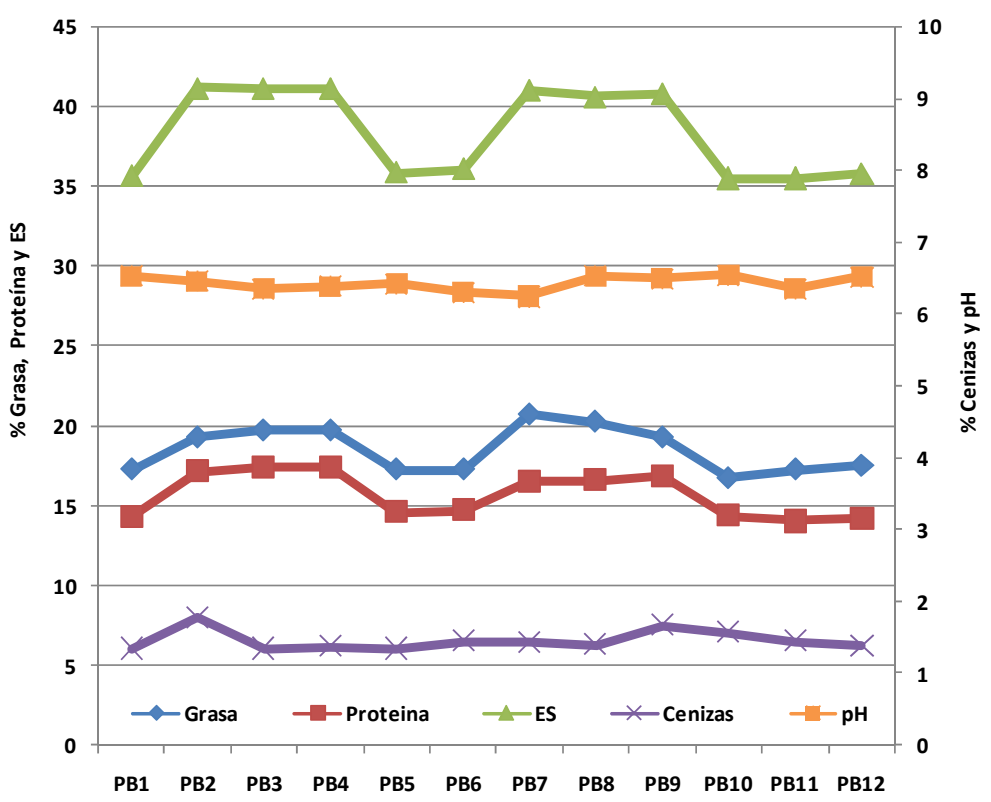

Figura 5.9. Composición química y pH de los retenidos de UF. Diseño Plackett-Burmann

En cuanto al contenido en cenizas, la diafiltración tiene un mayor efecto sobre la reducción de sales que la acidificación, ya que los experimentos en que se empleó diafiltración se agrupan en los niveles más bajos de cenizas. En el siguiente nivel se encuentran los experimentos en que se ultrafiltra la leche a un menor $\mathrm{pH}$, mientras que los de mayor concentración de cenizas se unen en 
varios grupos, correspondiente a la ultrafiltración sin diafiltración y al valor de pH normal de la leche.

Por su parte los valores de $\mathrm{pH}$ de los concentrados también difieren significativamente, dividiéndose en varios grupos muy interrelacionados. Aparecen dos tendencias, por un lado cuando la leche se filtró a su pH normal se obtuvieron valores entorno a $6,5 \mathrm{de} \mathrm{pH}$, mientras que en los que se disminuyó el pH inicial de la leche los concentrados se encontraban entorno a 6,3.

En este diseño los permeados no se analizaban ya que al diluirse con agua en las diafiltraciones, su composición real queda enmascarada.

\section{COMPOSICIÓN DE LOS QUESOS A LO LARGO DE LA MADURACIÓN}

Una vez completado el diseño, cuyos factores cubren las etapas de elaboración hasta la salida de prensa, se salan los quesos por inmersión en salmuera y se orean/maduran en condiciones controladas, durante 40 días, para proceder a su comparación.

Los datos de composición y pH a los 20 y 40 días de maduración para las 12 fabricaciones se recogen en la Tabla A.9 del Anexo A.2.

En la Figura 5.10 se representa la tendencia de las variables de composición y el pH para los distintos quesos, determinados a los 40 días de maduración. Se observan rangos estrechos para todas ellas con algún experimento puntual como PB5 con un exceso de sal $(\mathrm{NaCl})$, lo cuál se asocia principalmente a la variabilidad experimental.

En cuanto al extracto seco, los valores varían entre el 53 y $58 \%$ siguiendo una tendencia similar a la de grasa y proteína. Los valores tras el secado son apropiados para el tipo de queso a tratar, teniendo en cuenta que tanto en el queso, como en los retenidos, una proporción importante de la humedad está unida a las proteínas, no tratándose de agua libre (Maubois y Mocquot 1974).

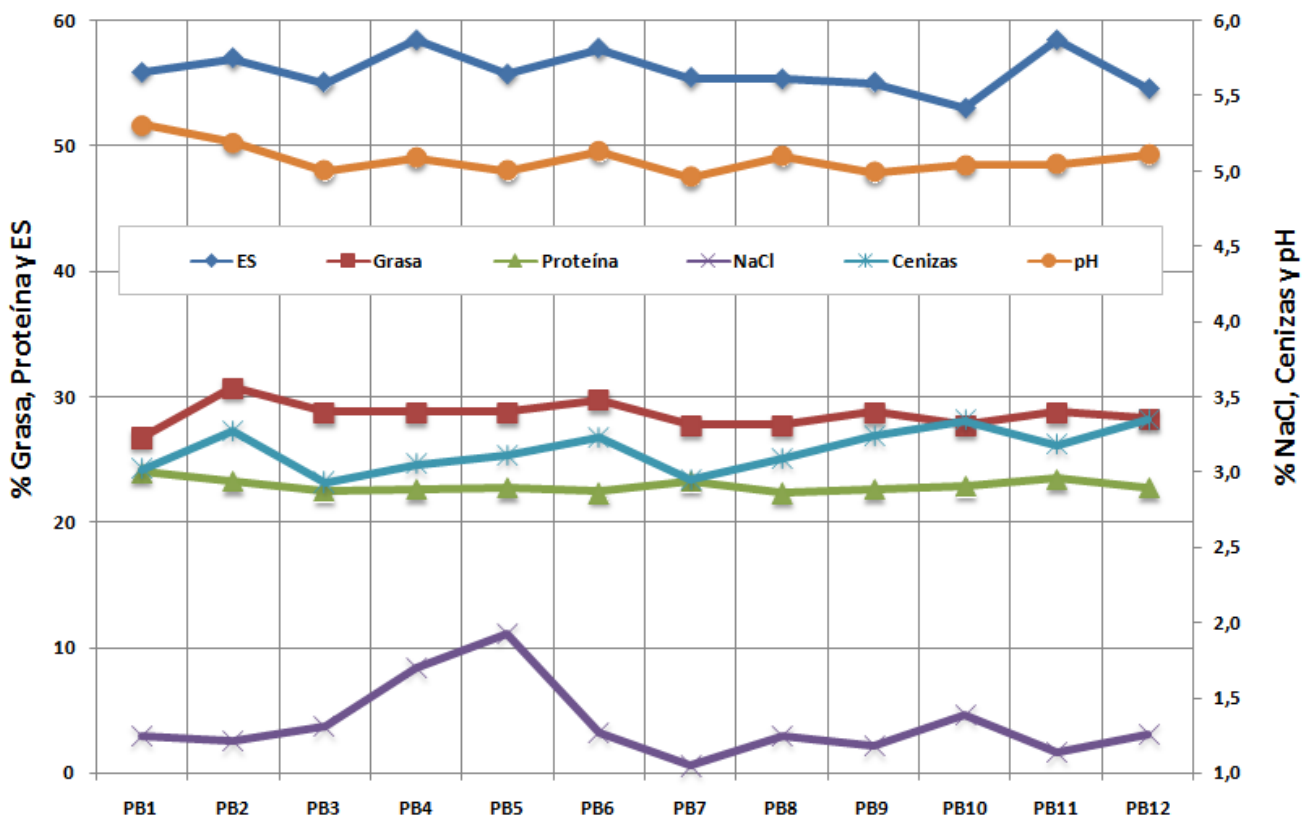

Figura 5.10. Composición de los quesos a los 40 días. Diseño Plackett-Burmann

Para estudiar el efecto de los ocho factores del diseño sobre la composición del queso, se resuelve dicho diseño (optimización) respecto a cada componente del ES y al pH. El análisis de los datos 
muestra que ninguno de los factores (o variables) afecta significativamente a la composición o al $\mathrm{pH}$.

En la Figura 5.11 se muestran los Diagramas de Pareto para los casos en que la respuesta, aún no viéndose afectada significativamente por los factores, muestra tendencias interesantes. En el primer caso se ve como el contenido en cenizas está en el límite para depender significativamente -a un $95 \%$ de probabilidad- por la diafiltración, apuntando que la ausencia de esta etapa aumenta el contenido en cenizas.

Así mismo, se muestra la optimización en cuanto a $\mathrm{pH}$, ya que será una variable importante a tener en cuenta en las futuras optimizaciones. Según los signos, concentraciones elevadas de fermento y tamaños de corte de la cuajada grandes favorecen la bajada final del $\mathrm{pH}$ a los 40 días de maduración.
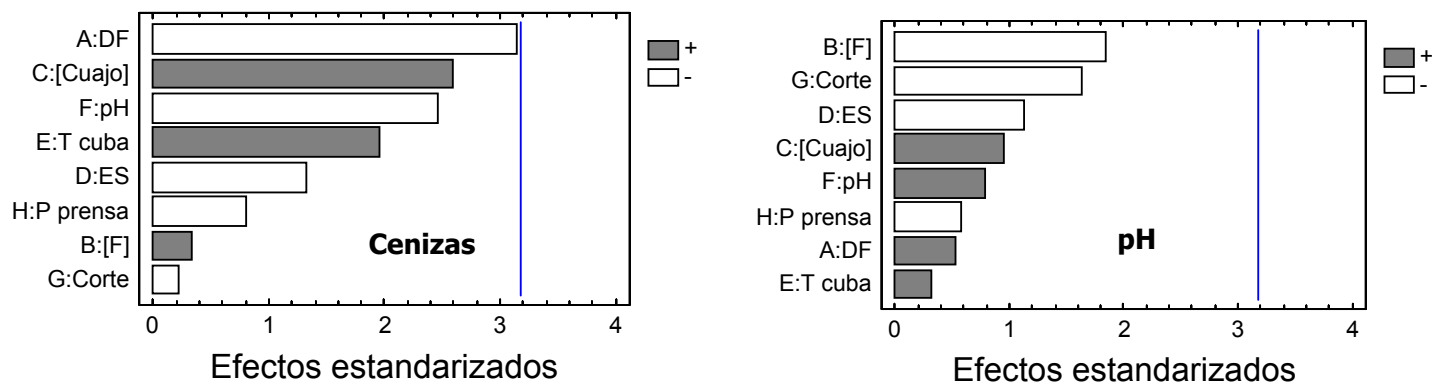

Figura 5.11. Optimización en cuanto a cenizas y pH. Diseño Palckett-Burmann

Debido al tipo de diseño y a la alta confusión que lleva asociado, los resultados no han de interpretarse como concluyentes, si no que serán tomados como puntos de partida para las investigaciones de los posteriores diseños. Este hecho habrá de tenerse en cuenta tanto en este estudio como en las siguientes resoluciones del presente diseño frente a los descriptores de textura y de la evaluación sensorial.

\subsubsection{ESTUDIO DE LA TEXTURA DEL QUESO}

El análisis de perfil de textura realizado a los quesos de las 12 fabricaciones, a los 40 días de maduración, proporciona una medida instrumental de propiedades como la firmeza, elasticidad, cohesividad, masticabilidad o adherencia de los distintos quesos. A continuación se realiza un análisis de cada una de ellas desde dos perspectivas. Por un lado se representa en gráficos circulares la magnitud de la propiedad obtenida en cada experimento. Por otro, mediante gráficos de Pareto, se observa el grado de significación de cada variable estudiada en el diseño sobre la propiedad de textura indicada en cada caso.

\section{FIRMEZA}

En la Figura 5.12 se muestran los valores de firmeza obtenidos en cada experimento, se observan valores similares para todos ellos (entorno a $10 \mathrm{~N}$ ) con excepción del experimento PB4 (corte pequeño y ES alto), que obtuvo una mayor puntuación. Ninguna de las variables resulta ser significativa respecto a esta propiedad, si bien se observa que para aumentar la firmeza del queso ayuda el tamaño de corte pequeño, presiones en prensa altas o elevadas dosis de cuajo filtrando la leche a su pH normal, para no desmineralizar la cuajada. 

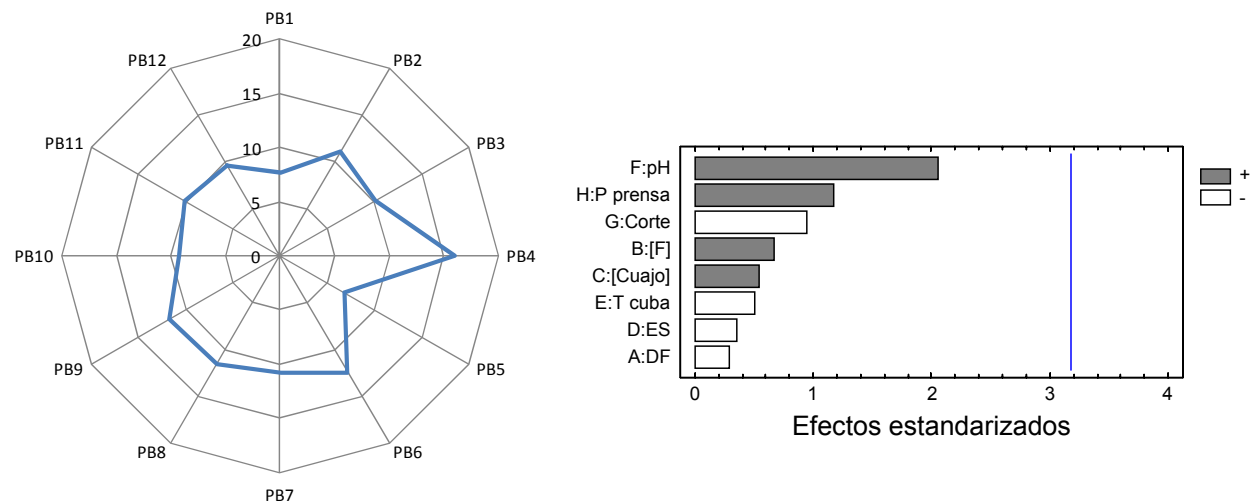

Figura 5.12. Medida de firmeza (N) y su significación en el diseño Plackett-Burmann

\section{ELASTICIDAD}

En los gráficos de elasticidad de la Figura 5.13 se aprecian pequeñas diferencias en cuanto a elasticidad para los distintos quesos. Optimizando el diseño respecto a esta respuesta, se observa que tanto el aumento en el extracto seco del concentrado como las concentraciones altas de cuajo conducen de forma significativa a una mayor elasticidad.
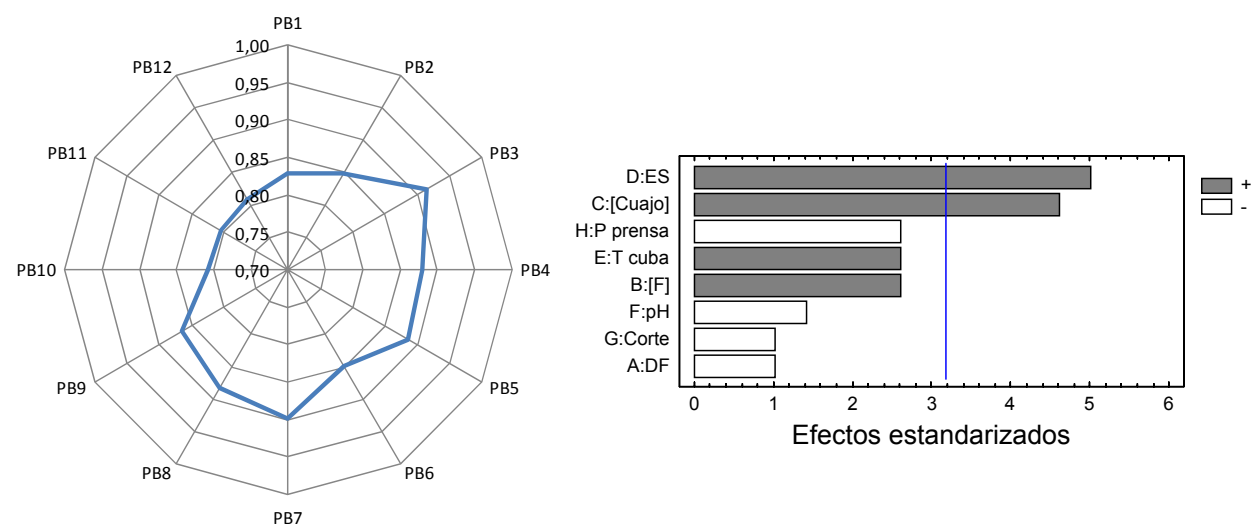

Figura 5.13. Medida de elasticidad y su significación en el diseño Plackett-Burmann

\section{ADHERENCIA}

En cuanto a la adherencia de los quesos, gráficos en Figura 5.14, ninguna variable resulta ser significativa. Atendiendo al signo de cada variable presiones bajas en la etapa de prensado, la no diafiltración o las concentraciones altas de fermento parecen aumentar la adherencia del queso.
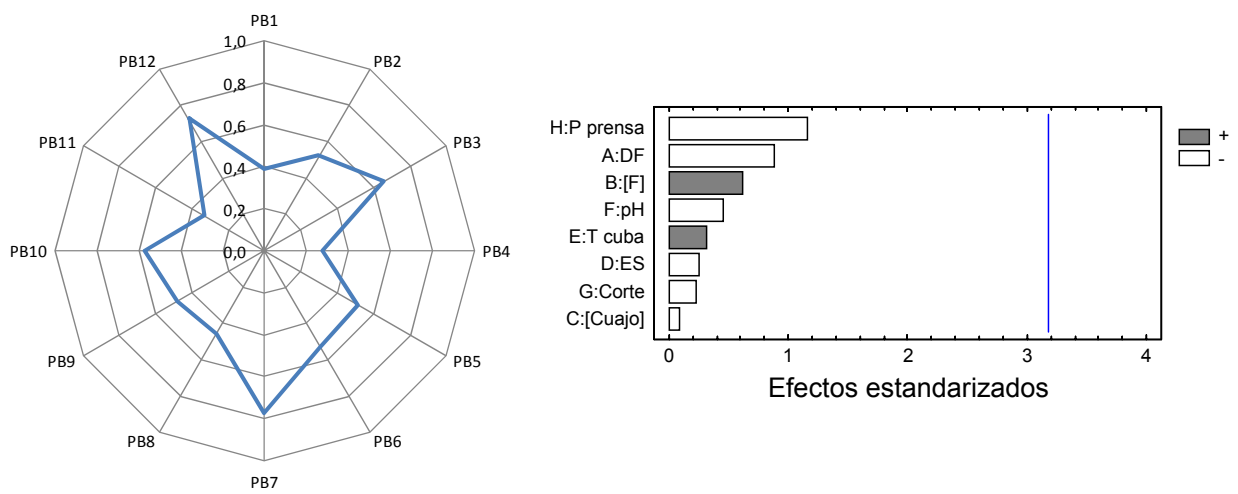

Figura 5.14. Medida de adherencia (N·s) y su significación en el diseño Plackett-Burmann 


\section{COHESIVIDAD}

Las fabricaciones PB10, PB11, PB12 y PB1 -coincidentes las 4 en que tienen ES bajo del concentrado-, al igual que sucedió con la firmeza y la elasticidad, resultan ser menos cohesivas que el resto. Respecto a los factores estudiados, el aumento del extracto seco del prequeso y de la concentración de cuajo aumentan la cohesividad del queso de manera significativa, al igual que la ultrafiltración de la leche previamente acidificada, como se observa en la Figura 5.15.
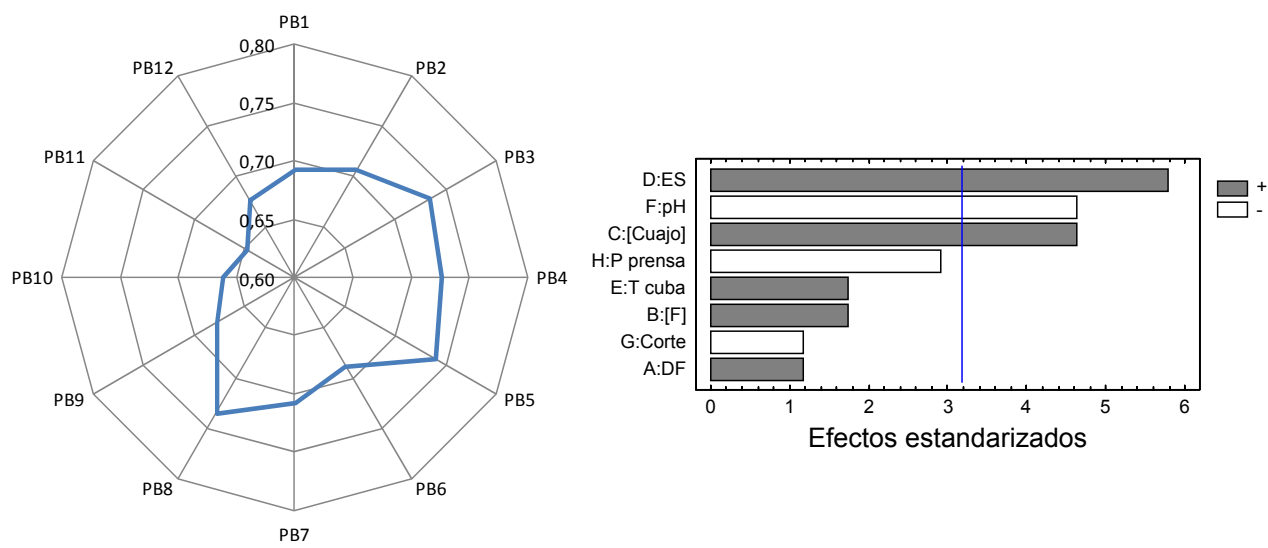

Figura 5.15. Medida de cohesividad y su significación en el diseño Plackett-Burmann

\section{MASTICABILIDAD}

En el estudio de la masticabilidad mostrado en la Figura 5.16, aunque a priori parece haber diferencias entre las fabricaciones, éstas no resultan ser significativas. Se observa que la masticabilidad aumenta con tamaños de corte pequeño, con concentraciones de cuajo elevadas o ultrafiltrando la leche a su pH normal.

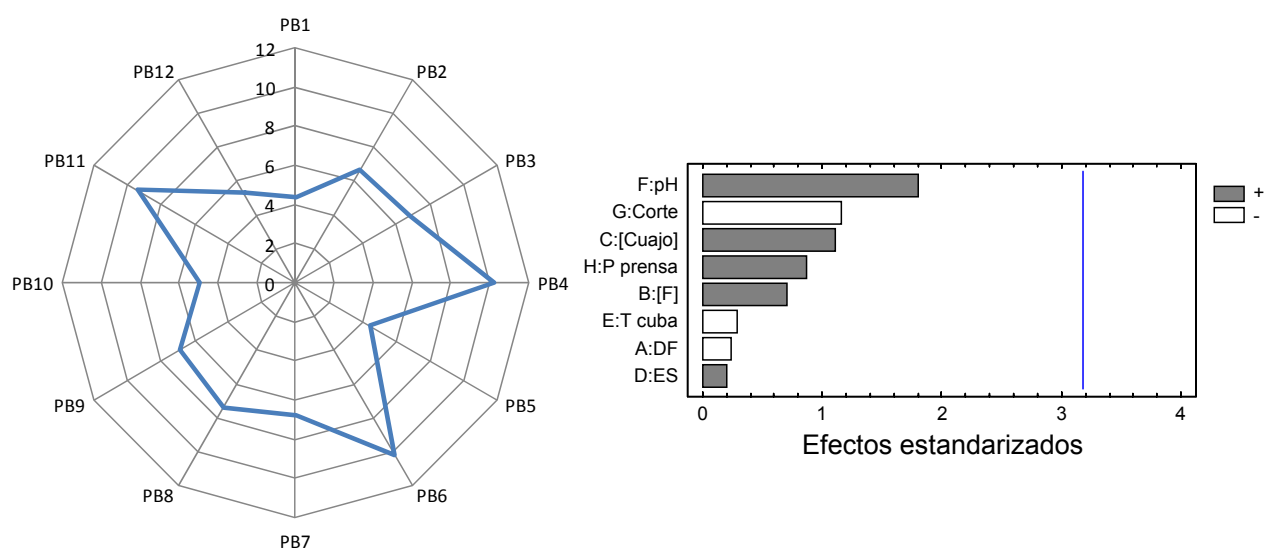

Figura 5.16. Medida de masticabilidad ( $\mathrm{N}$ ) y su significación en el diseño Plackett-Burmann

\subsubsection{ANÁLISIS SENSORIAL DE LOS QUESOS}

El estudio del efecto de los factores sobre la apreciación sensorial del queso, realizado por el panel de cata entrenado, se divide en dos fases:

r Sensación olfato-gustativa

c. Impresión visual 
Al final de ambas etapas se recoge una valoración global de todos los atributos caracterizados dentro de la etapa correspondiente. A raíz de ambas valoraciones se calcula la valoración global compuesta, recogida en la Tabla 5.5, a partir de la que se optimizará finalmente el diseño en el Apartado 5.2.6.

\section{SENSACIÓN OLFATO-GUSTATIVA}

La evaluación de la sensación olfato-gustativa se divide en cinco fases según los descriptores de olor, textura en mano, textura en boca, sensación generada en boca e identificación de sabores elementales.

\section{- Calidad e intensidad del olor}

En las gráficas de la Figura 5.17 se observan las puntuaciones obtenidas por cada queso respecto a la sensación olfativa percibida por el panel de cata, tanto en intensidad como calidad del mismo.

Las puntuaciones se mantienen por debajo de 4 en cuanto a la intensidad y por encima de cuatro respecto a la calidad del olor, en escala de 1 a 7.

Aparece como variable significativa en la calidad del olor el $\mathrm{pH}$ inicial de la leche, donde valores altos aumentan la respuesta. En cuanto a la intensidad del olor, esta cualidad se relaciona de forma significativa con el tamaño de corte de la cuajada, aumentando la intensidad a valores bajos de éste.
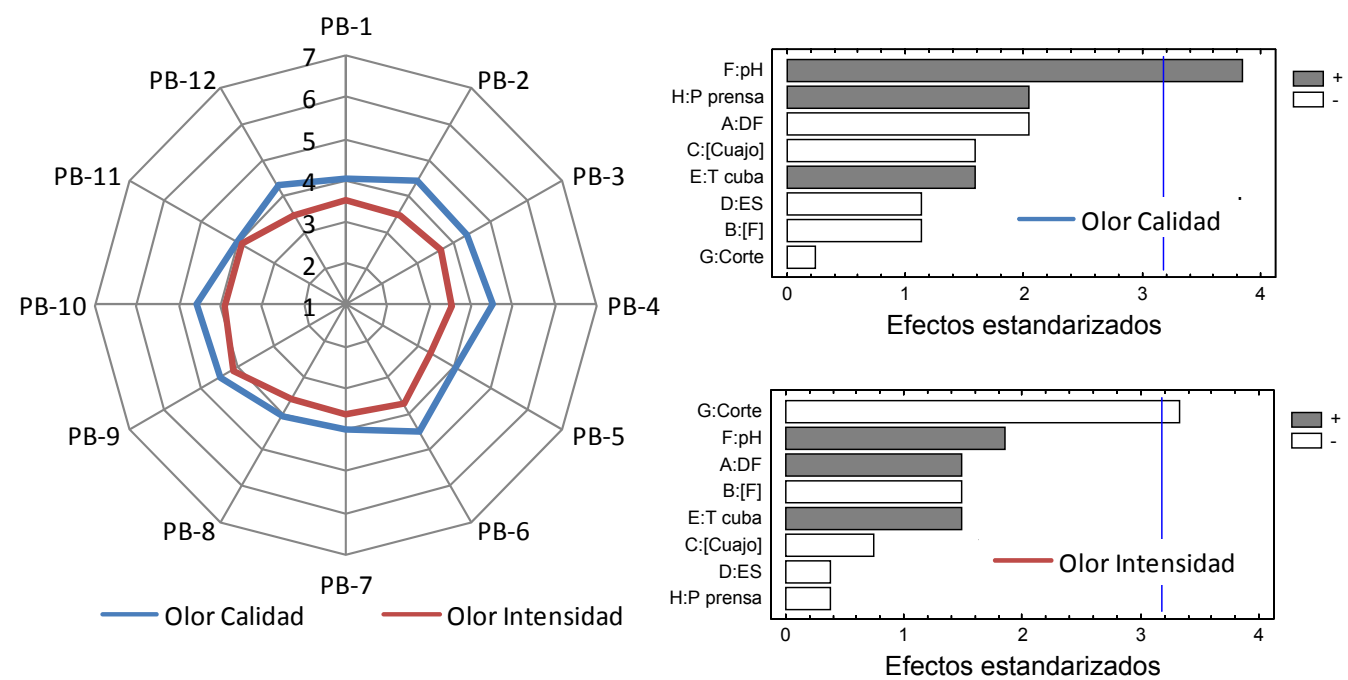

Figura 5.17. Puntuaciones de olor y su significación en el diseño Plackett-Burmann

\section{- Textura en mano: rugosidad, elasticidad y firmeza}

En cuanto a la evaluación táctil de la textura del queso, Figura 5.18, se observa que en todos los casos se trata de quesos poco rugosos (puntuación por debajo de 2), blandos y ligeramente elásticos.

Los rangos de valores para elasticidad y firmeza son similares a los obtenidos por Menéndez et al. (2000) al evaluar queso Arzúa-Ulloa mediante análisis descriptivo por panel de cata entrenado en escala 1-7. Esta similitud se mantiene a lo largo del resto de elaboraciones. 

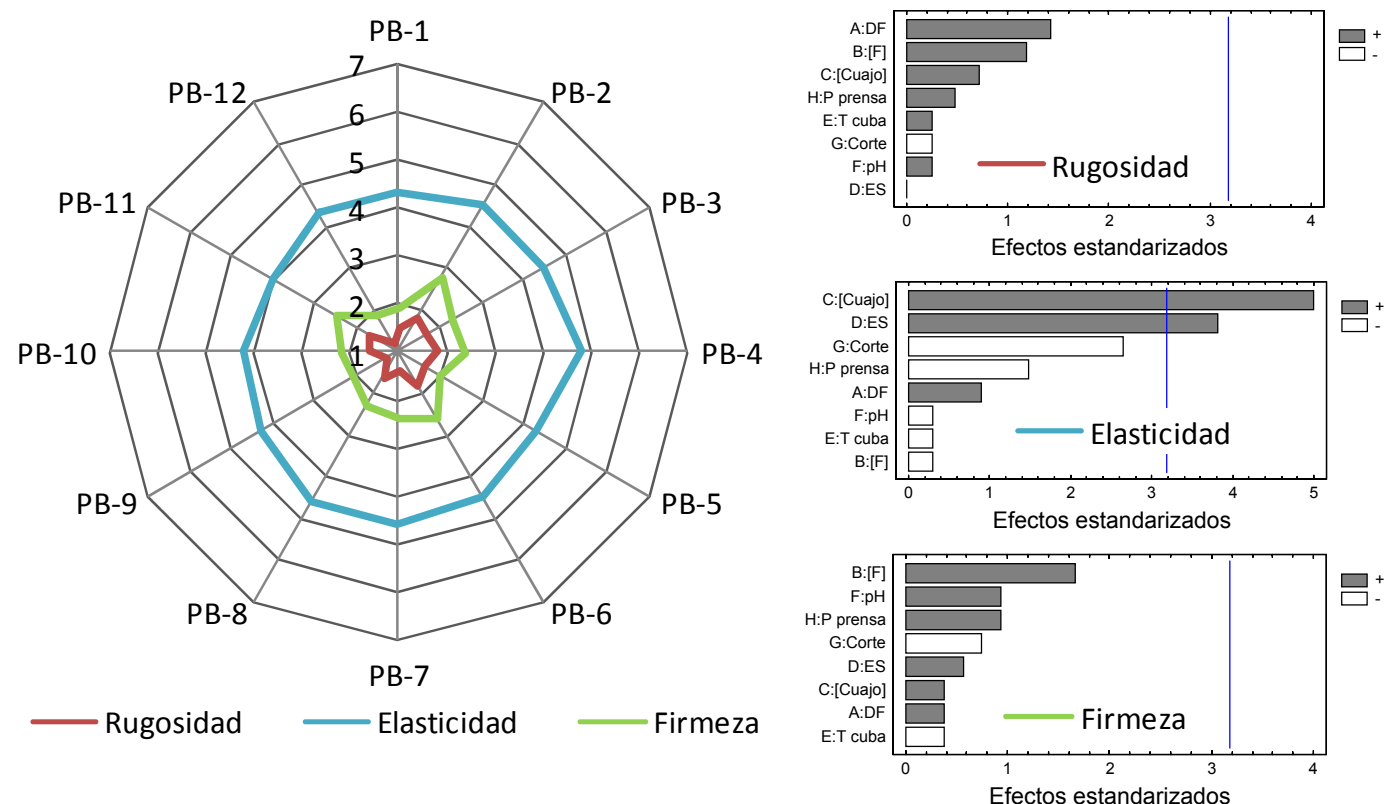

Figura 5.18. Puntuaciones de textura en mano y su significación en el diseño Plackett-Burmann

\section{- Textura en boca: friabilidad, adherencia, solubilidad, granulosidad y firmeza}

En cuanto a la textura se muestran a continuación en la Figura 5.19 las puntuaciones de los quesos y la significación de las variables en cuanto a friabilidad, adherencia, solubilidad, granulosidad y humedad del queso, evaluado en boca por el panel de cata.
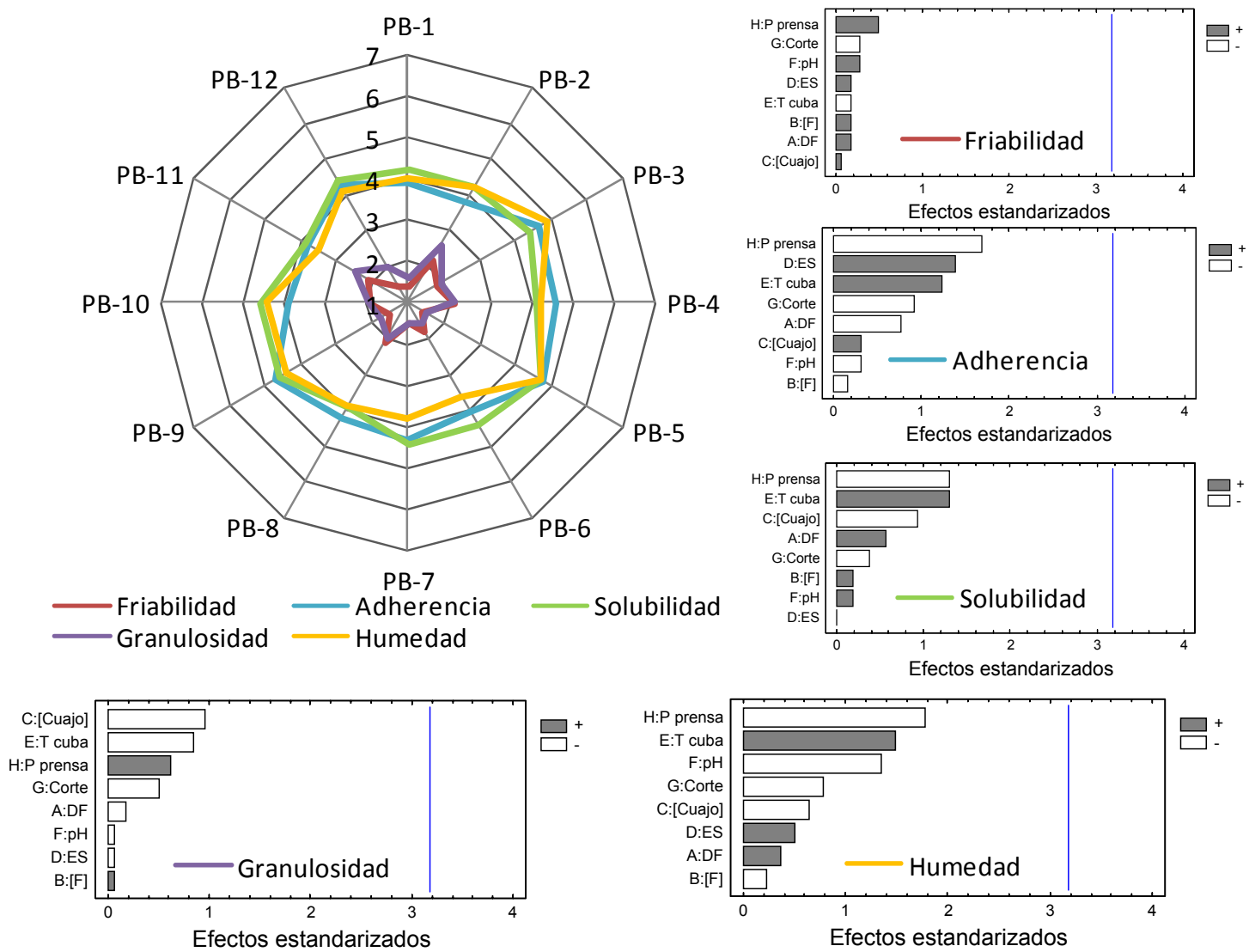

Figura 5.19. Puntuaciones de textura en boca y su significación en el diseño Plackett-Burmann 
Se observa que todos ellos son quesos muy poco friables y de muy baja granulosidad (puntuaciones entorno a 2), algo adherentes, de buena solubilidad y humedad media. En cuanto a la significación de las variables del diseño, ninguno de los atributos sensoriales aparece influenciado significativamente por ellas.

\section{- Sensación en boca: intensidad y calidad del sabor, regusto y persistencia}

En cuanto a la sensación en boca, en la Figura 5.20 se recogen las puntuaciones referentes a la sensación inicial de intensidad y calidad del sabor, así como las sensaciones finales de regusto y persistencia del sabor en el queso.

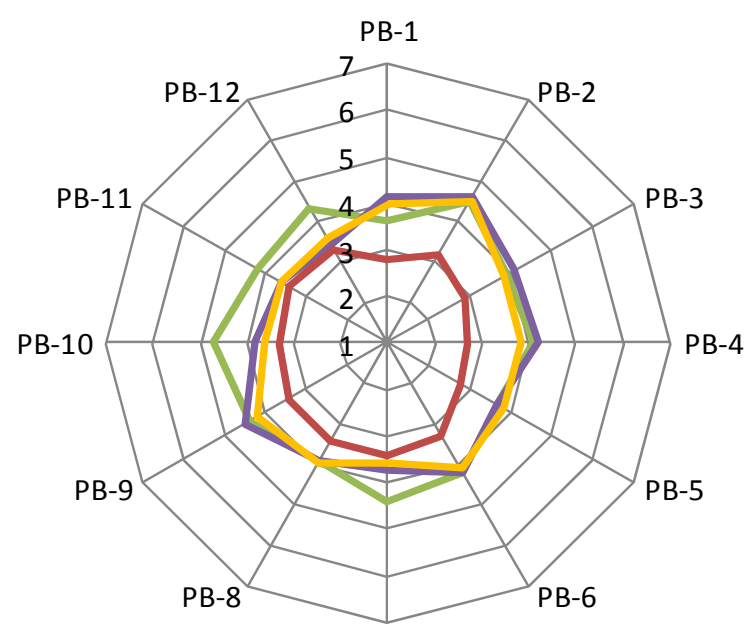

PB-7
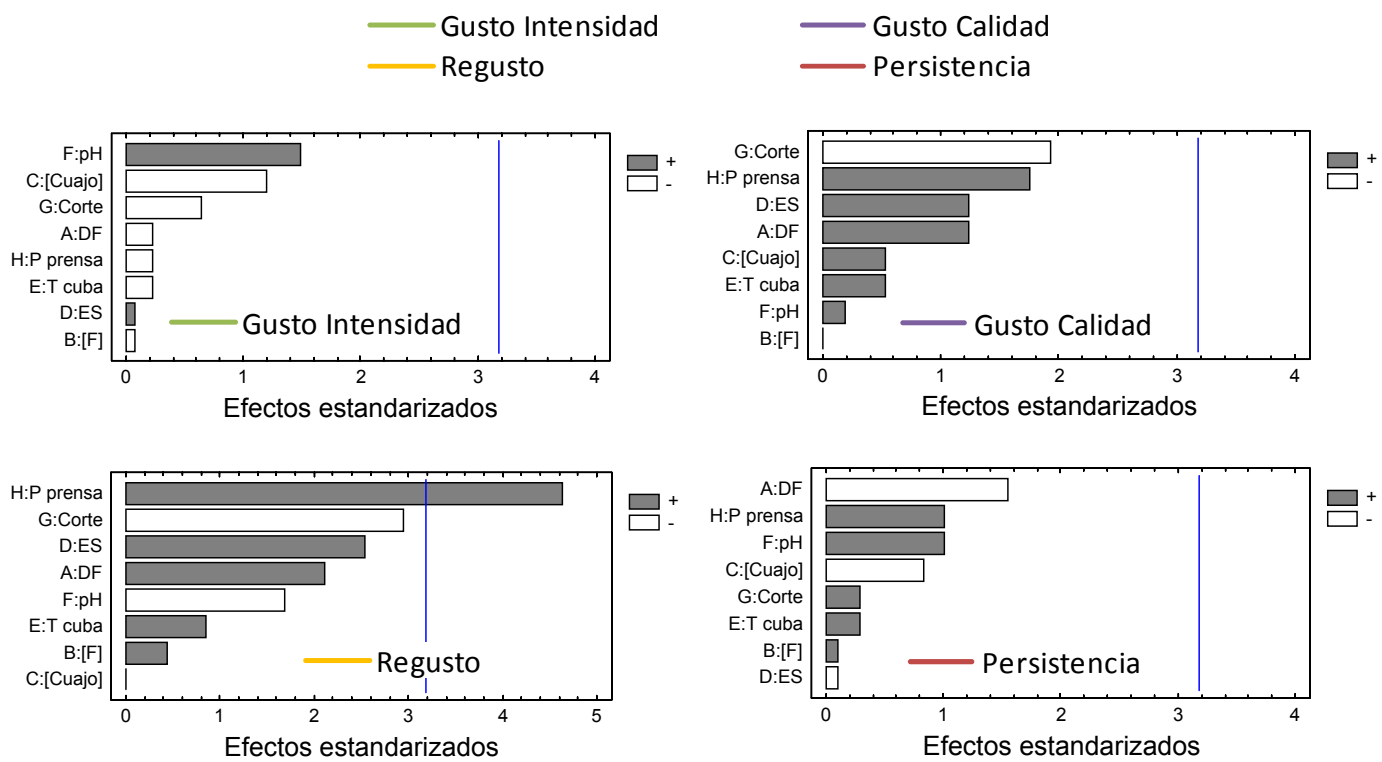

Figura 5.20. Puntuaciones de la sensación en boca y su significación en el diseño Plackett-Burmann

Analizando la calidad e intensidad del sabor se detallan puntuaciones medias para ambas sensaciones (entorno a 4) con distribución más homogénea para la intensidad. El regusto resultó ser puntuado muy similar a la calidad, mientras que la persistencia en general es baja (valores por debajo de 4), como corresponde al tipo de queso estudiado.

La única variable que aparece como significativa es la presión en prensa, aumentando el regusto del queso cuando está en su rango alto. 


\section{- Sabor: salado, ácido y amargo}

Se estudiaron los tres sabores más frecuentes para este tipo de queso: salado, ácido y amargo, cuyas puntuaciones y significación se recogen en la Figura 5.21.

El sabor amargo ha sido identificado en todos los casos como muy bajo o despreciable (por debajo de 2), mientras que la sensación salada aparece ligeramente (valores por debajo de 4) lo que hace considerar aceptable la etapa de salado para este tipo de quesos. Por otro lado, la sensación de acidez aparece claramente en alguno de los quesos (valores de 4).

Ninguna variable llega a ser significativa sobre los sabores, si bien en cuanto a la acidez las presiones bajas parecen favorecer el incremento de la sensación percibida, sin aparecer claramente identificada la relación entre la concentración de fermento y la acidez.
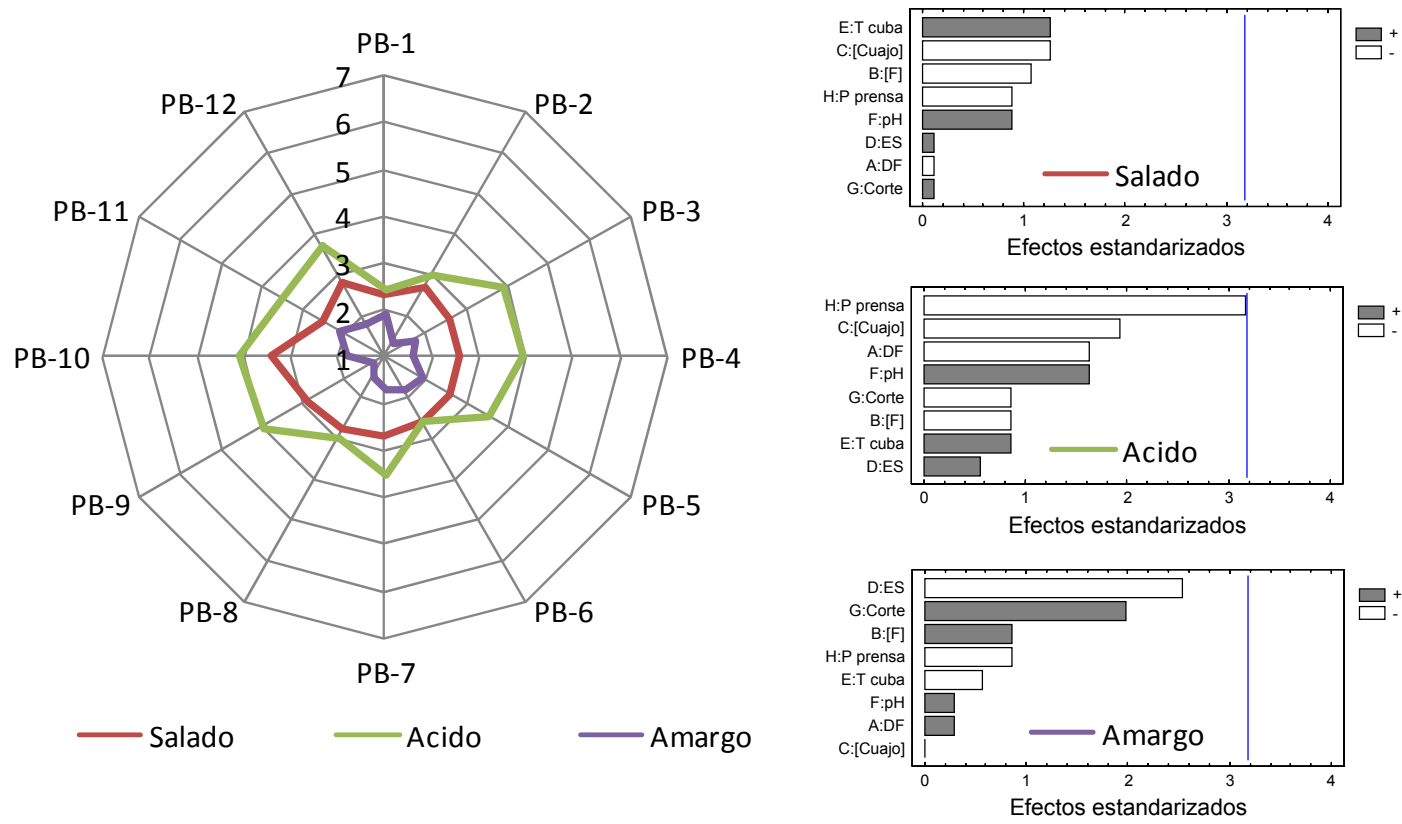

Figura 5.21. Puntuaciones de sabor y su significación en el diseño Plackett-Burmann

\section{VALORACIÓN VISUAL}

El aspecto exterior e interior del queso se representan conjuntamente, sus puntuaciones se recogen en la Figura 5.22. La valoración del aspecto exterior se realiza en cuanto a homogeneidad de forma/color. El aspecto interior se evalúa por un lado al corte en cuanto a la homogeneidad de pasta/color y por otro lado en cuanto a la valoración de los ojos mecánicos (número/forma/distribución) o aberturas.

En cuento al aspecto exterior de los quesos la aceptación general es buena (valores entre 5 y 6 ) no apareciendo factores significativos, en su variación, si bien aumentan la puntuación concentraciones altas de cuajo, presiones elevadas en la etapa de prensado o la ausencia de etapa de diafiltración.

La valoración es aceptable para el aspecto interior al corte (puntuaciones entre 4 y 5), sin encontrarse ninguna variable significativa para la respuesta. Por último, la valoración de las aberturas es desigual entre la aceptación y el ligero defecto, debido a la presencia de agujeros en algunos de los quesos, atribuibles a la mala fusión de los granos de cuajada; las puntuaciones 
mayores se obtienen, de manera significativa, cuando se ultrafiltra a un $\mathrm{pH}$ menor del de la propia leche.

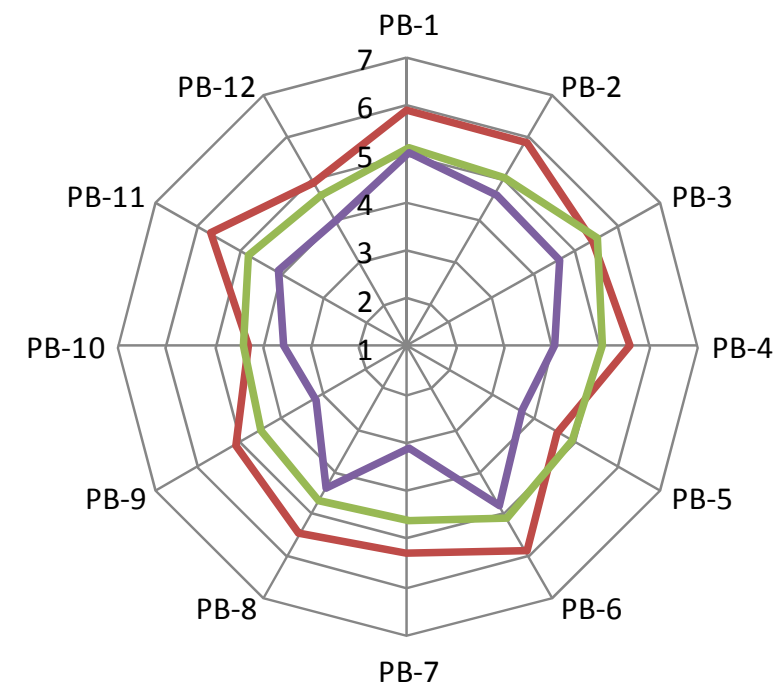

- Aspecto Exterior
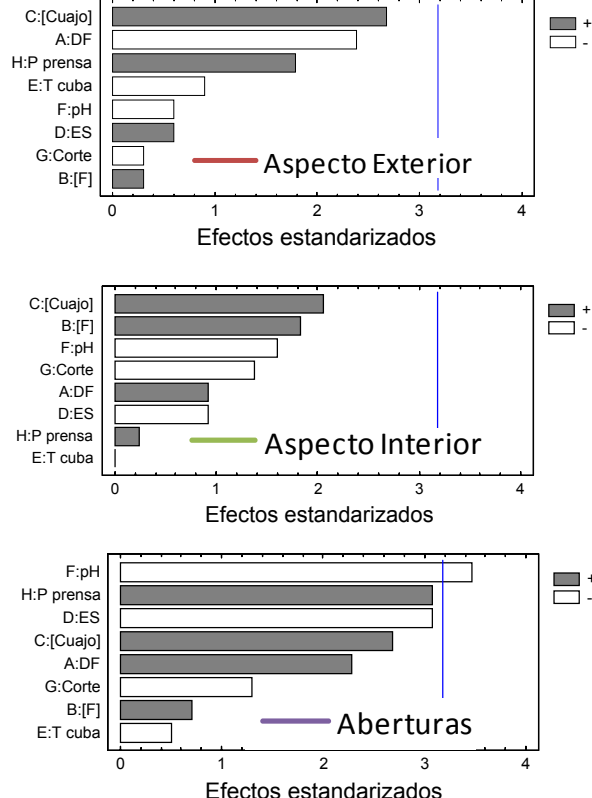

Figura 5.22. Puntuaciones fase visual y su significación en el diseño Plackett-Burmann

\section{VALORACIONES GLOBALES}

Por último, se puntuaba de forma global la valoración de los catadores respecto a ambas fases: olfato-gustativa y visual (Figura 5.23).
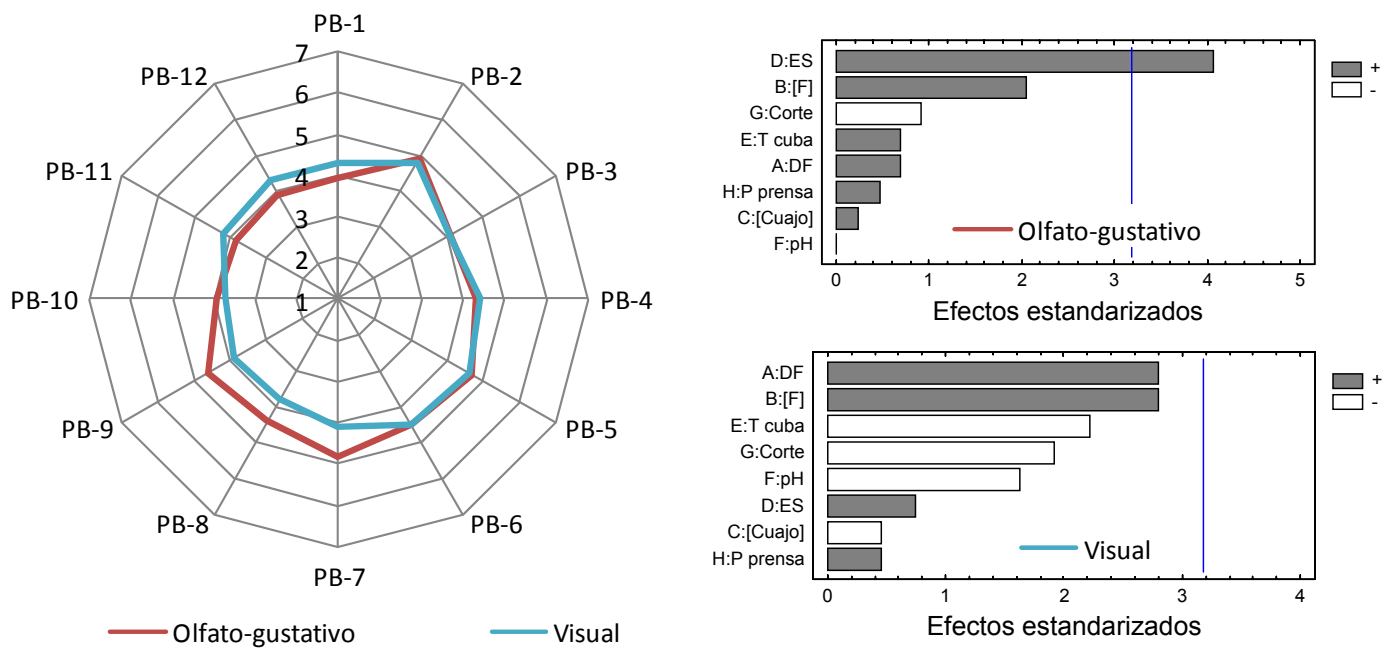

Figura 5.23. Puntuaciones globales y su significación en el diseño Plackett-Burmann

Las puntuaciones según la impresión global olfato-gustativa en esta primera optimización demuestran que los quesos, en general, son aceptables (valores entorno a 4), si bien deberá mejorarse en las posteriores etapas. Como significativo aparece el efecto del extracto seco del concentrado, el cual maximiza la valoración global olfato-gustativa en su nivel alto. 
En cuanto a la fase visual, las puntuaciones son similares a las anteriores. En algunos casos se obtienen puntuaciones menores (PB7, PB8 y PB9) lo que puede ser debido a la presencia de oquedades de gran tamaño en la pasta del queso como consecuencia de la deficiente fusión de los granos de cuajada, como se observa en las fotografías de estos quesos que se muestran en el Anexo 1.4 (Figura A.2). En este caso ninguna variable aparece como significativa.

\subsubsection{EVOLUCIÓN DEL PH A LO LARGO DE LAS ELABORACIONES}

La evolución del pH es un parámetro clave en la elaboración de cualquier tipo de queso -con especial interés de la cinética de acidificación producida durante el prensado- por sus efectos directos sobre la calidad y seguridad del producto. A continuación se presenta el seguimiento del $\mathrm{pH}$ en las 12 fabricaciones llevadas a cabo en el diseño (Figura 5.24).

Se aprecian inicialmente dos grandes grupos, por un lado las filtraciones realizadas al $\mathrm{pH}$ normal de la leche (PB1, PB2, PB8, PB9, PB10 y PB12) que parten de un pH inicial de 6,55. Por otro las realizadas a un $\mathrm{pH}$ inferior (PB3, PB4, PB5, PB6, PB7 y PB11) se agrupan entorno a valores de $\mathrm{pH}$ de 6,35 .

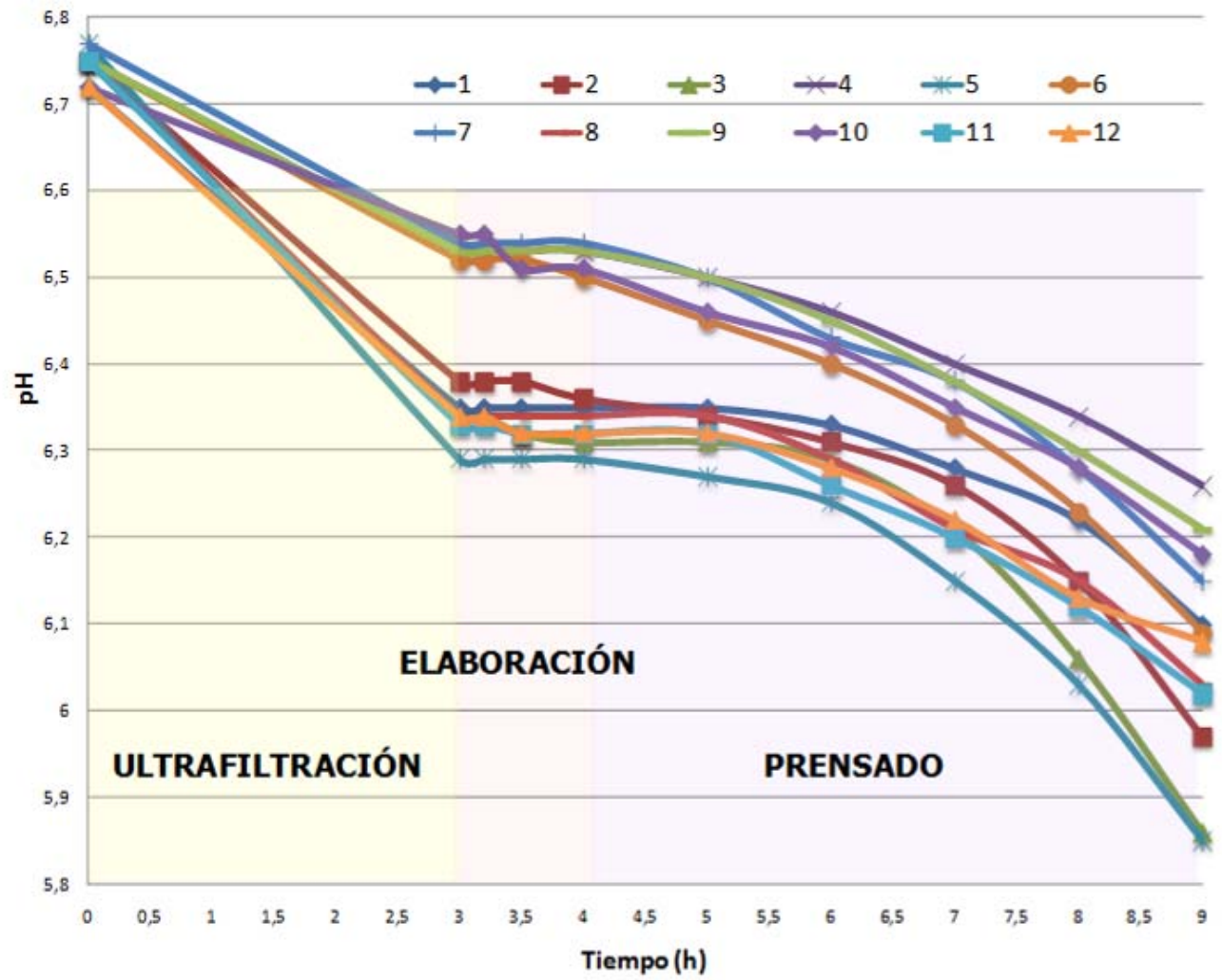

Figura 5.24. Evolución del pH en las fabricaciones del diseño Plackett-Burmann

La etapa de prensado, para todos los quesos, tuvo una duración total de 5 horas. El pH final de los quesos oscila entre valores de 6,2 y 5,9 dependiendo, de forma significativa, tanto del pH inicial del concentrado -aumentando a pH inicial alto- como de la concentración de fermento inoculada -aumentando a concentraciones pequeñas-, como muestra el gráfico de Pareto de la Figura 5.25.

Se observa que, debido al alto poder tampón de los concentrados, el pH final del queso a la salida de prensa es elevado, respecto al valor de 5,15-5,30 que debería tener el tipo de queso estudiado. 


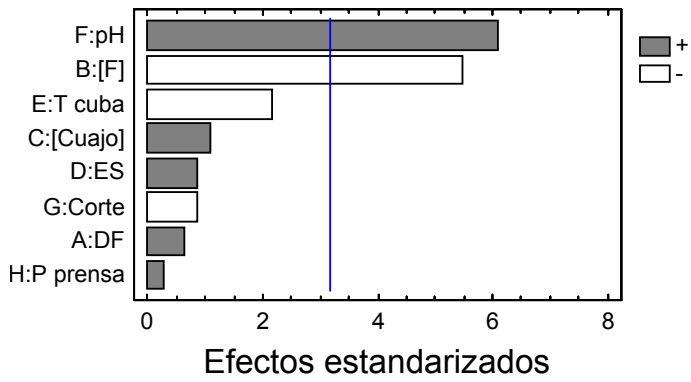

Figura 5.25. Significación de las variables sobre el pH a la salida de prensa. Diseño Plackett-Burmann

\subsubsection{OPTIMIZACIÓN DEL DISEÑO}

Si bien ya se ha determinado como afectan los factores de estudio a distintos cualidades sensoriales y de textura del queso, la optimización final para la elección de las condiciones de elaboración se realiza en base al rendimiento y al análisis sensorial global, según los valores de ambas respuestas que se recogen en la Tabla 5.5.

\section{RENDIMIENTO CORREGIDO}

En los datos de rendimiento recogidos de la Tabla 5.5 se observa un rango amplio de valores, que oscilan entre 12,6 y $15,2 \mathrm{~kg}$ por cada $100 \mathrm{~kg}$ de leche inicial. Estas diferencias se deben a que en la etapa de corte y prensado algunos de los quesos pierden una cantidad considerable de lactosuero, y con él parte de la grasa y la proteína soluble que se pretenden retener en el queso.

En la optimización del rendimiento aparecen como variables significativas el tamaño de corte de la cuajada y el pH inicial de la leche en la etapa de ultrafiltración, mostrando $\mathrm{p}$-valor $<0,05$ según los datos de la Tabla 5.8. En ella se recoge mediante un análisis de varianza (ANOVA) la contribución de cada factor a la variabilidad de los resultados y se compara con el error experimental (F-ratio).

Tabla 5.8. Datos del ANOVA y coeficientes de la regresión para rendimiento, diseño Plackett-Burmann ( $\mathrm{SC}=$ suma de cuadrados, $\mathrm{GL}=$ grados de libertad, $\mathrm{MC}=$ cuadrados medios)

\begin{tabular}{|c|c|c|c|c|c|c|c|}
\hline Fuente & SC & $\mathbf{G L}$ & MC & F-ratio & p-valor & \multirow{2}{*}{\multicolumn{2}{|c|}{$\begin{array}{c}\text { Coeficientes de la } \\
\text { regresión }\end{array}$}} \\
\hline A:DF & 0,224 & 1 & 0,224 & 2,31 & 0,226 & & \\
\hline$B:[F]$ & 0,105 & 1 & 0,105 & 1,08 & 0,376 & constante & $-3,60$ \\
\hline C:[Cuajo] & 0,048 & 1 & 0,048 & 0,5 & 0,532 & A:DF & $-0,01$ \\
\hline D:ES & 0,001 & 1 & 0,001 & 0,01 & 0,932 & $B:[F]$ & $-0,09$ \\
\hline E:T & 0,276 & 1 & 0,276 & 2,84 & 0,190 & C:[Cuajo] & 0,01 \\
\hline F:pH & 1,936 & 1 & 1,936 & 19,94 & 0,021 & D:ES & 0,00 \\
\hline G:Corte & 6,601 & 1 & 6,601 & 67,98 & 0,004 & E:T & $-0,06$ \\
\hline$H: P$ & 0,001 & 1 & 0,001 & 0,01 & 0,932 & F:pH & 2,68 \\
\hline Error Total & 0,291 & 3 & 0,097 & & & G:Corte & 0,99 \\
\hline Total & 9,482 & 11 & & & & H:P & $-0,01$ \\
\hline
\end{tabular}

La Figura 5.26 muestra el Diagrama de Pareto -que confirma los datos del ANOVA- y la evolución del rendimiento en la región estudiada, en función de las dos variables significativas. En la gráfica 
de superficie respuesta se observa como el tamaño de corte afecta en mayor medida (mayor pendiente) presentándose como una variable susceptible de futuras optimizaciones.
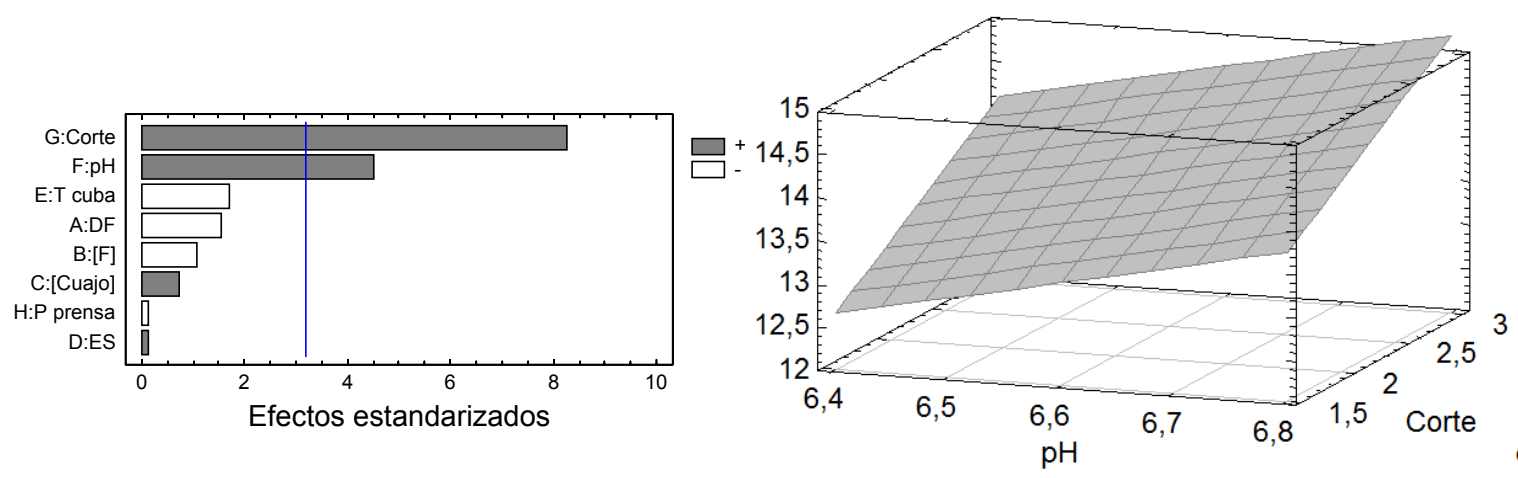

Figura 5.26. Optimización del rendimiento. Diseño Plackett-Burmann

En resumen, el rendimiento es máximo cuanto más grande se corte la cuajada y ultrafiltrando la leche a su pH normal, sin la etapa previa de acidificación. La dirección del resto de los factores, rango alto $(+)$ o rango bajo $(-)$, se puede observar siguiendo el código de colores de los Diagramas de Pareto.

\section{ACEPTACIÓN SENSORIAL GLOBAL}

En la aceptación sensorial global del queso, Figura 5.27, aparecen como variables significativas por un lado el extracto seco del concentrado y por otro la concentración de fermento. Ambas variables maximizan la valoración sensorial en sus niveles altos. En el gráfico de superficie respuesta se puede observar el plano que genera la puntuación sensorial al variar estas dos variables dentro del rango de niveles estudiados.
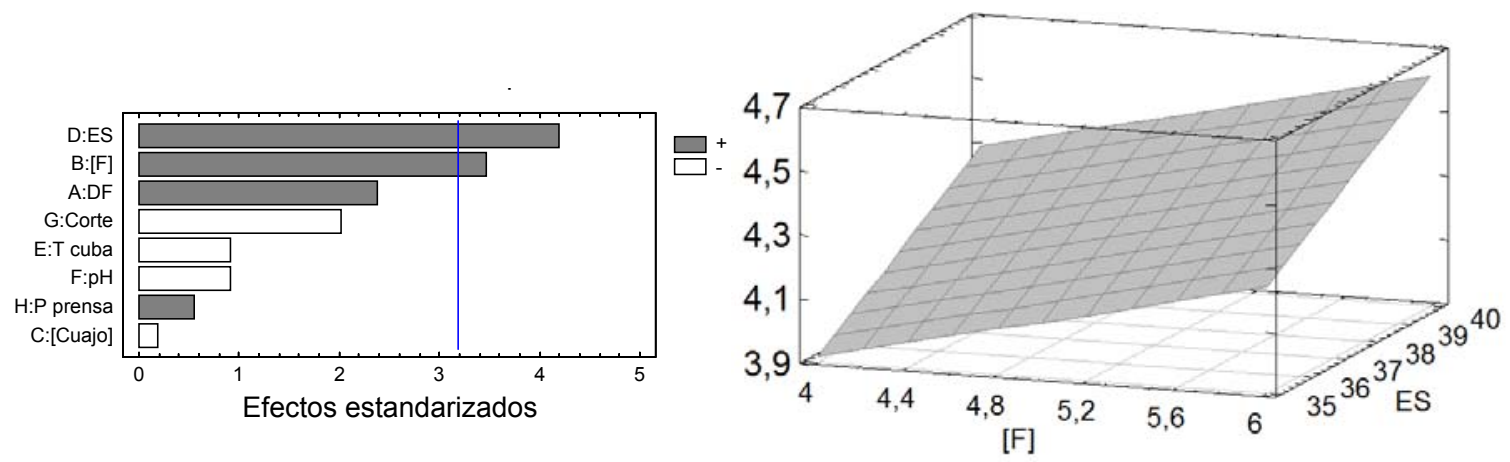

Figura 5.27. Optimización de la calidad sensorial. Diseño Plackett-Burmann

La Tabla 5.9 recoge los datos del ANOVA para la evaluación sensorial, donde se comprueba la significación de los dos factores indicada en el párrafo previo. También se recogen, como para el rendimiento, los coeficientes de la regresión que modelan el diseño y por los que se debe multiplicar el valor que tome cada factor (dentro del rango alto y bajo establecido) para predecir el valor de la variable respuesta (en el caso de factores categóricos se introducen los valores $+1 /-1$ ). 
Tabla 5.9. Datos del ANOVA y coeficientes de la regresión para calidad sensorial, diseño Plackett-Burmann ( $\mathrm{SC}=$ suma de cuadrados, $\mathrm{GL}=$ grados de libertad, $\mathrm{MC}=$ cuadrados medios)

\begin{tabular}{c|ccccc} 
Fuente & SC & GL & MC & F-ratio & p-valor \\
\hline A:DF & 0,141 & 1 & 0,141 & 5,57 & 0,099 \\
B:[F] & 0,301 & 1 & 0,301 & 11,90 & $\mathbf{0 , 0 4 1}$ \\
C:[Cuajo] & 0,001 & 1 & 0,001 & 0,03 & 0,868 \\
D:ES & 0,441 & 1 & 0,441 & 17,44 & $\mathbf{0 , 0 2 5}$ \\
E:T & 0,021 & 1 & 0,021 & 0,82 & 0,431 \\
F:pH & 0,021 & 1 & 0,021 & 0,82 & 0,431 \\
G:Corte & 0,101 & 1 & 0,101 & 3,99 & 0,140 \\
H:P & 0,008 & 1 & 0,008 & 0,30 & 0,624 \\
Error Total & 0,076 & 3 & 0,025 & & \\
\hline Total & 1,11 & 11 & & &
\end{tabular}

\begin{tabular}{|c|c|}
\hline \multicolumn{2}{|c|}{$\begin{array}{c}\text { Coeficientes de la } \\
\text { regresión }\end{array}$} \\
\hline constante & 3,21 \\
\hline A:DF & 0,01 \\
\hline B:[F] & 0,16 \\
\hline C:[Cuajo] & 0,00 \\
\hline D:ES & 0,08 \\
\hline E:T & $-0,02$ \\
\hline F:pH & $-0,28$ \\
\hline G:Corte & $-0,12$ \\
\hline H:P & 0,03 \\
\hline
\end{tabular}

\section{OPTIMIZACIÓN MÚLTIPLE}

Para fijar, simultáneamente, las condiciones de todas las variables se realiza una optimización de respuesta múltiple del diseño, en cuanto a rendimiento y valoración sensorial global. Los datos obtenidos se recogen en la Tabla 5.10.

Estos valores servirán para establecer las condiciones óptimas iniciales de elaboración del queso ultrafiltrado. Las optimizaciones individuales previamente realizadas de rendimiento y calidad sensorial, sirven para identificar futuras variables importantes en el proceso de optimización.

Tabla 5.10. Optimización de respuesta múltiple para el diseño Plackett-Burman

\begin{tabular}{|c|c|c|}
\hline VARIABLE & Óptimo & Unidades \\
\hline Etapa de Diafiltración (DF) & 0 & $\%$ de agua/leche de partida \\
\hline $\mathrm{pH}$ inicial de la leche filtrada & 6,7 & Unidades de $\mathrm{pH}$ \\
\hline Extracto seco del concentrado & 41 & $\%$ \\
\hline Cantidad de fermento & 6 & $\mathrm{DCU} / 100 \mathrm{~L}$ de concentrado \\
\hline Concentración de cuajo & 30 & $\mathrm{~mL} / 100 \mathrm{~L}$ de concentrado \\
\hline Temperatura de cuajado & 32 & oC \\
\hline Tamaño de corte de la cuajada & 3,0 & $\mathrm{~cm}$ de haz de lira \\
\hline Presión de prensado & $-1(2,5 / 2,0)$ & bar \\
\hline
\end{tabular}

Estas condiciones óptimas, aplicando el modelo, conducen a los siguientes valores de ambas respuestas:

c. Rendimiento $=15,2 \%$

c. Puntuación sensorial global compuesta $=4,4$ 
Estos datos obtenidos mediante el modelo se comparan con los resultados experimentales en el Apartado 5.5.9, donde se elabora queso por la tecnología tradicional y se compara con el obtenido bajo las condiciones establecidas en la Tabla 5.10.

\subsubsection{CONCLUSIONES DEL DISEÑO}

En el Anexo A.4 (Figuras A.1 y A.2) se muestran fotografías del aspecto exterior y al corte de las 12 elaboraciones realizadas en el curso de este diseño experimental, tomadas de los quesos a los 40 días de maduración.

Por último, una vez optimizado el diseño, se recoge en el Anexo A.3 (Tabla A.17) un resumen de los resultados obtenidos en la evaluación instrumental de la textura y en los descriptores del análisis sensorial, junto al rendimiento, comparándolos con las condiciones óptimas. En la fila "porcentaje de coincidencias" se recoge el número de veces que cada factor en su nivel óptimo (Tabla 5.10) coincide con el nivel obtenido de cada resolución individual (de textura y sensorial). En la fila de "\% de coincidencias significativas" se incorpora el porcentaje en el que los descriptores que fueron significativos en su evaluación individual coinciden con el valor óptimo de cada factor.

Mediante el estudio físico-químico, de textura y sensorial realizado en los Apartados 5.2.2, 5.2.3 y 5.2.4 se obtiene información detallada de cómo la variación de cada uno -o varios- de los factores analizados en este diseño puede afectar a una característica específica del queso, como su ES, firmeza, elasticidad, gusto, olor, acidez, etc. Del estudio del conjunto de descriptores se extrae la siguiente información sobre cada uno de los factores:

r. Diafiltración al $14 \%$ (A)

Esta variable no ha resultado significativa sobre ninguna de las respuestas estudiadas. El reparto entre ellas ha sido equilibrado; en un $40,6 \%$ de los casos se eligió el nivel bajo (ausencia de etapa de diafiltración) para optimizar el diseño. En la optimización final la ausencia de diafiltración aumenta los rendimientos pero disminuye la valoración sensorial, si bien de manera no significativa respecto a ambas respuestas.

Por todo ello su elección es complicada, si bien se opta por la eliminación de esta etapa -de acuerdo con la optimización múltiple- ya que simplifica el proceso de filtrado y, consecuentemente, tendrá una repercusión positiva en el coste operacional. En cuanto a los trabajos encontrados en la bibliografía para elaborar quesos similares al estudiado en esta Tesis, son muchos los casos en los que se emplea la diafiltración, con porcentajes de agua similares, para reducir el contenido en lactosa y tener una mejor regulación del pH final (Covacevich y Kosikowski 1978; Ernstrom et al. 1980; McGregor y White 1990b; Spangler et al. 1991; Guinee et al. 1995).

\section{c Disminución del pH inicial de la leche antes de la ultrafiltración (F)}

En cuanto a la incorporación de una etapa previa para disminuir el $\mathrm{pH}$ de la leche a valores próximos a 6,4 antes de la ultrafiltración, según los resultados de optimización múltiple no resulta necesaria su inclusión. Con respecto al total de parámetros o descriptores estudiados en la caracterización de los quesos, en un 58,6 \% de los casos los estudios aconsejaban la eliminación de la etapa de acidificación inicial de la leche. De todos ellos, la disminución del pH fue significativa en cuatro ocasiones, con resultados opuestos para la mitad de ellos. Su inclusión como etapa previa mejora significativamente la valoración de las aberturas del queso a la vez que aumenta su cohesividad, mientras que su eliminación aumenta la calidad del olor y el rendimiento quesero. Debido al gran peso que se ha dado al aumento de rendimiento en el objetivo de esta Tesis se 
decide eliminar dicha etapa. Por tanto, no será tenido en cuenta su efecto como reductor del poder tampón de los concentrados, debido a la mayor eliminación de fosfato cálcico en la etapa de ultrafiltración, como han demostrado numerosos investigadores (Covacevich y Kosikowski 1978; McGregor y White 1990a; McGregor y White 1990c; Spangler et al. 1991; O'Callaghan y Guinee 2004).

De acuerdo con la bibliografía sobre ultrafiltración aplicada a la elaboración de queso, en algunos trabajos -como el desarrollado por Green (1985) sobre queso Cheddar a partir de leche concentrada hasta VCR entre 3 y 6 - también se elimina tanto la etapa de preacidificación como la etapa de diafiltración en el proceso de elaboración, al no observarse ningún efecto significativo sobre la composición ni sobre las propiedades de textura de los quesos finales. Sutherland et al. (1981) encontraron problemas de excesiva humedad en el queso al preacidificar la leche a valores comprendidos entre 6,2 y 6,3 .

\section{Extracto seco del concentrado (D)}

Los resultados son bastante claros en cuanto al contenido en extracto seco (o al VCR alcanzado). La optimización múltiple apunta a un establecimiento en su rango alto ( $41 \%$ de ES) y con ello coinciden el $62 \%$ de las variables respuesta estudiadas. Además dentro de ese porcentaje de coincidencia, cinco veces fue significativo el efecto del extracto seco. Su rango alto maximiza la elasticidad del queso, tanto en la evaluación instrumental como en la sensorial, la cohesividad y la evaluación global tanto olfato-gustativa como compuesta. Se elige por tanto el nivel alto de concentración. No se continuará evaluando a mayores concentraciones en posteriores diseños debido a que se ha alcanzado el límite de concentración que posibilitan las membranas espirales.

Estos resultados son acordes con los obtenidos por Spangler et al. (1990) en la elaboración de queso Gouda, donde se daba preferencia a factores de concentración elevados (VCR de 5) en cuanto a calidad sensorial del queso, atribuyendo una relación directa entre el grado de concentración y la ausencia de sabores amargos en el queso.

\section{c. Concentración de fermento (B)}

La inoculación de fermento resulta óptima en su nivel alto de concentración (6 DCU/100 L), este comportamiento es acorde con el 58,6 \% de los parámetros estudiados (físico-químicos, de textura y descriptores sensoriales). De todos ellos la concentración de fermento resultó significativa en la optimización de la evaluación sensorial global compuesta a concentración alta. Por ello se continuará estudiando y optimizando la cantidad de inóculo en sucesivos estudios.

\section{r Concentración de cuajo (C)}

La concentración de cuajo seleccionada a través de la optimización múltiple corresponde con el nivel alto (30 mL/100 L). Esta misma situación se da en el 55,2 \% de los descriptores estudiados. De todos ellos en tres ocasiones resultó significativa en su rango alto, aumentando la elasticidad de los quesos, con coincidencias entre los resultados obtenidos mediante el texturómetro y mediante el panel de cata. De igual forma, el rango alto maximiza también la cohesividad.

Por otro lado, como apuntan Green et al. (1981), el grado de degradación de las proteínas en la maduración puede disminuir como consecuencia de la reducción de la concentración de cuajo, aunque valores elevados de enzima coagulante pueden desencadenar la aparición de sabores amargos en el queso (Spangler et al. 1990).

A esta concentración $-30 \mathrm{~mL} / 100 \mathrm{~L}-$ se consigue una reducción del cuajo empleado del $83 \%$ respecto a la elaboración tradicional, en base al volumen inicial de leche, acorde a lo recogido en la 
revisión bibliográfica sobre las aplicaciones de la tecnología de membranas en la elaboración de queso realizada por Mistry et al. (2004) donde se establecen reducciones máximas del $85 \%$.

\section{Temperatura de cuajado (E)}

La temperatura de cuajado, evaluada entre 32 y $37^{\circ} \mathrm{C}$, resulta óptima en su nivel bajo. El nivel de coincidencias se mantiene repartido, ya que el $51,7 \%$ de los descriptores maximizan su valor a temperatura baja de cuajado. Ninguno de ellos es afectado significativamente por la temperatura. De acuerdo con la optimización múltiple, para aumentar el rendimiento y la valoración sensorial ha de establecerse la temperatura en su nivel bajo, por lo que la temperatura se fija en $32{ }^{\circ} \mathrm{C}$ para los futuros diseños.

El hecho de cuajar a menor temperatura conlleva un ahorro energético, si bien puede afectar a etapas posteriores como el prensado. Spangler et al. (1990) estudiando un rango mayor de temperatura en la elaboración de queso Gouda (26-39 ${ }^{\circ} \mathrm{C}$ ) no encontraron ningún efecto significativo en cuanto a dureza, sabor amargo o valoración sensorial global del queso; sin embargo mostraron preferencia por valores bajos de temperatura, ya que al incrementarse la temperatura de cuajado menor cantidad de cuajo queda atrapado en la cuajada, con su consecuente efecto en la desaceleración de la maduración de los quesos.

\section{c Tamaño de corte de la cuajada (G)}

En este caso se eligió el mayor tamaño de haz de lira como óptimo, aunque los resultados pueden parecer contradictorios ya que sólo el 20,7 \% de los casos estudiados se corresponden con este resultado. Analizando más en detalle todos ellos, sólo en dos ocasiones fue significativo el factor, con resultados opuestos. Por un lado la intensidad del olor aumentaba significativamente al disminuir el tamaño de corte, lo cual puede ser debido a la confusión del modelo, mientas que por otro lado el rendimiento aumentaba de forma significativa al aumentar éste. Debido al gran peso que tiene el rendimiento en los objetivos finales del estudio se ratifica la elección de un mayor tamaño de corte y se continuará con su estudio en posteriores diseños.

\section{c Presión de prensado $(\mathrm{H})$}

La presión de la etapa de prensado se ha seleccionado en su rango bajo, si bien una baja presión aumenta la respuesta de los descriptores estudiados sólo en el $48 \%$ de los casos. De todos ellos resultó significativa en su nivel alto aumentando el regusto del queso. Los datos de evaluación sensorial muestran mejores puntuaciones a presiones elevadas, mientras que los de rendimiento señalan hacia presiones menores.

Durante las elaboraciones se observaba que en las realizadas a presión alta la cuajada se pegaba de forma excesiva a los trapos, lo que complicaba bastante la operación, pudiendo ser a su vez causante de pérdida de rendimiento. Por ello, y acorde a la optimización múltiple, se decide fijar la presión en su nivel bajo, que coincide con la presión ejercida en la elaboración tradicional. 


\subsection{OPTIMIZACIÓN DE LAS VARIABLES SIGNIFICATIVAS. DISEÑO FACTORIAL}

Mediante el diseño de experimentos anterior (Plackett-Burmann) se han obtenido como variables significativas -en la evaluación conjunta del rendimiento y la calidad sensorial- el tamaño de corte, la concentración de fermento, el extracto seco del concentrado y el pH de la leche en la ultrafiltración.

Como se ha indicado en el Apartado 5.2.7, en cuanto al extracto seco nos encontramos en el límite operacional alcanzable por las membranas espirales, por lo que queda fijado en su valor más elevado y no será factor de estudio en futuras optimizaciones. Así mismo, respecto al pH inicial de la leche, se continuará filtrando a su valor normal $(\approx 6,7)$.

Partiendo del tamaño de corte y la concentración de fermento como variables de estudio se continúa con la optimización del proceso de elaboración mediante el presente diseño.

Junto a las dos variables significativas susceptibles de optimización que nos muestra el diseño anterior, y dada la importancia tecnológica y sensorial atribuible a la composición del fermento, se incorpora como tercer factor a evaluar el tipo de fermento. Se introduce este nuevo factor ya que el uso de distintos fermentos puede afectar a la evaluación organoléptica del queso, debido a la ruptura específica de los distintos péptidos generados por las enzimas durante la maduración (Spangler et al. 1991) así como para comparar su efecto ante el poder tampón que tiene la leche concentrada, como se comprobó en el Apartado 5.1.2.

\subsubsection{DISEÑO EXPERIMENTAL}

Se utilizaron dos fermentos comerciales (factor $A$ ), por un lado el empleado en el diseño anterior, que a su vez se utiliza en la fabricación del queso tradicional (MA4001), por otro, un fermento de acidificación rápida mezcla de bacterias puramente acidificantes sin cepas productoras de aroma (R703). La composición de ambos fermento se recoge en el Capítulo III (Apartado 3.4).

El rango de concentración de fermento (B) se establece desde 6 hasta $14 \mathrm{DCU} / 100 \mathrm{~L}$, a partir del óptimo del diseño anterior ( $6 \mathrm{DCU} / 100 \mathrm{~L})$ y abarcando un rango elevado de concentraciones, según los resultados del Apartado 5.1.2 (Figura 5.6). El tamaño de corte (C) se varía desde 3 hasta $15 \mathrm{~cm}$ de haz de lira, el rango alto para el tamaño de corte es el máximo posible debido a las dimensiones del molde, por lo que el corte con lira de $15 \mathrm{~cm}$ equivale a ausencia de etapa de corte.

Los niveles de las variables estudiados se recogen en la Tabla 5.11.

Tabla 5.11. Niveles de las variables para el Diseño Factorial

\begin{tabular}{|c|c|c|c|c|}
\hline Código & FACTORES & $\begin{array}{c}\text { Rango } \\
\text { alto }\end{array}$ & $\begin{array}{c}\text { Rango } \\
\text { bajo }\end{array}$ & Unidades \\
\hline A & Fermento & $(1)$ R703 & $(-1)$ MA4001 & Tipo de fermento \\
\hline B & [Fermento] & 14 & 6 & *DCU/100 L de concentrado \\
\hline C & Tamaño de corte de la cuajada & 15 & 3 & $\mathrm{~cm}$ de haz de lira \\
\hline
\end{tabular}

*Una unidad DCU contiene aproximadamente de $1 \cdot 10^{11}$ a $2 \cdot 10^{11}$ bacterias 
El diseño se realiza por duplicado para tener mejor estimación del error experimental y en 4 bloques partiendo de 4 leches distintas para controlar la variabilidad que la materia prima pueda incorporar a los resultados.

Con cada tipo de leche (o bloque) se realiza una filtración y 4 fabricaciones con el concentrado obtenido en el proceso de ultrafiltración, según la matriz experimental de la Tabla 5.12.

Tabla 5.12. Matriz de experimentos del Diseño Factorial

\begin{tabular}{|c|c|c|c|c|c|c|}
\hline & Bloque & Fermento & [Fermento] & Corte & $\% \mathrm{R} *$ & Sensorial \\
\hline DF1 & 1 & 1,0 & 14 & 3 & 14,41 & 3,9 \\
\hline DF2 & 1 & $-1,0$ & 14 & 15 & 15,50 & 4,0 \\
\hline DF3 & 1 & 1,0 & 6 & 15 & 15,40 & 4,1 \\
\hline DF4 & 1 & $-1,0$ & 6 & 3 & 14,89 & 4,2 \\
\hline DF5 & 2 & 1,0 & 14 & 15 & 15,38 & 3,8 \\
\hline DF6 & 2 & $-1,0$ & 14 & 3 & 14,63 & 4,0 \\
\hline DF7 & 2 & $-1,0$ & 6 & 15 & 15,98 & 4,3 \\
\hline DF8 & 2 & 1,0 & 6 & 3 & 14,46 & 3,5 \\
\hline DF9 & 3 & 1,0 & 14 & 3 & 14,06 & 3,7 \\
\hline DF10 & 3 & $-1,0$ & 14 & 15 & 15,71 & 4,1 \\
\hline DF11 & 3 & 1,0 & 6 & 15 & 15,44 & 4,3 \\
\hline DF12 & 3 & $-1,0$ & 6 & 3 & 14,70 & 4,3 \\
\hline DF13 & 4 & 1,0 & 14 & 15 & 15,23 & 3,8 \\
\hline DF14 & 4 & $-1,0$ & 14 & 3 & 14,56 & 4,1 \\
\hline DF15 & 4 & $-1,0$ & 6 & 15 & 15,80 & 4,6 \\
\hline DF16 & 4 & 1,0 & 6 & 3 & 15,29 & 4,0 \\
\hline
\end{tabular}

* Rendimiento corregido para quesos de un $55 \%$ de extracto seco $(\mathrm{kg} / 100 \mathrm{~kg}$ de leche)

\subsubsection{ESTUDIO FÍSICO-QUÍMICO}

A continuación, se recogen los resultados de composición y $\mathrm{pH}$, tanto de la leche de mezcla de partida como de los permeados y concentrados generados en la etapa de ultrafiltración.

Así mismo se presentan estos mismos valores para los quesos finales, obtenidos de las 16 fabricaciones que forman el diseño, a los 20 y 40 días de maduración.

\section{LECHES, CONCENTRADOS Y PERMEADOS}

La primera etapa en todos los casos fue la estandarización en grasa y proteína de la leche de partida. Los valores de composición para las leches de vaca y oveja a partir de las que realiza la mezcla se recogen en las Tablas A.3 y A.4 del Anexo A.1.

Se comprobó la calidad de ambas leches a través del recuento de células somáticas obteniendo valores por debajo de las 400.000 células/mL en vaca, conformo al Reglamento 853/2004. Para el 
caso de la oveja se encontraron valores por debajo de las 800.000 células $/ \mathrm{mL}$. También se comprobó la ausencia de residuos de antibióticos.

Los datos obtenidos para la mezcla estandarizada se recogen en la Tabla 5.13. Se observa como en todos ellos se cumplen los requisitos establecidos tanto para la grasa $(4,0 \pm 0,2 \%)$ como para la proteína $(3,5 \pm 0,1 \%)$.

Cada una de las cuatro leches de partida (DF1-DF4, DF5-DF8, DF9-DF12 y DF13-DF16) fue ultrafiltrada bajo las mismas condiciones de operación.

Tabla 5.13. Composición química y pH de la leche de mezcla. Diseño Factorial

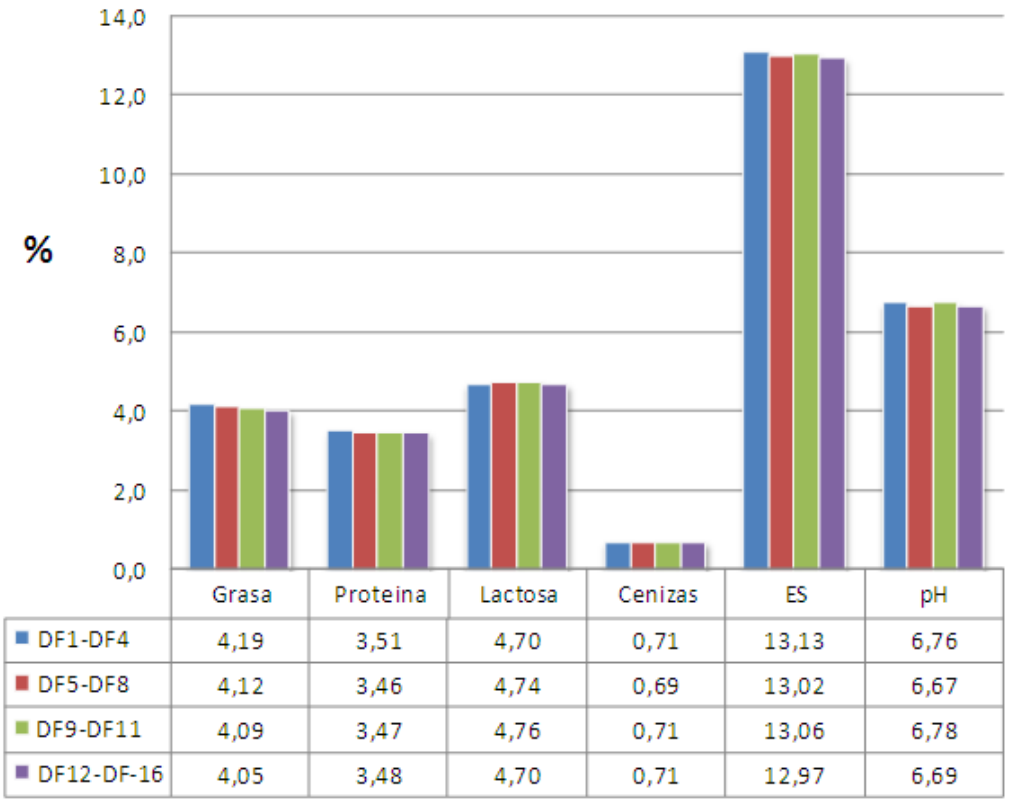

La composición de los permeados obtenidos en la etapa de ultrafiltación se recoge en la Tabla 5.14. Estadísticamente, a través del análisis de varianza, no se pueden considerar las composiciones iguales para todos ellos; a efectos prácticos los valores son aceptables ya que las diferencias pueden proceder del pequeño error experimental asociado a cada medida. Los datos se agrupan en dos sub-grupos interconectados entre sí. El porcentaje de lactosa está calculado por diferencia respecto al extracto seco.

Queda comprobado que la totalidad de la grasa se retiene por la membrana, al igual que la proteína (caseína y proteína soluble) ya que la cantidad de nitrógeno que atraviesa la membrana, mostrada como contenido en proteína, corresponde con el nitrógeno no proteico (NNP) de la leche (Luquet 1991).

Tabla 5.14. Composición química de los permeados. Diseño Factorial

\begin{tabular}{|c|c|c|c|c|}
\hline$\%$ peso & DF1-DF4 & DF5-DF8 & DF9-DF12 & DF13-DF16 \\
\hline Grasa & 0,00 & 0,00 & 0,00 & 0,00 \\
\hline Proteína & $0,19^{\mathrm{ab}} \pm 0,01$ & $0,18^{\mathrm{a}} \pm 0,01$ & $0,19^{\mathrm{ab}} \pm 0,01$ & $0,20^{\mathrm{b}} \pm 0,01$ \\
\hline Cenizas & $0,37^{\mathrm{ab}} \pm 0,02$ & $0,44^{\mathrm{c}} \pm 0,02$ & $0,34^{\mathrm{a}} \pm 0,01$ & $0,39^{\mathrm{bc}} \pm 0,01$ \\
\hline ES & $5,39^{\mathrm{a}} \pm 0,06$ & $5,46^{\mathrm{ab}} \pm 0,03$ & $5,54^{\mathrm{b}} \pm 0,03$ & $5,55^{\mathrm{b}} \pm 0,03$ \\
\hline Lactosa & 4,83 & 4,84 & 5,01 & 4,96 \\
\hline
\end{tabular}

${ }^{*}$ Valores designados en la misma fila con la misma letra no son significativamente diferentes $(p<0,05)$ 
Analizando la composición de los retenidos a partir de los que se realizan las 16 fabricaciones del diseño, Tabla 5.15, se puede asumir que todos ellos presentan la misma composición, por lo que la variación en la materia prima se considera despreciable.

Tabla 5.15. Composición química y pH de los retenidos de UF. Diseño Factorial

\begin{tabular}{|c|c|c|c|c|c|c|}
\hline$\%$ peso & Grasa & Proteína & Cenizas & ES & Lactosa & pH \\
\hline DF1 & $\begin{array}{l}19,00^{a} \\
\pm 0,00\end{array}$ & $\begin{array}{l}16,33^{a} \\
\pm 0,14\end{array}$ & $\begin{array}{l}1,54^{a} \\
\pm 0,02\end{array}$ & $\begin{array}{l}40,71^{a} \\
0 \pm, 20\end{array}$ & 3,84 & $\begin{array}{l}6,57^{\mathrm{e}} \\
\pm 0,01\end{array}$ \\
\hline DF2 & $\begin{array}{l}19,00^{a} \\
\pm 0,00\end{array}$ & $\begin{array}{l}16,50^{a} \\
\pm 0,96\end{array}$ & $\begin{array}{l}1,60^{a} \\
\pm 0,08\end{array}$ & $\begin{array}{l}40,72^{a} \\
\pm 0,18\end{array}$ & 3,63 & $\begin{array}{l}6,56^{\mathrm{e}} \\
\pm 0,01\end{array}$ \\
\hline DF3 & $\begin{array}{l}19,50^{a} \\
\pm 0,00\end{array}$ & $\begin{array}{l}16,24^{a} \\
\pm 0,21\end{array}$ & $\begin{array}{l}1,76^{a} \\
\pm 0,02\end{array}$ & $\begin{array}{l}41,18^{a} \\
\pm 0,12\end{array}$ & 3,69 & $\begin{array}{l}6,58^{\mathrm{e}} \\
\pm 0,01\end{array}$ \\
\hline DF4 & $\begin{array}{l}19,25^{a} \\
\pm 0,50\end{array}$ & $\begin{array}{l}16,36^{a} \\
\pm 0,11\end{array}$ & $\begin{array}{l}1,62^{a} \\
\pm 0,01\end{array}$ & $\begin{array}{r}41,06^{a} \\
\pm 0,04\end{array}$ & 3,84 & $\begin{array}{l}6,58^{\mathrm{e}} \\
\pm 0,01\end{array}$ \\
\hline DF5 & $\begin{array}{l}19,50^{a} \\
\pm 0,00\end{array}$ & $\begin{array}{l}16,36^{a} \\
\pm 0,08\end{array}$ & $\begin{array}{l}1,58^{a} \\
\pm 0,26\end{array}$ & $\begin{array}{l}41,07^{a} \\
\pm 0,23\end{array}$ & 3,63 & $\begin{array}{l}6,53^{d} \\
\pm 0,01\end{array}$ \\
\hline DF6 & $\begin{array}{l}19,00^{a} \\
\pm 0,00\end{array}$ & $\begin{array}{l}16,90^{a} \\
\pm 0,27\end{array}$ & $\begin{array}{l}1,50^{a} \\
\pm 0,03\end{array}$ & $\begin{array}{l}40,52^{a} \\
\pm 0,29\end{array}$ & 3,13 & $\begin{array}{l}6,52^{\text {cd }} \\
\pm 0,01\end{array}$ \\
\hline DF7 & $\begin{array}{l}19,50^{a} \\
\pm 0,00\end{array}$ & $\begin{array}{l}16,27^{a} \\
\pm 0,14\end{array}$ & $\begin{array}{l}1,61^{a} \\
\pm 0,02\end{array}$ & $\begin{array}{r}41,00^{a} \\
\pm 0,04\end{array}$ & 3,62 & $\begin{array}{c}6,51^{\text {bcd }} \\
\pm 0,01\end{array}$ \\
\hline DF8 & $\begin{array}{l}19,50^{a} \\
\pm 0,00\end{array}$ & $\begin{array}{l}16,25^{a} \\
\pm 0,12\end{array}$ & $\begin{array}{l}1,60^{a} \\
\pm 0,04\end{array}$ & $\begin{array}{l}40,97^{a} \\
\pm 0,01\end{array}$ & 3,62 & $\begin{array}{l}6,51^{\text {bcd }} \\
\pm 0,01\end{array}$ \\
\hline DF9 & $\begin{array}{l}19,25^{a} \\
\pm 0,50\end{array}$ & $\begin{array}{l}16,74^{a} \\
\pm 0,15\end{array}$ & $\begin{array}{l}1,63^{a} \\
\pm 0,05\end{array}$ & $\begin{array}{r}41,09^{a} \\
\pm 0,61\end{array}$ & 3,48 & $\begin{array}{l}6,58^{\mathrm{e}} \\
\pm 0,01\end{array}$ \\
\hline DF10 & $\begin{array}{l}19,25^{a} \\
\pm 0,50\end{array}$ & $\begin{array}{l}16,80^{a} \\
\pm 0,02\end{array}$ & $\begin{array}{l}1,62^{a} \\
\pm 0,08\end{array}$ & $\begin{array}{l}40,92^{a} \\
\pm 0,48\end{array}$ & 3,25 & $\begin{array}{l}6,58^{\mathrm{e}} \\
\pm 0,01\end{array}$ \\
\hline DF11 & $\begin{array}{c}19,25^{a} \\
0,50\end{array}$ & $\begin{array}{l}16,73^{a} \\
\pm 0,05\end{array}$ & $\begin{array}{l}1,69^{a} \\
\pm 0,02\end{array}$ & $\begin{array}{l}40,91^{a} \\
\pm 0,60\end{array}$ & 3,24 & $\begin{array}{l}6,56^{\mathrm{e}} \\
\pm 0,01\end{array}$ \\
\hline DF12 & $\begin{array}{l}19,00^{a} \\
\pm 0,50\end{array}$ & $\begin{array}{l}16,85^{a} \\
\pm 0,03\end{array}$ & $\begin{array}{l}1,63^{a} \\
\pm 0,15\end{array}$ & $\begin{array}{l}40,97^{a} \\
\pm 0,26\end{array}$ & 3,50 & $\begin{array}{l}6,56^{\mathrm{e}} \\
\pm 0,01\end{array}$ \\
\hline DF13 & $\begin{array}{l}19,75^{a} \\
\pm 0,50\end{array}$ & $\begin{array}{l}16,11^{a} \\
\pm 0,01\end{array}$ & $\begin{array}{l}1,58^{a} \\
\pm 0,05\end{array}$ & $\begin{array}{r}40,99^{a} \\
\pm 0,08\end{array}$ & 3,56 & $\begin{array}{l}6,48^{\mathrm{e}} \\
\pm 0,01\end{array}$ \\
\hline DF14 & $\begin{array}{c}19,75^{\mathrm{a}} \\
0,50\end{array}$ & $\begin{array}{c}16,29^{a} \\
0,04\end{array}$ & $\begin{array}{l}1,51^{a} \\
0,06\end{array}$ & $\begin{array}{l}40,89^{a} \\
\pm 0,10\end{array}$ & 3,34 & $\begin{array}{l}6,49^{a b} \\
\pm 0,01\end{array}$ \\
\hline DF15 & $\begin{array}{r}19,75^{a} \\
\pm 0,50\end{array}$ & $\begin{array}{l}16,12^{a} \\
\pm 0,21\end{array}$ & $\begin{array}{l}1,69^{a} \\
\pm 0,18\end{array}$ & $\begin{array}{l}41,02^{a} \\
\pm 0,16\end{array}$ & 3,46 & $\begin{array}{c}6,51^{\text {abcd }} \\
\pm 0,01\end{array}$ \\
\hline DF16 & $\begin{array}{l}19,00^{a} \\
\pm 0,00\end{array}$ & $\begin{array}{l}16,84^{a} \\
\pm 0,13\end{array}$ & $\begin{array}{l}1,59^{a} \\
\pm 0,03\end{array}$ & $\begin{array}{l}40,89^{a} \\
\pm 0,02\end{array}$ & 3,47 & $\begin{array}{c}6,50^{a b c} \\
\pm 0,01\end{array}$ \\
\hline
\end{tabular}

${ }^{*}$ Valores designados en la misma fila con la misma letra no son significativamente diferentes $(p<0,05)$ 
Los valores de $\mathrm{pH}$ de los concentrados se muestran estadísticamente distintos entre ellos, apareciendo grupos similares a los bloques del diseño, si bien la variación total entre el mayor y el menor valor es insignificante $(<0,1)$ para el presente estudio.

\section{COMPOSICIÓN DE LOS QUESOS A LO LARGO DE LA MADURACIÓN}

Tanto a los 20 como a los 40 días de maduración se realizaron análisis sobre los quesos de cada una de las fabricaciones en cuanto a extracto seco, grasa, proteína, sal $(\mathrm{NaCl})$ y cenizas. Igualmente, se determinó el $\mathrm{pH}$ de todos ellos. Estos datos se recogen en el Anexo A.2 en las Tablas A.10 y A.11.

La composición de los quesos realizados a partir de los concentrados de cada uno de los experimentos propuestos en el diseño factorial, a los 40 días de maduración, se recoge en la Figura 5.28. Se aprecian variaciones en el extracto seco de hasta un $4 \%$ entre las distintas fabricaciones, con valores medios del 55-56 \%, similar al extracto seco considerado estándar para este tipo de queso en el momento de consumo. El perfil de grasa entre los experimentos es similar al del ES, con valores del 28-29\%. La concentración de proteína se sitúa alrededor del $20 \%$. En cuanto al pH final del queso los valores se aproximan al valor de 5,0 00,3 .

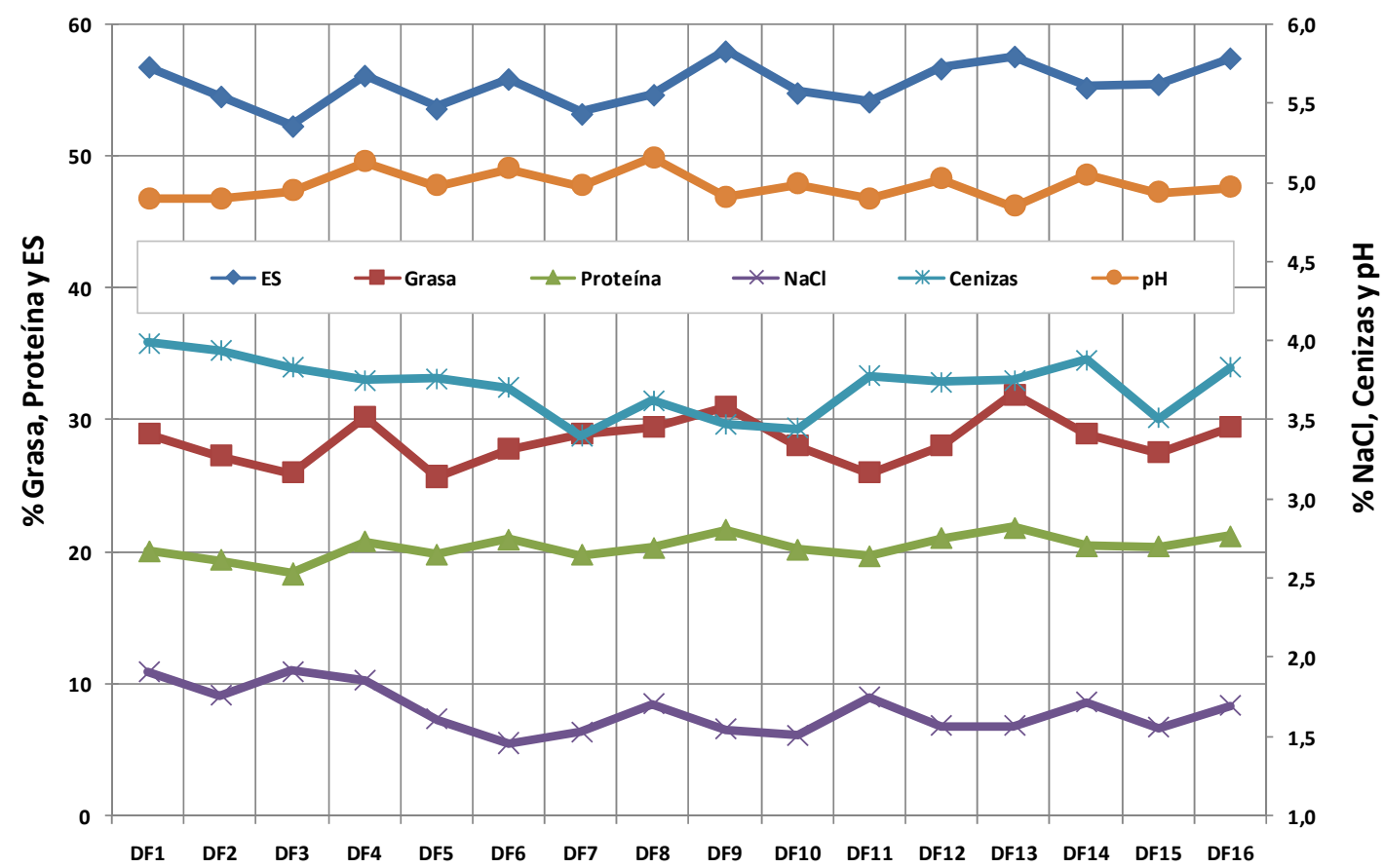

Figura 5.28. Composición de los quesos a los 40 días. Diseño Factorial

Al establecer los efectos de los tres factores estudiados sobre la composición química del queso, únicamente el extracto seco y el contenido proteico son afectados significativamente, como se recoge en la Figura 5.29. Mientras que el tipo de fermento y su concentración no afectan de manera significativa, si lo hace el tamaño de corte de la cuajada. Este tamaño, en su nivel bajo, aumenta el contenido proteico y el ES como consecuencia de una mayor eliminación de agua en los quesos cortados a menor tamaño.

Así mismo, el pH del queso a los 40 días es significativamente mayor a menores tamaños de corte (Figura 5.29). Este comportamiento coincide con la tendencia observada en el diseño anterior (PB), relacionándose con un mayor desarrollo del fermento a mayor actividad de agua $\left(\mathrm{a}_{\mathrm{w}}\right)$ en el queso (menor ES). 

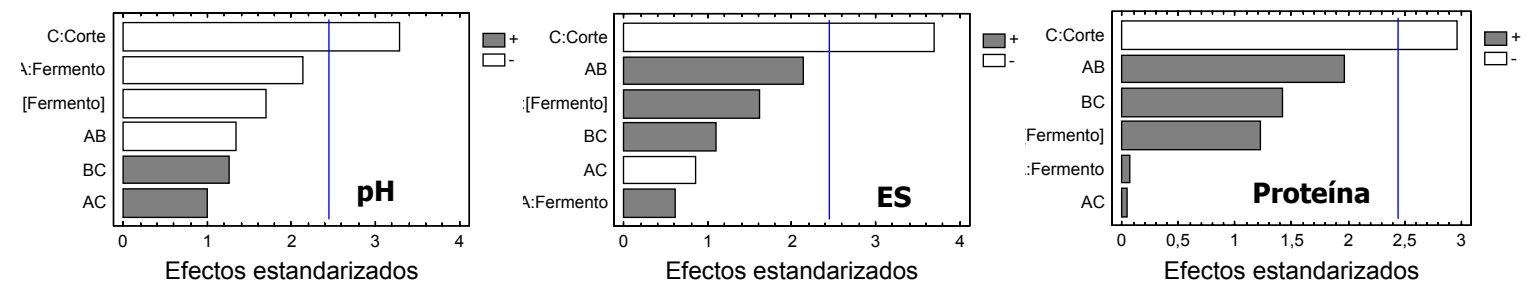

Figura 5.29. Variables significativas en la optimización en cuanto a pH, ES y proteína. Diseño Factorial

\subsubsection{ESTUDIO DE LA TEXTURA DEL QUESO}

Sobre los quesos elaborados en las 16 fabricaciones del diseño se realiza un análisis de perfil de textura (TPA) a los 40 días de maduración. Los resultados obtenidos en la evaluación instrumental de la textura se muestran a continuación.

\section{FIRMEZA}

Las gráficas de la Figura 5.30 recogen los resultados obtenidos en la evaluación instrumental de la firmeza de los quesos. Se observan diferencias en su valor que van desde 10 hasta $25 \mathrm{~N}$. El tamaño de corte afecta significativamente a la firmeza, aumentando la dureza a medida que disminuye este factor. De igual modo, aparecen significativas las interacciones entre el tipo de fermento y la concentración de fermento $(A B)$ y entre el tipo de fermento y el tamaño de corte (AC). A concentraciones bajas proporciona mayor firmeza el fermento MA4001 (-1) mientras que a elevadas el R703 (+1); a su vez a tamaños pequeños de corte la mayor firmeza se consigue con el fermento MA4001 y a mayor corte con el fermento R703.
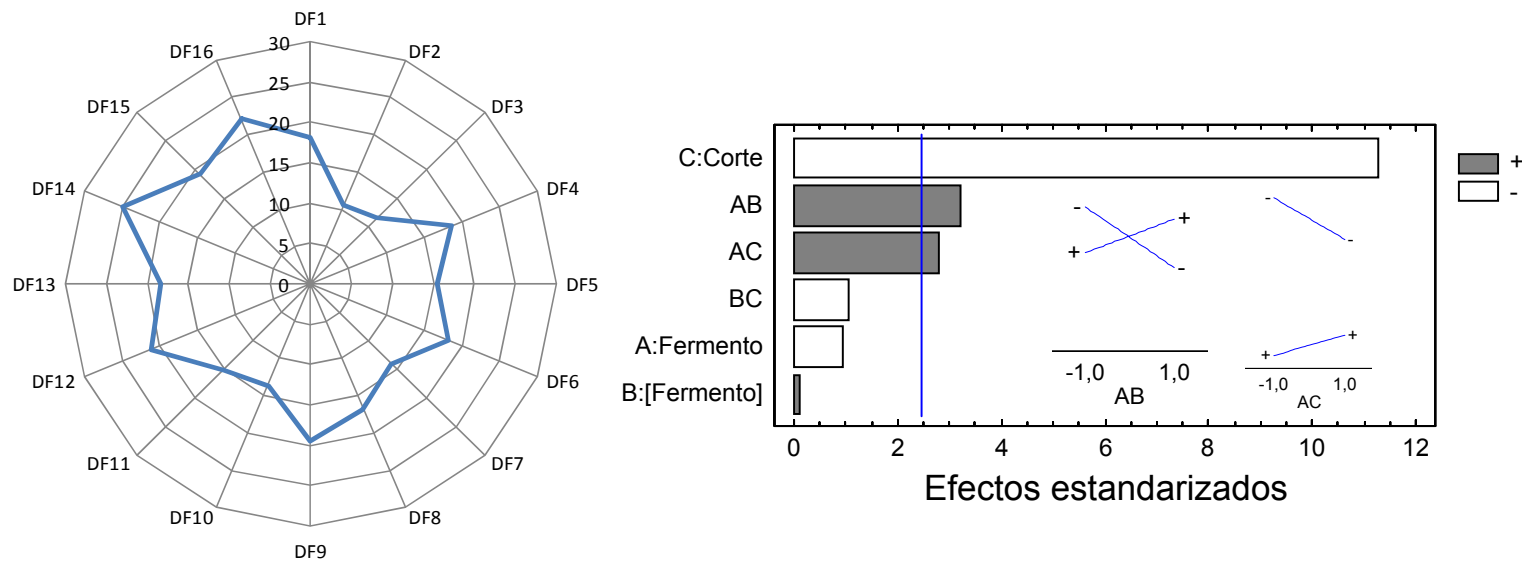

Figura 5.30. Medida de firmeza (N) y su significación en el Diseño Factorial

\section{$\underline{\text { ELASTICIDAD }}$}

En lo que se refiere a la elasticidad, Figura 5.31, no se determinan grandes diferencias entre los distintos quesos, obteniéndose valores comprendidos entre 0,6 y 0,8 . Ninguno de los factores del diseño aparece como significativo a un $95 \%$ de probabilidad, si bien el tamaño de corte casi llega a serlo, aumentando la elasticidad del queso con tamaños pequeños de corte, como consecuencia de la menor humedad (ver Figura 5.29) y mayor firmeza (ver Figura 5.30). 

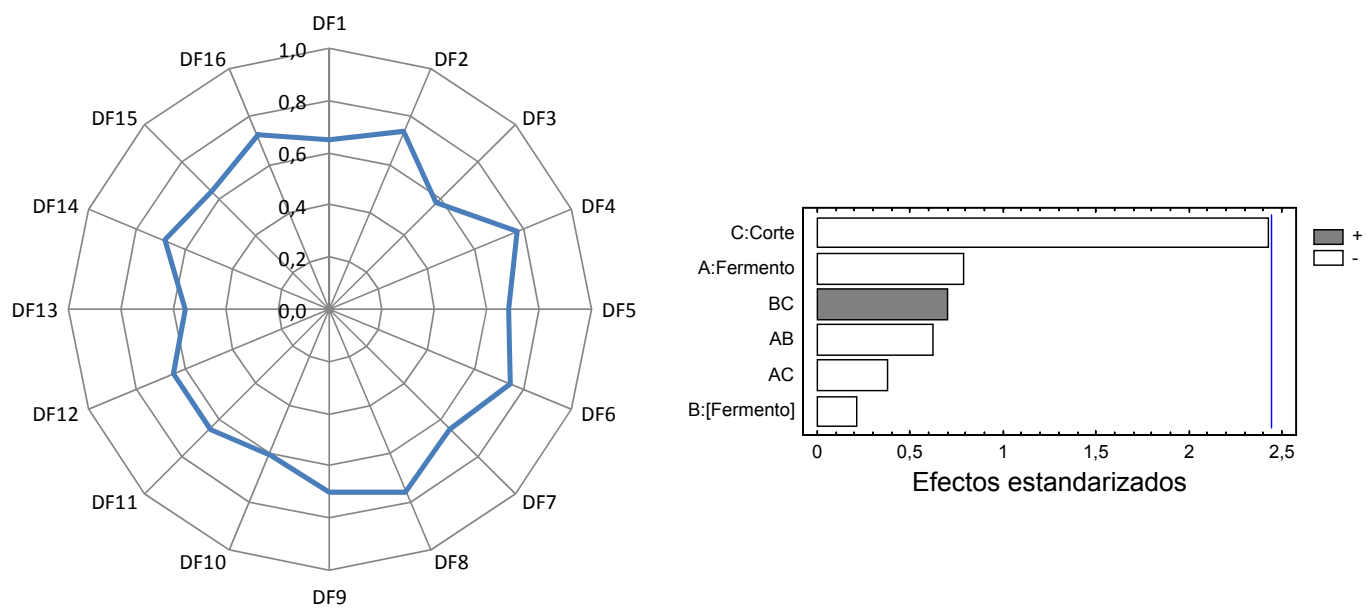

Figura 5.31. Medida de elasticidad y su significación en el Diseño Factorial

\section{ADHERENCIA}

Los datos de adherencia de la Figura 5.32 muestran valores muy variados entre los distintos quesos elaborados a partir de los 16 experimentos del diseño.

Se observa como el aumento de la concentración de fermento aumenta de forma significativa la adherencia de los quesos. Este comportamiento es debido a una excesiva acidificación de la pasta, que descompensa el equilibrio salino y afecta a la estructura del queso. Aparentemente el empleo del fermento MA4001 provoca quesos más adherentes, si bien su contribución no es significativa.
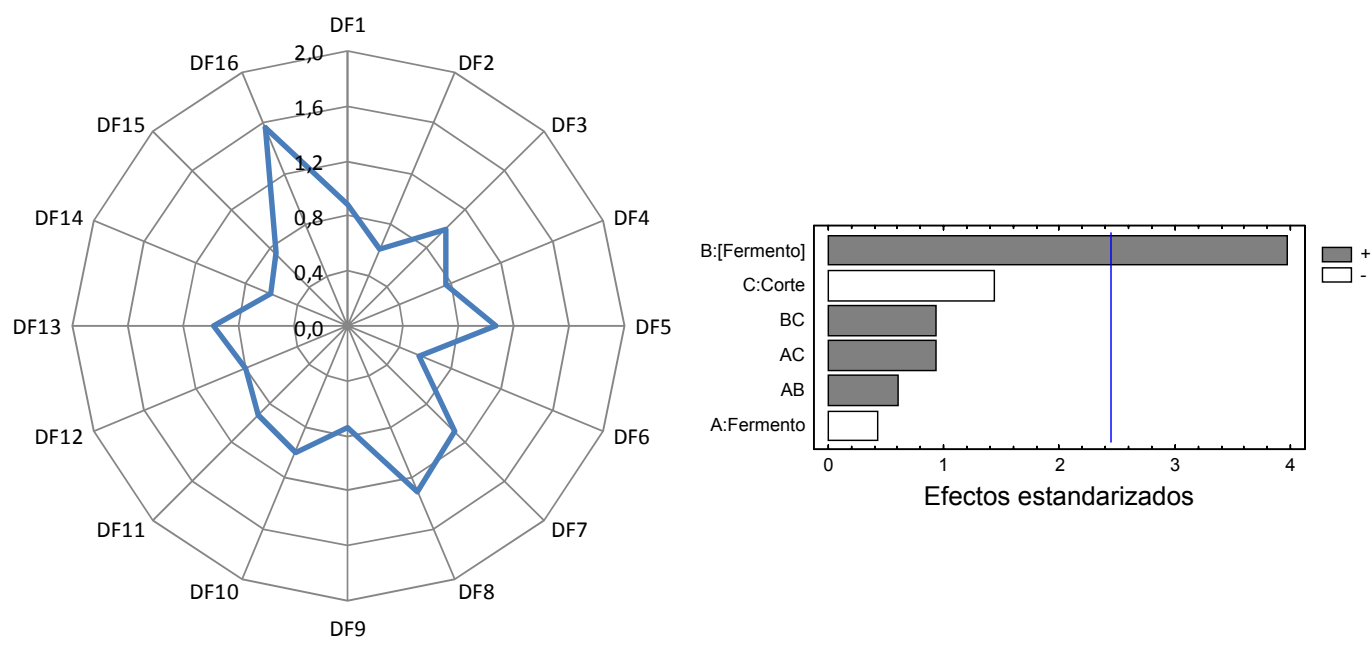

Figura 5.32. Medida de adherencia (N`s) y su significación en el Diseño Factorial

\section{COHESIVIDAD}

Respecto a la cohesividad, Figura 5.33, la diferencia observada entre los valores de los quesos de las distintas fabricaciones experimentales depende significativamente de dos factores. Por un lado, el uso del fermento tradicional (-1) hace que el queso sea más cohesivo. Por otra parte, el corte de la cuajada con liras de menor haz de paso aumenta de forma significativa la cohesividad del queso, como sucedía tanto con la firmeza como con la elasticidad. 

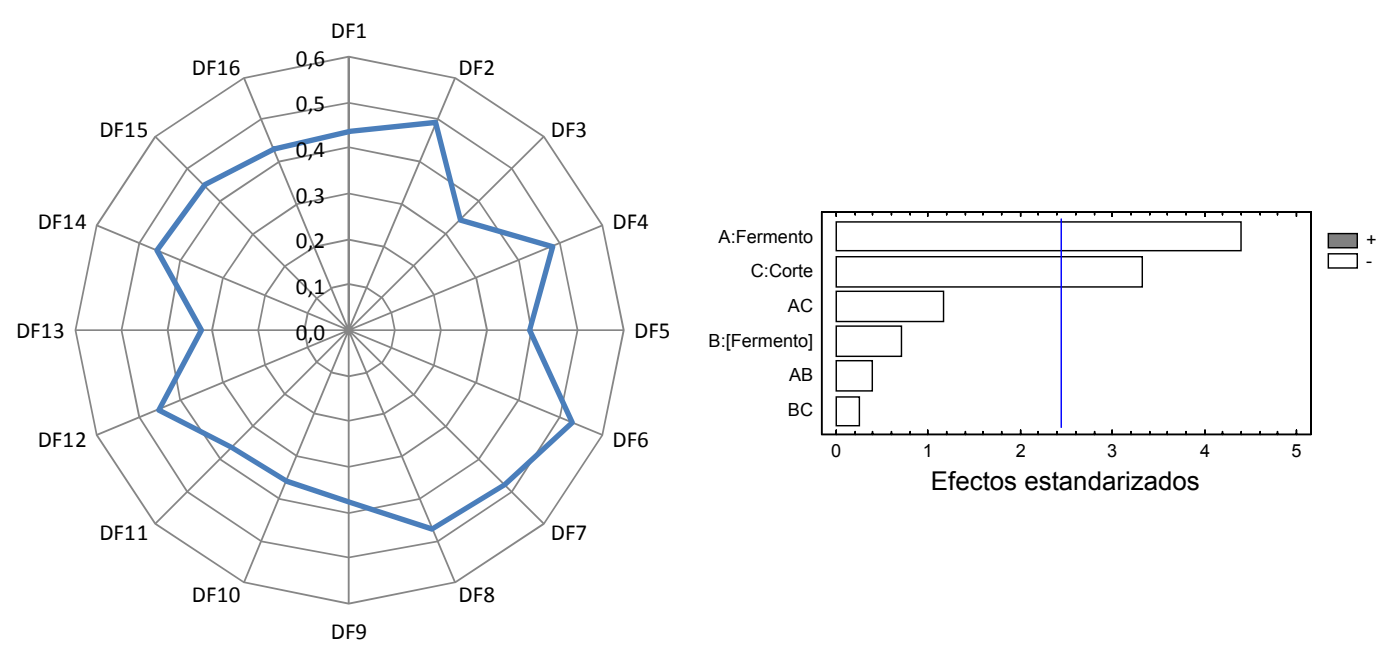

Figura 5.33. Medida de cohesividad y su significación en el Diseño Factorial

\section{MASTICABILIDAD}

En la medida instrumental de la masticabilidad, Figura 5.34, también se observan diferencias importantes entre las distintas fabricaciones. Esta variación depende significativamente del tamaño de corte, aumentando las masticabilidad a medida que éste disminuye, ya que se calcula a partir de los valores de firmeza, cohesividad y elasticidad.
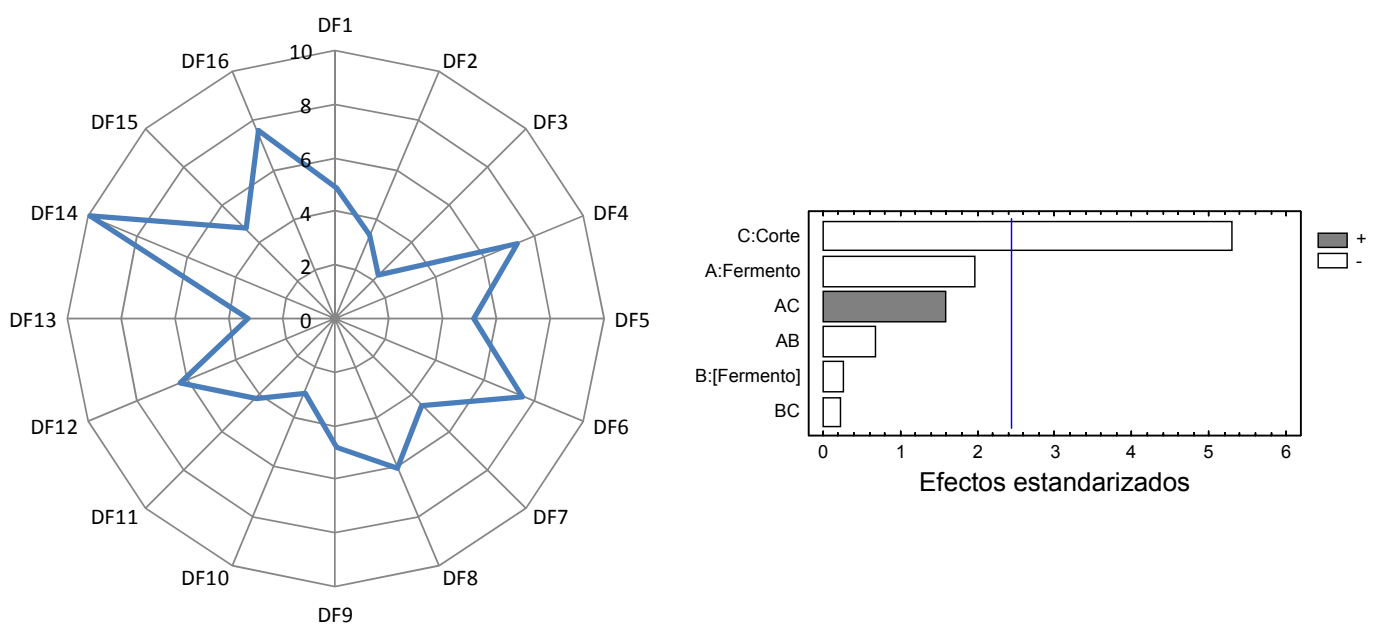

Figura 5.34. Medida de masticabilidad (N) y su significación en el Diseño Factorial

\subsubsection{ANÁLISIS SENSORIAL DE LOS QUESOS}

A continuación se muestran las puntuaciones alcanzadas por los quesos del diseño tanto en la sensación olfato-gustativa como en la impresión visual, al ser evaluados por el panel de cata.

\section{SENSACIÓN OLFATO-GUSTATIVA}

Se muestran los resultados de la fase olfato-gustativa agrupados según el atributo sensorial evaluado por cada uno de los sentidos (olfato, tacto y gusto). 


\section{- Calidad e intensidad del olor}

En lo que se refiere a la intensidad de la sensación olfativa se observa un amplio rango de valores, con puntuaciones entre 3 y 4, según los datos presentados en Figura 5.35. En cuanto a la calidad del olor, la aceptación general es buena con puntuaciones entorno a 4. Para ambas respuestas el uso del fermento MA4001 (-1) aumenta significativamente las puntuaciones.

La función principal de las bacterias lácticas en la elaboración de queso es la fermentación de la lactosa para generar ácido láctico -favoreciendo la expulsión de agua (suero)-. No obstante, otros subproductos generados en las fermentaciones que producen las bacterias lácticas, importantes en cuando al desarrollo del flavor del queso, son el diacetilo (2,3-butanodiona) y el acetato, mientras que para el desarrollo de la textura juega un papel importante la producción de dióxido de carbono (Cogan 1995).

Por todo ello los resultados alcanzados -mayor intensidad y calidad de la sensación olfativa- son acordes con la composición del fermento MA4001, ya que presenta cepas de bacterias productoras de diacetilo, como es el lactococcus lactis ssp. lactis var diacetylactis (Wood y Holzapfel 1995).
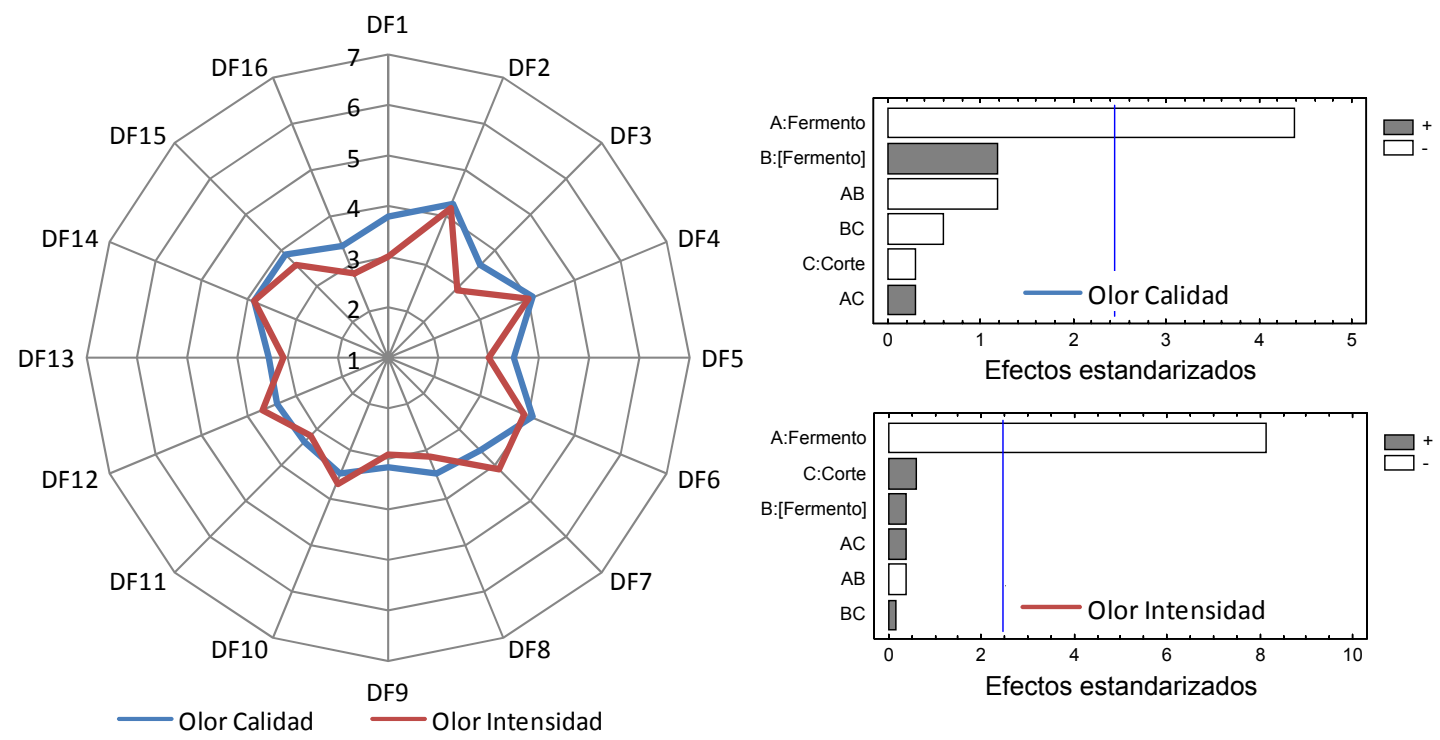

Figura 5.35. Puntuaciones de olor y su significación en el Diseño Factorial

\section{- Textura en mano: rugosidad, elasticidad y firmeza}

Los datos de textura en mano obtenidos tras la evaluación de los quesos por el panel de cata se recogen en la Figura 5.36.

Se encuentran puntuaciones bajas (por debajo de 4) para los tres descriptores utilizados: rugosidad, elasticidad y firmeza. Los valores más elevados corresponden a la elasticidad, si bien se obtienen valores menores que los alcanzados bajo las condiciones del diseño anterior, relacionados con el mayor tamaño de corte.

Como variable significativa aparece el tamaño de corte de la cuajada en lo que se refiere a firmeza -al igual que cuando se evaluó instrumentalmente mediante texturómetro- y rugosidad del queso. En ambos descriptores se obtienen puntuaciones mayores a medida que disminuye el tamaño de corte. 

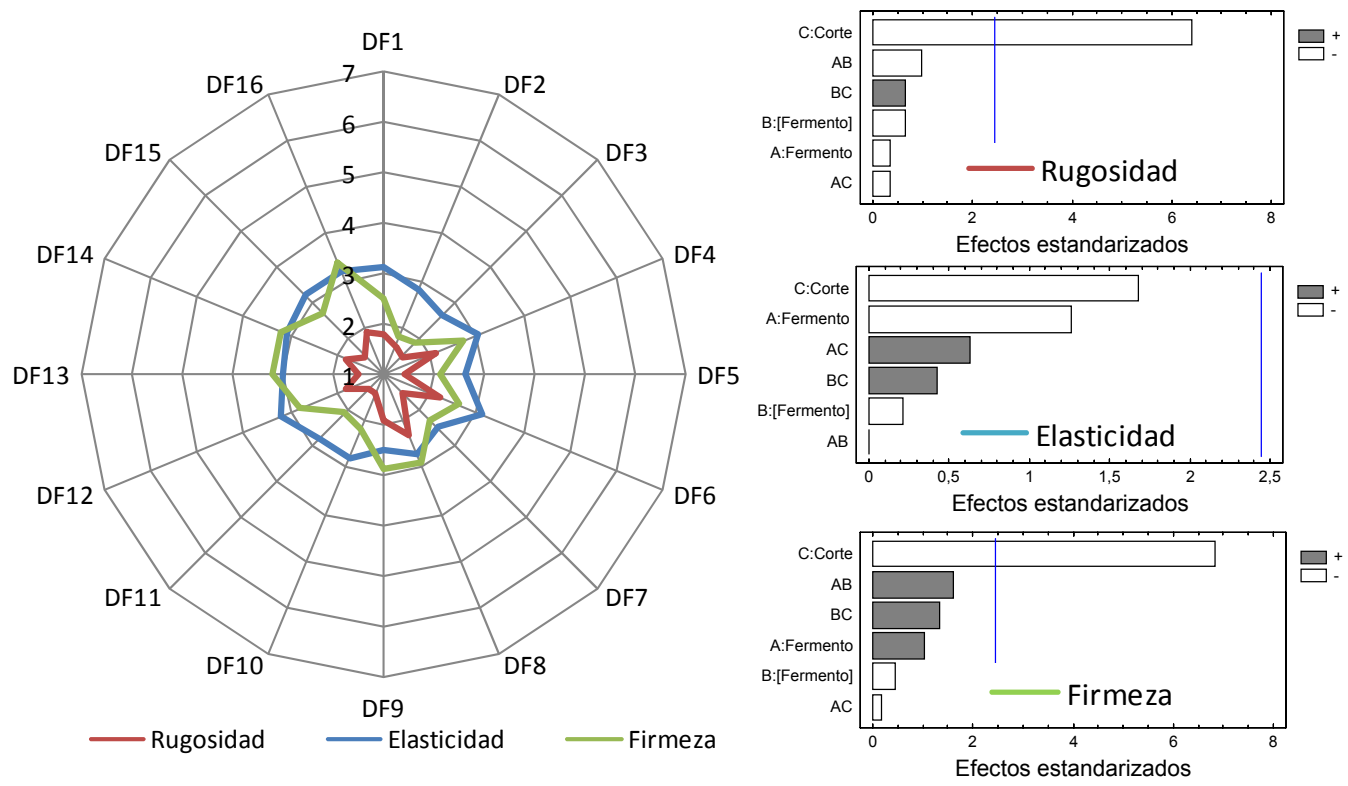

Figura 5.36. Puntuaciones de textura en mano y su significación en el Diseño Factorial

\section{- Textura en boca: friabilidad, adherencia, solubilidad, granulosidad y firmeza}

Analizando los datos de la Figura 5.37, se observa que para los descriptores de granulosidad y friabilidad se obtienen valores bajos en todas las fabricaciones (menores de 3 ), por lo que los quesos son caracterizados como poco granulosos y poco friables. Por otro lado, se alcanzan puntuaciones medias (entorno a 4) para el resto de variables, lo que caracteriza los quesos como adherentes, de buena solubilidad y humedad media.
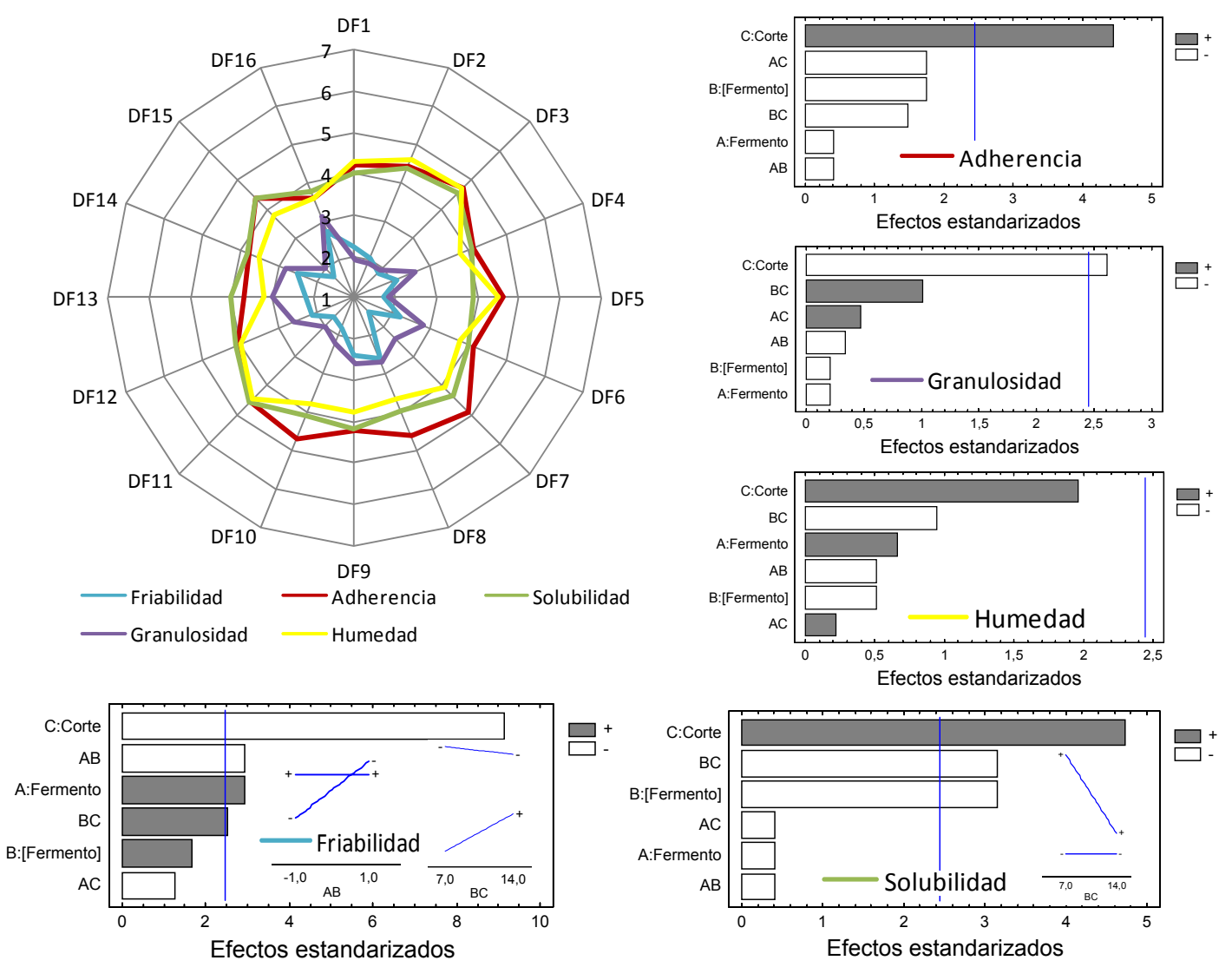

Figura 5.37. Puntuaciones de textura boca y su significación en el Diseño Factorial 
El tamaño de corte de la cuajada aparece como variable significativa para todos los descriptores, exceptuando el contenido en humedad. A medida que aumenta el tamaño de corte aumenta la solubilidad y la adherencia del queso, mientras que a medida que disminuye el tamaño de corte de la cuajada aumenta la friabilidad y la granulosidad del queso.

La friabilidad aumenta significativamente con el uso del fermento R703. Aparece como significativa la interacción del tipo de fermento con su concentración (AB) y de la concentración y el tamaño de corte (BC). A concentraciones reducidas de fermento el uso del fermento R703 proporciona quesos con mayor friabilidad mientras que a niveles altos no hay diferencias de friabilidad. A concentraciones elevadas de fermento la friabilidad aumenta con el tamaño de corte y a concentraciones bajas disminuye ligeramente al aumentar el corte (Figura 5.37).

La solubilidad también se ve afectada de manera significativa por la concentración de fermento, aumentando a medida que ésta disminuye, y por la interacción entre la concentración de fermento y el tamaño de corte. Cuando la concentración de fermento es elevada disminuye la solubilidad aún aumentando el tamaño de corte, mientras que a concentración baja de inóculo la solubilidad aumenta ligeramente al incrementar el tamaño.

\section{- Sensación en boca: intensidad y calidad del sabor, regusto y persistencia}

En la Figura 5.38 se presentan las puntuaciones obtenidas al evaluar la sensación en boca.
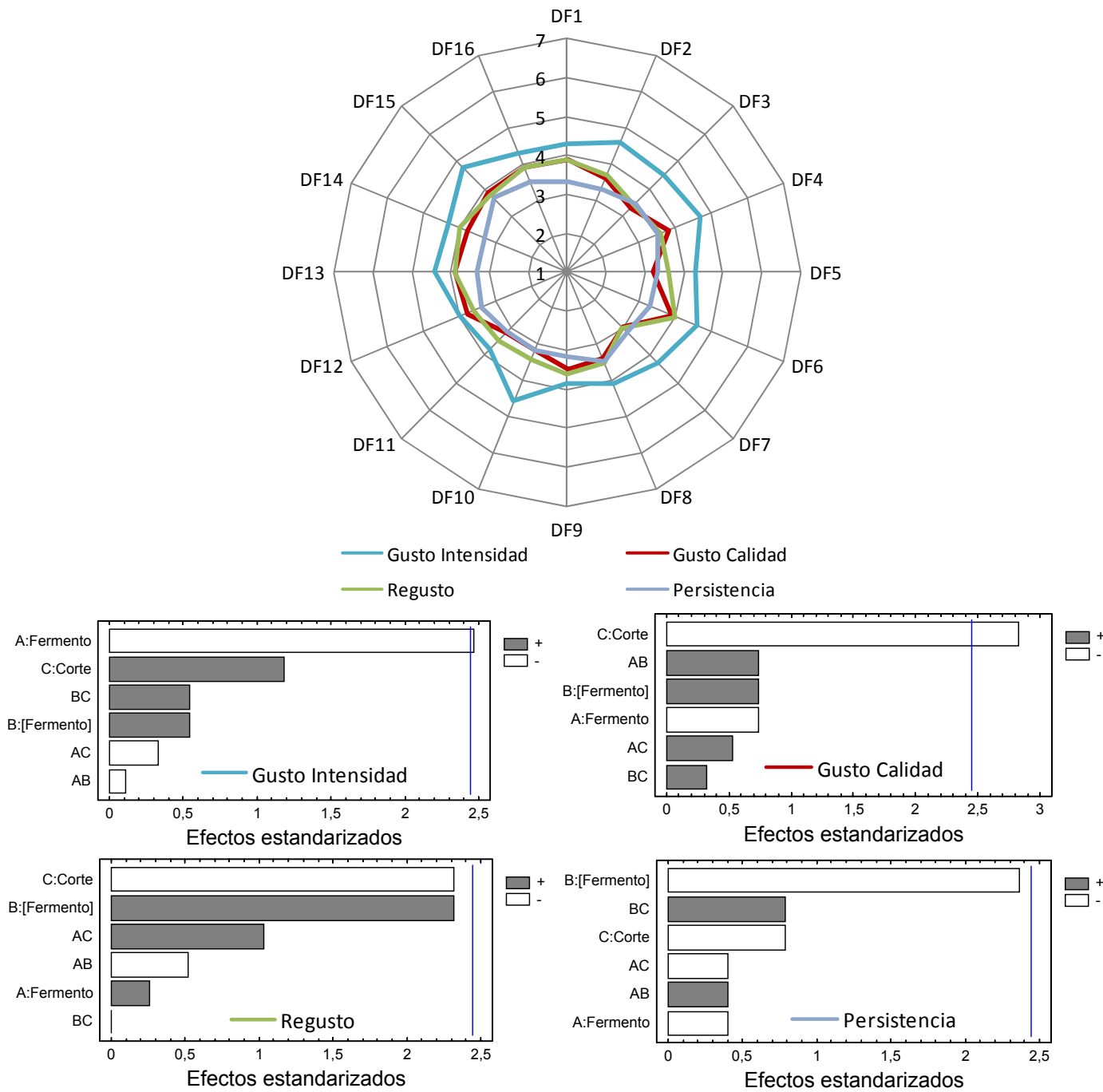

Figura 5.38. Puntuaciones de sensación en boca y su significación en el Diseño Factorial 
Los valores para la intensidad son elevados, por encima de 4 en todos los casos, mientras que los valores de calidad y regusto, nuevamente muy similares entre sí, se encuentran entre 3 y 4 . Por último la persistencia del sabor, una vez consumido el queso, resulta en general baja para todos ellos.

En cuanto a la significación de las variables optimizadas en el diseño, la intensidad del gusto resulta mejor puntuada a concentraciones bajas de fermento mientras que la calidad del gusto aumenta con tamaños de corte pequeños.

\section{- Sabor: salado, ácido y amargo}

En cuanto a los sabores elementales percibidos por los catadores, Figura 5.39, se describen ligeros amargores en algunos de los quesos y elevada acidez, que alcanza puntuaciones de 5 . En cuanto al salado también se observan diferencias entre los quesos aunque más moderadas y de valores aceptables, entre 3 y 4 en todos los casos.

La única variable que aparece como significativa es la concentración de fermento en relación con el sabor ácido del queso, observándose un aumento de acidez a medida que aumenta la concentración de fermento. El fermento R703, el cual es definido como muy acidificante por la casa comercial que lo distribuye, produce quesos con mayor acidez estando cerca de ser significativa al $95 \%$ de probabilidad.
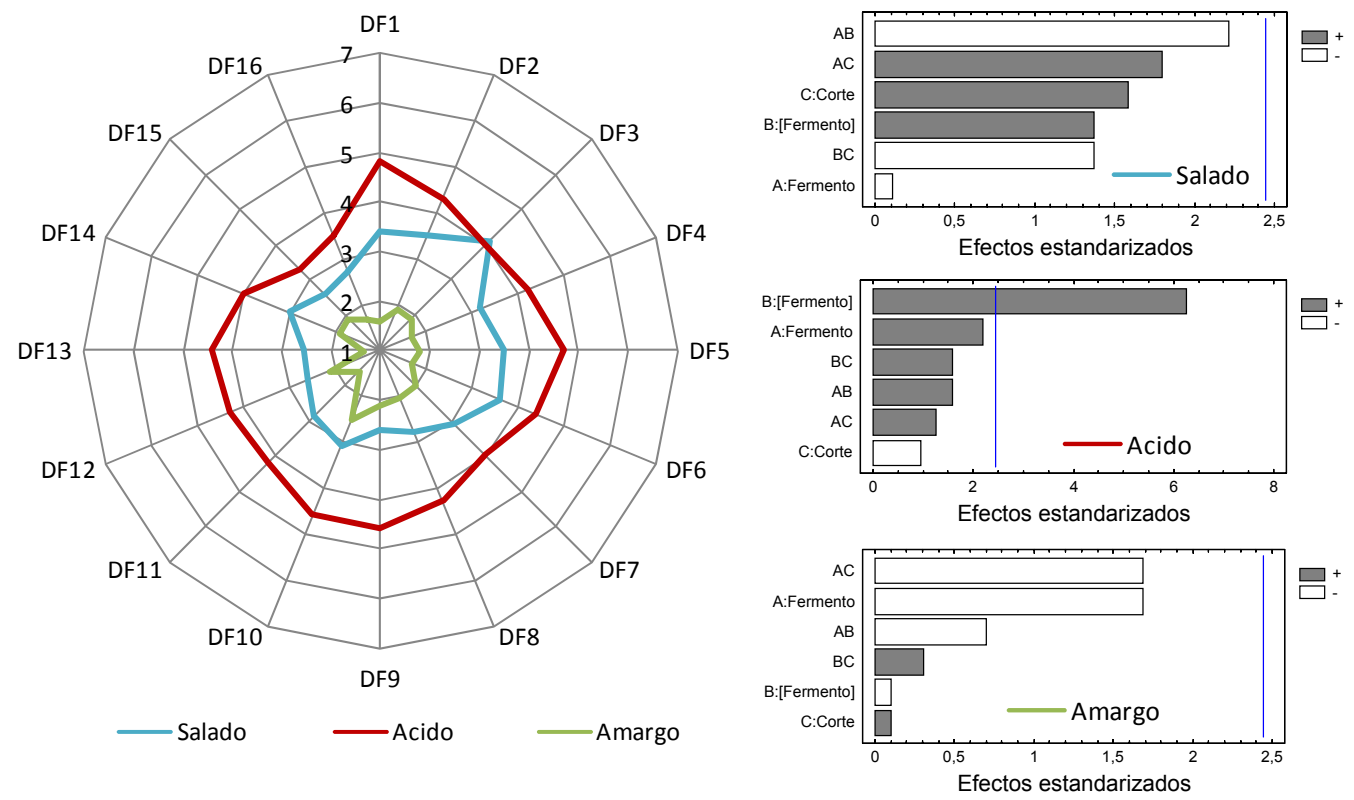

Figura 5.39. Puntuaciones de sabor y su significación en el Diseño Factorial

\section{VALORACIÓN VISUAL}

Los datos de la Figura 5.40 muestran las puntuaciones que obtuvieron los quesos en la evaluación de su aspecto interior y exterior por los catadores.

Las puntuaciones más altas y homogéneas se encuentran en la valoración del aspecto exterior, con valores entorno a 5. Para la valoración interior las puntuaciones son irregulares comprendiendo valores entre 3 y 5 , con mayores variaciones en la valoración de las aberturas derivadas de los dos tipos de corte utilizados, por un lado la lira de $3 \mathrm{~cm}$ y por otro el corte a $15 \mathrm{~cm}$. Las diferencias 
entre los distintos quesos se pueden observar en las fotografías recogidas en el Anexo 5, Figuras A.3, A.4 y A.5.
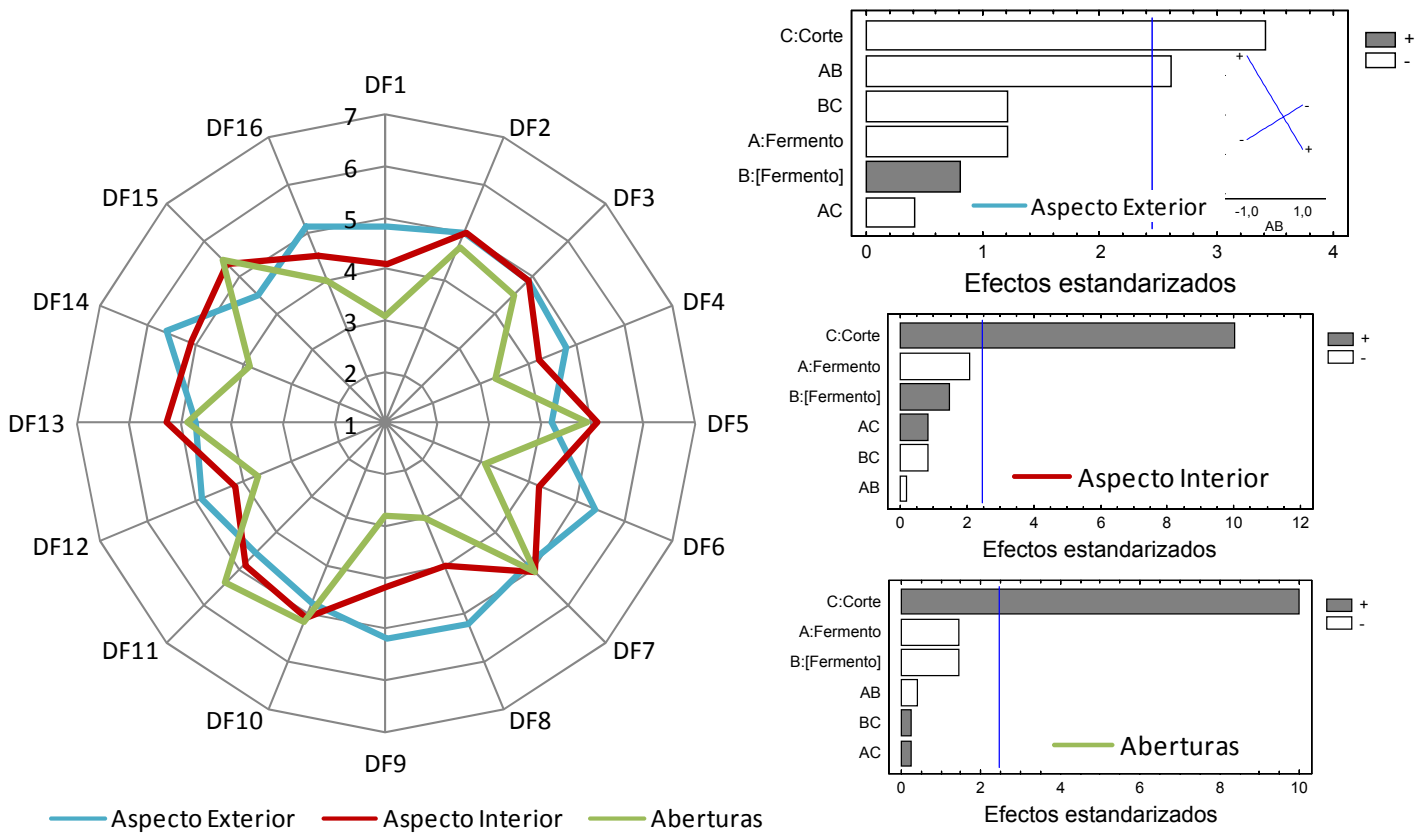

Figura 5.40. Puntuaciones fase visual y su significación en el Diseño Factorial

En todos los casos el tamaño de corte es un factor determinante del valor de la respuesta, aunque en sentidos opuestos. En la valoración exterior las puntuaciones aumentan cuando disminuye el tamaño de corte, debido a que presentan menor humedad en las primeras etapas de la maduración y consecuentemente mantienen más la forma inicial. Sin embargo los de tamaño de corte elevado tienden a atalonarse y deformarse por efecto de su propio peso. En la valoración interior ocurre lo contrario, son mejor valorados los quesos con mayor tamaño de corte en la cuajada debido a la ausencia de aberturas, en lo que se conoce como pastas ciegas.

La interacción entre el tipo de fermento y la concentración es significativa sobre el aspecto exterior, observando que a concentraciones bajas se puntua mejor por el panel de cata el queso inoculado con el fermento R703 mientras que a concentraciones altas el inoculado con el fermento MA4001.

En el estudio de Spangler et al. (1990) sobre queso Gouda, se encontraron mayor número de ojos mecánicos (aberturas) en queso ultrafiltrado elaborado mediante coagulación en continuo (coagulador Alcurd) que en la elaboración tradicional. Estos investigadores destacaban la necesidad del desarrollo de nuevos procesos tecnológicos para mejorar la fusión entre los granos de cuajada, resaltando la importancia de las etapas de sinéresis y de acidificación del coágulo para la mejora del aspecto interior del queso. En esta Tesis se propone la solución de estos problemas eliminando por completo la etapa de corte (ya que el nivel alto de este factor coincide con la medida del diámetro del molde).

\section{VALORACIONES GLOBALES}

En la valoración global de ambas etapas se alcanzan las puntuaciones de la Figura 5.41.

Se obtienen puntuaciones mayores para la valoración visual, que llegan a acercarse al 5 en alguna ocasión, donde las mejores puntuaciones corresponden a los quesos que fueron bien valorados en 
cuanto a aberturas (por ausencia de ellas). Por otra parte, los valores en la evaluación olfato-gustativa rondan la aceptabilidad y se sitúan entorno a 4.

La valoración global olfato-gustativa no se ve influenciada significativamente por ninguna de las variables. La valoración global visual se ve fuertemente influenciada por el tamaño de corte, mejorándo a tamaños de corte grandes. Aparecen significativamente mejor valoradas, a efectos globales de la fase visual, las pastas ciegas frente a los quesos que contienen ojos mecánicos o aberturas provenientes de las elaboraciones donde la cuajada se cortó en cubos de $3 \mathrm{~cm}$.
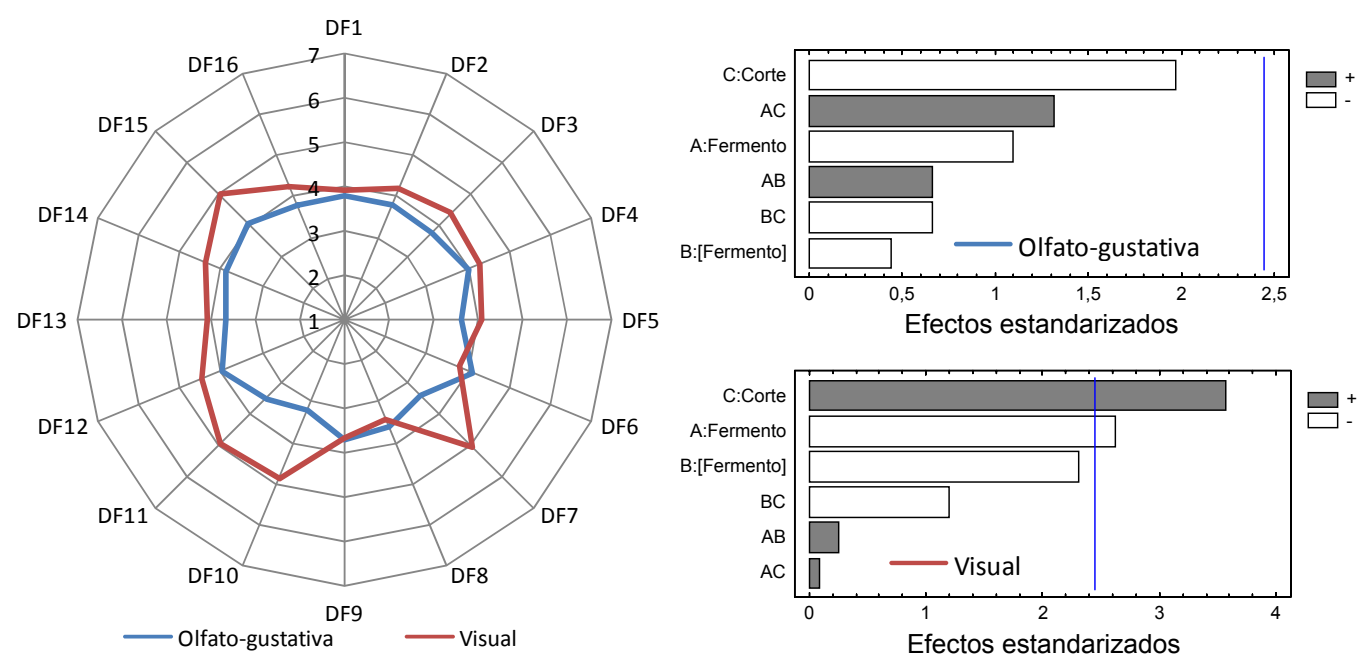

Figura 5.41. Puntuaciones globales y su significación en el Diseño Factorial

\subsubsection{EVOLUCIÓN DEL PH A LO LARGO DE LAS ELABORACIONES}

Debido a la importancia ya indicada del pH en las distintas etapas de fabricación, sobre el queso final, se realiza un seguimiento del mismo durante todo el proceso.

En la evolución del valor de pH a lo largo del proceso de fabricación, Figura 5.43, se observa como, dentro de un rango razonable $( \pm 0,5$ unidades de $\mathrm{pH})$, los datos parten de un estado similar para las primeras etapas y a lo largo del prensado se van dividiendo en dos grupos, a medida que el fermento va desarrollándose y acidificando el medio.

Analizando el efecto de los factores del diseño sobre el pH a la salida de prensa, Figura 5.42, se comprueba la gran influencia de la concentración de fermento, debida al amplio espectro de concentración estudiado. Al mismo tiempo, aparece como significativa la interacción entre la concentración de fermento y el tamaño de corte, observándose como al aumentar el tamaño de corte el pH del queso a la salida de prensa disminuye, con un descenso más acusado a concentraciones reducidas.

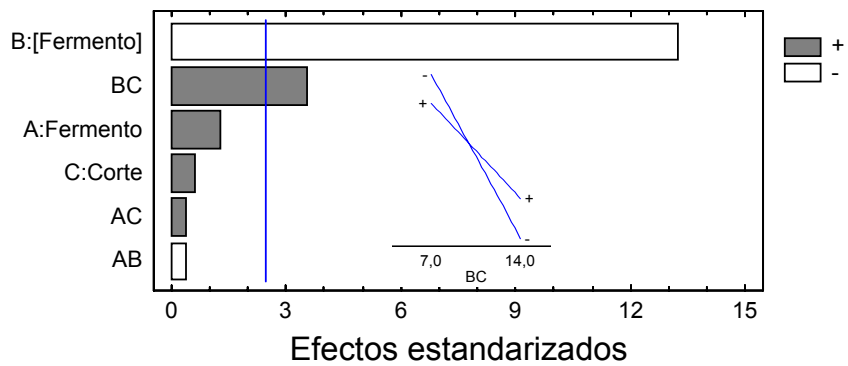

Figura 5.42. Significación del pH a la salida de prensa. Diseño Factorial 


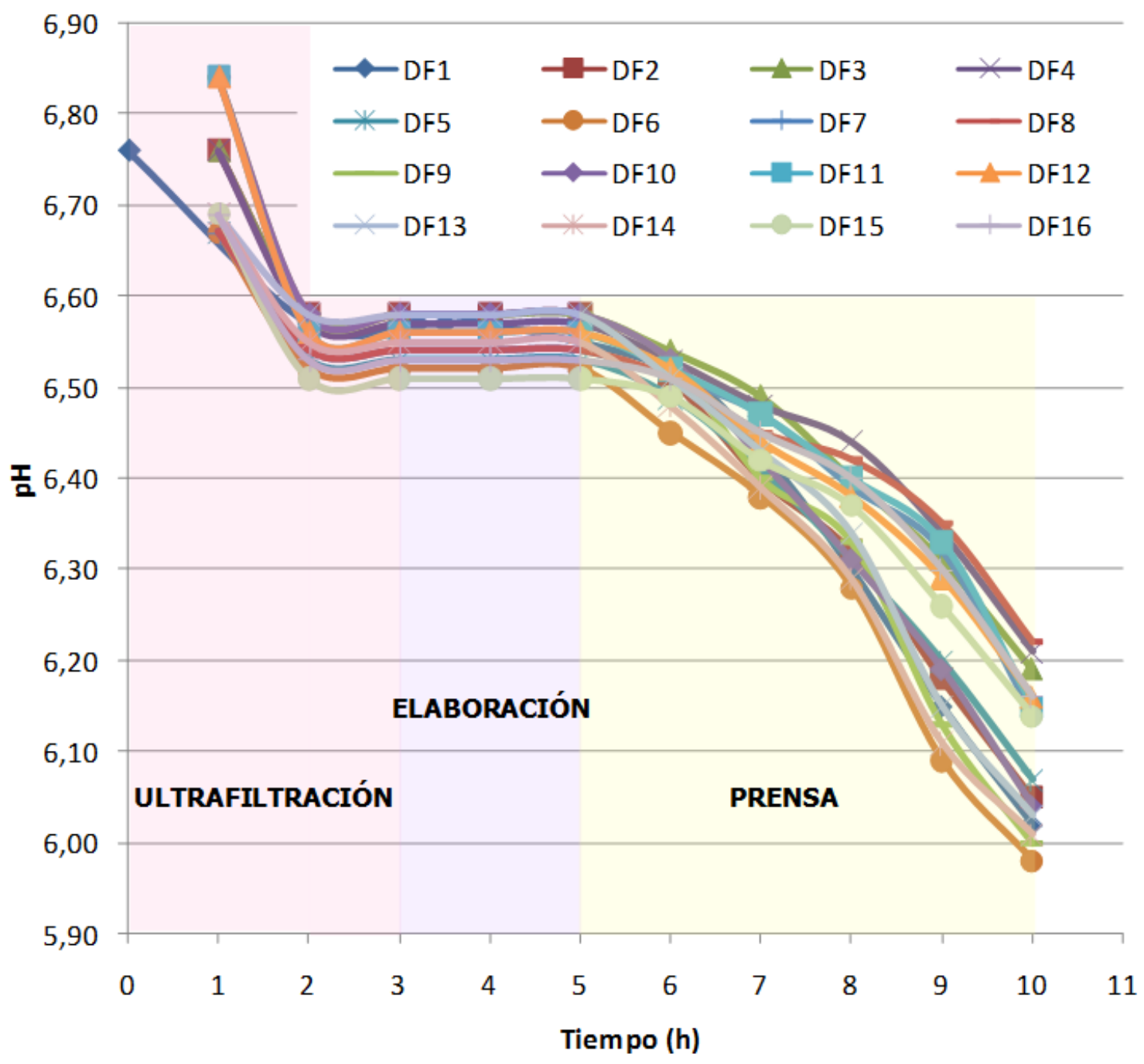

Figura 5.43. Evolución del pH en las fabricaciones del Diseño Factorial (La escala de tiempos desde la adición del fermento al prensado es cualitativa)

Como es normal, las fabricaciones realizadas con una cantidad mayor de fermento alcanzan menor $\mathrm{pH}$ a la salida de prensa, con valores entorno a 6,0 e independientes del tipo de fermento utilizado.

Por su parte, las fabricaciones con menor cantidad de fermento inoculada alcanzan valores entre una y dos décimas por encima de los anteriores.

Se demuestra, además, que la diferencia en el pH final del queso no es proporcional a la cantidad de fermento, sino que en la disminución del pH juega un papel esencial la capacidad tampón de los concentrados, con mayor influencia en los máximos observados en los estudios preliminares (Figura 5.4).

\subsubsection{OPTIMIZACIÓN DEL DISEÑO}

Como etapa final para la optimización de los tres factores estudiados en el diseño factorial -el tamaño de corte, tipo de fermento y concentración de fermento-, se realiza un último estudio en base a las variables respuesta de puntuación obtenida por los quesos en la evaluación sensorial global y de rendimiento quesero corregido, según los valores recogidos en la Tabla 5.12. 


\section{RENDIMIENTO CORREGIDO}

Los rendimientos corregidos de los 16 experimentos (Tabla 5.12) muestran valores comprendidos entre 14,5 y $16,0 \mathrm{~kg}$ de queso (normalizado al $55 \%$ de ES), por cada $100 \mathrm{~kg}$ de leche de mezcla estandarizada inicialmente.

Según se muestra en el diagrama de Pareto de la Figura 5.44 aparece nuevamente como variable significativa el tamaño de corte de la cuajada. Así mismo, se muestra en esta figura la superficie respuesta que genera la variación del rendimiento en función del tamaño de corte y de la concentración de fermento, a través de un plano que comprende la región de estudio. Se observa la mayor influencia del tamaño de corte sobre el rendimiento frente a la concentración de fermento, mediante el análisis de la pendiente del plano, acorde con la significación encontrada al resolver el diseño en base a rendimiento.
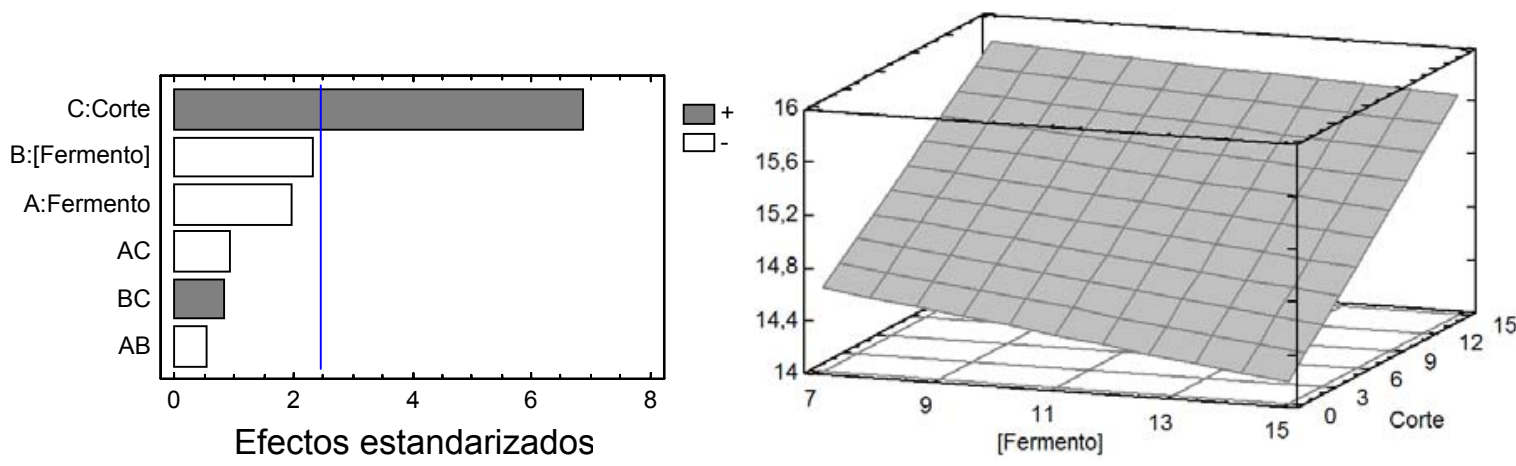

Figura 5.44. Optimización del rendimiento. Diseño Factorial

Las mismas conclusiones se obtienen al analizar los datos del análisis de varianza, Tabla 5.16, donde se aprecia un p-valor menor de 0,05 para el tamaño de corte.

Tabla 5.16. Datos del ANOVA y coeficientes de la regresión para rendimiento. Diseño Factorial

( $\mathrm{SC}=$ suma de cuadrados, $\mathrm{GL}=$ grados de libertad, $\mathrm{MC}=$ cuadrados medios)

\begin{tabular}{c|ccccc} 
Fuente & SC & GL & MC & F-ratio & p-valor \\
\hline A:Fermento & 0,276 & 1 & 0,276 & 3,73 & 0,102 \\
B:[Fermento] & 0,384 & 1 & 0,384 & 5,21 & 0,063 \\
C:Corte & 3,460 & 1 & 3,460 & 46,87 & $\mathbf{0 , 0 0 1}$ \\
AB & 0,018 & 1 & 0,018 & 0,25 & 0,637 \\
AC & 0,060 & 1 & 0,060 & 0,81 & 0,402 \\
BC & 0,048 & 1 & 0,048 & 0,66 & 0,449 \\
bloques & 0,127 & 3 & 0,042 & 0,57 & 0,654 \\
Error Total & 0,443 & 6 & 0,074 & & \\
\hline Total & 4,816 & 15 & & &
\end{tabular}

\begin{tabular}{|c|c|}
\hline \multicolumn{2}{|c|}{$\begin{array}{c}\text { Coeficientes de la } \\
\text { Regresión }\end{array}$} \\
\hline constante & 15,11 \\
\hline A:Fermento & 0,062 \\
\hline B:[Fermento] & $-0,068$ \\
\hline C:Corte & 0,050 \\
\hline AB & $-0,010$ \\
\hline AC & $-0,010$ \\
\hline BC & 0,003 \\
\hline
\end{tabular}

Mediante el ANOVA se comprueba que la variabilidad debida al bloque (leche de partida) no es significativa con respecto al error experimental, por lo que la estandarización ha sido efectiva para unificar la materia prima de partida. Por último, en el estudio de las interacciones dobles ninguna aparece como significativa. 
Según estos resultados el rendimiento aumenta a medida que aumenta el tamaño de corte. El resto de variables, aunque no son significativas, mejoran el rendimiento en su nivel bajo, lo que significa concentración baja del fermento empleado en la elaboración tradicional (MA4001).

\section{ACEPTACIÓN SENSORIAL GLOBAL}

En la optimización de la calidad sensorial de los distintos quesos elaborados, analizando conjuntamente el aspecto visual y la valoración olfato-gustativa, se observa una situación complementaria a lo ocurrido en la optimización en base a rendimiento. En este caso, aparecen como variables significativas el tipo de fermento utilizado y la concentración inoculada del mismo.

Las puntuaciones sensoriales se incrementan significativamente a valores bajos de inóculo así como mediante el empleo del fermento MA4001, como se puede observar en la Figura 5.45.
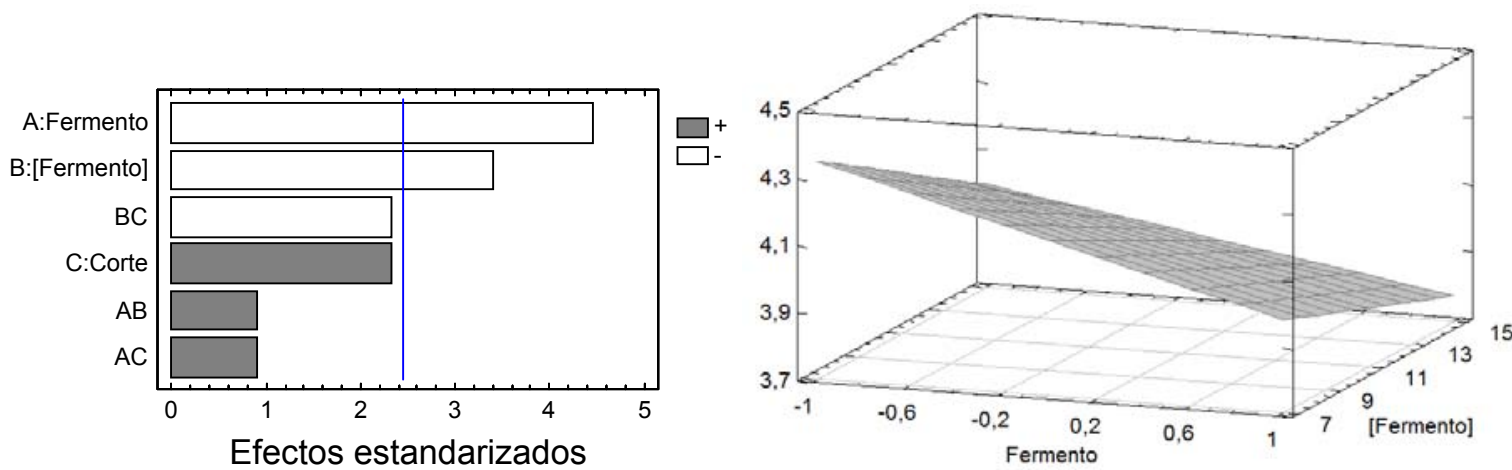

Figura 5.45. Optimización de la calidad sensorial. Diseño Factorial

Si bien el tamaño de corte no resulta significativo, se aumenta la valoración sensorial a valores elevados de éste.

De acuerdo con los datos del ANOVA, Tabla 5.17, se comprueba la significación de dichos factores así como la correcta estandarización de la leche ya que, al igual que ocurrió con el rendimiento, el factor bloque no resulta significativo.

Tabla 5.17. Datos del ANOVA y coeficientes de la regresión para calidad sensorial. Diseño Factorial ( $\mathrm{SC}=$ suma de cuadrados, $\mathrm{GL}=$ grados de libertad, $\mathrm{MC}=$ cuadrados medios)

\begin{tabular}{c|ccccc} 
Fuente & SC & GL & MC & F-ratio & p-valor \\
\hline A:Fermento & 0,366 & 1 & 0,366 & 18,47 & $\mathbf{0 , 0 0 5}$ \\
B:[Fermento] & 0,226 & 1 & 0,226 & 11,40 & $\mathbf{0 , 0 1 5}$ \\
C:Corte & 0,080 & 1 & 0,080 & 4,02 & 0,092 \\
AB & 0,016 & 1 & 0,016 & 0,79 & 0,409 \\
AC & 0,016 & 1 & 0,016 & 0,79 & 0,409 \\
BC & 0,106 & 1 & 0,106 & 5,34 & 0,060 \\
bloques & 0,122 & 3 & 0,041 & 2,05 & 0,208 \\
Error Total & 0,119 & 6 & 0,020 & & \\
\hline Total & 1,099 & 15 & & &
\end{tabular}

\begin{tabular}{|c|c|}
\hline \multicolumn{2}{|c|}{$\begin{array}{c}\text { Coeficientes de la } \\
\text { regresión }\end{array}$} \\
\hline constante & 3,91 \\
\hline A:Fermento & $-0,281$ \\
\hline B:[Fermento] & 0,001 \\
\hline C:Corte & 0,047 \\
\hline AB & 0,008 \\
\hline AC & 0,005 \\
\hline BC & $-0,003$ \\
\hline
\end{tabular}


A través de los coeficientes de regresión (Tabla 5.16 y 5.17), es posible predecir la respuesta correspondiente -rendimiento o calidad sensorial-, sumando al valor de la constante el resultado de multiplicar cada coeficiente por el valor deseado de los factores, dentro de la zona estudiada, lo que corresponde con la ecuación de los planos de las Figuras 5.44 y 5.45 .

\section{OPTIMIZACIÓN MÚLTIPLE}

A través de la optimización de respuesta múltiple (sensorial global y rendimiento) se obtienen los valores definitivos de los tres factores que maximizan conjuntamente ambas respuestas, Tabla 5.18 .

Tabla 5.18. Optimización de respuesta múltiple para el Diseño Factorial

\begin{tabular}{|c|c|c|}
\hline VARIABLE & Óptimo & Unidades \\
\hline Tipo de fermento & MA4001 & \\
\hline Concentración de fermento & 6 & DCU/100 L de concentrado \\
\hline Tamaño de corte de la cuajada & 15 & $\mathrm{~cm}$ de haz de lira \\
\hline
\end{tabular}

Estas condiciones óptimas conducen, a través de un modelo lineal de optimización múltiple, a los siguientes valores de las respuestas:

c Rendimiento $=15,8 \%$

c. Puntuación sensorial global compuesta $=4,5$

Estos datos de rendimiento y calidad sensorial obtenidos a través del modelo teórico en la optimización múltiple -al igual que las condiciones óptimas alcanzadas con el resto de diseños de la secuencia experimental- se comparan con los experimentales en el Apartado 5.5.9.

\subsubsection{CONCLUSIONES DEL DISEÑO}

A continuación se comparan las condiciones de cada factor que establece el óptimo de respuesta múltiple (calidad sensorial y rendimiento) con los resultados obtenidos en la evaluación instrumental de la textura y en los descriptores del análisis sensorial. El resumen comparativo de todos ellos se recoge en el Anexo A.3 (Tabla A.18).

Esta visión global permite conocer el grado de idoneidad de las decisiones tomadas, ya que son muchas las cualidades del queso que varían al cambiar el nivel de un factor.

\section{r. Tipo de fermento (A)}

Se decide continuar con el fermento usado en la elaboración tradicional, MA4001, de acuerdo con la optimización multiple. Este hecho está en concordancia con el análisis descriptivo del queso, donde el $79 \%$ de los descriptores analizados maximizan su respuesta con el fermento MA4001. De todos los casos el tipo de fermento ha resultado ser significativo en seis ocasiones. En cinco de ellas el fermento MA4001 afecta significativamente aumentando la puntuación en la calidad y la intensidad del olor (debido a la presencia de cepas productoras de aromas), en la calidad en boca 
así como en la puntuación global de la fase visual y de la global compuesta. Por su parte el fermento R703 resultó ser significativo en el aumento de la friabilidad en el queso.

c Concentración de fermento (B)

Si nos fijamos en la concentración de fermento, el $62 \%$ de los descriptores estudiados coinciden en la elección optima del nivel más bajo de inóculo (6 DCU/100 L) seleccionado en la optimización múltiple. En cuatro de ellos la variabilidad asociada a la concentración resultó ser significativa, aumentando la solubilidad del queso y la valoración global compuesta a niveles bajos, mientras que se produce un aumento de la adherencia y del sabor ácido a concentración elevada de fermento.

Estos resultados son acordes con los obtenidos por Spangler et al. (1991) en la elaboración de queso Gouda, quienes encontraron que a mayor concentración de fermento se favorecen los procesos de sinéresis, por lo que al aumentar la citada concentración los quesos son menos húmedos (y consecuentemente menos solubles), a la vez que se favorece la disminución del pH y los excesos de acidez.

\section{c Tamaño de corte de la cuajada (C)}

La aparición de defectos de textura como oquedades en el interior de los quesos, debido a la mala fusión de los granos de cuajada (en parte atribuible a su menor dureza) ha sido observada por Delbeke (1987) al elaborar queso Saint-Paulin mediante total concentración de la leche hasta prequeso líquido -proceso MMV (Maubois et al. 1969)-.

La magnitud de las oquedades encontradas en el interior de los quesos elaborados en el presente diseño se observa a través de las imágenes de los quesos de las 16 fabricaciones que se recogen en el Anexo A.6 (Figuras A.6-A.8).

La aparición de estos ojos mecánicos o aberturas hace que el algoritmo de optimización múltiple seleccione un mayor tamaño de corte, hasta valores iguales a los del diámetro del molde, como consecuencia de la mejor valoración visual de los quesos. Esto se traduce en la eliminación de la etapa de corte de la cuajada y la obtención de quesos de pasta ciego. La ausencia de corte en la cuajada, además de una simplificación tecnológica con reducción del tiempo total de procesado, presenta beneficios para una posible adaptación global del proceso para la fabricación en continuo.

Según la Tabla A.18 del Anexo A.3, de todas las variables respuesta analizadas en el diseño el tamaño de corte óptimo en su nivel alto coincide con el $41 \%$ de los casos. En 15 ocasiones resultó ser una variable significativa en la optimización, con valores enfrentados. El tamaño de corte pequeño maximiza la firmeza (tanto instrumental como sensorial), cohesividad, masticabilidad, rugosidad, friabilidad o granulosidad del queso, así como la calidad de la sensación generada en boca y la valoración exterior del queso. Por otra parte la ausencia de corte aumenta la solubilidad y la adherencia del queso, la valoración visual en cuanto al interior de la pasta y a la presencia de aberturas, la valoración global visual así como el rendimiento quesero.

Por todo ello, se considera adecuado el resultado de la optimización múltiple (Tabla 5.18), procediéndose a la eliminación de la etapa de corte en el proceso de elaboración de queso a partir de concentrados de ultrafiltración.

Los posibles defectos de textura originados a causa de esta manera de operar se intentarán amortiguar en la siguiente etapa de optimización actuando sobre la etapa de prensado. 


\subsection{OPTIMIZACIÓN DEL PROCESO DE ACIDIFICACIÓN EN PRENSA}

Como último paso de la secuencia experimental, una vez optimizado el tipo y la cantidad de fermento a utilizar, es necesario alcanzar a la salida de prensa el pH adecuado para el tipo de queso estudiado ( $\mathrm{pH}=5,15-5,30)$, en el menor tiempo y en las mejores condiciones posibles, para garantizar la calidad y seguridad del producto final.

Los resultados alcanzados en esta etapa, junto a los conseguidos en las anteriores, constituirán en su conjunto las condiciones tecnológicas finales del proceso de elaboración del queso de pasta prensada semicurado de mezcla elaborado a partir de retenidos de ultrafiltración, complementando la tecnología tradicional de elaboración con la tecnología de filtración tangencial.

\subsubsection{DISEÑO EXPERIMENTAL}

En este diseño se establece un modelo de superficie respuesta central compuesto, con las características indicadas en la Metodología (Apartado 3.4), estudiando el tiempo de premaduración de la leche y el tiempo de prensado, a los niveles de ambos factores recogidos en la Tabla 5.19. Al tratarse de un modelo polinomial son necesarios tres niveles para cada uno de los factores.

Se estudiará el efecto del tiempo de prensado, con valores entre 5 y 15 horas y del tiempo de premaduración del fermento a una temperatura de $37^{\circ} \mathrm{C}$, entre valores de 1 y 5 horas. El resto de variables se fijarán según las condiciones establecidas en los diseños anteriores, Plackett-Burmann (Tabla 5.10) y Factorial (Tabla 5.18).

La inclusión en la elaboración de una etapa de premaduración ha sido estudiada, también, por otros autores como un método para conseguir el pH final del queso en mejores condiciones, orientado a la elaboración de quesos madurados. Como ejemplo de este tipo de quesos, el Cheddar es el más ampliamente estudiado (Ernstrom 1980). La temperatura de $37^{\circ} \mathrm{C}$ para activar el fermento ha sido utilizada con anterioridad en la elaboración de quesos como Mozzarella o Cheddar (Covacevich y Kosikowski 1978).

Tabla 5.19. Niveles de las variables para el diseño de Superficie Respuesta

\begin{tabular}{|c|c|c|c|c|c|}
\hline Código & FACTORES & $\begin{array}{c}\text { Rango } \\
\text { alto }\end{array}$ & $\begin{array}{c}\text { Rango } \\
\text { Medio }\end{array}$ & $\begin{array}{c}\text { Rango } \\
\text { bajo }\end{array}$ & Unidades \\
\hline A & Tiempo de premaduración & 5 & 3 & 1 & $\mathrm{~h}$ \\
\hline B & Tiempo de prensado & 15 & 10 & 5 & $\mathrm{~h}$ \\
\hline
\end{tabular}

La matriz de experimentos se realiza a partir de un diseño factorial $2^{2}$ al que se le añaden dos réplicas en el punto central (rango medio) y cuatro puntos axiales. Mediante la inclusión de los puntos axiales se amplían los rangos de experimentación; para el prensado los tiempos se amplían desde las 3 a las 17 h y para el tiempo de premaduración de las 0,2 h (12 minutos) a las 5,8 h.

Con estas consideraciones, el resultado es un diseño que consta de 10 experimentos. Para estimar mejor el error se duplica el diseño, por lo que el número total de fabricaciones será de 20. Para evitar la posible variabilidad introducida por la leche de partida se bloquea el diseño en cuanto a la leche de fabricación. Los experimentos finales, divididos en cuatro bloques experimentales, se recogen en la Tabla 5.20. 
Tabla 5.20. Matriz de experimentos del diseño de Superficie Respuesta

\begin{tabular}{|c|c|c|c|c|c|}
\hline & BLOQUE & PRENSA & PREMADURA. & $\% \mathrm{R} *$ & Sensorial \\
\hline SR1 & 1 & 10 & 3 & 14,99 & 4,5 \\
\hline SR2 & 1 & 5 & 1 & 14,32 & 4,6 \\
\hline SR3 & 1 & 5 & 5 & 14,56 & 4,4 \\
\hline SR4 & 1 & 15 & 1 & 15,20 & 4,3 \\
\hline SR5 & 1 & 15 & 5 & 15,47 & 4,6 \\
\hline SR6 & 2 & 10 & 3 & 15,68 & 4,8 \\
\hline SR7 & 2 & 3 & 3 & 15,58 & 4,3 \\
\hline SR8 & 2 & 10 & 5,8 & 14,81 & 3,9 \\
\hline SR9 & 2 & 10 & 0,2 & 15,52 & 4,9 \\
\hline SR10 & 2 & 17 & 3 & 14,30 & 4,3 \\
\hline SR11 & 3 & 10 & 3 & 14,28 & 4,2 \\
\hline SR12 & 3 & 5 & 1 & 14,12 & 4,6 \\
\hline SR13 & 3 & 5 & 5 & 14,24 & 4,9 \\
\hline SR14 & 3 & 15 & 1 & 14,52 & 4,4 \\
\hline SR15 & 3 & 15 & 5 & 14,49 & 4,2 \\
\hline SR16 & 4 & 10 & 3 & 15,37 & 4,8 \\
\hline SR17 & 4 & 3 & 3 & 14,95 & 4,6 \\
\hline SR18 & 4 & 10 & 5,8 & 15,60 & 4,4 \\
\hline SR19 & 4 & 10 & 0,2 & 15,16 & 4,7 \\
\hline SR20 & 4 & 17 & 3 & 15,50 & 4,5 \\
\hline
\end{tabular}

* Rendimiento corregido para quesos de un $55 \%$ de extracto seco $(\mathrm{kg} / 100 \mathrm{~kg}$ de leche)

\subsubsection{ESTUDIO FÍSICO-QUÍMICO}

A continuación se recogen los resultados de composición y $\mathrm{pH}$, tanto de la leche de mezcla de partida como de los permeados y concentrados generados en la fase de ultrafiltración. Así mismo, se presentan estos mismos valores para los quesos finales a los 20 y 40 días de maduración.

\section{LECHES, CONCENTRADOS Y PERMEADOS}

Las variaciones en cuanto a composición de la leche de vaca y oveja que componen la mezcla se recogen en el Anexo A.1 (Tablas A.5 y A.6).

Al igual que en casos anteriores se comprueba la calidad de la leche inicial (vaca y oveja) mediante el recuento de células somáticas y el test de inhibidores. Los valores de células se encontraron siempre por debajo de las 400.000 células/mL en vaca, de acuerdo con el Reglamento 853/2004, y de 800.000 células/mL para oveja. También se comprueba la ausencia de residuos de antibióticos. 
En la Tabla 5.21 se muestran los datos de composición de la leche tras la etapa de estandarización en grasa y proteína, a través de la mezcla vaca/oveja. Los valores alcanzados son acordes con el criterio establecido tanto para la grasa $(4,0 \pm 0,2 \%)$ como para la proteína $(3,5 \pm 0,1 \%)$.

Tabla 5.21. Composición química de la leche de mezcla y pH. Diseño de Superficie Respuesta

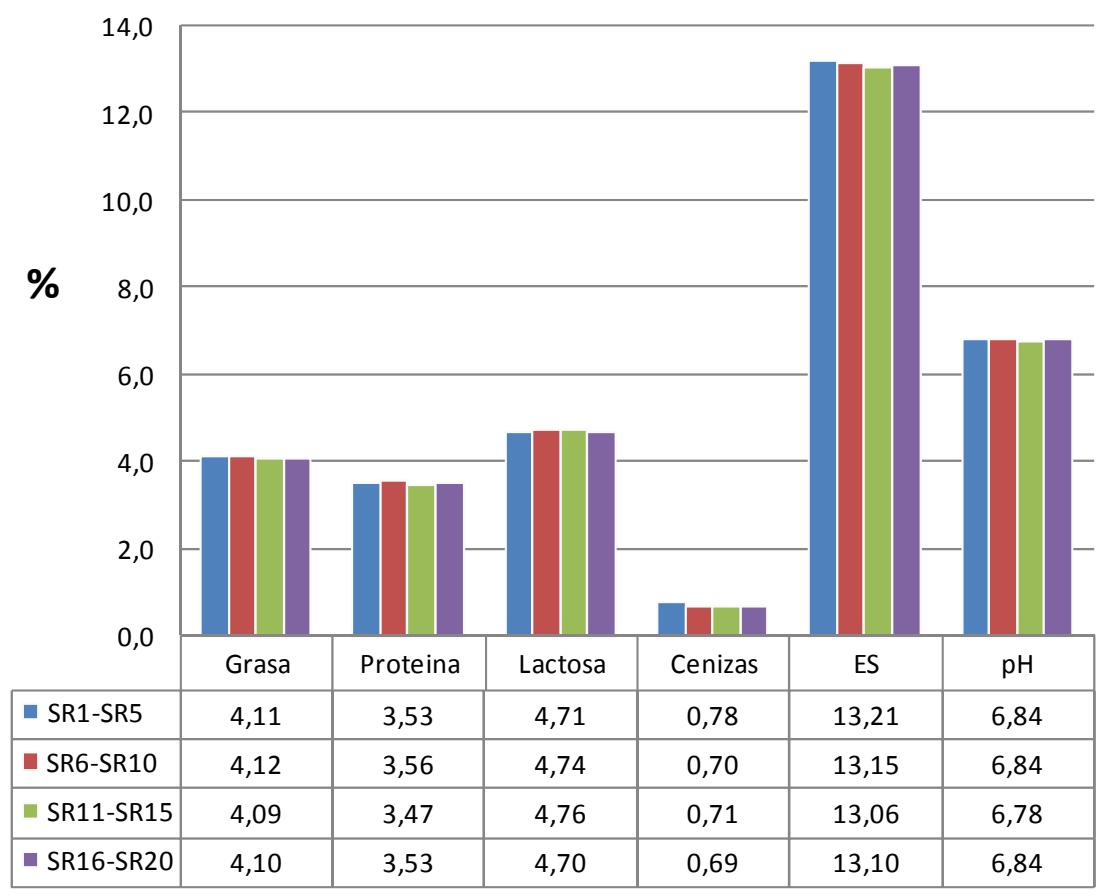

Como el diseño está estructurado en cuatro bloques de cinco experimentos cada uno (SR1-SR5, SR6-SR10, SR11-SR15 y SR16-SR20), las leches de partida coinciden con el número de bloques, al igual que los permeados de ultrafiltración. En cuanto a los retenidos se pasa a tener veinte muestras debido a que cada concentrado se divide en cinco lotes a partir de los que se realizan las distintas elaboraciones del diseño.

Los valores de composición de los permeados obtenidos tras la ultrafiltración de las cuatro leches de partida se recogen en la Tabla 5.22.

Tabla 5.22. Composición química de los cuatro permeados. Diseño Superficie Respuesta

\begin{tabular}{|c|c|c|c|c|}
\hline$\%$ en peso & SR1-SR5 & SR6-SR10 & SR11-SR15 & SR16-SR20 \\
\hline Grasa & 0,00 & 0,00 & 0,00 & 0,00 \\
\hline Proteína & $0,21^{\mathrm{b}} \pm 0,01$ & $0,18^{\mathrm{a}} \pm 0,01$ & $0,18^{\mathrm{a}} \pm 0,01$ & $0,24^{\mathrm{b}} \pm 0,01$ \\
\hline Cenizas & $0,41^{\mathrm{a}} \pm 0,01$ & $0,42^{\mathrm{a}} \pm 0,05$ & $0,40^{\mathrm{a}} \pm 0,03$ & $0,39^{\mathrm{a}} \pm 0,01$ \\
\hline ES & $5,48^{\mathrm{b}} \pm 0,05$ & $5,53^{\mathrm{b}} \pm 0,10$ & $5,49^{\mathrm{b}} \pm 0,06$ & $5,30^{\mathrm{a}} \pm 0,10$ \\
\hline Lactosa & 4,86 & 4,93 & 4,91 & 4,67 \\
\hline
\end{tabular}

${ }^{*}$ Valores con la misma letra en la misma fila no son significativamente diferentes $(p<0,05)$

Los valores de la concentración de proteína se dividen en dos grupos de concentración muy parecida. Algo similar ocurre con el extracto seco donde el permeado correspondiente al bloque SR16-SR20 tiene una cantidad de sólidos algo inferior al resto. Por su parte los valores de cenizas se pueden considerar iguales entre sí. Los resultados obtenidos se consideran correctos ya que las variaciones detectadas son muy pequeñas, al igual que el error experimental.

La composición y pH de los concentrados (retenidos de UF), se recogen en la Tabla 5.23. 
Tabla 5.23. Composición química y pH de los veinte retenidos de UF. Diseño Superficie Respuesta

\begin{tabular}{|c|c|c|c|c|c|c|}
\hline$\%$ en peso & Grasa & Proteína & Cenizas & ES & Lactosa & pH \\
\hline \multirow{2}{*}{ SR1 } & $19,50^{a}$ & $16,81^{a}$ & $1,68^{a}$ & $41,29^{\mathrm{abcd}}$ & \multirow{2}{*}{3,31} & $6,51^{\mathrm{bcd}}$ \\
\hline & $\pm 0,00$ & $\pm 0,33$ & $\pm 0,01$ & $\pm 0,02$ & & $\pm 0,01$ \\
\hline \multirow{2}{*}{ SR2 } & $19,75^{a}$ & $16,86^{a}$ & $1,63^{a}$ & $41,45^{\mathrm{bcd}}$ & \multirow{2}{*}{3,21} & $6,49^{\mathrm{ab}}$ \\
\hline & $\pm 0,49$ & $\pm 0,27$ & $\pm 0,16$ & $\pm 0,17$ & & $\pm 0,01$ \\
\hline \multirow{2}{*}{ SR3 } & $20,00^{a}$ & $16,47^{\mathrm{a}}$ & $1,65^{a}$ & $41,42^{\mathrm{bcd}}$ & \multirow{2}{*}{3,30} & $6,49^{a b}$ \\
\hline & $\pm 0,00$ & $\pm 0,86$ & $\pm 0,08$ & $\pm 0,29$ & & $\pm 0,01$ \\
\hline \multirow{2}{*}{ SR4 } & $20,00^{a}$ & $16,15^{\mathrm{a}}$ & $1,67^{a}$ & $41,29^{\mathrm{abcd}}$ & \multirow{2}{*}{3,47} & $6,53^{\mathrm{de}}$ \\
\hline & $\pm 0,00$ & $\pm 0,38$ & $\pm 0,14$ & $\pm 0,04$ & & $\pm 0,01$ \\
\hline \multirow{2}{*}{ SR5 } & $19,75^{a}$ & $16,34^{\mathrm{a}}$ & $1,66^{a}$ & $41,18^{\mathrm{abcd}}$ & \multirow{2}{*}{3,44} & $6,52^{\text {cde }}$ \\
\hline & $\pm 0,49$ & $\pm 1,02$ & $\pm 0,07$ & $\pm 0,29$ & & $\pm 0,01$ \\
\hline \multirow{2}{*}{ SR6 } & $19,75^{a}$ & $16,20^{a}$ & $1,55^{a}$ & $41,37^{\mathrm{abcd}}$ & \multirow{2}{*}{3,87} & $6,53^{\mathrm{de}}$ \\
\hline & $\pm 0,49$ & $\pm 0,79$ & $\pm 0,03$ & $\pm 0,62$ & & $\pm 0,01$ \\
\hline \multirow{2}{*}{ SR7 } & $20,00^{a}$ & $16,73^{a}$ & $1,53^{a}$ & $41,54^{\text {cd }}$ & \multirow{2}{*}{3,28} & $6,52^{\text {cde }}$ \\
\hline & $\pm 0,00$ & $\pm 0,25$ & $\pm 0,00$ & $\pm 0,13$ & & $\pm 0,01$ \\
\hline \multirow{2}{*}{ SR8 } & $19,50^{a}$ & $16,49^{a}$ & $1,72^{a}$ & $40,91^{\mathrm{ab}}$ & \multirow{2}{*}{3,20} & $6,51^{\mathrm{bcd}}$ \\
\hline & $\pm 0,50$ & $\pm 0,82$ & $\pm 0,04$ & $\pm 0,15$ & & $\pm 0,01$ \\
\hline \multirow{2}{*}{ SR9 } & $19,75^{a}$ & $16,49^{a}$ & $1,63^{a}$ & $40,86^{a b}$ & \multirow{2}{*}{3,00} & $6,51^{\text {bcd }}$ \\
\hline & $\pm 0,50$ & $\pm 0,82$ & $\pm 0,10$ & $\pm 0,22$ & & $\pm 0,01$ \\
\hline \multirow{2}{*}{ SR10 } & $19,25^{a}$ & $16,30^{a}$ & $1,57^{a}$ & $40,76^{a}$ & \multirow{2}{*}{3,65} & $6,51^{\mathrm{bcd}}$ \\
\hline & $\pm 0,50$ & $\pm 0,56$ & $\pm 0,04$ & $\pm 0,22$ & & $\pm 0,01$ \\
\hline \multirow{2}{*}{ SR11 } & $20,00^{a}$ & $16,40^{a}$ & $1,69^{a}$ & $41,49^{\mathrm{bcd}}$ & \multirow{2}{*}{3,40} & $6,53^{\mathrm{de}}$ \\
\hline & $\pm 0,00$ & $\pm 0,85$ & $\pm 0,04$ & $\pm 0,03$ & & $\pm 0,01$ \\
\hline \multirow{2}{*}{ SR12 } & $20,00^{a}$ & $16,51^{\mathrm{a}}$ & $1,69^{a}$ & $41,43^{\text {bcd }}$ & \multirow{2}{*}{3,24} & $6,50^{\mathrm{abc}}$ \\
\hline & $\pm 0,00$ & $\pm 0,70$ & $\pm 0,19$ & $\pm 0,10$ & & $\pm 0,01$ \\
\hline \multirow{2}{*}{ SR13 } & $20,00^{a}$ & $16,56^{a}$ & $1,59^{a}$ & $41,40^{\mathrm{abcd}}$ & ת & $6,51^{\mathrm{bcd}}$ \\
\hline & $\pm 0,00$ & $\pm 0,64$ & $\pm 0,01$ & $\pm 0,23$ & $3, \angle b$ & $\pm 0,01$ \\
\hline & $19,75^{a}$ & $16,32^{a}$ & $1,69^{a}$ & $41,38^{\mathrm{abcd}}$ & ra & $6,53^{\text {de }}$ \\
\hline SK 14 & $\pm 0,50$ & $\pm 0,72$ & $\pm 0,16$ & $\pm 0,02$ & (3,00 & $\pm 0,01$ \\
\hline - & $20,00^{a}$ & $16,38^{a}$ & $1,61^{a}$ & $41,57^{d}$ & 0 & $6,54^{\mathrm{e}}$ \\
\hline & $\pm 0,00$ & $\pm 0,84$ & $\pm 0,16$ & $\pm 0,01$ & 3,00 & $\pm 0,01$ \\
\hline CDI & $20,00^{a}$ & $16,71^{a}$ & $1,64^{a}$ & $41,63^{d}$ & 000 & $6,49^{a b}$ \\
\hline SN10 & $\pm 0,00$ & $\pm 0,30$ & $\pm 0,03$ & $\pm 0,17$ & $0, \angle 0$ & $\pm 0,01$ \\
\hline cnt7 & $19,75^{\mathrm{a}}$ & $16,63^{a}$ & $1,66^{a}$ & $41,26^{\mathrm{abcd}}$ & ר? ? & $6,51^{\mathrm{bcd}}$ \\
\hline 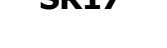 & $\pm 0,50$ & $\pm 0,04$ & $\pm 0,05$ & $\pm 0,27$ & & $\pm 0,01$ \\
\hline CD10 & $20,00^{a}$ & $16,66^{\mathrm{a}}$ & $1,62^{a}$ & $41,48^{\mathrm{bcd}}$ & 320 & $6,48^{a}$ \\
\hline & $\pm 0,00$ & $\pm 0,26$ & $\pm 0,05$ & $\pm 0,25$ & & $\pm 0,01$ \\
\hline CD10 & $20,00^{a}$ & $16,68^{a}$ & $1,61^{a}$ & $41,68^{d}$ & 230 & 6,48 \\
\hline SK 19 & $\pm 0,00$ & $\pm 0,33$ & $\pm 0,00$ & $\pm 0,23$ & 0,09 & $\pm 0,01$ \\
\hline CD? & $19,50^{\mathrm{a}}$ & $16,69^{a}$ & $1,62^{a}$ & $41,33^{\mathrm{abcd}}$ & 352 & $6,51^{\mathrm{bcd}}$ \\
\hline उNर20 & $\pm 0,00$ & $\pm 0,07$ & $\pm 0,13$ & $\pm 0,11$ & (3,0 & $\pm 0,01$ \\
\hline
\end{tabular}

${ }^{*}$ Valores con la misma letra en la misma columna no son significativamente diferentes $(p<0,05)$ 
Según los resultados del análisis de varianza, los valores de grasa, proteína y cenizas de los retenidos de UF se pueden considerar iguales, a un $95 \%$ de probabilidad.

En cuanto al extracto seco los datos se dividen en cuatro grupos, si bien uno de ellos engloba a diecisiete de los veinte concentrados y hay una muy alta interrelación entre los grupos, por lo que a efectos prácticos se considera que la materia prima de partida para elaborar los quesos del diseño no es un factor que aporte variabilidad al diseño, si bien se comprobará mediante el estudio de la significación de los bloques.

Para el pH de los concentrados ocurre algo similar a lo obtenido en la determinación del extracto seco; los valores se pueden considerar iguales dentro de cinco grupos dependientes unos de otros. La variación total entre el mayor y el menor valor no es superior a media décima de $\mathrm{pH}$, por lo que la división en grupos se debe más al bajo error experimental en la medida (error de 0,01) que a diferencias significativas entre experimentos. Esta igualdad en los valores del pH de partida es muy importante ya que esta variable será un factor clave en la optimización final.

\section{COMPOSICIÓN DE LOS QUESOS A LO LARGO DE LA MADURACIÓN}

Los datos del análisis de composición de los quesos de cada una de las fabricaciones, tanto a los 20 como a los 40 días de maduración, se recogen en el Anexo A.2 (Tablas A.12 y A.13).

La evolución de los constituyentes a los 40 días de maduración se muestra en la Figura 5.46. Se recogen variaciones muy grandes en cuanto a grasa y extracto seco, de hasta un $10 \%$ para éste último. También se detectan variaciones importantes en otros constituyentes como la proteína o el contenido en sal $(\mathrm{NaCl})$.

Por último, el pH presenta menos variaciones con valores en torno a 5 en el momento de consumo.

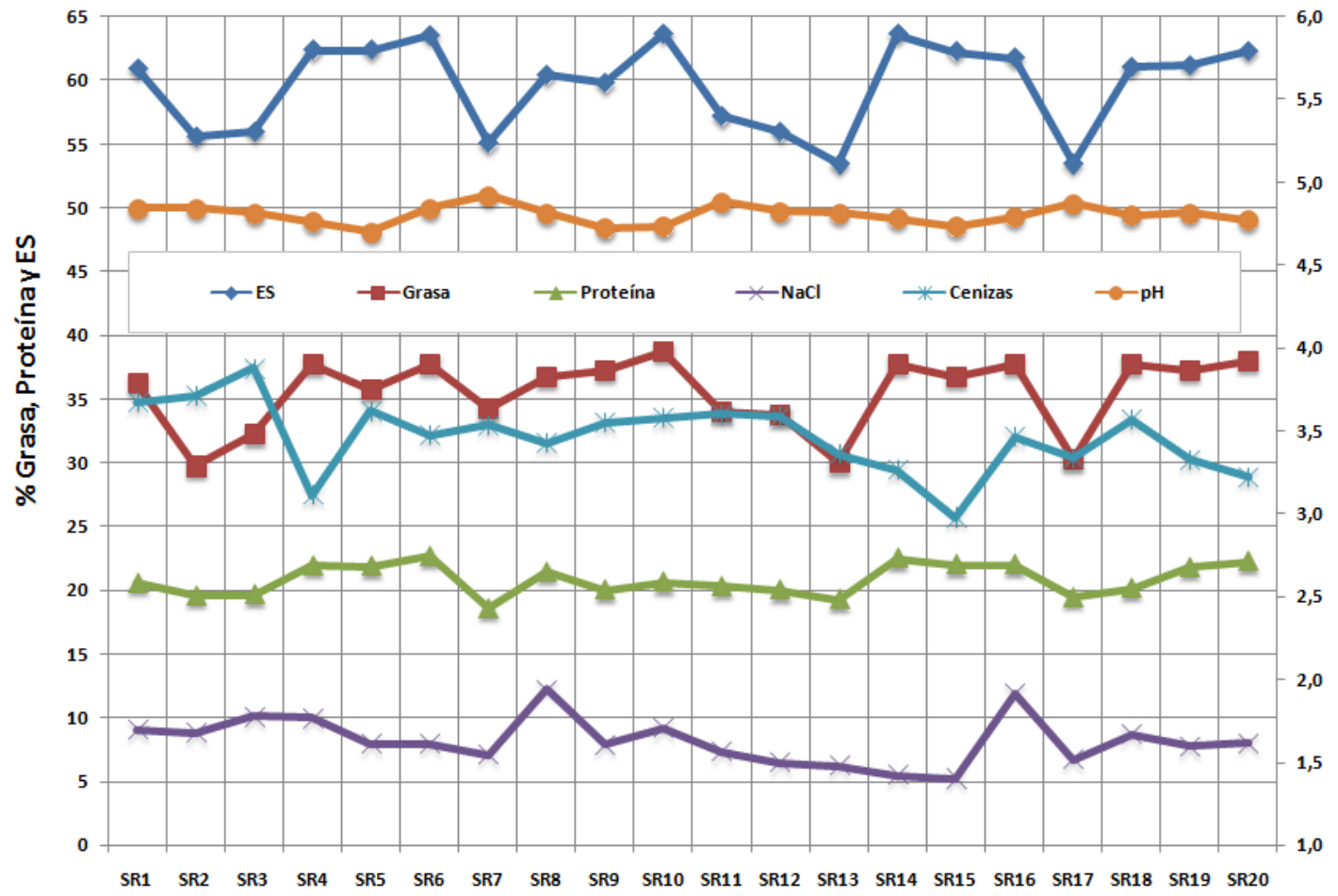

Figura 5.46. Composición de los quesos a los 40 días. Diseño Superficie Respuesta 
Según los Diagramas de Pareto de la Figura 5.47, obtenidos de la resolución del diseño a partir de los análisis físico-químicos, el tiempo de prensado influye significativamente en la concentración de proteína, grasa y ES de los quesos, a los 40 días de maduración, aumentando la concentración de todos ellos a medida que aumenta el tiempo de prensado debido a la mayor eliminación de agua de las cuajadas.

El término cuadrático en el tiempo de prensado es significativo para el contenido en grasa y proteína. Este signo negativo indica una atenuación del aumento en la concentración al pasar del nivel bajo de tiempo de prensado al alto, como se recoge el los gráficos de la Figura 5.47.
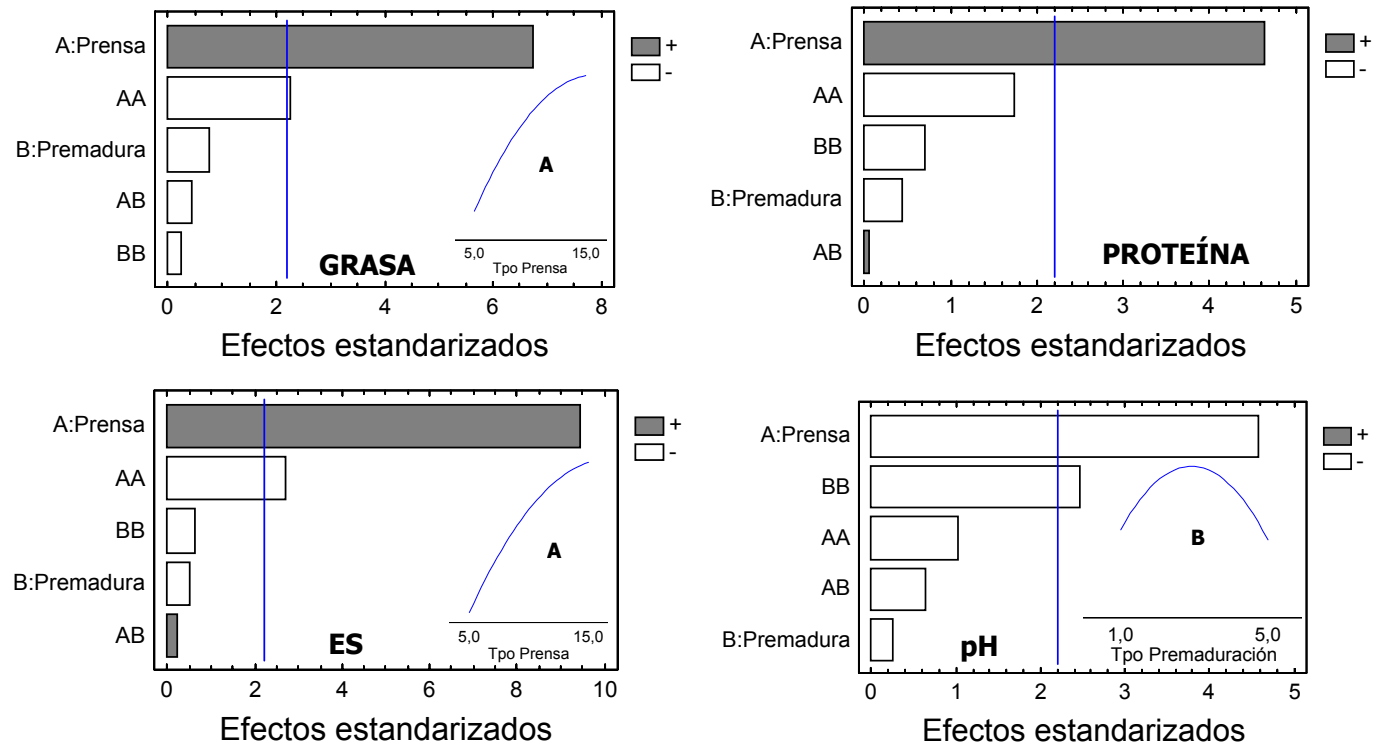

Figura 5.47. Variables significativas en la optimización en cuanto a grasa, proteína, extracto seco y pH

El pH del queso, a los 40 días de maduración, se ve afectado significativamente por el tiempo de prensado, aumentando a valores bajos. Esto es atribuible a un menor desarrollado de las bacterias del fermento antes del salado, donde se inhibe su desarrollo al modificarse la actividad de agua (Mahaut et al. 2003). El tiempo de premaduración aparece significativo en su término cuadrático, mostrando un máximo de pH a tiempos intermedios (ver Figura 5.47).

\subsubsection{ESTUDIO DE LA TEXTURA DEL QUESO}

Mediante texturómetro, a través de un análisis de perfil de textura (TPA), se evalúa instrumentalmente la firmeza, elasticidad, adherencia, masticabilidad y cohesividad de los quesos de los 20 experimentos del diseño, a los 40 días de maduración. Seguidamente se estudia el efecto de los factores -tiempo de prensado y premaduración- del diseño sobre los descriptores de textura.

\section{FIRMEZA}

Los datos de firmeza recogidos en la Figura 5.48 muestran como las fabricaciones SR4, SR5 y SR6 (al igual que sus réplicas SR14, SR15 y SR16) tienen durezas superiores al resto de experimentos. Este aumento en la dureza se corresponde de forma significativa, de acuerdo con el Diagrama de Pareto, con un mayor tiempo de prensado y la consecuente mayor eliminación de agua (mayor ES). En este caso la premaduración de la leche no afecta a la firmeza del queso. 

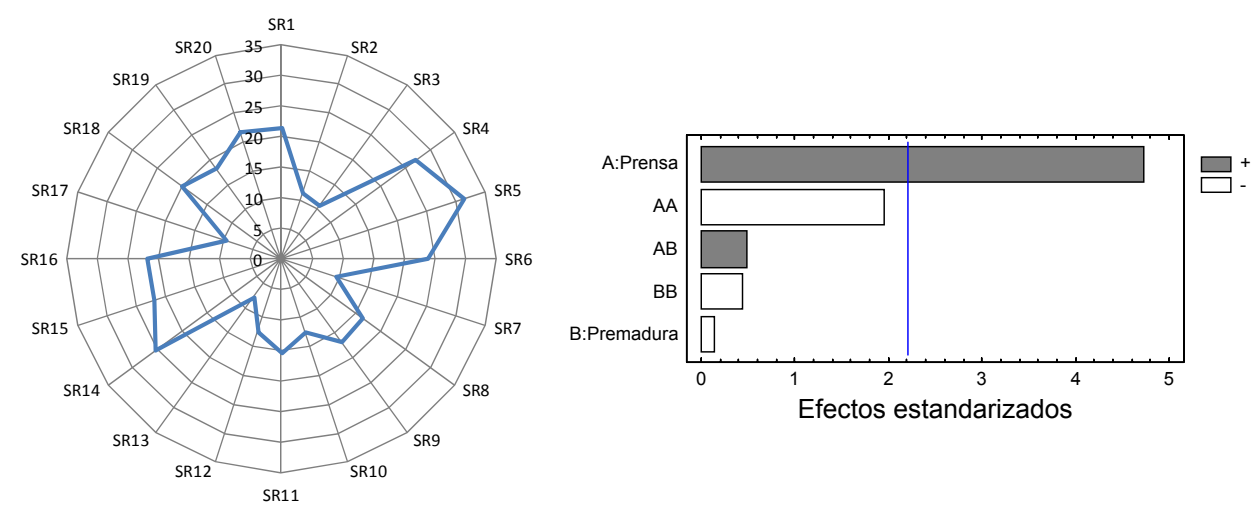

Figura 5.48. Medida de firmeza (N) y su significación en el diseño de Superficie Respuesta

\section{ELASTICIDAD}

Al evaluar la elasticidad, Figura 5.49, se observan diferencias entre los distintos quesos, con valores comprendidos entre 0,6 y 0,9 . El tiempo de prensado resulta ser significativo, aumentando la elasticidad a niveles bajos. Si bien el tiempo de premaduración no afecta significativamente, mejora la elasticidad con valores elevados.
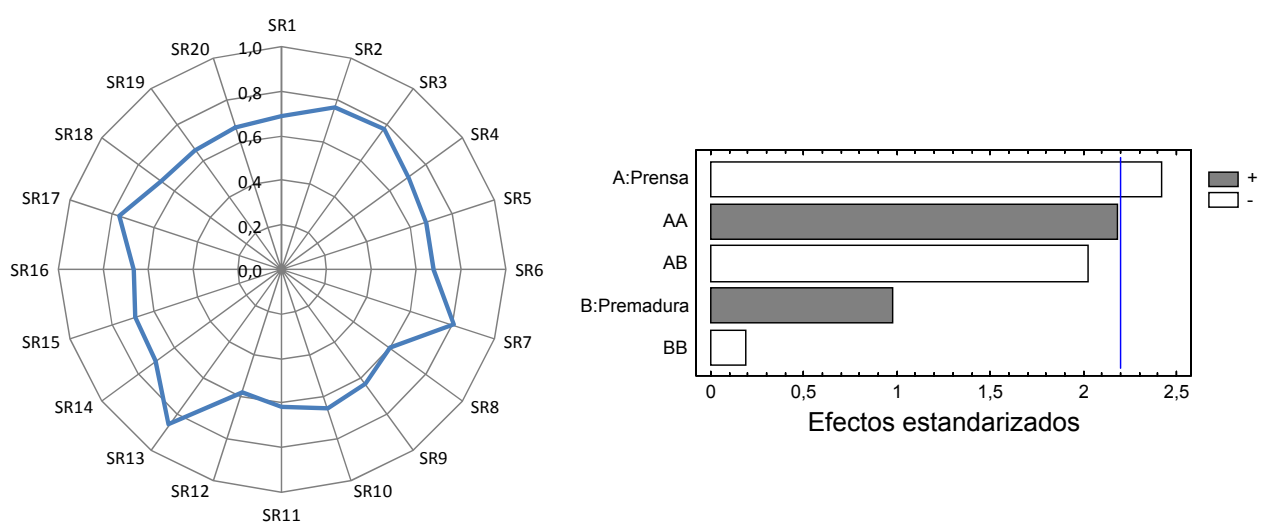

Figura 5.49. Medida de elasticidad y su significación en el diseño de Superficie Respuesta

\section{ADHERENCIA}

Al evaluar la adherencia, Figura 5.50, el tiempo de prensado resulta ser significativo, aumentandose la adherencia a valores bajos de éste. Sin embargo, el tiempo de premaduración, no afecta significativamente a la adherencia del queso a los 40 días.
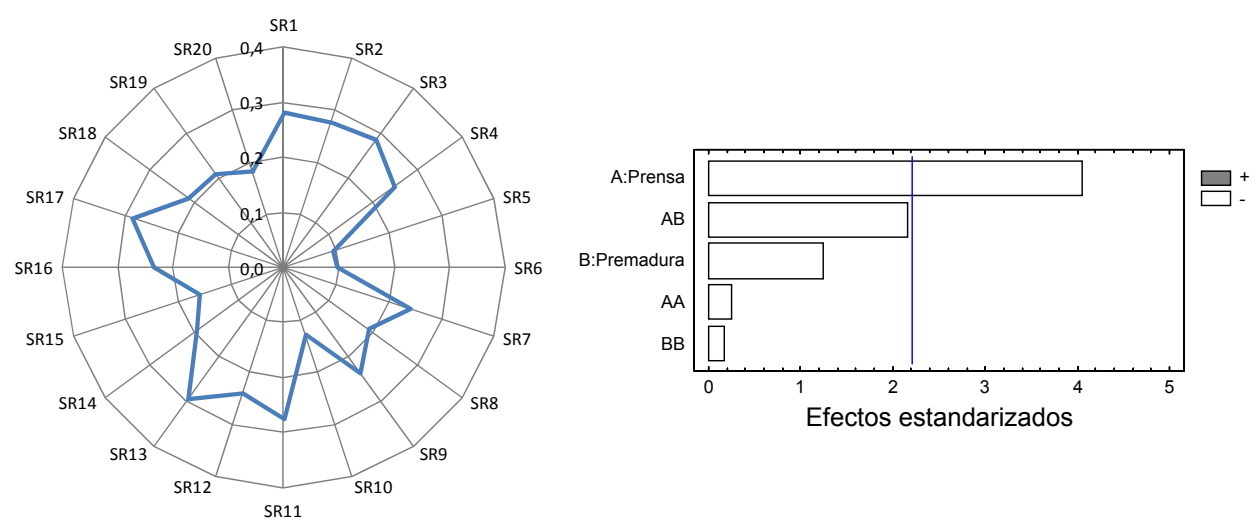

Figura 5.50. Medida de adherencia $(\mathrm{N} \cdot \mathrm{s})$ y su significación en el diseño de Superficie Respuesta 


\section{COHESIVIDAD}

Nuevamente aparece el tiempo de prensado como el causante de diferencias significativas, en este caso respecto a la cohesividad, entre los quesos elaborados en los distintos experimentos del diseño (Figura 5.51). Cuanto menor es el tiempo de prensado (dentro del rango de valores estudiado) mayor es la cohesividad del queso, mientras que la premaduración no tiene ningún efecto significativo respecto de esta variable.
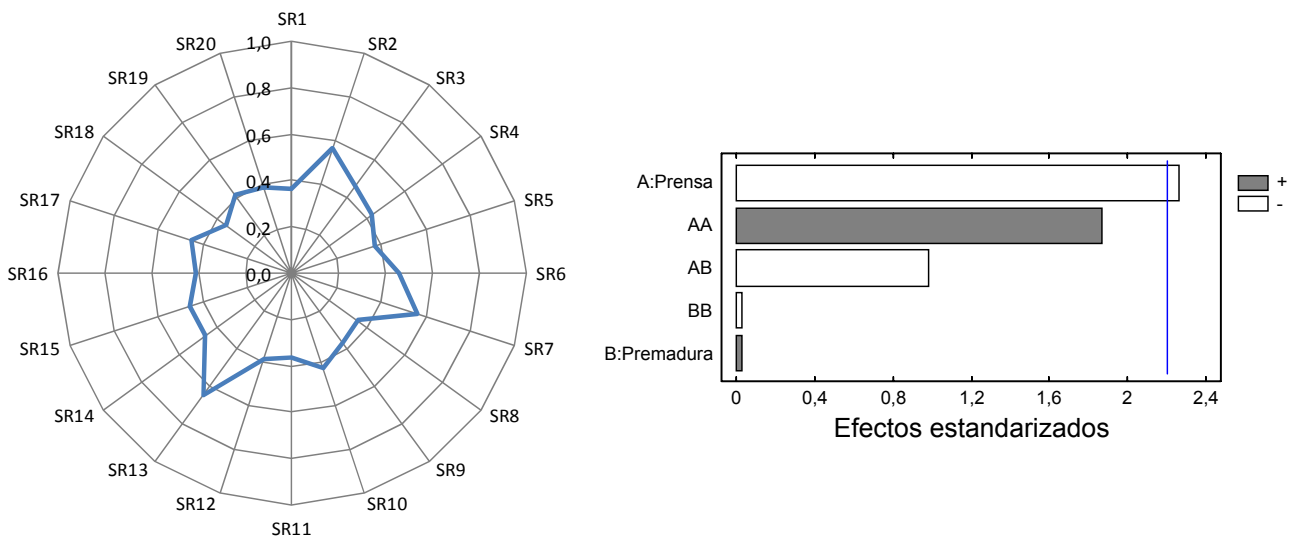

Figura 5.51. Medida de cohesividad y su significación en el diseño de Superficie Respuesta

\section{MASTICABILIDAD}

En la medida instrumental de la masticabilidad, Figura 5.52, se observa una cierta homogeneidad entre las muestras, con valores elevados de este parámetro. La variación entre los quesos depende significativamente del tiempo de prensado, aumentando a medida que este disminuye. La significación del tiempo de prensado en el término de segundo orden (AA) con signo positivo indica que en la región estudiada existe un mínimo para esta propiedad. Por su parte el tiempo de premaduración aumenta la masticabilidad a valores elevados.
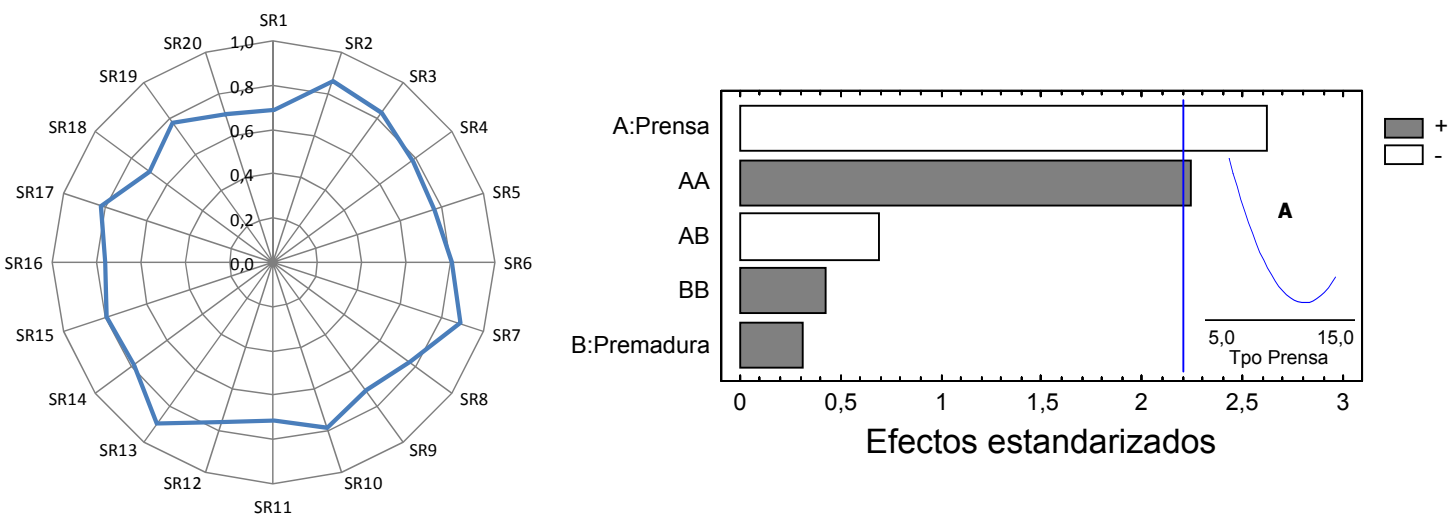

Figura 5.52. Medida de masticabilidad (N) y su significación en el diseño de Superficie Respuesta

\subsubsection{ANÁLISIS SENSORIAL DE LOS QUESOS}

Se determina el efecto de los dos factores evaluados, tiempo de prensado y de premaduración del fermento, sobre la apreciación sensorial del queso a los 40 días de maduración, tanto en la sensación olfato-gustativa como en la impresión visual, para el total de experimentos correspondientes al diseño de superficie respuesta (SR). 


\section{SENSACIÓN OLFATO-GUSTATIVA}

\section{- Calidad e intensidad del olor}

En las gráficas de la Figura 5.53 se representan los resultados obtenidos en la fase olfativa.
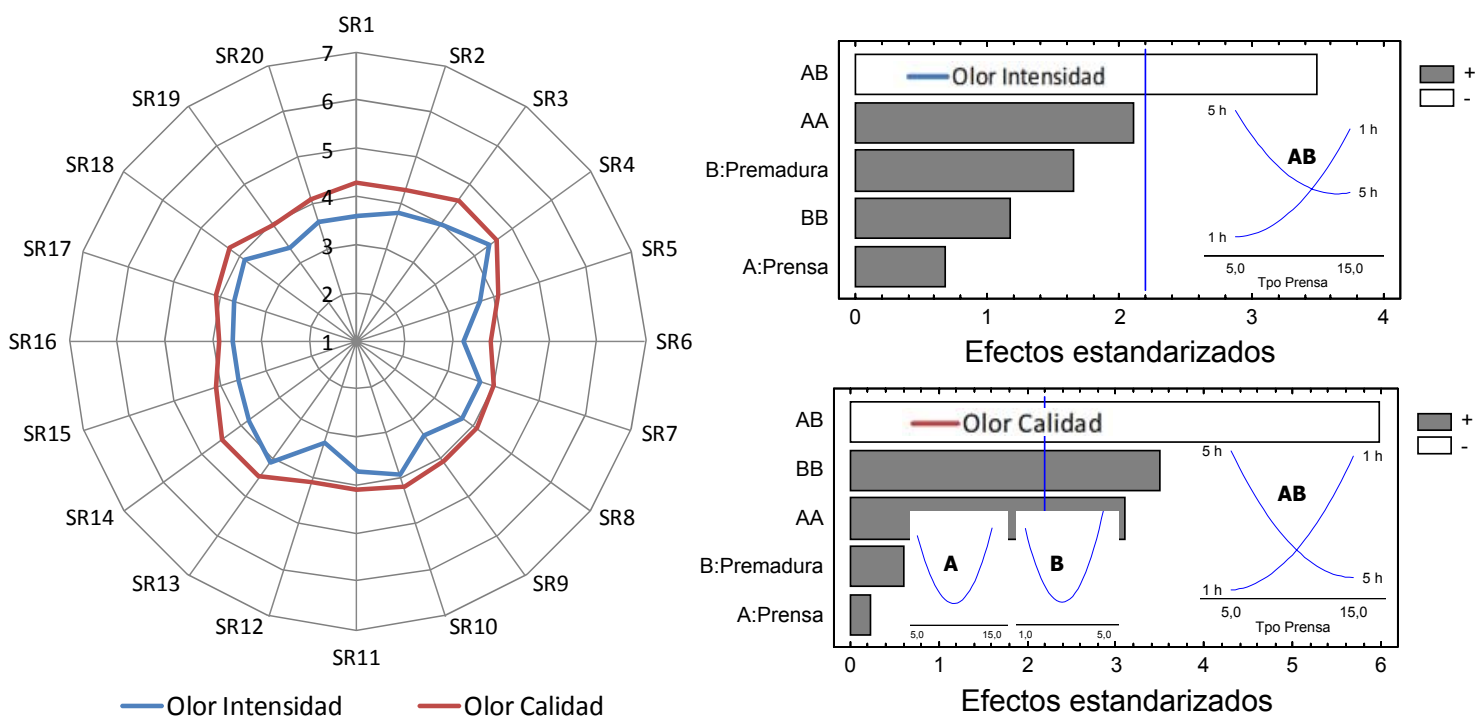

Figura 5.53. Puntuaciones de olor y su significación en el diseño de Superficie Respuesta

La sensación olfativa provocada, en general, es buena en cuanto a calidad (valores por encima de 4) y aceptable en cuanto a intensidad (valores ligeramente por debajo de cuatro).

En ambos casos aparece como significativa la interacción entre los factores, con un valor negativo. Esto significa que a tiempos bajos de premaduración tanto la intensidad como la calidad del olor aumentan al aumentar el tiempo de prensado, mientras que a tiempos elevados de premaduración ambas respuestas aumentan a tiempos bajos de prensado.

Para la evaluación de la calidad del olor aparecen significativos los dos términos cuadráticos, con signo negativo para ambos factores, lo que indica que el aumento de estas puntuaciones al aumentar tanto el tiempo de prensado como el tiempo de premaduración alcanza un mínimo dentro de la región estudiada.

\section{- Textura en mano: rugosidad, elasticidad y firmeza}

La evaluación de la textura en mano, Figura 5.54, se realiza a través de los descriptores de rugosidad, elasticidad y firmeza. Los valores obtenidos indican que se trata de quesos muy poco rugosos (valores por debajo de 2), levemente elásticos (valores en torno a 3) y de firmeza intermedia (valores entre 3 y 4 ).

El aumento del tiempo de prensado aumenta de manera significativa tanto la rugosidad como la firmeza de los quesos, obteniéndose un patrón idéntico de firmeza que el obtenido en la evaluación instrumental (Figura 5.48). En lo que se refiere a la elasticidad el tiempo de prensado no aparece como significativo, si bien aumenta la elasticidad al aumentar el tiempo.

El tiempo de premaduración no resulta significativo sobre ninguno de ellos. En cuanto a la rugosidad la favorecen tiempos altos mientras que a la firmeza y la elasticidad tiempos bajos. 


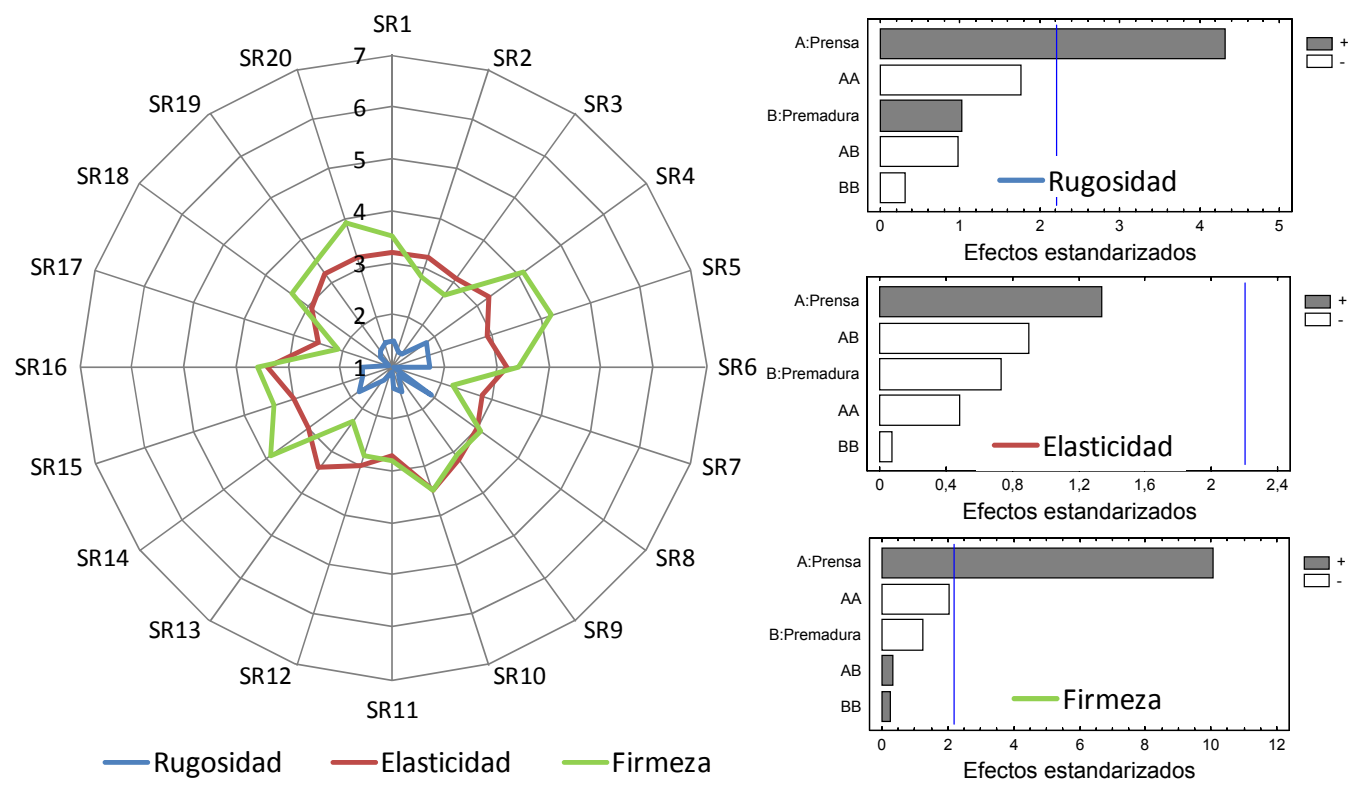

Figura 5.54. Puntuaciones de textura en mano y su significación en el diseño de Superficie Respuesta

\section{- Textura en boca: friabilidad, adherencia, solubilidad, granulosidad y firmeza}

Respecto a los valores de textura en boca representados en la Figura 5.55, se observan diferencias importantes en cuanto a friabilidad y granulosidad, con valores bajos (comprendidos entre 2 y 3 ). El patrón sensorial para ambos atributos es similar y en ambos casos los tiempos de prensado elevados favorecen significativamente el aumento de sus puntuaciones por el panel de cata. El tiempo de premaduración reducido, no siendo significativo, favorece las puntuaciones sensoriales.
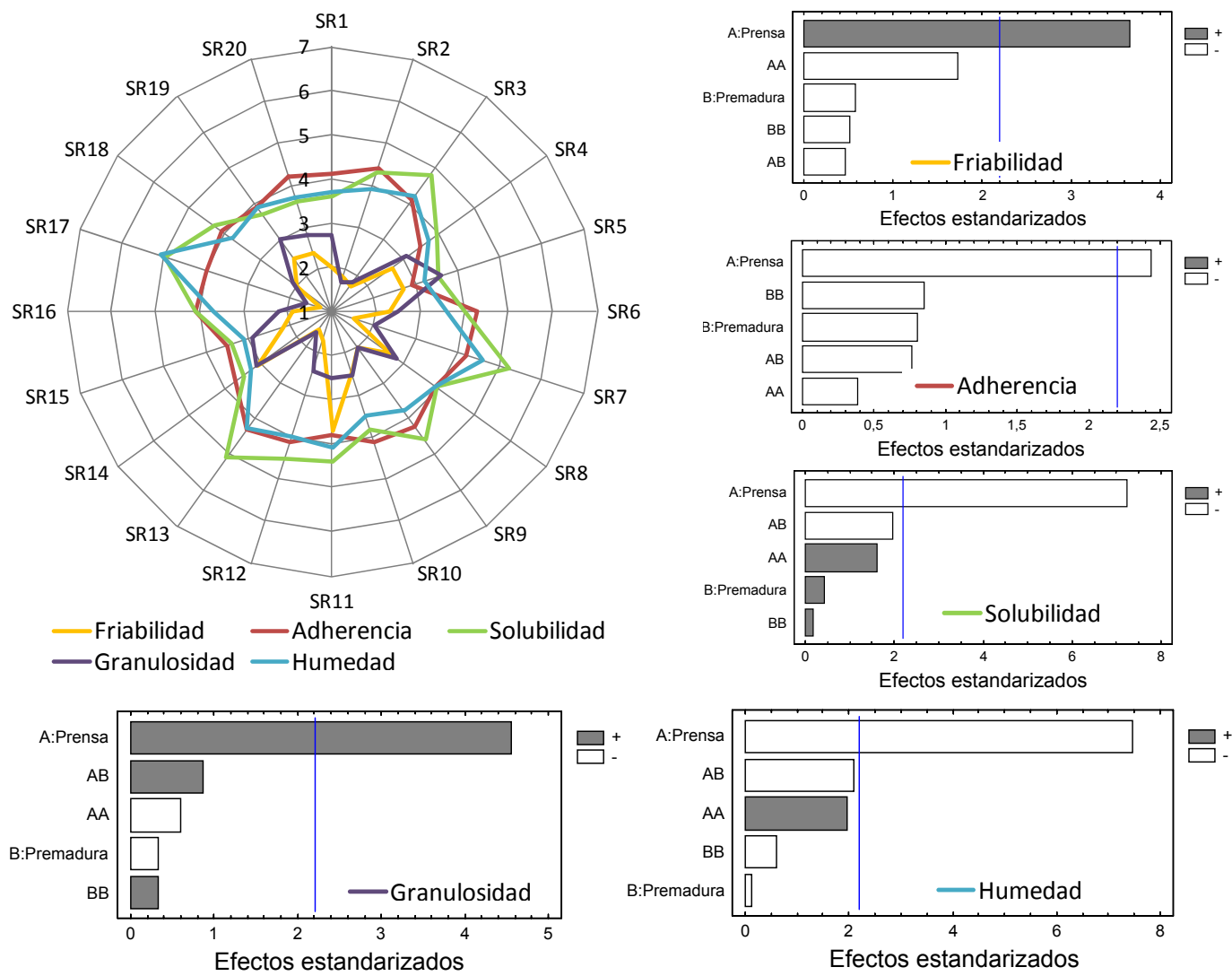

Figura 5.55. Puntuaciones de textura en boca y su significación en el diseño de Superficie Respuesta 
Los valores de adherencia $(\approx 4)$ aumentan a niveles bajos de ambos factores, siendo significativo el efecto del tiempo de prensado, al igual que ocurrió en la evaluación instrumental de dicho descriptor (Figura 5.50).

Tanto la humedad como la solubilidad de los quesos estudiados presentan un perfil similar, con valores algo superiores de solubilidad. Si disminuye el tiempo de prensado aumenta significativamente el valor de ambos descriptores, debido a la mayor retención de agua en el queso, como se comprueba al analizar el extracto seco (Figura 5.47). El tiempo de premaduración nuevamente no resulta significativo, pero valores elevados favorecen la solubilidad y valores reducidos incrementan la humedad de los quesos.

\section{- Sensación en boca: intensidad y calidad del sabor, regusto y persistencia}

La Figura 5.56 recoge las puntuaciones obtenidas en cuanto a sensación inicial de intensidad y calidad del sabor, así como de las sensaciones al final de la deglución del queso en cuanto a persistencia del sabor y regusto final en boca.
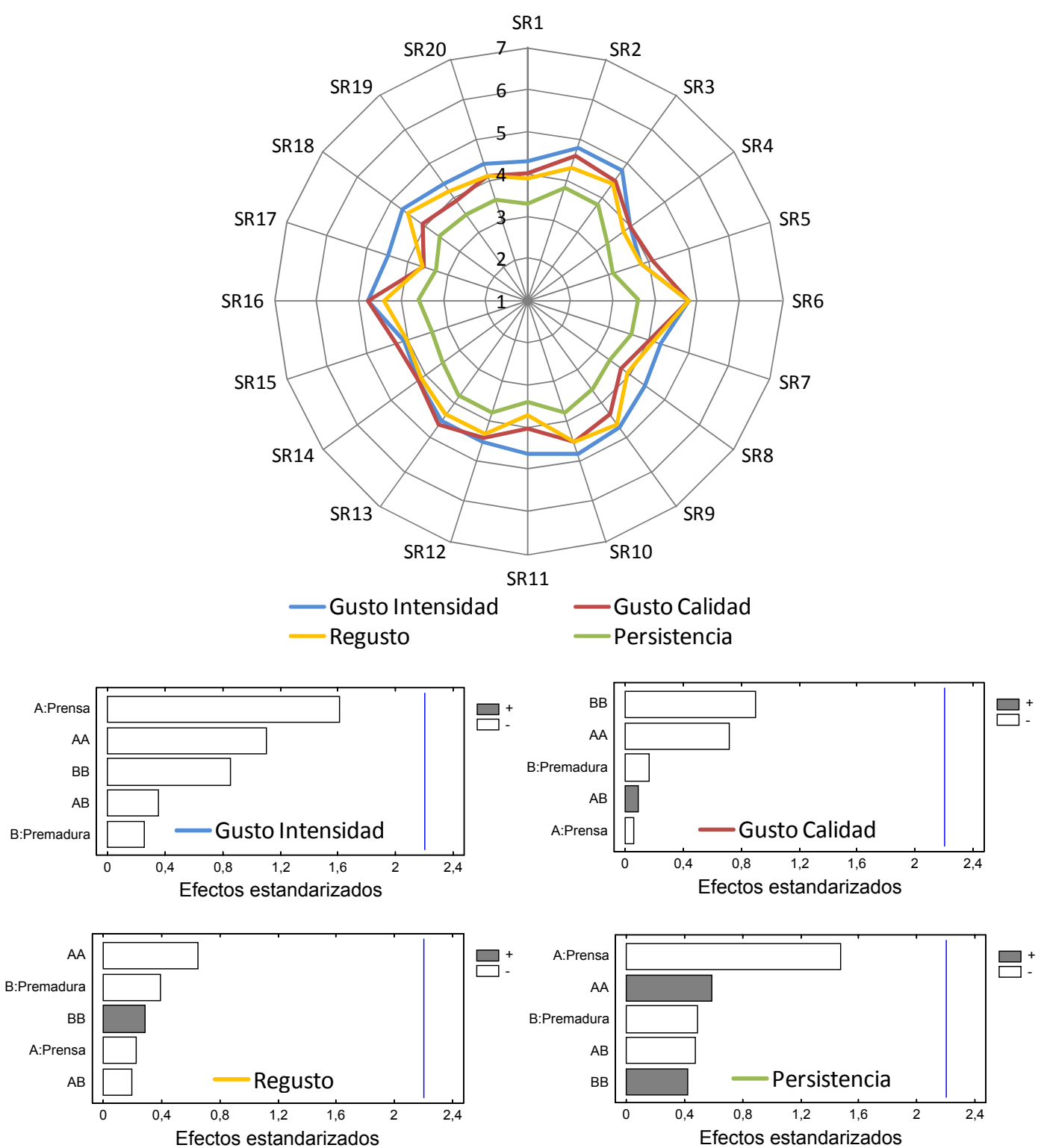

Figura 5.56. Puntuaciones de la sensación en boca y su significación en el diseño de Superficie Respuesta 
En ninguno de los cuatro descriptores aparecen los dos factores estudiados como significativos. Se observa, sin embargo, que valores bajos tanto del tiempo de premaduración como del tiempo de prensado aumentan la respuesta de todos los descriptores.

Son quesos con un gusto de intensidad y calidad apreciable (valores entorno 4-5, con mejor puntuación para la intensidad), que dejan un regusto bueno en boca, el cual se asemeja a la calidad percibida durante la masticación. La persistencia se puede considerar ligera, acorde al tipo de queso que se evalúa.

El perfil de los descriptores es similar para el total de experimentos, con especial coincidencia entre la calidad del gusto y el regusto final, como ocurría en los diseños anteriores.

\section{- Sabor: salado, ácido y amargo}

Para los tres sabores predominantes en este tipo de quesos (salado, ácido y amargo), las puntuaciones y la significación de los factores se recogen en la Figura 5.57.

Se obtienen valores muy poco o nada apreciables en cuanto al amargor (por debajo de 2), sensación leve de sal (entorno a 3 ) y acidez entre leve y apreciable (valores entre 3 y 4 ).

En lo que respecta al amargor, ningún factor afecta de forma significativa su aparición, si bien podría estar algo favorecido por tiempos altos de prensado relacionado con excesos de acidez. Tiempos cortos de prensado aumentan significativamente las puntuaciones tanto del sabor ácido como del salado, lo cual está relacionado con la mayor cantidad de humedad que presenta el queso a tiempos de prensado reducidos.
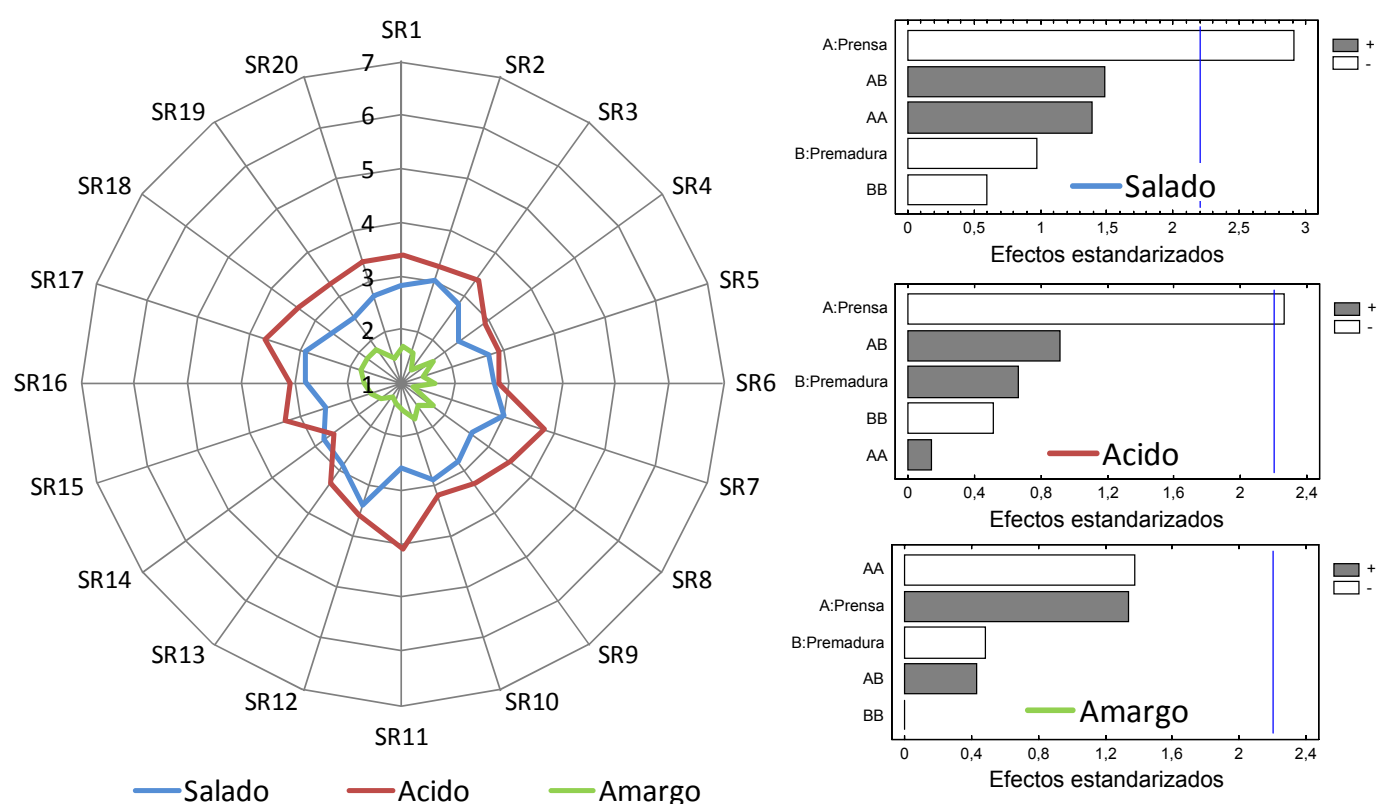

Figura 5.57. Puntuaciones de sabor y su significación en el diseño de Superficie Respuesta

\section{VALORACIÓN VISUAL}

En la Figura 5.58, se representa la valoración del aspecto exterior de los quesos en cuanto a homogeneidad de forma y color. Por otra parte, el aspecto interior al corte se evalúa en cuanto al color y la homogeneidad de la pasta. Por último se realiza una valoración de los ojos mecánicos o aberturas (número/forma/distribución). 

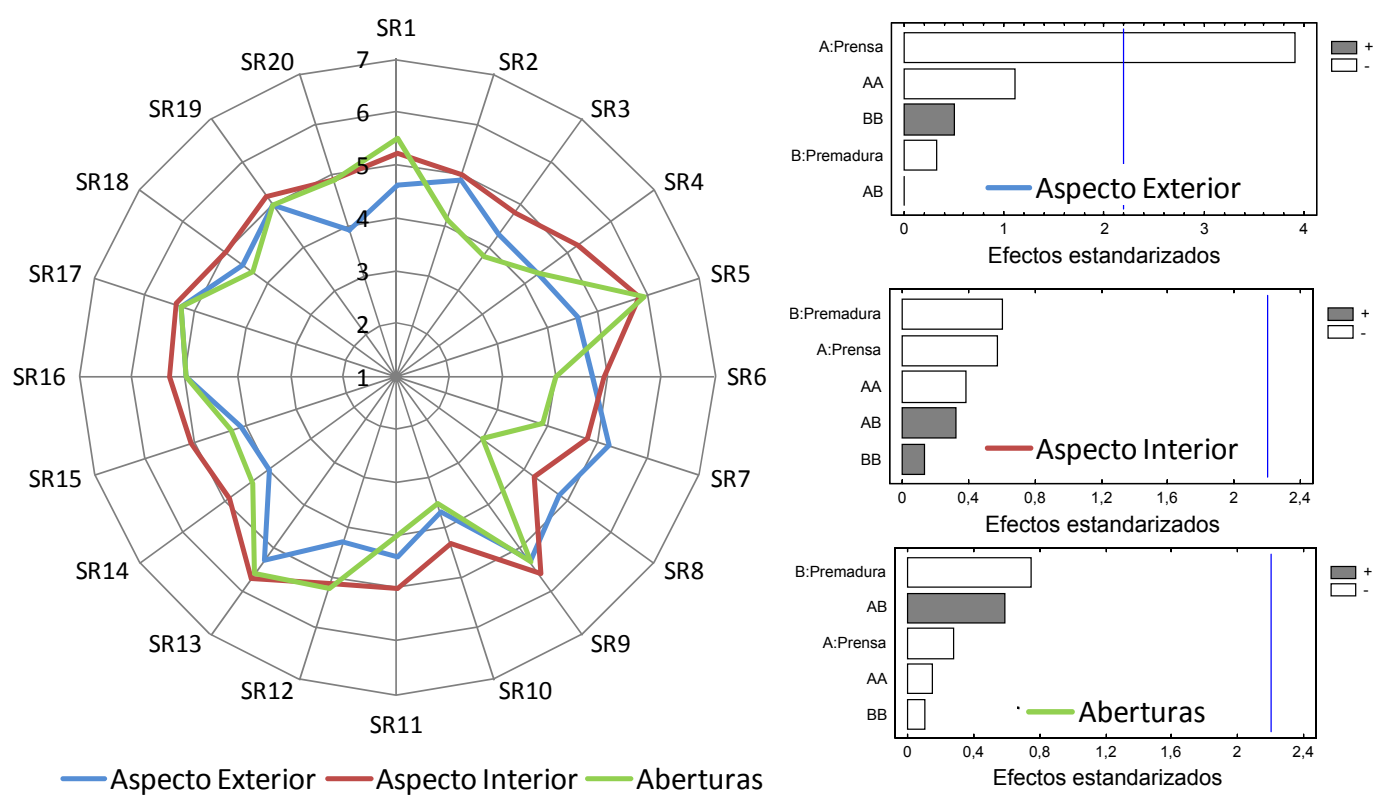

Figura 5.58. Puntuaciones fase visual y su significación en el diseño de Superficie Respuesta

La apariencia externa recibe puntuaciones aceptables/buenas (entre 4-5), algo menores que en diseños anteriores. El tiempo de prensado afecta significativamente a la valoración exterior, favoreciéndose una elevada puntuación de la apariencia externa del queso a tiempos reducidos. Este comportamiento se relaciona con la adhesión del trapo en aquellos quesos que tuvieron mayores tiempos de prensado. En esas condiciones el trapo se pegaba excesivamente el queso, quedando marcas apreciables en el exterior tras el desmoldeo, penalizadas en la valoración.

La apariencia interna no se ve afectada significativamente por ninguno de los dos factores, aumentando a niveles bajos de ambos. La puntuación del aspecto interior es bastante buena (entorno a 5), debido a que no se corta la cuajada, tratándose de pastas prácticamente ciegas. No obstante, la valoración de las aberturas fue catalogada como defectuosa en alguno de los quesos debido a la aparición de grietas en su interior. El defecto se asocia a tiempos de prensado excesivamente pequeños que no permiten la fusión uniforme de toda la matriz proteica. Este comportamiento puede observarse en las fotografías de los quesos de las veinte fabricaciones del diseño (SR) recogidas en el Anexo A.6 (Figuras A.6 a A.9).

\section{VALORACIONES GLOBALES}

En la valoración global de ambas etapas, olfato-gustativa y visual, se obtienen las puntuaciones de la Figura 5.59.

Se observan puntuaciones mayores para la valoración exterior, en la mayoría de los quesos, que ronda un valor de 5 en muchos de ellos. El perfil que siguen estas puntuaciones es prácticamente idéntico a las del aspecto interior al corte (Figura 5.58), con puntuación algo menor al ser penalizados algunos quesos por grietas o marcas de trapo en la corteza. Ninguno de los dos factores afecta significativamente a la puntuación global de la fase visual, mejorándose las características globales a tiempos elevados de prensa y reducidos de premaduración.

La puntuación global de la fase olfato-gustativa es buena (valores entorno a 4), resultando ser un queso equilibrado en cuanto a su sabor, olor y textura. Tampoco afecta de forma significativa ningún factor sobre esta valoración, si bien se mejora la respuesta a tiempos cortos tanto de prensa como de premaduración del fermento. 


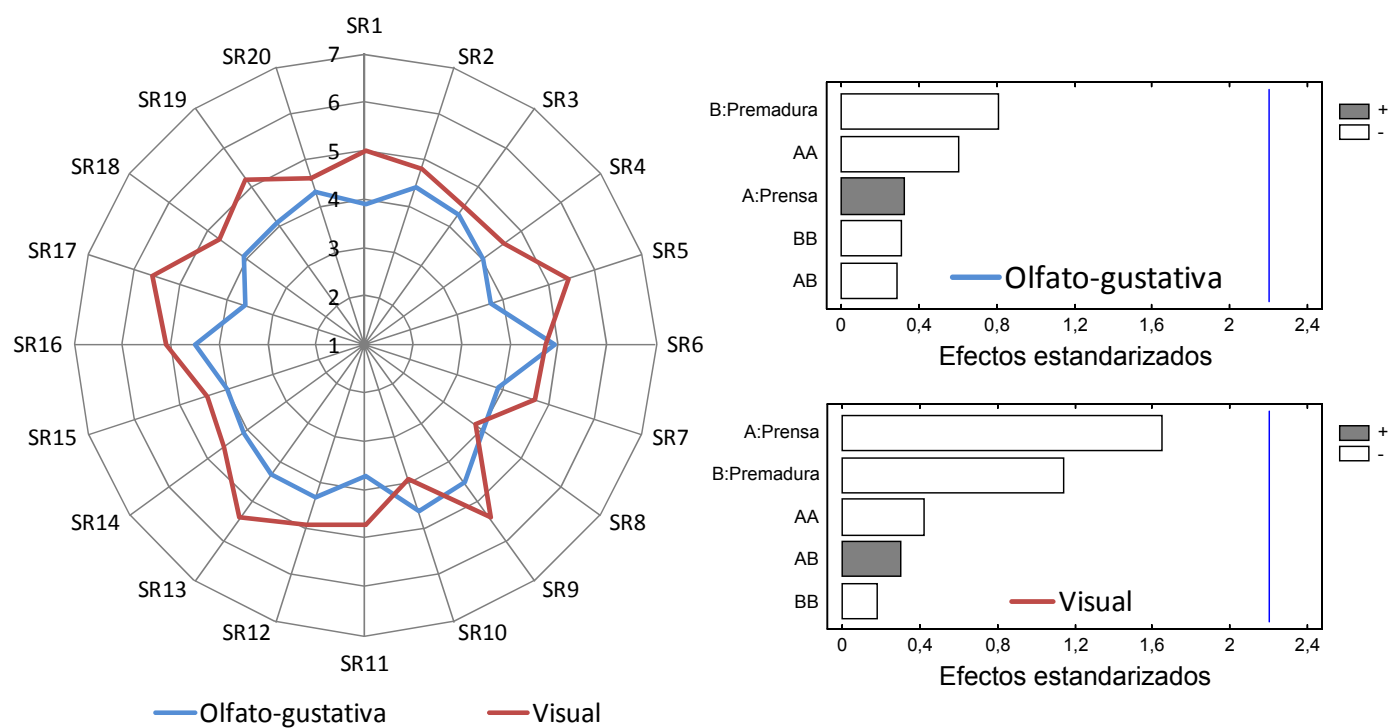

Figura 5.59. Puntuaciones globales y su significación en el diseño de Superficie Respuesta

\subsubsection{EVOLUCIÓN DEL PH A LO LARGO DE LAS ELABORACIONES}

Nuevamente, por su importancia, se realiza un seguimiento del pH durante la elaboración del queso, a lo largo de las distintas etapas, para las veinte fabricaciones del diseño SR.

En la Figura 5.60 se muestra la tendencia que siguió la acidificación en prensa de las 20 elaboraciones. Se aprecia como el pH inicial de todos los concentrados tiene el mismo valor, con significativas diferencias en la evolución final del mismo, que alcanza valores desde 4,83 hasta $6,28$ (1,5 unidades de $\mathrm{pH})$. Aunque ningún experimento alcanzó el valor óptimo de pH para estos quesos $(5,15-5,30)$, el rango estudiado comprende este valor objetivo.

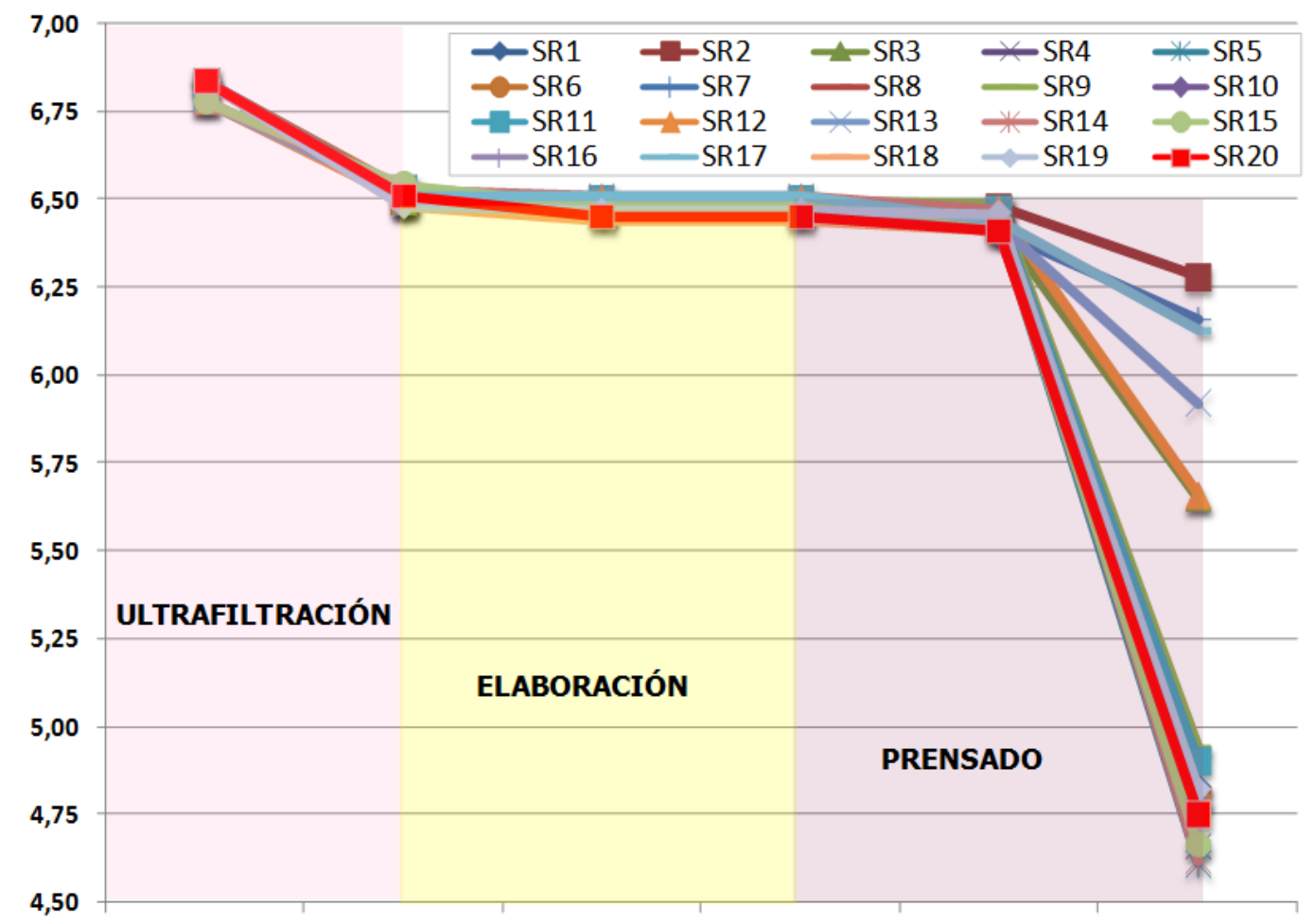

Figura 5.60. Evolución del pH en las fabricaciones del diseño de Superficie Respuesta 
Los datos de pH a la salida de prensa para el total de elaboraciones se recogen en la Tabla 5.24.

Tabla 5.24 Valores de pH a la salida de prensa, diseño Superficie Respuesta

\begin{tabular}{|c|c|c|c|c|c|c|c|c|c|}
\hline SR1 & SR2 & SR3 & SR4 & SR5 & SR6 & SR7 & SR8 & SR9 & SR10 \\
\hline 4,83 & 6,28 & 5,65 & 4,66 & 4,61 & 4,8 & 6,16 & 4,82 & 4,94 & 4,78 \\
\hline SR11 & SR12 & SR13 & SR14 & SR15 & SR16 & SR17 & SR18 & SR19 & SR20 \\
\hline 4,9 & 5,66 & 5,92 & 4,62 & 4,66 & 4,79 & 6,13 & 4,78 & 4,82 & 4,75 \\
\hline
\end{tabular}

En la Figura 5.61 se observa la alta significación que tiene el tiempo de prensado sobre el pH final del queso, disminuyendo significativamente el valor de $\mathrm{pH}$ cuanto mayor es la permanencia del queso en la prensa. Este comportamiento se debe a un mayor desarrollo, en el prensado, de las bacterias lácticas incorporadas con el fermento. La significación del término cuadrático con valor positivo indica la atenuación en el descenso del pH a tiempos elevados (ver Figura 5.61) de acuerdo con uno de los máximos encontrados en el estudio del poder tampón de las cuajadas (ver Figura 5.4).

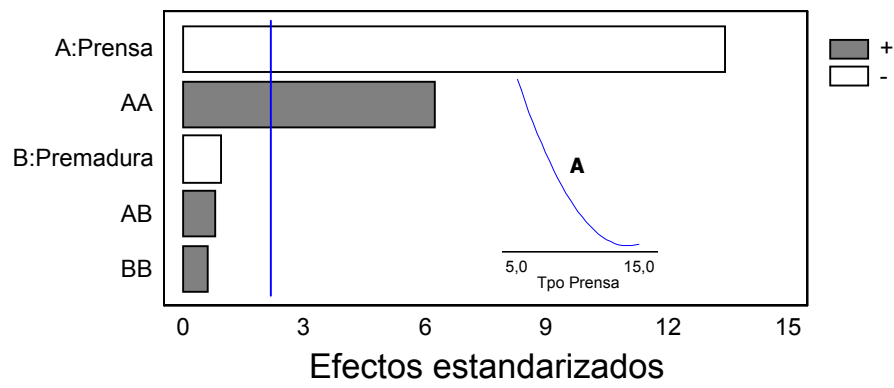

Figura 5.61. Significación del pH a la salida de prensa. Diseño Factorial

Frente a los diseños de experimentos previos, donde únicamente se pretendía la optimización del rendimiento y de la calidad sensorial, en este diseño se debe introducir el pH como condicionante del proceso de optimización, debido a la gran importancia que tiene la consecución del valor de pH óptimo, tanto para la seguridad del alimento como para la calidad sensorial del mismo.

\subsubsection{OPTIMIZACIÓN DEL DISEÑO}

A partir de los datos de rendimiento corregido y de valoración sensorial global del queso, recogidos en la Tabla 5.20, se procede a la optimización de los tiempos de prensado y premaduración. Además, se tendrá en cuenta el pH óptimo al final de fabricación para este tipo de queso (pastas prensadas de distinto grado de maduración) que ha de estar comprendido entre las 5,15-5,30 unidades de pH (Rodríguez et al. 1999).

\section{RENDIMIENTO CORREGIDO}

Los rendimientos obtenidos en los 20 experimentos (fabricaciones) recorren un amplio rango de valores, desde los 14,1 hasta los $15,6 \mathrm{~kg}$ por cada $100 \mathrm{~kg}$ de leche inicial estandarizada (Tabla 5.20). En la optimización individual del rendimiento ninguno de los dos factores afectan de forma significativa, como se observa en la Tabla 5.25, donde se recogen los resultados del análisis de varianza (ANOVA) realizado tanto sobre las variables de primer y segundo orden como sobre la interacción entre ambos factores. Como ningún p-valor es mayor de 0,05 la variabilidad de los 
resultados atribuida a cualquiera de ellos no se puede considerar distinta al error experimental. En este caso el efecto bloque resulta significativo para un $95 \%$ de probabilidad ( $p$-valor $<0,05$ ), por lo que aún estandarizando la leche, su composición o las condiciones de fabricación y/o ambientales entre los diferentes días de fabricación tienen influencia sobre el resultado final. Sin embargo, el bloqueo del experimento ha eliminado posibles errores en la interpretación de los resultados.

Tabla 5.25. Datos del ANOVA y coeficientes de la regresión para rendimiento. Diseño Superficie Respuesta ( $\mathrm{SC}=$ suma de cuadrados, $\mathrm{GL}=$ grados de libertad, $\mathrm{MC}=$ cuadrados medios)

\begin{tabular}{c|ccccc} 
Fuente & SC & GL & MC & F-ratio & p-valor \\
\hline A:Prensa & 0,127 & 1 & 0,127 & 0,58 & 0,461 \\
B:Premaduración & 0,003 & 1 & 0,003 & 0,01 & 0,907 \\
AA & 0,176 & 1 & 0,176 & 0,81 & 0,388 \\
AB & 0,002 & 1 & 0,002 & 0,01 & 0,929 \\
BB & 0,017 & 1 & 0,017 & 0,08 & 0,786 \\
bloques & 2,836 & 3 & 0,945 & 4,34 & $\mathbf{0 , 0 3 0}$ \\
Error Total & 2,394 & 11 & 0,218 & & \\
\hline Total & 5,553 & 19 & & &
\end{tabular}

\begin{tabular}{|c|c|}
\hline \multicolumn{2}{|c|}{$\begin{array}{c}\text { Coeficientes de la } \\
\text { regresión }\end{array}$} \\
\hline constante & 14,17 \\
\hline A:Prensa & 0,135 \\
\hline B:Premadura & 0,087 \\
\hline AA & $-0,006$ \\
\hline AB & $-0,002$ \\
\hline BB & $-0,011$ \\
\hline
\end{tabular}

Al tratarse de una optimización a través de un polinomio de segundo orden (véanse los coeficientes de la regresión en Tabla 5.25), los valores de rendimiento en la región estudiada se pueden modelar a través de una superficie, Figura 5.62. La región estudiada tiene forma convexa, lo que indica la existencia de un óptimo en ella, cuando menos local. El valor máximo de rendimiento (óptimo) se encuentra a las $11 \mathrm{~h}$ de prensado y a las $3 \mathrm{~h}$ de premaduración. Estos valores conducen a un óptimo económico, ya que maximizan el rendimiento.

Sin embargo, no se trata de unas condiciones de elaboración adecuadas, ya que, entre otros problemas, el queso a la salida de prensa presentaría un valor de $\mathrm{pH}$ de 4,7 que afecta de forma significativa a la calidad sensorial del queso.

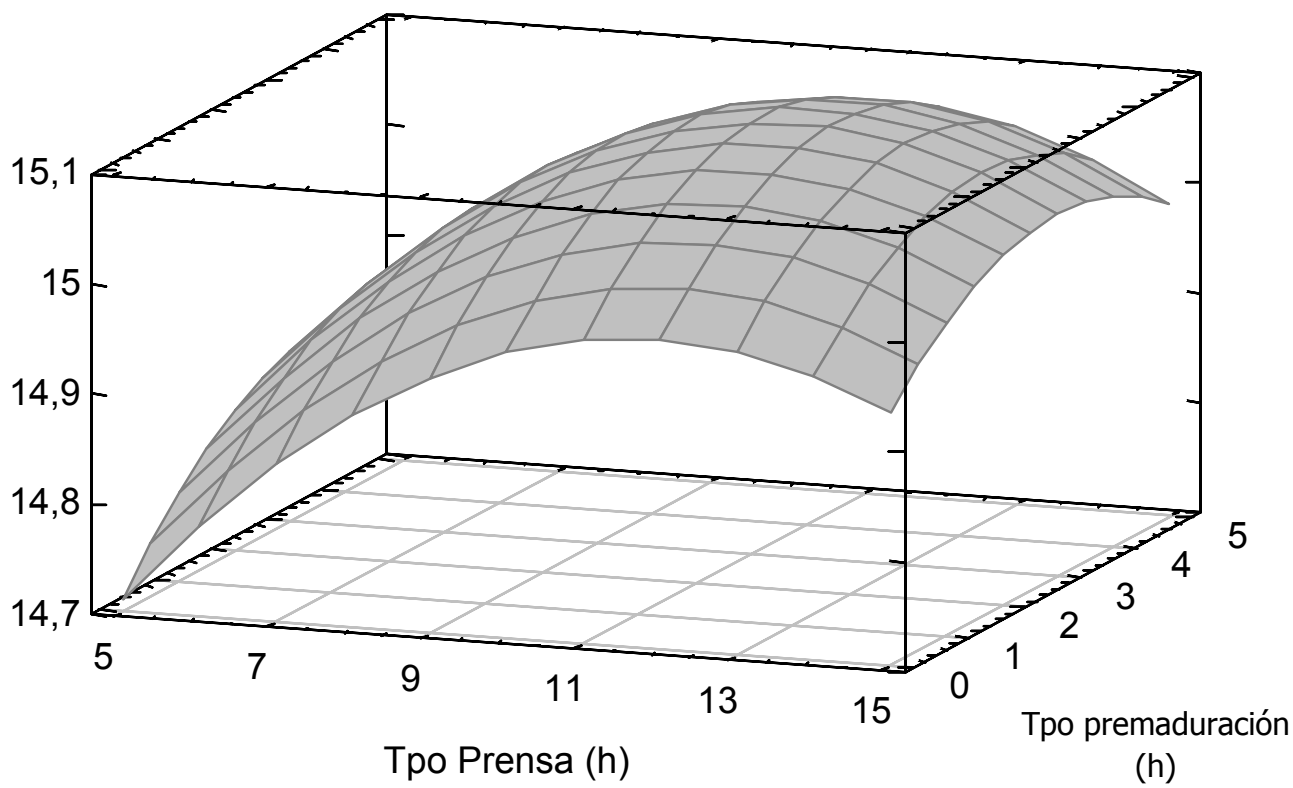

Figura 5.62. Superficie respuesta en la optimización del rendimiento 


\section{ACEPTACIÓN SENSORIAL GLOBAL}

Al realizar la optimización de los tiempos de prensado y premaduración en base a la valoración sensorial global (según datos recogidos en la Tabla 5.20) se obtiene que la variabilidad atribuida a los factores no es significativamente distinta al error experimental, ni siquiera para la variable bloqueada del diseño, como muestran los p-valores del ANOVA en la Tabla 5.26.

Tabla 5.26. Datos del ANOVA y coeficientes de la regresión para calidad sensorial. Diseño Superficie Respuesta ( $\mathrm{SC}=$ suma de cuadrados, $\mathrm{GL}=$ grados de libertad, $\mathrm{MC}=$ cuadrados medios)

\begin{tabular}{c|ccccc} 
Fuente & SC & GL & MC & F-ratio & p-valor \\
\hline A:Prensa & 0,110 & 1 & 0,110 & 1,35 & 0,269 \\
B:Premaduración & 0,172 & 1 & 0,172 & 2,11 & 0,175 \\
AA & 0,047 & 1 & 0,047 & 0,57 & 0,465 \\
AB & 0,001 & 1 & 0,001 & 0,01 & 0,933 \\
BB & 0,009 & 1 & 0,009 & 0,11 & 0,747 \\
bloques & 0,069 & 3 & 0,023 & 0,28 & 0,836 \\
Error Total & 0,897 & 11 & 0,082 & & \\
\hline Total & 1,297 & 19 & & &
\end{tabular}

\begin{tabular}{|c|c|}
\hline \multicolumn{2}{|c|}{$\begin{array}{c}\text { Coeficientes de la } \\
\text { regresión }\end{array}$} \\
\hline constante & 4,55 \\
\hline A:Prensa & 0,039 \\
\hline B:Premadura & $-0,013$ \\
\hline AA & $-0,003$ \\
\hline AB & 0,001 \\
\hline BB & $-0,008$ \\
\hline
\end{tabular}

Mediante la representación de la calidad sensorial global a través de la superficie que generan los coeficientes de la regresión (recogidos en la Tabla 5.26) se obtiene el gráfico de la Figura 5.63. En él se aprecia como al incrementar el tiempo de prensado disminuye la puntuación sensorial. Un comportamiento similar se observa con el tiempo de premaduración, si bien de manera más lenta. Ambos efectos pueden explicarse por excesos de acidez en el queso y/o por defectos en el exterior de los quesos.

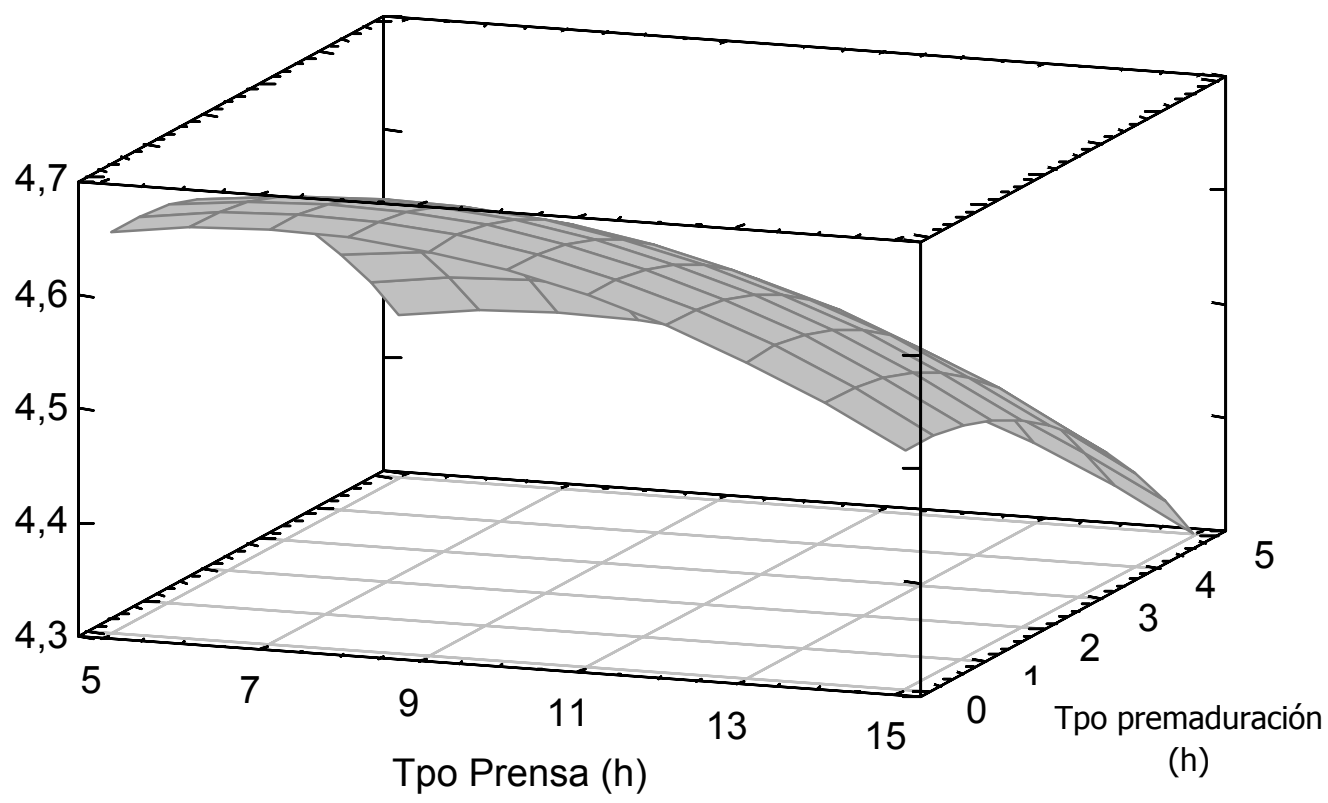

Figura 5.63. Superficie respuesta en la optimización sensorial 
Resolviendo la ecuación del modelo (coeficientes de regresión de la Tabla 5.26), se alcanza el máximo en la calidad sensorial para valores de 20 min de premaduración de la leche y $7 \mathrm{~h}$ de prensado. En estas condiciones el pH final del queso es de 5,7. Este valor, como recoge García (1994) en su revisión sobre puntos críticos en quesería, se considera elevado respecto al deseado para este tipo de queso, por motivos tanto sensoriales (desarrollo de la pasta del queso y regulación de la cinética enzimática) como de seguridad alimentaria (efecto inhibidor sobre bacterias indeseables), ya que una forma de controlar la proliferación de microorganismos patógenos en el queso, como por ejemplo Staphylococcus Aureus, es la disminución del pH (Walstra et al. 2001).

\section{VALOR DEL PH A LA SALIDA DE PRENSA}

Tras indicar en los dos apartados previos los problemas que se generan para óptimos que no tienen en cuenta el $\mathrm{pH}$ del queso de salida de prensa, y con el fin de establecer unas condiciones que satisfagan tanto el rendimiento como la evaluación sensorial, sin dejar a un lado la calidad y la seguridad del producto final, resulta interesante conocer el proceso de acidificación en prensa con algo más de detalle.

Para ello, en la Tabla 5.27 se recogen los datos del análisis de varianza obtenidos al resolver el diseño empleando como variable respuesta el pH a la salida de prensa (según los datos de la Tabla 5.24).

Tabla 5.27. Datos del ANOVA y coeficientes de la regresión para pH. Diseño Superficie Respuesta (SC=suma de cuadrados, $\mathrm{GL}=$ grados de libertad, $\mathrm{MC}=$ cuadrados medios)

\begin{tabular}{c|ccccc} 
Fuente & SC & GL & MC & F-ratio & p-valor \\
\hline A:Prensa & 4,916 & 1 & 4,916 & 182,80 & $\mathbf{0 , 0 0 0}$ \\
B:Premaduración & 0,023 & 1 & 0,023 & 0,86 & 0,375 \\
AA & 1,061 & 1 & 1,061 & 39,46 & $\mathbf{0 , 0 0 0}$ \\
AB & 0,016 & 1 & 0,016 & 0,60 & 0,454 \\
BB & 0,009 & 1 & 0,009 & 0,33 & 0,580 \\
bloques & 0,059 & 3 & 0,020 & 0,73 & 0,557 \\
Error Total & 0,296 & 11 & 0,027 & & \\
\hline Total & 6,516 & 19 & & &
\end{tabular}

\begin{tabular}{|c|c|}
\hline \multicolumn{2}{|c|}{$\begin{array}{c}\text { Coeficientes de la } \\
\text { regresión }\end{array}$} \\
\hline constante & 7,59 \\
\hline A:Prensa & $-0,401$ \\
\hline B:Premadura & $-0,111$ \\
\hline AA & 0,014 \\
\hline AB & 0,005 \\
\hline BB & 0,008 \\
\hline
\end{tabular}

En esta tabla se aprecia, como ya se observó en la Figura 5.61, que el tiempo de prensado afecta enormemente al pH final del queso (a más de un $99,99 \%$ de probabilidad) tanto en el término de primer orden como en el de segundo. Según el ANOVA, la posible variabilidad atribuible al efecto bloque no se presenta como significativa en esta ocasión.

Representando la superficie que se genera a partir de los coeficientes de la regresión (Tabla 5.27) se obtiene el gráfico de la Figura 5.64. En esta gráfica se observa como disminuye el valor del pH a medida que aumenta el tiempo de prensado asintóticamente a valores de $\mathrm{pH}$ de 4,7. A partir de valores de 4,9 la disminución del pH pierde su dependencia respecto al tiempo de prensado. Este comportamiento se vincula con el elevado poder tampón de los concentrados, que presenta un máximo para ese valor de $\mathrm{pH}$, como se estableció en los estudios preliminares (Figura 5.4). 


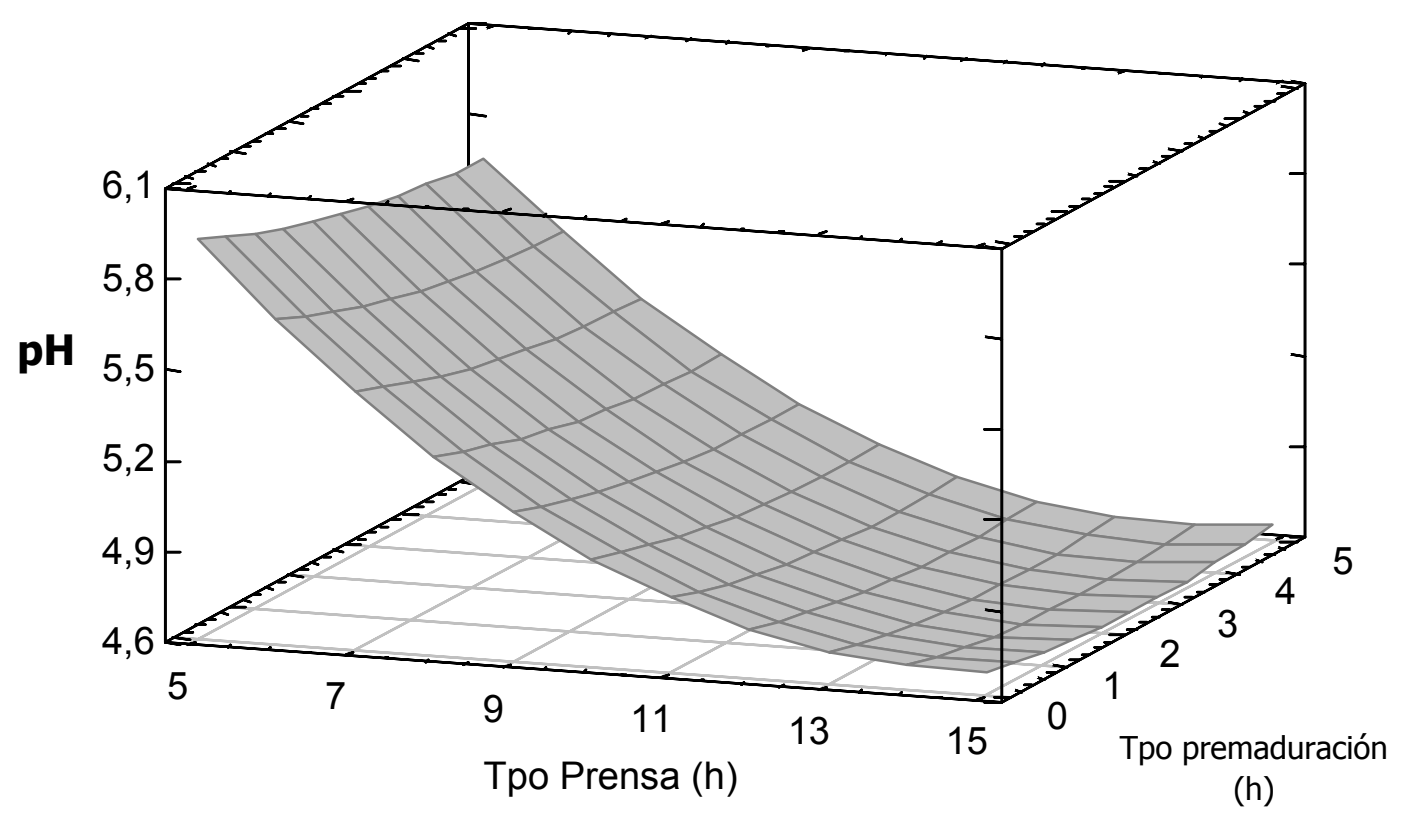

Figura 5.64. Superficie Respuesta en la optimización del valor de pH a la salida de prensa

\section{OPTIMIZACIÓN MÚLTIPLE}

Tratando conjuntamente todos los resultados obtenidos de las optimizaciones -considerando cada una de estas variables respuesta analizadas- y mediante una optimización múltiple sobre todas ellas (rendimiento, sensorial global y $\mathrm{pH}$ ), fijando como condición un $\mathrm{pH}$ a la salida de prensa de 5,15 se obtiene un óptimo, cuyo valor se consigue para:

๙ Tiempo de prensado $=8 \mathrm{~h}$
$\approx$ Tiempo de premaduración $=2 \mathrm{~h}$

Estas condiciones, junto con el resto de variables fijadas en los diseños experimentales anteriores, permiten -según el modelo polinomial empleado- la obtención de un queso que proporcione un $15,3 \%$ de rendimiento y una valoración global sensorial de 4,6 puntos.

Estos datos obtenidos mediante el modelo se compararán con los experimentales en el Apartado 5.5.9, para definir la bondad del ajuste realizado.

Frente a otros trabajos llevados a cabo sobre queso de mezcla semicurado (Rodríguez et al. 1999) donde el concentrado (VCR 6) una vez cuajado debía estar durante toda la noche en cámaras a $30^{\circ} \mathrm{C}$ hasta alcanzar valores de $\mathrm{pH}$ próximos a 5 , bajo las condiciones alcanzadas con esta optimización se disminuye notablemente el tiempo total de acidificación. Esto se consigue al establecer las condiciones de $\mathrm{pH}$ deseadas a la salida de prensa, actuando sobre factores que afectan a las cinéticas de acidificación (tiempo de prensado y preacidificación del fermento).

\subsubsection{CONCLUSIONES DEL DISEÑO}

Mediante el presente diseño de Superficie Respuesta (SR) queda resuelto otro de los problemas que se han planteado previamente en la bibliografía (Kosikowski 1986): la consecución del valor 
óptimo de pH en un tiempo razonable cuando se trabaja con concentrados de ultrafiltración. Este problema se debe, como se ha indicado previamente en este trabajo, a una mala definición de la etapa de prensado, lo cual tiene consecuencias negativas tanto sobre la calidad como sobre la seguridad del producto final, así como sobre las características tecnológicas del proceso productivo.

Para los dos factores del diseño, sus valores quedan resueltos hacia el nivel bajo-medio del rango estudiado.

Realizando un análisis de los valores óptimos en los tiempos de prensado y premaduración resultante de la optimización múltiple frente a los obtenidos al resolver el diseño con los descriptores de textura instrumental (Apartado 5.4.3) y del análisis sensorial (Apartado 5.4.4) se obtiene que:

\section{c Tiempo de premaduración (A)}

En el rango de valores de tiempo de premaduración estudiado, los resultados obtenidos al optimizar el diseño respecto a los parámetros de textura y los descriptores sensoriales no muestran significación en ninguno de los casos.

\section{c Tiempo de prensado (B)}

En cuanto a la duración de la etapa de prensado, el tiempo en el intervalo estudiado resulta ser un factor significativo sobre 15 de los 27 parámetros o descriptores estudiados. Niveles bajos de dicho factor aumentan la respuesta de variables de textura como elasticidad, adherencia (sensorial e instrumental), cohesividad y masticabilidad o de descriptores sensoriales como solubilidad, humedad, sabores ácido y amargo así como la apariencia exterior del queso, debido a que a presiones altas el trapo se pega excesivamente por efecto de la propia presión y de los excesos de acidez.

Por otro lado, tiempos elevados de prensado aumenta la firmeza del queso (tanto instrumental como sensorial) y descriptores sensoriales como rugosidad, friabilidad y granulosidad debido a los menores contenidos de humedad. 


\subsection{COMPARACIÓN RESPECTO A LA TECNOLOGÍA TRADICIONAL}

Tras obtener, a partir de los tres diseños experimentales (PB, DF y SR) optimizados en base a rendimiento y calidad sensorial -teniendo en cuenta las correspondientes restricciones de pH- los valores de los factores significativos en el proceso que maximicen ambas respuestas, se presenta una comparativa de los óptimos alcanzados en las distintas etapas (Apartados 5.2, 5.3 y 5.4). Al mismo tiempo, cada uno de ellos se compara respecto al queso de mezcla elaborado siguiendo la tecnología convencional de cuajado y desuerado en cuba.

Se realizaron tres elaboraciones (lotes) de cada tipo de queso, cada una de las tecnologías ensayadas se codifica como:

c M: queso elaborado mediante tecnología tradicional

c OPB: queso elaborado en las condiciones óptimas del diseño Plackett-Burmann

C ODF: queso elaborado en las condiciones óptimas del Diseño Factorial

c OSR: queso elaborado en las condiciones óptimas del diseño de Superficie Respuesta

Estas cuatro tecnologías de fabricación, la tradicional y las tres que combinan la tecnología tradicional con procesos de concentración por ultrafiltración, se comparan a continuación.

Previamente a la comparación frente al sistema tradicional, se resume el proceso tecnológico optimizado para la elaboración de un queso semicurado de mezcla a partir de concentrados de ultrafiltración.

\subsubsection{CONDICIONES ÓPTIMAS DE FABRICACIÓN A PARTIR DE CONCENTRADOS DE ULTRAFILTRACIÓN}

Mediante el desarrollo experimental, estudiando el proceso global y de acuerdo con los resultados obtenidos en cada uno ellos, se da por optimizado el proceso tecnológico de elaboración de queso de mezcla semicurado a partir de retenidos de ultrafiltración.

Las etapas de elaboración del queso mediante la nueva tecnología combinada (tradicional con ultrafiltración de la leche), resultado de la secuencia de optimización a partir de los tres diseños, se definen a continuación:

\section{Estandarización de la leche}

Se realiza la estandarización de la leche en cuanto a grasa y proteína para obtener un queso de calidad, con la mayor homogeneidad posible entre lotes, a través de la mezcla de leche vaca/oveja en relación aproximada $85 / 15 \%$.

\section{Concentración de la leche por ultrafiltración}

Se realiza la concentración de la leche mediante sistema de UF (Figura 5.65) hasta alcanzar un factor de concentración (VCR) de 4,5 lo que supone un contenido en sólidos totales de la leche concentrada del $41 \%$. 
Las condiciones hidrodinámicas del equipo que maximizan la densidad de flujo de permeación en la ultrafiltración, mediante membrana espiral modelo $\mathrm{ABCOR}^{\circledR} 3838$ HFK-FYT, son:
c. Temperatura $=45-50^{\circ} \mathrm{C}$
c $\mathrm{TMP}=3,0 \mathrm{bar}$

c Velocidad de barrido en la superficie de la membrana $=1,1 \mathrm{~m} / \mathrm{s}$

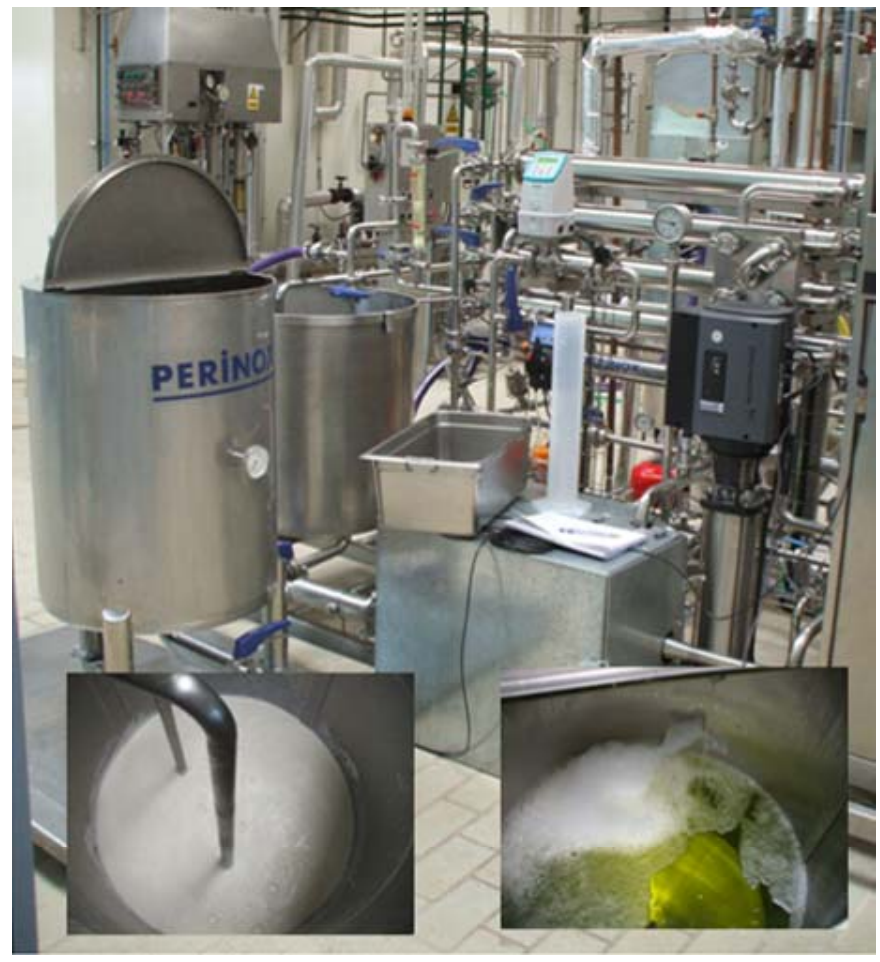

Figura 5.65. Ultrafiltración de leche de mezcla estandarizada

\section{Pasterización del concentrado}

Se somete al concentrado a un tratamiento térmico de pasterización en discontinuo $\left(63^{\circ} \mathrm{C} / 30 \mathrm{~min}\right)$, en el mismo recipiente donde se realizará la etapa de cuajado (Figura 5.66). Una vez pasterizado el concentrado se disminuye su temperatura a $32^{\circ} \mathrm{C}$.

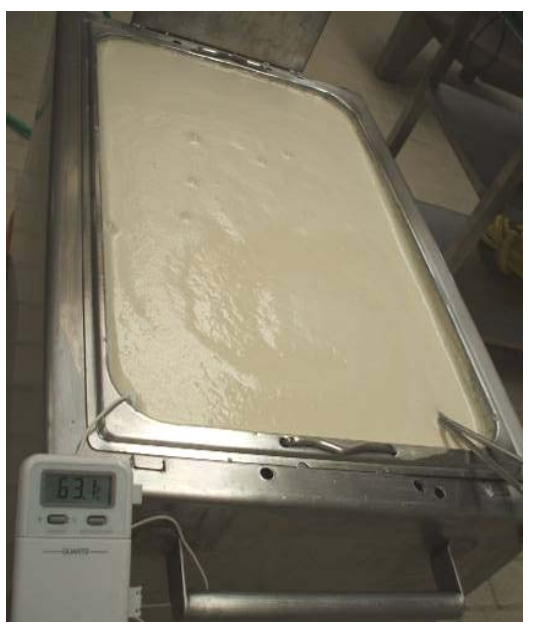

Figura 5.66. Pasterización de la leche concentrada 


\section{Adición de ingredientes}

En primer lugar se añade fermento comercial CHOOZIT ${ }^{\mathrm{TM}}$ MA4001. La dosis de inóculo será de $6 \mathrm{DCU} / 100 \mathrm{~L}$ de concentrado. El fermento se premadura previamente $\left(2 \mathrm{~h}\right.$ a $\left.37^{\circ} \mathrm{C}\right)$ en leche esterilizada, con agitación para favorecer un reparto homogéneo.

Posteriormente se incorpora el cuajo, transcurridos entre 15-30 minutos desde la adición del fermento, para favorecer el reparto del mismo. La concentración de cuajo será de $30 \mathrm{~mL} / 100 \mathrm{~L}$ de concentrado.

\section{Cuajado y corte}

Tras la adición del cuajo se elimina la agitación, dejando actuar la enzima coagulante 25 minutos aproximadamente. Trascurrido este tiempo se corta la cuajada en cubos de $15 \mathrm{~cm}$ de lado (Figura 5.67).
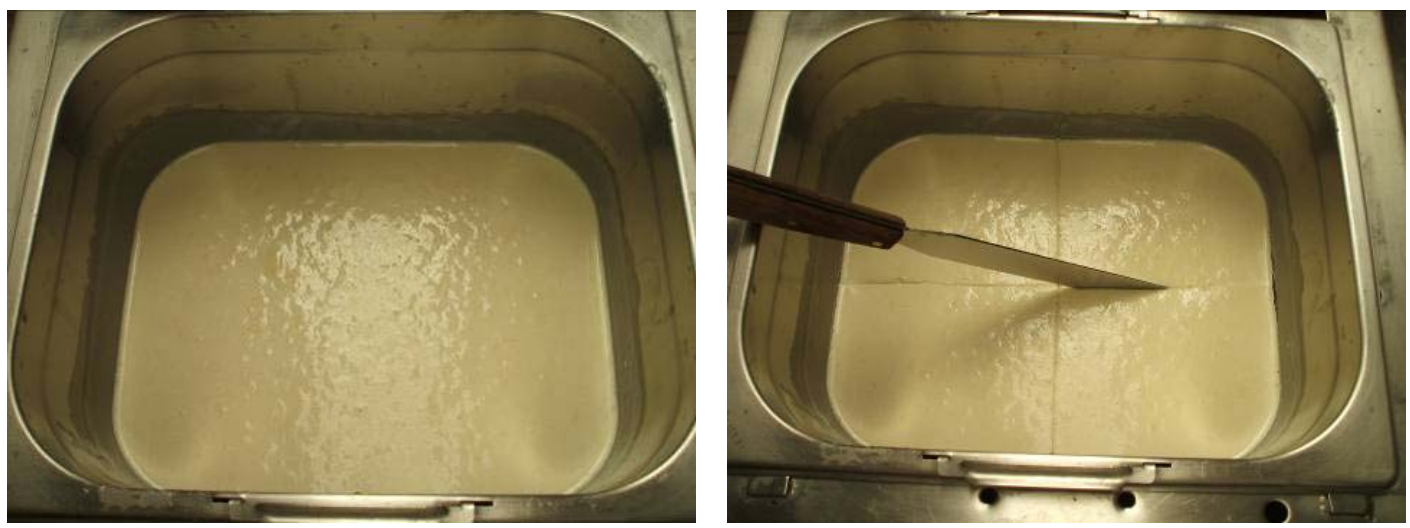

Figura 5.67. Etapas de cuajado (izquierda) y corte (derecha)

\section{Moldeo y prensado}

Se incorpora la cuajada en los moldes, con trapo para favorecer el desuerado.

Se introducen los moldes en la prensa a 2,0 bar de presión durante $1 \mathrm{~h}$. Se procede al volteo del queso y se somete nuevamente a presión ( 2,5 bar) durante $7 \mathrm{~h}$ (Figura 5.68).

Al final de esta etapa, el pH del queso alcanza un valor de entre 5,15 y 5,30, procediéndose al desmoldeo.
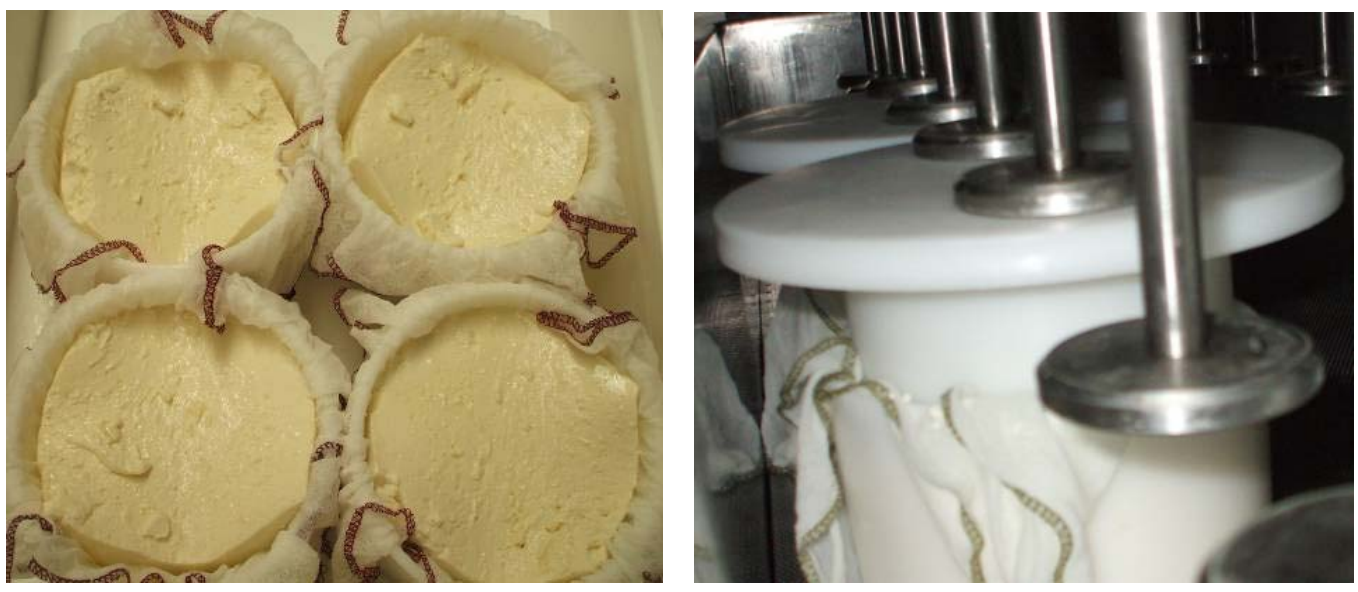

Figura 5.68. Moldeo y prensado del queso 


\section{Salado y afinado}

Los quesos se salan por inmersión en salmuera de concentración $20{ }^{\circ}$ Baumé durante $2 \mathrm{~h}$, a una temperatura de $8^{\circ} \mathrm{C}$.

Por último, todos los quesos tendrán un proceso de curado o afinado de 40 días, dividido en dos periodos de 20 días cada uno, a temperatura y humedad controladas, realizando volteos periódico para garantizar la uniformidad en el secado del queso, según se ha establecido en le Capítulo IV de Materiales y métodos (Apartado 4.2.4).

\subsubsection{COMPARACIÓN FÍSICO-QUÍMICA}

Tanto sobre las corrientes líquidas como sobre los quesos resultantes de las fabricaciones, se realiza una caracterización química de composición y física mediante medida de $\mathrm{pH}$.

\section{LECHES, CONCENTRADOS Y PERMEADOS}

Los quesos elaborados a partir de cada una de las condiciones óptimas de los diseño (OPB, ODF y OSR) se fabrican a partir de la misma leche concentrada, mientras que para la elaboración tradicional se emplearon tres leches (materia prima) distintas (M1, M2 y M3).

Los datos de composición y pH de las leches de partida (vaca y oveja) se pueden consultar en el Anexo A.1 (Tablas A.7 y A.8). En todos los casos se comprobaba la calidad de las leches de ambas especies a través del recuento de células somáticas. Los valores obtenidos se encontraron por debajo de las 400.000 células/mL en vaca, de acuerdo con el Reglamento 853/2004, y por debajo de las 800.000 células $/ \mathrm{mL}$ para el caso de la oveja. También se comprobaba la ausencia de residuos de antibióticos en las seis muestras de leche analizadas.

Los datos para la mezcla, una vez estandarizada, se recogen en la Tabla 5.28. Se comprueba la efectividad de la estandarización, ya que los valores se encuentran dentro de los rangos establecidos tanto para la grasa $(4,0 \pm 0,2 \%)$ como para la proteína $(3,5 \pm 0,1 \%)$.

Tabla 5.28. Composición química y pH de la leche. Comparación tecnológica

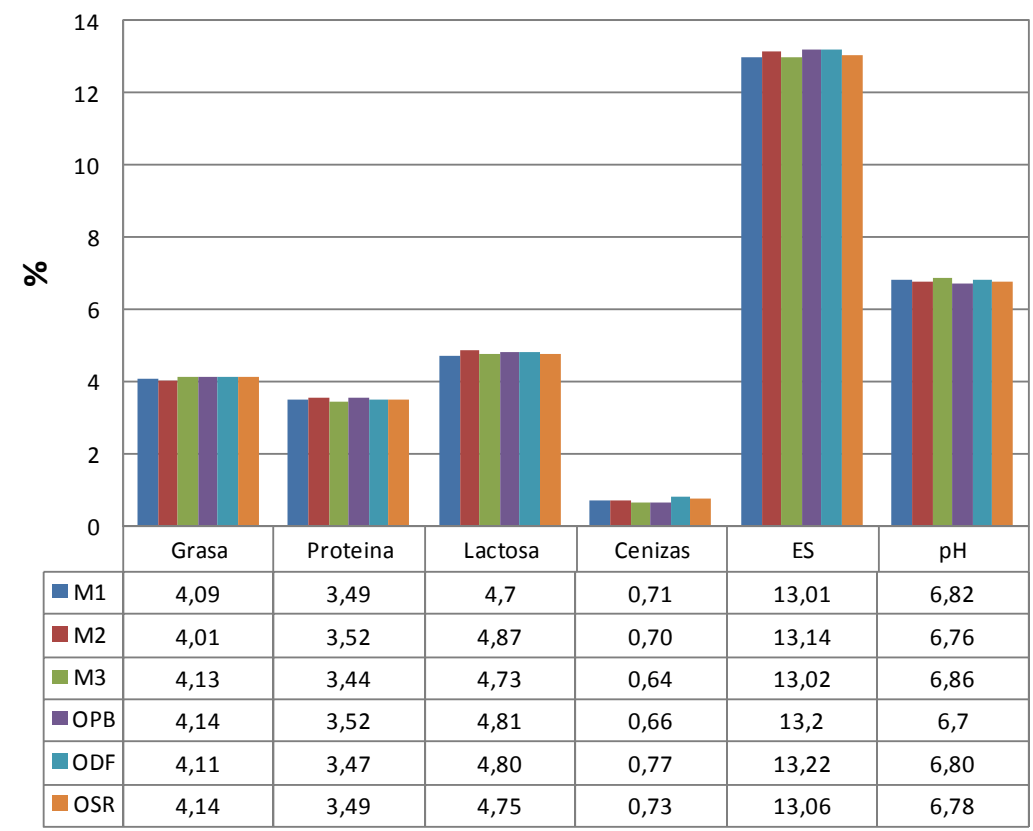


Las leches para elaborar en las condiciones óptimas de los diseños experimentales (OPB, ODF y OSR) fueron ultrafiltradas hasta VCR 4,5 con membranas espirales. La composición de los permeados obtenidos, Tabla 5.29, no muestra diferencias significativas entre las distintas filtraciones.

Tabla 5.29. Composición química de los permeados. Comparación tecnológica

\begin{tabular}{|c|c|c|c|c|c|}
\hline \% en peso & Grasa & Proteína & Cenizas & ES & Lactosa \\
\hline OPB & 0,00 & $0,19^{\mathrm{a}} \pm 0,02$ & $0,46^{\mathrm{a}} \pm 0,02$ & $5,51^{\mathrm{a}} \pm 0,04$ & 4,86 \\
\hline ODF & 0,00 & $0,19^{\mathrm{a}} \pm 0,02$ & $0,42^{\mathrm{a}} \pm 0,03$ & $5,55^{\mathrm{a}} \pm 0,03$ & 4,94 \\
\hline OSR & 0,00 & $0,20^{\mathrm{a}} \pm 0,02$ & $0,40^{\mathrm{a}} \pm 0,02$ & $5,47^{\mathrm{a}} \pm 0,01$ & 4,87 \\
\hline
\end{tabular}

* Valores con la misma letra en la misma columna no son significativamente diferentes $(p<0,05)$

Se comprueba como la totalidad de la grasa ha sido recuperada en la corriente de concentrado.

Respecto a la proteína contenida en la leche, el 5,4\% atraviesa la membrana; este porcentaje corresponde con el nitrógeno no proteico de la leche (principalmente urea) que atraviesa la membrana y se reparte entre el permeado y el retenido. Este porcentaje se encuentra dentro del rango normal de la fracción de nitrógeno no proteico sobre el contenido total de nitrógeno en la leche, el cual varía entre el 3,1 y el 7,0 \% para leche de vaca (Luquet 1991).

La concentración de lactosa se incrementa ligeramente en el permeado respecto de la leche de partida.

Las sales minerales se concentran en parte, debido a que algunas como el calcio se encuentran repartidas entre la fase acuosa y la suspensión de micelas de caseína.

En la composición de los concentrados, una vez separada cada filtración en tres lotes (datos en la Tabla 5.30), no hay diferencias significativas entre todos ellos en cuanto a grasa, proteína, cenizas y extracto seco.

En el $\mathrm{pH}$ de los concentrados se encuentran diferencias entre los distintos lotes, si bien estas diferencias observadas son debidas al pequeño error de medición, no encontrando diferencias entre el mayor y el menor de los valores superiores a 0,04 unidades de $\mathrm{pH}$, por lo que se consideran adecuados para no influir en las posteriores comparaciones.

Se ha demostrado por un lado que los nueve retenidos de partida para la elaboración de los quesos ultrafiltrados en los óptimos no son estadísticamente diferentes entre sí en cuanto a composición, y por otro lado que la estandarización de las tres leches a partir de las cuales se elaboraron los quesos de mezcla mediante tecnología tradicional ha sido correcta. Por este motivo a partir de ahora los datos presentados para cada una de las fabricaciones (M, OPB, ODF y OSR) serán el valor medio de los tres lotes elaborados según cada tecnología.

Si bien no se ha llevado a cabo la etapa de diafiltración en ninguno de los casos, la concentración de lactosa en el retenido es menor que la de la leche de partida, en aproximadamente un $30 \%$. Estos valores, al ser calculados por diferencia, llevan acumulado el error del resto de componentes y el dato no puede ser tomado como concluyente. La disminución se relaciona con procesos de hidrólisis de la lactosa por la acción de microorganismos, de acuerdo con las reducciones en el pH observadas (dos décimas respecto a a la leche de partida) ya que rechazos negativos atribuidos a efecto Donnan sólo son aplicables a compuestos cargados. Esta disminución en el contenido en lactosa puede servir para regular parte de los excesos de acidez en el queso, si bien la citada reducción no alcanza los valores típicos encontrados en la bibliografía mediante diafiltración 
(concentración menor de 1,7\%) para quesos semicurados elaborados con leche de mezcla (Goudedranche et al. 1980).

Tabla 5.30. Composición química y pH de los retenidos de UF. Comparación tecnológica

\begin{tabular}{|c|c|c|c|c|c|c|}
\hline$\%$ en peso & Grasa & Proteína & Cenizas & ES & Lactosa & pH \\
\hline OPB-1 & $\begin{array}{l}19,25^{\mathrm{a}} \\
\pm 0,50\end{array}$ & $\begin{array}{l}16,92^{a} \\
\pm 0,02\end{array}$ & $\begin{array}{l}1,64^{a} \\
\pm 0,01\end{array}$ & $\begin{array}{l}41,26^{a} \\
\pm 0,18\end{array}$ & 3,46 & $\begin{array}{l}6,50^{\mathrm{abc}} \\
\pm 0,01\end{array}$ \\
\hline OPB-2 & $\begin{array}{l}19,25^{a} \\
\pm 0,50\end{array}$ & $\begin{array}{l}17,09^{a} \\
\pm 0,01\end{array}$ & $\begin{array}{l}1,63^{a} \\
\pm 0,05\end{array}$ & $\begin{array}{l}41,33^{a} \\
\pm 0,27\end{array}$ & 3,36 & $\begin{array}{l}6,52^{\text {bc }} \\
\pm 0,01\end{array}$ \\
\hline OPB-3 & $\begin{array}{l}19,00^{a} \\
\pm 0,00\end{array}$ & $\begin{array}{l}16,76^{a} \\
\pm 0,03\end{array}$ & $\begin{array}{l}1,64^{a} \\
\pm 0,02\end{array}$ & $\begin{array}{l}40,73^{a} \\
\pm 0,41\end{array}$ & 3,33 & $\begin{array}{l}6,52^{c} \\
\pm 0,02\end{array}$ \\
\hline ODF-1 & $\begin{array}{l}19,25^{a} \\
\pm 0,50\end{array}$ & $\begin{array}{l}16,75^{a} \\
\pm 0,06\end{array}$ & $\begin{array}{l}1,57^{a} \\
\pm 0,07\end{array}$ & $\begin{array}{l}40,95^{a} \\
\pm 0,07\end{array}$ & 3,37 & $\begin{array}{l}6,49^{\text {acb }} \\
\pm 0,01\end{array}$ \\
\hline ODF-2 & $\begin{array}{l}19,25^{a} \\
\pm 0,50\end{array}$ & $\begin{array}{l}16,83^{a} \\
\pm 0,33\end{array}$ & $\begin{array}{l}1,61^{a} \\
\pm 0,04\end{array}$ & $\begin{array}{l}40,89^{a} \\
\pm 0,07\end{array}$ & 3,20 & $\begin{array}{l}6,49^{\mathrm{ab}} \\
\pm 0,01 \\
\end{array}$ \\
\hline ODF-3 & $\begin{array}{l}19,25^{a} \\
\pm 0,50\end{array}$ & $\begin{array}{l}16,79^{a} \\
\pm 0,13\end{array}$ & $\begin{array}{l}1,60^{a} \\
\pm 0,28\end{array}$ & $\begin{array}{l}40,88^{a} \\
\pm 0,22\end{array}$ & 3,25 & $\begin{array}{l}6,48^{a} \\
\pm 0,02\end{array}$ \\
\hline OSR-1 & $\begin{array}{l}19,25^{a} \\
\pm 0,50\end{array}$ & $\begin{array}{l}16,54^{a} \\
\pm 0,68\end{array}$ & $\begin{array}{l}1,58^{a} \\
\pm 0,18\end{array}$ & $\begin{array}{l}40,91^{a} \\
\pm 0,72\end{array}$ & 3,54 & $\begin{array}{l}6,50^{b c} \\
\pm 0,01\end{array}$ \\
\hline OSR-2 & $\begin{array}{l}19,00^{a} \\
\pm 0,50\end{array}$ & $\begin{array}{l}16,47^{a} \\
\pm 0,06\end{array}$ & $\begin{array}{l}1,68^{a} \\
\pm 0,06\end{array}$ & $\begin{array}{l}40,57^{a} \\
\pm 0,13\end{array}$ & 3,42 & $\begin{array}{l}6,51^{\text {bc }} \\
\pm 0,01\end{array}$ \\
\hline OSR-3 & $\begin{array}{l}19,00^{a} \\
\pm 0,00\end{array}$ & $\begin{array}{l}16,62^{a} \\
\pm 0,26\end{array}$ & $\begin{array}{l}1,63^{a} \\
\pm 0,23\end{array}$ & $\begin{array}{l}40,48^{a} \\
\pm 0,07\end{array}$ & 3,23 & $\begin{array}{l}6,51^{\mathrm{bc}} \\
\pm 0,01\end{array}$ \\
\hline
\end{tabular}

${ }^{*}$ Valores con la misma letra en la misma columna no son significativamente diferentes $(p<0,05)$

\section{COMPOSICIÓN DE LOS QUESOS A LO LARGO DE LA MADURACIÓN}

En las Tablas A.14, A.15 y A.16 que se recogen en el Anexo A.2 se observa la evolución del contenido en grasa, proteína, extracto seco, cenizas, contenido en sal $(\mathrm{NaCl})$ y $\mathrm{pH}$ en los quesos a los 0, 20 y 40 días de maduración.

Para el extracto seco de los quesos, Figura 5.69, a la salida de salmuera (día 0) los queso de la elaboración $\mathrm{M}$ tienen un valor significativamente mayor al resto.
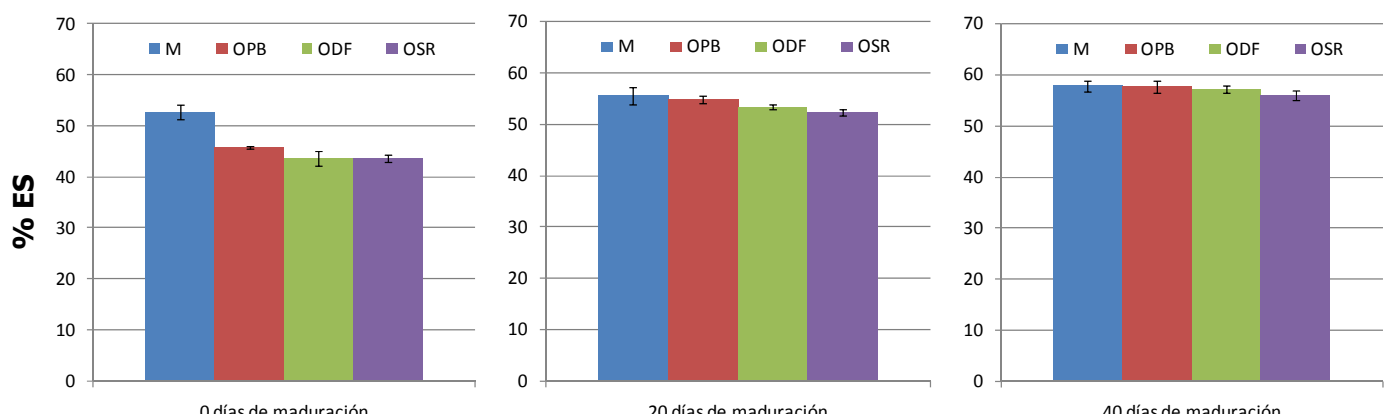

Figura 5.69. Porcentaje de extracto seco a lo largo de la maduración. Comparación tecnológica 
Los quesos fabricados a partir de concentrados de leche pierden mayor cantidad de humedad en el secado y a los 20 días prácticamente han igualado en humedad al queso tradicional, si bien todavía la humedad del queso OSR es significativamente mayor. Pasados 40 días de maduración, el contenido en sólidos se iguala en todos los casos, pudiéndose considerar igual para los cuatro tipos.

En estudios llevados a cabo por Rodríguez et al. (1996) sobre queso semicurado de mezcla, el secado era significativamente más lento que en el presente trabajo, ya que, partiendo de un contenido similar en sólidos a la salida de prensa, se necesitaban 90 días para alcanzar un ES del $53 \%$. Estas elevadas pérdidas de humedad por evaporación durante la maduración han sido catalogadas como problemáticas por algunos autores (Delbeke 1987). En el presente estudio, sin embargo, esta disminución de la humedad se considera un factor clave para alcanzar la composición final del queso, elaborado según el proceso MMV -generación de prequeso líquido- a partir de membranas espirales.

Esta mayor eliminación de agua en el secado para el queso ultrafiltrado va a provocar que se igualen las concentraciones del resto de constituyentes del extracto seco (tanto grasa como proteína) a los 40 días de maduración.

Estudios recientes llevados a cabo por Schreier et al. (2010) para la elaboración de queso semicurado partiendo de leche con un 3,2 \% de grasa, alcanzan mediante secuencia de MF/UF, un retenido con un ES del $44,8 \%$ que tras el cuajado y prensado se transforma en un queso con el $47,8 \%$ de ES a los cero días de maduración, un $4 \%$ mayor que el alcanzado en el presente trabajo.

El contenido en humedad de los quesos, a los 40 días de maduración, se asemeja a los quesos españoles de Cantabria, Gata-Hurdes, Gaztazarra, Palmero, Los Pedroches, Quesucos, La Serena, Servilleta, Torta del Casar o Urzúa-Ulloa (Sánchez 1999).

Los contenidos de grasa en base seca para los quesos se mantienen constantes a lo largo de la maduración, sin diferencias significativas entre los distintos tipos de elaboraciones. El valor medio de grasa sobre ES es del 51,33 1,18 \%, lo que lo incorpora, según la Norma de Calidad del Queso (RD 1113/2006), en la categoría de quesos grasos (contenido entre 45-60\% grasa en el ES). Estos valores son similares a los obtenidos por otros investigadores sobre queso Cheddar (Oommen et al. 2000).

En la Figura 5.70 se muestran los valores finales de grasa, cenizas y sal a los 40 días de maduración de los cuatro tipos de queso. La grasa, aunque con alguna diferencia, presenta valores similares en los 4 quesos, a pesar de que a los 0 días se mostraban dos grupos, uno de mayor concentración formado por la fabricación tradicional $\mathrm{M}$ y otro constituido por los quesos ultrafiltrados, de acuerdo con su menor extracto seco.
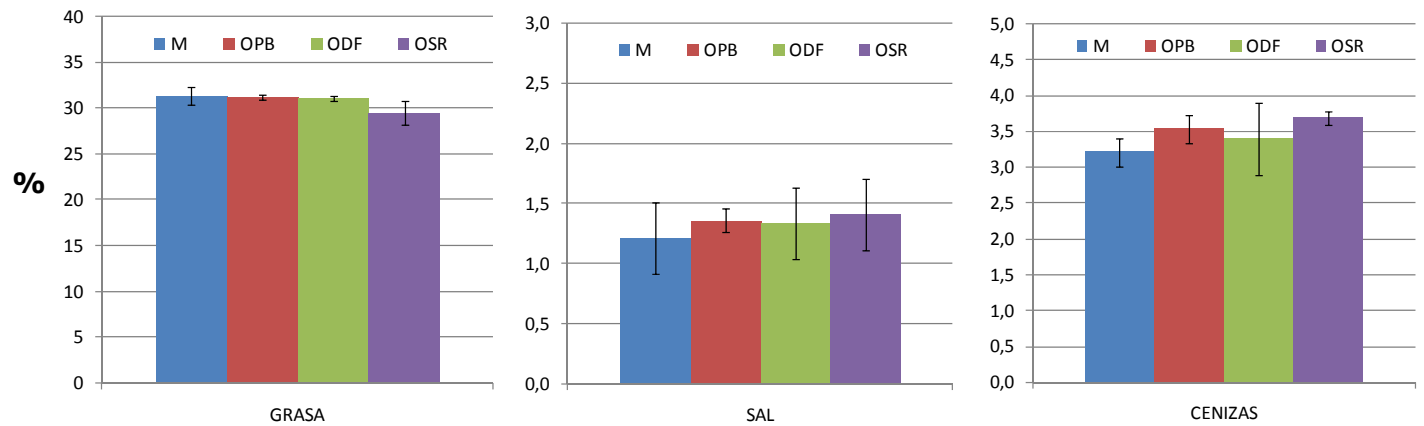

Figura 5.70. Porcentaje de grasa, sal y cenizas a los 40 días de maduración. Comparación tecnológica 
En cuanto al contenido en sal se observan pequeñas diferencias a los cero días de maduración; sin embargo, tanto a los 20 como a los 40 días las concentraciones no difieren significativamente entre las 4 tecnologías de fabricación. A los 40 días de maduración el contenido de sal en humedad no difiere significativamente entre los queso elaborados a partir de las cuatro tecnologías, tomando valores de $2,87 \%$ para el queso tradicional y algo más alto, sobre el 3,18\%, en los quesos ultrafiltrados. Este parámetro es importante para el desarrollo de la proteolisis ya que condiciona el crecimiento microbiano y la actividad enzimática. Según estudios realizados por Kelly et al. (1996) sobre queso Cheddar el aumento del contenido de sal en humedad (cuyo valor típico ronda el $4 \%$ ) disminuye la hidrólisis de la $\beta$-caseína y consecuentemente la producción de péptidos de menor tamaño.

Por último, el contenido de cenizas es significativamente mayor para el queso $\mathrm{M}$ a los cero días de maduración, igualándose para todos los quesos a partir de los 20 días. Acorde al análisis de varianza, los mayores valores del contenido en cenizas encontrados en los quesos ultrafiltrados, a los 40 días de maduración, no llegan a ser significativos respecto al contenido del queso tradicional (igual comportamiento que el observado con la sal).

Por ser un factor clave para los objetivos de este trabajo, se comparará la concentración de proteína sobre base seca en los quesos elaborados mediante las 4 tecnologías (M/OPB/ODF/OSR), según los datos que se recogen en la Tabla 5.31, obteniéndose una base común para las comparaciones.

Tabla 5.31. Porcentaje de proteína en el ES a lo largo de la maduración. Comparación tecnológica

\begin{tabular}{|c|c|c|c|c|}
\cline { 2 - 5 } & \multicolumn{5}{|c|}{ DÍAS DE MADURACIÓN } \\
\cline { 2 - 6 } & 0 días & 20 días & 40 días \\
\hline M & $38,28^{\mathrm{a}} \pm 1,43$ & $38,21^{\mathrm{a}} \pm 1,14$ & $38,53^{\mathrm{a}}$ & $\pm 1,93$ \\
\hline OPB & $40,95^{\mathrm{b}} \pm 0,49$ & $40,55^{\mathrm{ab}} \pm 1,52$ & $40,05^{\mathrm{b}} \pm 0,36$ \\
\hline ODF & $41,01^{\mathrm{b}} \pm 0,74$ & $40,06^{\mathrm{ab}} \pm 1,18$ & $39,61^{\mathrm{ab}} \pm 0,87$ \\
\hline OSR & $41,63^{\mathrm{b}} \pm 0,62$ & $41,09^{\mathrm{b}} \pm 0,74$ & $40,55^{\mathrm{b}} \pm 0,49$ \\
\hline
\end{tabular}

${ }^{*}$ Valores con la misma letra en la misma columna no son significativamente diferentes $(p<0,05)$

Se observa un aumento significativo en el contenido proteico -en base seca- de los quesos ultrafiltrados (OPB, ODF y OSR) respecto al tradicional (M) en todos los casos.

En la Figura 5.71 se representa la evolución del pH de los quesos desde su salida de prensa hasta los 40 días. Se observa como el pH del queso tradicional (M) y del óptimo final (OSR) son estadísticamente iguales desde el momento final de la elaboración con un pH entorno a 5,1 al final de la etapa de salado, hasta los cuarenta días de maduración con valores en torno a 4,95.
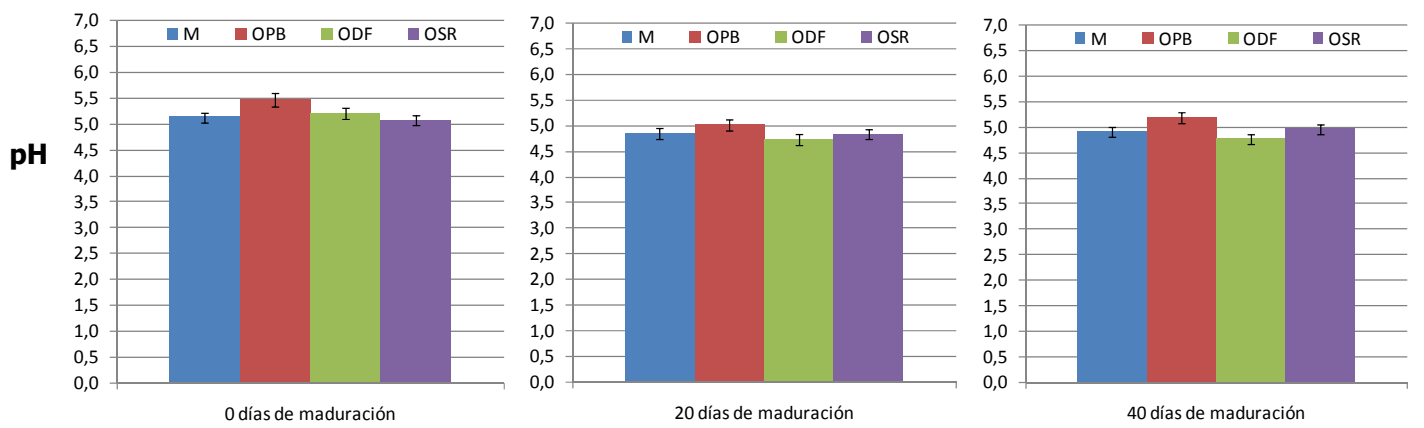

Figura 5.71. Evolución del pH a lo largo de la maduración. Comparación tecnológica 
En todos los casos se observa una disminución del pH al principio de la maduración, que se va frenando para sufrir un ligero aumento en las etapas finales. El queso OPB tiene valores de $\mathrm{pH}$ ligeramente superiores al óptimo mientras que el queso ODF presentó una acidificación excesiva a lo largo de la maduración, ya que en su optimización no se tubo en cuenta el pH.

Se compara, finalmente, el contenido mineral de los quesos mediante análisis de cationes (potasio, magnesio y calcio) y aniones (fósforo). Los datos obtenidos para los quesos elaborados a partir de los óptimos experimentales (OPB, ODF y OSR) y el queso tradicional (M) se recogen en la Tabla 5.32. Los análisis se realizaron a los 40 días de maduración.

Tabla 5.32. Contenido mineral del queso a los 40 días de maduración. Comparación tecnológica

\begin{tabular}{|c|c|c|c|c|c|}
\hline & $\mathrm{PO}_{4}(\mathrm{~g} / \mathrm{kg})$ & $K(g / k g)$ & $\mathrm{Ca}(\mathrm{g} / \mathbf{k g})$ & Mg & / / kg) \\
\hline$M$ & $6,1^{\mathrm{a}} \quad \pm 0,7$ & $1,3^{\mathrm{a}} \quad \pm 0,1$ & $7,1^{\mathrm{b}} \quad \pm 0,1$ & $0,42^{\mathrm{a}}$ & $\pm 0,03$ \\
\hline ODF & $4,3^{b} \quad \pm 0,3$ & $1,9^{b} \quad \pm 0,1$ & $5,5^{\mathrm{a}} \quad \pm 0,1$ & $0,40^{\mathrm{a}}$ & $\pm 0,02$ \\
\hline OSR & $3,6^{\mathrm{b}} \quad \pm 0,5$ & $2,1^{b} \quad \pm 0,1$ & $4,9^{\mathrm{a}} \quad \pm 0,1$ & $0,39^{a}$ & $\pm 0,02$ \\
\hline
\end{tabular}

${ }^{*}$ Valores con la misma letra en la misma columna no son significativamente diferentes $(p<0,05)$

El contenido de calcio y fósforo de los quesos elaborados a partir de leche concentrada (ODF y OSR) presenta valores significativamente menores que el queso tradicional. En el contenido en potasio ocurre lo contrario, obteniéndose concentraciones significativamente mayores en los quesos ultrafiltrados. En lo que respecta al magnesio las concentraciones pueden considerarse iguales para todos los quesos estudiados.

Del mismo modo Guinee et al. (1994) obtuvieron menores niveles de Ca y $\mathrm{P}$ al elaborar queso a partir de leche ultrafiltrada, lo cual atribuyeron al menor $\mathrm{pH}$ de los quesos durante el proceso de elaboración comparado con la elaboración tradicional. Otra posibilidad es la pérdida de parte de estos compuestos en la etapa de ultrafiltración -al disminuir el pH de la leche desde 6,75 hasta 6,50- si bien son necesarios futuros estudios de la concentración de calcio en la leche de partida, suero de prensa y permeado de ultrafiltración para conocer el momento exacto donde se produce la pérdida de esas sales.

Algunos quesos españoles con similares contenido de calcio que el queso ultrafiltrado son los quesos de Burgos, la Garrotxa, Gata-Hurdes, Murcia, Pasiego, La Peral, Picón, Torta del Casar o Arzúa-Ulloa (Sánchez 1999).

\section{ANÁLISIS DEL LACTOSUERO}

Para finalizar el estudio físico-químico se realizan análisis de los lactosueros obtenidos en las 12 fabricaciones, tres lotes empleando la tecnología tradicional y tres lotes en cada una de las condiciones optimas de cada diseño experimental. En la elaboración de queso por la tecnología tradicional se obtienen dos fracciones de lactosuero. El mayoritario, generado en la cuba en la etapa de sinéresis (Mc) y el liberado durante el prensado del queso (Mp). En los quesos ultrafiltrados únicamente se recoge la fracción obtenida en el prensado ya que el suero que se genera en el corte es prácticamente despreciable.

Los datos medios de los análisis se recogen en la Tabla 5.33.

En el queso OPB se pierde en el lactosuero una cantidad elevada de grasa en comparación con el resto de casos, relacionado con la etapa de corte de la cuajada. Por el contrario, la menor concentración de grasa es la del suero generado en el prensado del queso tradicional. 
Tabla 5.33. Análisis de lactosuero. Comparación tecnológica

\begin{tabular}{|c|cc|cc|cc|cc|cc|c|}
\cline { 2 - 11 } \multicolumn{1}{c|}{} & \multicolumn{2}{c|}{ GRASA } & \multicolumn{2}{c|}{ ES } & \multicolumn{2}{c|}{ PROTEÍNA } & CENIZAS & pH & $\begin{array}{c}\text { \% del } \\
\text { inicial** }\end{array}$ \\
\hline Mc & $0,44^{\mathrm{b}}$ & $\pm 0,10$ & $7,23^{\mathrm{a}}$ & $\pm 0,10$ & $0,97^{\mathrm{a}}$ & $\pm 0,02$ & $0,55^{\mathrm{a}}$ & $\pm 0,10$ & $6,37^{\mathrm{ab}}$ & $\pm 0,02$ & 78,2 \\
\hline Mp & $0,19^{\mathrm{a}}$ & $\pm 0,05$ & $7,05^{\mathrm{a}}$ & $\pm 0,06$ & $1,02^{\mathrm{a}}$ & $\pm 0,10$ & $0,51^{\mathrm{a}}$ & $\pm 0,10$ & $6,24^{\mathrm{a}}$ & $\pm 0,11$ & 3,3 \\
\hline OPB & $2,05^{\mathrm{c}}$ & $\pm 0,86$ & $10,47^{\mathrm{b}}$ & $\pm 0,45$ & $4,03^{\mathrm{b}}$ & $\pm 0,09$ & $0,48^{\mathrm{a}}$ & $\pm 0,03$ & $6,50^{\mathrm{b}}$ & $\pm 0,02$ & 6,8 \\
\hline ODF & $0,76^{\mathrm{b}}$ & $\pm 0,07$ & $9,43^{\mathrm{b}}$ & $\pm 0,69$ & $4,31^{\mathrm{bc}}$ & $\pm 0,29$ & $0,39^{\mathrm{a}}$ & $\pm 0,10$ & $6,50^{\mathrm{b}}$ & $\pm 0,03$ & 3,4 \\
\hline OSR & $0,45^{\mathrm{b}}$ & $\pm 0,15$ & $9,99^{\mathrm{b}}$ & $\pm 0,74$ & $4,55^{\mathrm{c}}$ & $\pm 0,23$ & $0,55^{\mathrm{a}}$ & $\pm 0,04$ & $6,49^{\mathrm{b}}$ & $\pm 0,11$ & 4,5 \\
\hline
\end{tabular}

${ }^{*}$ Valores con la misma letra en la misma columna no son significativamente diferentes $(p<0,05)$

** $\mathrm{kg}$ de lactosuero/- $\mathrm{kg}$ de leche inicial (M) o de concentrado (OPB, ODF y OSR)-

El extracto seco de los sueros obtenidos en los quesos ultrafiltrados es un $30 \%$ mayor que el generado en la producción tradicional. Este comportamiento se asocia a valores de proteína significativamente mayores en los sueros de ultrafiltrados que llegan a ser 4 veces mayores que los del suero de la elaboración tradicional (tanto en cuba como en prensa).

En lo referente al contenido de cenizas, en todos los casos se obtienen valores estadísticamente iguales.

El suero resultante de la fabricación OSR presenta menor contenido en grasa que el encontrado por Spangler et al. (1990), quienes obtuvieron un 1,13\% de grasa en el suero, elaborando queso Gouda a partir de leche con menor contenido en grasa $(3,1 \%)$.

En la Tabla 5.33 también se muestra (\% del inicial) el porcentaje en masa que representa el suero respecto a la leche de partida en los quesos tradicionales o respecto a la masa de concentrado en los quesos ultrafiltrados. Es de destacar que la materia perdida en las elaboraciones a partir de concentrados de ultrafiltración es mínima en comparación con el tradicional, ya que en la etapa previa de ultrafiltración ya se ha eliminado la mayor parte del agua. La cantidad de lactosuero es menor que la generada en el proceso APV-Sirocurd, donde se perdía un $8 \%$ (Garret y APVCoLtd 1987).

Las mayores concentraciones de proteína en el suero de prensa del procesado de los concentrados de ultrafiltración no debe ser un problema, siempre que se minimice la cantidad total generada.

La ausencia de corte de la cuajada resulta ser, como se vio en los diseños, un factor importante para el aumento de rendimiento asociado al aumento de proteína.

Es de destacar que los quesos elaborados a partir de concentrados de UF generan sueros con un $\mathrm{pH}$ significativamente superior a los tradicionales y más próximo a la neutralidad, por lo que el impacto ambiental generado es menor.

\subsubsection{SEguimiento DEL PROCESO DE MADURACIÓN: PROTEOLISIS $Y$ LIPOLISIS}

La maduración de los quesos (tradicional y UF) a lo largo del tiempo se estudia a través de las fracciones proteicas analizando el nitrógeno no caseínico (NNC) y el nitrógeno no proteico (NNP). Así mismo se estudian los compuestos orgánicos volátiles generados en la maduración. 


\section{SEGUIMIENTO DE LAS FRACCIONES PROTEICAS}

Según los datos recogidos en la Tabla 5.34 y representados en la Figura 5.72, se observa una diferencia significativa en cuanto al contenido en nitrógeno no caseínico (expresado como porcentaje del nitrógeno total) del queso tradicional (M) respecto al de los quesos OPB, ODF y OSR. Estos últimos presentan un porcentaje casi tres veces mayor, con valores en torno al $18 \%$, lo cual significa que prácticamente la totalidad de la proteína soluble ha sido retenida en el queso, al mantenerse la relación proteica de la propia leche (Luquet 1991). La proteína soluble, de acuerdo con los trabajos de Guinee et al. (1994), se espera esté en su estado nativo en un 90-95\%, debido al suave tratamiento térmico sometido al concentrado en la etapa de pasterización, si bien el proceso de ultrafiltración puede aumentar esta cantidad.
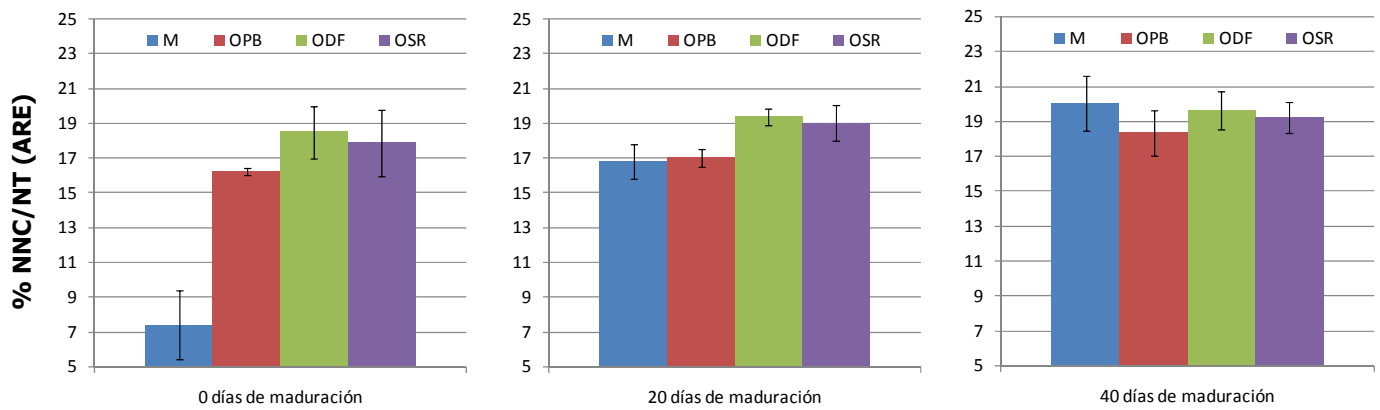

Figura 5.72. Nitrógeno no caseínico respecto del total (NNC/NT) a los 0, 20 y 40 días de maduración

En el queso tradicional a los 20 días de maduración el porcentaje de NNC aumenta hasta alcanzar el valor observado en el queso proveniente del primer óptimo (OPB) y a los 40 días el valor supera al de todos los quesos ultrafiltrados, si bien las diferencias no llegan a ser significativas y estadísticamente han de tratarse como iguales. Este comportamiento indica una desaceleración en los procesos de proteolisis y de degradación de las proteínas para los quesos ultrafiltrados en comparación con el queso tradicional.

Tabla 5.34. Nitrógeno no caseínico (NNC) respecto del total en la maduración. Comparación tecnológica

\begin{tabular}{|c|cc|cc|cc|}
\cline { 2 - 7 } \multicolumn{1}{c|}{} & \multicolumn{6}{c|}{ DÍAS DE MADURACIÓN } \\
\hline \% peso & \multicolumn{2}{c|}{ O días } & \multicolumn{2}{c|}{ 20 días } & \multicolumn{2}{c|}{ 40 días } \\
\hline M & $7,41^{\mathrm{a}}$ & $\pm 2,05$ & $16,81^{\mathrm{a}}$ & $\pm 1,01$ & $20,04^{\mathrm{a}}$ & $\pm 1,62$ \\
\hline OPB & $16,19^{\mathrm{b}}$ & $\pm 0,16$ & $17,00^{\mathrm{a}}$ & $\pm 0,51$ & $18,36^{\mathrm{a}}$ & $\pm 1,28$ \\
\hline ODF & $18,50^{\mathrm{b}}$ & $\pm 1,48$ & $19,37^{\mathrm{b}}$ & $\pm 0,47$ & $19,63^{\mathrm{a}}$ & $\pm 1,11$ \\
\hline OSR & $18,22^{\mathrm{b}}$ & $\pm 2,12$ & $19,02^{\mathrm{b}}$ & $\pm 0,96$ & $19,21^{\mathrm{a}}$ & $\pm 0,86$ \\
\hline
\end{tabular}

${ }^{*}$ Valores con la misma letra en la misma columna no son significativamente diferentes $(p<0,05)$

Estudios relacionados, sobre queso de pasta blanda obtenidos a partir de retenidos de UF (Furtado y Partridge 1988), muestran esta misma tendencia en la evolución del NNC, con valores significativamente menores que en las elaboraciones tradicionales para el índice de maduración aparente (ARE) a partir de los 14 días de maduración.

Siguiendo la evolución de la relación del nitrógeno no proteico (NNP) respecto al nitrógeno total (NT) a lo largo de la maduración, según los datos recogidos en la Tabla 5.35, se observa como a la salida de salmuera (cero días) el queso tradicional muestra valores significativamente menores de NNP que los quesos ultrafiltrados. A los 20 días de maduración la relación en cada uno de ellos se puede considerar igual. Alcanzados los 40 días de maduración el porcentaje sigue aumentando para todos ellos, con mayor proporción para los quesos tradicionales. 
Tabla 5.35. Nitrógeno no proteico (NNP) respecto del total en la maduración. Comparación tecnológica

\begin{tabular}{|c|cc|cc|cc|}
\cline { 2 - 8 } \multicolumn{1}{c|}{} & \multicolumn{6}{c|}{ DÍAS DE MADURACIÓN } \\
\hline \% peso & \multicolumn{2}{|c|}{ O días } & \multicolumn{2}{c|}{ 20 días } & \multicolumn{2}{c|}{ 40 días } \\
\hline M & $3,27^{\mathrm{a}}$ & $\pm 0,82$ & $8,99^{\mathrm{a}}$ & $\pm 0,41$ & $11,51^{\mathrm{a}}$ & $\pm 2,15$ \\
\hline OPB & $4,89^{\mathrm{b}}$ & $\pm 0,22$ & $7,73^{\mathrm{a}}$ & $\pm 1,21$ & $9,26^{\mathrm{a}}$ & $\pm 1,23$ \\
\hline ODF & $4,70^{\mathrm{b}}$ & $\pm 1,02$ & $7,86^{\mathrm{a}}$ & $\pm 1,00$ & $10,02^{\mathrm{a}}$ & $\pm 0,41$ \\
\hline OSR & $5,58^{\mathrm{b}}$ & $\pm 0,76$ & $8,36^{\mathrm{a}}$ & $\pm 1,20$ & $10,30^{\mathrm{a}}$ & $\pm 0,99$ \\
\hline
\end{tabular}

* Valores con la misma letra en la misma columna no son significativamente diferentes $(p<0,05)$

Esta tendencia observada en el NNP, gráficos en Figura 5.73, es otro indicador del retardo en la maduración para los quesos elaborados a partir de concentrados de ultrafiltración.
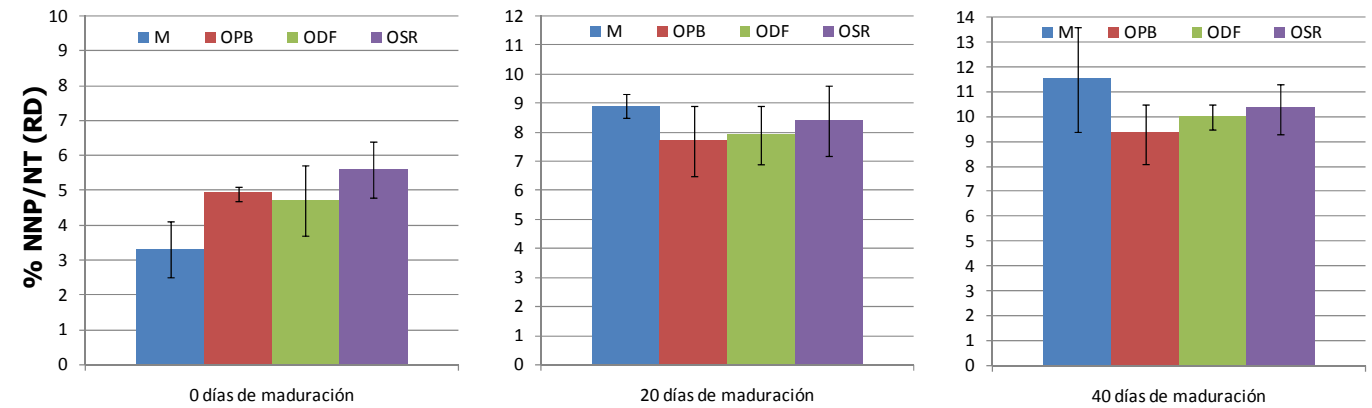

Figura 5.73. Nitrógeno no proteico respecto del total (NNP/NT) a los 0, 20 y 40 días de maduración

El índice RD (NNP/NT) da una idea de la producción de compuestos nitrogenados solubles en TCA al $12 \%$ como péptidos de cadena corta, aminoácidos, amoniaco u otros compuestos minoritarios producidos por las bacterias lácticas (Desmazeaud y Gripon 1977).

Estudios similares realizados por Bech (1993) sobre queso Havarti, partiendo de leche concentrada y leche concentrada acidificada, mostraron en ambos casos menor contenido en aminoácidos a partir de los 20 días de maduración que el queso tradicional.

Los valores para los índices de maduración (ARE y RD) en el queso tradicional son similares a los encontrados por Spadoti et al. (2005) al seguir la maduración de queso Prato. Estos investigadores obtuvieron, a los 25 días de maduración, valores del índice ARE del 15-20\% y del 6-8 \% para el índice RD, similares a su vez a los recogidos por Van der Berg et al. (1993) en su revisión tecnológica del proceso de maduración, trabajando con queso Gouda.

Numerosos estudios (Green et al. 1981; Green 1985; Qvist et al. 1987) sobre distintos tipos de queso han demostrado retardos en la maduración respecto al queso tradicional para las elaboraciones a partir de leche concentrada mediante el estudio de las fracciones nitrogenadas.

Como indica Bech (1993), esta maduración más lenta es atribuible a una menor descomposición de las moléculas de $\beta$-caseína ya que su hidrólisis primaria, catalizada parcialmente por la plasmina, es inhibida por la presencia de $\beta$-lactoglubulina. Según estudios realizados por Christensen et al. (1991) con queso Danbo y Havarti, la hidrólosis de la $\beta$-caseína es entre un 20 y un $40 \%$ menor en el queso al partir de leche ultrafiltrada, con la consecuente reducción del contenido en $\gamma$-caseína. Según De Koning et al. (1981) la hidrólisis de la $\alpha_{s_{1}}$-caseína también se ve ralentizada, mientras que las proteínas solubles no son hidrolizadas durante la maduración. 


\section{COMPUESTOS ORGÁNICOS VOLÁTILES}

Se presentan, en la Tabla 5.36, los resultados del estudio de los compuestos orgánicos volátiles producidos a los 40 días de maduración, tanto para el queso tradicional (M) como para las fabricaciones en las condiciones óptimas de los diseños ODF y OSR. El óptimo del diseño inicial (OPB) no ha sido analizado en cuanto a volátiles.

Tabla 5.36. Compuestos orgánicos volátiles en los quesos a los 40 días. Comparación tecnológica

\begin{tabular}{|c|c|c|c|c|c|c|c|}
\hline & & & & ol & & OS & \\
\hline \multirow{7}{*}{ 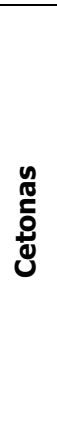 } & 2-Propanona & $0,122^{b}$ & $\pm 0,018$ & $0,055^{a}$ & $\pm 0,015$ & $0,107^{b}$ & $\pm 0,014$ \\
\hline & 2-Butanona & $0,017^{a}$ & $\pm 0,006$ & $0,038^{a}$ & $\pm 0,026$ & $0,010^{a}$ & $\pm 0,003$ \\
\hline & Isopropanol & $0,011^{a}$ & $\pm 0,004$ & $0,013^{a}$ & $\pm 0,005$ & $0,007^{a}$ & $\pm 0,002$ \\
\hline & 2-Pentanona & $0,008^{a}$ & $\pm 0,002$ & $0,008^{a}$ & $\pm 0,003$ & $0,008^{a}$ & $\pm 0,002$ \\
\hline & 2,3-Butanodiona & $0,558^{a}$ & $\pm 0,082$ & $0,582^{a}$ & $\pm 0,086$ & $0,542^{a}$ & $\pm 0,072$ \\
\hline & 2-Heptanona & $0,008^{a}$ & $\pm 0,003$ & $0,011^{a}$ & $\pm 0,004$ & $0,010^{a}$ & $\pm 0,003$ \\
\hline & 3-Hidroxi-2-butanona & $1,641^{a}$ & $\pm 0,239$ & $2,443^{b}$ & $\pm 0,290$ & $1,703^{a}$ & $\pm 0,198$ \\
\hline \multirow{2}{*}{$\begin{array}{l}\frac{y}{0} \\
\frac{0}{0} \\
\frac{0}{\alpha}\end{array}$} & Etanol & $3,433^{b}$ & $\pm 0,330$ & $2,345^{a}$ & $\pm 0,263$ & $1,953^{a}$ & $\pm 0,267$ \\
\hline & 2-Butanol & $0,017^{b}$ & $\pm 0,007$ & $0,017^{\mathrm{ab}}$ & $\pm 0,005$ & $0,008^{a}$ & $\pm 0,002$ \\
\hline
\end{tabular}

${ }^{*}$ Valores con la misma letra en la misma fila no son significativamente diferentes $(p<0,05)$ UNIDADES: \% respecto al patrón interno (ciclohexanona)

Como indican McSweeney et al. (2000) los compuestos volátiles en el queso se generan por el catabolismo de los azúcares (glicolisis), proteínas (proteolisis) y grasas (lipolisis) y son los responsables del flavor característico de cada tipo de queso.

Los compuestos mayoritarios encontrados en los quesos estudiados se recogen en dos grandes grupos, cetonas y alcoholes.

Las cetonas son compuestos intermedios de la maduración, que a su vez pueden ser reducidos a alcoholes (Fernández-García et al. 2004). Entre las más importantes se encuentran, por orden descendente de concentración, la 3-hidroxi-2-butanona, 2,3-butanodiona (diacetilo) y la 2-propanona, mientras que de forma minoritaria aparecen la 2-butanona, isopropanol, 2-pentanona y la 2-heptanona. La concentración de todos ellos no presenta diferencias significativas en los distintos quesos, salvo para el queso ODF que presentó mayor porcentaje de 3-hidroxi-2-butanona y menor de 2-propanona. La 2,3-butanodiona se relaciona significativamente con la intensidad del aroma a mantequilla en el queso (Menéndez et al. 2000).

Los alcoholes se generan a partir de aldehídos y cetonas favorecidos por el bajo potencial redox del queso (Fernández-García et al. 2004). Se genera mayoritariamente etanol, con mayores concentraciones en el queso de mezcla tradicional. Estos resultados indican una mayor degradación de la caseína y el lactato, así como de los metabolitos intermedios que genera cada uno de ellos (McSweeney y Sousa 2000). Como alcohol minoritario encontramos el 2-butanol, con concentración mayor en los quesos tradicionales que en el óptimo OSR. Los resultados obtenidos en el análisis de los alcoholes, fundamentalmente del etanol, son otro indicador de la maduración más lenta de los quesos elaborados con concentrados de leche respecto al tradicional.

Comparando los valores obtenidos en el presente trabajo con la bibliografía, se encuentra el mismo perfil de compuestos volátiles que en quesos de mezcla como el Hispánico (Garde et al. 2007) o 
quesos de oveja con denominación de origen como el Zamorano, Roncal, Idiazábal o Manchego (Barron et al. 2005) pero con menor número de compuestos identificados y en menores concentraciones debido, entre otros factores, a su menor tiempo de maduración.

\subsubsection{COMPARACIÓN REOLÓGICA Y ESTRUCTURAL}

A continuación se realiza una comparación instrumental de la textura y el color de los quesos elaborados según las cuatro tecnologías de fabricación estudiadas.

A su vez se realiza un estudio estructural de la matriz de proteína mediante microscopía de barrido electrónico ambiental (ESEM).

\section{ESTUDIO DE LA TEXTURA DEL QUESO}

El queso es considerado un material viscoelástico, por lo que para la caracterización de su textura es común mezclar medidas reológicas con medidas de deformación y fractura (Lucey 2008). Mediante análisis instrumental del perfil de textura en los quesos (TPA) se evalúa, estudiando las deformaciones realizadas, la firmeza, elasticidad, adherencia, masticabilidad y cohesividad de los quesos a los 40 días de maduración. Los datos obtenidos se recogen en la Tabla 5.37.

Para la firmeza se obtienen valores mayores en el queso de mezcla tradicional, que no difieren significativamente de los obtenidos en la fabricación ODF. El menor valor observado en el queso OPB puede deberse a las aberturas que aparecen en el interior de la pasta por la mala fusión de los granos de cuajada.

Las diferencias de firmeza encontradas entre el queso tradicional y los quesos ultrafiltrados, se asocian con la particular estructura del queso obtenido a partir de concentrados de leche en cuanto a tamaño de las micelas de caseína y estado de agregación, así como al contenido mineral o la interacción entre las micelas, las proteínas solubles y los glóbulos de grasa, ya que en el estudio físico-químico, Figura 5.69, se encontró que el contenido en humedad no difiere significativamente entre los quesos elaborados mediante la tecnología tradicional y los que se elaboraron con leche ultrafiltrada.

Tabla 5.37. Datos de textura instrumental. Comparación tecnológica

\begin{tabular}{|c|cc|cc|cc|cc|cc|}
\cline { 2 - 10 } \multicolumn{1}{c|}{} & \multicolumn{2}{c|}{$\begin{array}{c}\text { Firmeza } \\
(\mathbf{N})\end{array}$} & \multicolumn{2}{c|}{ Cohesividad } & \multicolumn{2}{c|}{$\begin{array}{c}\text { Adhesividad } \\
\mathbf{( N} \cdot \mathbf{S})\end{array}$} & Elasticidad & \multicolumn{2}{c|}{$\begin{array}{c}\text { Masticabilidad } \\
(\mathbf{N})\end{array}$} \\
\hline $\mathbf{M}$ & $23,38^{\mathrm{c}}$ & $\pm 1,23$ & $0,63^{\mathrm{b}}$ & $\pm 0,09$ & $0,14^{\mathrm{a}}$ & $\pm 0,02$ & $0,88^{\mathrm{b}}$ & $\pm 0,02$ & $11,83^{\mathrm{b}}$ & $\pm 2,82$ \\
\hline OPB & $19,01^{\mathrm{a}}$ & $\pm 0,98$ & $0,61^{\mathrm{b}}$ & $\pm 0,10$ & $0,18^{\mathrm{ab}}$ & $\pm 0,02$ & $0,83^{\mathrm{b}}$ & $\pm 0,04$ & $9,89^{\mathrm{b}}$ & $\pm 1,35$ \\
\hline ODF & $21,62^{\mathrm{bc}}$ & $\pm 1,52$ & $0,35^{\mathrm{a}}$ & $\pm 0,04$ & $0,22^{\mathrm{b}}$ & $\pm 0,07$ & $0,69^{\mathrm{a}}$ & $\pm 0,07$ & $6,29^{\mathrm{a}}$ & $\pm 0,46$ \\
\hline OSR & $20,66^{\mathrm{ab}}$ & $\pm 0,67$ & $0,54^{\mathrm{b}}$ & $\pm 0,05$ & $0,14^{\mathrm{a}}$ & $\pm 0,04$ & $0,80^{\mathrm{b}}$ & $\pm 0,03$ & $11,34^{\mathrm{b}}$ & $\pm 1,48$ \\
\hline
\end{tabular}

Spangler et al. (1990) en su estudio sobre queso Gouda, elaborado por tecnología de ultrafiltración, también obtenían diferencias significativas en cuanto a la firmeza o dureza de los quesos, con mayores valores para los quesos elaborados mediante la tecnología tradicional. Estos investigadores atribuyeron estas diferencias a que las proteínas solubles retenidas en la cuajada actúan como relleno inerte aumentando la retención de agua (Karlsson et al. 2007a). 
Se obtienen valores elevados para la adherencia en el queso ODF, seguido del OPB y valores menores tanto para el queso tradicional como para el OSR. Esta menor adherencia, como se aprecia en los gráficos de la Figura 5.74, se atribuye a la correcta regulación del pH llevada acabo en la elaboración del queso OSR.
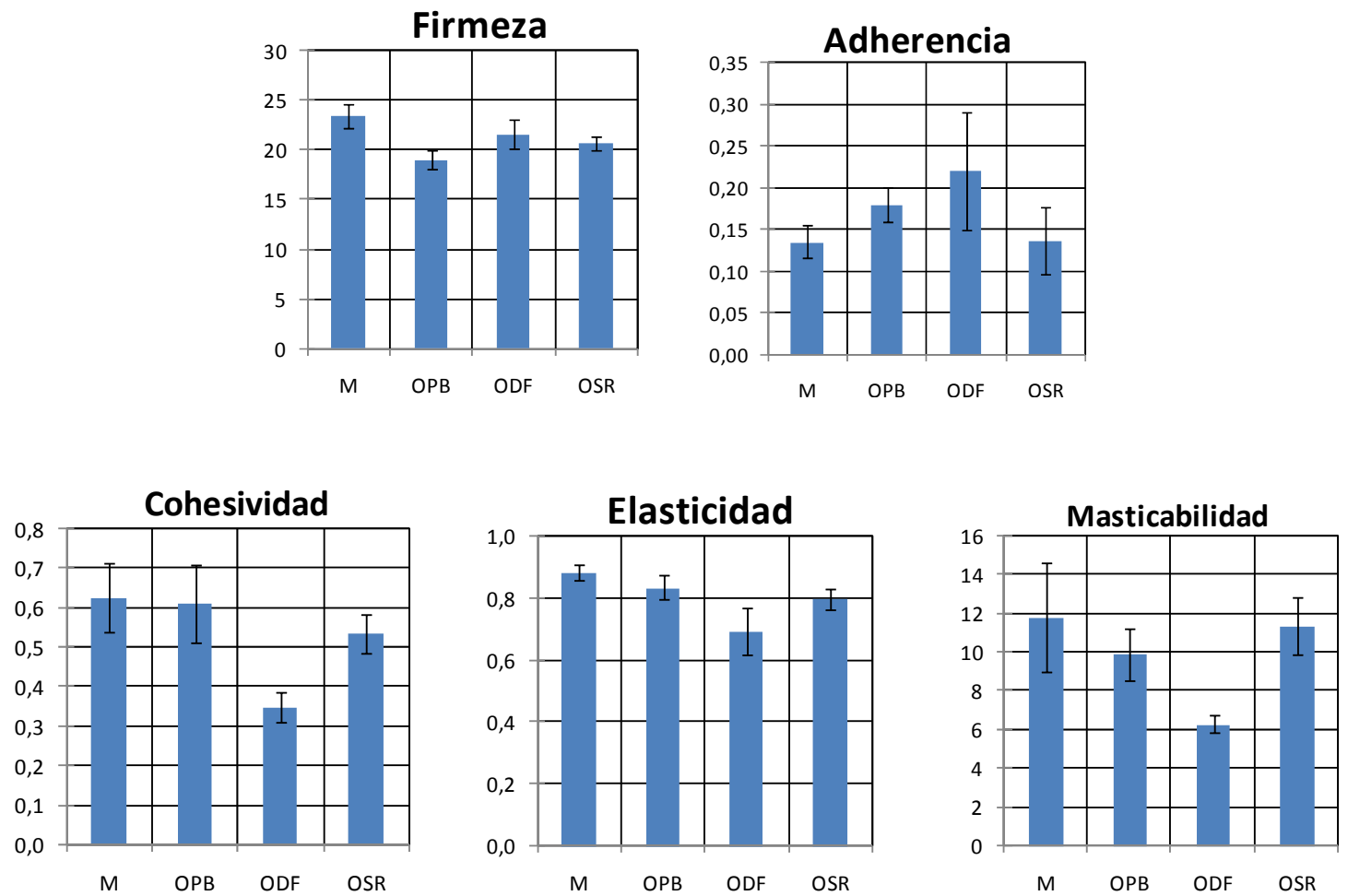

Figura 5.74. Textura instrumental. Comparación tecnológica.

Unidades: firmeza y masticabilidad $(\mathrm{N})$, adherencia $(\mathrm{N} \cdot \mathrm{s})$, elasticidad y cohesividad adimensionales

Por su parte la cohesividad, elasticidad y masticabilidad de los quesos presentan un patrón similar, con mayores valores para el queso tradicional $(M)$ seguido de OPB y OSR. Los valores de M, OPB y OSR no difieren significativamente entre ellos pero sí con los obtenidos por la tecnología ODF, cuyo valor para las tres propiedades es significativamente menor.

El comportamiento encontrado para cohesividad, elasticidad y masticabilidad es consecuencia de la mayor adherencia y menor $\mathrm{pH}$ del queso ODF, ya que en las dos primeras optimizaciones (OPB y ODF) no se llevó a cabo el ajuste de pH como se realizó en la optimización final OSR.

\section{MEDIDA DEL COLOR}

La medida del color ha sido utilizada en numerosos estudios para seguir la maduración de los quesos como parámetro de calidad (Dufossé et al. 2005).

Durante el proceso de optimización se observaron, cualitativamente, diferencias en el color de los quesos ultrafiltrados respecto al tradicional. Por ello, se ha estudiado este hecho cuantitativamente mediante colorímetro sobre el óptimo final (OSR) y el queso de mezcla elaborado mediante tecnología tradicional (M). 
Los valores obtenidos a lo largo del tiempo, tanto para el exterior como para el interior de los quesos, se recogen en la Tabla 5.38.

Tabla 5.38. Medida instrumental de color en los quesos M y OSR

\begin{tabular}{|c|c|c|c|c|c|c|c|}
\cline { 3 - 8 } \multicolumn{2}{c|}{} & \multicolumn{4}{c|}{ EXTERIOR } & \multicolumn{3}{c|}{ INTERIOR } \\
\cline { 3 - 8 } \multicolumn{2}{c|}{} & O días & 20 días & $\mathbf{4 0}$ días & 0 días & 20 días & 40 días \\
\hline \multirow{2}{*}{$\boldsymbol{L}$} & $\mathbf{M}$ & $75,84 \pm 0,11$ & $76,55 \pm 0,60$ & $75,84 \pm 0,11$ & $90,24 \pm 0,13$ & $86,43 \pm 0,12$ & $84,75 \pm 0,14$ \\
\cline { 2 - 8 } & OSR & $76,60 \pm 020$ & $77,73 \pm 0,27$ & $76,60 \pm 0,19$ & $91,61 \pm 0,26$ & $88,66 \pm 0,12$ & $85,16 \pm 0,26$ \\
\hline \multirow{2}{*}{$\boldsymbol{a}^{*}$} & $\mathbf{M}$ & $-1,40 \pm 0,05$ & $2,50 \pm 0,50$ & $3,72 \pm 0,53$ & $-1,04 \pm 0,51$ & $-0,15 \pm 0,24$ & $-1,00 \pm 0,52$ \\
\cline { 2 - 8 } & $\mathbf{O S R}$ & $-1,00 \pm 0,15$ & $4,98 \pm 0,19$ & $5,06 \pm 0,16$ & $-0,27 \pm 0,40$ & $-0,05 \pm 0,28$ & $-0,54 \pm 0,40$ \\
\hline \multirow{2}{*}{$\boldsymbol{b}^{*}$} & $\mathbf{M}$ & $22,03 \pm 0,40$ & $42,93 \pm 0,67$ & $40,42 \pm 0,40$ & $20,70 \pm 0,26$ & $26,33 \pm 0,12$ & $27,20 \pm 0,26$ \\
\cline { 2 - 8 } & $\mathbf{O S R}$ & $19,98 \pm 0,26$ & $35,85 \pm 0,35$ & $31,80 \pm 0,26$ & $15,18 \pm 0,20$ & $21,03 \pm 0,20$ & $22,23 \pm 0,66$ \\
\hline
\end{tabular}

Según los valores $L_{-} a^{*}-b^{*}$ a los 0,20 y 40 días de maduración, los quesos tradicionales coinciden con los ultrafiltrados en luminosidad exterior $(L)$ a los tres tiempos de medida, mientras que el mismo parámetro para el interior coincide a los 0 y 40 días de maduración pero no a los 20 .

En la coordenada de cromaticidad $a^{*}$ a los 20 días de maduración para el interior de la pasta se pueden considerar iguales las medidas para ambos quesos.

El comportamiento de las coordenadas de color al evaluar el interior de la pasta se recoge en la Figura 5.75 .
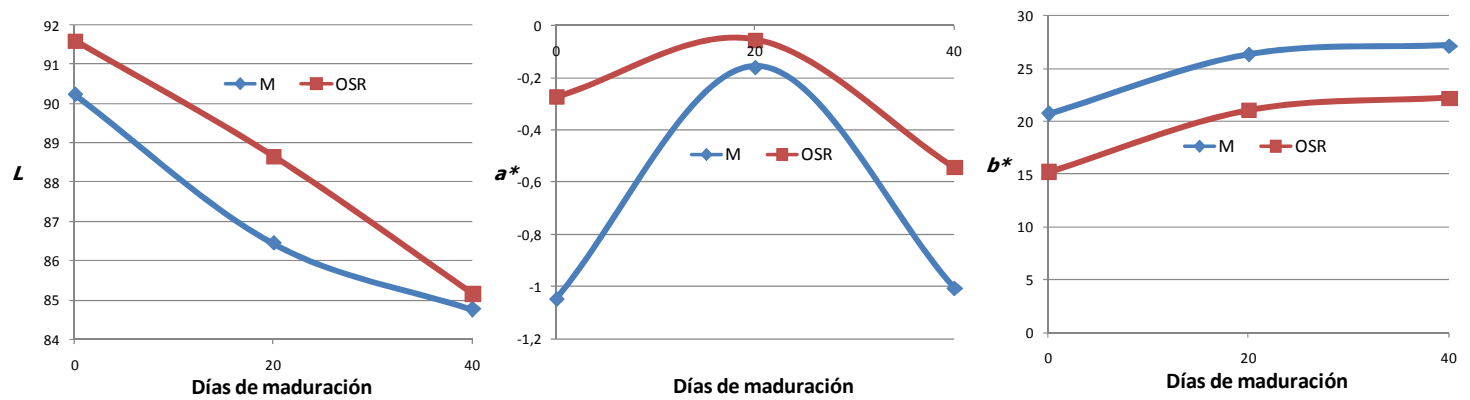

Figura 5.75. Evolución del color en el interior del queso

Se observa una disminución en la luminosidad o brillo de la pasta ( $L$ ) a lo largo de la maduración, un alejamiento del verde ( $a^{*}$ negativo) hasta la mitad de la maduración seguido de un acercamiento hasta los 40 días y un aumento hacia el amarillo (valores positivos de $b^{*}$ ), más acusado en las primeras etapas de maduración. Los valores de $\angle$ y $a^{*}$ son mayores para los quesos ultrafiltrados mientras que los de $b^{*}$ lo son para el queso tradicional.

En cuanto al color exterior del queso, Figura 5.76, al tomar medidas intermedias se observa una evolución más clara de cada una de las coordenadas. El brillo aumenta hasta un máximo en los primeros 10 días para volver a valores similares a los iniciales al final de la maduración. La coordenada $a^{*}$ pasa de la zona del verde (valores negativos) al rojo (positivos), con mayor intensidad para el queso ultrafiltrado. Esta mayor intensidad se observa también para el parámetro $L$. Por último, la coordenada $b^{*}$ muestra una tendencia creciente hacia el amarillo (valores positivos) con mayor intensidad para el queso elaborado por el método tradicional. 

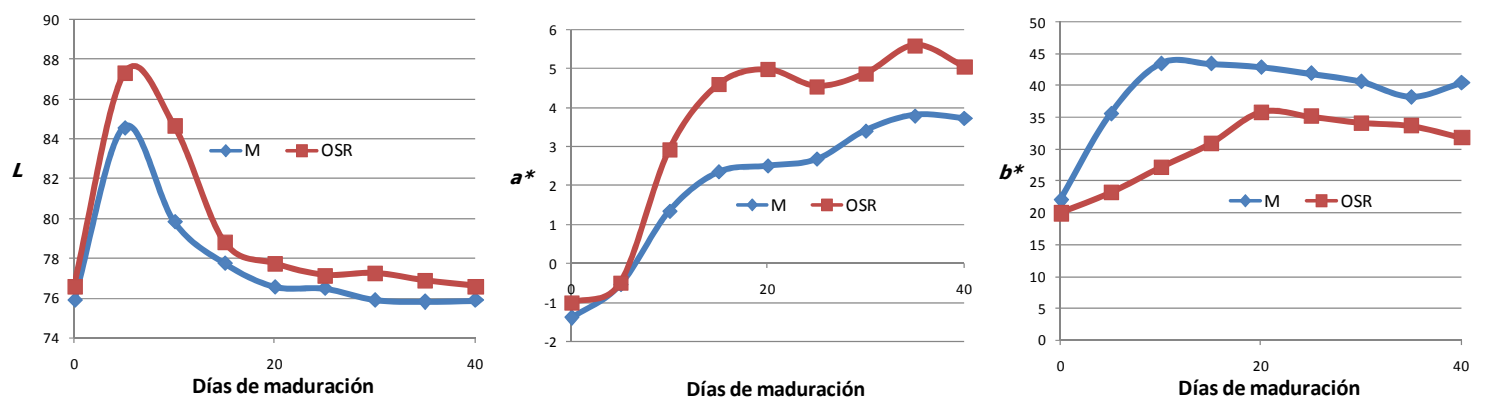

Figura 5.76. Evolución del color en el exterior del queso

La tendencia obtenida en este trabajo en los datos de color exterior es acorde con la encontrada en la bibliografía con disminución del valor de $\angle$ y aumento de los valores de $a^{*}$ y $b^{*}$ a lo largo de la maduración (Rohm y Jaros 1996a; Rohm y Jaros 1996b; Buffa et al. 2001).

Estas diferencias de color se comprueban cualitativamente a través de las fotografías recogidas en el Anexo A.7 (Figuras A.10-A.12) donde se muestra el aspecto interior y exterior del queso tradicional y el óptimo de ultrafiltración a los 0,20 y 40 días de maduración.

\section{ESTRUCTURA INTERNA DE LOS QUESOS}

Mediante microscopía ESEM (Environmental Scanning Electron Microscope) se realiza el estudio estructural de la matriz proteica para cada uno de los quesos estudiados. Para ello se toman microfotografías a tres aumentos distintos.

En primer lugar (Figura 5.77 a 5.80 ) se muestra una vista general de todos los quesos con un aumento de $\times 2.000$. La zona gris corresponde con la matriz proteica y la negra con los huecos donde quedan atrapados los glóbulos de grasa en el proceso de coagulación y sinéresis.

Se aprecian dos tipos de estructuras, una para los quesos M/OPB y otra para los quesos ODF/OSR. En el primer grupo (quesos M y OPB) se observa una estructura más ordenada, con huecos más redondeados y de menor tamaño, similar a la encontrada por Guinee et al. (1994) al elaborar quesos semicurados mediante ultrafiltración y coagulación en continuo (cortando la cuajada en un coagulador Aldcurd). En el segundo grupo aparecen huecos más grandes con forma irregular.

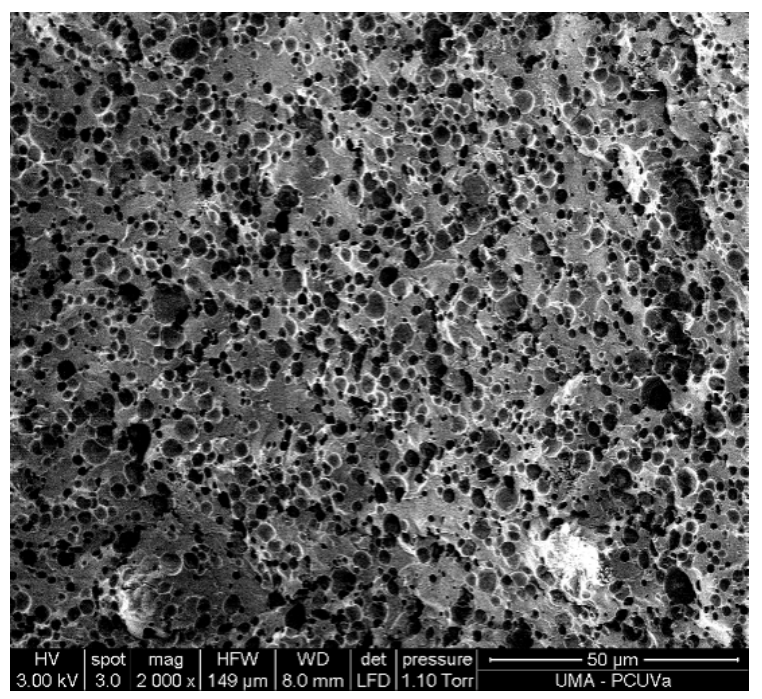

Figura 5.77. Micrografía ESEM queso $M$

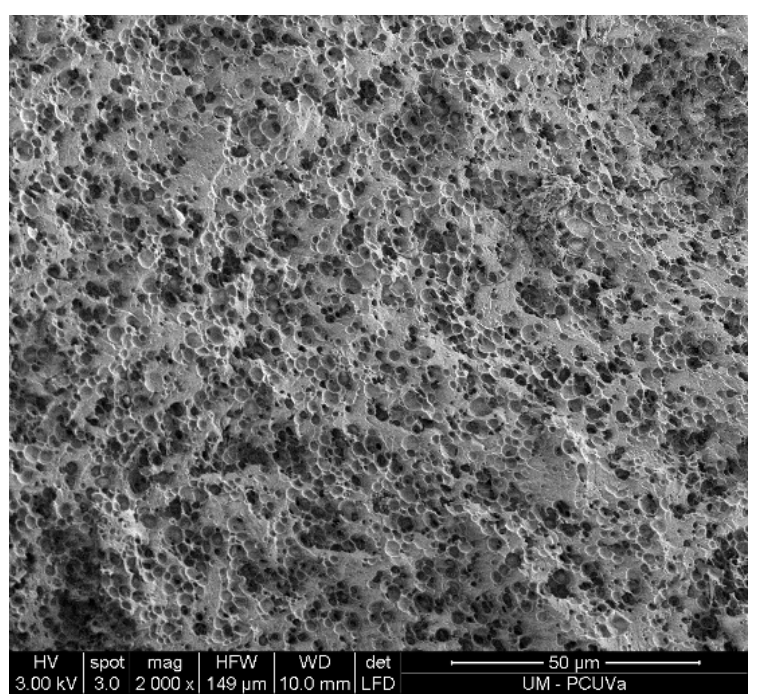

Figura 5.78. Micrografía ESEM queso OPB 


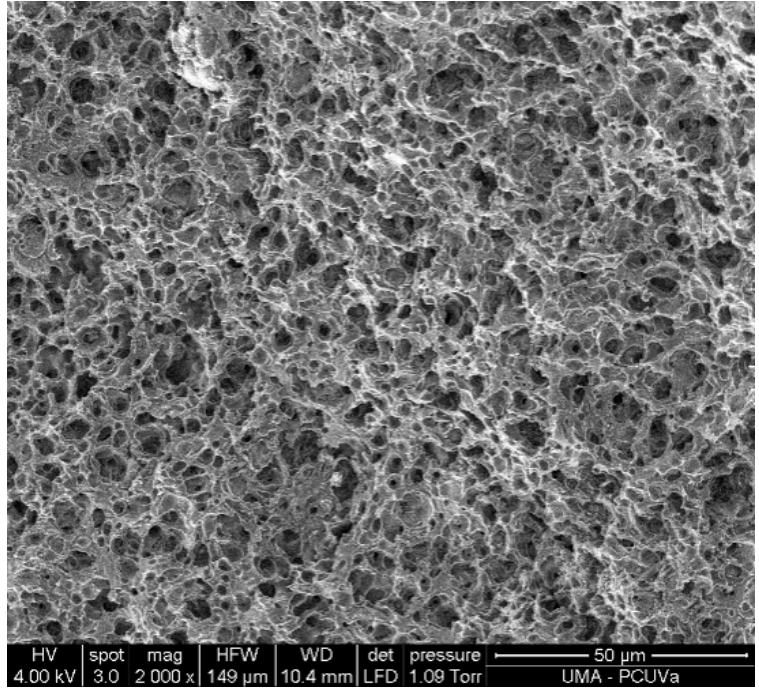

Figura 5.79. Micrografía ESEM queso ODF

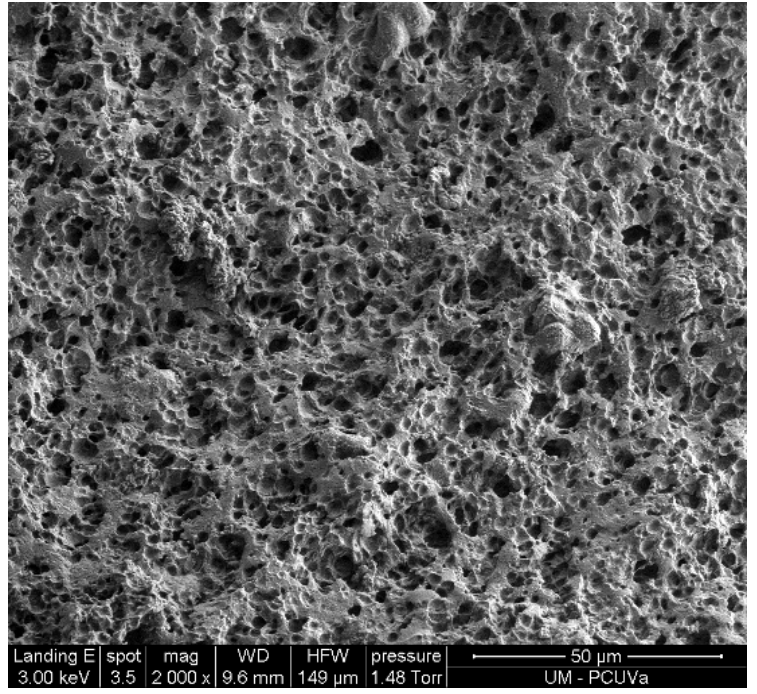

Figura 5.80. Micrografía ESEM queso OSR

En segundo lugar, para constatar dicha apreciación se realiza un análisis cuantitativo. Se parte de cuatro micrografías de cada uno de los quesos, tomadas a x5.000 aumentos, Figura 5.81, 5.83, 5.85 y 5.87 .

Mediante análisis de las imágenes se calculan los valores de porosidad (porcentaje de huecos), diámetro de poro (calculado a partir de la media y de la mediana) y factor de forma (diferencia respecto al círculo) para cada uno de los quesos (Tabla 5.39).

Tabla 5.39. Parámetros estructurales de los quesos: M, OPB, ODF y OSR

\begin{tabular}{|c|rl|rl|rl|rl|}
\cline { 2 - 9 } \multicolumn{1}{c|}{} & \multicolumn{2}{c|}{$\mathbf{M}$} & \multicolumn{2}{c|}{ OPB } & \multicolumn{2}{c|}{ ODF } & \multicolumn{2}{c|}{ OSR } \\
\hline Porosidad & $34,1^{\mathrm{a}}$ & $\pm 1,0$ & $34,5^{\mathrm{a}}$ & $\pm 2,6$ & $50,9^{\mathrm{b}}$ & $\pm 6,2$ & $53,0^{\mathrm{b}}$ & $\pm 3,3$ \\
\hline $\mathbf{D}_{\text {medio }}(\mu \mathbf{m})$ & $11,1^{\mathrm{a}}$ & $\pm 1,9$ & $14,3^{\mathrm{a}}$ & $\pm 1,5$ & $12,7^{\mathrm{a}}$ & $\pm 1,2$ & $14,1^{\mathrm{a}}$ & $\pm 2,1$ \\
\hline $\mathbf{D}_{\text {mediana }}(\mu \mathbf{m})$ & $4,6^{\mathrm{a}}$ & $\pm 0,7$ & $11,3^{\mathrm{b}}$ & $\pm 1,2$ & $5,6^{\mathrm{a}}$ & $\pm 0,6$ & $5,9^{\mathrm{a}}$ & $\pm 1,4$ \\
\hline Factor de forma & $0,81^{\mathrm{b}}$ & $\pm 0,03$ & $0,84^{\mathrm{ab}}$ & $\pm 0,05$ & $0,77^{\mathrm{a}}$ & $\pm 0,05$ & $0,76^{\mathrm{a}}$ & $\pm 0,08$ \\
\hline
\end{tabular}

* Valores con la misma letra en la misma fila no son significativamente diferentes $(p<0,05)$

En el análisis se encuentran diferencias significativas en la porosidad entre los quesos M/OPB y los quesos ODF/OSR, cómo se había planteado a priori a partir de las micrografías generales. En los quesos ODF/OSR se obtiene un mayor porcentaje de huecos, que está relacionado con la ausencia de corte de la cuajada y la consecuente mayor retención inicial de agua.

Karlsson et al. (2007b) también encontraron diferencias estructurales entre geles obtenidos a partir de leche desnatada concentrada respecto a los geles obtenidos de leche sin concentrar. Observaron un mayor grado de agregación, o lo que es lo mismo una menor porosidad, en los geles elaborados con leche sin concentrar, que relacionaron con un mayor grado de hidrólisis de la к-caseína. La menor hidrólisis en los quesos ultrafiltrados descrita en el estudio de Karlsson, así como la ausencia de corte para las fabricaciones ODF y OSR de este trabajo, se relaciona con un menor grado de difusión de las micelas de caseína y menores frecuencias de colisión entre dichas micelas en la etapa de sinéresis, contribuyendo todo ello al menor grado de agregación de la matriz proteica que forma el queso. 

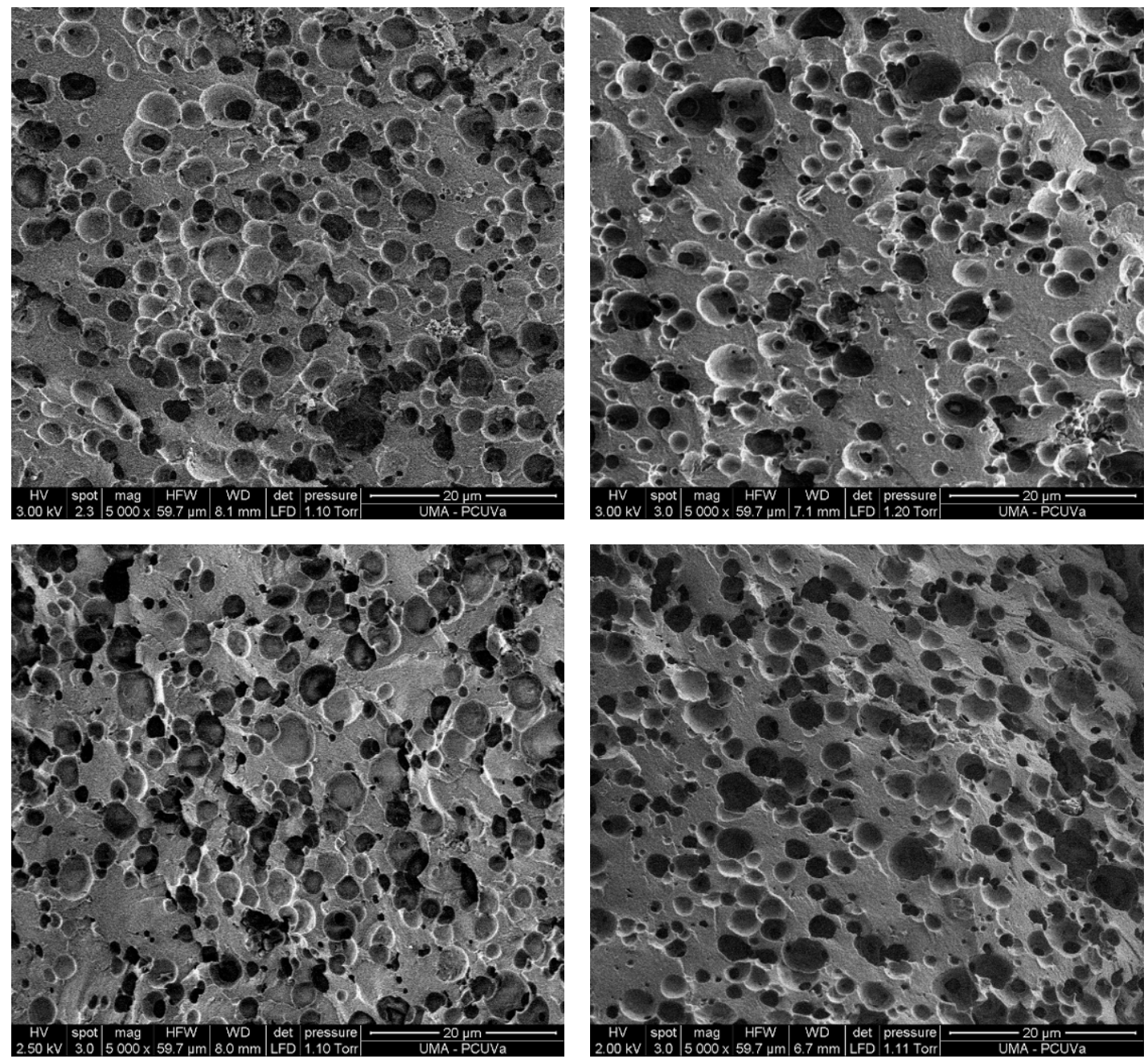

Figura 5.81. Micrografías ESEM queso M. Estudio cuantitativo

En la Figura 5.82 se representa la distribución de diámetros para las cuatro micrografías realizadas sobre el queso tradicional (M) que se muestran en la Figura 5.81.
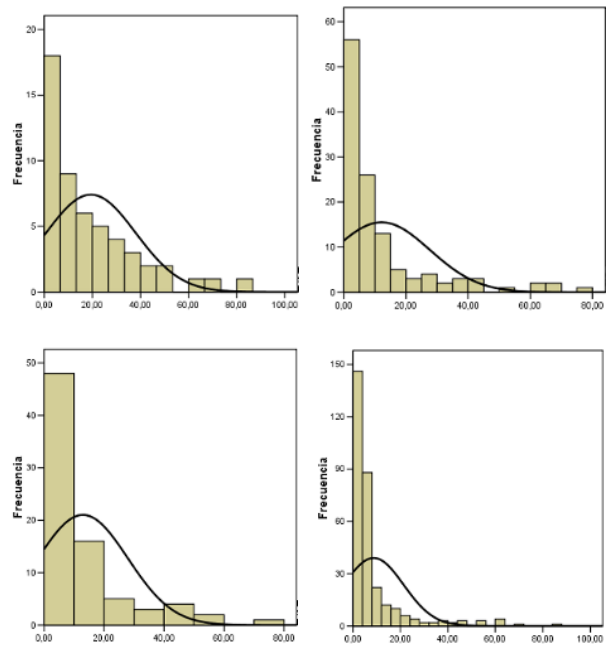

Figura 5.82. Distribución del diámetro de poro $(\mu \mathrm{m})$. Quesos M 

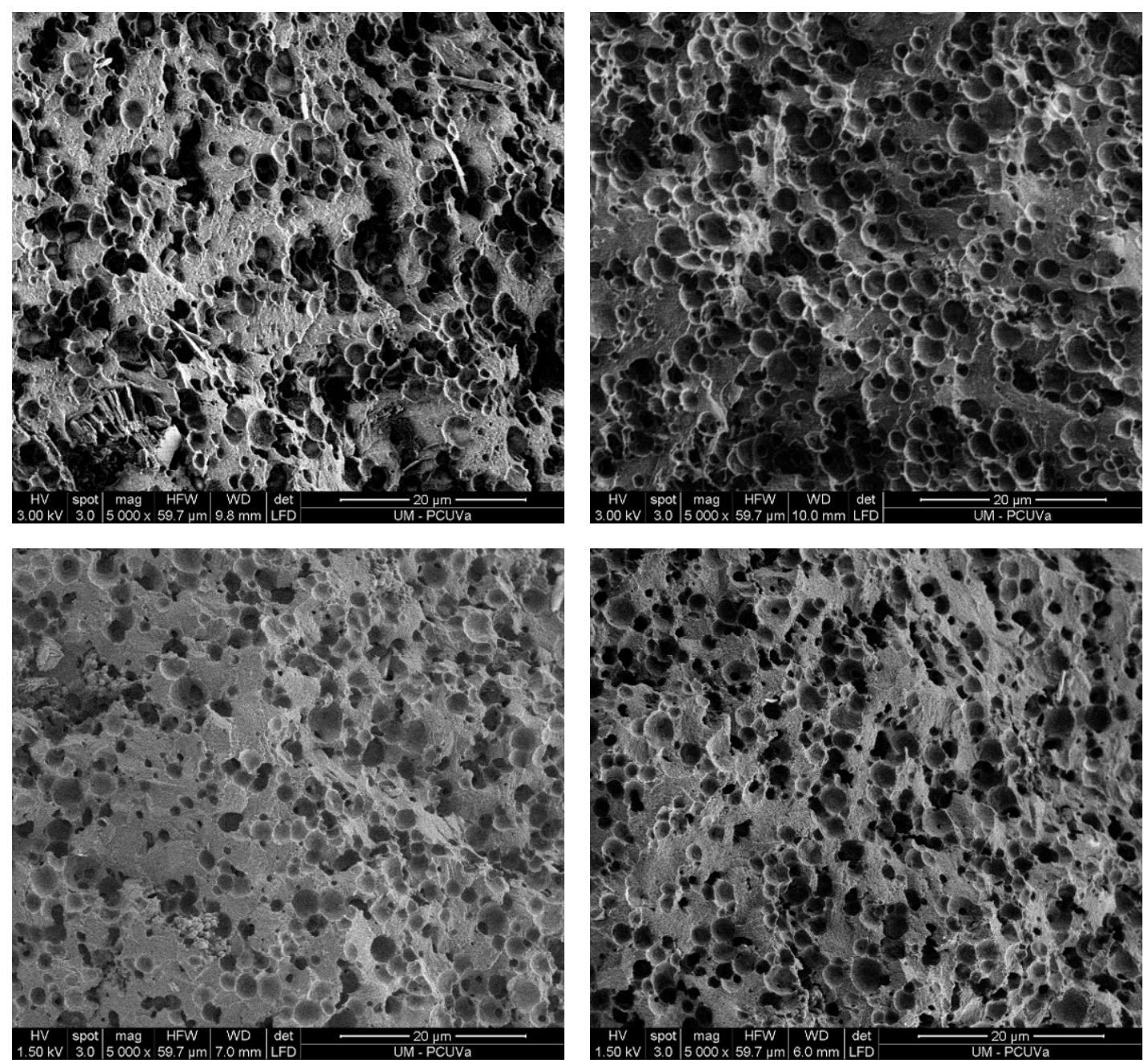

Figura 5.83. Micrografías ESEM queso OPB. Estudio cuantitativo

En la Figura 5.84 se representa la distribución de diámetros para las cuatro micrografías realizadas sobre el queso elaborado en el óptimo del diseño inicial (OPB) que se muestran en la Figura 5.83.
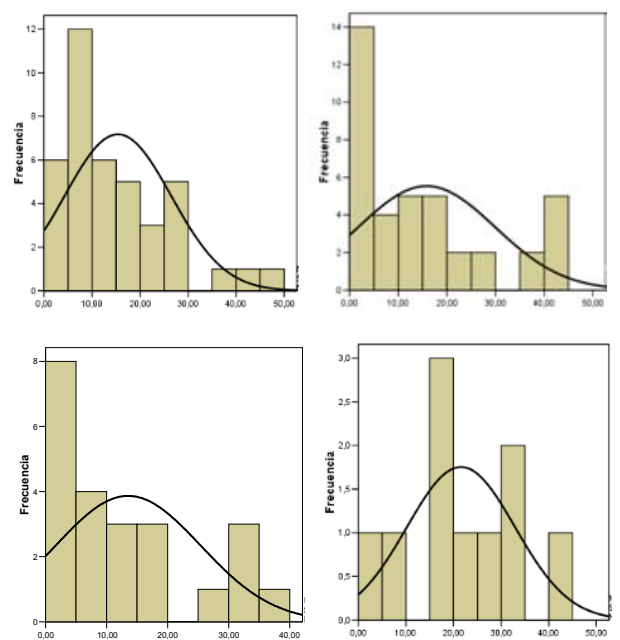

Figura 5.84. Distribución del diámetro de poro $(\mu \mathrm{m})$. Quesos OPB 

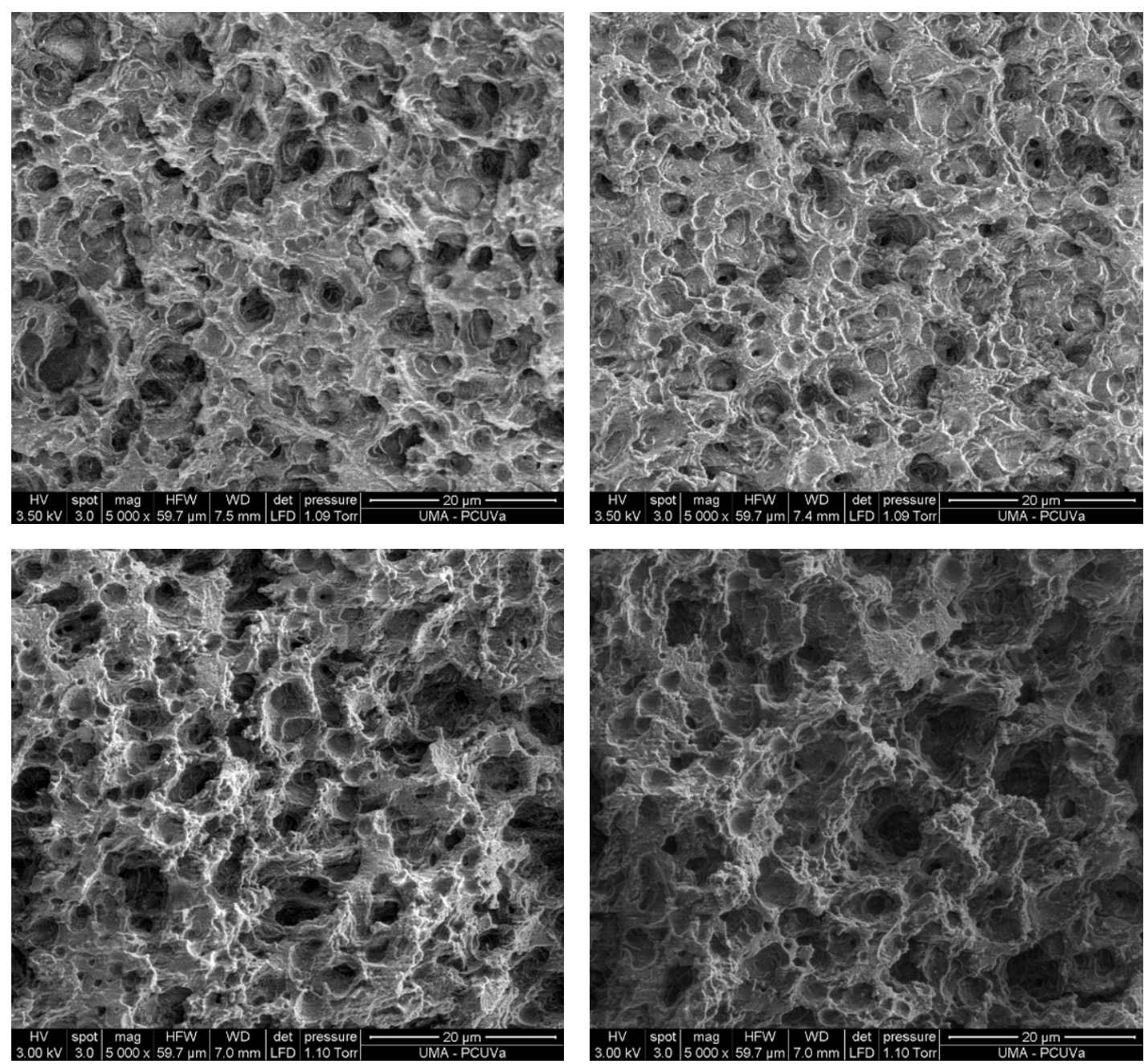

Figura 5.85. Micrografías ESEM queso ODF. Estudio cuantitativo

En la Figura 5.86 se representa la distribución de diámetros para las cuatro micrografías realizadas sobre el queso elaborado en el óptimo del diseño factorial (ODF) que se muestran en la Figura 5.85 .
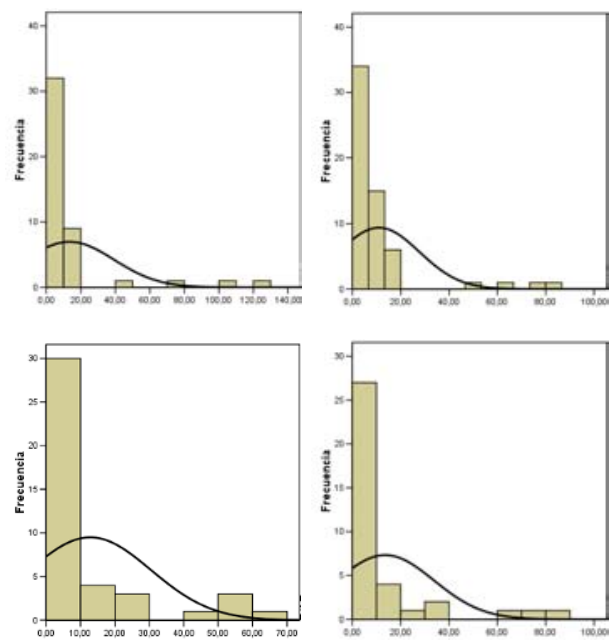

Figura 5.86. Distribución del diámetro de poro $(\mu \mathrm{m})$. Quesos ODF 

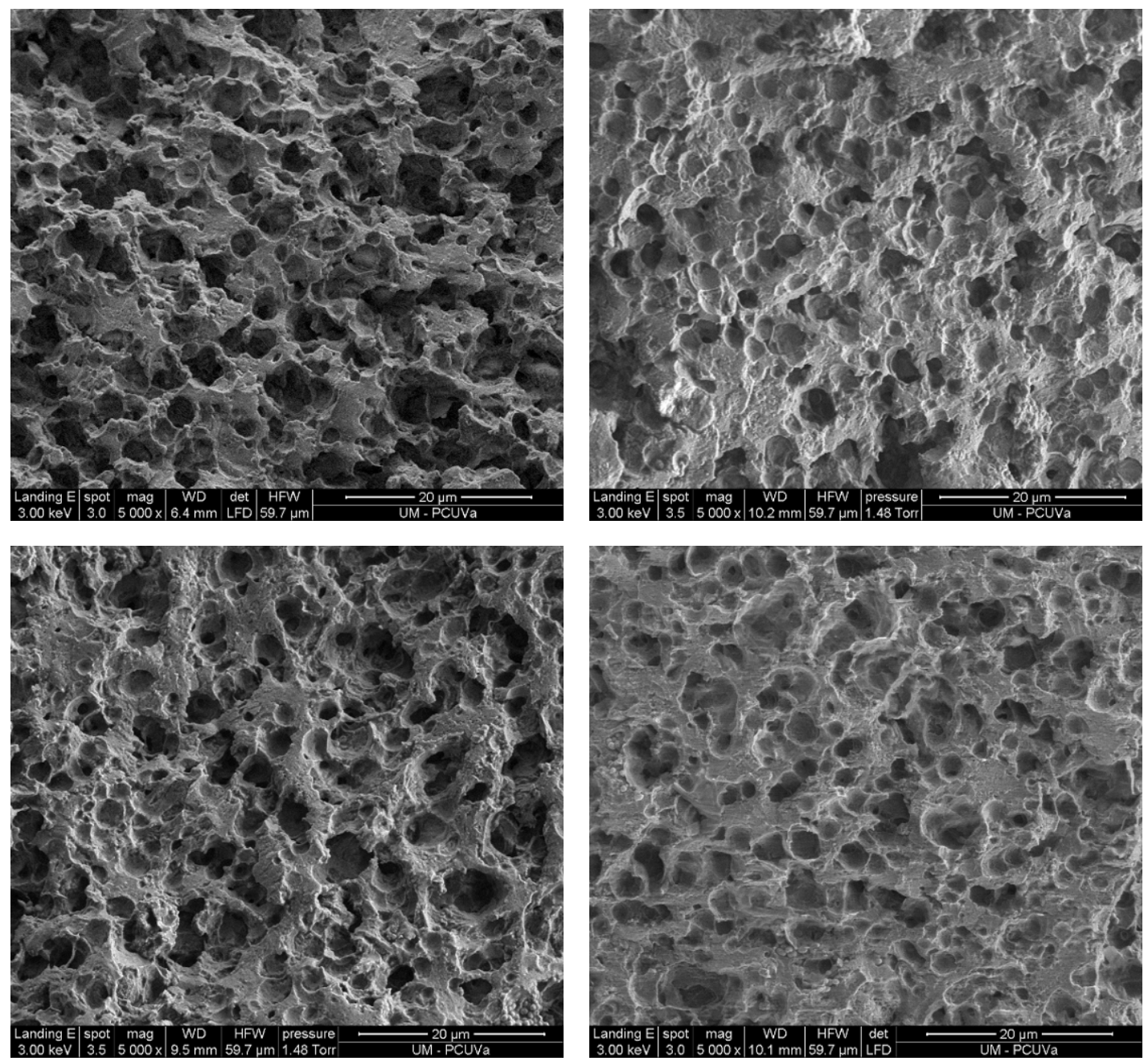

Figura 5.87. Micrografías ESEM queso OSR. Estudio cuantitativo

En la Figura 5.88 se representa la distribución de diámetros para las cuatro micrografías realizadas sobre el queso elaborado en el óptimo del diseño de superficie respuesta (OSR) que se muestran en la Figura 5.87.
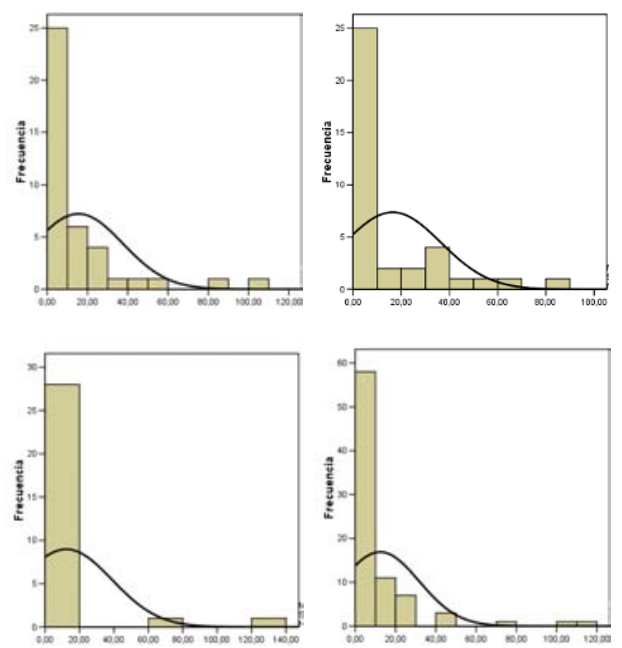

Figura 5.88. Distribución del diámetro de poro $(\mu \mathrm{m})$. Quesos OSR 
En el análisis cuantitativo de las imágenes se encuentra una gran dispersión en el diámetro de poro, como se muestra en los histogramas de la Figura 5.82, 5.84, 5.86 y 5.88. El diámetro calculado a partir de la media aritmética no presenta diferencias entre las distintas micrografías, mientras que calculado a través de la mediana, los quesos OPB presentan un mayor diámetro o, lo que es lo mismo, un mayor número de huecos de tamaño superior (histograma de la Figura 5.84). Este hecho puede estar ocasionado por la unión de huecos en el momento de la fractura del gel al preparar la muestra, por lo que no se considera relevante.

Los resultados del diámetro de poro calculado a partir de la mediana son acordes con el tamaño de los glóbulos de grasa, cuyo diámetro medio está entre 3 y 5 m (Collins et al. 2003).

Los diámetros de poro mayores de ese valor se deben a fenómenos de coalescencia y/o agrupación entre glóbulos grasos de menor tamaño o a efecto de la preparación de la muestra (fractura en nitrógeno líquido).

Los diámetros de huecos más pequeño son acordes con los encontrados por Rodríguez et al. (1999) trabajando con queso semicurado bajo en grasa. La presencia de huecos de tamaño menor al diámetro del glóbulo de grasa se deben a la parcial homogenización de la grasa en la etapa de ultrafiltración (Green et al. 1984). Si bien la homogenización de la grasa presenta ventajas en la elaboración de algunos tipos de queso, como los de pasta azul, en quesos de pasta prensada se atribuyen a la homogenización defectos como: alteraciones de la red de proteínas (Nair et al. 2000), problemas en el secado y la eliminación de agua (DePeters y Taylor 1985), fracturas en la estructura de la cuajada (Tunick 2000) o disminución de la elasticidad y/o firmeza del queso (Green et al. 1983). Para minimizar estos defectos, la optimización de las condiciones hidrodinámicas realizada en el Apartado 5.1.1 resulta ser un factor clave, no sólo desde un punto de vista económico si no también estructural, ya que cuanto menor sea el tiempo de procesado, menor porcentaje de grasa será susceptible de ser homgeneizada por efecto del bombeo.

No se encuentran diferencias significativas para el factor de forma medio de los poros entre los quesos ultrafiltrados (OPB, ODF y OSR). Sin embargo, es significativa la diferencia entre el queso tradicional (M) y los quesos ultrafiltrados en los que la cuajada no fue cortada (ODF y OSR) según indica el análisis de varianza (Tabla 5.39).

Por último, se realiza un estudio en detalle (Figura 5.89 a 5.92) a mayor resolución (entre $x 6.000$ y x30.000) para resaltar características singulares de las matrices proteicas. Se observa en todos los quesos la presencia de cristales y colonias de microorganismos.
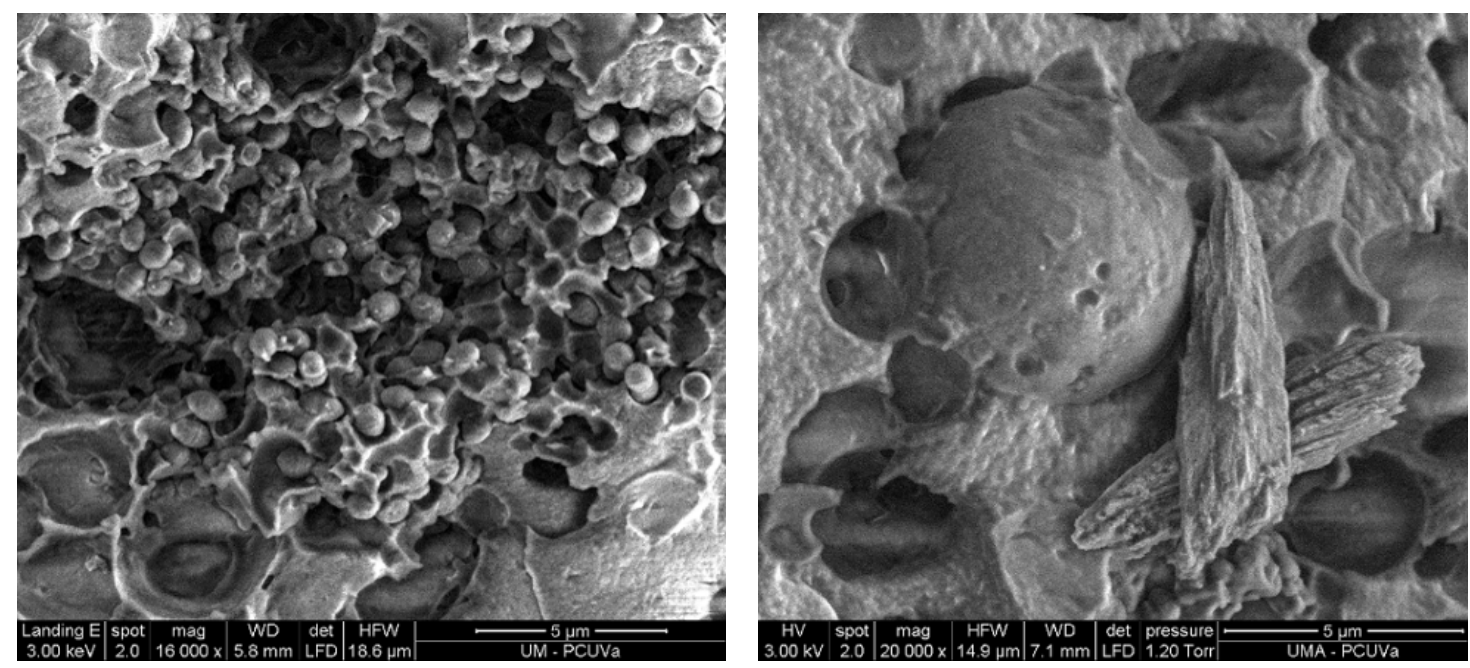

Figura 5.89. Micrografías ESEM en detalle. Quesos M 

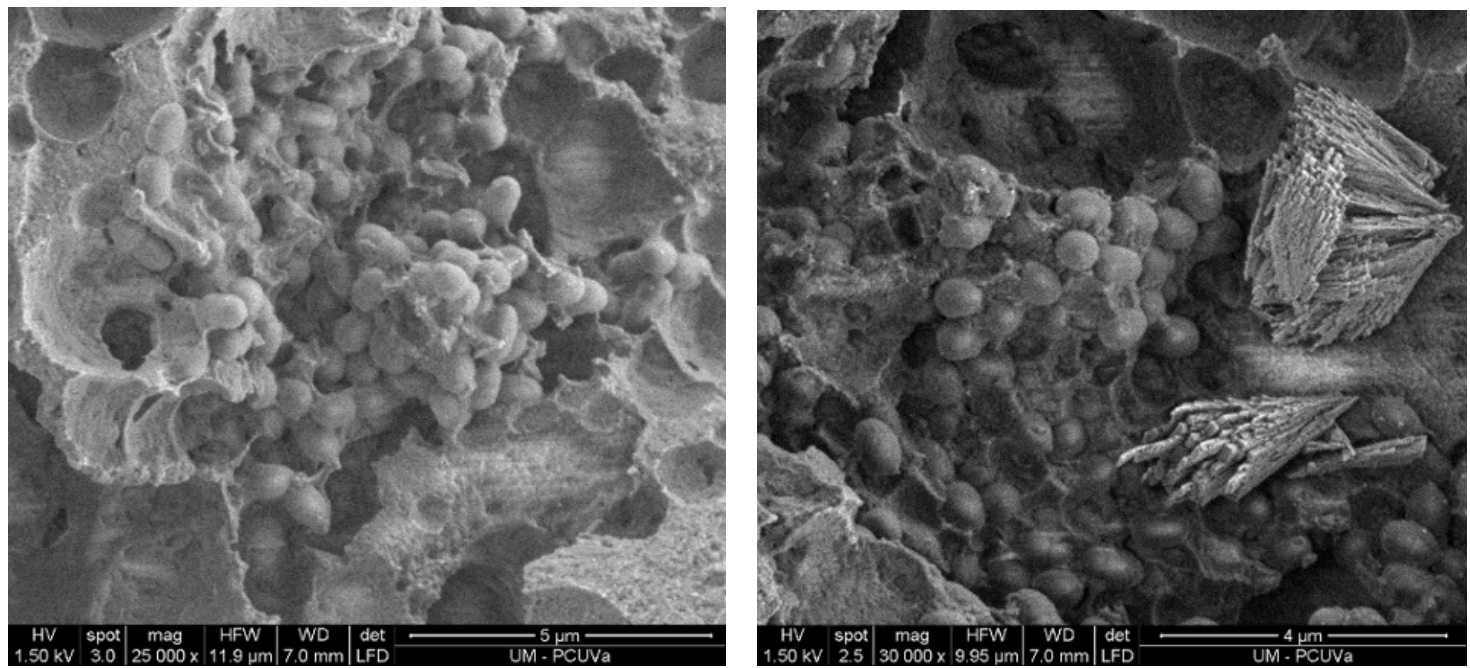

Figura 5.90. Micrografías ESEM en detalle. Quesos OPB
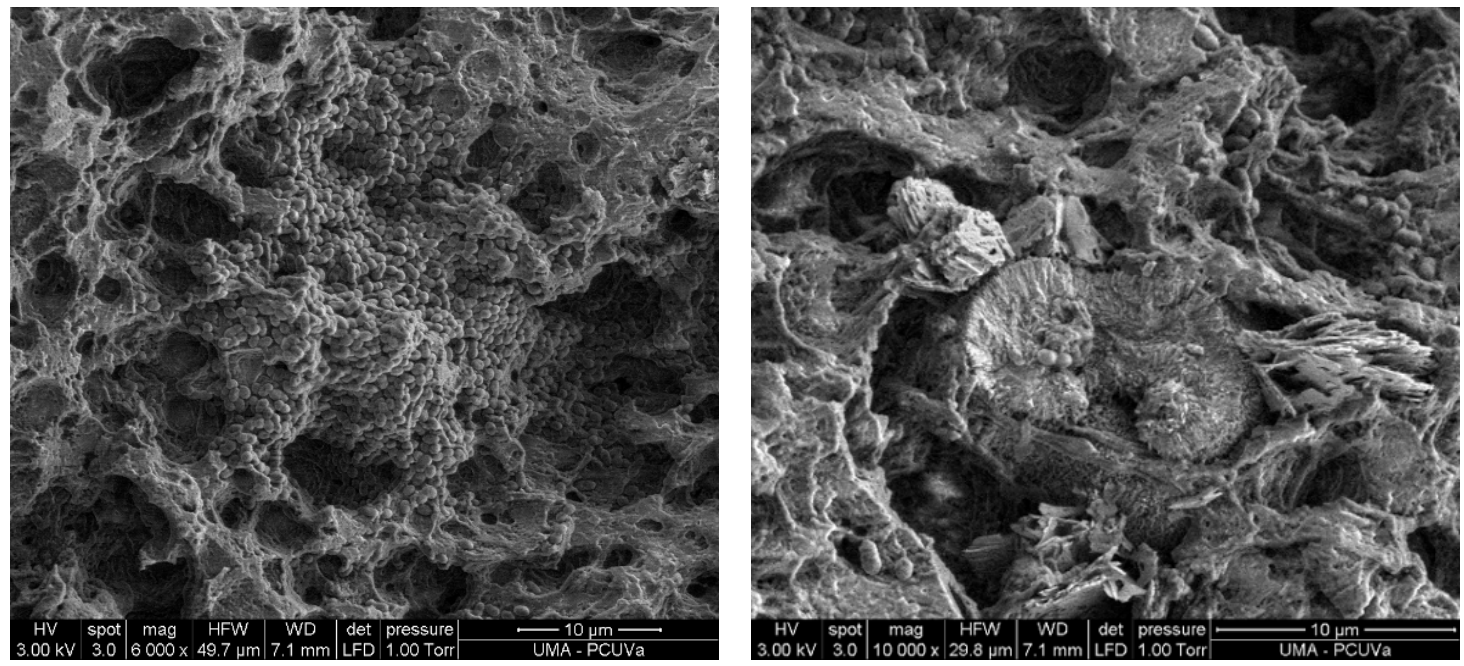

Figura 5.91. Micrografías ESEM en detalle. Quesos ODF
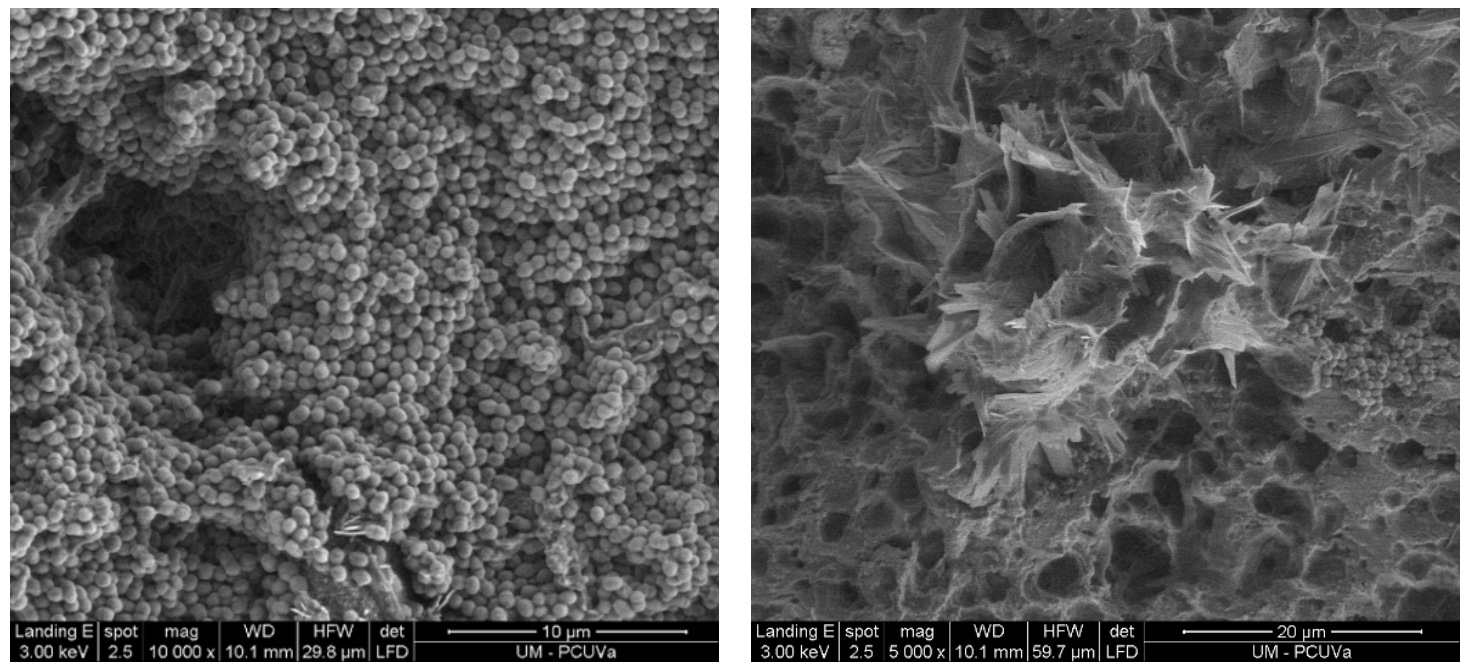

Figura 5.92. Micrografías ESEM en detalle. Quesos OSR 
El tamaño medio de los microorganismos encontrados, con forma de elipse, es menor a $1 \mu \mathrm{m}$. Por su forma y tamaño coinciden con las bacterias del fermento, las cuales han sido encontradas también en otros tipos de queso (McMahon et al. 1999). En la Figura 5.93 se muestra una imagen de bacterias lácticas, donde se aprecia su semejanza con las encontradas en los quesos, en cuanto a forma y tamaño, descartándose que puedan corresponder con otro tipo de microorganismos contaminantes, como mohos o levaduras.

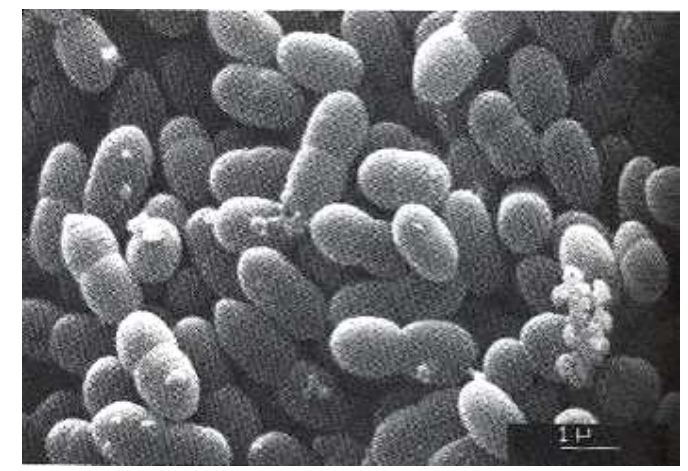

Figura 5.93. Micrografía SEM de lactococcus lactis. Fuente: (Wood y Holzapfel 1995)

La presencia de bacterias del fermento (mayoritariamente lactococcos) también ha sido observada en otras investigaciones (Rodríguez et al. 1999). Normalmente las bacterias aparecen en contacto con los glóbulos de grasa o en la interfase grasa/proteína, debido a su afinidad por la grasa (Laloy et al. 1996). Esta tendencia se observa claramente en los quesos M y OPB, donde las bacterias se enmarcan alrededor de los huecos que se generaron previamente a partir de los glóbulos grasos. Sin embargo, en los quesos ODF y OSR la presencia de bacterias es mucho más notable, con poblaciones mayores, que se localizan en zonas más amplias que las correspondientes a la interfase grasa/proteína. Este mayor crecimiento se relaciona con la ausencia de corte en las cuajadas de estos quesos, que provoca una mayor eliminación de humedad en el prensado y la maduración del queso. Los canales de eliminación de lactosuero generados en esas etapas proporcionan un espacio adicional para el crecimiento microbiano. Posteriormente, la reorganización de la matriz caseínica hace que esos canales reduzcan su tamaño y las colonias de microorganismos se incluyan en la matriz, como muestran las micrografías (Everett y Auty 2008).

En las Figura 5.89 a 5.92 también se observa la aparición de cristales en todos los quesos. Históricamente la aparición de cristales en el queso, sobre todo en su superficie, se asocia a la formación de lactato cálcico a través de distintos mecanismos (Omar y Hosaja 1986; Severn et al. 1986; Dybing et al. 1988). Acorde con este planteamiento, Agarwall et al. (2006) estudiaron la influencia de la concentración de la leche y el pH en la formación de cristales de lactato cálcico en el queso, concluyendo que ambas variables son factores que condicionan significativamente su formación. Tanto la concentración de lactato como el calcio soluble aumentan a medida que disminuye el $\mathrm{pH}$, formándose precipitaciones a valores de $\mathrm{pH}$ inferior a 5,1 cuando se opera con leche desnatada. Cuando la leche desnatada se ultrafiltraba antes de la elaboración del queso, estos investigadores encontraron que las cristalizaciones comenzaban a producirse a valores de $\mathrm{pH}$ por debajo de 5,3. De acuerdo con estos resultados, los quesos de las cuatro fabricaciones estudiados en este trabajo estarían dentro del rango de $\mathrm{pH}$ susceptible de generar cristales de este tipo.

Por otro lado, el fosfato cálcico es el mineral más abundante en la leche y en el queso. Everett et al. (2008) en su estudio sobre la estructura del queso constataron la presencia de cristales de fosfato cálcico en algunas variedades de queso, que podían generarse a partir de lactosuero atrapado en la estructura del queso. En este sentido, los quesos elaborados por ultrafiltración atrapan en su interior gran cantidad de suero ligado a las proteínas. Los cristales de fosfato 
cálcico, con tamaños entre 10 y $30 \mu \mathrm{m}$, han sido identificados como brusita $\left(\mathrm{CaHPO}_{4} \cdot 2 \mathrm{H}_{2} \mathrm{O}\right)$. Sin embargo, los cristales de lactato (D(-)-lactato cálcico), de acuerdo con el estudio de Everett, se forman en la superficie de quesos curados, con tamaños de $80 \mu \mathrm{m}$ aproximadamente, visibles al ojo humano e identificables en boca por su textura crujiente.

Se referencia la aparición de otros dos tipos de cristales en el queso, junto al lactato cálcico y fosfato cálcico, en queso italiano tipo Grana (Bottazzi et al. 1994). Por un lado cristales formados por residuos de aminoácidos, compuestos predominantemente por tirosina y en menor medida de fenilalanina y ácido glutámico (Bianchi et al. 1974), que se generan a lo largo de la proteolisis en la maduración; estos cristales o gránulos pueden llegar a ser identificados a simple vista. Por otro lado, en más raras ocasiones, se han llegado a encontrar cristales de cloruro sódico en quesos de elevado grado de maduración.

Los cuatro tipos de cristales encontrados en queso Grana Padano se recogen en la Figura 5.94.
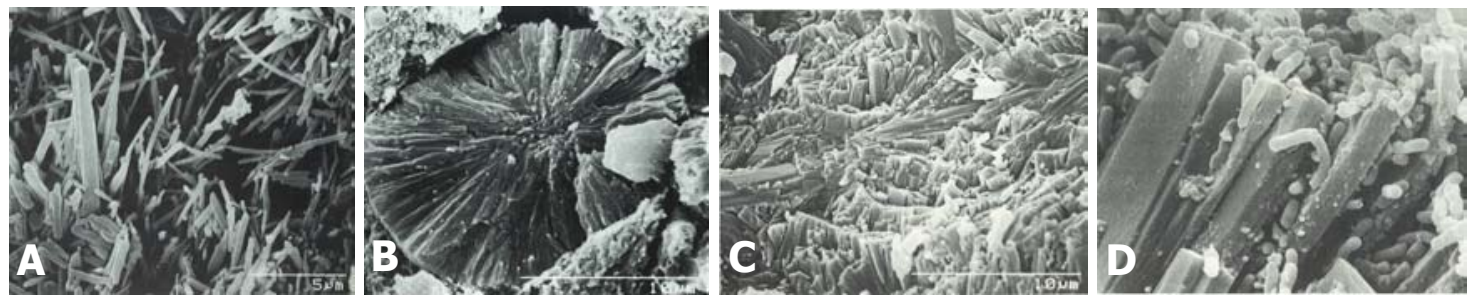

Figura 5.94. Microcristales encontrados en queso Grana Padano. Fuente: (Bottazzi et al. 1994).

(A: lactato cálcico; B: fosfato cálcico; C: tirosina y D: cloruro sódico)

Según lo expuesto anteriormente y debido a que en ningún caso el panel de cata detectó la presencia de cristales en ninguna de las etapas de la evaluación sensorial, ni la olfato-gustativa ni la visual, se descarta la posibilidad de cristales de lactato cálcico o de tirosina. Asimismo, los cristales de cloruro sódico son descartados por su reducida probabilidad de aparición, restringida a quesos de muy larga curación.

Por lo tanto, y a la vista de la Figura 5.94 (B) cuyos cristales en forma y tamaño coinciden con los cristales encontrados en las micrografías de los cuatro quesos ensayados, se afirma que los cristales encontrados se producen en el proceso de acidificación del queso por debajo de pH de 5,3 por la precipitación del fosfato cálcico micelar. En la Figura A.13 del Anexo A.8, se recogen más ejemplos de cristales encontrados en las distintas elaboraciones que sustentan esta teoría.

\subsubsection{COMPARACIÓN SENSORIAL}

La comparación mediante análisis organoléptico de los quesos obtenidos a través de las cuatro tecnologías ensayadas -a los 40 días de maduración- se realiza nuevamente en dos etapas, olfato-gustativa y visual, realizando también una valoración global de cada una de ellas.

En todos los casos se presentan valores medios obtenidos en la evaluación por el panel de cata de tres quesos para cada tecnología, correspondientes a distintos lotes. Así mismo, el error se calcula a un $95 \%$ de probabilidad, a partir de la desviación estándar de los resultados.

\section{SENSACIÓN OLFATO-GUSTATIVA}

En primer lugar se presentan los resultados correspondientes a la evaluación olfato-gustativa de los quesos. 


\section{- Calidad e intensidad del olor}

El queso tradicional (M) presenta intensidad del olor significativamente superior a los quesos ultrafiltrados, con valores por encima de 4, mientras que los ultrafiltrados no llegan a superar dicho valor (Tabla 5.40).

Tabla 5.40. Datos de calidad e intensidad del olor. Comparación tecnológica

\begin{tabular}{|c|c|c|}
\hline & Intensidad Olor & Calidad Olor \\
\hline $\mathbf{M}$ & $4,5^{\mathrm{b}} \quad \pm 0,1$ & $4,7^{\mathrm{b}} \quad \pm 0,2$ \\
\hline OPB & $3,4^{a} \quad \pm 0,4$ & $4,1^{\mathrm{ab}} \quad \pm 0,1$ \\
\hline ODF & $3,7^{\mathrm{a}} \quad \pm 0,6$ & $3,9^{a} \quad \pm 0,6$ \\
\hline OSR & $3,6^{\mathrm{a}} \quad \pm 0,2$ & $4,3^{\mathrm{ab}} \quad \pm 0,1$ \\
\hline
\end{tabular}

* Valores con la misma letra en la misma columna no son significativamente diferentes $(p<0,05)$

La puntuación de cada descriptor se observa en la Figura 5.95.
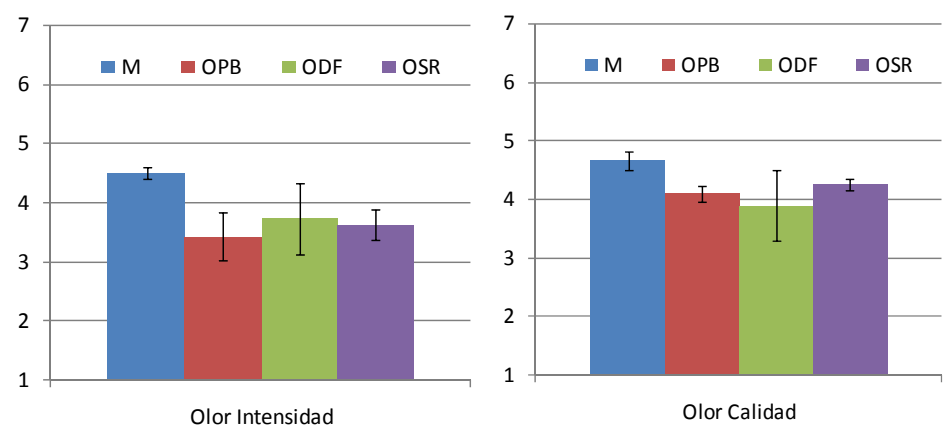

Figura 5.95. Gráfico de calidad e intensidad del olor. Comparación tecnológica

La calidad del olor obtiene puntuaciones por encima de 4 tanto para la tecnología tradicional (M) como para los óptimos OPB y OSR, con valores estadísticamente semejantes, mientras que el queso ODF obtiene puntuaciones algo menores.

\section{- Textura en mano: rugosidad, elasticidad y firmeza}

La evaluación de la textura en mano, Tabla 5.41 , se realiza a través de tres descriptores: rugosidad, elasticidad y firmeza. En general todos los quesos son poco rugosos, de elasticidad media y baja firmeza.

Tabla 5.41. Datos de textura en mano. Comparación tecnológica

\begin{tabular}{|c|c|c|c|}
\hline & Rugosidad & Elasticidad & Firmeza \\
\hline$M$ & $2,4^{b} \quad \pm 0,2$ & $4,5^{\mathrm{b}} \quad \pm 0,1$ & $3,6^{b} \quad \pm 0,7$ \\
\hline OPB & $1,7^{\mathrm{a}} \quad \pm 0,2$ & $3,5^{\mathrm{a}} \quad \pm 0,5$ & $2,2^{\mathrm{a}} \quad \pm 0,4$ \\
\hline ODF & $1,5^{\mathrm{a}} \quad \pm 0,3$ & $3,6^{\mathrm{a}} \quad \pm 0,4$ & $3,6^{\mathrm{b}} \quad \pm 0,5$ \\
\hline OSR & $1,7^{\mathrm{a}} \quad \pm 0,2$ & $3,9^{\mathrm{a}} \quad \pm 0,5$ & $3,7^{\mathrm{b}} \quad \pm 0,5$ \\
\hline
\end{tabular}

${ }^{*}$ Valores con la misma letra en la misma columna no son significativamente diferentes $(p<0,05)$

Las diferencias entre los distintos quesos se encuentran representadas en la Figura 5.96. Los quesos tradicionales son significativamente más rugosos que los ultrafiltrados, los cuales se 
describen como muy poco rugosos, acorde con lo observado por otros investigadores al comparar quesos ultrafiltrados con quesos elaborados mediante desuerado en cuba (Lawrence 1989).

La elasticidad del queso tradicional (M), presenta valores significativamente superiores que el resto. Por su parte, los quesos ultrafiltrados se agrupan conjuntamente en cuanto a elasticidad, si bien el óptimo final (OSR) presenta mayores valores que el resto.

La firmeza final de los quesos a los 40 días muestra valores que no difieren significativamente entre sí para los casos M, ODF y OSR, con puntuaciones menores de firmeza para el queso OPB, que estaría relacionado con las aberturas generadas por el corte y la deficiente fusión de los granos de cuajada.
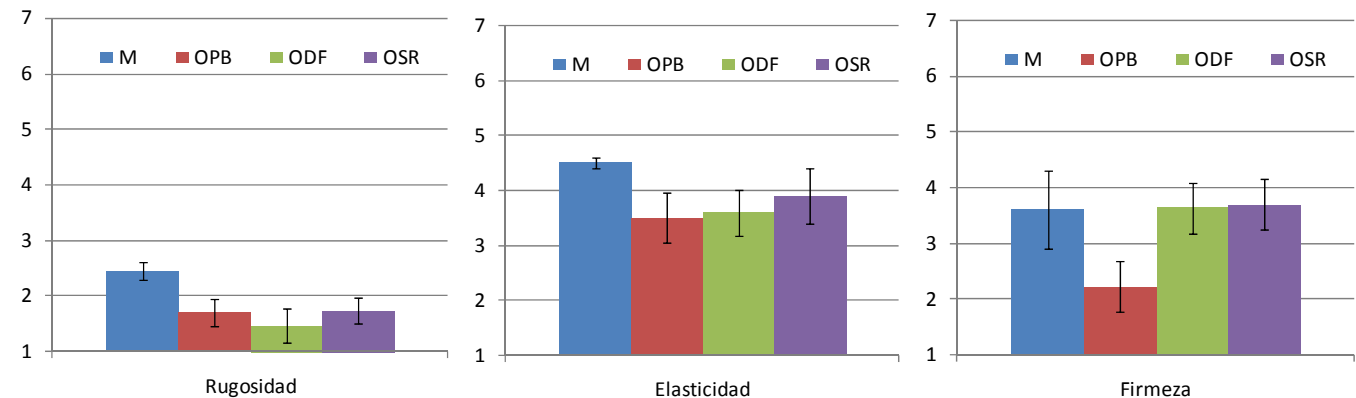

Figura 5.96. Gráficos de textura en mano. Comparación tecnológica

\section{- Textura en boca: friabilidad, adherencia, solubilidad, granulosidad y firmeza}

En los valores de textura en boca recogidos en la Tabla 5.42 y representados en la Figura 5.97, se observan tendencias similares para los descriptores de friabilidad y granulosidad, con puntuaciones bajas para todos ellos que no difieren significativamente entre sí.

Los quesos ultrafiltrados se presentan como más adherentes que el tradicional, llegando a ser la diferencia significativa para el queso ODF, como ocurría en la evaluación instrumental.

El queso ODF presenta unas puntuaciones en humedad significativamente mayores al resto de los quesos, así como una mayor adherencia y acidez (como se verá en la evaluación del gusto).

Los valores de solubilidad son similares, presentando un valor significativamente mayor el queso del óptimo final (OSR) respecto al queso tradicional.

Tabla 5.42. Datos de textura en boca. Comparación tecnológica

\begin{tabular}{|c|c|c|c|c|c|c|c|c|c|c|}
\hline \multirow[b]{2}{*}{$\mathbf{M}$} & \multicolumn{2}{|c|}{ Friabilidad } & \multicolumn{2}{|c|}{ Adherencia } & \multicolumn{2}{|c|}{ Solubilidad } & \multicolumn{2}{|c|}{ Granulosidad } & \multicolumn{2}{|c|}{ Humedad } \\
\hline & $2,3^{\mathrm{a}}$ & $\pm 0,2$ & $3,7^{\mathrm{a}}$ & $\pm 0,3$ & $3,9^{\mathrm{a}}$ & $\pm 0,1$ & $2,7^{b}$ & $\pm 0,1$ & $3,5^{\mathrm{a}}$ & $\pm 0,1$ \\
\hline OPB & $1,9^{\mathrm{a}}$ & $\pm 0,2$ & $3,9^{\mathrm{ab}}$ & $\pm 0,4$ & $4,2^{\mathrm{ab}}$ & $\pm 0,5$ & $1,9^{\mathrm{a}}$ & $\pm 0,2$ & $3,7^{\mathrm{a}}$ & $\pm 0,2$ \\
\hline ODF & $2,3^{\mathrm{a}}$ & $\pm 0,3$ & $4,6^{b}$ & $\pm 0,4$ & $4,2^{a b}$ & $\pm 0,1$ & $2,5^{\mathrm{b}}$ & $\pm 0,2$ & $4,2^{b}$ & $\pm 0,1$ \\
\hline OSR & $2,2^{a}$ & $\pm 0,7$ & $4,0^{a b}$ & $\pm 0,4$ & $4,5^{b}$ & $\pm 0,4$ & $2,5^{\mathrm{ab}}$ & $\pm 0,6$ & $3,7^{\mathrm{a}}$ & $\pm 0,3$ \\
\hline
\end{tabular}

La mayor adherencia y solubilidad, junto a la menor granulosidad y firmeza detectados en los quesos ultrafiltrados pueden relacionarse con la mayor arenosidad que se genera en la pasta al introducir las proteínas solubles, como indican los trabajos de Covacevich et al. (1987) en la elaboración de quesos de pasta prensada de distinto grado de maduración, como el Cheddar. 


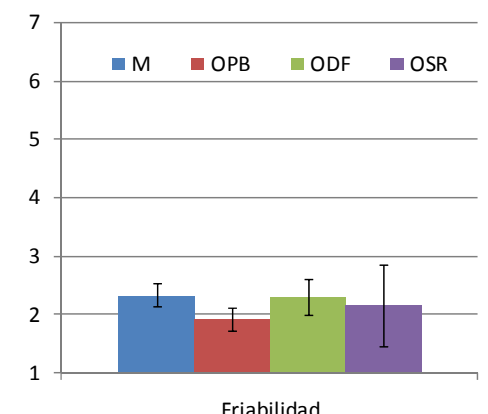

Friabilidad

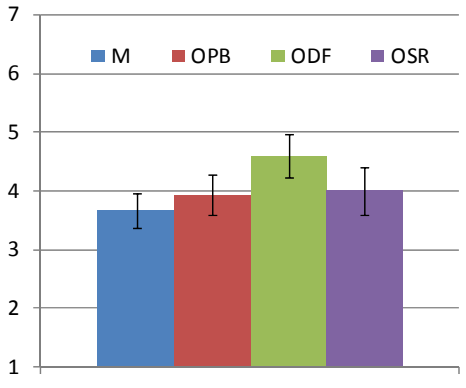

Adherencia

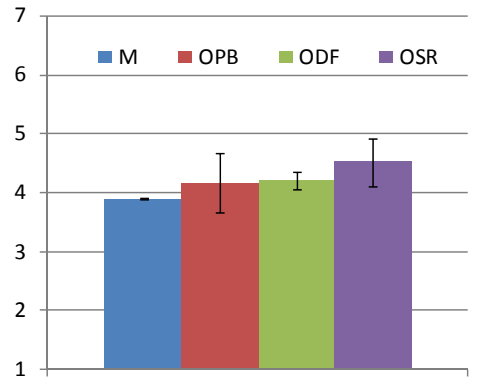

Solubilidad

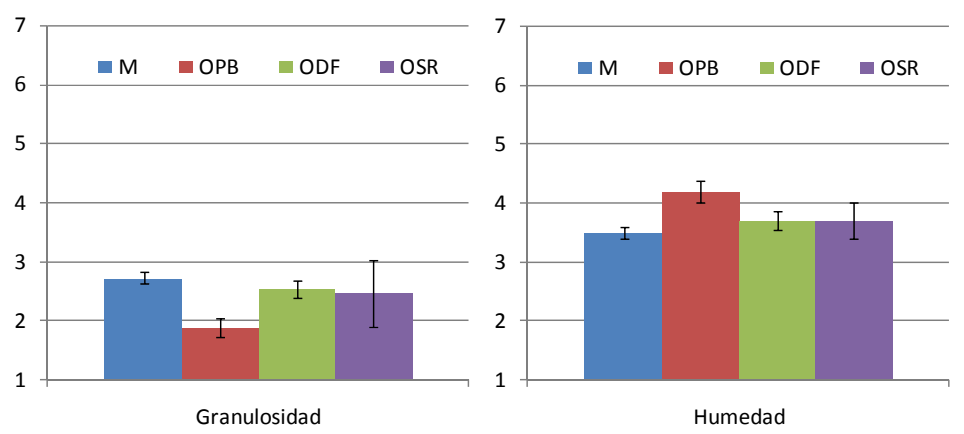

Figura 5.97. Gráfico de textura en boca. Comparación tecnológica

\section{- Sensación en boca: intensidad y calidad del gusto, regusto y persistencia}

Los datos de sensación en boca de la Tabla 5.43 muestran la obtención de valores aceptables (por encima de 4), que no difieren significativamente entre los cuatro quesos estudiados, tanto para la intensidad del gusto como del regusto generado después de la masticación.

Tabla 5.43. Datos de sensación en boca. Comparación tecnológica

\begin{tabular}{|c|rl|rl|rl|rl|}
\cline { 2 - 8 } \multicolumn{1}{c|}{} & \multicolumn{2}{c|}{ Gusto Intensidad } & \multicolumn{2}{|c|}{ Gusto Calidad } & \multicolumn{2}{c|}{ Regusto } & \multicolumn{2}{c|}{ Persistencia } \\
\hline M & $4,7^{\mathrm{a}}$ & $\pm 0,1$ & $4,1^{\mathrm{a}}$ & $\pm 0,1$ & $4,1^{\mathrm{a}}$ & $\pm 0,2$ & $3,6^{\mathrm{b}}$ & $\pm 0,1$ \\
\hline OPB & $4,4^{\mathrm{a}}$ & $\pm 0,1$ & $3,9^{\mathrm{a}}$ & $\pm 0,1$ & $4,2^{\mathrm{a}}$ & $\pm 0,4$ & $3,2^{\mathrm{a}}$ & $\pm 0,2$ \\
\hline ODF & $4,5^{\mathrm{a}}$ & $\pm 0,5$ & $4,0^{\mathrm{a}}$ & $\pm 0,3$ & $4,3^{\mathrm{a}}$ & $\pm 0,3$ & $3,6^{\mathrm{ab}}$ & $\pm 0,3$ \\
\hline OSR & $4,7^{\mathrm{a}}$ & $\pm 0,5$ & $4,7^{\mathrm{b}}$ & $\pm 0,5$ & $4,6^{\mathrm{a}}$ & $\pm 0,2$ & $3,5^{\mathrm{b}}$ & $\pm 0,2$ \\
\hline
\end{tabular}

${ }^{*}$ Valores con la misma letra en la misma columna no son significativamente diferentes $(p<0,05)$

La tendencia observada muestra una progresión en las puntuaciones a lo largo de la secuencia de optimización que llega a ser significativamente superior en el caso de la calidad del gusto, superando al queso tradicional (Figura 5.98).

La persistencia del sabor es baja en todos los casos, obteniéndose los menores valores para el óptimo del diseño inicial, OPB.

No se cumple la tendencia general encontrada en la bibliografía (Mistry y Maubois 2004) sobre el desarrollo del flavor, donde se relaciona una pérdida de sabor con el aumento de la cantidad de proteína soluble en el queso, como cabría esperar por los retardos en la proteolisis encontrados. Por tratarse de quesos de corta maduración las diferencias no llegan a ser apreciables.

Así mismo, la optimización realizada de la dosis de fermento, en base a la valoración sensorial, juega un papel importante respecto a la calidad del gusto alcanzada. 

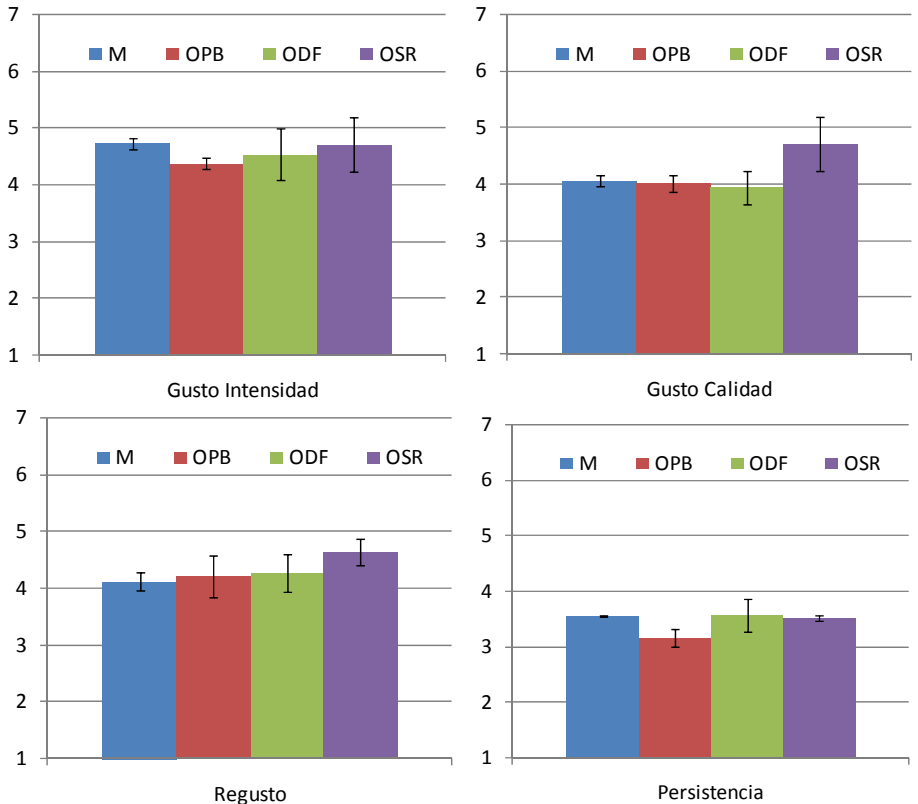

Gusto Calidad

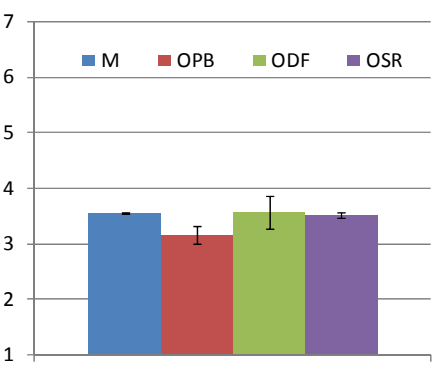

Persistencia

Figura 5.98. Gráfico de sensación en boca. Comparación tecnológica

Defectos en la calidad del sabor recogidas en algunas investigaciones han sido atribuidas a la variación en los niveles de inmunoglobulinas y proteasopeptonas en las proteínas del suero, si bien en este estudio no han sido detectadas por el panel de catadores (Lawrence 1989).

\section{- Sabor: salado, ácido y amargo}

Los valores obtenidos en la evaluación de los sabores elementales, salado, ácido y amargo se recogen el la Tabla 5.44 .

Tabla 5.44. Datos de sabor. Comparación tecnológica

\begin{tabular}{|c|c|c|c|c|c|c|}
\hline & \multicolumn{2}{|c|}{ Salado } & \multicolumn{2}{|c|}{ Ácido } & \multicolumn{2}{|c|}{ Amargo } \\
\hline $\mathbf{M}$ & $2,7^{\mathrm{a}}$ & $\pm 0,1$ & $2,9^{\mathrm{a}}$ & $\pm 0,4$ & $1,0^{\mathrm{a}}$ & $\pm 0,0$ \\
\hline OPB & $2,8^{\mathrm{a}}$ & $\pm 0,1$ & $3,6^{\mathrm{ab}}$ & $\pm 0,3$ & $1,7^{\mathrm{b}}$ & $\pm 0,2$ \\
\hline ODF & $2,7^{\mathrm{a}}$ & $\pm 0,3$ & $4,1^{b}$ & $\pm 0,2$ & $1,6^{\mathrm{b}}$ & $\pm 0,3$ \\
\hline OSR & $2,6^{a}$ & $\pm 0,1$ & $3,3^{\mathrm{a}}$ & $\pm 0,3$ & $1,2^{\mathrm{a}}$ & $\pm 0,1$ \\
\hline
\end{tabular}

* Valores con la misma letra en la misma columna no son significativamente diferentes $(p<0,05)$

No aparecen diferencias significativas en la apreciación del sabor salado por el panel de cata entre los quesos estudiados, con valores moderados de sal por debajo de 3, como se muestra en la Figura 5.99. Esto supone que la etapa de salado, en lo referente a tiempo y concentración alcanzada, es apropiada para los tipos de queso estudiados.

Para la sensación de acidez en boca se obtienen valores significativamente elevados en el queso ODF respecto al queso tradicional y al óptimo final, los cuales obtienen puntuaciones bajas y similares, de entorno a 3.

Los defectos de acidez encontrados al elaborar quesos mediante concentrados de leche suelen estar relacionados con los quesos de coagulación láctica (Fernández-Albalat 2002). Por su parte, en los de coagulación enzimática se puede controlar mejor la aparición de estos sabores mediante una buena dosificación del fermento y una adecuada elección de las etapas del proceso. 
Respecto a la valoración del amargor, los datos se separan en dos grupos: por un lado los quesos OPB y ODF son valorados como muy poco amargos, detectándose dicho sabor muy levemente con valores por debajo de 2 , mientras que los quesos $\mathrm{M}$ y OSR (el tradicional y el óptimo final) obtienen puntuaciones de 1 , lo que significa ausencia de amargor. La no apreciación de sabores amargos es indicativa de una buena elección de la concentración de cuajo y de la temperatura de coagulación (Spangler et al. 1990; Spangler et al. 1991).
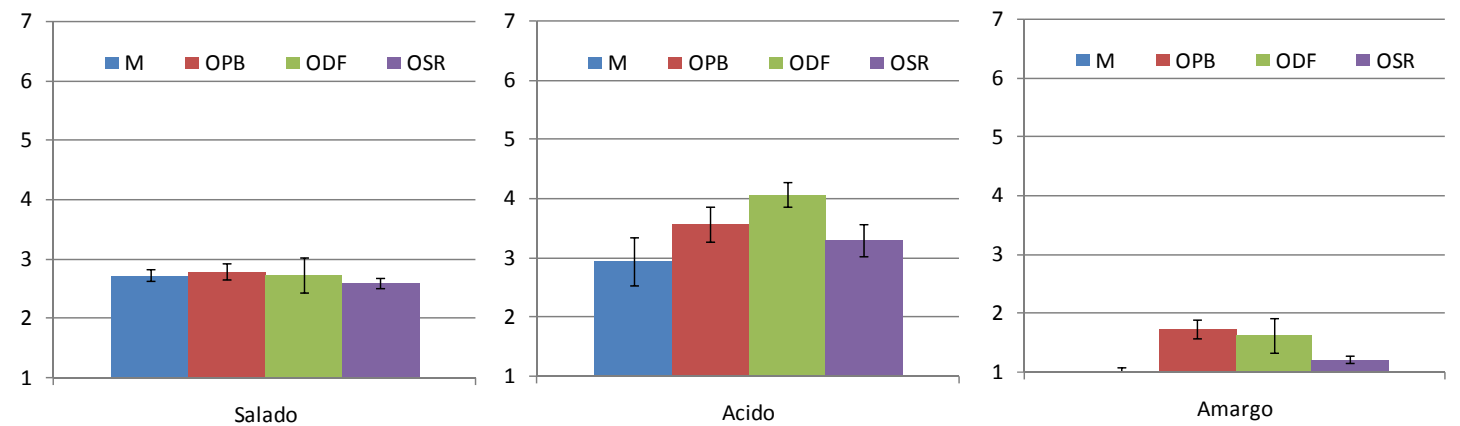

Figura 5.99. Gráficos de gusto. Comparación tecnológica

\section{VALORACIÓN VISUAL}

Los datos de la valoración visual, Tabla 5.46, tanto del exterior como del interior de los quesos, reflejan la progresión alcanzada en la optimización secuencial en cuanto a la aceptación de los quesos por los catadores.

Tabla 5.45. Datos de valoración visual. Comparación tecnológica

\begin{tabular}{|c|c|c|c|c|c|c|}
\hline \multirow[b]{2}{*}{$M$} & \multicolumn{2}{|c|}{ Aspecto Exterior } & \multicolumn{2}{|c|}{ Aspecto Interior } & \multicolumn{2}{|c|}{ Aberturas } \\
\hline & $5,5^{b}$ & $\pm 0,4$ & $5,4^{b}$ & $\pm 0,2$ & $5,2^{b}$ & $\pm 1,2$ \\
\hline OPB & $3,8^{\mathrm{a}}$ & $\pm 0,4$ & $4,1^{\mathrm{a}}$ & $\pm 0,2$ & $3,1^{\mathrm{a}}$ & $\pm 0,2$ \\
\hline ODF & $4,0^{a}$ & $\pm 0,5$ & $4,7^{\mathrm{a}}$ & $\pm 0,5$ & $4,1^{\mathrm{ab}}$ & $\pm 0,7$ \\
\hline OSR & $4,9^{b}$ & $\pm 0,2$ & $5,6^{b}$ & $\pm 0,4$ & $4,8^{b}$ & $\pm 0,2$ \\
\hline
\end{tabular}

${ }^{*}$ Valores con la misma letra en la misma columna no son significativamente diferentes $(p<0,05)$

La puntuación en la valoración exterior aumenta desde valores inferiores a 4 para el queso OPB hasta valores cercanos a 5 para el queso OSR, estos últimos no son estadísticamente distintos de la puntuación alcanzada para el queso tradicional $(5,5)$.

La misma tendencia se presenta en la evaluación interior (Figura 5.100), donde se aprecian dos grupos: los quesos OPB y ODF obtienen menores puntuaciones, si bien aceptables por encima de 4 , mientras que los quesos OSR alcanzan y superan, aunque no de forma significativa, al queso tradicional. Esta evolución se debe a las mejoras establecidas en lo referente al corte de la cuajada y a la adecuada selección del tiempo de prensado, lo que conduce a puntuaciones entre 5 y 6 para el queso OSR.

Las aberturas del interior de los quesos han evolucionado hacia quesos ciegos, con ausencia de ojos debido a la eliminación de la etapa de corte, lo cual ha sido valorado positivamente por el panel de cata ya que las dos últimas tecnologías optimizadas (ODF y OSR) no difieren significativamente del queso tradicional, si bien obtienen menores puntuaciones. En el queso OPB las aberturas son evaluadas como ligero defecto, debido a la mala fusión de los granos de cuajada durante el prensado. 


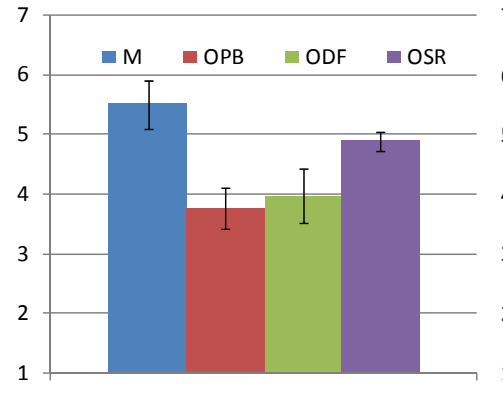

Aspecto Exterior

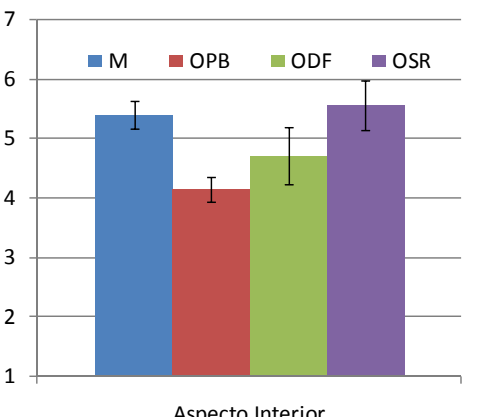

Aspecto Interior

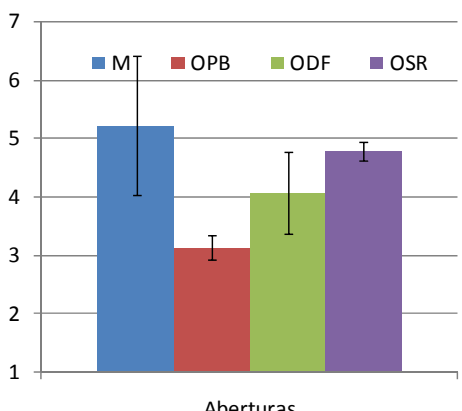

Aberturas

Figura 5.100. Gráficos de valoración visual. Comparación tecnológica

\section{VALORACIONES GLOBALES}

Tanto en la fase olfato-gustativa como en la visual se llevó a cabo una valoración global, cuyos datos se recogen en la Tabla 5.46 y se representan en la Figura 5.101.

Tabla 5.46. Datos valoración global. Comparación tecnológica

\begin{tabular}{|c|cc|cc|}
\cline { 2 - 5 } \multicolumn{1}{c|}{} & \multicolumn{1}{c|}{ Olfato-Gustativa } & \multicolumn{2}{c|}{ Visual } \\
\hline M & $4,5^{\mathrm{a}}$ & $\pm 0,2$ & $5,3^{\mathrm{b}}$ & $\pm 0,2$ \\
\hline OPB & $4,3^{\mathrm{a}}$ & $\pm 0,3$ & $4,3^{\mathrm{a}}$ & $\pm 0,2$ \\
\hline ODF & $4,3^{\mathrm{a}}$ & $\pm 0,6$ & $4,5^{\mathrm{a}}$ & $\pm 0,7$ \\
\hline OSR & $4,7^{\mathrm{a}}$ & $\pm 0,3$ & $5,0^{\mathrm{b}}$ & $\pm 0,2$ \\
\hline
\end{tabular}

${ }^{*}$ Valores con la misma letra en la misma columna no son significativamente diferentes $(p<0,05)$

En la fase olfato-gustativa se observa un aumento en las puntuaciones acorde a la secuencia de optimización, si bien se pueden considerar iguales entre todas ellas e iguales al queso tradicional. En la fase visual, el aumento progresivo entre optimizaciones es más pronunciado llegando nuevamente a la puntuación más elevada en el óptimo final (OSR), la cual no difiere significativamente del queso tradicional.
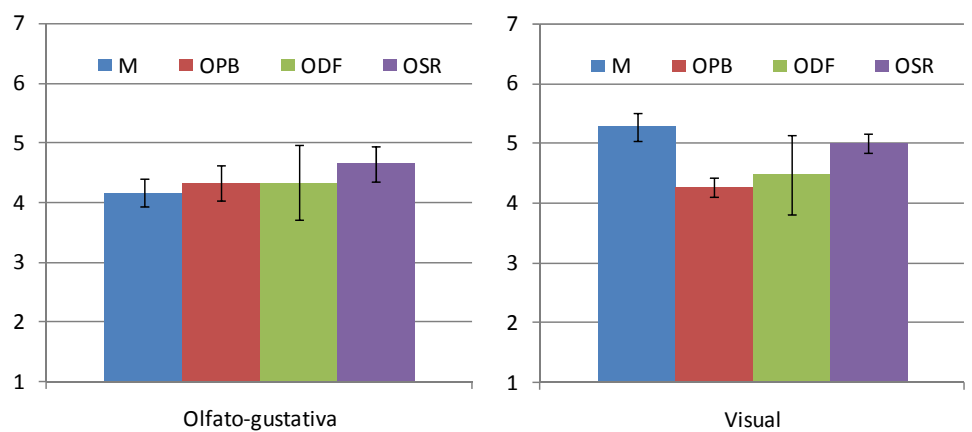

Figura 5.101. Gráficos de valoración global. Comparación tecnológica

Los datos en cuanto a la valoración olfato-gustativo han sido alentadores desde un primer momento, con valores similares de preferencia global en los quesos elaborados con concentrados de leche (OPB, ODF y OSR) frente a la elaboración tradicional (M). Trabajos realizados por otros investigadores, sobre distintos tipos de quesos madurados, obtuvieron diferencias entre ambas tecnologías, con mejores puntuaciones para el queso tradicional, como en los trabajos de Spangler et al. (1990) con queso Gouda. 


\section{RESUMEN COMPARACIÓN ORGANOLÉPTICA}

Como resumen final de las pruebas sensoriales se presenta en la Figura 5.102 la evolución de todos los descriptores evaluados respecto al queso de mezcla tradicional.

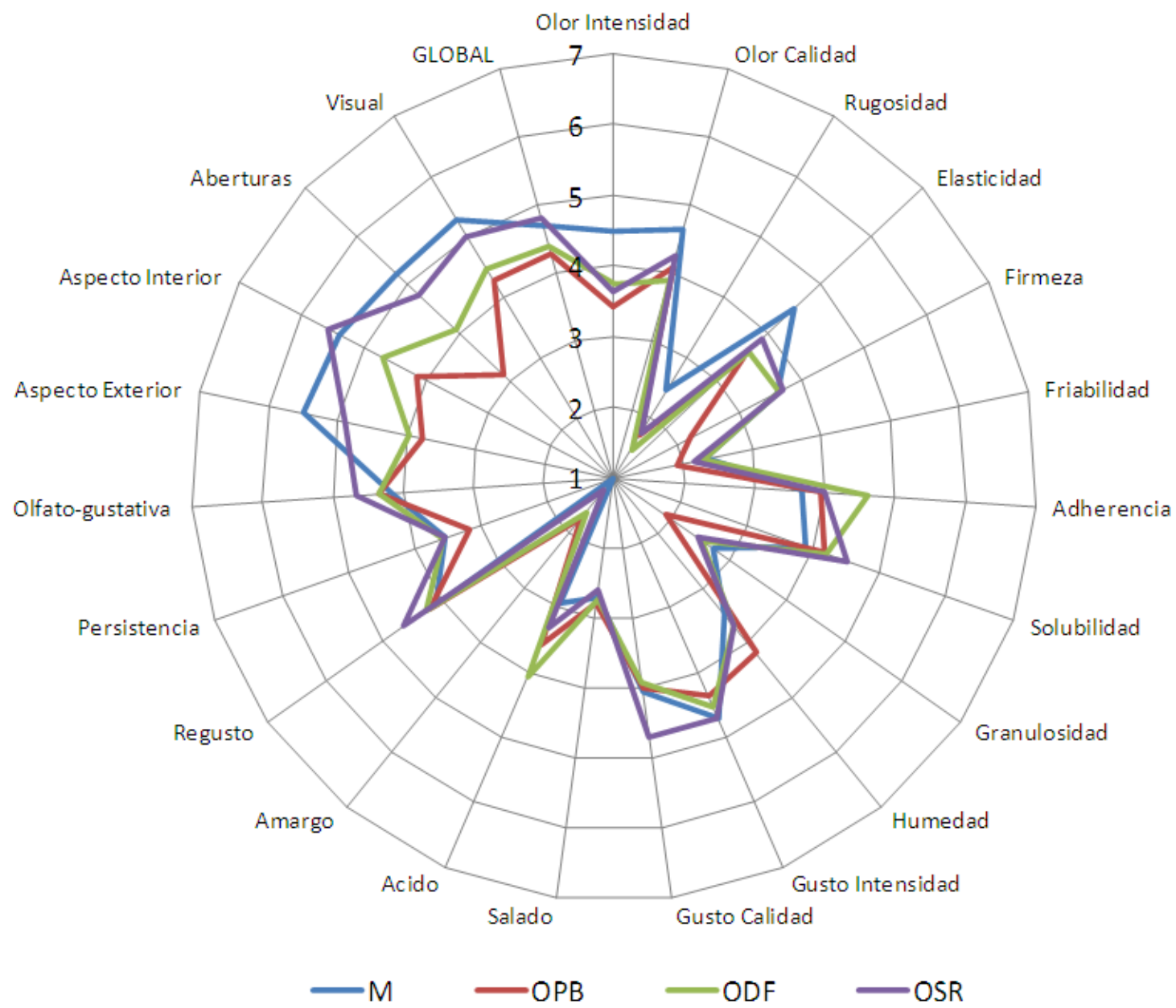

Figura 5.102. Resumen comparación organoléptica

Queda patente la mejora conseguida en la secuencia de optimización relativa al aspecto visual del queso, influenciada en gran medida por el tamaño de corte del grano de cuajada. El queso obtenido con la elaboración optimizada final (OSR) es diferente al queso tradicional, tanto en su interior como en su exterior. Esta diferencia es más acusada al aumentar el tiempo de maduración, como se observa en las fotografías de ambos quesos (M y OSR) recogidas en el Anexo A.7 (Figuras A.10, A.11 y A.12). No obstante, estas diferencias son apreciadas positivamente por el panel de cata como demuestran los datos presentados.

La fase olfato-gustativo muestra valores adecuados comparables al queso tradicional. Nuevamente, el queso final (OSR) es claramente diferente al tradicional, sobre todo en propiedades de textura como elasticidad, solubilidad, adherencia, rugosidad o microestructura del queso. También es diferente en descriptores del sabor como calidad del gusto y regusto final del queso donde las puntuaciones han llegado a superar a las del queso tradicional.

En el trabajo de Schreier et al. (2010) sobre queso semicurado, a partir de leche concentrada, se introduce la posibilidad de eliminar las aberturas $u$ ojos indeseables en el queso manteniéndolo a vacío durante dos días tras la etapa de salmuera. Los resultados alcanzados por estos investigadores se comparan con los del presente trabajo en la Figura 5.103. Las fotografías A y B 
corresponden a los quesos del trabajo de Schreier (ambos obtenidos por MF) mientras que C y D son las obtenidas en la presente Tesis (tradicional y ultrafiltrado -OSR-).

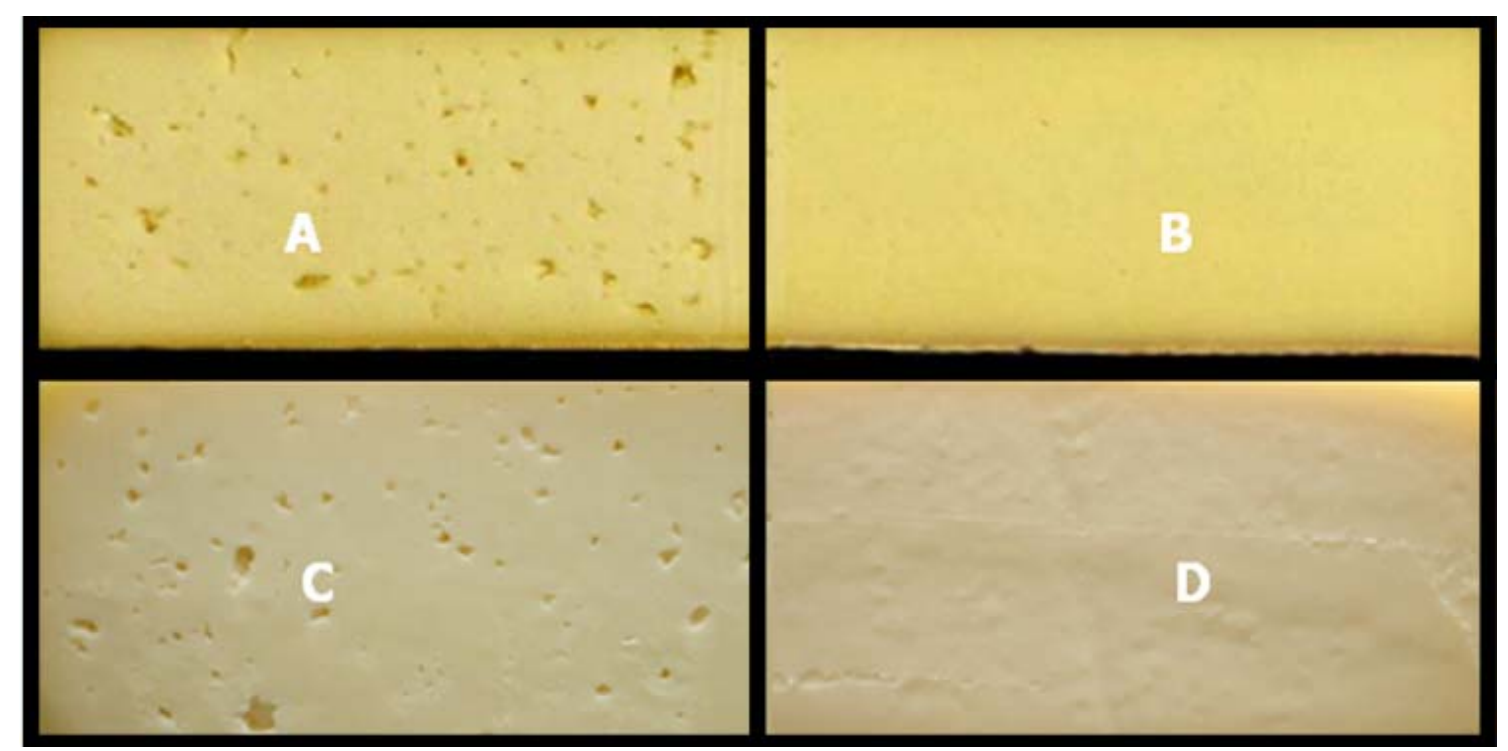

Figura 5.103. Comparación de tecnologías para la eliminación de ojos en el queso.

(Fotografías A y B: trabajo de Schreier et al. (2010); C y D trabajo desarrollado en la presente Tesis)

Los resultados de ambos estudios son comparables, siendo más sencilla operacionalmente la consecución de mejores resultados con la propuesta de esta Tesis, donde la ausencia de corte planteada facilita la automatización del proceso para la elaboración en continuo.

\subsubsection{ESTUDIO CONJUNTO DE VARIABLES}

Se realiza un estudio global de todos los descriptores utilizados en el análisis sensorial, junto con los atributos de textura medidos con el texturómetro y la composición físico-química. De esta manera se obtiene una visión global del proceso de optimización que permite realizar una reducción de variables que facilite el estudio, mediante el análisis de componentes principales, o conocer la correlación entre los distintos descriptores a través de su estudio bilateral.

\section{ANÁLISIS DE COMPONENTES PRINCIPALES}

Se presenta un análisis de componentes principales (PC) realizado tanto sobre las variables de textura instrumental medidas con el texturómetro (Apartado 5.5.2) como sobre el total de descriptores evaluados en el análisis sensorial de los quesos por el panel de cata, incluyendo un total de 27 variables.

Los resultados del análisis se muestran en la Tabla 5.47.

El análisis multivariante mediante componentes principales se ha realizado a partir de la matriz de correlaciones debido a que los datos no tienen todos la misma escala, según las recomendaciones de Borgognone et al. (2001).

Se seleccionan en el análisis cinco componentes cuyos autovalores, superiores a 1 , explican el $88,7 \%$ de la varianza total, si bien sólo las tres primeras explican, por sí solas, el $76 \%$. 
Tabla 5.47. Análisis de Componentes Principales. Autovalores y varianza explicada

\begin{tabular}{|c|c|c|c|}
\hline CP & Auto Valor & \% Varianza & \% Acumulado \\
\hline $\mathbf{1}$ & 11,2 & 41,7 & 41,7 \\
\hline $\mathbf{2}$ & 5,4 & 20,1 & 61,9 \\
\hline $\mathbf{3}$ & 3,9 & 14,4 & 76,3 \\
\hline $\mathbf{4}$ & 1,9 & 7,1 & 83,4 \\
\hline $\mathbf{5}$ & 1,4 & 5,2 & 88,7 \\
\hline
\end{tabular}

En la Figura 5.104 se observa la ubicación de cada grupo de elaboraciones respecto a las dos primeras componentes principales. Estos resultados establecen que la componente 1 diferencia entre quesos ultrafiltrados (OPB, ODF y OSR) y queso tradicional (M). En mayor medida, esta componente permite definir diferencias entre los quesos obtenidos en las distintas optimizaciones, separando las mejoras conseguidas en cada uno de los diseños, a través del acercamiento al queso tradicional.

Analizando los coeficientes del PC1 a partir de la matriz de componentes (Tabla A.19 del Anexo A.9) se observa que tienen un papel importante en la separación de las tecnologías, con valores positivos $(>0,7)$, los descriptores de la valoración visual así como propiedades de textura (firmeza, granulosidad y rugosidad) o la intensidad y calidad del olor. Por el contrario, atributos de textura como adherencia y humedad o sabores ácidos y amargos presentan coeficientes negativos.

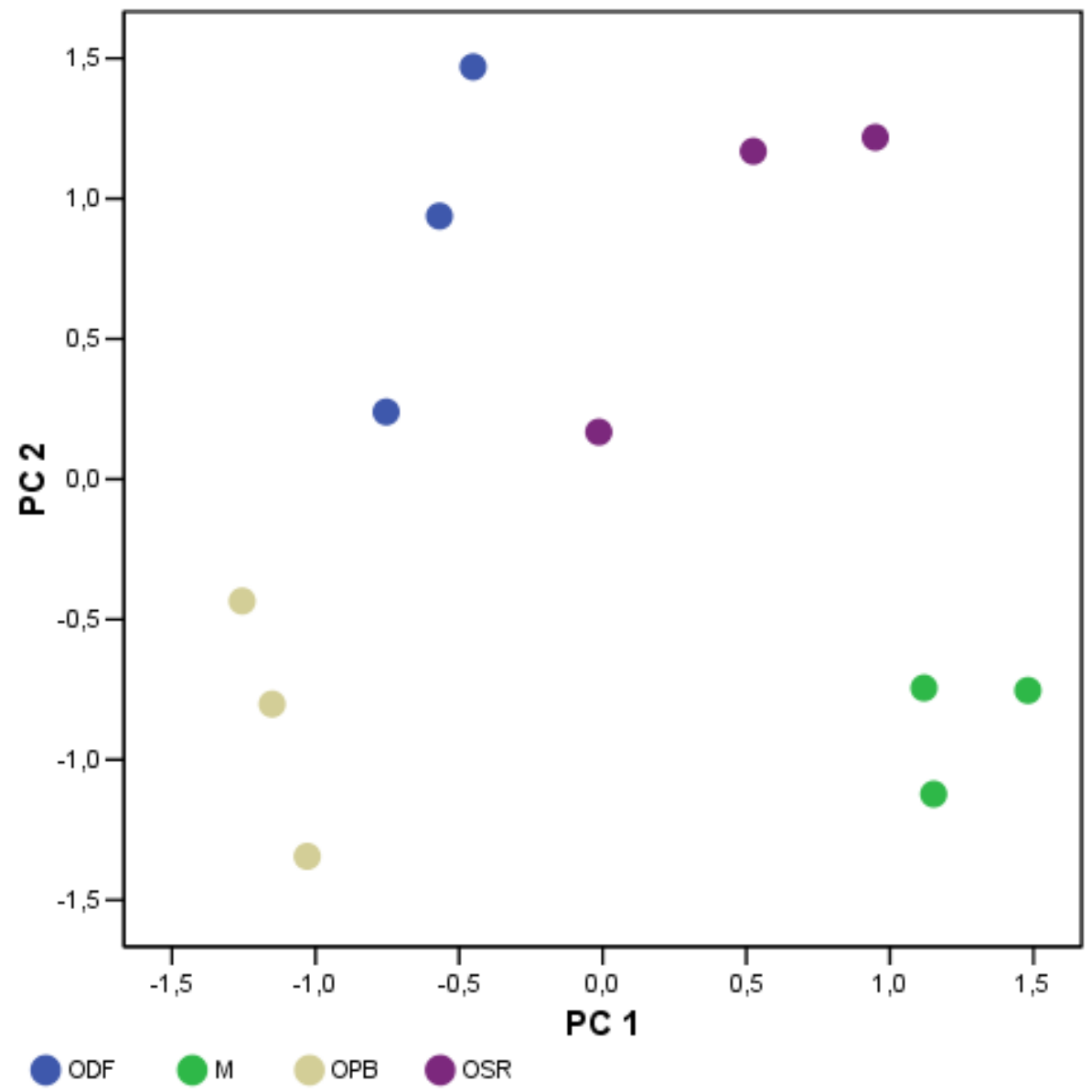

Figura 5.104. Representación de las componentes principales. Comparación tecnológica 
A través de la segunda componente se separan las elaboraciones ODF/OSR de M/OPB. Como la diferencia más importante entre ambos grupos es la ausencia o presencia de etapa de corte en el proceso de elaboración, se concluye que esta componente diferencia entre elaboraciones en función de la presencia de etapa de corte de la cuajada.

Para esta segunda componente presentan coeficientes positivos $(>0,7)$ el regusto y la valoración olfato-gustativa global. Los coeficientes negativos obtenidos en atributos de textura, como cohesividad y elasticidad, tienen un mayor peso en la separación en base a la etapa de corte.

Empleando ambas componentes (PC1 y PC2) se establecen criterios de diferenciación entre las fabricaciones con las distintas tecnologías, por lo que se eligen como las representativas, consiguiendo explicar un $62 \%$ de la variabilidad de los resultados.

\section{CORRELACIÓN ENTRE VARIABLES}

Debido al elevado número de variables estudiadas en la caracterización de los quesos, resulta interesante comprobar la dependencia y la correlación lineal que existe entre cada una de ellas.

Para ello se analizan un total de 33 variables correspondientes a los cinco descriptores de la textura calculados mediante el análisis del perfil de textura, los veintidós descriptores empleados en la evaluación sensorial por el panel de cata, cinco parámetros de composición y el rendimiento final del queso.

El análisis se efectúa sobre los resultados de los tres lotes de las cuatro tecnologías estudiadas: $M$, OPB, ODF y OSR con un total de 12 medidas por cada variable.

Como resultado del análisis, a partir de un gran número de variables estudiadas, se obtiene una elevada correlación entre ellas. A continuación se recogen únicamente las variables en las que la correlación resulta significativa con valores de coeficiente de Pearson ( $r$ ) mayor, en valor absoluto, de 0,75 (lo que en todos los casos supone la significación con una probabilidad mayor del 99,9\%).

\section{r. Medida instrumental de la textura}

A través del estudio de correlación, se obtiene que la firmeza presenta una correlación directa con la granulosidad. Cuando la firmeza se evalúa por el panel de cata existe correlación significativa con la instrumental, acorde a lo recogido por Xiong et al. (2002) en su estudio sobre distintos quesos comerciales.

La cohesividad se relaciona de forma directa con la elasticidad instrumental y consecuentemente con la masticabilidad, ya que la masticabilidad se mide indirectamente a partir de los datos de firmeza, cohesividad y elasticidad. De manera inversa se relaciona con la adherencia evaluada por el panel de cata.

La adherencia se relaciona con muchos de los descriptores, en mayor medida y de manera directa, con el amargor y el aspecto exterior del queso mientras que de forma inversa con la firmeza evaluada por el panel de cata y la valoración de las aberturas.

La elasticidad se correlaciona inversamente con la adherencia evaluada por el panel de cata y directamente con la cohesividad, la masticabilidad y la rugosidad del queso.

\section{c Descriptores del análisis sensorial}

En la sensación olfativa, la intensidad y la calidad se correlacionan mutuamente de manera directa. De forma individual, la intensidad se relaciona inversamente con el amargor del queso, mientras 
que la calidad lo hace de manera directa con la rugosidad y el aspecto interior e inversamente con el amargor.

Para la textura evaluada en mano, la rugosidad está altamente correlacionada con la disminución de la adherencia, del sabor ácido y del rendimiento. Se relaciona de forma directa con la elasticidad instrumental, la calidad del sabor y el aspecto exterior del queso. La firmeza presenta relación inversa con la adherencia instrumental y con la humedad y directa con la granulosidad del queso.

Para la textura evaluada en boca la adherencia tiene relación directa con la acidez mientras que inversa con la cohesividad y elasticidad medidas con texturómetro, así como con la rugosidad; estos resultados son coincidentes con los de Raphaelides et al. (1995) al evaluar queso Teleme elaborado mediante tecnología de ultrafiltración. La granulosidad se relaciona directamente con la firmeza (tanto instrumental como sensorial) y el aspecto interior del queso e inversamente con la humedad. La humedad, además de con la granulosidad, se relaciona inversamente con la firmeza sensorial y la persistencia del sabor.

En cuanto al gusto, la intensidad se relaciona de forma directa con la persistencia y la calidad con el regusto. A su vez el regusto se relaciona directamente con la valoración global olfato-gustativa mientras que la persistencia lo hace de manera inversa con la humedad.

En la evaluación del sabor, para la acidez se encuentra una relación directa con la adherencia evaluada por el panel de cata e inversa con la rugosidad. El amargor presenta relación lineal directa con la adherencia instrumental e inversa respecto a la intensidad y calidad del olor. Estudios realizados por Menéndez et al. (2000) sobre queso Arzúa-Ulloa mostraron gran correlación $(r=0,85)$ entre el amargor detectado en los quesos y el porcentaje de degradación de la $\beta$-caseína atribuyendo el amargor a los péptidos generados de la porción C-terminal de la $\beta$-caseína.

Para los descriptores de la fase visual, existe una gran relación directa entre todos ellos. Así mismo, el aspecto exterior se relaciona de manera directa con la calidad del olor y la rugosidad e inversa con la adherencia. La valoración interior se relaciona directamente con la granulosidad y las aberturas de manera inversa con la adherencia y el contenido de proteína.

La valoración visual global está condicionada de manera directa por los descriptores individuales analizados en la citada fase; en primer lugar por el aspecto exterior, seguido del interior y de la valoración de las aberturas. La puntuación global de la fase olfato-gustativa se relaciona directamente con el regusto del queso.

\subsubsection{ESTUDIO MICROBIOLÓGICO}

En este apartado se incorporan los resultados de la calidad microbiológica de los quesos obtenidos, desde el punto de vista de la seguridad alimentaria.

Por tratarse de un producto elaborado a partir de leche pasterizada, listo para el consumo a los 40 días de su elaboración, según el Reglamento(CE) 2073/2005 de la Comisión donde se establecen los criterios microbiológicos aplicables a los productos alimentarios, los quesos de características similares al elaborado han de cumplir unos criterios en cuanto a recuento de $E$. Coli -por ser un queso a base de leche tratada térmicamente- y de Estafilococos Coagulasa positivos -por estar sometidos a maduración-, así como de Listeria monocytogenes -por ser alimentos de consumo-. 
Se ampliará el estudio que establece la legislación realizando también recuento de Coliformes totales y Levaduras.

Los recuentos obtenidos para cada uno de los microorganismos se recogen en la Tabla 5.48. Estos datos corresponden con los valores medios encontrados en el estudio de tres lotes para cada tipo de queso.

Queda comprobada la ausencia de riesgos para la salud del producto final en todos los casos, acorde con la legislación vigente.

Tabla 5.48. Estudio microbiológico. Comparación tecnológica

\begin{tabular}{|c|c|c|c|c|c|c|}
\hline & \multirow{3}{*}{$\begin{array}{l}\text { M } \\
\mathrm{ND}\end{array}$} & \multirow{3}{*}{$\begin{array}{c}\text { OPB } \\
\mathrm{ND}\end{array}$} & \multirow{3}{*}{$\frac{\text { ODF }}{\mathrm{ND}}$} & \multirow{3}{*}{$\begin{array}{c}\text { OSR } \\
N D\end{array}$} & \multirow{3}{*}{$\begin{array}{c}\text { Unidades } \\
\text { NMP } \\
\text { gérmenes } \mathrm{mL}\end{array}$} \\
\hline & & & & & & \\
\hline \multirow{5}{*}{ 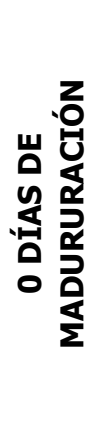 } & Escherichia Coli & & & & & \\
\hline & $\begin{array}{c}\text { Staphylococcus } \\
\text { coagulasa positivo }\end{array}$ & ND & ND & ND & ND & ufc/g \\
\hline & $\begin{array}{c}\text { Listeria } \\
\text { Monocytogenes }\end{array}$ & Ausencia & Ausencia & Ausencia & Ausencia & en $25 \mathrm{~g}$ \\
\hline & Coliformes totales & ND & ND & ND & ND & ufc/g \\
\hline & Levaduras & ND & ND & ND & ND & ufc/g \\
\hline \multirow{5}{*}{ 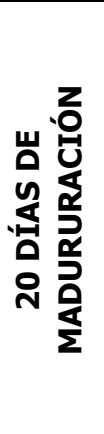 } & Escherichia Coli & ND & ND & ND & ND & $\begin{array}{c}\text { NMP } \\
\text { gérmenes } \mathrm{mL}\end{array}$ \\
\hline & $\begin{array}{c}\text { Staphylococcus } \\
\text { coagulasa positivo }\end{array}$ & ND & ND & ND & ND & ufc/g \\
\hline & $\begin{array}{c}\text { Listeria } \\
\text { Monocytogenes }\end{array}$ & Ausencia & Ausencia & Ausencia & Ausencia & en $25 \mathrm{~g}$ \\
\hline & Coliformes totales & ND & ND & ND & ND & ufc/g \\
\hline & Levaduras & ND & $5,1 \pm 0,9$ & $3,0 \pm 0,7$ & $3,0 \pm 1,0$ & ufc/g \\
\hline \multirow{5}{*}{ 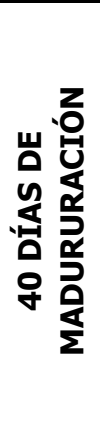 } & Escherichia Coli & ND & ND & ND & ND & $\begin{array}{c}\text { NMP } \\
\text { gérmenes } \mathrm{mL}\end{array}$ \\
\hline & $\begin{array}{l}\text { Staphylococcus } \\
\text { coagulasa positivo }\end{array}$ & ND & ND & ND & ND & ufc/g \\
\hline & $\begin{array}{c}\text { Listeria } \\
\text { Monocytogenes }\end{array}$ & Ausencia & Ausencia & Ausencia & Ausencia & en $25 \mathrm{~g}$ \\
\hline & Coliformes totales & ND & ND & ND & ND & ufc/g \\
\hline & Levaduras & $3,5 \pm 0,2$ & $5,0 \pm 1,0$ & $5,0 \pm 1,0$ & $5 \pm 2,0$ & ufc/g \\
\hline
\end{tabular}

Resultados expresados como logaritmo decimal sobre el recuento microbiano. ND $=<10 \mathrm{ufc} / \mathrm{g}$

Se observa en todos los quesos un aumento del recuento de levaduras -contaminante alterante no patógeno- a lo largo de la maduración. Este incremento es más notable en los quesos ultrafiltrados debido a su mayor humedad en las primeras etapas de maduración.

Los mayores recuentos de levaduras encontrados cuando el queso es elaborado a partir de concentrados de leche no afectan a la seguridad del producto si bien han de ser conocidos, contemplados y minimizados. 


\subsubsection{COMPARACIÓN TECNOLÓGICA}

En este apartado se realiza un estudio comparativo de las variables más importantes del proceso, tanto en la ultrafiltración como en la elaboración del queso tradicional (M) y de los elaborados ultrafiltrando leche -a partir de las condiciones óptimas de cada diseño (OPB, ODF y OSR)- como son la hidrodinámica de filtración o la evolución del $\mathrm{pH}$ y la temperatura en las etapas de elaboración.

\section{HIDRODINÁMICA DE FILTRACIÓN}

Durante todas las filtraciones se realizó un seguimiento de la densidad de flujo de permeado (J) y la presión transmembrana (TMP) para comprobar que se opera en las condiciones de flujo límite obtenidas en los estudios preliminares.

En el gráfico de la Figura 5.105 se representa la densidad de flujo de permeado a lo largo del tiempo, obtenido en las tres filtraciones a partir de las que se elaboró en los óptimos de los diseños experimentales (OPB, ODF y OSR). Se confirman los resultados obtenidos en el Apartado 5.1.1 donde se obtenían unos flujos iniciales de $35-37 \mathrm{~L} /\left(\mathrm{h} \cdot \mathrm{m}^{2}\right)$ para presión transmembrana entorno a 3 bar.

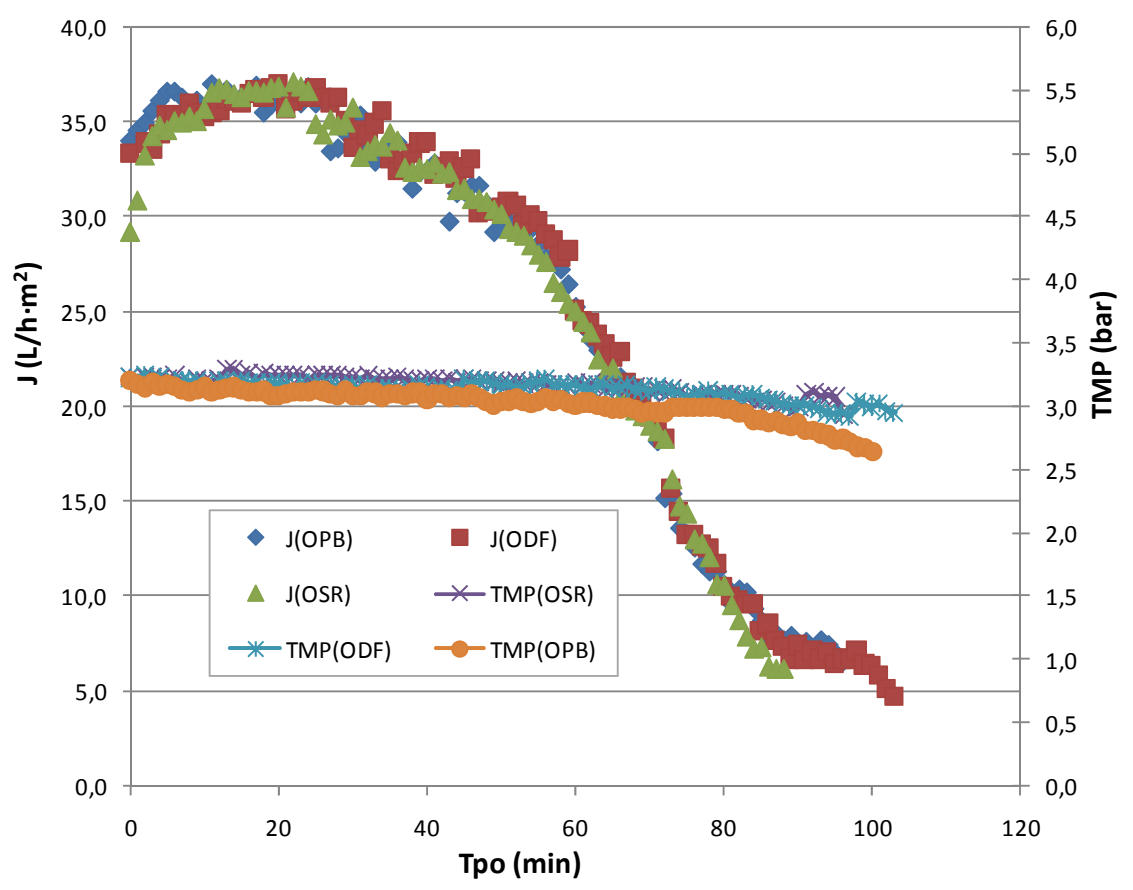

Figura 5.105. Evolución del flujo de permeado y la TMP con el tiempo en los óptimos OPB, ODF y OSR

Representando el flujo de permeado frente al VCR (Figura 5.106), se obtienen el comportamiento lineal definido en los estudios preliminares con la Ecuación [5.1]. Tomando valores medios de los parámetros de regresión de las tres ultrafiltraciones que dan lugar a las fabricaciones en los óptimos (OPB, ODF y OSR) se obtiene la Ecuación [5.2].

$$
J=(-7,5 \pm 0,4) \cdot(V C R)+(46,7 \pm 0,5)
$$

Teniendo en cuenta el error experimental, esta ecuación engloba a la regresión de la Ecuación [5.1], lo que demuestra que los protocolos de limpieza en todos los casos han sido adecuados y que el equipo operó en condiciones óptimas en todo momento. 


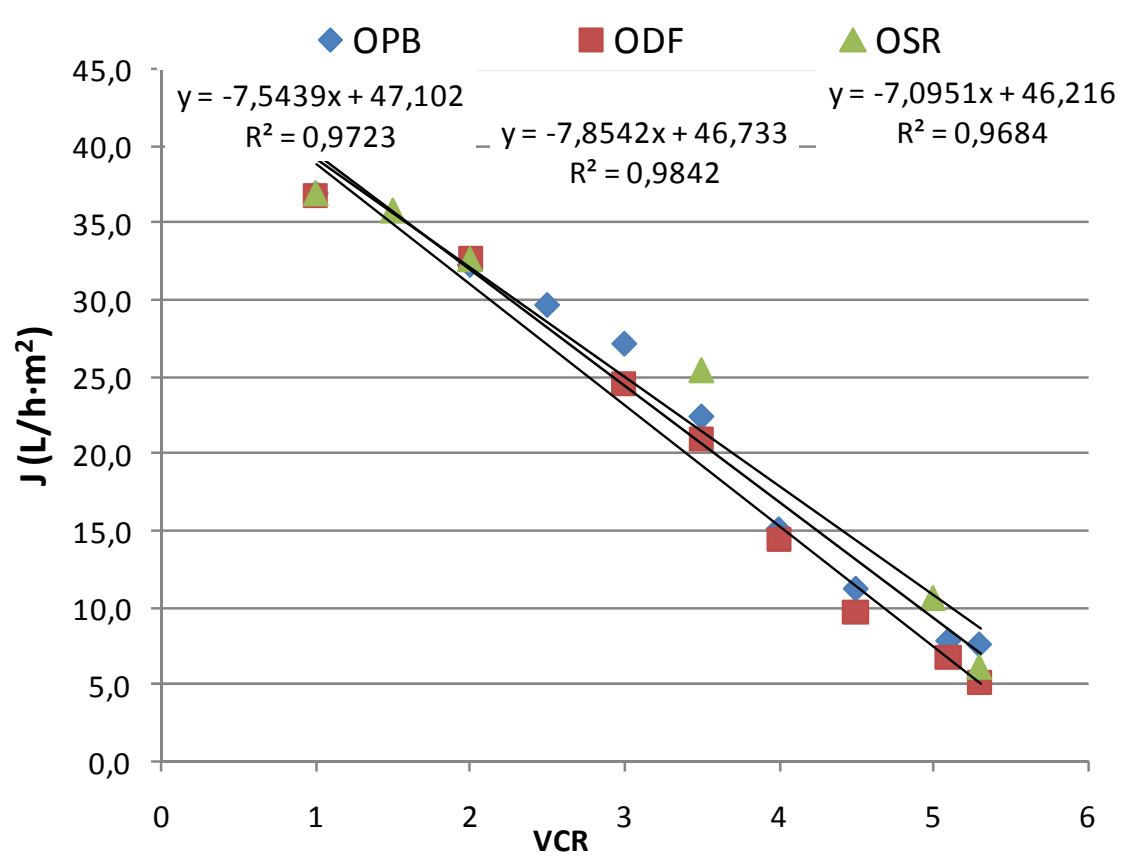

Figura 5.106. Flujo de permeado en función del VCR, filtraciones OPB, ODF y OSR

\section{EVOLUCIÓN DEL PH Y LA TEMPERATURA A LO LARGO DE LAS FABRICACIONES}

Además de otros parámetros -como por ejemplo la acidez de la leche- el pH y la temperatura son dos variables fundamentales para el seguimiento y control de los procesos de elaboración de queso.

En la gráfica de la Figura 5.107 se recoge la evolución comparada de ambas variables, pH y temperatura, en la elaboración mediante tecnología tradicional (M) y mediante tecnología de ultrafiltración en la optimización final (OSR).

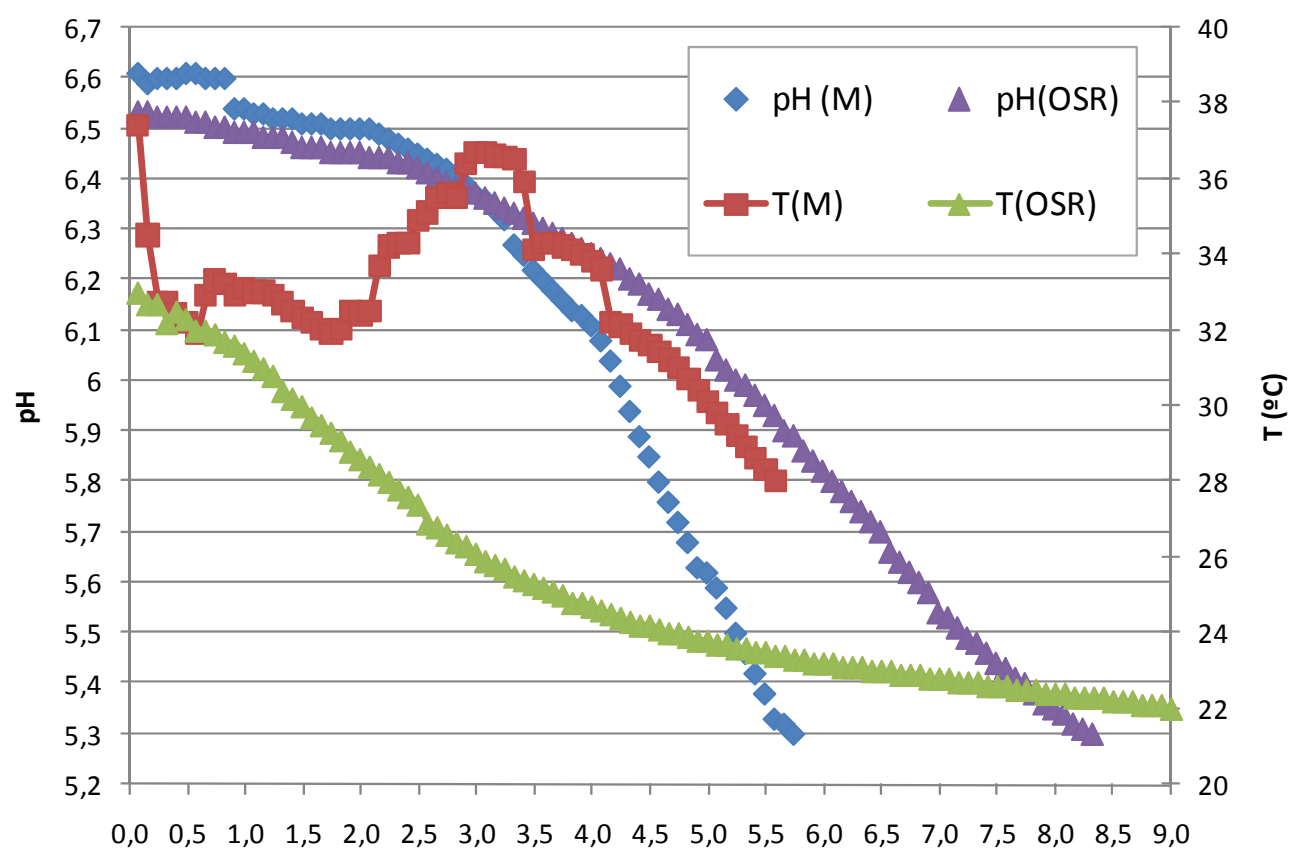

Tiempo (h)

Figura 5.107. Evolución del pH y la T en la fabricación M y OSR 
Para el queso tradicional se observa como la temperatura alcanza los $37^{\circ} \mathrm{C}$ en la etapa de sinéresis, empezando a descender a la entrada en prensa. Al partir de una mayor temperatura que el queso ultrafiltrado al inicio de la etapa de prensado, unido al menor poder tampón de la leche, la cinética de acidificación es más rápida para el queso tradicional.

Se produce un incremento total en el tiempo de fabricación para la elaboración a partir de concentrados de UF de entre 2,5 y 3,0 h. Este aumento se genera en la etapa de prensado, la cual se incrementa de 2,5 a 8,0 h respecto a la elaboración tradicional. Por otro lado, el trabajo en cuba se simplifica casi totalmente, pasando de 3,5 a 0,5 h, como consecuencia de la eliminación de las etapas de desuerado (sinéresis) y corte.

\section{PÉRDIDAS DE PESO EN OREO Y MADURACIÓN}

Mediante el seguimiento del peso del queso a lo largo del proceso de maduración se comprueba la gran diferencia en la etapa de secado que existe entre el queso tradicional y el ultrafiltrado. Se realiza el seguimiento de peso del queso obtenido con el diseño de experimentos del óptimo final (fabricación OSR) para su comparación con el tradicional (M).

Los resultados de la Figura 5.108 muestran que el afinado, para ambos quesos, tiene dos fases. Durante los 20 primeros días -etapa de oreo- se pierde aproximadamente el $85 \%$ del peso asociado a la humedad total eliminada; en los 20 días siguientes -etapa de maduración- la eliminación de agua es mucho menor, representando aproximadamente el $15 \%$ del total.

En la elaboración con ultrafiltración de la leche (OSR) se pierde aproximadamente un $35 \%$ de peso al finalizar la maduración (agua principalmente), respecto al obtenido al finalizar la etapa de prensado, mientras que las pérdidas para la elaboración tradicional no superan el $20 \%$.

Estos resultados son acordes con los datos de extracto seco recogidos en el Anexo A.3 (Tablas A.14, A.15 y A.16) donde se observa que el extracto seco del queso tradicional aumenta en 40 días del 52 al $57 \%$, mientras que en el queso ultrafiltrado (OSR) se incrementan del 43 al $56 \%$.

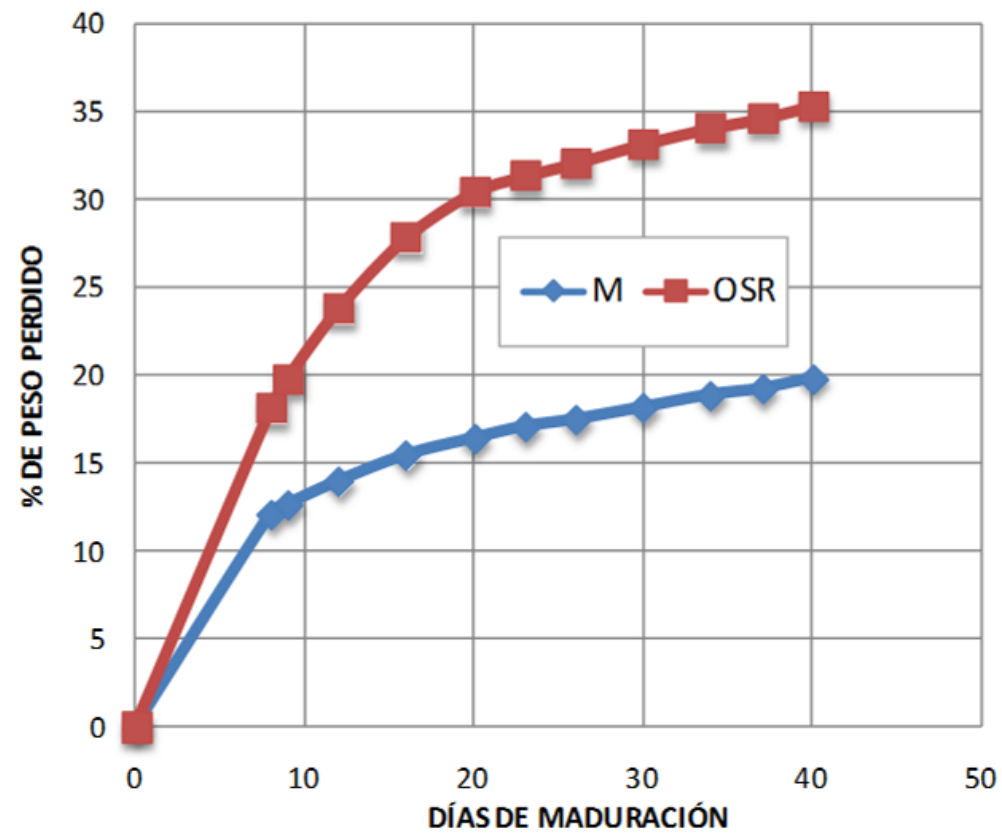

Figura 5.108. Pérdidas de peso durante la maduración del queso tradicional (M) y óptimo OSR 
Estas pérdidas tan elevadas de humedad condicionan enormemente la forma final del queso, como se observa en las fotografías recogidas en el Anexo A.7 (Figuras A.10, A.11 y A.12). El exceso de humedad inicial del queso ultrafiltrado provoca que en las etapas iniciales de secado el queso ultrafiltrado no tenga la consistencia suficiente para soportar su propio peso, lo que se traduce en un atalonamiento, aumentando su diámetro y disminuyendo en altura.

\subsubsection{ESTUDIOS DE RENDIMIENTO Y CALIDAD SENSORIAL}

Por servir como variable de decisión en las optimizaciones realizadas, a continuación se calcula el rendimiento corregido y la puntuación sensorial global compuesta (visual más olfato-gustativo) alcanzado en las fabricaciones mediante ultrafiltración de la leche para su comparación con los alcanzados para el queso tradicional.

Así mismo, aprovechando los modelos predictivos de los tres diseños factoriales (Apartados 5.2.6, 5.3.6 y 5.4.6), se comparan los valores de rendimiento y calidad sensorial que se obtuvieron teóricamente en cada optimización, con los obtenidos experimentalmente para las fabricaciones en las condiciones óptimas de cada diseño (OPB, ODF y OSR).

\section{RENDIMIENTO CORREGIDO}

El cálculo de rendimiento se realiza a través de la Ecuación [3.2] corrigiendo el valor obtenido a la salida de salmuera por el supuesto para un queso de un $55 \%$ de extracto seco. Los datos para las cuatro fabricaciones se recogen en la Tabla 5.49.

Tabla 5.49. Rendimiento corregido. Comparación tecnológica

\begin{tabular}{|c|c|c|c|c|}
\hline kg queso/kg leche & M & OPB & ODF & OSR \\
\hline Rendimiento & $13,3^{\mathrm{a}} \pm 0,5$ & $15,3^{\mathrm{b}} \pm 0,2$ & $15,5^{\mathrm{b}} \pm 0,3$ & $15,5^{\mathrm{b}} \pm 0,4$ \\
\hline
\end{tabular}

${ }^{*}$ Valores con la misma letra no son significativamente diferentes $(p<0,05)$

Los datos obtenidos denotan un aumento significativo del rendimiento quesero que llega a ser hasta un $15 \%$ más elevado en el queso al ultrafiltrar la leche, respecto al queso tradicional.

En la bibliografía se encuentran diversos porcentajes de incremento del rendimiento en la fabricación de queso empleando concentrados de ultrafiltración respecto a la elaboración tradicional, que pueden alcanzar hasta el 20 \% (Saboya et al. 2001).

Este aumento se debe fundamentalmente a la retención de la proteína soluble; su contenido en la leche de partida es del 0,4-0,7\% (menos del $20 \%$ de la proteína total), por lo que su total incorporación al queso aumentaría el rendimiento hasta en un 17 \% (Lawrence 1989) -suponiendo una cantidad de agua unida a las proteínas del mismo orden para las proteínas solubles que para la caseína-. Por tanto, el incremento en el rendimiento del $3 \%$ restante se debe a las menores pérdidas de grasa y de finos de cuajada. Consecuentemente, aumentos de rendimiento por encima del $20 \%$ no pueden ser realistas.

Muchos son los ejemplos de variedades de queso elaboradas mediante tecnología de ultrafiltración en las que se aumenta el rendimiento en distinta proporción. Se citan aumentos del $21 \%$ de rendimiento en queso Domiati (Mehaia 2002), 14,7\% para quesos de coagulación ácida (Hydamaka et al. 2001), 19 \% para la elaboración de queso Saint-Paulin (Goudedranche et al. 
1980), entre el 3,9 y el 12,25 \% para queso Feta (Boyazoglu y Morand-Fehr 2001) o los recogidos por Lawrence (1989) en su revisión de la ultrafiltración aplicada a la elaboración de queso, con incrementos del $12-18 \%$ en queso Camembert, $18 \%$ para Mozarella, 10-12 \% para Cottage o del 16-20 \% para queso azul. En todos los casos los valores se encuentran dentro de los márgenes indicados, si bien no es posible compararlos debido a que en muchos casos la base de cálculo es distinta o no está claramente especificada.

Debido a que el coste de la leche es responsable del 60-80 \% del coste final del queso (Lawrence 1989), es interesante considerar el aumento de rendimiento como ahorro en la cantidad inicial de leche. Para ello se pueden adaptar los estudios realizados por Dejmek (1986), quien separa los posibles beneficios de la tecnología de ultrafiltración según la estrategia de concentración llevada a cabo en el proceso:

c Para bajo factor de concentración $(\mathrm{VCR}<2)$ el aumento de rendimiento es despreciable ya que las diferencias observadas pueden ser fruto del proceso de elaboración.

r. Para concentraciones medias (VCR 2-5), el coste del proceso no depende sólo del grado de concentración alcanzado, sino que el tipo de queso elaborado juega un papel fundamental. El beneficio puede ser el doble al elaborar, a partir de un concentrado con el $40 \%$ de ES, una pasta blanda tipo Camembert que al elaborar una pasta dura, por ejemplo queso Cheddar.

c Según el concepto de prequeso líquido (LPC) el beneficio referido a leche (en el estudio de Dejmek con base en leche desnatada) es menor del $20 \%$.

El coste del proceso de UF es lineal con la concentración hasta que el aumento de la viscosidad domina el proceso. En ese momento, los costes de operación aumentan exponencialmente, haciendo poco probable que mejoras en la tecnología de ultrafiltración hagan sostenibles los descensos de la densidad de flujo de permeado. Por ello, la elaboración de quesos de pasta dura en base a retenidos de ultrafiltración de alto grado de concentración sólo tendría aceptación si se modifica toda la tecnología de procesado, tanto en la filtración como en la elaboración, incluyendo el moldeo y salado del queso.

El queso desarrollado en la presente Tesis se encuentra en una situación intermedia entre los dos últimos casos. Por un lado se opera con un factor de concentración medio -VCR de 4,5- si bien, por otra parte no se contempla la etapa de desuerado tras el cuajado, lo que hace considerar el concentrado como un prequeso.

La eliminación de agua no alcanzada en el proceso de UF con membranas espirales, se realiza forzando la etapa de oreo/maduración hasta obtener un extracto seco (ES) final comparable al del tipo de queso tratado.

Siguiendo con el estudio de Dejmek (1986), mediante la gráfica de la Figura 5.109 se puede predecir el ahorro en leche desnatada a partir de los datos de la presente Tesis. Tomando en abscisas un valor de 0,7 a partir de los datos de ES para el concentrado (41\%), la leche (13\%) y el queso $(55 \%)$, se alcanza un ahorro -referido a leche desnatada- del $11 \%$ respecto al proceso tradicional.

Este valor teórico es algo inferior al alcanzado en el proceso de optimización de esta Tesis (15\% de aumento de rendimiento). 


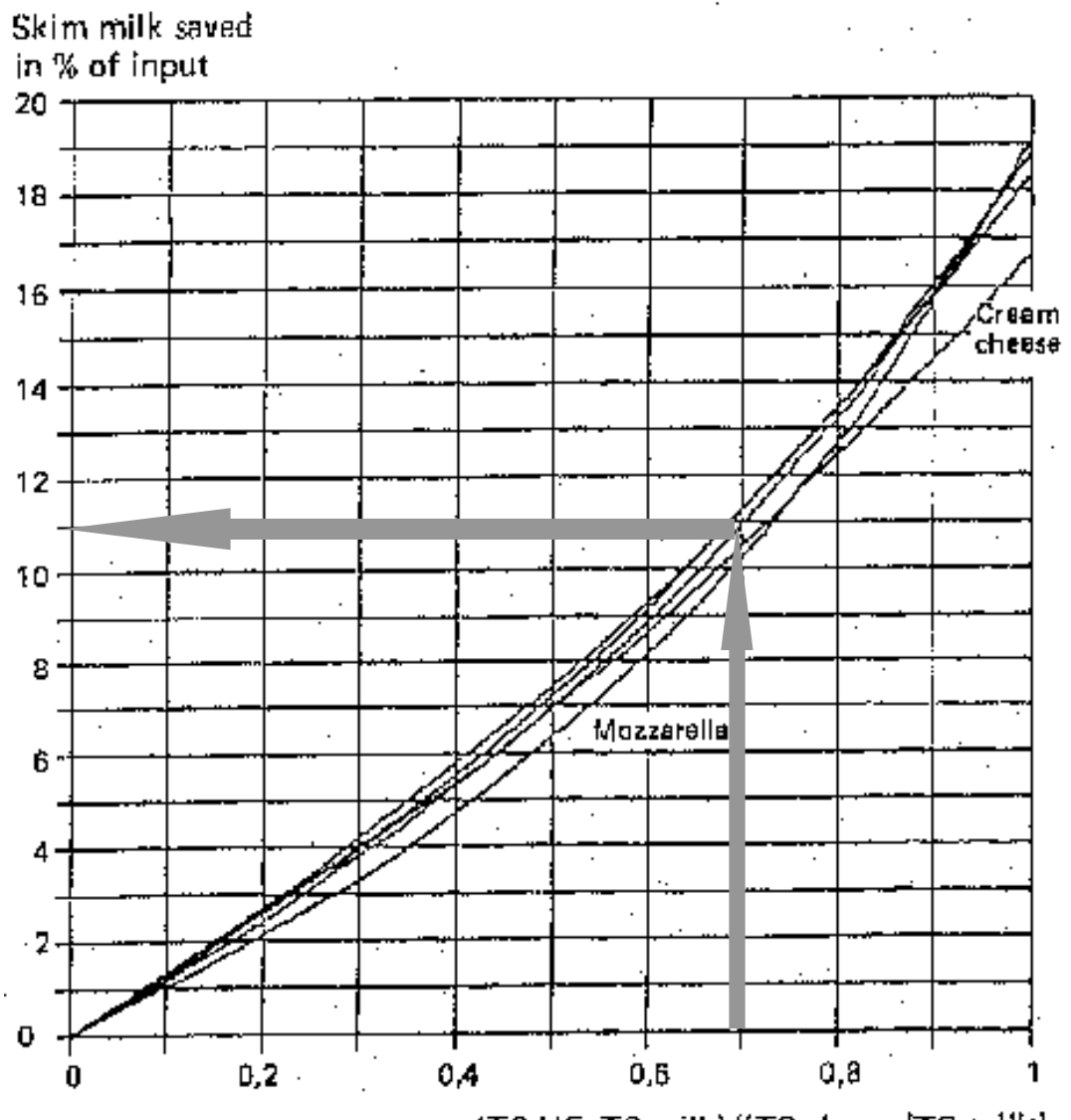

(TS UF-TS mik)/TTS cheestiTS milk!

Figura 5.109. Ahorro de leche al realizar queso a partir de concentrados de UF.

(TS UF: ES del concentrado; TS milk: ES de la leche y TS cheese: ES del queso). Fuente: (Dejmek 1986)

\section{CALIDAD SENSORIAL}

La puntuación sensorial, global compuesta (olfato-gustativa y visual), de los quesos se recoge en la Tabla 5.50. Las puntuaciones del queso tradicional y del óptimo final (OSR) del estudio son estadísticamente iguales y superiores a los óptimos de los diseños OPB y ODF.

Tabla 5.50. Puntuación global compuesta. Comparación tecnológica

\begin{tabular}{|c|c|c|c|c|}
\hline & M & OPB & ODF & OSR \\
\hline $\begin{array}{c}\text { Global } \\
\text { Compuesta }\end{array}$ & $4,7^{\mathrm{bc}} \quad \pm 0,2$ & $4,3^{\mathrm{a}} \quad \pm 0,15$ & $4,4^{\mathrm{ab}} \quad \pm 0,2$ & $4,8^{c} \quad \pm 0,2$ \\
\hline
\end{tabular}

${ }^{*}$ Valores con la misma letra no son significativamente diferentes $(p<0,05)$

Estos resultados muestran la adecuada progresión en el desarrollo de las optimizaciones mediante los diseños que permiten alcanzar un queso de tan alta calidad sensorial global como el tradicional.

\section{ROBUSTEZ DE LOS MODELOS TEÓRICOS}

Con los modelos obtenidos en cada optimización múltiple (Apartados 5.2.6, 5.3.6 y 5.4.6) es posible predecir, en las condiciones óptimas de los factores considerados en cada uno de ellos, tanto el rendimiento como la calidad sensorial (Tabla 5.51). 
Tabla 5.51. Predicciones en los óptimos de los diseños experimentales

\begin{tabular}{|c|c|c|c|}
\cline { 2 - 4 } \multicolumn{1}{c|}{} & OPB & ODF & OSR \\
\hline Rendimiento (\%) & 15,2 & 15,8 & 15,1 \\
\hline Sensorial Global & 4,4 & 4,5 & 4,6 \\
\hline
\end{tabular}

Comparando estos valores con los resultados experimentales de las correspondientes fabricaciones (Tablas 5.49 y 5.50), se observa una total coincidencia en los resultados de los tres diseños para ambas respuestas (rendimiento y calidad sensorial), teniendo en cuenta el error experimental.

Acorde a estos resultados, los modelos matemáticos planteados se consideran adecuados para la optimización realizada, por lo que las conclusiones obtenidas de ellos también se consideran robustas. 



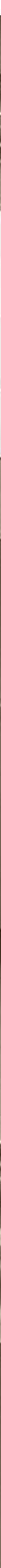





\section{CONCLUSIONES}

1. Las membranas de ultrafiltración en configuración espiral permiten concentrar leche entera hasta VCR de 4,5 (41 \% de ES) trabajando en condiciones de flujo límite (TMP de 3 bar y $v_{t}$ de $1,1 \mathrm{~m} / \mathrm{s}$ a $\left.45-50^{\circ} \mathrm{C}\right)$. El concentrado así obtenido se puede tratar como prequeso líquido para la elaboración de queso semicurado de pasta prensada en formatos de $1 \mathrm{~kg}$.

2. El poder tampón de la leche aumenta linealmente con la concentración. Al aumentar el factor de concentración (VCR) alcanzado se observan dos máximos en la capacidad tampón a pH de 5,15 y 4,90. Estos máximos condicionan la cinética de acidificación de las bacterias lácticas en la elaboración, con especial significación en la etapa de prensado.

3. A partir de los diseños experimentales se comprueba como el rendimiento quesero aumenta significativamente al ultrafiltrar la leche a su pH normal y con tamaños de corte de la cuajada grandes, hasta eliminar por completo la etapa de corte.

4. Del estudio de los diseños experimentales se obtiene que para maximizar la calidad sensorial es muy importante la adecuada elección tanto del tipo como de la concentración de fermento, así como la obtención de un prequeso con un ES elevado, similar al del queso elaborado con la tecnología tradicional a su entrada en prensa, al no llevarse a cabo la etapa de sinéresis.

5. El proceso tecnológico final optimizado para la elaboración de queso semicurado de mezcla a partir de concentrados de ultrafiltración presenta como mayores diferencias respecto al proceso tradicional:

a. Ahorro significativo de ingredientes, de un $83 \%$ para la concentración de cuajo y de un $66 \%$ en la concentración de fermento (MA4001), ambos ahorros referenciados a la leche inicial. Por otra parte se elimina el empleo de $\mathrm{CaCl}_{2}$.

b. Incremento de la capacidad productiva de la planta, ya que el volumen a tratar se reduce en 4,5 veces el inicial. Este hecho es de especial relevancia en la etapa de pasterización, si bien el ahorro energético no es lineal con la concentración debido al aumento de viscosidad del producto.

c. Retención de la proteína soluble de la leche en porcentaje tres veces superior al alcanzado en la fabricación tradicional. Esto supone un incremento del valor nutritivo del queso, ya que son consideradas proteínas de alto valor biológico al contener todos los aminoácidos esenciales.

d. El estudio detallado de la etapa de prensado, realizado para alcanzar el pH óptimo del queso al final de esta etapa, se considera fundamental para controlar los excesos de 
acidez relacionados con el aumento del poder tampón de los concentrados de ultrafiltración.

e. Incremento del tiempo total de elaboración en aproximadamente dos horas y media, debido al aumento del poder tampón que retrasa los procesos de acidificación en la etapa de prensado. No obstante se produce una notable simplificación operacional en el proceso, por la minimización del trabajo en cuba y la eliminación de las etapas de sinéresis y corte de la cuajada, factores que contribuyen a la adaptación a la producción en continuo.

f. Como factor económico más significativo, junto al ahorro de ingredientes, se presenta el aumento del rendimiento quesero en un $15 \%$ respecto al conseguido en la elaboración tradicional, debido a la incorporación de la proteína soluble y a menores pérdidas de grasa y caseína.

6. Mediante la caracterización físico-química, estructural y sensorial se obtiene un amplio rango de descriptores que permiten comparar el queso tradicional con el elaborado a partir de concentrados de ultrafiltración.

a. Se encuentran diferencias en cuanto a la composición en las primeras etapas de maduración, debido al exceso de humedad que presentan los quesos ultrafiltrados a la salida de prensa. Este exceso se compensa en la maduración con un mayor secado frente a los quesos tradicionales.

b. Se observa una desaceleración en los fenómenos de proteolisis y lipolisis a lo largo de la maduración respecto a la elaboración tradicional, como consecuencia de la incorporación de proteína soluble en el queso que, sin embargo, no afecta a la apreciación sensorial del mismo.

c. El análisis micrográfico denota una mayor porosidad en los quesos en los que no se corta la cuajada, con presencia de poros más heterogéneos. En todos los casos se han identificado cristalizaciones de fosfato cálcico.

d. El queso ultrafiltrado presenta un color amarillo menos intenso que los tradicionales, tanto en su interior como en su exterior.

e. Se obtienen diferencias claras en cuanto al aspecto visual exterior del queso relacionadas con su forma y color. También se indican diferencias en el aspecto interior, al tratarse de pastas ciegas por la ausencia de etapa de corte en la tecnología de ultrafiltración. Las características diferenciadoras han sido mejoradas en la secuencia experimental de optimización hasta alcanzar puntuaciones similares al queso tradicional en su evaluación sensorial mediante panel de cata entrenado.

f. Los quesos fabricados a partir de concentrados de ultrafiltración se presentan como más solubles, húmedos y adherentes a la vez que de menor friabilidad, elasticidad, granulosidad o cohesividad. Tanto el olor como el sabor del queso elaborado con leche 
concentrada se consideran equilibrados, con ausencia de sabores atípicos (como amargores o excesos de acidez) obteniendo puntuaciones similares al queso tradicional en la evaluación sensorial.

7. El queso obtenido tras la optimización desarrollada en la presente Tesis, si bien presenta diferencias respecto al tradicional, recibe buenas puntuaciones en cuanto a su calidad sensorial, lo que se relaciona con una potencial buena aceptación por parte del consumidor.

8. La rentabilidad final del proceso, basada en el aumento de rendimiento y avalada por la simplificación operacional, sólo podrá conseguirse mediante la completa sustitución de los equipos convencionales de elaboración, prestando especial atención en el uso de sistemas de bombeo adecuados para tratar productos altamente viscosos.

En base a estas conclusiones se recomienda la reorientación del proceso tradicional hacia una fabricación en continuo, que permita la ultrafiltración de la leche y pasterización del concentrado, pasando a un sistema de mezcla (para la adecuada distribución de ingredientes) y la posterior coagulación en continuo con incorporación directa de la cuajada en los moldes. A partir de este momento se continuará con el sistema tradicional de prensado y afinado. 



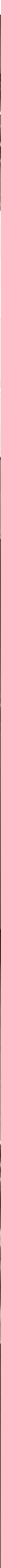





\section{BIBLIOGRAFÍA}

Agarwal, S., J.R. Powers, B.G. Swanson, S. Chen, y S. Clark. 2006. Cheese pH, Protein Concentration, and Formation of Calcium Lactate Crystals. Journal of Dairy Science. 89(11):41444155.

Ardö, Y. 1999. Evaluating proteolysis by analysing the $N$ content of cheese fractions. International Dairy Federation Bulletin. 337:4-9.

Arroyo, M. y C. García. 1988. Quesos de España. Espasa-Calpe S.A. ed. Madrid.

Atra, R., G. Vatai, E. Bekassy-Molnar, y A. Balint. 2005. Investigation of ultra- and nanofiltration for utilization of whey protein and lactose. Journal of Food Engineering. 67(3):325-332.

Balannec, M., M. Vourch, B. Rabiller, y B. Chaufer. 2005. Comparative study of different nanofiltration and reverse osmosis membranes for dairy effluent treatment by dead-end filtration. Separation and Purification Technology. 42(2):195-200.

Balcones, M.E. 1996. Proceso de sinéresis en la elaboración quesera: revisión. Alimentación, equipos y tecnología. julio/agosto 1996:73-77.

Barbano, D.M., R.R. Rasmussen, y J.M. Lynch. 1991. Influence of Milk Somatic Cell Count and Milk Age on Cheese Yield. Journal of Dairy Science. 74(2):369-388.

Barron, L.J.R., Y. Redondo, C.E. Flanagan, F.J. Pérez-Elortondo, A. Marta, A.I. Nájera, M. de Renobales, y E. Fernández-García. 2005. Comparison of the volatile composition and sensory characteristics of Spanish PDO cheeses manufactured from ewes' raw milk and animal rennet. International Dairy Journal. 15(4):371-382.

Bech, A.M. 1993. Characterising ripening in UF-cheese. International Dairy Journal. 3(4-6):329-342.

Bianchi, A., G. Beretta, G. Caserio, y G. Giolitti. 1974. Amino Acid Composition of Granules and Spots in Grana Padano Cheeses. Journal of Dairy Science. 57(12):1504-1508.

Bonet, B., M. Juárez, B. Moreno, R.M. Ortega, y L. Suárez. 2009. Libro Blanco de los Lácteos. Federación Nacional de Industrias Lácteas. Madrid.

Borgognone, M.G., J. Bussi, y G. Hough. 2001. Principal component analysis in sensory analysis: covariance or correlation matrix?. Food Quality and Preference. 12:323-326.

Bottazzi, V., F. Lucchini, A. Rebecchi, y G. Scolari. 1994. I cristalli del formaggio Grana. Scienza e Tecnica Latteiro-Casearia. 45(1):7-14. 
Boyazoglu, J. y P. Morand-Fehr. 2001. Mediterranean dairy sheep and goat products and their quality: A critical review. Small Ruminant Research. 40(1):1-11.

Brans, G., C.G.P.H. Schroën, R.G.M. Van der Sman, y R.M. Boom. 2004. Membrane fractionation of milk: state of the art and challenges. Journal of Membrane Science. 243(1-2):263-272.

Brulé, G., J.L. Maubois, y J. Fauquant. 1974. Etude de la teneur en éléments minéraux des produits obtenus lors de l'ultrafiltration du lait sur membrane. Le Lait. 54(539-540):600-615.

Buffa, M.N., A.J. Trujillo, M. Pavia, y B. Guamis. 2001. Changes in textural, microstructural, and colour characteristics during ripening of cheeses made from raw, pasteurized or high-pressuretreated goats' milk. International Dairy Journal. 11(11-12):927-934.

Bush, C.S., C.A. Caroutte, C.H. Amundson, y N.F. Olson. 1983. Manufacture of Colby and Brick Cheeses from Ultrafiltered Milk. Journal of Dairy Science. 66(3):415-421.

Casado, P. 1991. Guía para el análisis químico de la leche y los derivados lácteos. Ayala S.A. ed. Madrid.

Castillo, M. 2001. Predicción del tiempo de corte en la elaboración de queso mediante dispersión de radiacción de infrarrojo próximo. Tesis Doctoral. Universidad de Murcia. Murcia.

Chacón, A. 2006. Tecnología de membranas en la industria láctea. Agronomía Mesoamericana. 17(02):243-263.

Chaufer, B., A. Muller, U. Merin, y G. Daufin. 2003. Prepurification of $\alpha$-lactalbumin with ultrafiltration ceramic membranes from acid casein whey: study of operating conditions. Le Lait. 83:397-408.

Cheryan, M. y D. Wilson. 2000a. Food Technology - Membrane Separations. Páginas 2849-2855 en Encyclopedia of Separation Science. Academic Press, Oxford.

Cheryan, M. y D. Wilson. 2000b. Membrane Separations - Ultrafiltration. Páginas 1797-1802 en Encyclopedia of Separation Science. Academic Press, Oxford.

Cheryan, M. 1998. Ultrafiltration and microfiltration handbook. Technomic Publishing Company ed. Pensylvania.

Christensen, T.M.I.E., K.R. Kristiansen, y H. Werner. 1991. Casein hydrolisis in cheeses manufactured traditionally and by ultrafiltration technique. Milchwissenschaft. 46(5):279-283.

Christian, R. 2007. Coagulation of milk: processes and characteristics. Bulletin of the International Dairy Federation. 420:1-27.

Cogan, T.M. 1995. Flavor production by dairy starter cultures. Journal of Applied Bacteriology, Symposium Supplement. 79(46s-64s).

Collins, Y.F., P.L.H. McSweeney, y M.G. Wilkinson. 2003. Lipolysis and free fatty acid catabolism in cheese: a review of current knowledge. International Dairy Journal. 13(11):841-866.

Covacevich, H.R. y F.V. Kosikowski. 1978. Mozzarella and Cheddar Cheese Manufacture by Ultrafiltration Principles. Journal of Dairy Science. 61:701-709. 
da Cunha, C.R., W.H. Viotto, y L.A. Viotto. 2006. Use of low concentration factor ultrafiltration retentates in reduced fat "Minas Frescal" cheese manufacture: Effect on composition, proteolysis, viscoelastic properties and sensory acceptance. International Dairy Journal. 16(3):215-224.

Daufin, G., J.-P. Escudier, H. Carrere, S.L. Berot, y M. Decloux. 2001. Recent and emerging applications of membrane processes in the food and dairy industry. Trans IChemE. 79(Part C):89.

de Koning, P.J., R. de Boer, P. Both, y P.F.C. Nooy. 1981. Comparison of proteolysis in a low fat, semi-hard type of cheese manufactured by standard and by ultrafiltration techniques. Netherlands Milk and Dairy Journal. 35:35-46.

Dejmek, P. 1986. Milk saving in cheesemaking by ultrafiltration. Milchwissenschaft. 41(11):686-688.

Delbeke, R. 1987. Experiments on making Saint-Paulin by full concentration of milk with ultrafiltration. Milchwissenschaft. 42(4):222-225.

de Peters, E.J. y S.J. Taylor. 1985. Effects of Feeding Corn or Barley on Composition of Milk and Diet Digestibility. Journal of Dairy Science. 68(8):2027-2032.

Desmazeaud, M.J. y J.C. Gripon. 1977. General mechanism of protein breakdown during cheese ripening. Milchwissenschaft. 32:731-743.

Doyen, W., W. Adriansens, B. Molenberghs, y R. Leysen. 1996. A comparison between polysulfone, zirconia and organo-mineral membranes for use in ultrafiltration. Journal of Membrane Science. 113(2):247-258.

Dresch, M., G. Daufin, y B. Chaufer. 1999. Membrane processes for the recovery of dairy cleaningin-place solutions. Le Lait. 79:245-259.

Dufossé, L., P. Galaup, E. Carlet, C. Flamin, y A. Valla. 2005. Spectrocolorimetry in the CIE L*a*b* color space as useful tool for monitoring the ripening process and the quality of PDO red-smear soft cheeses. Food Research International. 38(8-9):919-924.

Dybing, S.T., J.A. Wiegand, S.A. Brudvig, E.A. Huang, y R.C. Chandan. 1988. Effect of Processing Variables on the Formation of Calcium Lactate Crystals on Cheddar Cheese. Journal of Dairy Science. 71(7):1701-1710.

Ernstrom, C.A., B.J. Sutherland, y G.W. Jameson. 1980. Cheese Base for Processing. A High Yield Product from Whole Milk by Ultrafiltration. Journal of Dairy Science. 63(2):228-234.

Everett, D.W. y M.A.E. Auty. 2008. Cheese structure and current methods of analysis. International Dairy Journal. 18(7):759-773.

Fernández-Albalat, M.P. 2002. Aplicación de la ultrafiltración en la elaboración de un queso tipo Cebreiro. Tesis Doctoral. Universidad de Santiago de Compostela.Lugo.

Fernández-García, E., M. Carbonell, P. Gaya, y M. Nuñez. 2004. Evolution of the volatile components of ewes raw milk Zamorano cheese. Seasonal variation. International Dairy Journal. 14:701-711.

Field, R.W., D. Wu, J.A. Howell, y B.B. Gupta. 1995. Critical flux concept for microfiltration fouling. Journal of membrane technology. 100(3):259-272. 
Furtado, M.M. y J.A. Partridge. 1988. Characterization of Nitrogen Fractions During Ripening of a Soft Cheese Made from Ultrafiltration Retentates. Journal of Dairy Science. 71(11):2877-2884.

García, M. 1994. Identificación y control de puntos críticos en la industria quesera. ILE. Enero-Febrero:50-63.

Garde, S., M. Ávila, E. Fernández-García, M. Medina, y M. Nuñez. 2007. Volatile compounds and aroma of Hispánico cheese manufactured using lacticin 481-producing Lactococcus lactis subsp. lactis INIA 639 as an adjunct culture. International Dairy Journal. 17(6):717-726.

Garnot, P., T.C. Rank, y N.F. Olson. 1982. Influence of Protein and Fat Contents of Ultrafiltered Milk on Rheological Properties of Gels Formed by Chymosin. Journal of Dairy Science. 65(12):22672273.

Garret, N.L.T. y APVCoLtd. 1987. The Sirocurd process for cheese manufacture. Journal of the Society of Dairy Technology. 40(3):68-70.

Goudédranche, H., J. Fauquant, y J.L. Maubois. 2000. Fractionation of globular milk fat by membrane microfiltration. Le Lait. 80(1):93-98.

Goudédranche, H., J.L. Maubois, P. Ducruet, y M. Mahaut. 1980. Utilization of the new mineral Uf membranes for making semi-hard cheeses. Desalination. 35:243-258.

Govindasamy-Lucey, S., J.J. Jaegg, A.L. Bostley, J.M.E., y J.A. Lucey. 2004. Standardization of Milk Using Cold Ultrafiltration Retentates for the Manufacture of Parmesan Cheese. Journal of Dairy Science. 87:2789-2799.

Govindasamy-Lucey, S., J.J. Jaeggi, M.E. Johnson, T. Wang, y J.A. Lucey. 2005. Use of cold ultrafiltered retentates for standardization of milks for pizza cheese: Impact on yield and functionality. International Dairy Journal. 15(6-9):941-955.

Grandison, A.S., W. Youravong, y M.J. Lewis. 2000. Hydrodynamic factors affecting flux and fouling during ultrafiltration of skimmed milk. Le Lait. 80:165-174.

Green, M.L. 1985. Effect of milk pretreatment and making conditions on the properties of Cheddar cheese from milk concentrated by ultrafiltration. Journal of Dairy Research. 52:555-562.

Green, M.L., F.A. Glover, E.M.W. Scurlock, R.J. Marshall, y D.S. Hatfield. 1981. Effect of use of milk concentrated by ultrafiltration on the manufacture and ripening of Cheddar cheese. Journal of Dairy Research. 48:333-341.

Green, M.L., K.J. Scott, M. Anderson, y M.C.A. Griffin. 1984. Chemical characterization of milk concentrated by ultrafiltration. Journal of Dairy Research. 51:267-278.

Green, M.L., R.J. Marshall, y F.A. Glover. 1983. Influence of homogenization of concentrated milks on the structure and properties of rennet curds. Journal of Dairy Research. 50:341-348.

Guinee, T.P., P.D. Pudja, y E.O. Mulholland. 1994. Effect of milk protein standardization, by ultrafiltration, on the manufacture, composition and maturation of Cheddar cheese. Journal of Dairy Research. 61:117-131.

Guinee, T.P., P.D. Pudja, W.J. Reville, D. Harrington, E.O. Mulholland, M. Cotter, y T.M. Cogan. 1995. Composition, microstructure and maturation of semi-hard cheeses from high protein 
ultrafiltered milk retentates with different levels of denatured whey protein. International Dairy Journal.5(6):543-568.

Hinrichs, J. 2001. Incorporation of whey proteins in cheese. International Dairy Journal. 11(4-7):495-503.

Howell, J.A. 1995. Sub-critical flux operation of microfiltration. Journal of Membrane Science. 107(1-2):165-171.

Hydamaka, A.W., R.A. Wilbey, M.J. Lewis, y A.W. Kuo. 2001. Manufacture of heat and acid coagulated cheese from ultrafiltered milk retentates. Food Research International. 34(2-3):197-205.

Ibañez, F.C., Y. Barcina. 2001. Análisis sensorial de alimentos. Springer-Verlag Ibérica ed. Barcelona.

Ibañez, J.A. 1989. Fundamentos de los procesos de transporte y separación en membranas. Universidad de Murcia. Murcia.

ISO 11290-1:1996. Microbiology of food and animal feeding stuffs - Horizontal method for the detection and enumeration of Listeria monocytogenes - Part 1: Detection method.

ISO 13366-2:2006. Milk - Enumeration of somatic cells - Part 2: Guidance on the operation of fluoro-opto-electronic counters.

ISO 16649-2:2001. Microbiology of food and animal feeding stuffs-Horizontal method for the enumeration of beta-glucuronidase-positive Escherichia coli-Part 2: Colony-count technique at 44 degrees C using 5-bromo-4-chloro-3-indolyl beta-D-glucuronide.

ISO 3433:2008. Cheese - Determination of fat content - Van Gulik method.

ISO 4832:2006. Microbiology of food and animal feeding stuffs - Horizontal method for the enumeration of coliforms - Colony-count technique.

ISO 488/2008. Milk - Determination of fat content - Gerber butyrometers.

ISO 5534:2004. Cheese and processed cheese - Determination of the total solids content (Reference method).

ISO 6611:2004. Milk and milk products - Enumeration of colony-forming units of yeasts and/or moulds - Colony-count technique at 25 degrees $C$.

ISO 6888-2:1999. Microbiology of food and animal feeding stuffs - Horizontal method for the enumeration of coagulase-positive staphylococci (Staphylococcus aureus and other species) - Part 2: Technique using rabbit plasma fibrinogen agar medium.

ISO 8968-1:2001. Milk - Determination of nitrogen content - Part 1: Kjeldahl method.

Jeantet, R., J. Rodríguez, y A. Garem. 2000. Nanofiltration of sweet whey by spiral wound organic membranes: Impact of hydrodynamics. Le Lait. 80:155-163.

Karlsson, A.O., R. Ipsen, y Y. Ardo. 2007. Rheological properties and microstructure during rennet induced coagulation of UF concentrated skim milk. International Dairy Journal. 17(6):674-682. 
Kelly, M., P.F. Fox, y P.L.H. McSweeney. 1996. Effect of salt-in-moisture on proteolysis in Cheddartype cheese. Milchwissenschaft. 51(9):498-501.

Kirchmeier, O. 1980. Buffer capacities and buffer equilibrium of milk. Milchwissenschaft. 35:667670.

Kosikowski, F.V. 1986. New cheese-making procedures utilizing ultrafiltration. Food Technology. 40:71-77.

Kosikowski, F.V. y V.V. Mistry. 1988. Yield and quality of cheese made from high somatic cell milks supplemented with retentes of ultrafiltration. Milchwissenschaft. 43(1):27-30.

Kuo, M.-I. y S. Gunasekaran. 2009. Effect of freezing and frozen storage on microstructure of Mozzarella and pizza cheeses. LWT - Food Science and Technology. 42(1):9-16.

Laloy, E., J.-C. Vuillemard, M. El Soda, y R.E. Simard. 1996. Influence of the fat content of Cheddar cheese on retention and localization of starters. International Dairy Journal. 6(7):729-740.

Lawrence, R.C. 1989. The use of ultrafiltration technology in cheesemaking. Bulletin of the International Dairy Federation. 240:2-13.

Lucey, J.A. 2008. Some perspectives on the use of cheese as a food ingredient. Dairy Science and Technology. 88:573-594.

Luquet, F. M. 1991a. Leche y productos lacteos. Vaca-oveja-cabra. 1-La leche de la mama a la lechería. Acribia S.A ed. Zaragoza.

Luquet, F.M. 1991b. Leche y productos lacteos. Vaca-oveja-cabra. 2-Los productos lácteos transformación y tecnología. Acribia S.A. ed. Zaragoza.

Madadlou, A., M.E. Mousavi, A. Khosrowshahi asl, Z. Emam-Djome, y M. Zargaran. 2007. Effect of cream homogenization on textural characteristics of low-fat Iranian White cheese. International Dairy Journal. 17(5):547-554.

Mahaut, M., R. Jeantet, y G. Brulé. 2003. Introducción a la tecnología quesera. Acribia S.A. ed., Zaragoza.

Makardij, A., X.D. Chen, y M.M. Farid. 1999. Microfiltration and ultrafiltration of milk: Some Aspects Of Fouling And Cleaning. Trans IChemE. 77(Part C):107.

Marshall, A.D., P.A. Munro, y G. Trägårdh. 1993. The effect of protein fouling in microfiltration and ultrafiltration on permeate flux, protein retention and selectivity: A literature review. Desalination. 91(1):65-108.

Maubois, J.L. y F.V. Kosikowski. 1978. Making Ricotta Cheese by Ultrafiltration. Journal of Dairy Science. 61(7):881-884.

Maubois, J.L. y G. Brulé. 1982. Utilisation des techniques à membrane pour la séparation, la purification et la fragmentation des protéines laitières. Le Lait. 62:484-510.

Maubois, J.L. y G. Mocquot. 1974. Application of membrane ultrafiltration to preparation of various types of cheese. Journal of Dairy Science. 58(7):1001-1007. 
Maubois, J.L. 1989. Applications of membrane techniques in the dairy industry. Bulletin of the International Dairy Federation. 244:26-29.

Maubois, J.L., G. Mocquot, y L. Vassal. 1969. Procédé de traitement du lait et de sous produits laitiers. Patente: FR2052121.

Maubois, J.L., G. Mocquot, J.L. Thapon, M.C. Humilier, A. Chopin, H. Goudedranche, C. Dupas, E. Blanc-Patin, M. Piot, y F. Fauquant. 1971. Préparation de fromage à partir de "pré-fromage liquide" obtenu par ultrafiltration du lait. Le Lait. 51(508):495-533.

McGregor, J.U. y C.H. White. 1990. Optimizing Ultrafiltration Parameters for the Development of a Lowfat Cheddar Cheese. Journal of Dairy Science. 73:314-318.

McGregor, J.U. y C.H. White. 1990a. Effect of Enzyme Treatment and Ultrafiltration on the Quality of Lowfat Cheddar Cheese. Journal of Dairy Science. 73:571-578.

McGregor, J.U. y C.H. White. 1990b. Optimizing Ultrafiltration Parameters for the Development of a Lowfat Cheddar Cheese. Journal of Dairy Science. 73:314-318.

McMahon, D.J., R.L. Fife, y C.J. Oberg. 1999. Water Partitioning in Mozzarella Cheese and Its Relationship to Cheese Meltability. Journal of Dairy Science. 82(7):1361-1369.

McSweeney, P.L.H. y J. Sousa. 2000. Biochemical pathways for the production of flavour compounds in cheeses during ripening: A review. Le Lait. 80:293-324.

Mehaia, M.A. 2002. Manufacture of fresh soft white cheese (Domiati-type) from ultrafiltered goats' milk. Food Chemistry. 79(4):445-452.

Menéndez, S., J.A. Centeno, R. Godínez, y J.L. Rodríguez-Otero. 2000. Effects of Lactobacillus strains on the ripening and organoleptic characteristics of Arzúa-Ulloa cheese. International Journal of Food Microbiology. 59(1-2):37-46.

Mistry, V.V. y F.V. Kosikowski. 1985. Growth of Lactic Acid Bacteria in Highly Concentrated Ultrafiltered Skim Milk retentates. Journal of Dairy Science. 68(10):2536-2543.

Mistry, V.V. y F.V. Kosikowski. 1986. A Naturally Buffered Bulk Retentate Starter from Ultrafiltered Milk. Journal of Dairy Science. 69(4):945-950.

Mistry, V.V. y J.L. Maubois. 2004. Application of membrane separation technology to cheese production. Páginas 261-285 en Cheese: Chemistry, Physics and Miccrobiology. Elsevier Academic Press. London.

Mistry, V.V. 2002. Manufacture and application of high milk protein powder. Le Lait. 82:515-522.

Mistry, V.V., L.E. Metzger, y J.L. Maubois. 1996. Use of Ultrafiltered Sweet Buttermilk in the Manufacture of Reduced Fat Cheddar Cheese. Journal of Dairy Science. 79(7):1137-1145.

Mohr, C.M., D.E. Engelgau, S.A. Leeper, y B.L. Charboneau. 1989. Membrane applications and research in food processing. Noyes Data Corporation ed. New Jersey.

Mucchetti, G., G. Zardi, F. Orlandini, y C. Gostoli. 2000. The pre-concentration of milk by nanofiltration in the production of Quarg-type fresh cheeses. Le Lait. 80:43-50. 
Muller, A., B. Chaufer, U. Merin, y G. Daufin. 2003. Purification of $\alpha$-lactalbumin from a prepurified acid whey: Ultrafiltration or precipitation. Le Lait. 83:439-451.

Murray, J.M., C.M. Delahunty, y I.A. Baxter. 2001. Descriptive sensory analysis: past, present and future. Food Research International. 34(6):461-471.

Nair, M.G., V.V. Mistry, y B.S. Oommen. 2000. Yield and functionality of Cheddar cheese as influenced by homogenization of cream. International Dairy Journal. 10:647-657.

Neocleous, M., D.M. Barbano, y M.A. Rudan. 2002a. Impact of Low Concentration Factor Microfiltration on Milk Component Recovery and Cheddar Cheese Yield. Journal of Dairy Science. 85(10):2415-2424.

O'Callaghan, D.O. y T.P. Guinee. 2004. Rheology and Texture of Cheese. Páginas 511-540 en Cheese: Chemistry, Physics and Microbiology. Elsevier Academic Press. London.

Omar, M.M. y M. Hosaja. 1986. Microstructure and chemical changes in Twarog cheese made from ultrafiltrated milk and from lactose-hydrolysed milk. Food Chemistry. 22(2):147-163.

Oommen, B.S., V.V. Mistry, y M.G. Nair 2000. Effect of homogenization of cream on composition, yield, and functionality of Cheddar cheese made from milk supplemented with ultrafiltered milk. Le Lait. 80:77-91.

ORDEN 16728/1987 de 9 de julio de 1987 por la que se aprueban las normas de composición y características específicas para los quesos Hispánico, Ibérico y De la Mesta, destinados al mercado interior.

Ould-Dris, A., M.Y. Jaffrin, D. Si-Hassen, y Y. Neggaz. 2000. Effect of cake thickness and particle polydispersity on prediction of permeate flux in microfiltration of particulate suspensions by a hydrodynamic diffusion model. Journal of Membrane Science. 164(1-2):211-227.

Poulsen, P.R. 1978. Feasibility of Ultrafiltration for Standardizing Protein in Milk. Journal of Dairy Science. 61:807-814.

Punidadas, P. y S.S.H. Rizvi. 1998. Separation of milk proteins into fractions rich in casein or whey proteins by cross flow filtration. Food Research International. 31(4):265-272.

Qvist, K.B., D. Thomsen, y E. Hoier. 1987. Effect of ultrafiltered milk and use of different starters on the manufacture, fermentation and ripening of Havarti cheese. Journal of Dairy Research. 54 (437-446).

Ramírez, M.A. y ILE. 2009. Guía de los Quesos Españoles. Publicaciones Técnicas Alimentarias S.A. ed. Madrid.

Ramírez, M.A. 2005. Manual práctico de Quesería. Ayala S.A. ed. Madrid.

Rao, D.V. y E. Renner. 1988. Studies of the application of ultrafiltration for the manufacture of Cheddar cheese. 1. Determination of the optimum temperature for heat denaturation of whey proteins in the ultrafiltration concentrate. Milchwissenschaft. 43(4):216-218.

Raphaelides, S., K.D. Antoniou, y D. Petridis. 1995. Texture evaluation of ultrafiltered Teleme cheese. Journal of Food Science. 60(6):1211-1215. 
Rash, K.E. y F.V. Kosikowski. 1982. Behavior of Enteropathogenic Escherichia coli in Camembert Cheese Made From Ultrafiltered Milk. Journal of Food Science. 47(3):728-732.

RD 1113/2006 de 29 de septiembre, por el que se aprueban las normas de calidad para quesos y quesos fundidos.

Reglamento (CE) 2073/2005 de la comisión de 15 de noviembre de 2005 relativo a los criterios microbiológicos aplicables a los productos alimenticios.

Reglamento (CE) 853/2004 del parlamento europeo y del consejo de 29 de abril de 2004 por el que se establecen normas específicas de higiene de los alimentos de origen animal.

Rodríguez, J., T. Requena, y M. Juárez. 1999. Procedimiento para la elaboración de quesos frescos con contenido en grasa reducido, a partir de leche concentrada por ultrafiltración. Patente: ES 2133120.

Rodríguez, J., T. Requena, H. Goudédranche, J.L. Maubois, y M. Juárez. 1996. Accelerated ripening of reduced fat semi-hard cheese from a mixture of cow's, goat 's and ewe's ultrafiltrated milk by using a Lac- Prt- strain of lactococci. Le Lait. 76:513-522.

Rodriguez, J., T. Requena, J. Fontecha, H. Goudedranche, y M. Juarez. 1999. Effect of Different Membrane Separation Technologies (Ultrafiltration and Microfiltration) on the Texture and Microstructure of Semihard Low-Fat Cheeses. Journal of Agricultural Food Chemistry. 47(2):558565.

Rohm, H. y D. Jaros. 1996a. Colour of hard cheese-1. Description of colour properties and effects of madurations. Zeitschrift fur Lebensmittel Untersuchung Forschung. 203:241-244.

Rohm, H. y D. Jaros. 1996b. Colour of hard cheese-2. Factors of influence and relation to compositional parameters. Zeitschrift fur Lebensmittel Untersuchung Forschung. 204:259-264.

Romero del Castillo, R. y J. Mesters. 2004. Productos Lacteos Tecnología. UPC ed. Barcelona.

Romero, C.A. y R.H. Davis. 1988. Global model of crossflow microfiltration based on hydrodynamic particle diffusion. Journal of Membrane Science. 39(2):157-185.

Romero, C.A. y R.H. Davis. 1991. Experimental verification of the shear-induced hydrodynamic diffusion model of crossflow microfiltration. Journal of Membrane Science. 62(3):249-273.

Sablani, S.S., M.F.A. Goosen, R. Al-Belushi, y M. Wilf. 2001. Concentration polarization in ultrafiltration and reverse osmosis: a critical review. Desalination. 141(3):269-289.

Saboya, L.V. y J.L. Maubois. 2000. Current developments of microfiltration technology in the dairy industry. Le Lait. 80:541-553.

Saboya, L. V., H. Goudédranche, J. L. Maubois, A. L. S. Lerayer, y S. Lortal. 2001. Impact of broken cells of lactococci or propionibacteria on the ripening of Saint-Paulin UF-cheeses: extent of proteolysis and GC-MS profiles. Lait. 81:699-713.

Salaün, F., B. Mietton, y F. Gaucheron. 2005. Buffering capacity of dairy products. International Dairy Journal. 15(2):95-109.

Sánchez, P.J. 1999. Composición de quesos artesanos españoles. Constituyentes inorgánicos. Tesis Doctoral. Universidad de Córdoba. Córdoba. 
Schaap, J., P. Nooy, y R. Boer. 1982. Manufacture of semi-hard cheese by ultrafiltration. Patente: A23C 19/028

Schreier, K., K. Schafroth, y A. Thomet. 2010. Application of cross-flow microfiltration to semi-hard cheese production from milk retentates. Desalination. 250:1091-1094.

Severn, D.J., M.E. Jhonson, y N.F. Olson. 1986. Determination of Lactic Acid in Cheddar Cheese and Calcium Lactate Crystals. Journal of Dairy Science. 69:2027-2030.

Singh, H. y A. Waungana. 2001. Influence of heat treatment of milk on cheesemaking properties. International Dairy Journal. 11(4-7):543-551.

Sood, V.K. y F.V. Kosikowski. 1979. Process Cheddar Cheese from Plain and Enzyme Treated Retentates. Journal of Dairy Science. 62(11):1713-1718.

D'Souza, N.M y D.E. Wiley. (2003). Whey Ultrafiltration: Effect of operating parameters on flux and rejection. Proceedings of the 5th International Membrane Science and Technology Conference, Sydney, Australia.

Spadoti, L.M., J.R. Ferreira, y S. Massaguer. 2005. Proteolysis of Prato type cheese produced using ultrafiltration. Scientia Agricola. 62(3):235-239.

Spangler, P.L., L.A. Jensen, C.H. Amundson, N.F. Olson, y C.G. Hill. 1990. Gouda Cheese Made from Ultrafiltered Milk: Effects of Concentration Factor, Rennet Concentration, and Coagulation Temperature. Journal of Dairy Science. 73:1420-1428.

Spangler, P.L., L.A. Jensen, C.H. Amundson, N.F. Olson, y C.G. Hill. 1991. Ultrafiltered Gouda Cheese: Effects of Preacidification, Diafiltration, Rennet and Starter Concentration, and Time to Cut. Journal of Dairy Science. 74(9):2809-2819.

Srilaorkul, S., L. Ozimek, F. Wolfe, y J. Dziuba. 1989. The effect of ultrafiltration on physicochemical properties of retentate. Candian Institute of Food Science Technology Journal. 22:56-62.

Stenne, M.P. 1973. Procédé de fabrication d'aliments protéiques, notamment de fromages. Patente: FR2232999.

St-Gelais, D., D. Roy, y P. Audet. 1998. Manufacture and composition of low fat Cheddar cheese from milk enriched with different protein concentrate powders. Food Research International. 31(2):137-145.

St-Gelais, D., S. Hache, y M. Gros-Louis. 1992. Combined Effects of Temperature, Acidification, and Diafiltration on Composition of Skim Milk Retentate and Permeate. Journal of Dairy Science. 75(5):1167-1172.

St-Pierre, N.R. y W.P. Weiss. 2009. Technical note: designing and analyzing quantitative factorial experiments. Journal of Dairy Science. 92:4581-4588.

Suárez, E., A. Lobo, S. Alvarez, F.A. Riera, y R. Álvarez. 2009. Demineralization of whey and milk ultrafiltration permeate by means of nanofiltration. Desalination. 241(1-3):272-280.

Tanahashi, N., F. Yamada, y M. Tomoyeda. 1975. Purification and Properties of Galactosyltransferase from Human Colostrum. Journal of Dairy Science. 58(9):1276-1281. 
Tunick, M.H. 2000. Rheological of dairy foods that gel, stretch, and fracture. Journal of Dairy Science. 83:1892-1898.

Vadi, P.K. y S.S.H. Rizvi. 2001. Experimental evaluation of a uniform transmembrane pressure crossflow microfiltration unit for the concentration of micellar casein from skim milk. Journal of Membrane Science. 189(1):69-82.

Van den Berg, G. y F.A. Exterkate. 1993. Technological parameters involved in cheese ripening. International Dairy Journal. 3(4-6):485-507.

Van der Horst, H.C., J.M.K. Timmer, T. Robbertsen, y J. Leenders. 1995. Use of nanofiltration for concentration and demineralization in the dairy industry: Model for mass transport. Journal of Membrane Science. 104(3):205-218.

Van Leeuwen, J., H. Freeman, B. Sutherland, y G. Jameson. 1990. Preparation of hard cheese from concentrated milk. Patente: A23C 19/024.

Van Leeuwen, J., H. Freeman, J. Sutherland, y W. Jameson. 1984. Hard cheese from milk concentrate. Patente: WO 84/01268.

Van Slyke, D.D. 1922. On the measurement of buffer values and on the relathionship of buffer value to the dissociation constant of the buffer and the concentration and reaction of the buffer solution. Journal of Biological Chemistry. 52(2):525-570.

Voutsinas, L.P., M.C. Katsiari, C.P. Pappas, y H. Mallatou. 1995a. Production of brined soft cheese from frozen ultrafiltered sheep's milk. Part 1. Physicochemical, microbiological and physical stability properties of concentrates. Food Chemistry. 52(3):227-233.

Voutsinas, L. P., M. C. Katsiari, C. P. Pappas, y H. Mallatou. 1995b. Production of brined soft cheese from frozen ultrafiltered sheep's milk. Part 2 compositional, physicochemical, microbiological and organoleptic properties of cheese. Food Chemistry. 52(3):235-247.

Walstra, P., T.J. Geurts, A. Noomen, A. Jellema, y M. A.J.S. van Boekel. 2001. Ciencia de la leche y tecnología de los productos lácteos. Acribia S.A. ed. Zaragoga.

Wijmans, H. y D. Wilson. 2000. Membrane Separations - Concentration Polarization. Páginas 16821687 in Encyclopedia of Separation Science. Academic Press ed. Oxford.

Wood, B.J.B. y W.H. Holzapfel. 1995. The genera of lactic acid bacteria. Black Academic y Professional. Glasgow.

Xiong, R., J.-F. Meullenet, J.A. Hankins, y W.K. Chung. 2002. Relathionship between sensory and instrumental hardness of commercial cheeses. Journal of Food Science. 67(2):877-883.

Zall, R.R. y J.H. Chen. 1986. Thermalizing milk as opposed to milk concentrate in a UF system affects cheese yield. Milchwissenschaft. 41(4):217-218.

Zulaica, M.J. 2002. Elaboración de quesos frescos por tecnología de filtración tangencial. Tesis Doctoral. Universidad del Pais Vasco, Vitoria.

Zydney, A.L. 1998. Protein Separations Using Membrane Filtration: New Opportunities for Whey Fractionation. International Dairy Journal 8(3):243-250. 



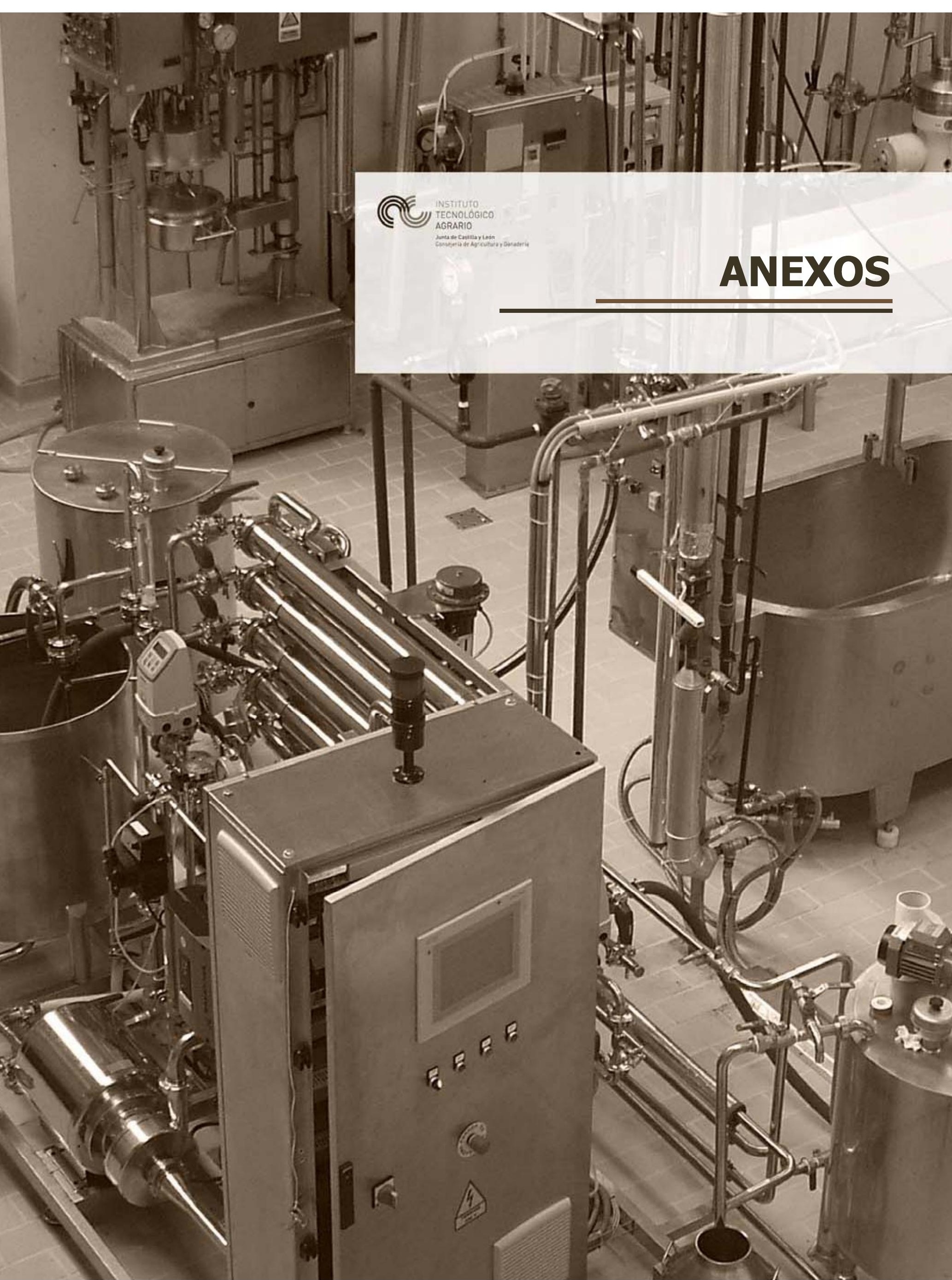





\section{A. ANEXOS}

\section{A.1. COMPOSICIÓN FÍSICO-QUÍMICA DE LAS LECHES DE VACA Y OVEJA}

A continuación se recogen los datos de composición y pH de las leches de vaca y oveja a partir de las cuales han sido elaboradas las distintas fabricaciones de queso para el desarrollo de esta Tesis.

Tabla A.1. Composición química y pH de la leche de oveja. Diseño Plackett-Burmann

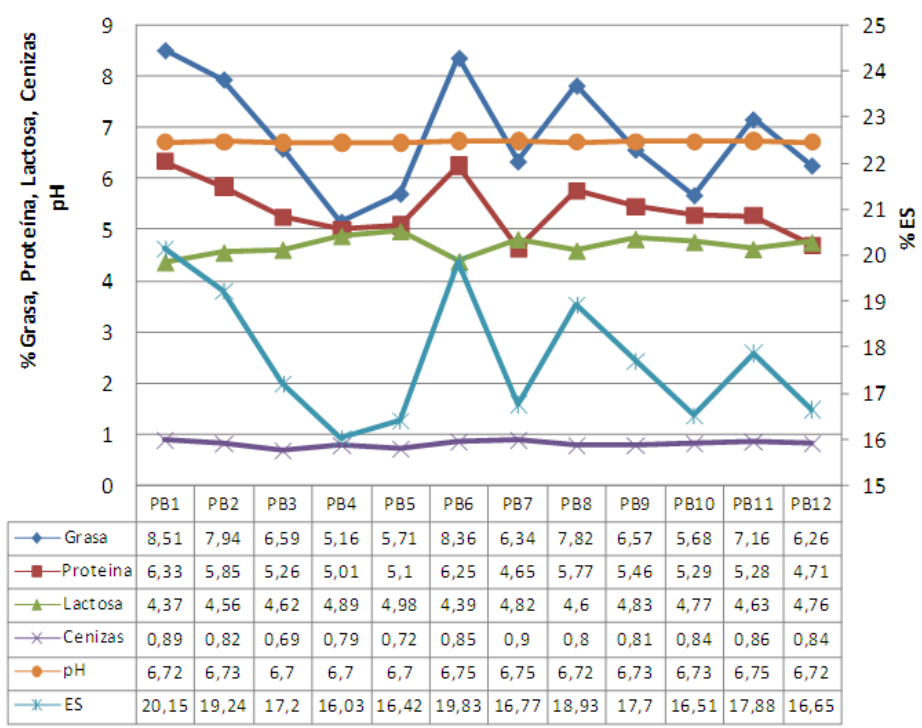

Tabla A.2. Composición química y pH de la leche de vaca. Diseño Plackett-Burmann

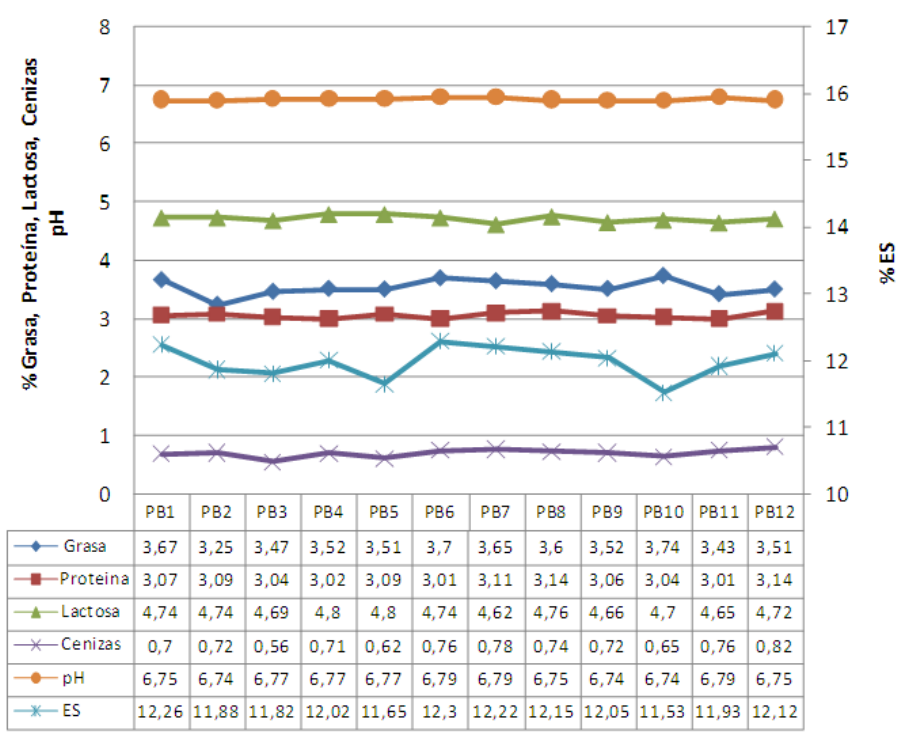


Tabla A.3. Composición química y pH de la leche de oveja. Diseño Factorial

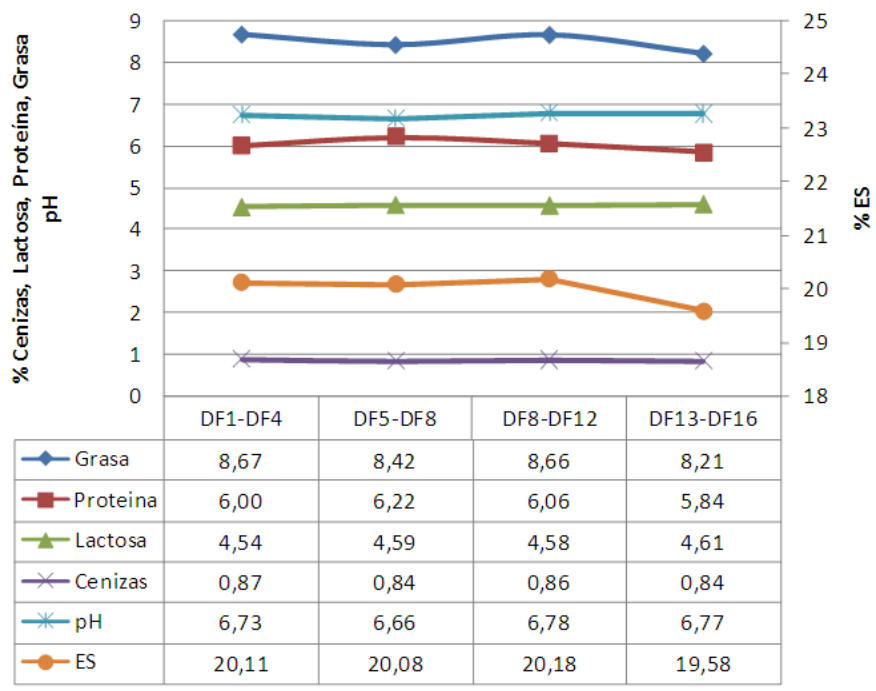

Tabla A.4. Composición química y pH de la leche de vaca. Diseño Factorial

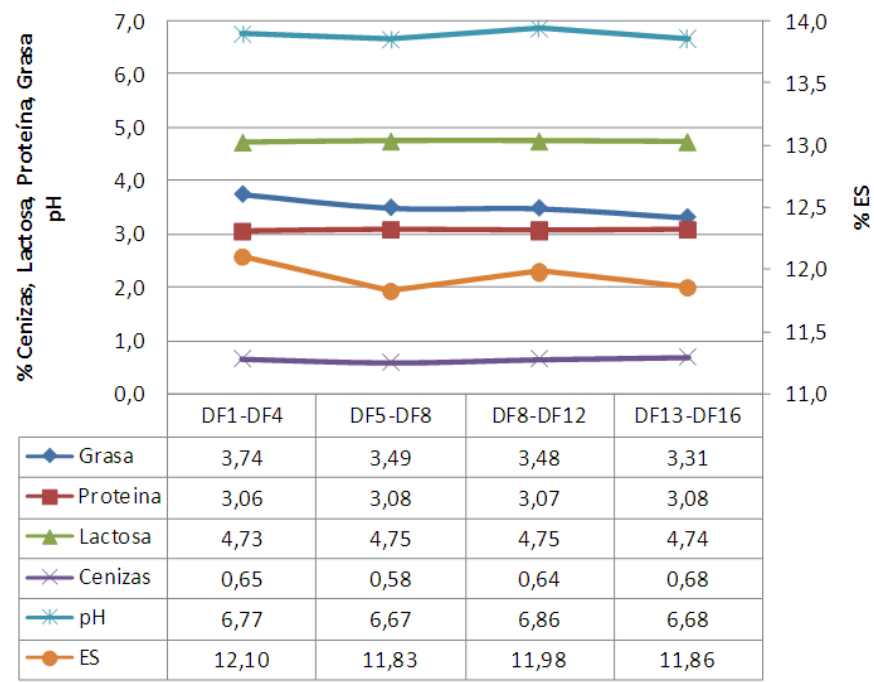

Tabla A.5. Composición química y pH de la leche de oveja. Diseño Superficie Respuesta

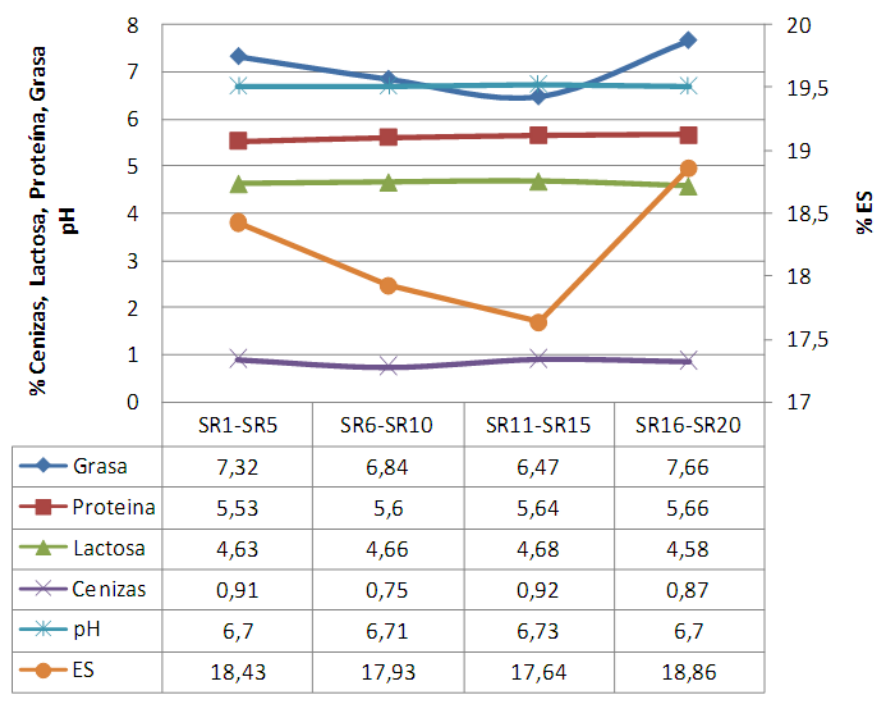


Tabla A.6. Composición química y pH de la leche de vaca. Diseño Superficie Respuesta

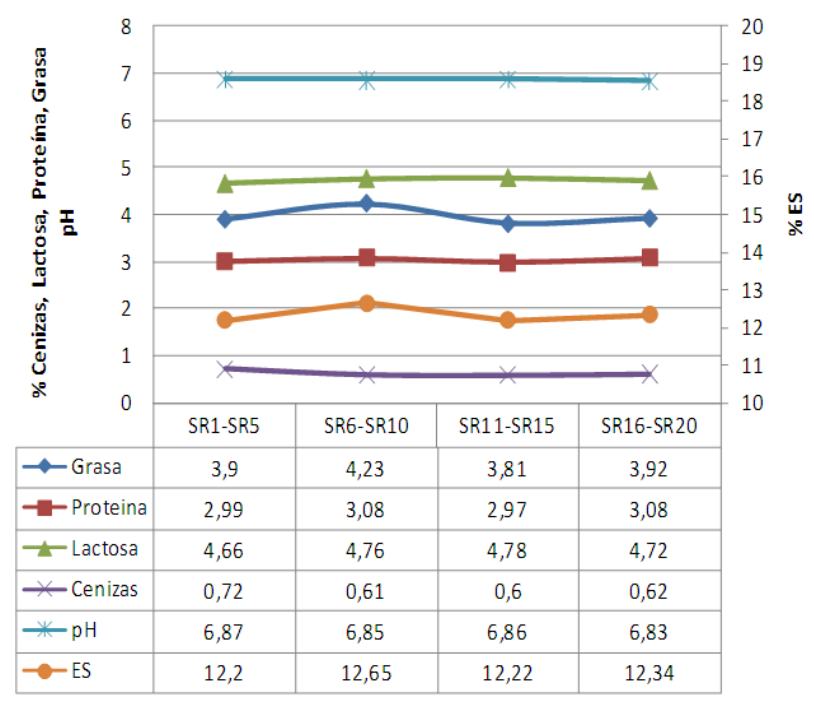

Tabla A.7. Composición química y pH de la leche de oveja. Queso tradicional y óptimos diseños

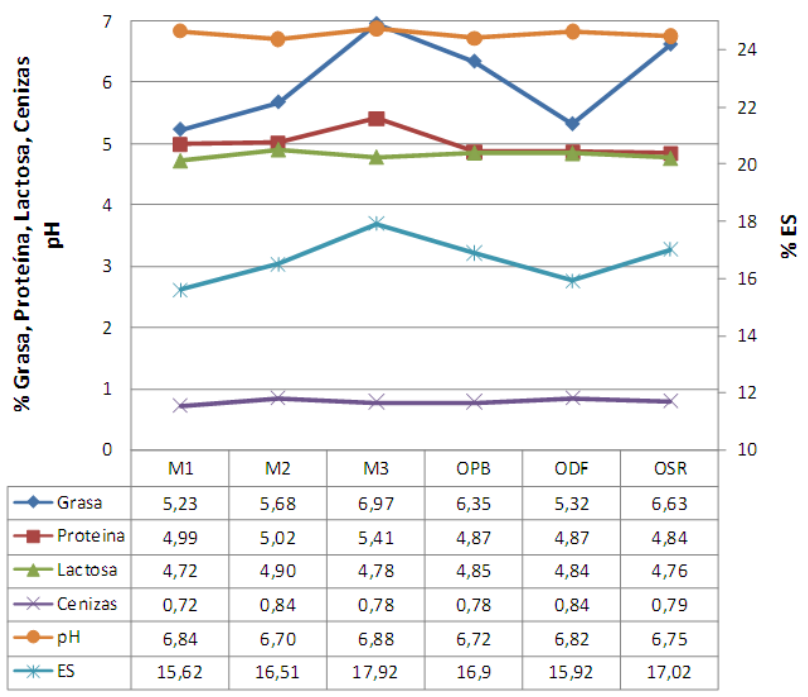

Tabla A.8. Composición química y pH de la leche de vaca. Queso tradicional y óptimos diseños

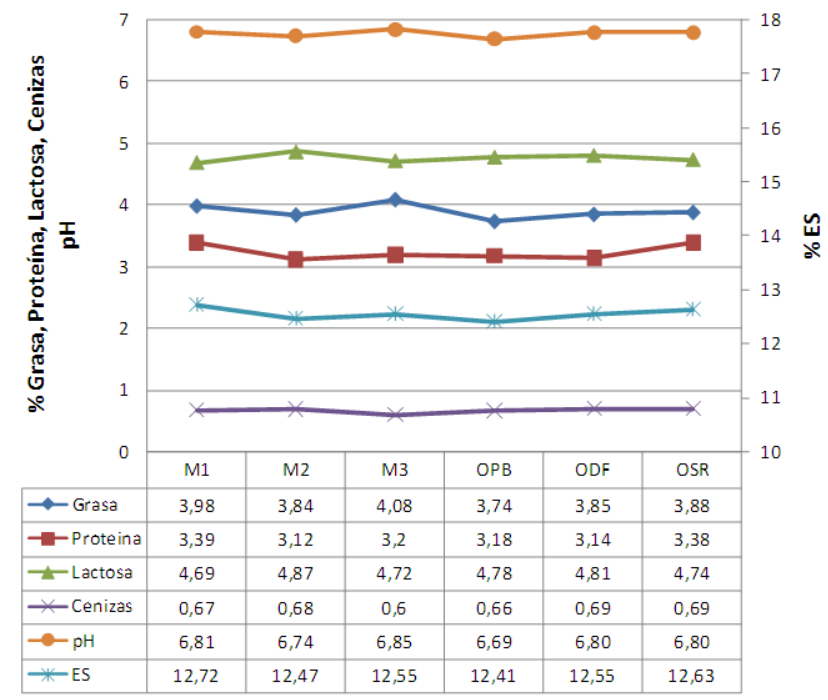





\section{A.2. COMPOSICIÓN QUÍMICA DE LOS QUESOS A LO LARGO DE LA MADURACIÓN}

En este anexo se recogen los datos de composición química (grasa, proteína, $\mathrm{pH}$, cenizas y sal) y el pH tanto del queso tradicional (M) como de la totalidad de quesos elaborados a partir de concentrados de leche por ultrafiltración: diseño Plackett-Burmann (PB) y óptimo (OPB), Diseño Factorial (DF) y óptimo (ODF) y diseño Superficie Respuesta (SR) y óptimo (OSR).

Tabla A.9. Composición química y pH de los quesos. Diseño Plackett-Burmann

\begin{tabular}{|c|c|c|c|c|c|c|c|c|c|c|c|c|c|}
\hline & \multirow{2}{*}{$\begin{array}{c}\text { PB1 } \\
25,75 \\
\pm 0,50\end{array}$} & \multirow{2}{*}{$\begin{array}{c}\text { PB2 } \\
26,75 \\
\pm 0,50\end{array}$} & \multirow{2}{*}{$\begin{array}{c}\text { PB3 } \\
26,25 \\
\pm 0,50\end{array}$} & \multirow{2}{*}{$\begin{array}{l}\text { PB4 } \\
26,75 \\
\pm 0,50\end{array}$} & \multirow{2}{*}{$\begin{array}{l}\text { PB5 } \\
26,25 \\
\pm 0,50\end{array}$} & \multirow{2}{*}{$\begin{array}{l}\text { PB6 } \\
25,75 \\
\pm 0,50\end{array}$} & \multirow{2}{*}{$\begin{array}{l}\text { PB7 } \\
\\
25,75 \\
\pm 0,50\end{array}$} & \multirow{2}{*}{$\begin{array}{l}\text { PB8 } \\
26,25 \\
\pm 0,50\end{array}$} & \multirow{2}{*}{$\begin{array}{l}\text { PB9 } \\
25,75 \\
\pm 0,50\end{array}$} & \multirow{2}{*}{$\begin{array}{l}\text { PB10 } \\
25,25 \\
\pm 0,50\end{array}$} & \multirow{2}{*}{$\begin{array}{c}\text { PB11 } \\
26,25 \\
\pm 0,50\end{array}$} & \multirow{2}{*}{$\begin{array}{l}\text { PB12 } \\
25,75 \\
\pm 0,50\end{array}$} \\
\hline \multirow[b]{2}{*}{$\checkmark$} & 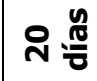 & & & & & & & & & & & & \\
\hline & q & $\begin{array}{l}28,75 \\
\pm 0,50\end{array}$ & $\begin{array}{l}30,75 \\
\pm 0,50\end{array}$ & $\begin{array}{l}26,75 \\
\pm 0,50\end{array}$ & $\begin{array}{l}28,75 \\
\pm 0,50\end{array}$ & $\begin{array}{l}28,75 \\
\pm 0,50\end{array}$ & $\begin{array}{l}27,75 \\
\pm 0,50\end{array}$ & $\begin{array}{l}29,75 \\
\pm 0,50\end{array}$ & $\begin{array}{l}28,75 \\
\pm 0,50\end{array}$ & $\begin{array}{l}28,75 \\
\pm 0,50\end{array}$ & $\begin{array}{l}27,75 \\
\pm 0,50\end{array}$ & $\begin{array}{l}27,75 \\
\pm 0,50\end{array}$ & $\begin{array}{l}28,25 \\
\pm 0,50\end{array}$ \\
\hline \multirow{2}{*}{ 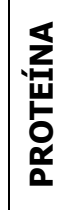 } & 윤 & $\begin{array}{l}21,24 \\
\pm 0,23\end{array}$ & 21,89 & $\begin{array}{r}21,59 \\
\pm 034\end{array}$ & 20,75 & $\begin{array}{r}21,03 \\
+0.03\end{array}$ & 21,19 & $\begin{array}{r}21,40 \\
+0\end{array}$ & $\begin{array}{l}21,44 \\
+0\end{array}$ & $\begin{array}{l}20,97 \\
+0,84\end{array}$ & $\begin{array}{r}21,55 \\
+084\end{array}$ & $\begin{array}{r}21,39 \\
+0.53\end{array}$ & $\begin{array}{l}21,13 \\
+027\end{array}$ \\
\hline & 오 플 & $\begin{array}{l}22,46 \\
\pm 0,04\end{array}$ & $\begin{array}{l}23,29 \\
\pm 0,04\end{array}$ & $\begin{array}{l}24,01 \\
\pm 0,84\end{array}$ & $\begin{array}{c}22,65 \\
\pm 0,9\end{array}$ & $\begin{array}{l}22,76 \\
\pm 0,23\end{array}$ & $\begin{array}{l}23,24 \\
\pm 0,06\end{array}$ & $\begin{array}{l}22,45 \\
\pm 0,31\end{array}$ & $\begin{array}{l}23,45 \\
\pm 0,09\end{array}$ & $\begin{array}{l}22,67 \\
\pm 0,05\end{array}$ & $\begin{array}{l}22,85 \\
\pm 0,31\end{array}$ & $\begin{array}{l}22,35 \\
\pm 0,57\end{array}$ & $\begin{array}{l}22,79 \\
\pm 0,32\end{array}$ \\
\hline \multirow{2}{*}{ ऊో } & $0 \stackrel{\underline{*}}{\underline{*}}$ & $\begin{array}{c}0,92 \\
\pm 0,05\end{array}$ & $\begin{array}{c}1,07 \\
\pm 0,05\end{array}$ & $\begin{array}{c}1,12 \\
\pm 0,04\end{array}$ & $\begin{array}{c}0,98 \\
\pm 0,03\end{array}$ & $\begin{array}{c}1,08 \\
\pm 0,02\end{array}$ & $\begin{array}{c}0,98 \\
\pm 0,06\end{array}$ & $\begin{array}{r}1,02 \\
\pm 0,01\end{array}$ & $\begin{array}{c}0,98 \\
\pm 0,04\end{array}$ & $\begin{array}{c}1,08 \\
\pm 0,06\end{array}$ & $\begin{array}{c}1,29 \\
\pm 0,02\end{array}$ & $\begin{array}{c}1,00 \\
\pm 0,04\end{array}$ & $\begin{array}{c}1,09 \\
\pm 0,04\end{array}$ \\
\hline & $0 \stackrel{1}{1}$ & $\begin{array}{c}1,31 \\
\pm 0,01\end{array}$ & $\begin{array}{c}1,21 \\
\pm 0,04\end{array}$ & $\begin{array}{c}1,25 \\
\pm 0,05\end{array}$ & $\begin{array}{c}1,70 \\
\pm 0,04\end{array}$ & $\begin{array}{c}1,93 \\
\pm 0,03\end{array}$ & $\begin{array}{c}1,05 \\
\pm 0,03\end{array}$ & $\begin{array}{c}1,27 \\
\pm 0,04\end{array}$ & $\begin{array}{c}1,14 \\
\pm 0,01\end{array}$ & $\begin{array}{c}1,18 \\
\pm 0,02\end{array}$ & $\begin{array}{c}1,39 \\
\pm 0,02\end{array}$ & $\begin{array}{c}1,25 \\
\pm 0,02\end{array}$ & $\begin{array}{c}1,26 \\
\pm 0,04\end{array}$ \\
\hline \multirow{2}{*}{ 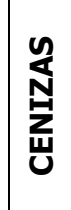 } & 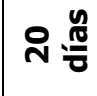 & $\begin{array}{c}2,99 \\
\pm 0,01\end{array}$ & $\begin{array}{c}3,10 \\
\pm 0,10\end{array}$ & $\begin{array}{c}2,83 \\
\pm 0,10\end{array}$ & $\begin{array}{c}2,87 \\
\pm 0,25\end{array}$ & $\begin{array}{c}2,85 \\
\pm 0,28\end{array}$ & $\begin{array}{r}2,58 \\
\pm 0,01\end{array}$ & $\begin{array}{c}3,17 \\
\pm 0,05\end{array}$ & $\begin{array}{c}3,04 \\
\pm 0,09\end{array}$ & $\begin{array}{c}2,94 \\
\pm 0,01\end{array}$ & $\begin{array}{c}3,14 \\
\pm 0,02\end{array}$ & $\begin{array}{c}2,80 \\
\pm 0,01\end{array}$ & $\begin{array}{c}2,97 \\
\pm 0,07\end{array}$ \\
\hline & 욯 & $\begin{array}{c}2,93 \\
\pm 0,06\end{array}$ & $\begin{array}{c}3,27 \\
\pm 0,27\end{array}$ & $\begin{array}{c}3,02 \\
\pm 0,01\end{array}$ & $\begin{array}{c}3,05 \\
\pm 0,06\end{array}$ & $\begin{array}{c}3,11 \\
\pm 0,08\end{array}$ & $\begin{array}{c}2,95 \\
\pm 0,01\end{array}$ & $\begin{array}{c}3,23 \\
\pm 0,49\end{array}$ & $\begin{array}{c}3,18 \\
\pm 0,04\end{array}$ & $\begin{array}{c}3,24 \\
\pm 0,32\end{array}$ & $\begin{array}{c}3,34 \\
\pm 0,12\end{array}$ & $\begin{array}{c}3,09 \\
\pm 0,12\end{array}$ & $\begin{array}{c}3,35 \\
\pm 0,30\end{array}$ \\
\hline \multirow{2}{*}{ u } & 옹 & $\begin{array}{l}53,56 \\
\pm 0,27\end{array}$ & $\begin{array}{l}54,47 \\
\pm 0,20\end{array}$ & $\begin{array}{l}55,29 \\
\pm 0,29\end{array}$ & $\begin{array}{l}56,33 \\
\pm 0,15\end{array}$ & $\begin{array}{l}51,61 \\
\pm 0,04\end{array}$ & $\begin{array}{l}53,49 \\
\pm 0,17\end{array}$ & $\begin{array}{l}56,71 \\
\pm 005\end{array}$ & $\begin{array}{l}55,05 \\
\pm 0,08\end{array}$ & $\begin{array}{l}50,95 \\
\pm 0,02\end{array}$ & $\begin{array}{l}50,77 \\
\pm 0,30\end{array}$ & $\begin{array}{l}54,20 \\
\pm 0,02\end{array}$ & $\begin{array}{l}51,96 \\
\pm 0,04\end{array}$ \\
\hline & 웅 & $\begin{array}{l}55,03 \\
\pm 0,07\end{array}$ & $\begin{array}{l}57,01 \\
\pm 0,28\end{array}$ & $\begin{array}{l}55,90 \\
\pm 0,07\end{array}$ & $\begin{array}{l}58,51 \\
\pm 0,05\end{array}$ & $\begin{array}{l}55,77 \\
\pm 0,06\end{array}$ & $\begin{array}{l}55,45 \\
\pm 0,08\end{array}$ & $\begin{array}{l}57,77 \\
\pm 0,06\end{array}$ & $\begin{array}{l}58,51 \\
\pm 0,05\end{array}$ & $\begin{array}{l}55,05 \\
\pm 0,34\end{array}$ & $\begin{array}{l}53,06 \\
\pm 0,18\end{array}$ & $\begin{array}{l}55,38 \\
\pm 0,19\end{array}$ & $\begin{array}{r}54,62 \\
\pm 0,17\end{array}$ \\
\hline \multirow{2}{*}{$\frac{T}{2}$} & 융 & $\begin{array}{r}4,96 \\
\pm 0,01\end{array}$ & $\begin{array}{c}4,98 \\
\pm 0,02\end{array}$ & $\begin{array}{c}5,22 \\
\pm 0,04\end{array}$ & $\begin{array}{r}4,94 \\
\pm 0,02\end{array}$ & $\begin{array}{c}4,90 \\
\pm 0,02\end{array}$ & $\begin{array}{r}4,98 \\
\pm 0,02\end{array}$ & $\begin{array}{c}5,11 \\
\pm 0,04\end{array}$ & $\begin{array}{c}5,05 \\
\pm 0,01\end{array}$ & $\begin{array}{c}4,95 \\
\pm 0,02\end{array}$ & $\begin{array}{c}4,79 \\
\pm 0,03\end{array}$ & $\begin{array}{c}5,09 \\
\pm 0,02\end{array}$ & $\begin{array}{c}5,12 \\
\pm 0,03\end{array}$ \\
\hline & 우 $\frac{y}{\mathrm{I}}$ & $\begin{array}{c}4,99 \\
\pm 0,02\end{array}$ & $\begin{array}{c}5,18 \\
\pm 0,02\end{array}$ & $\begin{array}{c}5,32 \\
\pm 0,02\end{array}$ & $\begin{array}{c}5,11 \\
\pm 0,03\end{array}$ & $\begin{array}{c}5,02 \\
\pm 0,03\end{array}$ & $\begin{array}{c}4,98 \\
\pm 0,03\end{array}$ & $\begin{array}{c}5,12 \\
\pm 0,03\end{array}$ & $\begin{array}{c}5,06 \\
\pm 0,03\end{array}$ & $\begin{array}{c}4,98 \\
\pm 0,03\end{array}$ & $\begin{array}{c}5,06 \\
\pm 0,03\end{array}$ & $\begin{array}{c}5,11 \\
\pm 0,01\end{array}$ & $\begin{array}{c}5,12 \\
\pm 0,03\end{array}$ \\
\hline
\end{tabular}


Tabla A.10. Composición química y pH de los quesos a los 20 días. Diseño Factorial

\begin{tabular}{|c|c|c|c|c|c|c|}
\hline$\%$ & Grasa & Proteína & Cenizas & ES & Sal & pH \\
\hline \multirow{2}{*}{ DF1 } & 26,50 & 18,20 & 3,36 & 50,94 & 1,53 & 4,70 \\
\hline & $\pm 0,00$ & $\pm 0,03$ & $\pm 0,02$ & $\pm 0,23$ & $\pm 0,01$ & $\pm 0,01$ \\
\hline \multirow{2}{*}{ DF2 } & 24,25 & 17,24 & 3,01 & 47,64 & 1,31 & 4,70 \\
\hline & $\pm 0,50$ & $\pm 0,11$ & $\pm 0,08$ & $\pm 0,37$ & $\pm 0,01$ & $\pm 0,01$ \\
\hline \multirow{2}{*}{ DF3 } & 24,25 & 16,78 & 3,27 & 47,54 & 1,70 & 4,73 \\
\hline & $\pm 0,50$ & $\pm 0,01$ & $\pm 0,21$ & $\pm 0,16$ & $\pm 0,04$ & $\pm 0,01$ \\
\hline \multirow{2}{*}{ DF4 } & 26,75 & 18,97 & 3,62 & 52,11 & 1,43 & 4,74 \\
\hline & $\pm 0,50$ & $\pm 1,01$ & $\pm 0,20$ & $\pm 0,18$ & $\pm 0,04$ & v0,01 \\
\hline \multirow{2}{*}{ DF5 } & 23,25 & 18,38 & 2,95 & 48,13 & 1,27 & 4,77 \\
\hline & $\pm 0,50$ & $\pm 0,15$ & $\pm 0,06$ & $\pm 0,25$ & $\pm 0,01$ & $\pm 0,01$ \\
\hline \multirow{2}{*}{ DF6 } & 26,25 & 19,57 & 3,36 & 52,50 & 1,29 & 5,02 \\
\hline & $\pm 0,50$ & $\pm 0,24$ & $\pm 0,09$ & $\pm 0,20$ & $\pm 0,00$ & $\pm 0,01$ \\
\hline \multirow{2}{*}{ DF7 } & 23,00 & 18,13 & 3,15 & 48,33 & 1,36 & 4,80 \\
\hline & $\pm 0,00$ & $\pm 0,07$ & $\pm 0,11$ & $\pm 0,68$ & $\pm 0,03$ & $\pm 0,01$ \\
\hline \multirow{2}{*}{ DF8 } & 25,25 & 19,09 & 3,14 & 49,80 & 1,46 & 4,90 \\
\hline & $\pm 0,50$ & $\pm 0,19$ & $\pm 0,21$ & $\pm 0,13$ & $\pm 0,01$ & $\pm 0,01$ \\
\hline \multirow{2}{*}{ DF9 } & 25,25 & 19,13 & 3,11 & 50,52 & 1,31 & 4,90 \\
\hline & $\pm 0,50$ & $\pm 0,26$ & $\pm 0,06$ & $\pm 0,22$ & $\pm 0,02$ & $\pm 0,01$ \\
\hline \multirow{2}{*}{ DF10 } & 22,25 & 17,69 & 3,11 & 47,18 & 1,33 & 4,76 \\
\hline & $\pm 0,50$ & $\pm 0,11$ & $\pm 0,08$ & $\pm 0,02$ & $\pm 0,01$ & $\pm 0,01$ \\
\hline \multirow{2}{*}{ DF11 } & 23,00 & 17,61 & 2,81 & 47,07 & 1,32 & 4,75 \\
\hline & $\pm 0,00$ & $\pm 0,02$ & $\pm 0,03$ & $\pm 0,77$ & $\pm 0,01$ & $\pm 0,01$ \\
\hline \multirow{2}{*}{ DF12 } & 22,75 & 17,97 & 3,09 & 47,67 & 1,36 & 4,81 \\
\hline & $\pm 0,50$ & $\pm 0,02$ & $\pm 0,04$ & $\pm 0,23$ & $\pm 0,02$ & $\pm 0,01$ \\
\hline \multirow{2}{*}{ DF13 } & 24,00 & 18,69 & 3,58 & 49,42 & 1,36 & 4,70 \\
\hline & $\pm 0,00$ & $\pm 0,10$ & $\pm 0,06$ & $\pm 0,10$ & $\pm 0,01$ & $\pm 0,01$ \\
\hline \multirow{2}{*}{ DF14 } & 26,50 & 19,56 & 3,48 & 53,01 & 1,36 & 4,81 \\
\hline & $\pm 0,00$ & $\pm 0,77$ & $\pm 0,02$ & $\pm 0,28$ & $\pm 0,01$ & $\pm 0,01$ \\
\hline \multirow{2}{*}{ DF15 } & 23,00 & 17,96 & 3,26 & 47,04 & 1,41 & 4,89 \\
\hline & $\pm 0,00$ & $\pm 0,29$ & $\pm 0,12$ & $\pm 0,04$ & $\pm 0,02$ & $\pm 0,01$ \\
\hline \multirow{2}{*}{ DF16 } & 23,00 & 17,96 & 3,26 & 47,04 & 1,41 & 4,89 \\
\hline & $\pm 0,00$ & $\pm 0,09$ & $\pm 0,22$ & $\pm 0,44$ & & $\pm 0,01$ \\
\hline
\end{tabular}


Tabla A.11. Composición química y pH de los quesos a los 40 días. Diseño Factorial

\begin{tabular}{|c|c|c|c|c|c|c|}
\hline$\%$ & Grasa & Proteína & Cenizas & ES & Sal & pH \\
\hline \multirow{2}{*}{ DF1 } & 29,00 & 20,05 & 3,99 & 56,72 & 1,91 & 4,90 \\
\hline & $\pm 0,50$ & $\pm 0,17$ & $\pm 0,05$ & $\pm 0,03$ & $\pm 0,05$ & $\pm 0,01$ \\
\hline \multirow{2}{*}{ DF2 } & 27,25 & 19,35 & 3,94 & 54,52 & 1,76 & 4,90 \\
\hline & $\pm 0,50$ & $\pm 0,01$ & $\pm 0,13$ & $\pm 0,69$ & $\pm 0,13$ & $\pm 0,01$ \\
\hline \multirow{2}{*}{ DF3 } & 26,00 & 18,39 & 3,83 & 52,33 & 1,92 & 4,95 \\
\hline & $\pm 0,50$ & $\pm 0,27$ & $\pm 0,02$ & $\pm 0,07$ & $\pm 0,02$ & $\pm 0,01$ \\
\hline \multirow{2}{*}{ DF4 } & 30,25 & 20,76 & 3,75 & 56,10 & 1,86 & 5,13 \\
\hline & $\pm 0,50$ & $\pm 0,37$ & $\pm 0,10$ & $\pm 0,95$ & $\pm 0,10$ & $\pm 0,01$ \\
\hline \multirow{2}{*}{ DF5 } & 25,75 & 19,81 & 3,76 & 53,69 & 1,61 & 4,98 \\
\hline & $\pm 0,50$ & $\pm 0,27$ & $\pm 0,15$ & $\pm 0,51$ & $\pm 0,15$ & $\pm 0,01$ \\
\hline \multirow{2}{*}{ DF6 } & 27,75 & 20,97 & 3,70 & 55,86 & 1,46 & 5,09 \\
\hline & $\pm 0,50$ & $\pm 0,07$ & $\pm 0,01$ & $\pm 0,03$ & $\pm 0,01$ & $\pm 0,01$ \\
\hline \multirow{2}{*}{ DF7 } & 29,00 & 19,71 & 3,40 & 53,32 & 1,53 & 4,98 \\
\hline & $\pm 0,00$ & $\pm 0,25$ & $\pm 0,01$ & $\pm 0,03$ & $\pm 0,01$ & $\pm 0,01$ \\
\hline \multirow{2}{*}{ DF8 } & 29,50 & 20,34 & 3,62 & 54,67 & 1,71 & 5,16 \\
\hline & $\pm 0,50$ & $\pm 0,49$ & $\pm 0,08$ & $\pm 0,25$ & $\pm 0,08$ & $\pm 0,01$ \\
\hline \multirow{2}{*}{ DF9 } & 31,00 & 21,66 & 3,47 & 58,01 & 1,55 & 4,91 \\
\hline & $\pm 0,00$ & $\pm 0,16$ & $\pm 0,01$ & $\pm 0,11$ & $\pm 0,01$ & $\pm 0,01$ \\
\hline \multirow{2}{*}{ DF10 } & 28,00 & 20,21 & 3,44 & 54,90 & 1,51 & 4,99 \\
\hline & $\pm 0,50$ & $\pm 0,03$ & $\pm 0,05$ & $\pm 0,07$ & $\pm 0,05$ & $\pm 0,01$ \\
\hline \multirow{2}{*}{ DF11 } & 26,00 & 19,64 & 3,78 & 54,15 & 1,75 & 4,90 \\
\hline & $\pm 0,00$ & $\pm 0,11$ & $\pm 0,01$ & $\pm 0,06$ & $\pm 0,01$ & $\pm 0,01$ \\
\hline \multirow{2}{*}{ DF12 } & 28,00 & 21,05 & 3,74 & 56,68 & 1,57 & 5,02 \\
\hline & $\pm 0,49$ & $\pm 0,05$ & $\pm 0,12$ & $\pm 0,24$ & $\pm 0,12$ & $\pm 0,01$ \\
\hline \multirow{2}{*}{ DF13 } & 32,00 & 21,90 & 3,75 & 57,54 & 1,57 & 4,85 \\
\hline & $\pm 0,00$ & $\pm 0,34$ & $\pm 0,02$ & $\pm 0,48$ & $\pm 0,02$ & $\pm 0,01$ \\
\hline \multirow{2}{*}{ DF14 } & 29,00 & 20,46 & 3,88 & 55,26 & 1,72 & 5,05 \\
\hline & $\pm 0,49$ & $\pm 0,21$ & $\pm 0,05$ & $\pm 0,09$ & $\pm 0,05$ & $\pm 0,01$ \\
\hline \multirow{2}{*}{ DF15 } & 27,50 & 20,36 & 3,51 & 55,48 & 1,56 & 4,94 \\
\hline & $\pm 0,00$ & $\pm 0,10$ & $\pm 0,11$ & $\pm 0,16$ & $\pm 0,11$ & $\pm 0,01$ \\
\hline \multirow{2}{*}{ DF16 } & 29,50 & 21,22 & 3,83 & 57,37 & 1,70 & 4,97 \\
\hline & $\pm 0,00$ & $\pm 0,07$ & $\pm 0,02$ & $\pm 0,06$ & $\pm 0,02$ & $\pm 0,01$ \\
\hline
\end{tabular}


Tabla A.12. Composición química y pH de los quesos a los 20 días. Diseño Superficie Respuesta

\begin{tabular}{|c|c|c|c|c|c|c|}
\hline$\%$ & Grasa & Proteína & Cenizas & ES & Sal & pH \\
\hline SR1 & $\begin{array}{r}31,50 \\
\pm 0,00\end{array}$ & $\begin{array}{l}20,15 \\
\pm 0,02\end{array}$ & $\begin{array}{r}3,58 \\
\pm 0,02\end{array}$ & $\begin{array}{r}57,39 \\
\pm 0,39\end{array}$ & $\begin{array}{c}1,46 \\
\pm 0,02\end{array}$ & $\begin{array}{r}4,72 \\
\pm 0,01\end{array}$ \\
\hline SR2 & $\begin{array}{l}28,75 \\
\pm 0,50\end{array}$ & $\begin{array}{l}19,01 \\
\pm 0,03\end{array}$ & $\begin{array}{r}3,63 \\
\pm 0,00\end{array}$ & $\begin{array}{r}53,66 \\
\pm 0,26\end{array}$ & $\begin{array}{r}1,48 \\
\pm 0,01\end{array}$ & $\begin{array}{r}4,75 \\
\pm 0,01\end{array}$ \\
\hline SR3 & $\begin{array}{r}28,00 \\
\pm 0,00\end{array}$ & $\begin{array}{r}18,95 \\
\pm 0,28\end{array}$ & $\begin{array}{r}3,22 \\
\pm 0,04\end{array}$ & $\begin{array}{r}53,27 \\
\pm 0,63\end{array}$ & $\begin{array}{r}1,55 \\
\pm 0,01\end{array}$ & $\begin{array}{r}4,71 \\
\pm 0,01\end{array}$ \\
\hline SR4 & $\begin{array}{r}31,00 \\
\pm 0,00\end{array}$ & $\begin{array}{l}20,67 \\
\pm 0,07\end{array}$ & $\begin{array}{r}2,64 \\
\pm 0,41\end{array}$ & $\begin{array}{l}58,18 \\
\pm 0,27\end{array}$ & $\begin{array}{r}1,40 \\
\pm 0,01\end{array}$ & $\begin{array}{r}4,71 \\
\pm 0,01\end{array}$ \\
\hline SR5 & $\begin{array}{l}32,25 \\
\pm 0,50\end{array}$ & $\begin{array}{l}20,84 \\
\pm 0,02\end{array}$ & $\begin{array}{c}3,27 \\
\pm 0,02\end{array}$ & $\begin{array}{l}58,28 \\
\pm 0,06\end{array}$ & $\begin{array}{r}1,41 \\
\pm 0,03\end{array}$ & $\begin{array}{r}4,63 \\
\pm 0,01\end{array}$ \\
\hline SR6 & $\begin{array}{r}32,50 \\
\pm 0,99\end{array}$ & $\begin{array}{r}20,22 \\
\pm 0,31\end{array}$ & $\begin{array}{c}3,23 \\
\pm 0,07\end{array}$ & $\begin{array}{r}58,46 \\
\pm 0,37\end{array}$ & $\begin{array}{c}1,28 \\
\pm 0,02\end{array}$ & $\begin{array}{c}4,74 \\
\pm 0,01\end{array}$ \\
\hline SR7 & $\begin{array}{r}28,75 \\
\pm 0,50\end{array}$ & $\begin{array}{r}17,34 \\
\pm 0,01\end{array}$ & $\begin{array}{r}3,21 \\
\pm 0,16\end{array}$ & $\begin{array}{r}53,36 \\
\pm 0,04\end{array}$ & $\begin{array}{r}1,39 \\
\pm 0,05\end{array}$ & $\begin{array}{r}4,81 \\
\pm 0,01\end{array}$ \\
\hline SR8 & $\begin{array}{r}33,00 \\
\pm 0,00\end{array}$ & $\begin{array}{r}19,76 \\
\pm 0,07\end{array}$ & $\begin{array}{r}3,20 \\
\pm 0,02\end{array}$ & $\begin{array}{r}56,75 \\
\pm 0,00\end{array}$ & $\begin{array}{r}1,31 \\
\pm 0,01\end{array}$ & $\begin{array}{r}4,74 \\
\pm 0,01\end{array}$ \\
\hline SR9 & $\begin{array}{l}34,50 \\
\pm 0,00\end{array}$ & $\begin{array}{r}19,48 \\
\pm 0,08\end{array}$ & $\begin{array}{r}3,19 \\
\pm 0,03\end{array}$ & $\begin{array}{l}55,08 \\
\pm 0,31\end{array}$ & $\begin{array}{c}1,41 \\
\pm 0,02\end{array}$ & $\begin{array}{c}4,67 \\
\pm 0,01\end{array}$ \\
\hline SR10 & $\begin{array}{r}34,25 \\
\pm 0,50\end{array}$ & $\begin{array}{r}19,17 \\
\pm 0,16\end{array}$ & $\begin{array}{r}3,40 \\
\pm 0,00\end{array}$ & $\begin{array}{l}57,81 \\
\pm 0,02\end{array}$ & $\begin{array}{r}1,49 \\
\pm 0,01\end{array}$ & $\begin{array}{r}4,69 \\
\pm 0,01\end{array}$ \\
\hline SR11 & $\begin{array}{l}30,25 \\
\pm 0,50\end{array}$ & $\begin{array}{r}18,71 \\
\pm 0,26\end{array}$ & $\begin{array}{r}3,46 \\
\pm 0,08\end{array}$ & $\begin{array}{l}52,86 \\
\pm 0,43\end{array}$ & $\begin{array}{r}1,43 \\
\pm 0,04\end{array}$ & $\begin{array}{c}4,67 \\
\pm 0,01\end{array}$ \\
\hline SR12 & $\begin{array}{l}29,00 \\
\pm 0,00\end{array}$ & $\begin{array}{r}18,72 \\
\pm 0,05\end{array}$ & $\begin{array}{r}3,40 \\
\pm 0,26\end{array}$ & $\begin{array}{r}52,30 \\
\pm 0,27\end{array}$ & $\begin{array}{r}1,44 \\
\pm 0,05\end{array}$ & $\begin{array}{r}4,75 \\
\pm 0,01\end{array}$ \\
\hline SR13 & $\begin{array}{l}28,00 \\
\pm 0,00\end{array}$ & $\begin{array}{r}18,47 \\
\pm 0,63\end{array}$ & $\begin{array}{r}3,30 \\
\pm 0,19\end{array}$ & $\begin{array}{r}51,43 \\
\pm 0,44\end{array}$ & $\begin{array}{c}1,25 \\
\pm 0,04\end{array}$ & $\begin{array}{r}4,73 \\
\pm 0,01\end{array}$ \\
\hline SR14 & $\begin{array}{l}33,25 \\
\pm 0,50\end{array}$ & $\begin{array}{l}20,51 \\
\pm 0,52\end{array}$ & $\begin{array}{r}2,90 \\
\pm 0,32\end{array}$ & $\begin{array}{l}56,99 \\
\pm 0,03\end{array}$ & $\begin{array}{r}1,12 \\
\pm 0,04\end{array}$ & $\begin{array}{r}4,72 \\
\pm 0,01\end{array}$ \\
\hline SR15 & $\begin{array}{l}33,25 \\
\pm 0,50\end{array}$ & $\begin{array}{l}20,72 \\
\pm 0,06\end{array}$ & $\begin{array}{r}2,62 \\
\pm 0,11\end{array}$ & $\begin{array}{l}55,52 \\
\pm 0,12\end{array}$ & $\begin{array}{c}1,29 \\
\pm 0,02\end{array}$ & $\begin{array}{r}4,70 \\
\pm 0,01\end{array}$ \\
\hline SR16 & $\begin{array}{l}33,75 \\
\pm 0,50\end{array}$ & $\begin{array}{l}20,13 \\
\pm 0,20\end{array}$ & $\begin{array}{r}3,15 \\
\pm 0,22\end{array}$ & $\begin{array}{l}56,07 \\
\pm 0,27\end{array}$ & $\begin{array}{r}1,28 \\
\pm 0,01\end{array}$ & $\begin{array}{c}4,72 \\
\pm 0,01\end{array}$ \\
\hline SR17 & $\begin{array}{l}28,75 \\
\pm 0,50\end{array}$ & $\begin{array}{r}18,74 \\
\pm 0,22\end{array}$ & $\begin{array}{r}2,95 \\
\pm 0,11\end{array}$ & $\begin{array}{l}52,92 \\
\pm 0,17\end{array}$ & $\begin{array}{r}1,35 \\
\pm 0,01\end{array}$ & $\begin{array}{r}4,72 \\
\pm 0,01\end{array}$ \\
\hline SR18 & $\begin{array}{l}33,25 \\
\pm 0,50\end{array}$ & $\begin{array}{r}19,60 \\
\pm 0,38\end{array}$ & $\begin{array}{c}3,18 \\
\pm 0,05\end{array}$ & $\begin{array}{l}56,11 \\
\pm 0,04\end{array}$ & $\begin{array}{c}1,28 \\
\pm 0,01\end{array}$ & $\begin{array}{r}4,69 \\
\pm 0,01\end{array}$ \\
\hline SR19 & $\begin{array}{l}33,25 \\
\pm 0,50\end{array}$ & $\begin{array}{l}20,18 \\
\pm 0,34\end{array}$ & $\begin{array}{r}2,96 \\
\pm 0,02\end{array}$ & $\begin{array}{l}56,13 \\
\pm 0,11\end{array}$ & $\begin{array}{c}1,21 \\
\pm 0,00\end{array}$ & $\begin{array}{r}4,73 \\
\pm 0,01\end{array}$ \\
\hline SR20 & $\begin{array}{r}34,00 \\
\pm 0,00\end{array}$ & $\begin{array}{r}20,24 \\
\pm 0,33\end{array}$ & $\begin{array}{r}3,06 \\
\pm 0,06\end{array}$ & $\begin{array}{l}56,27 \\
\pm 0,14\end{array}$ & $\begin{array}{r}1,38 \\
\pm 0,05\end{array}$ & $\begin{array}{r}4,71 \\
\pm 0,01\end{array}$ \\
\hline
\end{tabular}


Tabla A.13. Composición química y pH de los quesos a los 40 días. Diseño Superficie Respuesta

\begin{tabular}{|c|c|c|c|c|c|c|}
\hline$\%$ & Grasa & Proteína & Cenizas & ES & Sal & pH \\
\hline \multirow{2}{*}{ SR1 } & 36,25 & 20,62 & 3,67 & $\pm 60,91$ & 1,70 & 4,84 \\
\hline & $\pm 0,50$ & $\pm 0,54$ & $\pm 0,00$ & $\pm 0,05$ & $\pm 0,03$ & $\pm 0,01$ \\
\hline \multirow{2}{*}{ SR2 } & 29,75 & 19,62 & 3,71 & 55,60 & 1,68 & 4,84 \\
\hline & $\pm 0,50$ & $\pm 0,29$ & $\pm 0,04$ & $\pm 0,49$ & $\pm 0,03$ & $\pm 0,01$ \\
\hline \multirow{2}{*}{ SR3 } & 32,25 & 19,67 & 3,88 & 56,01 & 1,78 & 4,81 \\
\hline & $\pm 0,50$ & $\pm 0,21$ & $\pm 0,00$ & $\pm 0,18$ & $\pm 0,00$ & $\pm 0,01$ \\
\hline \multirow{2}{*}{ SR4 } & 37,75 & 21,99 & 3,11 & 62,36 & 1,77 & 4,76 \\
\hline & $\pm 0,50$ & $\pm 0,18$ & $\pm 0,10$ & $\pm 0,20$ & $\pm 0,06$ & $\pm 0,01$ \\
\hline \multirow{2}{*}{ SR5 } & 35,75 & 21,92 & 3,62 & 62,39 & 1,61 & 4,70 \\
\hline & $\pm 0,50$ & $\pm 0,26$ & $\pm 0,91$ & $\pm 0,04$ & $\pm 0,03$ & $\pm 0,01$ \\
\hline \multirow{2}{*}{ SR6 } & 37,75 & 22,74 & 3,48 & 63,58 & 1,61 & 4,84 \\
\hline & $\pm 0,50$ & $\pm 0,20$ & $\pm 0,09$ & $\pm 0,17$ & $\pm 0,01$ & $\pm 0,01$ \\
\hline \multirow{2}{*}{ SR7 } & 34,25 & 18,63 & 3,54 & 55,09 & 1,55 & 4,92 \\
\hline & $\pm 0,50$ & $\pm 0,34$ & $\pm 0,07$ & $\pm 0,50$ & $\pm 0,01$ & $\pm 0,01$ \\
\hline \multirow{2}{*}{ SR8 } & 36,75 & 21,49 & 3,43 & 60,42 & 1,94 & 4,81 \\
\hline & $\pm 0,50$ & $\pm 0,10$ & $\pm 0,17$ & $\pm 0,05$ & $\pm 0,05$ & $\pm 0,01$ \\
\hline \multirow{2}{*}{ SR9 } & 37,25 & 20,04 & 3,55 & 59,78 & 1,61 & 4,72 \\
\hline & $\pm 0,50$ & $\pm 0,40$ & $\pm 0,08$ & $\pm 0,11$ & $\pm 0,05$ & $\pm 0,01$ \\
\hline \multirow{2}{*}{ SR10 } & 38,75 & 20,63 & 3,58 & 63,71 & 1,70 & 4,73 \\
\hline & $\pm 0,50$ & $\pm 0,36$ & $\pm 0,01$ & $\pm 0,13$ & $\pm 0,04$ & $\pm 0,01$ \\
\hline \multirow{2}{*}{ SR11 } & 34,00 & 20,33 & 3,60 & 57,17 & 1,56 & 4,88 \\
\hline & $\pm 0,00$ & $\pm 0,35$ & $\pm 0,10$ & $\pm 0,24$ & $\pm 0,01$ & $\pm 0,01$ \\
\hline \multirow{2}{*}{ SR12 } & 33,75 & 20,01 & 3,59 & 55,98 & 1,49 & 4,82 \\
\hline & $\pm 0,50$ & $\pm 0,00$ & $\pm 0,05$ & $\pm 0,04$ & $\pm 0,01$ & $\pm 0,01$ \\
\hline \multirow{2}{*}{ SR13 } & 30,00 & 19,29 & 3,36 & 53,47 & 1,48 & 4,81 \\
\hline & $\pm 0,00$ & $\pm 0,21$ & $\pm 0,08$ & $\pm 0,40$ & $\pm 0,04$ & $\pm 0,01$ \\
\hline \multirow{2}{*}{ SR14 } & 37,75 & 22,53 & 3,26 & 63,60 & 1,42 & 4,78 \\
\hline & $\pm 0,50$ & $\pm 0,25$ & $\pm 0,20$ & $\pm 0,12$ & $\pm 0,05$ & $\pm 0,01$ \\
\hline \multirow{2}{*}{ SR15 } & 36,75 & 22,03 & 2,98 & 62,24 & 1,40 & 4,73 \\
\hline & $\pm 0,50$ & $\pm 0,00$ & $\pm 0,05$ & $\pm 0,13$ & $\pm 0,01$ & $\pm 0,01$ \\
\hline \multirow{2}{*}{ SR16 } & 37,75 & 22,05 & 3,46 & 61,77 & 1,92 & 4,79 \\
\hline & $\pm 0,50$ & $\pm 0,18$ & $\pm 0,06$ & $\pm 0,24$ & $\pm 0,03$ & $\pm 0,01$ \\
\hline \multirow{2}{*}{ SR17 } & 30,25 & 19,50 & 3,34 & 53,51 & 1,52 & 4,87 \\
\hline & $\pm 0,50$ & $\pm 0,32$ & $\pm 0,03$ & $\pm 0,90$ & $\pm 0,04$ & $\pm 0,01$ \\
\hline \multirow{2}{*}{ SR18 } & 37,75 & 20,17 & 3,57 & 61,05 & 1,67 & 4,80 \\
\hline & $\pm 0,50$ & $\pm 0,11$ & $\pm 0,07$ & $\pm 0,52$ & $\pm 0,02$ & $\pm 0,01$ \\
\hline \multirow{2}{*}{ SR19 } & 37,25 & 21,82 & 3,33 & 61,22 & 1,59 & 4,81 \\
\hline & $\pm 0,50$ & $\pm 0,24$ & $\pm 0,01$ & $\pm 0,25$ & $\pm 0,02$ & $\pm 0,01$ \\
\hline \multirow{2}{*}{ SR20 } & 38,00 & 22,29 & 3,22 & 62,28 & 1,62 & 4,77 \\
\hline & $\pm 0,00$ & $\pm 0,27$ & $\pm 0,10$ & $\pm 0,04$ & $\pm 0,05$ & $\pm 0,01$ \\
\hline
\end{tabular}


Tabla A.14. Composición química y pH de los quesos a los 0 días. Comparación tecnológica

\begin{tabular}{|c|c|c|c|c|c|c|}
\hline \% & Grasa & Proteína & Cenizas & ES & Sal & pH \\
\hline \multirow{2}{*}{ M } & $26,17^{\mathrm{b}}$ & $20,15^{\mathrm{b}}$ & $2,44^{\mathrm{c}}$ & $52,64^{\mathrm{b}}$ & $0,58^{\mathrm{ab}}$ & $5,13^{\mathrm{a}}$ \\
& $\pm 0,44$ & $\pm 3,10$ & $\pm 0,21$ & $\pm 1,40$ & $\pm 0,25$ & $\pm 0,12$ \\
\hline \multirow{2}{*}{ OPB } & $23,08^{\mathrm{a}}$ & $19,19^{\mathrm{b}}$ & $2,09^{\mathrm{b}}$ & $45,75^{\mathrm{a}}$ & $0,83^{\mathrm{b}}$ & $5,46^{\mathrm{c}}$ \\
& $\pm 0,59$ & $\pm 0,27$ & $\pm 0,09$ & $\pm 0,19$ & $\pm 0,10$ & $\pm 0,16$ \\
\hline \multirow{2}{*}{ ODF } & $21,00^{\mathrm{a}}$ & $17,88^{\mathrm{a}}$ & $1,70^{\mathrm{a}}$ & $43,60^{\mathrm{a}}$ & $0,54^{\mathrm{a}}$ & $5,21^{\mathrm{b}}$ \\
& $\pm 1,70$ & $\pm 0,39$ & $\pm 0,10$ & $\pm 1,47$ & $\pm 0,08$ & $\pm 0,06$ \\
\hline \multirow{2}{*}{ OSR } & $22,33^{\mathrm{a}}$ & $18,18^{\mathrm{a}}$ & $2,25^{\mathrm{b}}$ & $43,67^{\mathrm{a}}$ & $0,69^{\mathrm{ab}}$ & $5,07^{\mathrm{ab}}$ \\
& $\pm 1,03$ & $\pm 0,19$ & $\pm 0,16$ & $\pm 0,72$ & $\pm 0,11$ & $\pm 0,01$ \\
\hline
\end{tabular}

${ }^{*}$ Valores con la misma letra en la misma columna no son significativamente diferentes $(p<0,05)$

Tabla A.15. Composición química y pH de los quesos a los 20 días. Comparación tecnológica

\begin{tabular}{|c|c|c|c|c|c|c|}
\hline \% & Grasa & Proteína & Cenizas & ES & Sal & pH \\
\hline \multirow{2}{*}{ M } & $28,08^{\mathrm{a}}$ & $21,17^{\mathrm{a}}$ & $3,08^{\mathrm{a}}$ & $55,39^{\mathrm{b}}$ & $1,11^{\mathrm{a}}$ & $4,85^{\mathrm{b}}$ \\
& $\pm 0,33$ & $\pm 0,63$ & $\pm 0,26$ & $\pm 1,75$ & $\pm 0,36$ & $\pm 0,04$ \\
\hline \multirow{2}{*}{ OPB } & $27,25^{\mathrm{a}}$ & $22,23^{\mathrm{a}}$ & $3,11^{\mathrm{a}}$ & $54,81^{\mathrm{b}}$ & $1,21^{\mathrm{a}}$ & $5,01^{\mathrm{c}}$ \\
& $\pm 0,75$ & $\pm 0,83$ & $\pm 0,32$ & $\pm 0,68$ & $\pm 0,06$ & $\pm 0,14$ \\
\hline \multirow{2}{*}{ ODF } & $27,00^{\mathrm{a}}$ & $21,40^{\mathrm{a}}$ & $2,95^{\mathrm{a}}$ & $53,35^{\mathrm{ab}}$ & $1,12^{\mathrm{a}}$ & $4,73^{\mathrm{a}}$ \\
& $\pm 1,85$ & $\pm 0,38$ & $\pm 0,21$ & $\pm 0,47$ & $\pm 0,17$ & $\pm 0,01$ \\
\hline \multirow{2}{*}{ OSR } & $26,08^{\mathrm{a}}$ & $21,45^{\mathrm{a}}$ & $3,18^{\mathrm{a}}$ & $52,22^{\mathrm{a}}$ & $1,28^{\mathrm{a}}$ & $4,84^{\mathrm{b}}$ \\
& $\pm 0,33$ & $\pm 0,39$ & $\pm 0,16$ & $\pm 0,57$ & $\pm 0,21$ & $\pm 0,01$ \\
\hline
\end{tabular}

${ }^{*}$ Valores con la misma letra en la misma columna no son significativamente diferentes $(p<0,05)$

Tabla A.16. Composición química y pH de los quesos a los 40 días. Comparación tecnológica

\begin{tabular}{|c|c|c|c|c|c|c|}
\hline \% & Grasa & Proteína & Cenizas & ES & Sal & pH \\
\hline M & $31,33^{\mathrm{a}}$ & $22,27^{\mathrm{a}}$ & $3,20^{\mathrm{a}}$ & $57,78^{\mathrm{a}}$ & $1,21^{\mathrm{a}}$ & $4,91^{\mathrm{b}}$ \\
& $\pm 1,00$ & $\pm 1,12$ & $\pm 0,25$ & $\pm 1,06$ & $\pm 0,35$ & $\pm 0,03$ \\
\hline \multirow{2}{*}{ OPB } & $31,75^{\mathrm{a}}$ & $24,19^{\mathrm{ab}}$ & $3,53^{\mathrm{a}}$ & $57,65^{\mathrm{a}}$ & $1,36^{\mathrm{a}}$ & $5,18^{\mathrm{c}}$ \\
& $\pm 0,75$ & $\pm 0,21$ & $\pm 0,24$ & $\pm 1,33$ & $\pm 0,06$ & $\pm 0,09$ \\
\hline \multirow{2}{*}{ ODF } & $30,42^{\mathrm{a}}$ & $23,33^{\mathrm{ab}}$ & $3,39^{\mathrm{a}}$ & $57,16^{\mathrm{a}}$ & $1,34^{\mathrm{a}}$ & $4,77^{\mathrm{a}}$ \\
& $\pm 0,33$ & $\pm 0,62$ & $\pm 0,55$ & $\pm 0,67$ & $\pm 0,33$ & $\pm 0,02$ \\
\hline \multirow{2}{*}{ OSR } & $29,50^{\mathrm{a}}$ & $23,26^{\mathrm{ab}}$ & $3,69^{\mathrm{a}}$ & $55,97^{\mathrm{a}}$ & $1,41^{\mathrm{a}}$ & $4,96^{\mathrm{b}}$ \\
& $\pm 1,31$ & $\pm 0,28$ & $\pm 0,11$ & $\pm 0,97$ & $\pm 0,10$ & $\pm 0,04$ \\
\hline
\end{tabular}

${ }^{*}$ Valores con la misma letra en la misma columna no son significativamente diferentes $(p<0,05)$ 


\section{A.3. RESÚMENES DE LAS OPTIMIZACIONES PB Y DF}

Tabla A.17. Resumen optimizaciones diseño Plackett-Burmann

\begin{tabular}{|c|c|c|c|c|c|c|c|c|c|}
\hline & $A: D F$ & $\mathrm{~B}:[\mathrm{F}]$ & C:[Cuajo] & D:ES & $E: T$ & F:pH & G:Corte & $\mathrm{H}: \mathrm{P}$ \\
\hline \multicolumn{2}{|c|}{ ÓPTIMO } & - & + & + & + & - & + & + & - \\
\hline \multirow{5}{*}{ 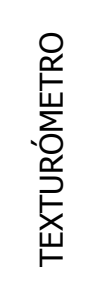 } & Firmeza & - & + & + & - & - & + & - & + \\
\hline & Elasticidad & - & + & + & + & + & - & - & - \\
\hline & Adherencia & - & + & - & - & + & - & - & - \\
\hline & Cohesividad & + & + & + & + & + & - & - & - \\
\hline & Masticabilidad & - & + & + & + & - & + & - & + \\
\hline \multirow{2}{*}{ 옹 } & Calidad & - & - & - & - & + & + & - & + \\
\hline & Intensidad & + & - & - & - & + & + & - & - \\
\hline \multirow{3}{*}{ 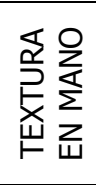 } & Rugosidad & + & + & + & + & + & + & - & + \\
\hline & Elasticidad & + & - & + & + & - & - & - & - \\
\hline & Firmeza & + & + & + & + & - & + & - & + \\
\hline \multirow{5}{*}{ 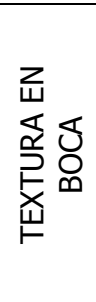 } & Friabilidad & + & + & + & + & - & + & - & + \\
\hline & Adherencia & - & - & + & + & + & - & - & - \\
\hline & Solubilidad & + & - & - & + & + & - & - & - \\
\hline & Granulosidad & - & + & - & - & - & - & - & + \\
\hline & Humedad & + & - & - & + & + & - & - & - \\
\hline \multirow{4}{*}{ 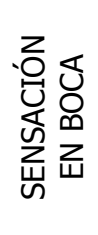 } & Intensidad & - & - & - & + & - & + & - & - \\
\hline & Calidad & - & - & + & + & + & + & + & + \\
\hline & Regusto & - & - & + & - & - & + & + & - \\
\hline & Persistencia & - & + & - & - & + & + & + & + \\
\hline \multirow{3}{*}{$\begin{array}{l}\stackrel{0}{\circ} \\
\stackrel{ }{2}\end{array}$} & Salado & - & - & - & + & + & + & + & - \\
\hline & Ácido & - & - & - & + & + & + & - & - \\
\hline & Amargo & + & + & - & - & - & + & + & - \\
\hline \multirow{3}{*}{$\begin{array}{l}\stackrel{+}{S} \\
\stackrel{5}{>}\end{array}$} & Exterior & + & + & + & - & - & + & - & + \\
\hline & Interior & + & + & + & - & - & - & - & + \\
\hline & Aberturas & + & + & + & - & - & - & - & + \\
\hline \multirow{3}{*}{$\begin{array}{l}\frac{1}{1} \\
\text { Ô. } \\
\text { J }\end{array}$} & O-G & + & + & + & + & + & + & - & + \\
\hline & VISUAL & + & + & - & + & - & - & - & + \\
\hline & COMPUESTO & + & + & - & + & - & - & - & + \\
\hline \multicolumn{2}{|c|}{ RENDIMIENTO } & - & - & + & + & - & + & + & - \\
\hline \multicolumn{2}{|c|}{ \% COINCIDENCIAS } & 40,6 & 58,6 & 55,2 & 62 & 51,7 & 58,6 & 20,7 & 48 \\
\hline \multicolumn{2}{|c|}{$\begin{array}{l}\text { \% DE COINCIDENCIAS } \\
\text { SIGNIFICATIVAS }\end{array}$} & & 100 & 100 & 100 & 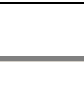 & 50 & 50 & \\
\hline
\end{tabular}

*Factores con signos en negrita resultaron significativos en la optimización del descriptor correspondiente 
Tabla A.18. Resumen optimizaciones Diseño Factorial

\begin{tabular}{|c|c|c|c|c|}
\hline & A:Fermento & B:[Fermento] & C:Corte \\
\hline \multicolumn{2}{|c|}{ ÓPTIMO } & - & - & + \\
\hline \multirow{5}{*}{ TEXTURÓMETRO } & Firmeza & - & + & - \\
\hline & Elasticidad & - & - & - \\
\hline & Adherencia & - & + & + \\
\hline & Cohesividad & - & - & - \\
\hline & Masticabilidad & - & - & - \\
\hline \multirow{2}{*}{ OLOR } & Calidad & - & + & + \\
\hline & Intensidad & $=$ & + & - \\
\hline \multirow{3}{*}{ TEXTURA EN MANO } & Rugosidad & - & - & - \\
\hline & Elasticidad & - & - & - \\
\hline & Firmeza & + & - & - \\
\hline \multirow{5}{*}{ TEXTURA EN BOCA } & Friabilidad & + & + & - \\
\hline & Adherencia & - & - & + \\
\hline & Solubilidad & - & - & + \\
\hline & Granulosidad & - & - & - \\
\hline & Humedad & + & - & + \\
\hline \multirow{4}{*}{ SENSACIÓN EN BOCA } & Intensidad & - & + & + \\
\hline & Calidad & - & + & - \\
\hline & Regusto & + & + & - \\
\hline & Persistencia & - & - & - \\
\hline \multirow{3}{*}{ GUSTO } & Salado & - & + & + \\
\hline & Ácido & + & + & - \\
\hline & Amargo & - & - & + \\
\hline \multirow{3}{*}{ VISUAL } & Exterior & - & + & - \\
\hline & Interior & - & + & + \\
\hline & Aberturas & - & - & + \\
\hline \multirow{3}{*}{ GLOBAL } & O-G & - & - & - \\
\hline & VISUAL & - & - & + \\
\hline & COMPUESTO & - & - & + \\
\hline \multicolumn{2}{|c|}{ RRENDIMIENTO } & - & - & + \\
\hline \multicolumn{2}{|c|}{ PORCENTAJE DE COINCIDENCIAS } & 79 & 62 & 41 \\
\hline \multicolumn{2}{|c|}{ \% DE COINCIDENCIAS SIGNIFICATIVAS } & 75 & 75 & 40 \\
\hline
\end{tabular}

*Factores con signos en negrita resultaron significativos en la optimización del descriptor correspondiente 


\section{A.4. FOTOGRAFÍAS QUESOS DISEÑO PLACKETT-BURMANN}
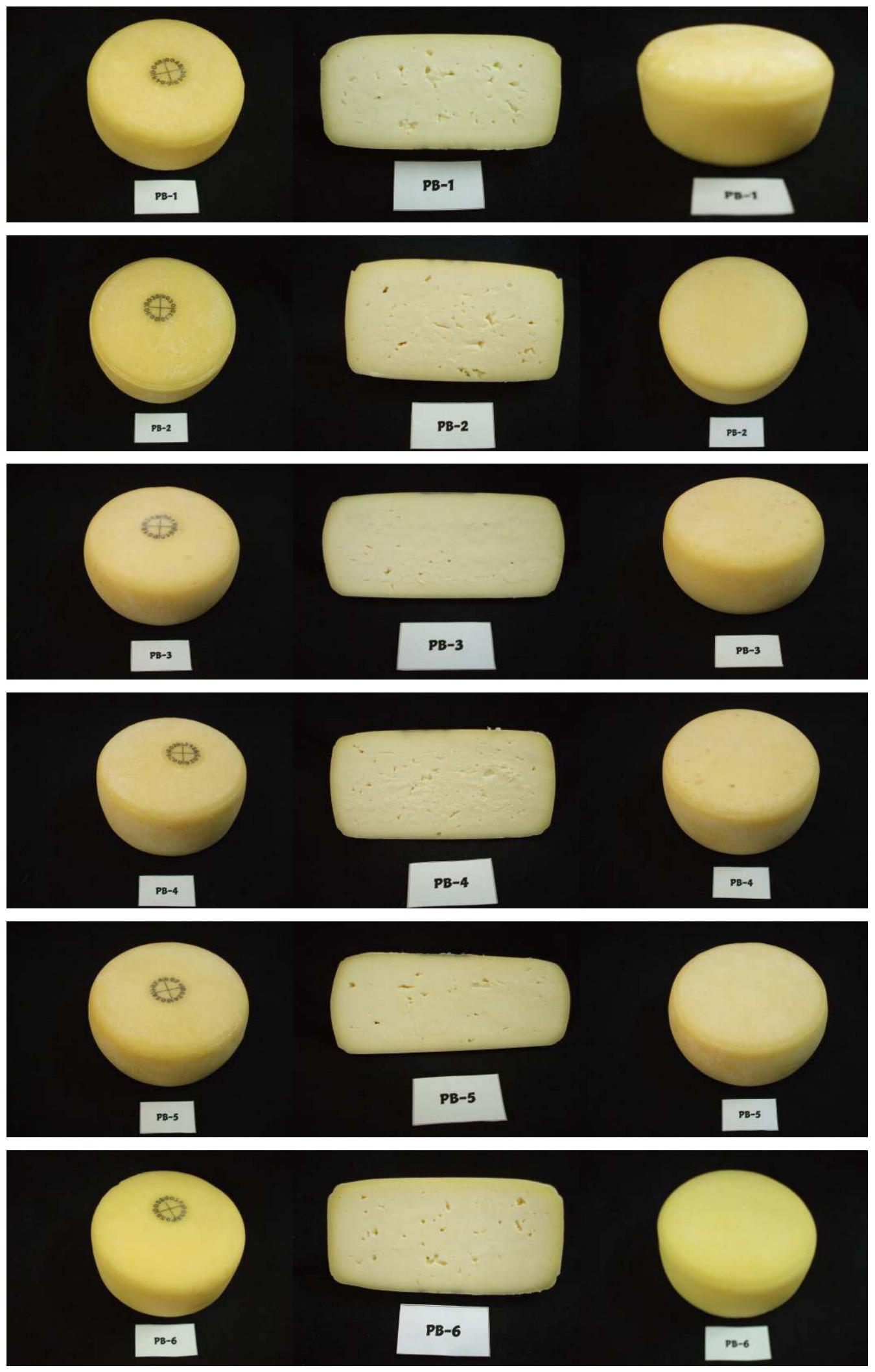

Figura A.1. Fotografías quesos PB1 a PB6 

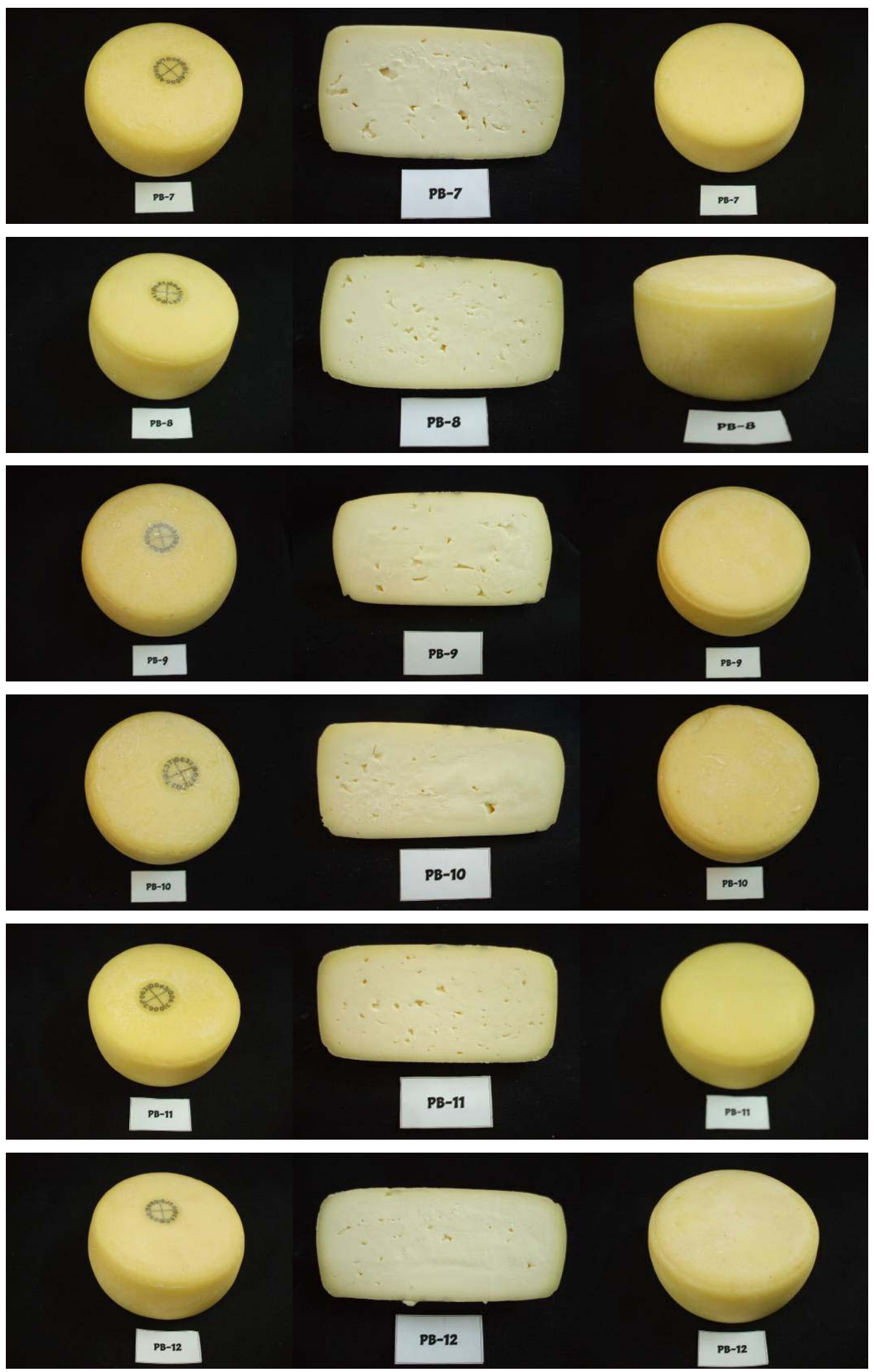

Figura A.2. Fotografías quesos PB7 a PB12 


\section{A.5. FOTOGRAFÍAS QUESOS DISEÑO FACTORIAL}
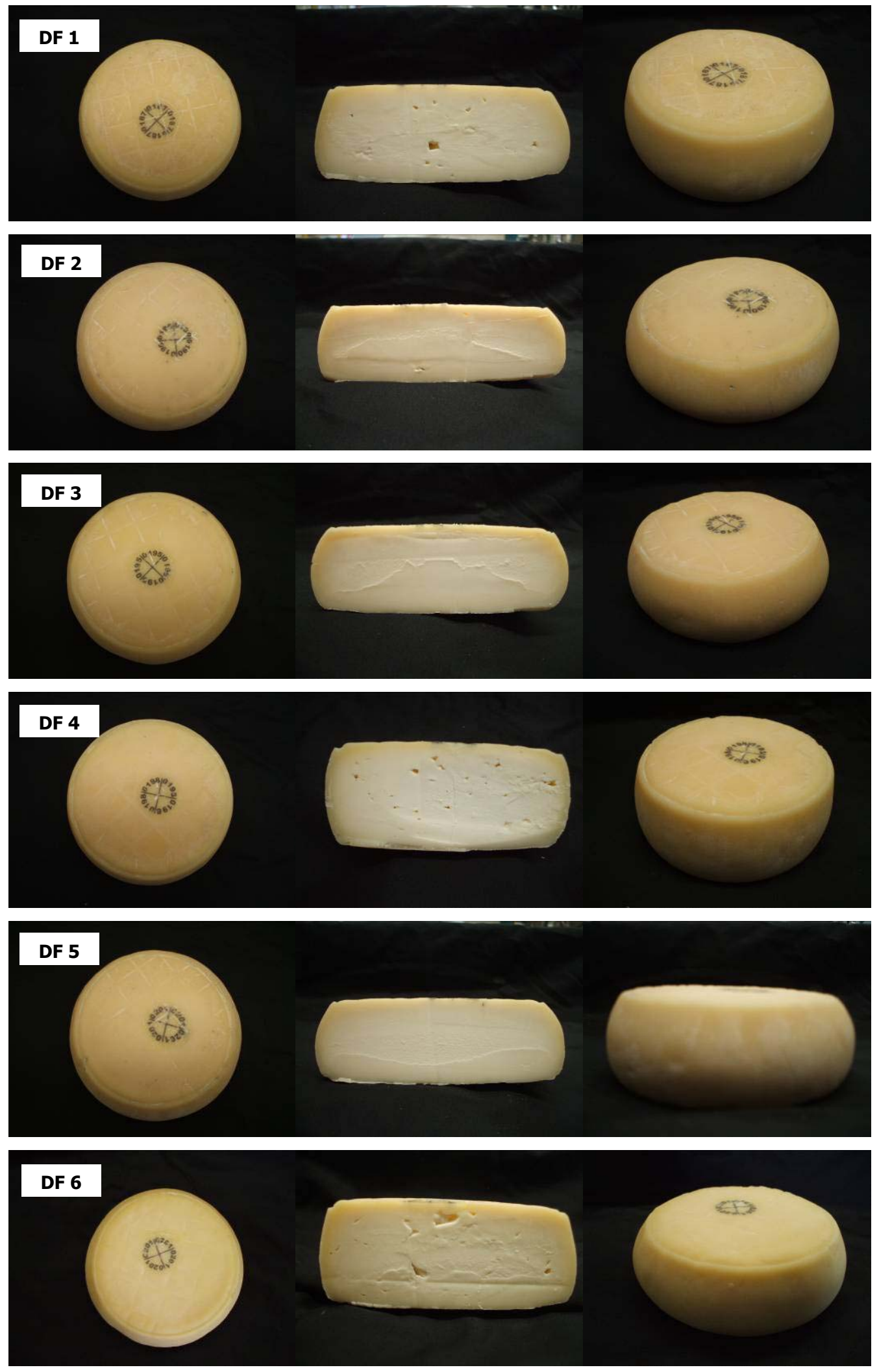

Figura A.3. Fotografías quesos DF1 a DF6 

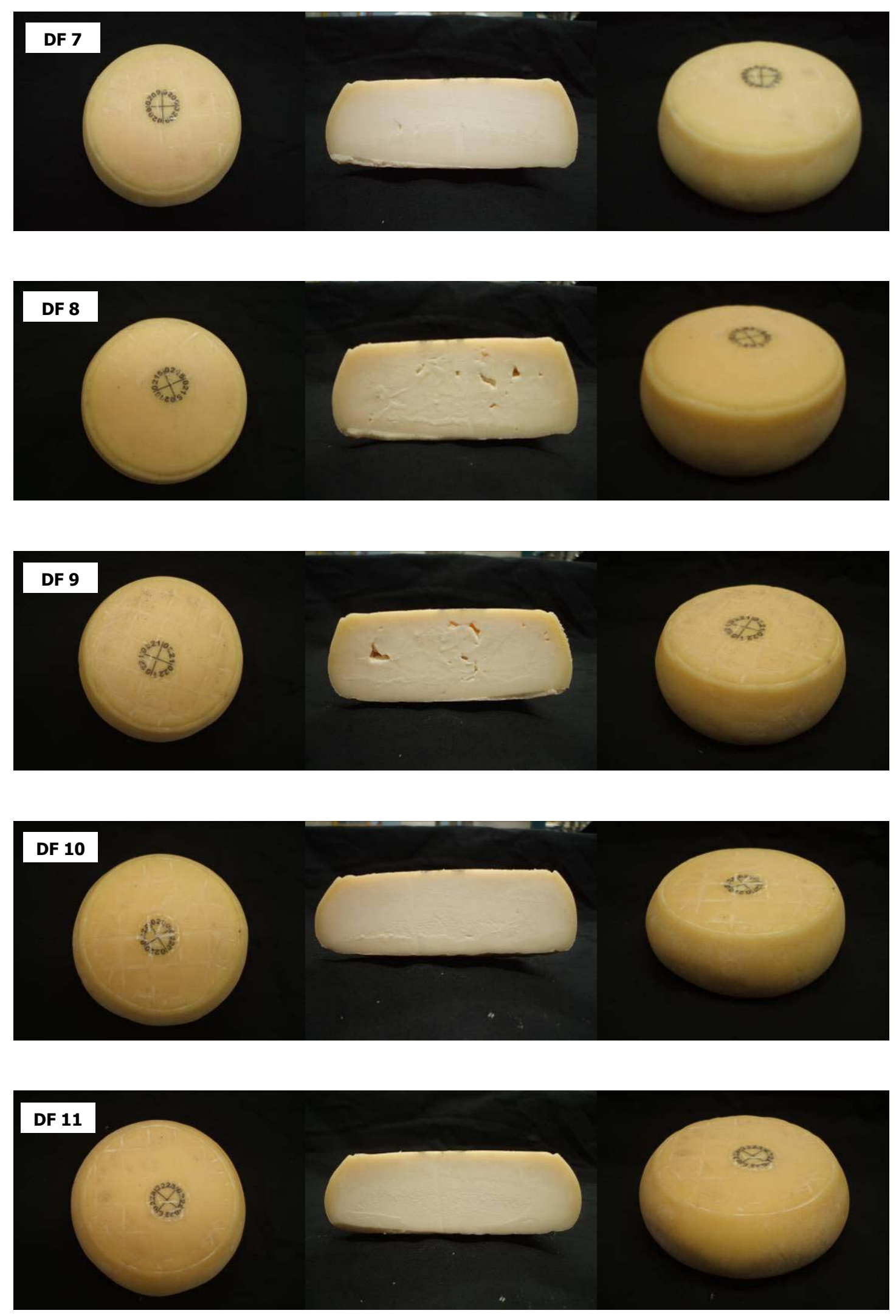

Figura A.4. Fotografías quesos DF7 a DF11 

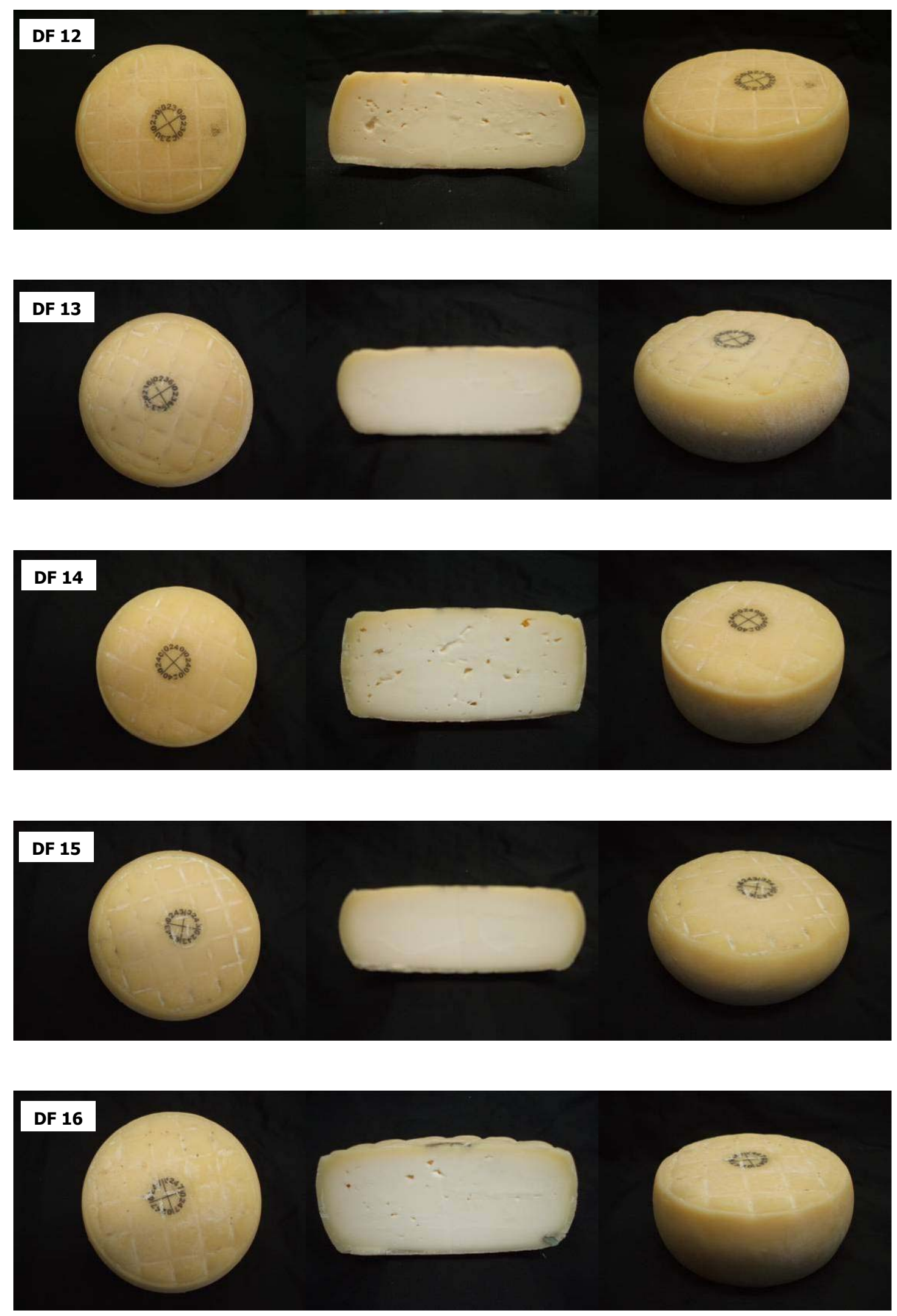

Figura A.5. Fotografías quesos DF12 a DF16 



\section{A.6. FOTOGRAFÍAS QUESOS DISEÑO SUPERFICIE RESPUESTA}
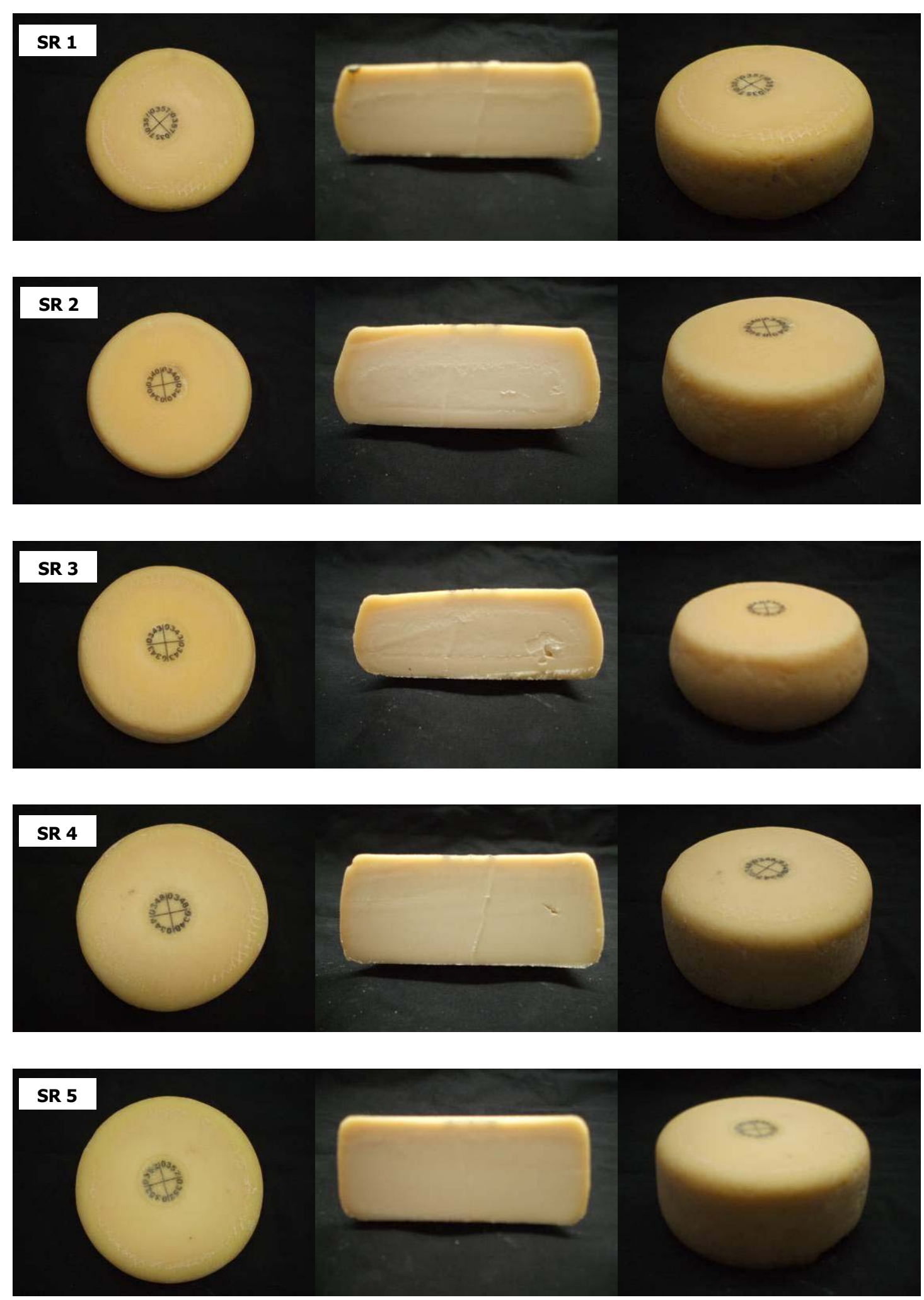

Figura A.6. Fotografías quesos SR1 a SR5 

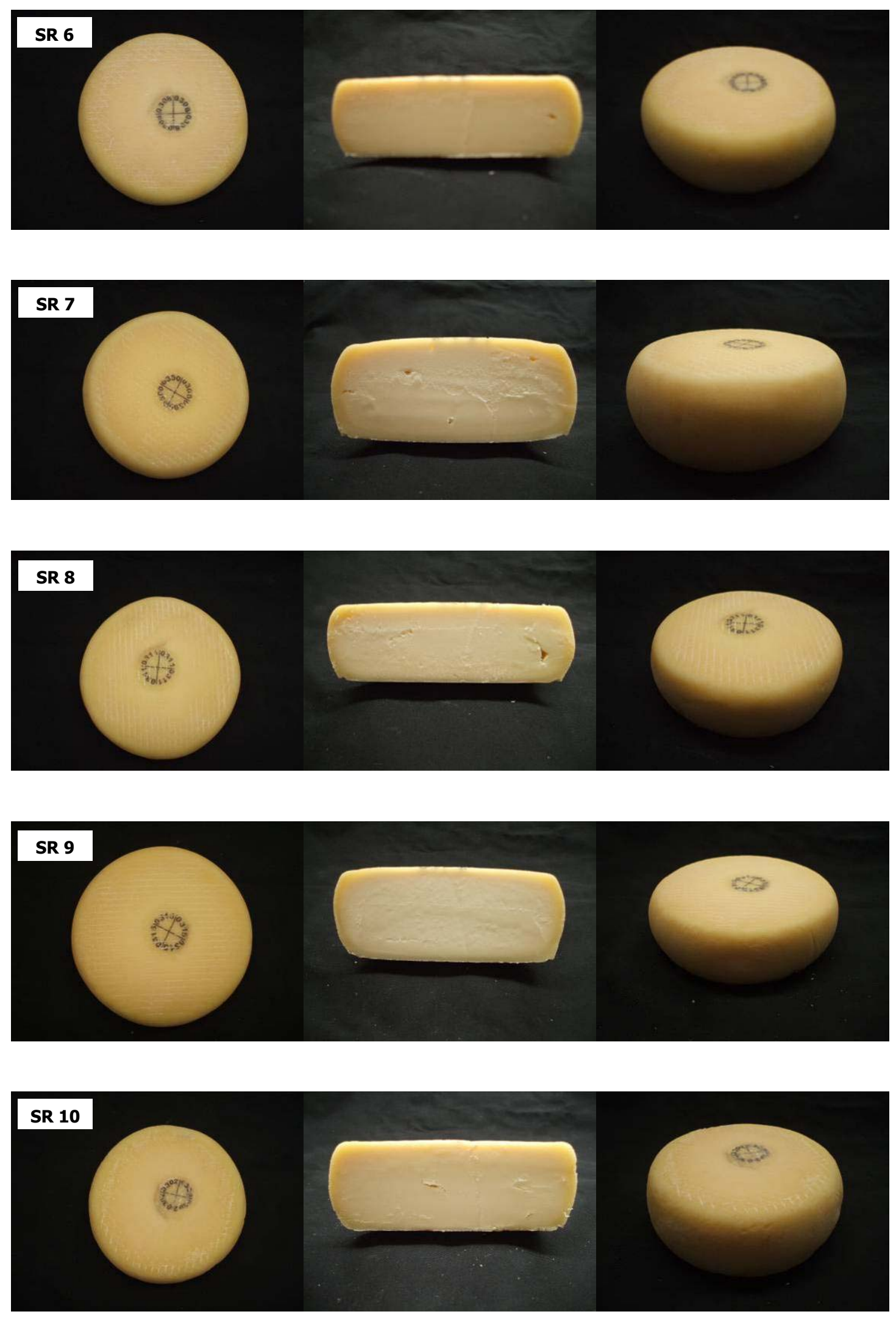

Figura A.7. Fotografías quesos SR6 a SR10 

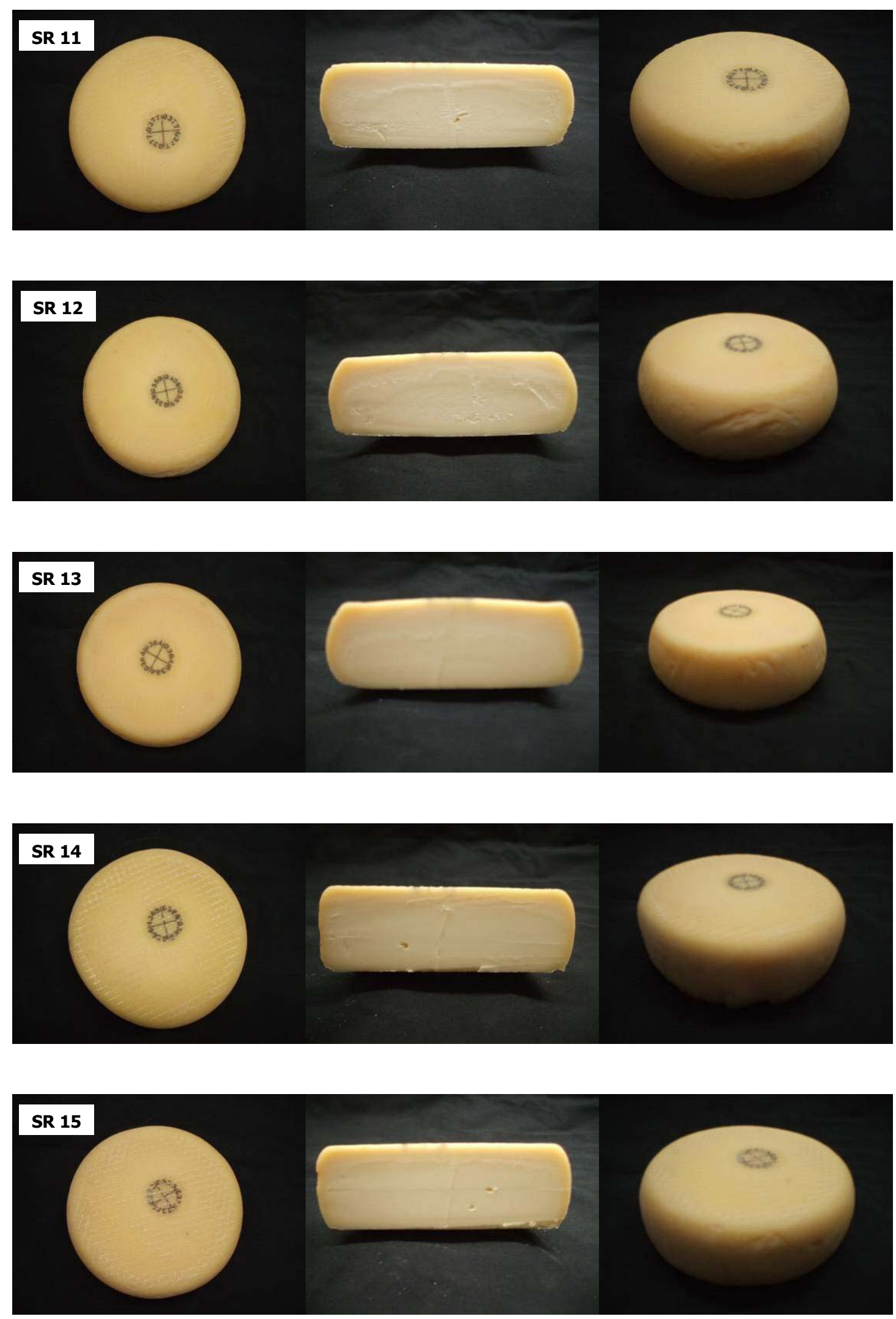

Figura A.8. Fotografías quesos SR11 a SR15 

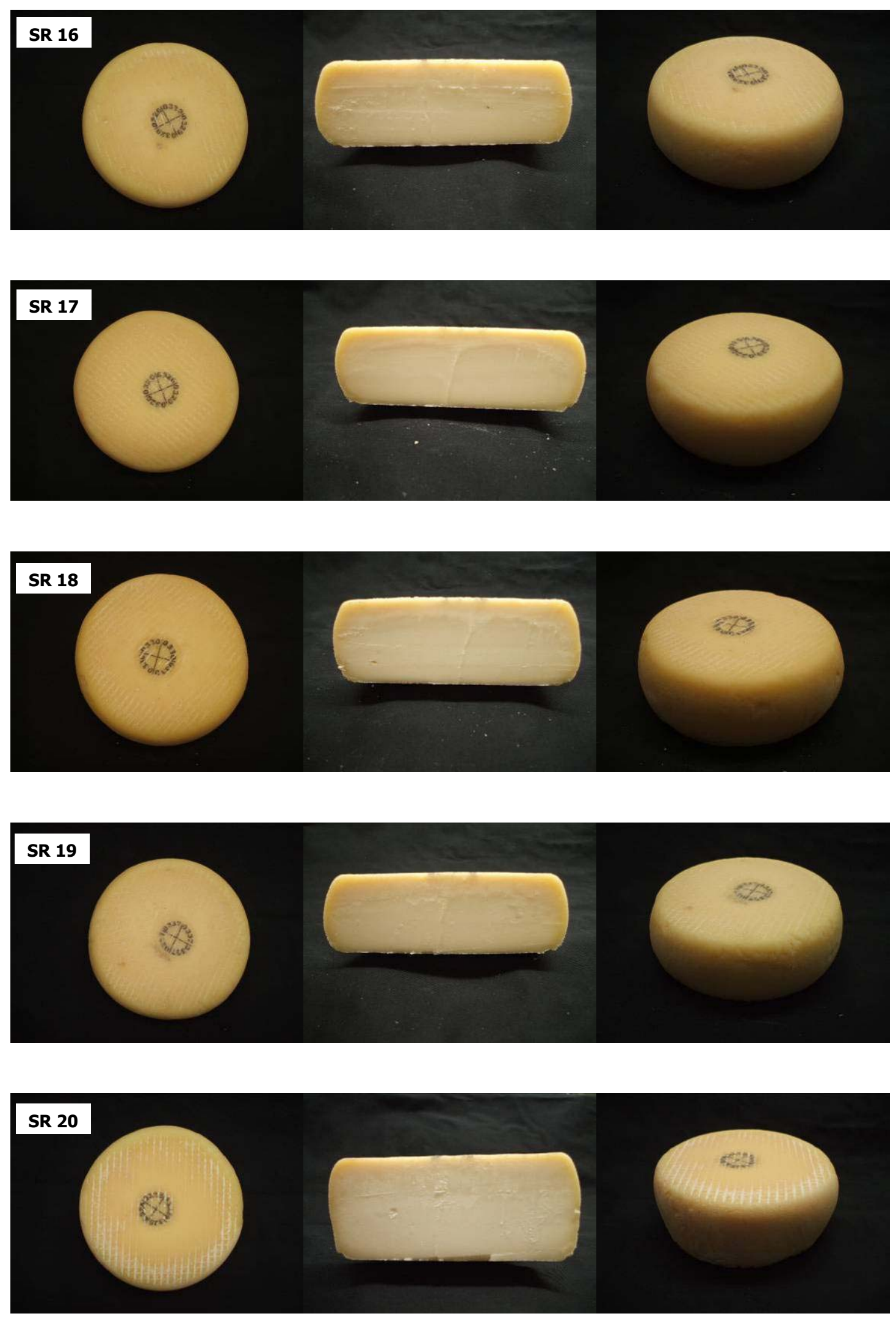

Figura A.9. Fotografías quesos SR16 a SR20 


\section{A.7. FOTOGRAFÍAS DEL QUESO TRADICIONAL Y EL ÓPTIMO FINAL}
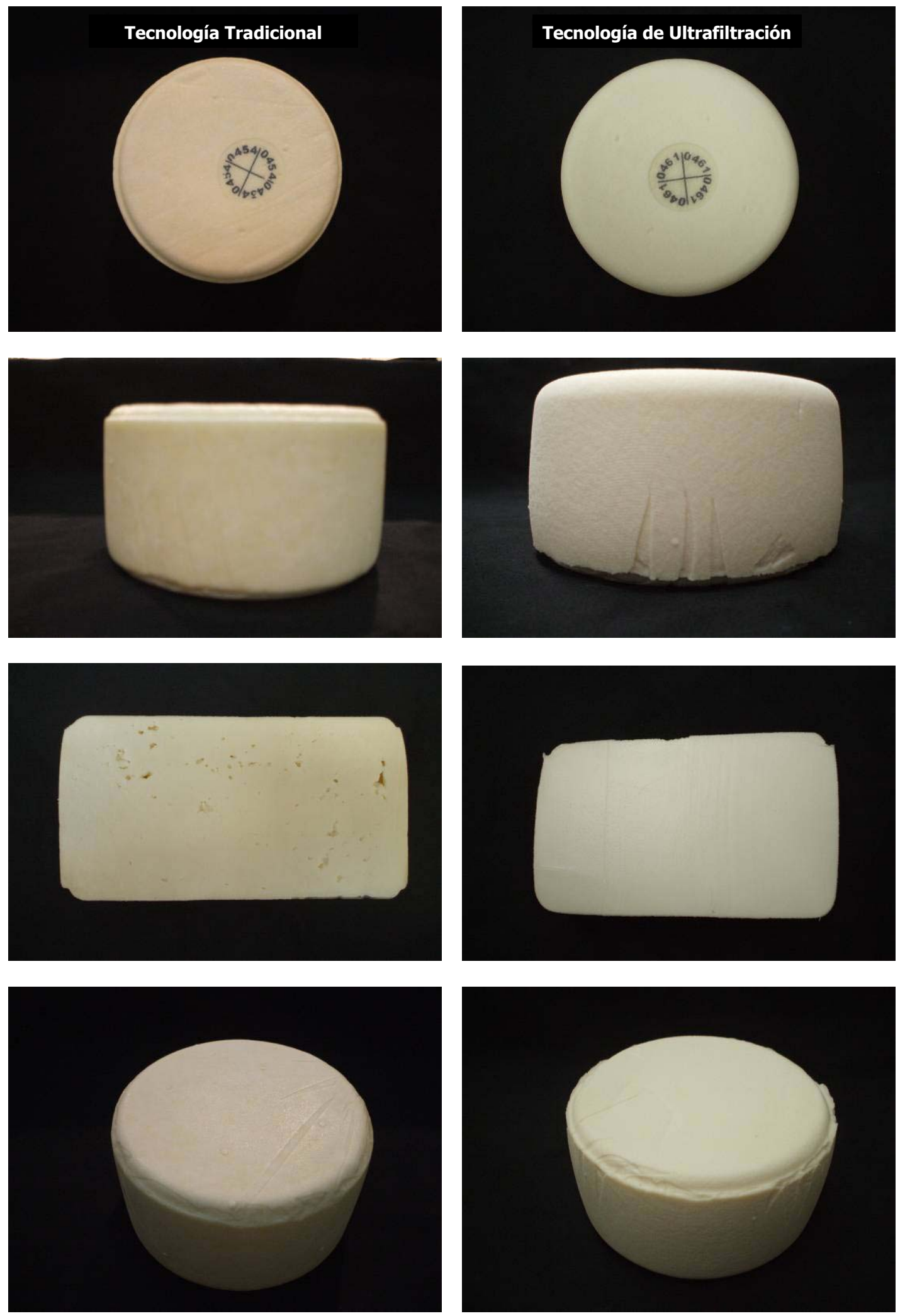

Figura A.10. Queso tradicional (izquierda) y ultrafiltrado (derecha) a los cero días de maduración 

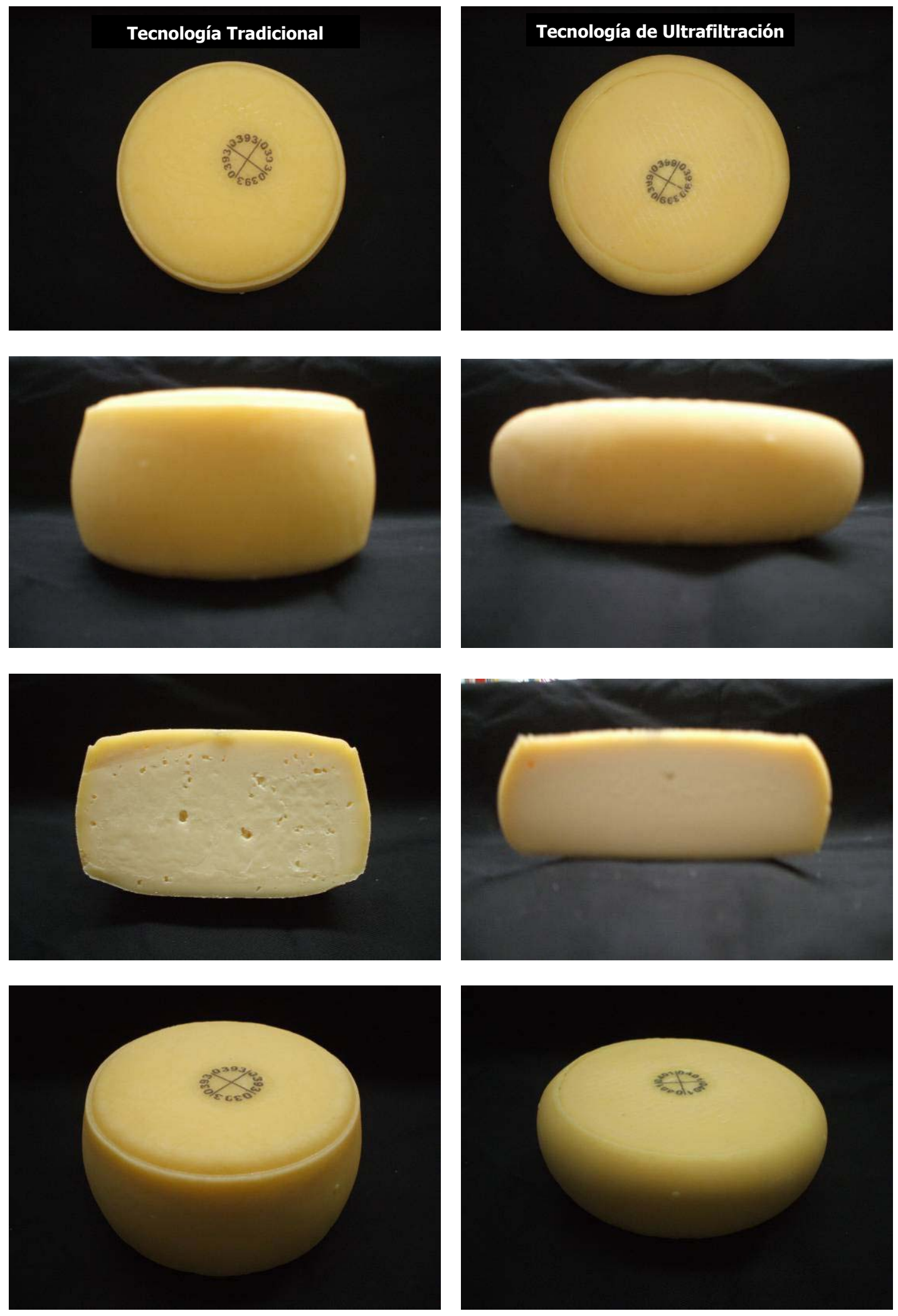

Figura A.11. Queso tradicional (izquierda) y ultrafiltrado (derecha) a los 20 días de maduración 

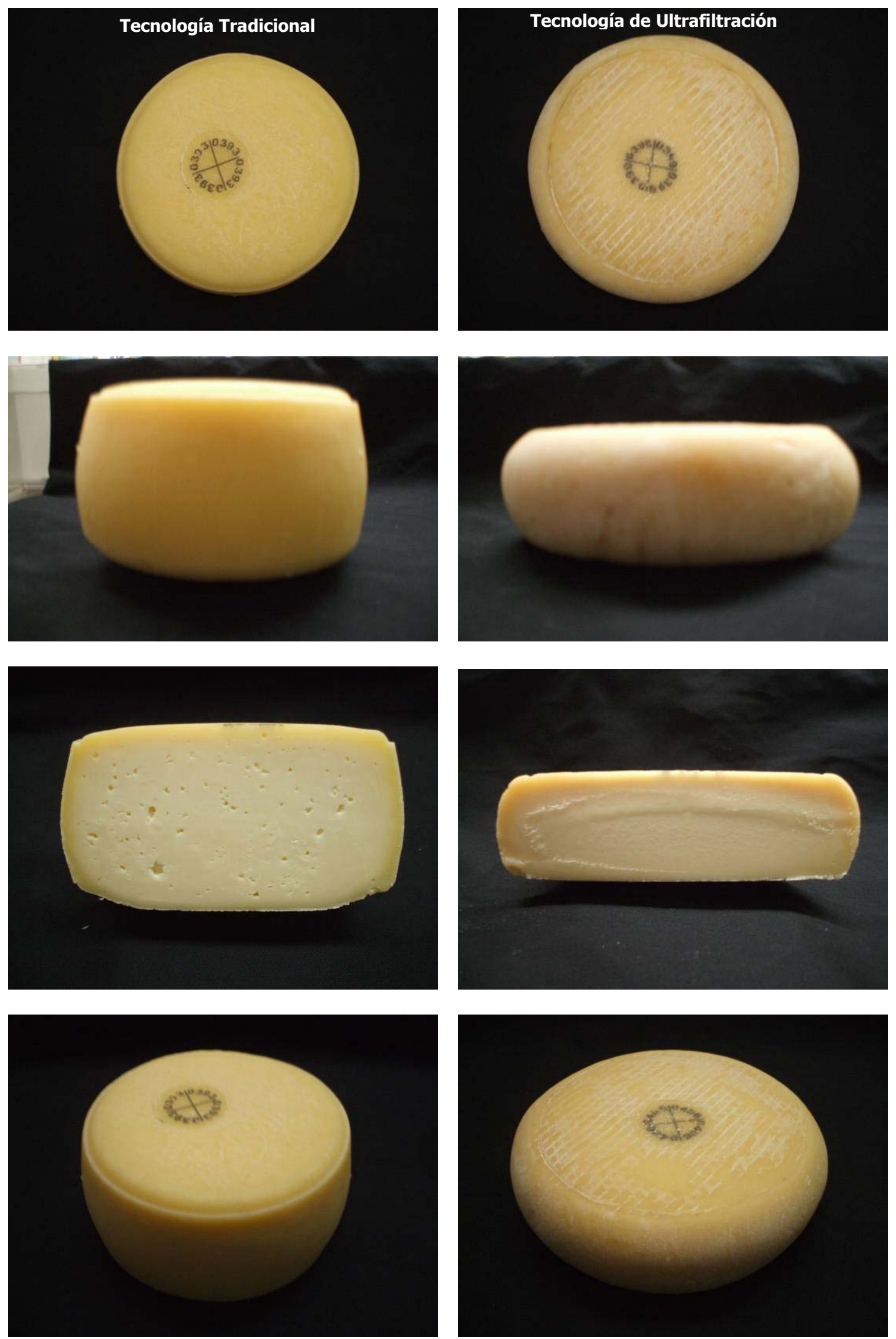

Figura A.12. Queso tradicional (izquierda) y ultrafiltrado (derecha) a los 40 días de maduración 



\section{A.8. MICROGRAFÍAS EN DETALLE DE LOS QUESOS}
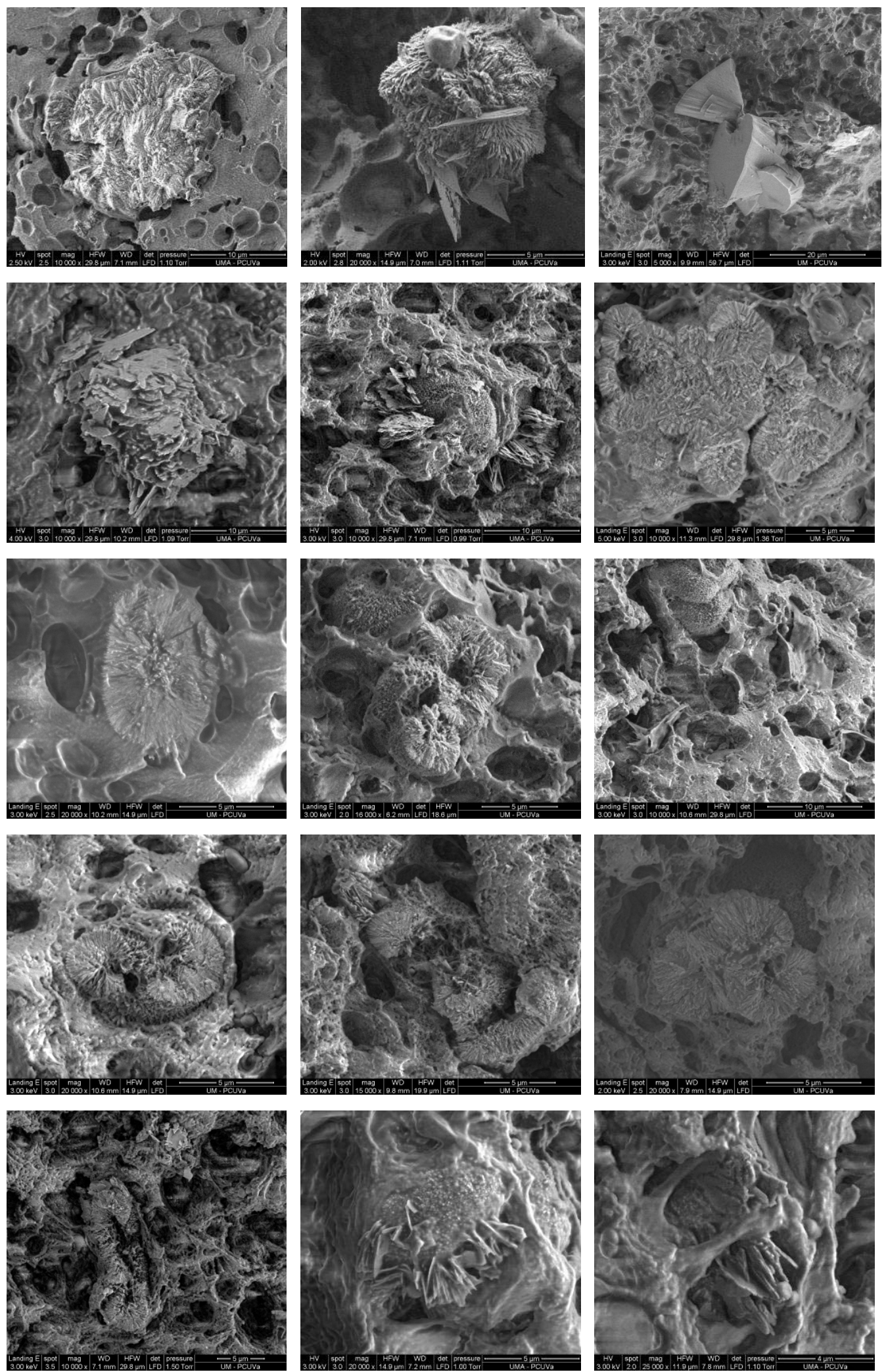

Figura A.13. Cristalizaciones encontrados en los quesos M, OPB, ODF y OSR 



\section{A.9. ANÁLISIS DE COMPONENTES PRINCIPALES}

A continuación se recogen los coeficientes que corresponden con cada una de las cinco componentes principales resultado de la combinación de los parámetros de textura instrumental y de los descriptores del análisis sensorial, en el estudio realizado en el Apartado 5.5.6.

Tabla A.19. Matriz de componentes

\begin{tabular}{|c|c|c|c|c|c|}
\hline & \multicolumn{5}{|c|}{ Componente } \\
\hline & 1 & 2 & 3 & 4 & 5 \\
\hline Firmeza (instrumental) & 70 &,- 06 &,- 58 & $\overline{111}$ & ,20 \\
\hline Cohesividad (instrumental) & ,29 &,- 76 &, 52 &,- 06 &,- 03 \\
\hline Adherencia (instrumental) &,- 81 &,- 34 &,- 01 & ,33 &,- 02 \\
\hline Elasticidad (instrumental) & ,41 &,- 81 & ,34 & ,09 & , 10 \\
\hline Masticabilidad (instrumental) &, 57 &,- 44 &, 57 & ,07 & ,25 \\
\hline Olor Intensidad & ,75 &,- 14 &,- 28 &,- 10 &,- 38 \\
\hline Olor Calidad & ,74 &,- 32 &, 16 &,- 30 &,- 16 \\
\hline Rugosidad & ,79 &,- 49 &, 06 & 09 &,- 22 \\
\hline Elasticidad &,- 24 &,- 50 &,- 58 & ,25 & ,20 \\
\hline Firmeza & ,68 &, 59 &,- 28 &,- 06 & 05 \\
\hline Friabilidad & ,45 & ,37 &,- 35 &,- 54 &,- 41 \\
\hline Adherencia &,- 50 & ,58 &,- 43 &,- 04 & ,36 \\
\hline Solubilidad &,- 22 & ,61 & ,49 &,- 14 &, 37 \\
\hline Granulosidad & ,78 & ,31 &,- 42 & ,01 &,- 14 \\
\hline Humedad &,- 83 &,- 27 & ,36 &,- 12 & ,22 \\
\hline Gusto Intensidad &, 59 & ,12 & ,07 & ,75 &,- 06 \\
\hline Gusto Calidad & ,43 &, 51 & ,67 & ,15 &,- 01 \\
\hline Salado &,- 33 &,- 48 &,- 33 &,- 54 & ,22 \\
\hline Ácido &,- 73 & ,35 &,- 37 & 01 & ,16 \\
\hline Amargo &,- 93 & ,05 &,- 08 & ,14 &,- 14 \\
\hline Regusto & ,13 & ,75 &, 57 & ,06 &,- 01 \\
\hline Persistencia & ,60 & ,36 &,- 30 &, 55 &,- 03 \\
\hline Global Olfato-gustativo & ,06 & ,70 &, 57 &,- 21 &,- 16 \\
\hline Aspecto interior (visual) & ,94 &,- 14 & ,01 &,- 10 & ,23 \\
\hline Aspecto exterior (visual) & ,86 & ,28 & ,05 &,- 07 & ,31 \\
\hline Aberturas (visual) & ,84 & ,07 &,- 17 &,- 06 & ,33 \\
\hline Global Visual & ,86 &,- 10 &,- 08 &,- 15 & ,39 \\
\hline
\end{tabular}

Método de extracción: Análisis de componentes principales.

a. 5 componentes extraídos 



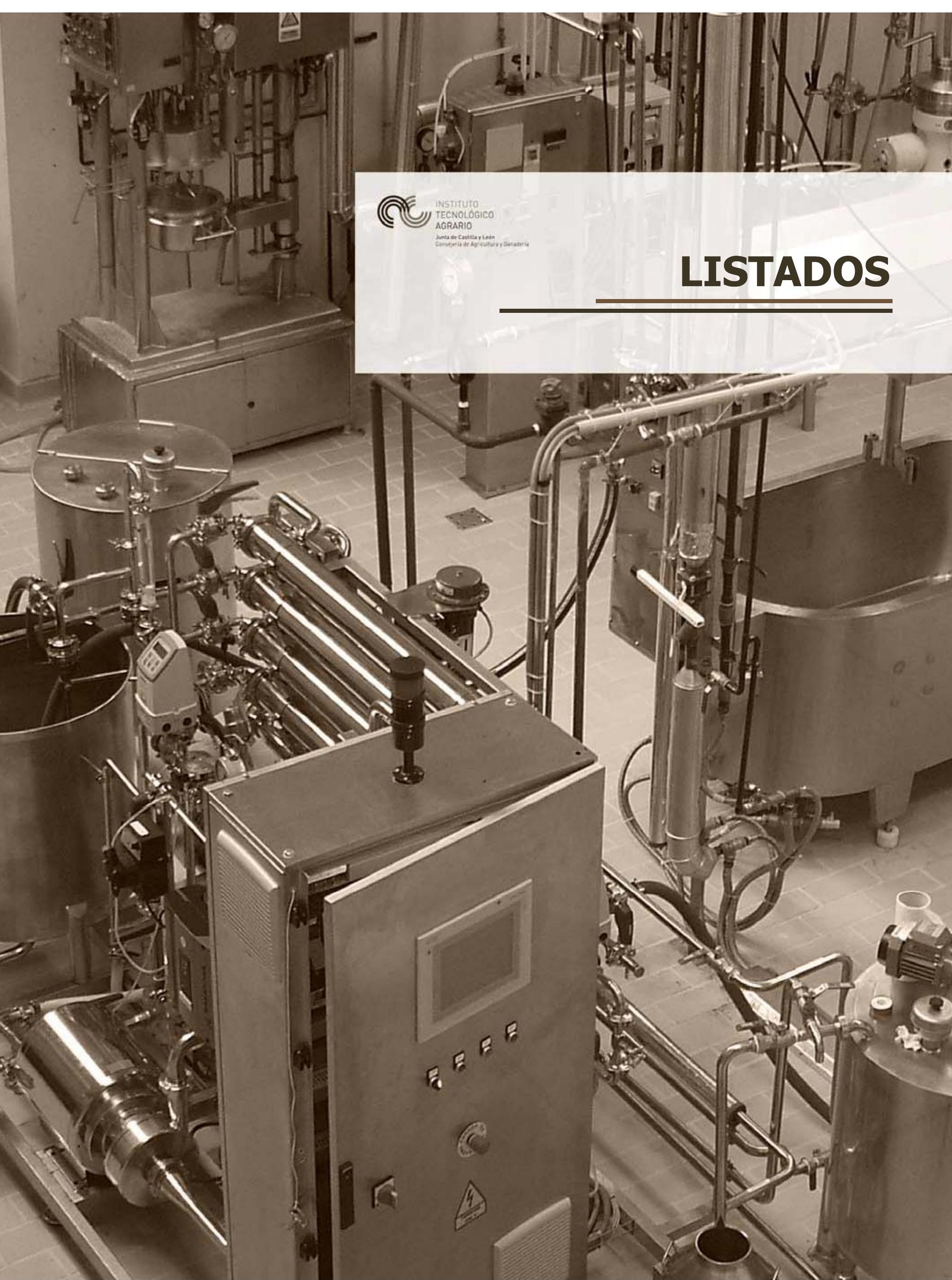





\section{TABLAS}

\section{CAPÍTULO I}

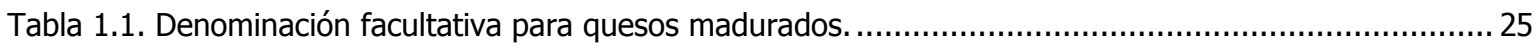

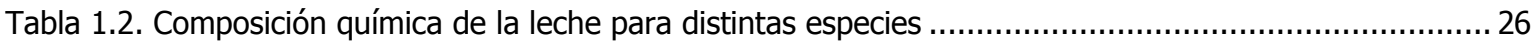

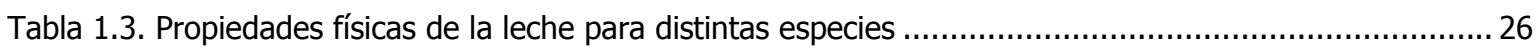

Tabla 1.4. Mezclas de leche para queso Hispánico, Ibérico y De la Mesta................................................... 30

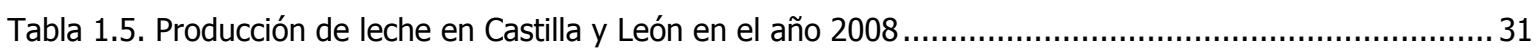

Tabla 1.6. Consumo en hogares según el tipo de queso para el año 2008................................................. 33

\section{CAPÍTULO III}

Tabla 3.1. Determinaciones realizadas a las corrientes líquidas............................................................ 73

Tabla 3.2. Análisis realizados a los quesos de los distintos experimentos................................................. 73

Tabla 3.3. Análisis generales realizados a los quesos de las fabricaciones: OPB, ODF, OSR y M ...................... 75

Tabla 3.4. Análisis específicos realizados a los quesos de las fabricaciones: OPB, ODF, OSR y M .................. 75

\section{CAPÍTULO $V$}

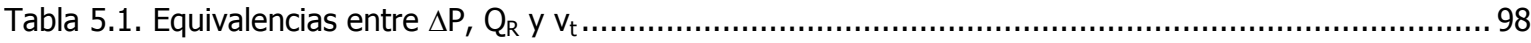

Tabla 5.2. Datos para la optimización de la densidad de flujo de permeado .............................................. 99

Tabla 5.3. Valores máximos de poder tampón del concentrado y relación respecto a la leche....................... 103

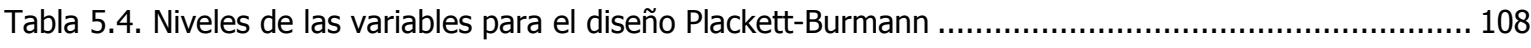

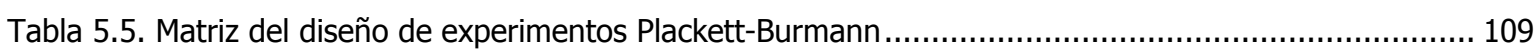

Tabla 5.6. Composición química y pH de la leche de mezcla. Diseño Plackett-Burmann ............................... 110

Tabla 5.7. Composición química y pH de los retenidos de UF. Diseño Plackett-Burmann................................ 111

Tabla 5.8. Datos del ANOVA y coeficientes de la regresión para rendimiento, diseño PB ........................... 122

Tabla 5.9. Datos del ANOVA y coeficientes de la regresión para calidad sensorial, diseño PB...................... 124

Tabla 5.10. Optimización de respuesta múltiple para el diseño Plackett-Burman ......................................... 124

Tabla 5.11. Niveles de las variables para el Diseño Factorial.............................................................. 128

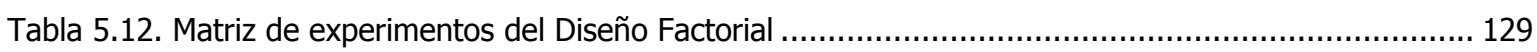

Tabla 5.13. Composición química y pH de la leche de mezcla. Diseño Factorial......................................... 130

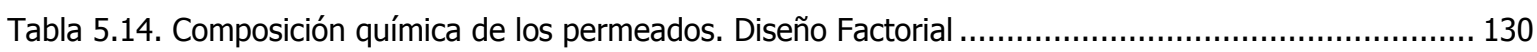

Tabla 5.15. Composición química y pH de los retenidos de UF. Diseño Factorial ....................................... 131 
Tabla 5.16. Datos del ANOVA y coeficientes de la regresión para rendimiento. Diseño Factorial..................143

Tabla 5.17. Datos del ANOVA y coeficientes de la regresión para calidad sensorial. Diseño Factorial ........... 144

Tabla 5.18. Optimización de respuesta múltiple para el Diseño Factorial............................................... 145

Tabla 5.19. Niveles de las variables para el diseño de Superficie Respuesta....................................... 147

Tabla 5.20. Matriz de experimentos del diseño de Superficie Respuesta .......................................... 148

Tabla 5.21. Composición química de la leche de mezcla y pH. Diseño de Superficie Respuesta ................... 149

Tabla 5.22. Composición química de los cuatro permeados. Diseño Superficie Respuesta........................... 149

Tabla 5.23. Composición química y pH de los veinte retenidos de UF. Diseño Superficie Respuesta ............ 150

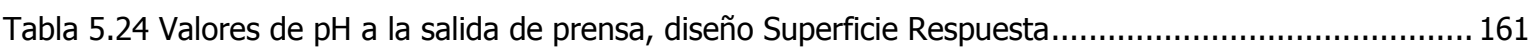

Tabla 5.25. Datos del ANOVA y coeficientes de la regresión para rendimiento. Diseño SR .......................... 162

Tabla 5.26. Datos del ANOVA y coeficientes de la regresión para calidad sensorial. Diseño SR.....................163

Tabla 5.27. Datos del ANOVA y coeficientes de la regresión para pH. Diseño SR..................................... 164

Tabla 5.28. Composición química y pH de la leche. Comparación tecnológica ........................................170

Tabla 5.29. Composición química de los permeados. Comparación tecnológica ......................................171

Tabla 5.30. Composición química y pH de los retenidos de UF. Comparación tecnológica .......................... 172

Tabla 5.31. Porcentaje de proteína en el ES a lo largo de la maduración. Comparación tecnológica .............174

Tabla 5.32. Contenido mineral del queso a los 40 días de maduración. Comparación tecnológica................ 175

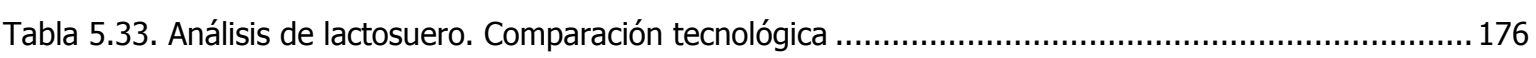

Tabla 5.34. Nitrógeno no caseínico (NNC) respecto del total en la maduración. Comp tecnológica ...............177

Tabla 5.35. Nitrógeno no proteico (NNP) respecto del total en la maduración. Comp tecnológica................178

Tabla 5.36. Compuestos orgánicos volátiles en los quesos a los 40 días. Comparación tecnológica .............. 179

Tabla 5.37. Datos de textura instrumental. Comparación tecnológica ................................................... 180

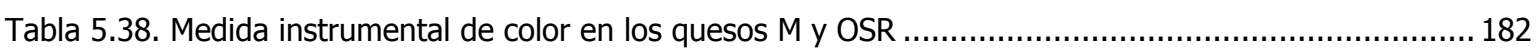

Tabla 5.39. Parámetros estructurales de los quesos: M, OPB, ODF y OSR.......................................... 184

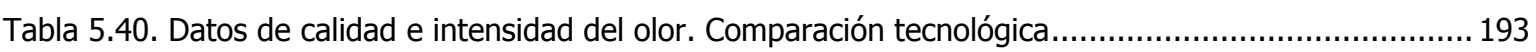

Tabla 5.41. Datos de textura en mano. Comparación tecnológica .................................................... 193

Tabla 5.42. Datos de textura en boca. Comparación tecnológica.................................................. 194

Tabla 5.43. Datos de sensación en boca. Comparación tecnológica................................................. 195

Tabla 5.44. Datos de sabor. Comparación tecnológica................................................................. 196

Tabla 5.45. Datos de valoración visual. Comparación tecnológica..................................................... 197

Tabla 5.46. Datos valoración global. Comparación tecnológica......................................................... 198

Tabla 5.47. Análisis de Componentes Principales. Autovalores y varianza explicada ...................................201

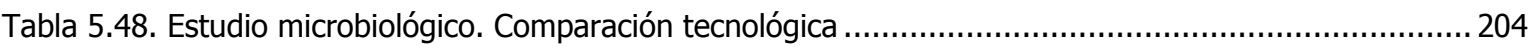

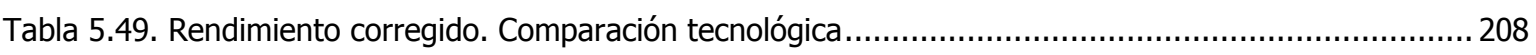

Tabla 5.50. Puntuación global compuesta. Comparación tecnológica ...............................................210

Tabla 5.51. Predicciones en los óptimos de los diseños experimentales .......................................... 211

\section{ANEXOS}

Tabla A.1. Composición química y pH de la leche de oveja. Diseño Plackett-Burmann ............................ 235

Tabla A.2. Composición química y pH de la leche de vaca. Diseño Plackett-Burmann .................................2235 
Tabla A.3. Composición química y pH de la leche de oveja. Diseño Factorial .........................................236

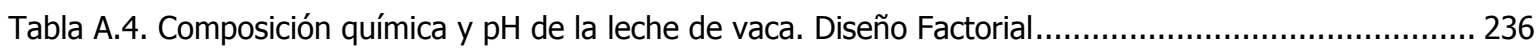

Tabla A.5. Composición química y pH de la leche de oveja. Diseño Superficie Respuesta ............................236

Tabla A.6. Composición química y pH de la leche de vaca. Diseño Superficie Respuesta............................2237

Tabla A.7. Composición química y pH de la leche de oveja. Queso tradicional y óptimos diseños ................ 237

Tabla A.8. Composición química y pH de la leche de vaca. Queso tradicional y óptimos diseños .................237

Tabla A.9. Composición química y pH de los quesos. Diseño Plackett-Burmann .........................................239

Tabla A.10. Composición química y pH de los quesos a los 20 días. Diseño factorial ...............................240

Tabla A.11. Composición química y pH de los quesos a los 40 días. Diseño factorial .................................2 241

Tabla A.12. Composición química y pH de los quesos a los 20 días. Diseño Superficie Respuesta ............... 242

Tabla A.13. Composición química y pH de los quesos a los 40 días. Diseño Superficie Respuesta ............... 243

Tabla A.14. Composición química y pH de los quesos a los 0 días. Comparación tecnológica .......................244

Tabla A.15. Composición química y pH de los quesos a los 20 días. Comparación tecnológica ....................244

Tabla A.16. Composición química y pH de los quesos a los 40 días. Comparación tecnológica. ...................244

Tabla A.17. Resumen optimizaciones diseño Plackett-Burmann .................................................. 245

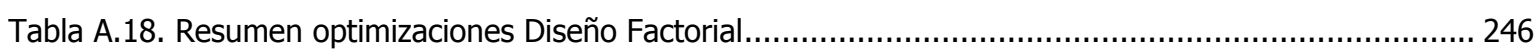

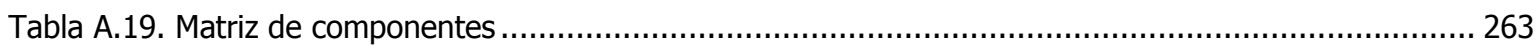





\section{FIGURAS}

\section{CAPÍTULO I}

Figura 1.1. Friso de Lechería 23

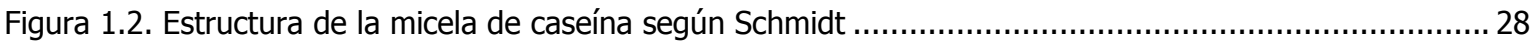

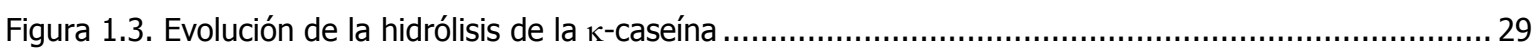

Figura 1.4. Evolución del consumo de queso en España en los últimos años............................................... 32

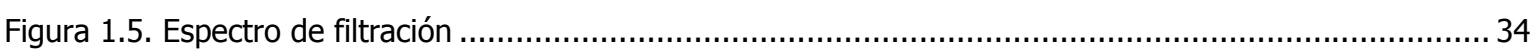

Figura 1.6. Flujo de permeado en función de la presión transmembrana .................................................... 40

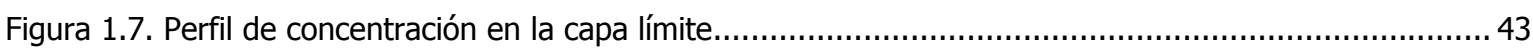

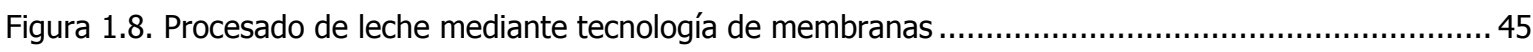

Figura 1.9. Procesado de suero mediante tecnología de membranas......................................................... 46

\section{CAPÍTULO IV}

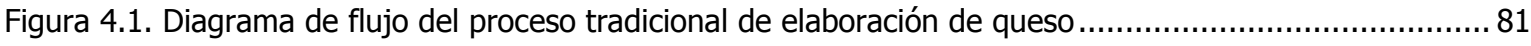

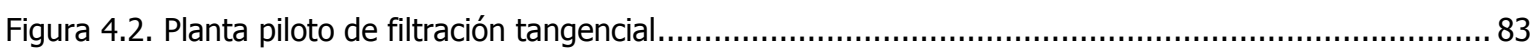

Figura 4.3. Diagrama de flujo del equipo de filtración tangencial ............................................................. 83

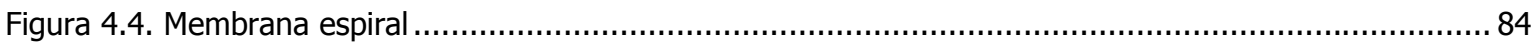

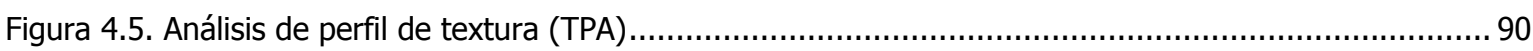

\section{CAPÍTULO V}

Figura 5.1. Densidad de flujo de permeado en función de la TMP en la UF de leche .............................. 100

Figura 5.2. Evolución de $\mathrm{J}$ en la ultrafiltración de leche entera con membranas poliméricas......................... 101

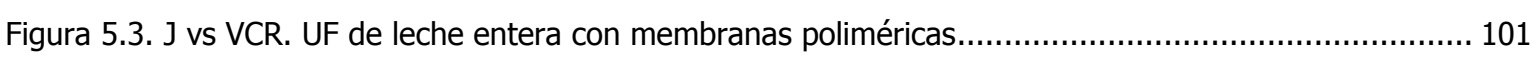

Figura 5.4. Evolución del poder tampón en función del pH, para leche y concentrados .............................. 103

Figura 5.5. Relación entre el poder tampón y el factor de concentración para la UF de leche entera ............ 104

Figura 5.6. Curvas de acidificación para leche y concentrado a VCR 4,5. Fermento MA4001 …..................... 104

Figura 5.7. Dureza de los geles cuajados con $40 \mathrm{~mL}$ de cuajo por cada $100 \mathrm{~L}$ de leche o concentrado ......... 106

Figura 5.8. Dureza de los geles cuajados con 30 y $15 \mathrm{~mL}$ de cuajo por cada $100 \mathrm{~L}$ de concentrado............. 107

Figura 5.9. Composición química y pH de los retenidos de UF. Diseño Plackett-Burmann ............................ 111

Figura 5.10. Composición de los quesos a los 40 días. Diseño Plackett-Burmann ...................................... 112

Figura 5.11. Optimización en cuanto a cenizas y pH. Diseño Palckett-Burmann ....................................... 113 
Figura 5.12. Medida de firmeza $(\mathrm{N})$ y su significación en el diseño Plackett-Burmann .............................. 114

Figura 5.13. Medida de elasticidad y su significación en el diseño Plackett-Burmann ...............................114

Figura 5.14. Medida de adherencia ( $\mathrm{N} \cdot \mathrm{s})$ y su significación en el diseño Plackett-Burmann .........................114

Figura 5.15. Medida de cohesividad y su significación en el diseño Plackett-Burmann .............................115

Figura 5.16. Medida de masticabilidad (N) y su significación en el diseño Plackett-Burmann ...................... 115

Figura 5.17. Puntuaciones de olor y su significación en el diseño Plackett-Burmann .............................. 116

Figura 5.18. Puntuaciones de textura en mano y su significación en el diseño Plackett-Burmann .................117

Figura 5.19. Puntuaciones de textura en boca y su significación en el diseño Plackett-Burmann.................. 117

Figura 5.20. Puntuaciones de la sensación en boca y su significación en el diseño Plackett-Burmann ..........118

Figura 5.21. Puntuaciones de sabor y su significación en el diseño Plackett-Burmann ...............................119

Figura 5.22. Puntuaciones fase visual y su significación en el diseño Plackett-Burmann...........................120

Figura 5.23. Puntuaciones globales y su significación en el diseño Plackett-Burmann ..............................120

Figura 5.24. Evolución del pH en las fabricaciones del diseño Plackett-Burmann ................................ 121

Figura 5.25. Significación de las variables sobre el pH a la salida de prensa. Diseño PB............................ 122

Figura 5.26. Optimización del rendimiento. Diseño Plackett-Burmann .......................................... 123

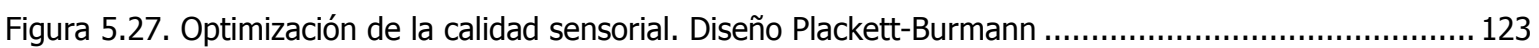

Figura 5.28. Composición de los quesos a los 40 días. Diseño Factorial ............................................ 132

Figura 5.29. Variables significativas en la optimización en cuanto a pH, ES y proteína. DF........................133

Figura 5.30. Medida de firmeza $(\mathrm{N})$ y su significación en el Diseño Factorial .......................................133

Figura 5.31. Medida de elasticidad y su significación en el Diseño Factorial .......................................134

Figura 5.32. Medida de adherencia ( $\mathrm{N} \cdot \mathrm{s})$ y su significación en el Diseño Factorial ....................................134

Figura 5.33. Medida de cohesividad y su significación en el Diseño Factorial................................... 135

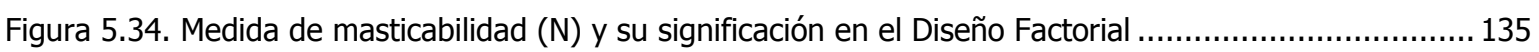

Figura 5.35. Puntuaciones de olor y su significación en el Diseño Factorial ..........................................136

Figura 5.36. Puntuaciones de textura en mano y su significación en el Diseño Factorial .............................137

Figura 5.37. Puntuaciones de textura boca y su significación en el Diseño Factorial ................................ 137

Figura 5.38. Puntuaciones de sensación en boca y su significación en el Diseño Factorial ...........................138

Figura 5.39. Puntuaciones de sabor y su significación en el Diseño Factorial........................................139

Figura 5.40. Puntuaciones fase visual y su significación en el Diseño Factorial ....................................... 140

Figura 5.41. Puntuaciones globales y su significación en el Diseño Factorial .......................................... 141

Figura 5.42. Significación del pH a la salida de prensa. Diseño Factorial ............................................. 141

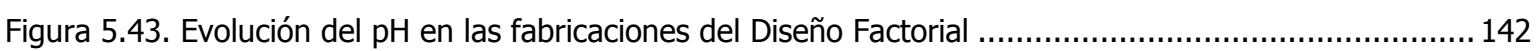

Figura 5.44. Optimización del rendimiento. Diseño Factorial ....................................................... 143

Figura 5.45. Optimización de la calidad sensorial. Diseño Factorial .................................................. 144

Figura 5.46. Composición de los quesos a los 40 días. Diseño Superficie Respuesta ................................. 151

Figura 5.47. Variables significativas en la optimización en cuanto a grasa, proteína, ES y pH.................... 152

Figura 5.48. Medida de firmeza $(\mathrm{N})$ y su significación en el diseño de Superficie Respuesta.......................153

Figura 5.49. Medida de elasticidad y su significación en el diseño de Superficie Respuesta .......................153

Figura 5.50. Medida de adherencia (N`s) y su significación en el diseño de Superficie Respuesta ................ 153

Figura 5.51. Medida de cohesividad y su significación en el diseño de Superficie Respuesta ......................154

Figura 5.52. Medida de masticabilidad (N) y su significación en el diseño de Superficie Respuesta...............154 
Figura 5.53. Puntuaciones de olor y su significación en el diseño de Superficie Respuesta........................ 155

Figura 5.54. Puntuaciones de textura en mano y su significación en el diseño de SR................................ 156

Figura 5.55. Puntuaciones de textura en boca y su significación en el diseño de SR.............................. 156

Figura 5.56. Puntuaciones de la sensación en boca y su significación en el diseño de SR .......................... 157

Figura 5.57. Puntuaciones de sabor y su significación en el diseño de Superficie Respuesta ...................... 158

Figura 5.58. Puntuaciones fase visual y su significación en el diseño de Superficie Respuesta ................... 159

Figura 5.59. Puntuaciones globales y su significación en el diseño Superficie Respuesta ...........................160

Figura 5.60. Evolución del pH en las fabricaciones del diseño Superficie Respuesta ................................ 160

Figura 5.61. Significación del pH a la salida de prensa. Diseño Factorial .............................................. 161

Figura 5.62. Superficie respuesta en la optimización del rendimiento ............................................ 162

Figura 5.63. Superficie respuesta en la optimización sensorial .................................................... 163

Figura 5.64. Superficie Respuesta en la optimización del valor de $\mathrm{pH}$ a la salida de prensa ....................... 165

Figura 5.65. Ultrafiltración de leche de mezcla estandarizada .................................................. 168

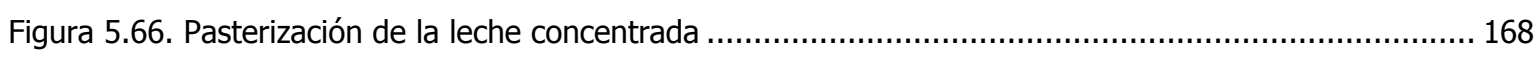

Figura 5.67. Etapas de cuajado (izquierda) y corte (derecha) ................................................... 169

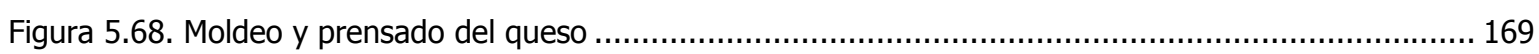

Figura 5.69. Porcentaje de extracto seco a lo largo de la maduración. Comparación tecnológica ................ 172

Figura 5.70. Porcentaje de grasa, sal y cenizas a los 40 días de maduración. Comp tecnológica ................. 173

Figura 5.71. Evolución del pH a lo largo de la maduración. Comparación tecnológica............................... 174

Figura 5.72. Nitrógeno no caseínico respecto del total (NNC/NT) a los 0,20 y 40 días ........................... 177

Figura 5.73. Nitrógeno no proteico respecto del total (NNP/NT) a los 0,20 y 40 días........................... 178

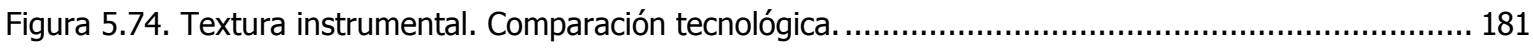

Figura 5.75. Evolución del color en el interior del queso ........................................................... 182

Figura 5.76. Evolución del color en el exterior del queso ......................................................... 183

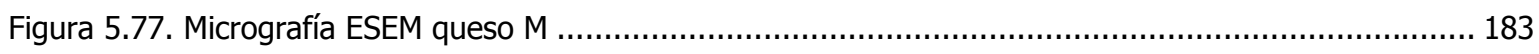

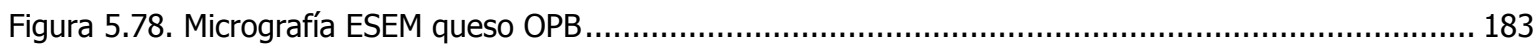

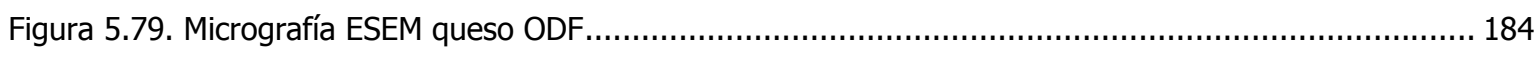

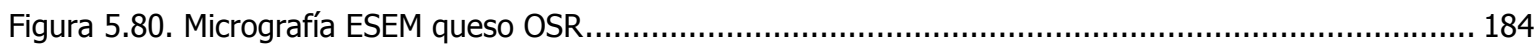

Figura 5.81. Micrografías ESEM queso M. Estudio cuantitativo ....................................................... 185

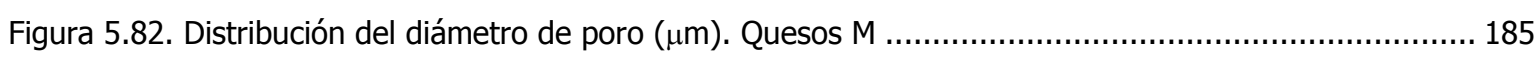

Figura 5.83. Micrografías ESEM queso OPB. Estudio cuantitativo .................................................... 186

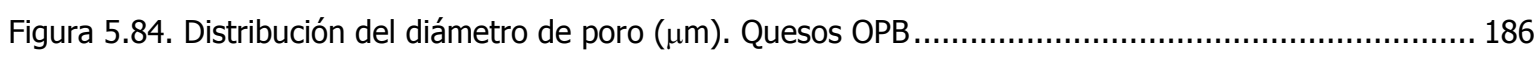

Figura 5.85. Micrografías ESEM queso ODF. Estudio cuantitativo .................................................. 187

Figura 5.86. Distribución del diámetro de poro $(\mu \mathrm{m})$. Quesos ODF................................................. 187

Figura 5.87. Micrografías ESEM queso OSR. Estudio cuantitativo ................................................... 188

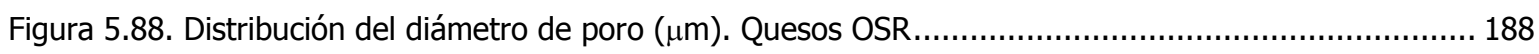

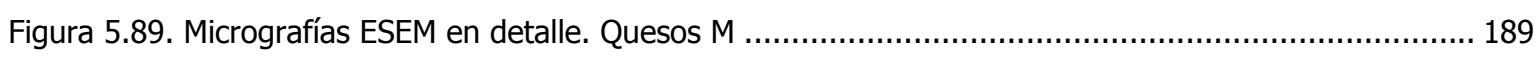

Figura 5.90. Micrografías ESEM en detalle. Quesos OPB .......................................................... 190

Figura 5.91. Micrografías ESEM en detalle. Quesos ODF............................................................... 190

Figura 5.92. Micrografías ESEM en detalle. Quesos OSR ............................................................ 190

Figura 5.93. Micrografía SEM de lactococcus lactis.......................................................... 191 
Figura 5.94. Microcristales encontrados en queso Grana Padano................................................ 192

Figura 5.95. Gráfico de calidad e intensidad del olor. Comparación tecnológica....................................... 193

Figura 5.96. Gráficos de textura en mano. Comparación tecnológica .................................................... 194

Figura 5.97. Gráfico de textura en boca. Comparación tecnológica..................................................... 195

Figura 5.98. Gráfico de sensación en boca. Comparación tecnológica............................................... 196

Figura 5.99. Gráficos de gusto. Comparación tecnológica .............................................................. 197

Figura 5.100. Gráficos de valoración visual. Comparación tecnológica ................................................. 198

Figura 5.101. Gráficos de valoración global. Comparación tecnológica................................................198

Figura 5.102. Resumen comparación organoléptica................................................................... 199

Figura 5.103. Comparación de tecnologías para la eliminación de ojos en el queso. ...............................200

Figura 5.104. Representación de las componentes principales. Comparación tecnológica ..........................201

Figura 5.105. Evolución del flujo de permeado y la TMP con el tpo en los óptimos OPB, ODF y OSR ........... 205

Figura 5.106. Flujo de permeado en función del VCR, filtraciones OPB, ODF y OSR ................................206

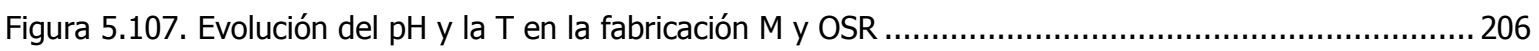

Figura 5.108. Pérdidas de peso durante la maduración del queso tradicional (M) y óptimo OSR.................207

Figura 5.109. Ahorro de leche al realizar queso a partir de concentrados de UF.....................................210

\section{ANEXOS}

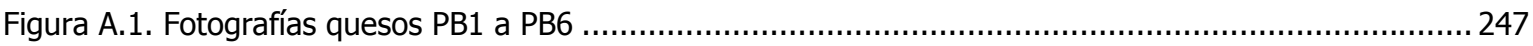

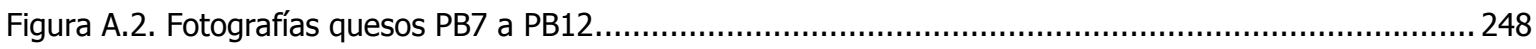

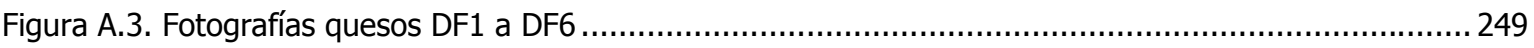

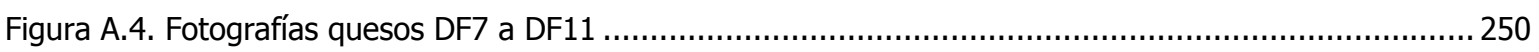

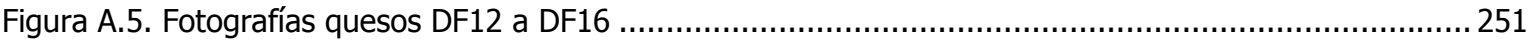

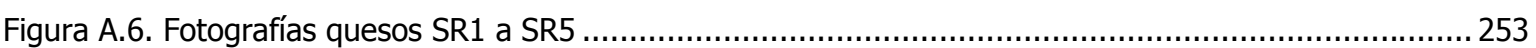

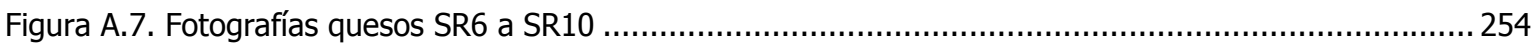

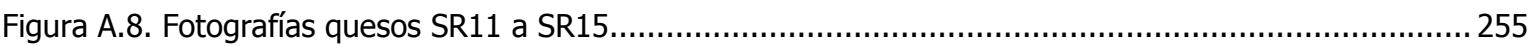

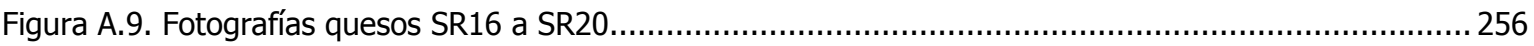

Figura A.10. Queso tradicional y ultrafiltrado a los cero días de maduración .........................................257

Figura A.11. Queso tradicional y ultrafiltrado a los 20 días de maduración .............................................258

Figura A.12. Queso tradicional y ultrafiltrado a los 40 días de maduración ........................................259

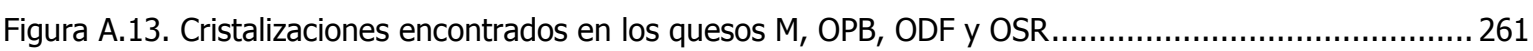




\section{ABREVIATURAS}

\begin{tabular}{|c|c|}
\hline$\% \mathrm{~m} / \mathrm{m}$ & porcentaje masa/masa \\
\hline$\% \mathrm{R}$ & porcentaje de rendimiento \\
\hline$\% \mathrm{R}_{\mathrm{i}}$ & porcentaje de rechazo de la membrana o de retención de un componente \\
\hline$a^{*}$ & índice de cromaticidad verde-rojo \\
\hline ANOVA & análisis de varianza \\
\hline ARE & índice de maduración aparente \\
\hline$a_{w}$ & actividad de agua \\
\hline$b^{*}$ & índice de cromaticidad azul-amarillo \\
\hline $\mathrm{Ca}$ & calcio \\
\hline CE & Comisión Europea \\
\hline$c_{i}$ & fracción en peso del componente i \\
\hline $\mathrm{cm}$ & centímetro \\
\hline CMP & caseinomacropéptido \\
\hline $\mathrm{CP}$ & componentes principales \\
\hline $\mathrm{Da}$ & Dalton \\
\hline DCU & una unidad DCU contiene aproximadamente de $1 \cdot 10^{11}$ a $2 \cdot 10^{11}$ bacterias \\
\hline DF & diseño factorial \\
\hline$D_{\text {mediana }}$ & diámetro calculado a partir de la mediana \\
\hline$D_{\text {medio }}$ & diámetro calculado a partir de la media aritmética \\
\hline$\Pi Р$ & presión osmótica de la disolución \\
\hline$\Delta \mathrm{P}$ & caida de presión \\
\hline ES & extracto seco \\
\hline ESEM & microscopía de barrido electrónico ambiental \\
\hline $\mathrm{F}$ & fermento \\
\hline FAPRI & Food and Agricultural Police Research Institute \\
\hline FDA & Food and Drug Administration \\
\hline FENIL & Federación Nacional de Industrias Lácteas \\
\hline GL & grados de libertad \\
\hline $\mathrm{HCl}$ & ácido clorhídrico \\
\hline $\mathrm{Hz}$ & hercio \\
\hline ISO & organización internacional de estandarización \\
\hline$J$ & densidad de flujo de permeado \\
\hline K & potasio \\
\hline$k_{b l}$ & coeficiente de transferencia de materia \\
\hline $\mathrm{kg}$ & kilogramo \\
\hline L & litros \\
\hline$L$ & luminosidad \\
\hline LCR & retenidos de bajo factor de concentración \\
\hline LPC & prequeso líquido \\
\hline$\mu$ & viscosidad \\
\hline
\end{tabular}


M

$\mathrm{m}$

M.A.R.M

$\mathrm{MC}$

MF

$\mathrm{Mg}$

min

$\mathrm{mL}$

NMP

MMV

MWCO

$\mathrm{N}$

$\mathrm{n}$

$\mathrm{NaCl}$

NF

NNC

NNP

NT

${ }^{\circ} \mathrm{C}$

OD

ODF

OI

OPB

OSR

$\mathrm{P}$

PB

p-valor

$\mathrm{Q}_{\mathrm{R}}$

$\rho$

R.D.

RD

$\mathrm{R}_{\mathrm{f}}$

$\mathrm{R}_{\mathrm{gel}}$

$\mathrm{R}_{\mathrm{m}}$

$\mathrm{R}_{\text {tot }}$

$S$

$\mathrm{S}$

SC

SEM

SR

$\mathrm{T}$

TCA

$\mathrm{Tm}$

TMP

TPA fabricación del queso de mezcla tradicional

metro

Ministerio de Medio Ambiente y Medio Rural y Marino

cuadrados medios para el análisis de varianza

microfiltración

magnesio

minutos

mililitro

número más probable

proceso de obtención de prequeso por ultrafiltarción patentado por Maubois, Mocquot y Vassal

tamaño de corte de la membrana

Newton

núemro de réplicas

cloruro sódico

nanofiltración

nitrógeno no caseínico

nitrógeno no proteico

nitrógeno total

grado Celsius

grado Dornic

fabricación el el óptimo del diseño factorial

ósmosis inversa

fabricación en le óptimo del diseño Plackett-Burmann

fabricación en el óptimo del diseño de superficie Respuesta

fósforo

diseño Plackett-Burmann

nivel de significación empírico para los contrastes de hipótesis

caudal de recirculación en el equipo de ultrafiltración

densidad

real decreto

índice de profundidad de la maduración

resistencia al flujo por colmatación y/o ensuciamiento

resistencia al flujo por formación de una capa de gel

resistencia hidraúlica de la membrana

resistencia la flujo total

desviación estándar

segundo

suma de cuadrados para el análisis de varianza

microscopía de barrido electrónico

diseño de superficie respuesta

temperatura

ácido tricloroacético

tonelada métrica

presión transmembrana

análisis de perfil de textura 


$\begin{array}{ll}\text { Tpo } & \text { tiempo } \\ \text { UF } & \text { ultrafiltración } \\ \text { ufc } & \text { unidad formadora de colonias } \\ V & \text { volumen } \\ V_{a} & \text { velocidad del aire } \\ \text { VCR } & \text { factor de concentración volumétrico } \\ V_{t} & \text { velocidad tangencial en la superficie de la membrana } \\ \varphi & \text { humedad relativa del aire }\end{array}$




